NATIONAL LABORATORY

MANAGED BY UT-BATTELLE

FOR THE DEPARTMENT OF ENERGY

\title{
Durability-Based Design Properties of Reference Crossply Carbon-Fiber Composite
}

\author{
J. M. Corum \\ R. L. Battiste \\ S. Deng \\ K. C. Liu \\ M. B. Ruggles \\ Y. J. Weitsman
}

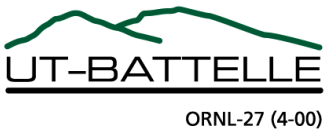




\section{DOCUMENT AVAILABILITY}

Reports produced after January 1, 1996, are generally available free via the U.S. Department of Energy (DOE) Information Bridge.

Web site http://www.osti.gov/bridge

Reports produced before January 1, 1996, may be purchased by members of the public from the following source.

National Technical Information Service

5285 Port Royal Road

Springfield, VA 22161

Telephone 703-605-6000 (1-800-553-6847)

TDD 703-487-4639

Fax 703-605-6900

E-mail info@ntis.fedworld.gov

Web site http://www.ntis.gov/support/ordernowabout.htm

Reports are available to DOE employees, DOE contractors, Energy Technology Data Exchange (ETDE) representatives, and International Nuclear Information System (INIS) representatives from the following source.

Office of Scientific and Technical Information

P.O. Box 62

Oak Ridge, TN 37831

Telephone 865-576-8401

Fax 865-576-5728

E-mail reports@adonis.osti.gov

Web site http://www.osti.gov/contact.html

This report was prepared as an account of work sponsored by an agency of the United States Government. Neither the United States Government nor any agency thereof, nor any of their employees, makes any warranty, express or implied, or assumes any legal liability or responsibility for the accuracy, completeness, or usefulness of any information, apparatus, product, or process disclosed, or represents that its use would not infringe privately owned rights. Reference herein to any specific commercial product, process, or service by trade name, trademark, manufacturer, or otherwise, does not necessarily constitute or imply its endorsement, recommendation, or favoring by the United States Government or any agency thereof. The views and opinions of authors expressed herein do not necessarily state or reflect those of the United States Government or any agency thereof. 


\title{
DURABILITY-BASED DESIGN PROPERTIES OF REFERENCE CROSSPLY CARBON-FIBER COMPOSITE
}

\author{
J. M. Corum \\ R. L. Battiste \\ S. Deng \\ K. C. Liu \\ M. B. Ruggles \\ Y. J. Weitsman
}

Manuscript completed: February 2001

Date Published: April 2001

Prepared by the

OAK RIDGE NATIONAL LABORATORY

Oak Ridge, Tennessee 37831-6285

managed by

UT-BATTELLE, LLC

for the

U.S. DEPARTMENT OF ENERGY

under contract DE-AC05-00OR22725 


\section{CONTENTS}

Page

ABSTRACT

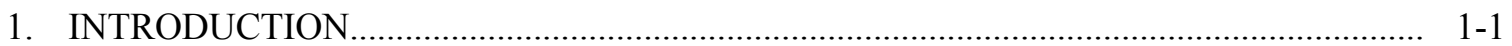

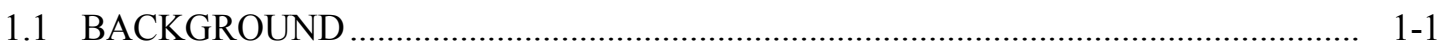

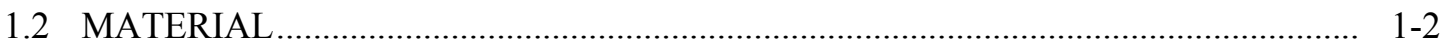

1.3 LOADINGS AND ENVIRONMENTS ……....................................................... $1-3$

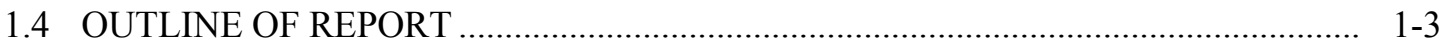

1.5 DEFINITIONS USED IN PART 1 ....................................................................... 1 1-4

\section{PART 1. DESIGN CRITERIA}

2. ELASTIC AND CREEP PROPERTIES FOR DESIGN ANALYSIS ................................... 2-1

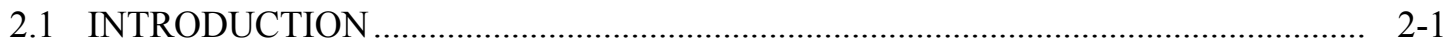

2.2 ELASTIC PROPERTIES FOR DESIGN ................................................................ 2-1

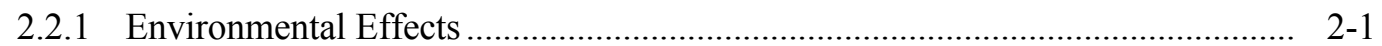

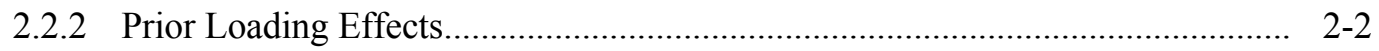

2.2.3 Prior Temperature Cycling ......................................................................... 2-2

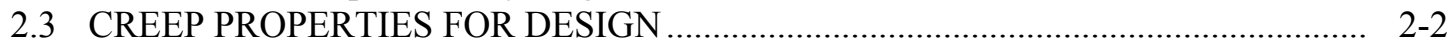

2.3.1 Basic Creep Equations...................................................................... 2-3

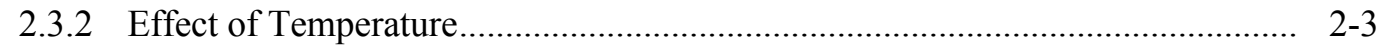

2.3.3 Environmental Effects ..................................................................................... 2-3

2.3.4 Isochronous Stress-Strain Curves ................................................................. 2-3

3. DESIGN ALLOWABLES FOR STATIC LOADINGS ….............................................

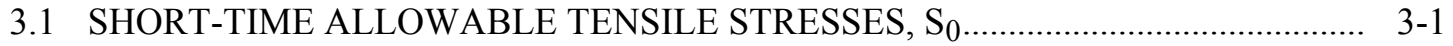

3.2 SHORT-TIME ALLOWABLE COMPRESSIVE STRESSES …............................... 3-1

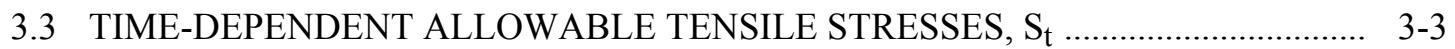

3.4 TIME-DEPENDENT ALLOWABLE COMPRESSIVE STRESSES …........................ $3-4$

3.5 TREATMENT OF MEMBRANE AND BENDING STRESSES................................... 3-5

3.6 TREATMENT OF INCREMENTS OF SUSTAINED LOADS ................................... $3-5$

4. DESIGN LIMITS FOR CYCLIC LOADINGS .............................................................. 4-

4.1 BASIC FATIGUE DESIGN CURVES ……....................................................... $4-1$

4.2 EFFECTS OF TEMPERATURE .......................................................................... 4

4.3 ENVIRONMENTAL AND PRIOR LOAD EFFECTS ................................................ 4-2

4.4 TREATMENT OF VARYING STRESS AMPLITUDES …….................................. $4-3$

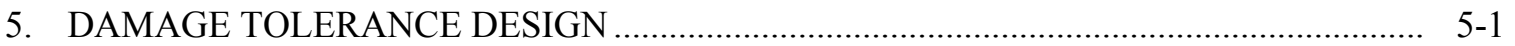

5.1 GENERAL REQUIREMENTS ................................................................................. $5-1$

5.2 DETERMINATION OF IMPACT DAMAGE AREA ……...................................... $5-1$

5.3 DETERMINATION OF STRENGTH AND STIFFNESS DEGRADATION .............. $5-1$

6. SUMMARY AND COMPARISON WITH CHOPPED-GLASS-FIBER COMPOSITE...... 6- 6-1

6.1 ELASTIC AND CREEP PROPERTIES FOR DESIGN ANALYSIS ............................ $6-1$

6.2 ALLOWABLE STRESSES FOR STATIC AND CYCLIC LOADINGS ....................... $6-2$

6.3 SIMPLIFIED SUMMARY OF ALLOWABLE STRESSES ......................................... $6-4$

6.4 DAMAGE TOLERANCE EVALUATION ……......................................................... $6-5$ 


\section{PART 2. BACKGROUND DATA AND MODELS}

7. BASIC TENSILE, COMPRESSIVE, AND SHEAR PROPERTIES ….................................

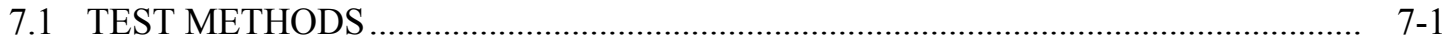

7.2 SPECIMEN WIDTH EFFECTS..............................................................................

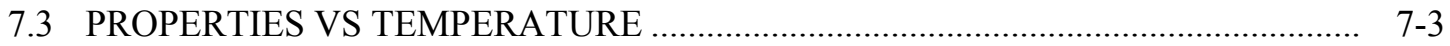

7.4 EFFECTS OF PLAQUE THICKNESS VARIATIONS.................................................

7.5 EFFECT OF STRAIN RATE ON TENSILE PROPERTIES …....................................

7.6 EFFECTS OF THERMAL CYCLING ……...............................................................

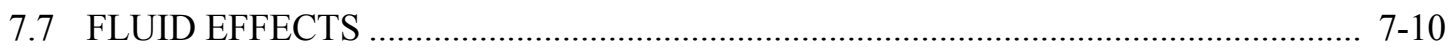

7.7.1 Screening Tests.............................................................................................. 7-10

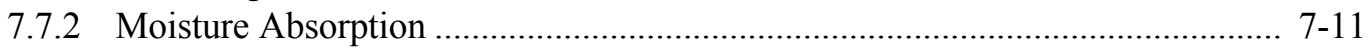

7.7.3 Windshield Washer Fluid............................................................................... 7-13

7.7.4 Fluid Reduction Factors for Standard Exposures............................................. 7-14

8. UNIAXIAL AND BIAXIAL FLEXURE PROPERTIES .................................................. $8-1$

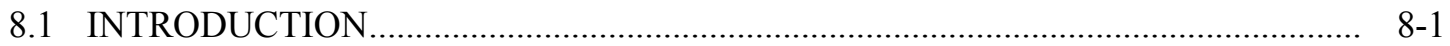

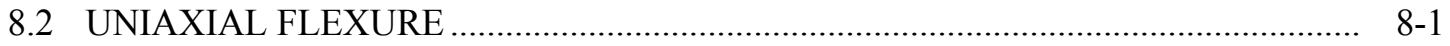

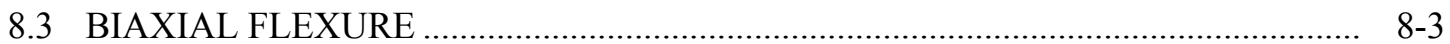

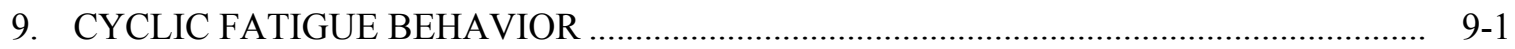

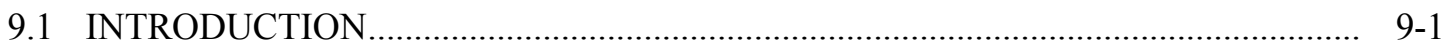

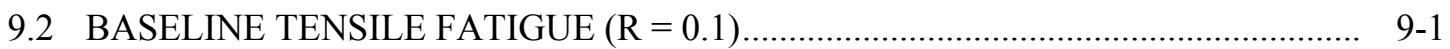

9.3 QUANTIFICATION OF TEMPERATURE EFFECTS............................................... 9-3

9.4 FLUID EFFECTS …............................................................................. 9-4

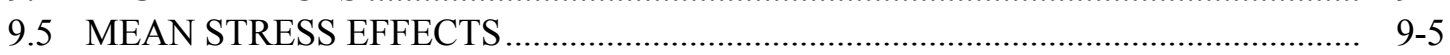

9.5.1 The $\pm 45^{\circ}$ Fiber Orientation ....................................................................... 9-6

9.5.2 The $0 / 90^{\circ}$ Fiber Orientation ....................................................................... 9-7

9.6 CONCLUSIONS AND RECOMMENDATIONS …............................................ 9-7

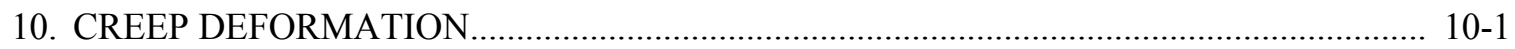

10.1 SPECIMENS AND TEST PROCEDURE …....................................................... 10-3

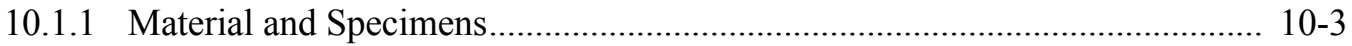

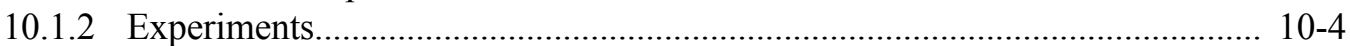

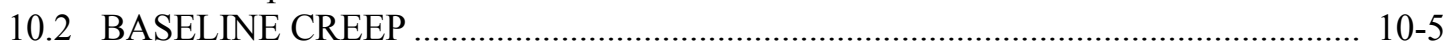

10.2.1 Room-Temperature, In-Air Tensile Deformation........................................... 10-5

10.2.2 Creep Equation Development.............................................................. 10-6

10.3 TEMPERATURE EFFECTS …….............................................................. 10 10

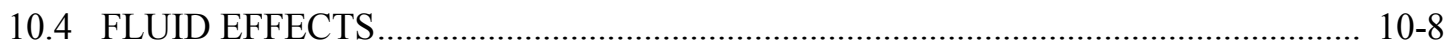

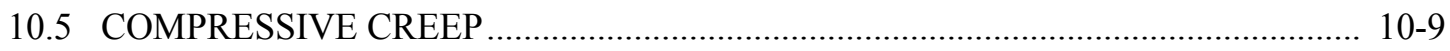

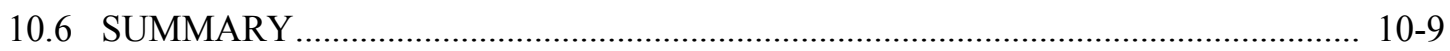

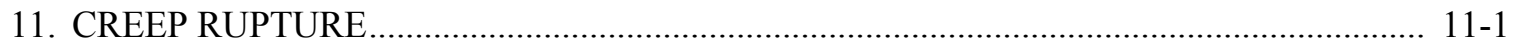

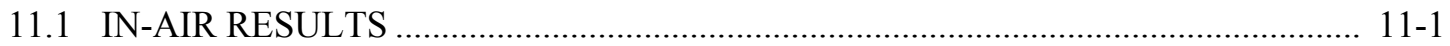

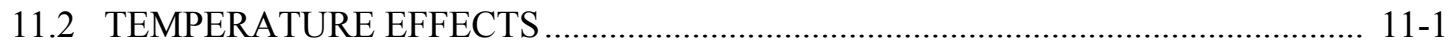

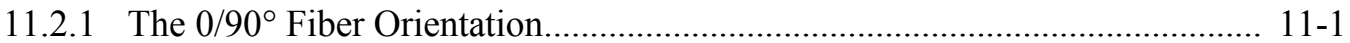

11.2.2 The $\pm 45^{\circ}$ Fiber Orientation...................................................................... 11-2

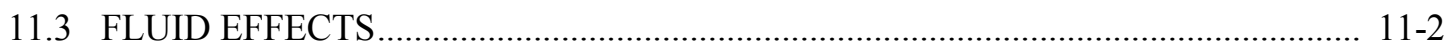

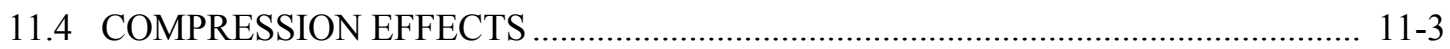

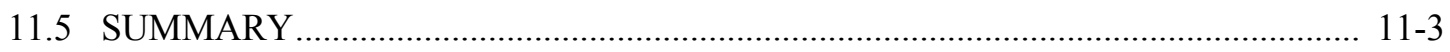

12. TIME-DEPENDENT DEFORMATION RESPONSE: DATA AND MODELING ............. 12-1

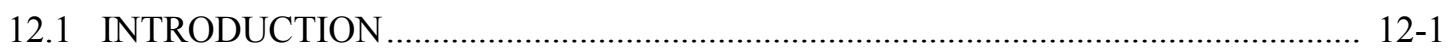


12.2 CREEP AND RECOVERY STRAINS OF $\left( \pm 45^{\circ}\right)_{3 \mathrm{~S}}$ COUPONS AT ROOM

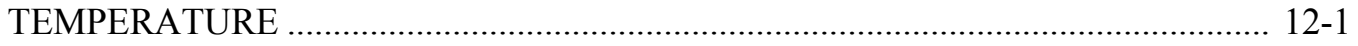

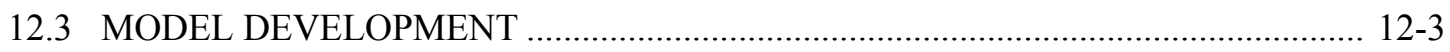

12.3.1 Linear-Elastic Behavior of Crossply Laminates .......................................... 12-3

12.3.2 Time-Dependent Behavior.......................................................................... 12-4

12.3.3 Calibration of Creep Data at $\phi=45^{\circ}$ to Determine the Time-Dependent

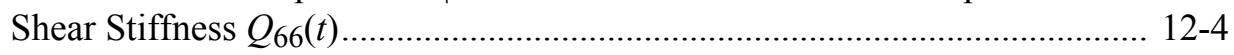

12.4 PREDICTIONS FOR OTHER ORIENTATIONS …................................................... 12-4

12.5 NONLINEAR CREEP OF $\pm 45^{\circ}$ COUPONS ........................................................... 12-5

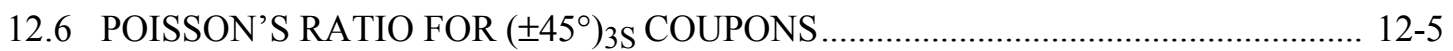

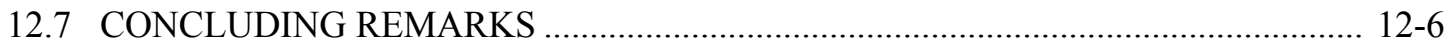

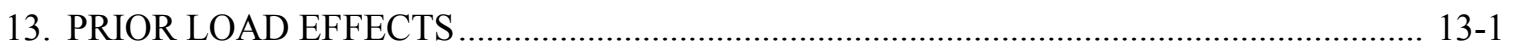

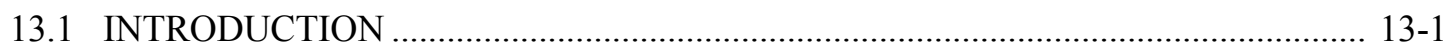

13.2 EFFECT OF PRIOR SHORT-TIME STATIC LOADINGS …................................... 13-1

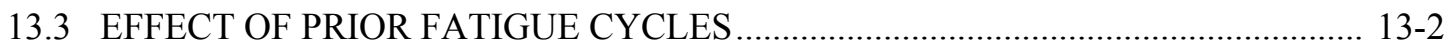

13.3.1 Effect on Tensile Properties....................................................................... 13-2

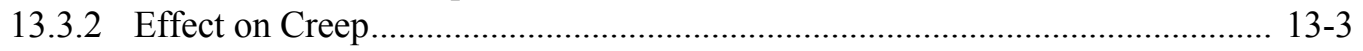

13.4 EFFECT OF PRIOR CREEP DEFORMATION................................................... 13-4

13.4.1 Effect on Tensile Properties............................................................................ 13-4

13.4.2 Effect on Fatigue Strength ....................................................................... 13-4

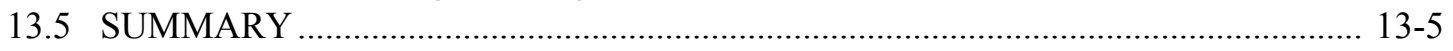

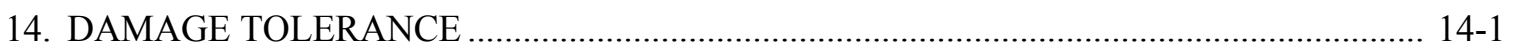

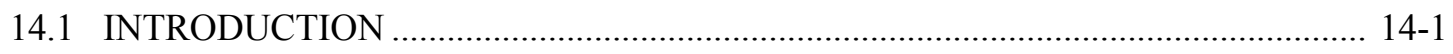

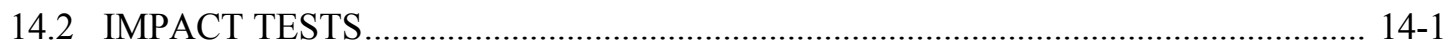

14.2.1 Baseline Results .............................................................................. 14-1

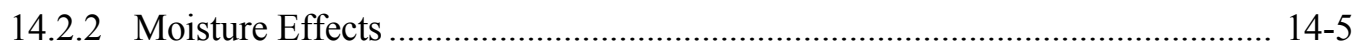

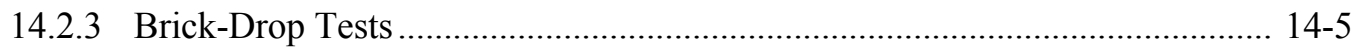

14.3 DEGRADATION OF STRENGTH PROPERTIES................................................... 14-6

14.3.1 Tensile and Compressive Strengths........................................................... 14-6

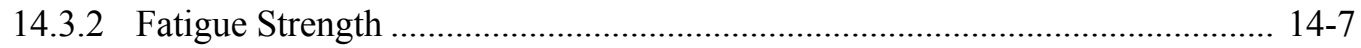

14.3.3 Effects of Moisture on Strength Degradation ................................................ 14-7

14.3.4 Strength Degradation Produced by Brick Drops............................................ 14-7

14.4 SUMMARY AND DISCUSSION ...................................................................... 14- 14

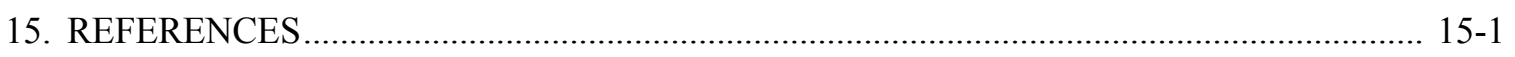

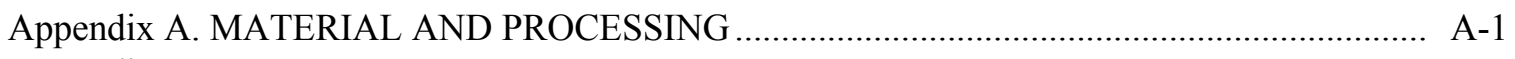

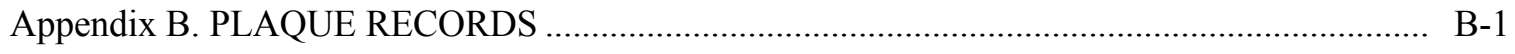




\section{LIST OF FIGURES}

Figure

Page

1.1 Schematic of reinforcement arrangement.

2.1 Time-dependent creep strain curves for RT ambient air conditions:

(a) $0 / 90^{\circ}$ fiber orientation and $(b) \pm 45^{\circ}$ fiber orientation

Creep strain multipliers for temperature effects.

Isochronous stress-strain curves for RT ambient air $-0 / 90^{\circ}$ fiber orientation

$2-6$

Isochronous stress-strain curves for RT ambient air $- \pm 45^{\circ}$ fiber orientation...

$2-7$

Tensile and compressive strength multiplication factors to account for temperature

Allowable $\pm 45^{\circ}$ tensile stresses, $\mathrm{S}_{\mathrm{t}}$, without fluid and prior load effects

Allowable $\pm 45^{\circ}$ tensile stresses, $S_{t}$, with reductions to account for fluid and prior load effects.

Stress-strain curves and X-ray photograph of 50.8-mm-wide

specimen C48-2.

Stress-strain curves and X-ray photograph of 76.2-mm-wide specimen C48-3.

Stress-strain curves and X-ray photograph of 101.6-mm-wide specimen C48-8.

7.13 Typical stress-strain curves: $(a) 0 / 90^{\circ}$ fiber orientation and

(b) $\pm 45^{\circ}$ fiber orientation

7.14 Temperature multiplication factors for relating stiffness and strength to room-temperature values: (a) $0 / 90^{\circ}$ fiber orientation and

(b) $\pm 45^{\circ}$ fiber orientation ....

7.15 Typical stress-strain response to failure at various orientation angles...

7.16 Tensile strength vs orientation angle.....

7.17 Measured and predicted variation of elastic properties with orientation:

(a) stiffness and (b) Poisson's ratio

7.18 Variation in tensile properties with specimen thickness for $0 / 90^{\circ}$ fiber orientation: $(a)$ stiffness and $(b)$ strength ......

7.19 Variation in tensile properties with specimen thickness for $\pm 45^{\circ}$ fiber orientation: $(a)$ stiffness and $(b)$ strength 
7.20 Relative stiffness and strength vs adjusted fiber volume content for $0 / 90^{\circ}$ fiber orientation: $(a)$ relative stiffness and $(b)$ relative strength.

7.21 Relative stiffness and strength vs adjusted fiber volume content for $\pm 45^{\circ}$ fiber orientation: $(a)$ relative stiffness and $(b)$ relative strength.

Effect of rate on $0 / 90^{\circ}$ tensile properties: $(a)$ strength and $(b)$ stiffness .

Stress-strain curves at different strain rates: $(a) \pm 45^{\circ}$ and $(b) 0 / 90^{\circ}$.

$7-35$

Thermal cycle.

Effects of automotive fluids on apparent shear strength: $(a) 0 / 90^{\circ}$

and $(b) \pm 45^{\circ}$.

7.27 Percent weight change due to exposure in room-temperature distilled water and in $70 \% \mathrm{RH}$ air.

Fixture for biaxial flexure tests

Load vs deflection curves for biaxial flexure tests

Tensile fatigue $(\mathrm{R}=0.1)$ curves at $23^{\circ} \mathrm{C}$ and $120^{\circ} \mathrm{C}$

9.2 Mixed-mode ply failures and interlaminar shear failures exhibited by specimens with $\pm 45^{\circ}$ fiber orientation

9.3 Maximum strain behavior at room temperature in specimens with $\pm 45^{\circ}$ fiber orientation.

9.4 Maximum strain and temperature vs cycle number for $\pm 45^{\circ}$ specimen with maximum stress of $49 \%$ UTS

9.5 Maximum strain and temperature vs cycle number for $\pm 45^{\circ}$ specimen with maximum stress of $68 \%$ UTS Tensile fatigue $(\mathrm{R}=0.1)$ curves for $\pm 45^{\circ}$ specimens at $23^{\circ} \mathrm{C}$ and $120^{\circ} \mathrm{C}$

9.8 Maximum strain behavior in specimens with $0 / 90^{\circ}$ fiber orientation: (a) $23^{\circ} \mathrm{C}$ and $(b) 120^{\circ} \mathrm{C}$.

Stiffness loss vs cycle fraction, $\mathrm{n} / \mathrm{N}_{\mathrm{f}}$, in $\pm 45^{\circ}$ specimens: (a) $23^{\circ} \mathrm{C}$ and $(b) 120^{\circ} \mathrm{C}$.

Stiffness loss vs cycle fraction, $\mathrm{n} / \mathrm{N}_{\mathrm{f}}$, in $0 / 90^{\circ}$ specimens: (a) $23^{\circ} \mathrm{C}$ and $(b) 120^{\circ} \mathrm{C}$.

9.11 Tensile fatigue curves for $\pm 45^{\circ}$ specimens (plaque $\mathrm{C} 17$ ) for various temperatures: $(a)$ failure based on specimen separation or instability and $(b)$ failure based on $0.2 \%$-offset definition (solid curves)

9.13 Effects of fluids on room-temperature tensile fatigue strength of $\pm 45^{\circ}$ specimens.

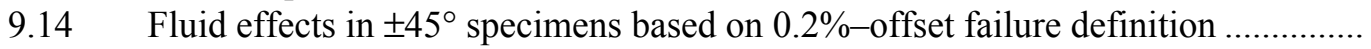

9.17 Hourglass specimen configuration used for mean stress tests $(1$ in. $=25.4 \mathrm{~mm})$.

9.18 Comparison of tensile fatigue curves $(\mathrm{R}=0.1)$ generated using $\pm 45^{\circ}$ dogbone specimens and hourglass specimens

9.19 Maximum strain vs cycle number for $\pm 45^{\circ}$ specimens undergoing tensile cycling: (a) $\mathrm{R}=0$, and (b) 50\% UTS mean stress . 
9.20 Maximum strain vs cycle number for $\pm 45^{\circ}$ specimens undergoing cycling involving compressive stresses: $(a)$ reversed fatigue $\mathrm{R}=-1$, and

(b) $\mathrm{R}=-\infty$ and 10

9.21 Stiffness loss vs cycle fraction, $\mathrm{n} / \mathrm{N}_{\mathrm{f}}$, in $\pm 45^{\circ}$ specimens undergoing tensile cycling: $(a) \mathrm{R}=0$, and $(b) 50 \%$ UTS mean stress

9.22 Stiffness loss vs cycle fraction, $\mathrm{n} / \mathrm{N}_{\mathrm{f}}$, in $\pm 45^{\circ}$ specimens undergoing cycling involving compressive stresses: $(a) \mathrm{R}=-1$, and $(b) \mathrm{R}=-\infty$ or 10 .

9.23 Mean stress fatigue results for $\pm 45^{\circ}$ specimens correlated using maximum (or absolute value of minimum) stress in cycle

9.24 Mean stress fatigue results for $\pm 45^{\circ}$ specimens correlated using alternating stress component

9.25 Mean stress fatigue results for $\pm 45^{\circ}$ specimens correlated using stress parameter $\sqrt{\mathrm{S}_{\max } \times \mathrm{S}_{\mathrm{a}}}$ or $\sqrt{\left|\mathrm{S}_{\max }\right| \times \mathrm{S}_{\mathrm{a}}}$

9.26 Mean stress fatigue results for $\pm 45^{\circ}$ specimens correlated using stress parameter $\sqrt{\mathrm{S}_{\max } \times \mathrm{S}_{\mathrm{a}}}$ or $\sqrt{\left|\mathrm{S}_{\max }\right| \times \mathrm{S}_{\mathrm{a}}}$ with failure defined by the $0.2 \%$-offset method

9.27 Mean stress fatigue results for $0 / 90^{\circ}$ specimens correlated using alternating stress component $\mathrm{S}_{\mathrm{a}}$

9.28 Mean stress fatigue results for $0 / 90^{\circ}$ specimens correlated using other stress parameters: $(a) \mathrm{S}_{\max }$ and $(b) \sqrt{\mathrm{S}_{\max } \times \mathrm{S}_{\mathrm{a}}}$

Room-temperature fatigue design curves for tension $(\mathrm{R}=0)$ cycling

9-30

10.1

Tabbed dogbone tensile specimens used for creep tests

10.2

Specimen assembly for creep test.

$10-11$

10.3

Heating tape arrangement used to heat specimen

$10-12$

10.4

Plexiglass cup surrounding specimens for fluid tests

$10-13$

10.5

Compressive creep-test fixture

$10-14$

10.6 Summary of time-dependent creep data for plaques C22 and C23 (DEV) and plaque $\mathrm{C} 2$ (TBC) in the $0 / 90^{\circ}$ direction

10.7 Time-dependent deformation in the $0 / 90^{\circ}$ direction showing sensitivity to changes in laboratory $\mathrm{RH}$

10.8 Comparison of $0 / 90^{\circ}$ model predictions $(\mathrm{M}=1)$ with the as-acquired and normalized (50\% RH) time-dependent creep data of $\mathrm{C} 22$ and $\mathrm{C} 23$ specimens tested at room temperature

10.9 Comparison of $0 / 90^{\circ}$ predictions $(\mathrm{M}=2)$ and time-dependent creep data from $\mathrm{C} 2$ specimens tested at room temperature....

10.10 Comparison of $\pm 45^{\circ}$ model predictions and time-dependent creep data for $\mathrm{C} 6$ and $\mathrm{C} 24$ specimens tested at room temperature

10.11 Comparison of creep model predictions and time-dependent creep data for $\mathrm{C} 24$ specimens tested at room temperature

10.12 Comparison of $0 / 90^{\circ}$ model predictions and time-dependent creep data for $\mathrm{C} 22$ specimens tested at elevated temperatures

10.13 Comparison of $\pm 45^{\circ}$ model predictions and time-dependent creep data for $\mathrm{C} 24$ specimens tested at $70^{\circ} \mathrm{C}$.

10.14 Comparison of $0 / 90^{\circ}$ model predictions $(\mathrm{M}=1, \mathrm{~K}=4)$ and time-dependent creep data from $\mathrm{C} 22$ specimens tested in distilled water and windshield washer fluid 
10.15 Comparison of $\pm 45^{\circ}$ model predictions $(\mathrm{M}=1, \mathrm{~K}=2.5)$ and time-dependent creep data from $\mathrm{C} 24$ specimens tested in water and windshield washer fluid ....

10.16 Comparison of simulated $0 / 90^{\circ}$ compressive creep curves $(\mathrm{M}=1, \mathrm{~K}=1.5)$ and creep data from $\mathrm{C} 23$ specimens tested in either tension or compression

10.17 Comparison of $\pm 45^{\circ}$ model predictions $(\mathrm{M}=1, \mathrm{~K}=1.5)$ and time-dependent creep data from $\mathrm{C} 24$ specimens tested in compression.

11.1 Stress-rupture data and relationships for $0 / 90^{\circ}$ specimens

11.2 Stress-rupture data and relationships for $\pm 45^{\circ} \mathrm{C} 24$ specimens......

11.3 Comparison of creep behavior of $0 / 90^{\circ}$ specimens tested at $200 \mathrm{MPa}$ at elevated temperatures and in distilled water...

11.4 Comparison of creep behavior of $0 / 90^{\circ}$ specimens tested at $300 \mathrm{MPa}$ at elevated temperatures and in distilled water and windshield washer fluid

11.5 Comparison of creep behavior of $0 / 90^{\circ}$ specimens tested at $400 \mathrm{MPa}$ at $23^{\circ}$ and $70^{\circ} \mathrm{C}$

11.6 Creep data for $\pm 45^{\circ} \mathrm{C} 24$ specimens at room temperature and $70^{\circ} \mathrm{C}$

11.7 MDAS curves for plaques C22 and C23 $\left(0 / 90^{\circ}\right)$ for fluid environments and for compressive loading....

11.8 MDAS curves for plaque $\mathrm{C} 24\left( \pm 45^{\circ}\right)$ for fluid environments and for compressive loading.

12.1 Schematic drawing of crossply-stitched T300 mat/urethane 420 IMR resin composite laminate $\left( \pm 45^{\circ}\right)_{3}$ S , showing load orientation angle $\phi$

12.2 Average values and standard deviations for 1-h creep data of $45^{\circ}$ coupons at $23^{\circ} \mathrm{C}$ and their power-law fits for various stress levels.....

12.3 Average values and standard deviations during 15-h recovery, following 1-h creep, and their power-law predictions under various stress levels for $45^{\circ}$ coupons at $23^{\circ} \mathrm{C}$.

12.4 Average values and standard deviations for 5-h creep data of $45^{\circ}$ coupons at $23^{\circ} \mathrm{C}$ and their power-law fits for various stress levels.

12.5 Average values and standard deviations during 15-h recovery, following 5-h creep, and their power-law predictions under various stress levels for $45^{\circ}$ coupons at $23^{\circ} \mathrm{C}$.

12.6 Average values and standard deviations for 24-h creep data of $45^{\circ}$ coupons at $23^{\circ} \mathrm{C}$ and their power-law fits for various stress levels...

12.7 Average values and standard deviations during 48-h recovery, following 24-h creep, and their power-law predictions under various stress levels for $45^{\circ}$ coupons at $23^{\circ} \mathrm{C}$.....

12.8 Creep and recovery data collected on a multigaged $45^{\circ}$ coupon exhibiting nonuniform deformation within a test specimen ....

12.9 Baseline creep data to establish power-law stress-strain parameters within the linear range $\left(\phi=45^{\circ}, 24-\mathrm{h}\right.$ creep, and $\left.23^{\circ} \mathrm{C}\right)$

12.10 Use of baseline creep data for predicting the short-term stress-strain response within the linear range $\left(\phi=45^{\circ}, 5\right.$-h creep, and $\left.23^{\circ} \mathrm{C}\right)$

12.11 Comparison of creep data with theoretical predictions for stress-strain response within linear range $\left(\phi=15^{\circ}, 24-\mathrm{h}\right.$ creep, and $\left.23^{\circ} \mathrm{C}\right)$

12.12 Comparison of creep data with theoretical predictions for stress-strain response within the linear range $\left(\phi=15^{\circ}, 5\right.$-h creep, and $\left.23^{\circ} \mathrm{C}\right)$

12.13 Comparison of creep data with theoretical predictions for stress-strain response within the linear range $\left(\phi=34^{\circ}, 24-\mathrm{h}\right.$ creep, and $\left.23^{\circ} \mathrm{C}\right)$ 
12.14 Comparison of creep data with theoretical predictions for stress-strain response within the linear range $\left(\phi=34^{\circ}, 5\right.$-h creep, and $\left.23^{\circ} \mathrm{C}\right)$.

12.15 Creep and recovery data of $0^{\circ}$ coupons under a stress level of $350 \mathrm{MPa}$ $\left(\phi=0^{\circ}, 5\right.$-h creep, 15 -h recovery, and $\left.23^{\circ} \mathrm{C}\right)$

12.16 Experimental data and model prediction under a two-step load history for $45^{\circ}$ coupons at $23^{\circ} \mathrm{C}$

12.17 Relationship between Poisson's ratio and creep time for a multigaged coupon $\left(\phi=45^{\circ}, 5\right.$-h creep, and $\left.23^{\circ} \mathrm{C}\right)$.

13.1 Effect of prior short-time loads on stiffness: $(a) \pm 45^{\circ}$ orientation and (b) $0 / 90^{\circ}$ orientation.

13.2 Effect of prior fatigue cycles on $\pm 45^{\circ}$ tensile strength and stiffness: (a) UTS and $(b)$ stiffness

13.3 Time-dependent creep curves for specimens precycled in tension $(\mathrm{R}=0.1)$ at a maximum stress of $86 \mathrm{MPa}$.

13.4 Results of fatigue tests of three precrept $\pm 45^{\circ}$ specimens compared to baseline fatigue data from Fig. 9.1

14.1 Photograph of back of specimen C38-1, impacted by air-gun projectile......... C-scan of impact specimen C38-1

Photograph of back of specimen C43-1, impacted by pendulum

C-scan of impact specimen C43-1

Photograph of back of specimen C33-4, impacted by pendulum

C-scan of impact specimen C33-4.

14.7 Baseline impact damage areas (with delaminations) vs kinetic energy 14-13

14.8 Comparison of peak impact forces measured in pendulum tests of crossply carbon-fiber composite and chopped-glass-fiber composite.

14.9 Baseline impact damage areas (with delaminations) $\mathrm{vs}^{0.527} \mathrm{v}$.

14.10 Baseline impact damage areas (without delaminations) vs kinetic energy.......... $14-14$

14.11 Baseline impact damage areas (without delaminations) vs $\mathrm{m}^{0.533} \mathrm{~V}$ $14-15$

14.12 Effect of prior 1000-h soak in distilled water on damage: $(a)$ delaminations included in areas and $(b)$ delaminations excluded from areas.....

14.13 Impact damage data for specimens subjected to brick drops compared to baseline correlations: $(a)$ delaminations included in areas and

(b) delaminations excluded from areas.

14.14 Schematic of cutting plan for tensile specimens obtained from impacted plate specimens.

14.15 Relative retained tensile strength (as measured in 25.4-mm-wide specimen) vs damage area: $(a)$ delaminations included in areas and $(b)$ delaminations excluded from areas

14.16 Relative retained compressive strength of center 25.4-mm-wide specimens vs damage area: $(a)$ delaminations included in areas and $(b)$ delaminations excluded from areas

14.17 Tensile fatigue results superimposed on $\pm 45^{\circ}$ tensile strength degradation data from Fig. 14.15(a)

14.18 Comparison of compressive strength retention in presoaked impact specimens compared to baseline data

14.19 Relative retained strength in specimens impacted by dropped bricks compared to baseline pendulum and air-gun data: $(a)$ tensile strength and (b) compressive strength 
14.20 Suggested curve for conservatively estimating impact damage areas ................... 14-24

14.21 Suggested curve for conservatively estimating strength loss ................................ 14-24 


\section{LIST OF TABLES}

Table

2.1 Recommended elastic properties for design analysis

\section{1}

3.2

3.3

3.4

4.1

4.2

4.3

6.1

6.2

6.3

6.4

6.5

6.6

6.7

6.8

6.9

7.1

7.2

7.3

7.4

7.5

7.6

7.7

7.8

7.9

7.10

7.11

7.12

7.13

7.14

7.15

8.1

Allowable uniaxial tensile stresses, $\mathrm{S}_{0}(\mathrm{MPa})$.

for $\pm 45^{\circ}$ fiber orientation

Fatigue strength factors to account for temperature.

Elastic constants

$\mathrm{S}_{\mathrm{t}}$ values in air $(\mathrm{MPa})$.

at $0 \mathrm{~h}$ and $5000 \mathrm{~h}$

room-temperature UTS

Damage areas from design curve (Fig. 5.1)

Strength reduction ratios caused by impact damage.

fiber orientation.....

fiber orientation.

temperatures strength and stiffness.

by freezing

distilled water

Flexure properties at $23^{\circ} \mathrm{C}$ and $120^{\circ} \mathrm{C}$.
Estimated allowable short-time uniaxial compressive stresses (MPa).

Allowable time-dependent uniaxial tensile stresses, $\mathrm{S}_{\mathrm{t}}(\mathrm{MPa})$.

Allowable time-dependent uniaxial tensile stresses, $\mathrm{S}_{\mathrm{t}}(\mathrm{MPa})$, with reductions

to account for fluid, temperature cycling, and prior load effects.

Fatigue strength multiplication factors for evaluating compressive cycles

Fatigue strength factors to account for two bounding fluid environments.

Time-dependent creep strains due to $100 \mathrm{MPa}$ applied for $5000 \mathrm{~h}$.

Bounding fluid and prior load reduction factors for allowable stresses

Allowable maximum cyclic stresses for tensile cycling

Bounding fluid and prior load reduction factors for cyclic stresses

Key allowable tensile stresses, expressed as a percentage of average

Average in-air room-temperature baseline properties

Average properties from temperature dependence study for $0 / 90^{\circ}$

Average properties from temperature dependence study for $\pm 45^{\circ}$

Temperature multiplication factors for determining at-temperature modulus

and strength from room-temperature values for $0 / 90^{\circ}$ fiber orientation

Temperature multiplication factors for determining at-temperature modulus

and strength from room-temperature values for $\pm 45^{\circ}$ fiber orientation ......

Baseline properties at different temperatures for $0 / 90^{\circ}$ fiber orientation.

Baseline properties at different temperatures for $\pm 45^{\circ}$ fiber orientation.

Calculated and experimental values of shear modulus $G$ at different

Details of automotive fluids used in environmental screening...

Effects of fluid environments on apparent shear strength in short-beam shear.........

Effects of exposure in $23^{\circ} \mathrm{C}$ distilled water and in $70 \% \mathrm{RH}$ air on tensile

Effects on stiffness and strength of exposure to moisture followed

Effects on stiffness and strength of exposure in windshield washer fluid

Fluid reduction factors for 1000-h exposure in room-temperature

Fluid reduction factors for 100 -h exposure in windshield washer fluid.
Page

$2-1$

3-2

$3-2$

$3-3$

3-4

4-1

4-2

4-2

6-1

6-2

6-2

6-3

$6-3$

6-3

6-4

6-5

6-6

7-4

7-5

7-5

7-6

7-6

7-7

7-7

7-8

7-10

$7-11$

7-12

7-13

7-13

7-14

7-14

8-1 
8.2 Effects of environment on flexure properties …….............................................. 8-2

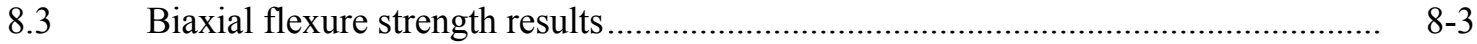

8.4 Strength reduction factors relative to in-air room-temperature values ...................... $8-4$

9.1 Fatigue strength multiplication factors for temperature ........................................... 9-4

9.2 Fatigue strength multiplication factors to account for fluid effects ........................... 9-5

9.3 Fatigue strength multiplication factors for the $\pm 45^{\circ}$ fiber orientation to account

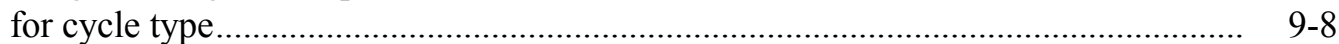

10.1 Summary of test parameters and results of creep and creep-rupture tests in first test series (mold-run TBC) ......................................................................... 10 10

10.2 Summary of test parameters and results of creep and creep-rupture tests in second test series (mold-run DEV) .................................................................. 10-2

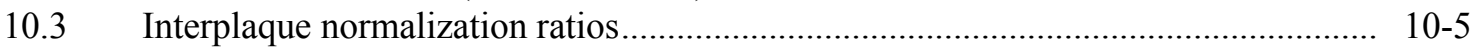

10.4 Creep strain multiplication factors, $\mathrm{K}$, for various environmental and

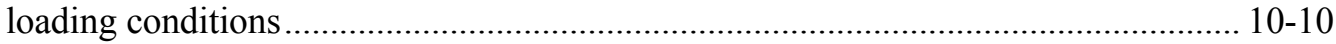

11.1 Stress reduction factors to account for fluids and compression ............................. 11-3

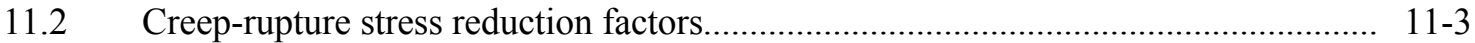

12.1 Parameters used for fitting the creep and recovery data of $45^{\circ}$ coupons................... 12-2

13.1 Average UTS values from groups of specimens subjected to prior short-time static loads

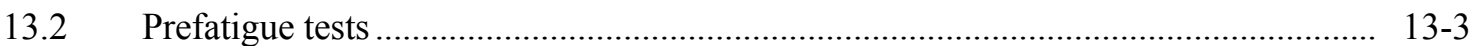

13.3 Results of tensile tests on precrept specimens .................................................... 13-4

13.4 Summary of property reductions due to prior load effects....................................... 13-5

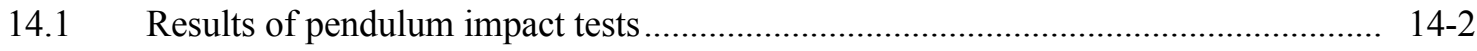

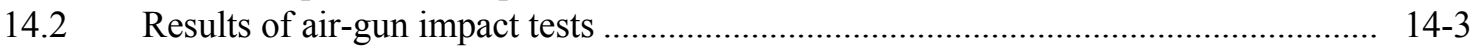

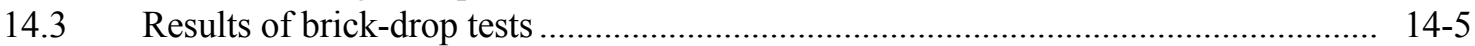




\title{
DURABILITY-BASED DESIGN PROPERTIES OF A REFERENCE CROSSPLY CARBON-FIBER COMPOSITE
}

\author{
J. M. Corum \\ K. C. Liu \\ R. L. Battiste \\ M. B. Ruggles \\ S. Deng \\ Y. J. Weitsman
}

\begin{abstract}
This report provides recommended durability-based design properties and criteria for a crossply carbon-fiber composite for possible automotive structural applications. Although the composite utilized aerospace-grade carbon-fiber reinforcement, it was made by a rapid-molding process suitable for high-volume automotive use. The material is the first in a planned progression of candidate composites to be characterized as part of an Oak Ridge National Laboratory project entitled Durability of Carbon-Fiber Composites. The overall goal of the project, which is sponsored by the U.S. Department of Energy's Office of Advanced Automotive Technologies and is closely coordinated with the Advanced Composites Consortium, is to develop durability-driven design data and criteria to assure the long-term integrity of carbon-fiber-based composite systems for automotive structural applications.

The composite addressed in this report is a $\left( \pm 45^{\circ}\right)_{3 \mathrm{~S}}$ crossply consisting of continuous Thornel T300 fibers in a Baydur 420 IMR urethane matrix. This composite is highly anisotropic with two dominant fiber orientations $-0 / 90^{\circ}$ and $\pm 45^{\circ}$. Properties and models were developed for both orientations.

This document is in two parts. Part 1 provides design data and correlations, while Part 2 provides the underlying experimental data and models. The durability issues addressed include the effects of short-time, cyclic, and sustained loadings; temperature; fluid environments; and low-energy impacts (e.g., tool drops and kickups of roadway debris) on deformation, strength, and stiffness. Guidance for design analysis, time-independent and time-dependent allowable stresses, rules for cyclic loadings, and damage-tolerance design guidance are provided.
\end{abstract}

\section{INTRODUCTION}

\subsection{BACKGROUND}

This report is the third in a series providing durability-based design data and criteria for polymeric composites suitable for producing large structural automotive components. The previous two addressed random-glass-fiber composites - one with swirled continuous-strand-mat reinforcement and one with chopped-fiber reinforcement. ${ }^{1-3}$ This third report is the first to address carbon-fiber composites, which will be ultimately required to meet weight goals for new lightweight vehicles.

The work reported here was part of a project at Oak Ridge National Laboratory (ORNL) entitled Durability of Carbon-Fiber Composites. The project is sponsored by the U.S. Department of Energy Office of Advanced Automotive Technologies and is closely coordinated with the Automotive Composites Consortium (ACC). Both the random-glass-fiber composites and the 
subject crossply carbon-fiber composite were fabricated by ACC in the form of 3.2-mm-thick plaques.

The primary project goal is to develop experimentally based, durability-driven guidelines to assure the long-term (15-year) integrity of representative carbon-fiber-based composite systems that can be used to produce large structural automotive components. Durability issues being considered include the potentially degrading effect that both cyclic and sustained loadings, exposure to automotive fluids, temperature extremes, and low-energy impacts from such things as tool drops and kickups of roadway debris can have on structural strength, stiffness, and dimensional stability.

The near-term plan for characterizing and modeling the durability of carbon-fiber composites is to focus on the following sequence of materials, each of which has the same urethane matrix:

- reference $\left( \pm 45^{\circ}\right)_{3 \mathrm{~S}}$ crossply composite,

- $\left(0 / 90^{\circ} / \pm 45^{\circ}\right)_{\mathrm{S}}$ quasi-isotropic composite, and

- chopped-fiber composite.

The quasi-isotropic composite utilizes the same $\pm 45^{\circ}$ stitched-mat reinforcement as the crossply composite discussed here.

\subsection{MATERIAL}

The reference carbon-fiber composite addressed here is a $\left( \pm 45^{\circ}\right)_{3 \mathrm{~S}}$ crossply consisting of Thornel T300 continuous fibers (6K version) in a Baydur 420 IMR urethane matrix. The material was supplied by ACC in the form of fifty-five $610 \times 610 \times 3.2$-mm-thick plaques. The average fiber-volume content varied between molding runs, with values ranging from 39.0 to $44.3 \%$. The constituent materials, as well as the rapid-molding process used to mold the plaques, are described in Appendix A. Properties of individual plaques are tabulated in Appendix B.

As described in Appendix B, inherent features of rapid-molding processes that are suitable for high-volume automotive structural applications lead to variations in fiber orientations and material thickness. The resulting variabilities in mechanical response are frequently discussed throughout this report.

Figure 1.1 depicts the stack of six $\pm 45^{\circ}$ stitch-bonded mats that make up the reinforcement in the crossply composite. The resulting composite is highly anisotropic in the plane of the plaque. Specimens cut with the fibers oriented at $0 / 90^{\circ}$ to the specimen axis exhibit strong fiberdominated behavior. In contrast, specimens cut with a $\pm 45^{\circ}$ fiber orientation relative to the specimen axis exhibit relatively weak matrix-dominated behavior. Throughout the characterization and modeling of the crossply composite, both fiber orientations were addressed. It is believed that these two extremes bound the durability behavior, which makes the crossply composite wellsuited to be the reference material against which the behavior of future carbon-fiber composites can be judged.

Throughout this report, comparisons are made between the properties of the crossply carbonfiber composite, in the two fiber orientations, and the corresponding properties of the choppedglass-fiber composite previously characterized. ${ }^{3}$ The comparative glass-fiber composite used preforms of 50-mm-long chopped E-glass fibers. The preforms were produced by a robotic performing system developed by Owens Corning in Battice, Belgium, and entitled the Programmable, Powder, Preform Process, or P4. The preforms were produced with the proper areal density, so no lay up was required. The resulting composite, which had an average fiber content of 28.9 vol \%, closely resembles that used in the ACC Focal Project II composite pickup truck box. ${ }^{4}$ The 
chopped-glass-fiber composite had the same matrix material as the current carbon-fiber composite. Thus, comparisons between the two are particularly germane.

\subsection{LOADINGS AND ENVIRONMENTS}

From a durability standpoint, it is assumed here that an automobile with a composite structure must last for 15 years $(131,500 \mathrm{~h})$ and 150,000 miles. It is further assumed that during the 15 years, the vehicle will actually be operated between 3000 and $5000 \mathrm{~h}$ (based on an average speed of 30 to $50 \mathrm{mph})$.

The design temperature range is taken to vary from a minimum of $-40^{\circ} \mathrm{C}$ to a maximum of $120^{\circ} \mathrm{C}$, with the higher temperatures occurring only during operation. The effects of thermal cycling are also a concern.

In addition to functional stiffness and deformation requirements, structures must support and resist a variety of live and dead loads. During operation, for example, live loads might include a combination of pothole impact, hard turn, and maximum acceleration. Dead loads during the 15-year life would include those from the weight of the vehicle or more importantly, sustained loads in the bed of a light truck.

Structures will also be subjected to common vehicle fluids and operating atmospheres, and design limits must take the resulting property degradation into account. The effects of a variety of fluids and moisture conditions were examined in the case of the glass-fiber composites and in screening tests, reported here, on the carbon-fiber composite. Based on the combined findings, the fluids most extensively examined were reduced primarily to distilled water and windshield washer fluid (a methanol/water mix).

\subsection{OUTLINE OF REPORT}

This report is divided into two parts, in a manner analogous to the arrangement used in the previous glass-fiber composite reports. Part 1 , which consists of five chapters, provides guidelines for (1) the properties to be used in structural analysis, (2) design allowables for static loadings, (3) design rules for cyclic loadings, and (4) damage tolerance design for low-energy impacts. A final Part 1 chapter summarizes the crossply carbon-fiber composite criteria and compares the allowables with the corresponding values for the chopped-glass-fiber composite. Note that the criteria of Part 1 are incomplete because only properties and allowables for the two bounding orientations $-0 / 90^{\circ}$ and $\pm 45^{\circ}$ - are given. Because of the anisotropy of the crossply composite, it was not possible to develop and recommend a simple biaxial strength theory, as was done for the isotropic random-glass-fiber composites.

Part 2, which consists of eight chapters, provides the experimental data and models on which the guidance and criteria of Part 1 are based. Those readers wishing to understand the basic behavioral characteristics of the crossply carbon-fiber composite should read Part 2 prior to reading Part 1. Part 2 has chapters on basic properties, including flexure, cyclic fatigue, timedependent creep and creep rupture, prior load effects, and impact. A chapter on time-dependent deformation modeling presents a constitutive model that can be used to predict not only creep strains, but recovery strains and the response to changing load levels. The model also allows response predictions to be made for fiber orientations other than $0 / 90^{\circ}$ and $\pm 45^{\circ}$. 


\subsection{DEFINITIONS USED IN PART I}

E Elastic modulus (often referred to simply as stiffness)

$\mathrm{G} \quad$ Shear modulus

K Temperature-dependent factor on allowable bending stress

$\mathrm{m} \quad$ Mass of impacting object

$\mathrm{n} \quad$ Number of applied fatigue cycles for a given stress

$\mathrm{N}_{\mathrm{d}} \quad$ Number of allowable design cycles for a given stress

$\mathrm{P} \quad$ Calculated membrane stress at a point in the plane of a plate or shell structure

Q Calculated bending stress at a point

$\mathrm{R} \quad$ Ratio of minimum to maximum stress in a fatigue cycle

$\mathrm{S}_{0} \quad$ Basic short-time allowable stress (time $\mathrm{t}=0$ )

$\mathrm{S}_{\mathrm{t}} \quad$ Time-dependent allowable stress

$\mathrm{S}_{\mathrm{r}} \quad$ Minimum creep-rupture strength at a given time

$\mathrm{t} \quad$ Time at a given stress

$\mathrm{T}_{\mathrm{d}} \quad$ Allowable design time at a given stress

UTS Ultimate tensile strength

$\mathrm{v} \quad$ Velocity of impacting object

$\varepsilon \quad$ Normal strain

$\varepsilon_{\mathrm{c}} \quad$ Normal creep strain

$\sigma \quad$ Normal stress

$v \quad$ Poisson's ratio

ORNL 2001-735 EFG

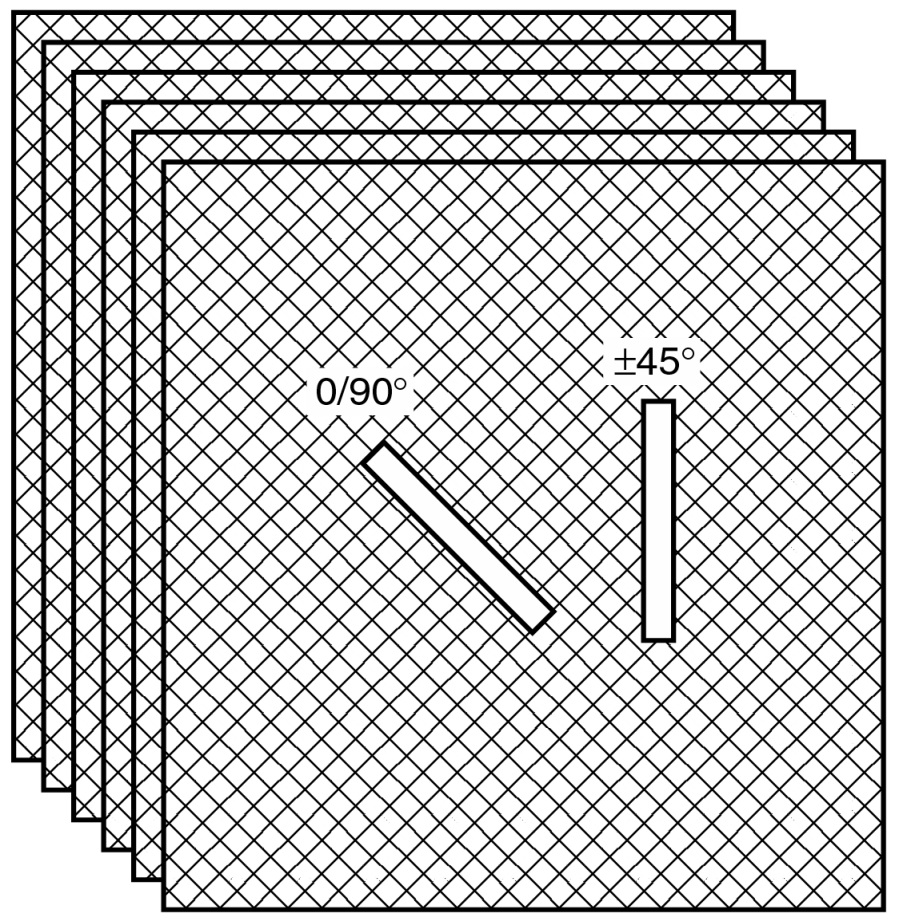

Fig. 1.1. Schematic of reinforcement arrangement. The $\pm 45^{\circ}$ fibers in each of the six mat layers are stitch-bonded together. 
PART 1

DESIGN CRITERIA 


\section{ELASTIC AND CREEP PROPERTIES FOR DESIGN ANALYSIS}

\subsection{INTRODUCTION}

Unlike the previously investigated random-glass-fiber composites, which were relatively isotropic in the plane of the plaques, the crossply carbon-fiber composite addressed here is highly anisotropic. As explained in Chap. 1, the direction having fibers oriented at $0 / 90^{\circ}$ exhibits strong fiber-dominated behavior, while the direction having fibers oriented at $\pm 45^{\circ}$ exhibits relatively weak matrix-dominated behavior. This means that simple in-plane isotropic design analyses will, in general, no longer suffice.

In this chapter, in-plane elastic and creep properties for the two dominant directions will be recommended. With certain restrictions, properties for other orientations can be calculated using classical lamination and viscoelasticity theories (see Chap. 12).

\subsection{ELASTIC PROPERTIES FOR DESIGN}

Table 2.1 tabulates the recommended modulus of elasticity and Poisson's ratio values for the two fiber orientations and for the $-40^{\circ}$ to $120^{\circ} \mathrm{C}$ temperature range of interest. These values are tensile test results reported in Chap. 7 (see Tables 7.6 and 7.7). Shear modulus values, G, are also given in Chap 7.

Table 2.1. Recommended elastic properties for design analysis

\begin{tabular}{rcccc}
\hline \multirow{2}{*}{ Properties } & \multicolumn{5}{c}{ Temperature } \\
\cline { 2 - 5 } & $\mathbf{- 4 0 ^ { \circ } \mathbf { C }}$ & $\mathbf{2 3}^{\circ} \mathbf{C}$ & $\mathbf{7 0}^{\circ} \mathbf{C}$ & $\mathbf{1 2 0}^{\circ} \mathbf{C}$ \\
\hline \multicolumn{5}{c}{$\mathbf{0 / 9 0 ^ { \circ }}$ Fiber orientation } \\
Modulus, GPa & 46.7 & 46.7 & 45.8 & 42.0 \\
Poisson's ratio & 0.05 & 0.05 & 0.04 & 0.04 \\
& $\mathbf{\pm 4 5}$ Fiber orientation & \\
Modulus, GPa & 14.6 & 11.3 & 8.93 & 6.22 \\
Poisson's ratio & 0.70 & 0.76 & 0.74 & 0.87 \\
\hline
\end{tabular}

For temperatures other than those in Table 2.1, modulus of elasticity values can be determined by multiplying the room-temperature values by a factor given by one of the following equations:

$$
\begin{gathered}
0 / 90^{\circ}: \text { Factor }=0.994+5.11 \times 10^{-4} \mathrm{~T}-1.05 \times 10^{-5} \mathrm{~T}^{2} . \\
\pm 45^{\circ}: \text { Factor }=1.11-4.63 \times 10^{-3} \mathrm{~T} .
\end{gathered}
$$

In these equations, $\mathrm{T}$ is temperature in degrees Celsius.

\subsubsection{Environmental Effects}

In Chap. 7, Tables 7.14 and 7.15 summarize the stiffness reduction factors for the two standard bounding fluid exposures-1000-h presoak in distilled water and 100-h presoak in 
windshield washer fluid ( $70 \%$ methanol $/ 30 \%$ distilled water). A stiffness reduction factor of 0.93 covers both degrading fluid exposures and all stress states.

\subsubsection{Prior Loading Effects}

As described later in Chap. 13, prior loadings, whether short-time static, cyclic, or long-term sustained, produce microstructural damage that is manifest as a reduction in stiffness. These reductions should be accounted for in design analyses. Recommended reduction factors, taken from Table 13.4, are tabulated below.

\begin{tabular}{|c|c|c|}
\hline \multirow[b]{2}{*}{ Prior load } & \multicolumn{2}{|c|}{ Stiffness reduction factor } \\
\hline & $\mathbf{0} / 90^{\circ}$ & $\pm 45^{\circ}$ \\
\hline Short- $t$ & 1.00 & 0.96 \\
\hline Fatigue cycling & 0.97 & 0.90 \\
\hline Long-term sustained & 0.95 & 0.96 \\
\hline
\end{tabular}

Each value in the above tabulation corresponds to maximum allowable prior loading conditions. The prior short-time static load corresponds to the maximum allowable stress, $\mathrm{S}_{0}$ (see Chap. 3). The prior cycling corresponds to $5 \%$ of the cyclic life, which is the design limit (see Chap. 4); and the long-term sustained load corresponds to the allowable design time (see Chap. 3). The lowest reduction factor in the tabulation corresponds to prior fatigue cycling in the $\pm 45^{\circ}$ fiber orientation. At elevated temperatures, this factor can become much smaller, so caution should be used to preclude cyclic loadings at elevated temperatures in the weak, matrixdominated, fiber orientation.

\subsubsection{Prior Temperature Cycling}

Chapter 7 contains a section on the effects of cycling the temperature slowly between $-40^{\circ}$ and $120^{\circ} \mathrm{C}$. Stiffness in the $0 / 90^{\circ}$ fiber orientation is reduced just $1.8 \%$ by the prior temperature cycling. The $\pm 45^{\circ}$ stiffness, which is matrix-dominated and sensitive to the fiber-matrix interface, is reduced by $15.5 \%$. These reductions are likely due to microstructural damage caused by the large thermal expansion mismatch between fiber and matrix.

\subsection{CREEP PROPERTIES FOR DESIGN}

In the case of long-term sustained loadings - either those associated with the 3000- to 5000-h operating life of an automobile or the nominally 15-year overall life - creep deformations may become an important consideration and need to be accounted for in design analyses. This can be done at one of three levels of sophistication:

- using a time-dependent isochronous stress-strain curve in an inelastic (elastic-plastic) analysis,

- using a creep equation in an inelastic (elastic-creep) analysis, or

- using a damage-based constitutive model derived for the material that can predict the effects of changing load levels as well as recovery strains upon unloading.

Guidance for the first two levels is given in the following sections. The recommended constitutive model is described in Chap. 12. 


\subsubsection{Basic Creep Equations}

Equations describing the room-temperature time-dependent creep response to uniaxial loadings were derived in Chap. 10 from tensile creep data. The recommended versions of the equations for design analysis use are given below.

$$
\begin{gathered}
0 / 90^{\circ}: \varepsilon_{\mathrm{c}}=0.8304 \times 10^{-4} \sigma \mathrm{t}^{0.112} . \\
\pm 45^{\circ}: \varepsilon_{\mathrm{c}}=2.974 \times 10^{-6} \sigma^{2.634} \mathrm{t}^{0.20} .
\end{gathered}
$$

Here, $\varepsilon_{\mathrm{c}}$ is time-dependent creep strain in percent, $\sigma$ is applied stress in megeapascals, and $\mathrm{t}$ is time in hours. Equation (2.3) holds up to about $400 \mathrm{MPa}$, while Eq. (2.4) applies up to $100 \mathrm{MPa}$. For stresses within the design range, where the stress-strain curves do not depart too far from linearity, total strains can be estimated by adding elastic loading strains to the creep strains given by Eqs. (2.3) and (2.4).

Time-dependent creep curves, as predicted by Eqs. (2.3) and (2.4), are plotted in Fig. 2.1(a) and $(b)$. Note that the predicted strains corresponding to a common stress level differ by more than two orders of magnitude between the two fiber orientations.

As was the case for elastic moduli, creep strains are affected by temperature, fluid environments, and, probably, prior cyclic loadings. The first two effects are described in the following two subsections. The latter effect has not been adequately quantified.

\subsubsection{Effect of Temperature}

The effect of increasing temperature on time-dependent creep strain can be accounted for by multiplying the strains predicted by Eqs. (2.3) and (2.4) by a factor. For the $0 / 90^{\circ}$ fiber orientation, an equation for the factor as a function of temperature is derived in Chap 10. For the $\pm 45^{\circ}$ fiber orientation, excessive creep strains rapidly accumulated at $120^{\circ} \mathrm{C}$. Limited unpublished data by Deng and Weitsman indicate a factor of about 41 at $120^{\circ} \mathrm{C}$. These factors are represented in Fig. 2.2. Creep conditions should be avoided in the $\pm 45^{\circ}$ direction at temperatures much above $70^{\circ} \mathrm{C}$.

Also, compressive stresses should be avoided in areas of elevated temperature. It is shown in Chap. 10 that, at room-temperature, creep in compression is about 1.5 times that in tension, for both fiber orientations. This factor would be expected to increase significantly at elevated temperatures.

\subsubsection{Environmental Effects}

Creep strain multiplication factors were developed in Chap. 10 for the two reference fluids - distilled water and windshield washer fluid. In both cases, specimens were presoaked for $100 \mathrm{~h}$ in the fluid and then tested in the fluid. A single creep-strain multiplication factor -4.0 for the $0 / 90^{\circ}$ fiber orientation and 2.5 for the $\pm 45^{\circ}$ fiber orientation — was found to conservatively cover both fluids.

\subsubsection{Isochronous Stress-Strain Curves}

The use of isochronous stress-strain curves, which show the total strain at a given time resulting from a constant applied stress, provides a convenient way to approximately predict creep deformations in a structure. When one of these curves, corresponding to a specific time, is 
used in an elastic-plastic analysis, the creep deformation occurring during the time period can often be predicted reasonably well.

An isochronous curve for a specific time is constructed by adding the predicted timedependent creep strain at each stress level to the "instantaneous" strains represented by the shorttime stress-strain curve. For the current composite, the short-time $0 / 90^{\circ}$ stress-strain curve is just a straight line (strain linear with stress). Similarly, the creep strains [Eq. (2.3)] are linear with stress. Thus, the resulting isochronous curves are straight lines. For the $\pm 45^{\circ}$ orientation, however, the short-time stress-strain curve becomes nonlinear, and creep strains [Eq. (2.4)] are nonlinear with stress. The resulting isochronous curves are thus nonlinear as well.

The isochronous curves for the two fiber orientations are shown in Figs. 2.3 and 2.4. Equations for the curves are also given. The curves labeled "tensile" are the short-time (0-h) stress-strain curves. The 131,000-h curves show the total strain that would accumulate at a given stress level over the 15 -year life of an automobile. For the $0 / 90^{\circ}$ fiber orientation, the creep strain over 15 years is about $14 \%$ of the initial elastic loading strain. For the $\pm 45^{\circ}$ fiber orientation, the time-dependent strain after 15 years is seen to be about equal to the "instantaneous" loading strain at approximately $35 \mathrm{MPa}$. The short-time allowable stress, $\mathrm{S}_{0}$, for the composite in the $\pm 45^{\circ}$ orientation is $83 \mathrm{MPa}$ (see Chap. 3). At this stress level, the 15-year creep strain is about 3.5 times the initial loading strain. In this weak fiber orientation, deformation could likely be the limiting factor in a design. 


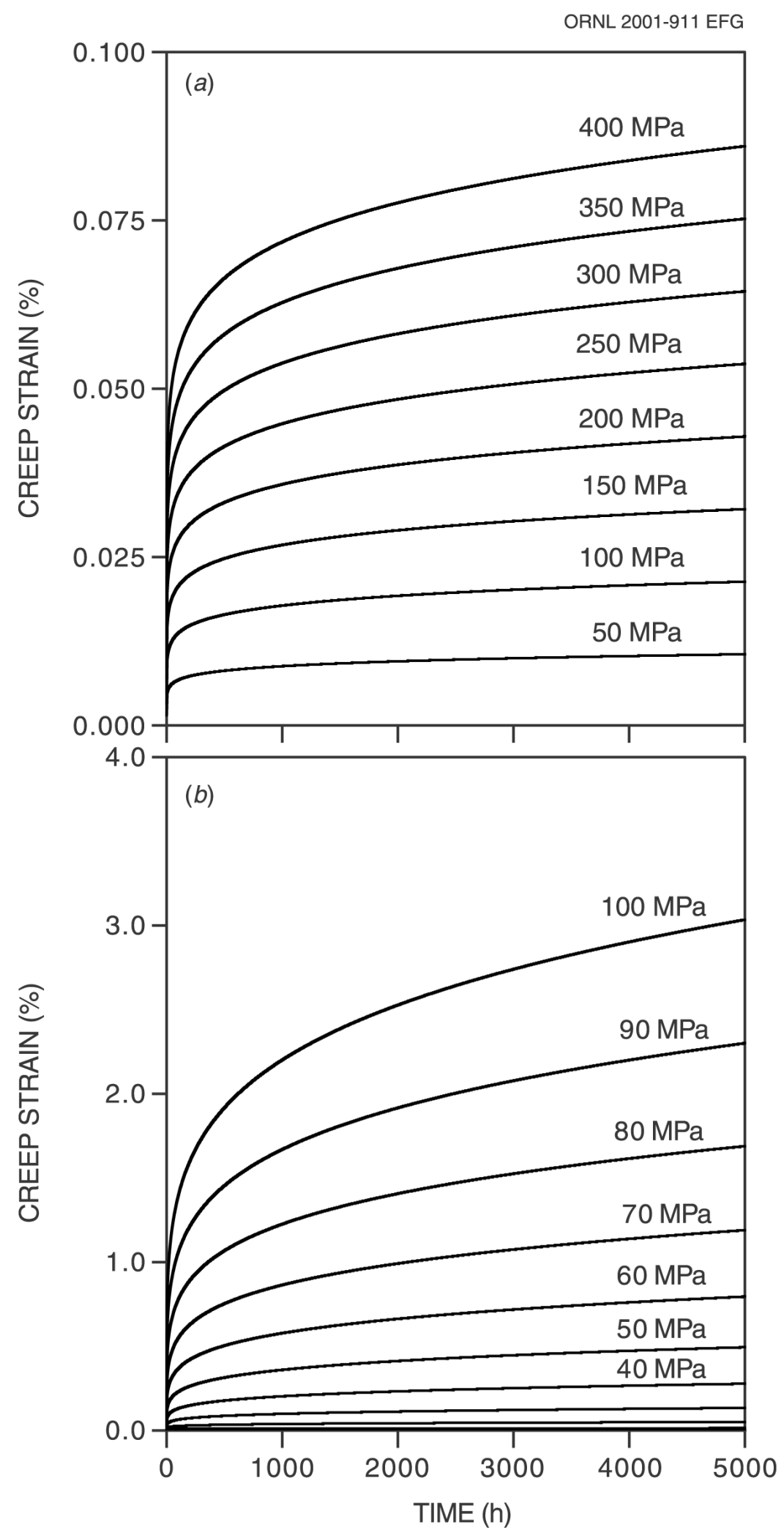

Fig. 2.1. Time-dependent creep strain curves for $R T$ ambient air conditions: (a) $0 / 90^{\circ}$ fiber orientation and (b) $\pm 45^{\circ}$ fiber orientation. 


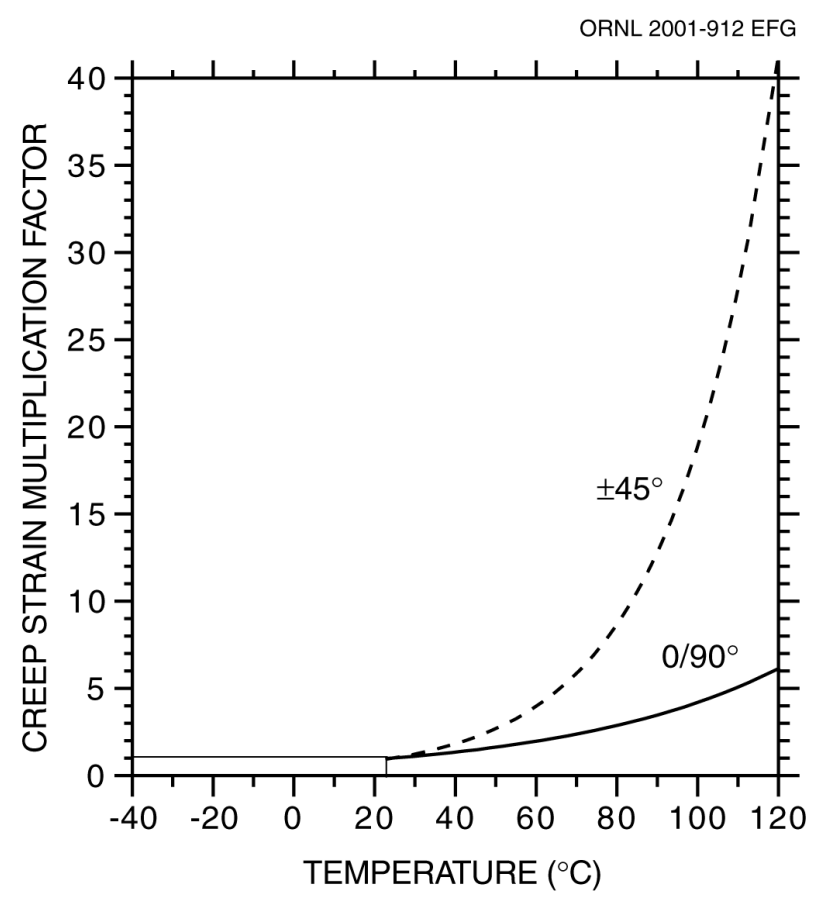

Fig. 2.2. Creep strain multipliers for temperature effects.

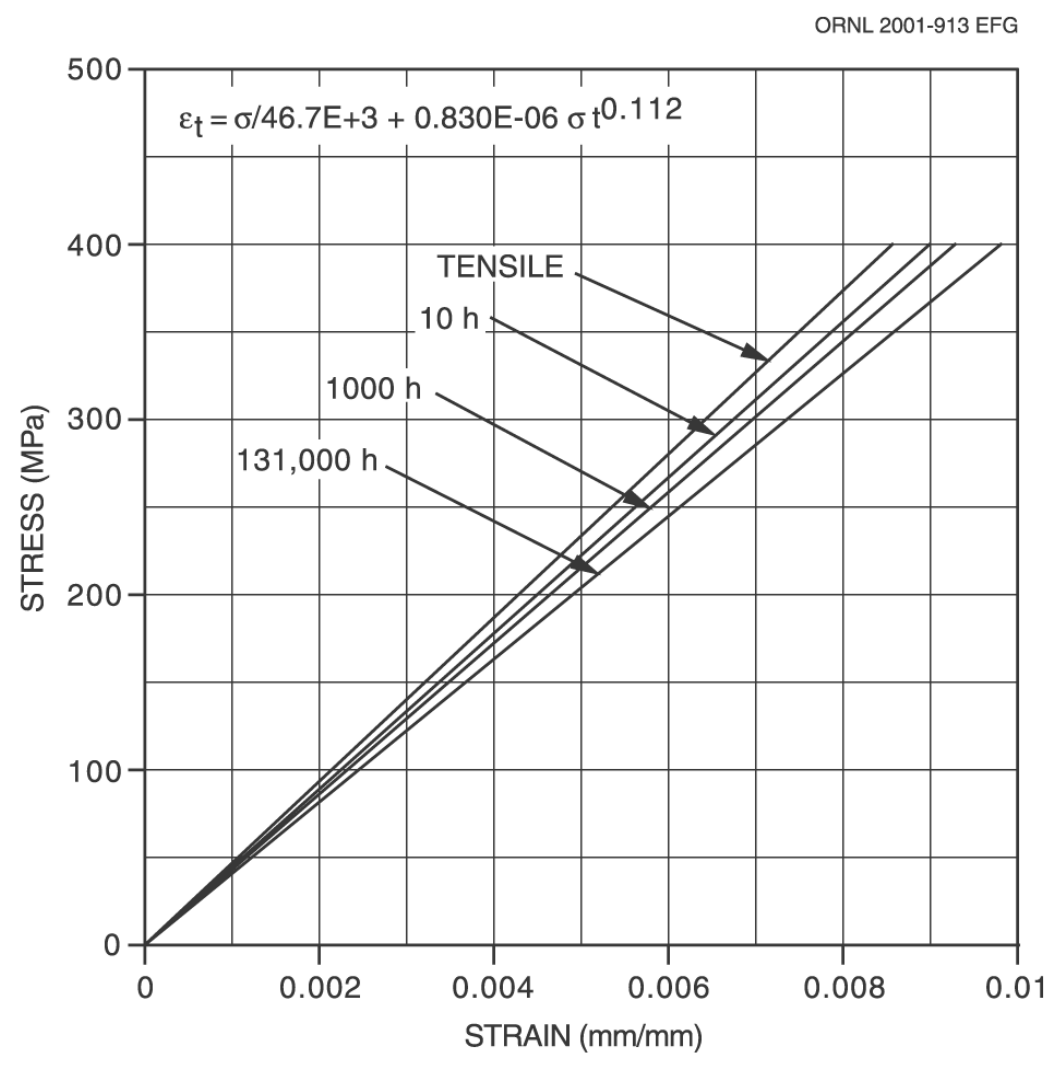

Fig. 2.3. Isochronous stress-strain curves for $\mathrm{RT}$ ambient air $-0 / 90^{\circ}$ fiber orientation. 


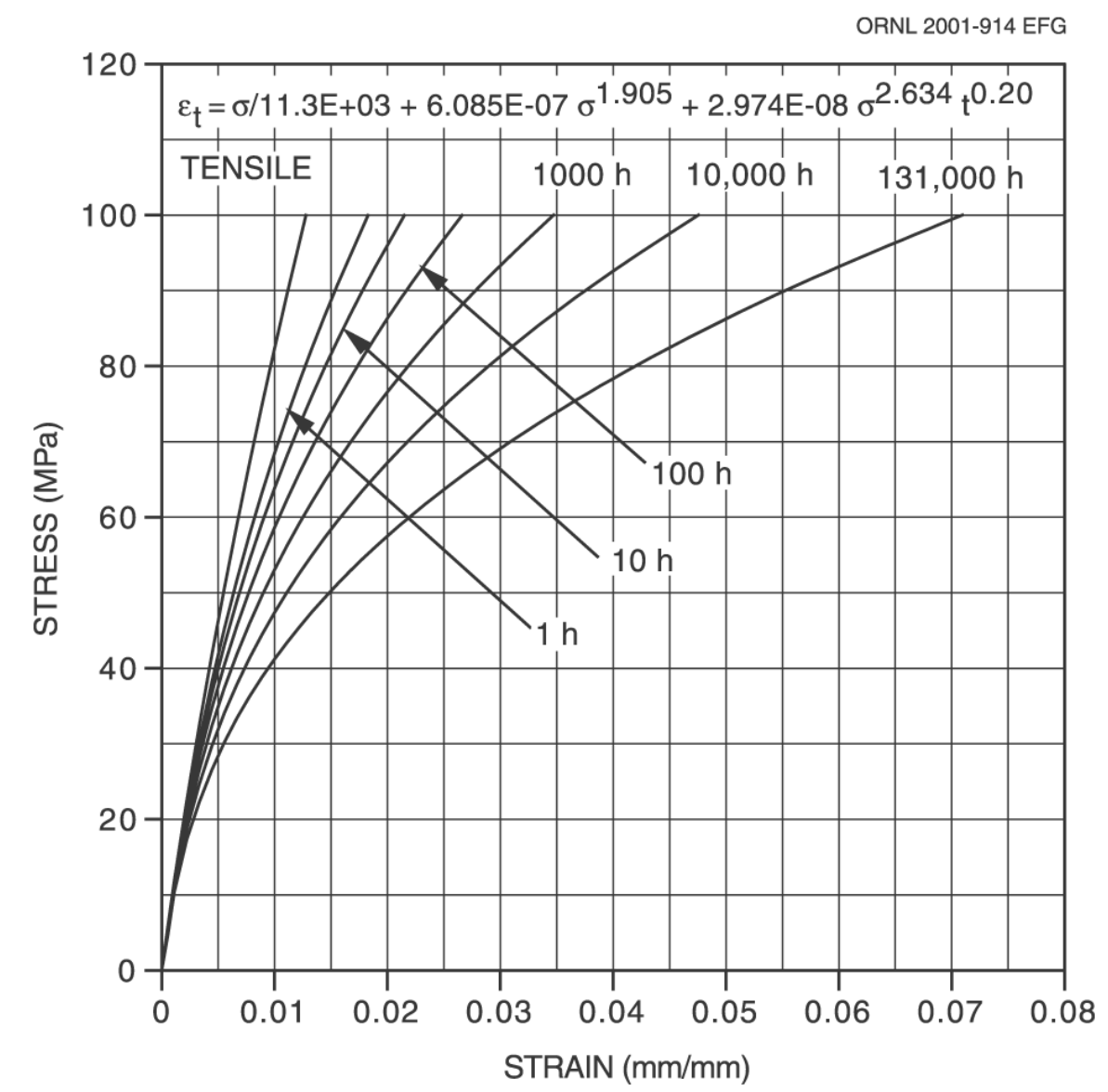

Fig. 2.4. Isochronous stress-strain curves for $R T$ ambient air $- \pm 45^{\circ}$ fiber orientation. 


\section{DESIGN ALLOWABLES FOR STATIC LOADINGS}

As was stated in Chap. 1, only design allowable stresses applicable to the two bounding fiber orientations $-0 / 90^{\circ}$ and $\pm 45^{\circ}$ - are given in this chapter. The anisotropy of the crossply composite precludes recommendation of a simple biaxial strength criterion needed for general application of the allowable stresses. The basic allowables, $\mathrm{S}_{0}$ and $\mathrm{S}_{t}$, are derived from uniaxial tensile tests, both "instantaneous" and time dependent." They are thus applicable only to uniaxial tensile stress states. Separate allowable stresses for uniaxial compression are estimated and tabulated. Factors are given to account for fluid effects, temperature cycling, and prior load effects on the allowables.

\subsection{SHORT-TIME ALLOWABLE TENSILE STRESSES, $\mathbf{S}_{0}$}

The basic short-time, or instantaneous, allowable stress is based on the minimum roomtemperature ultimate tensile strength (UTS), which is defined as the "B-basis stress" specified in MIL-HDBK-17. ${ }^{5}$ The minimum room-temperature values for the crossply carbon-fiber composite are based on statistical treatment of $n=90$ UTS values for the $0 / 90^{\circ}$ orientation and $n=107$ UTS values for the $\pm 45^{\circ}$ orientation such that the survival probability at the minimum stresses is $90 \%$ at a confidence level of $95 \%$. The room-temperature minimum UTS values were calculated to be 396 and $126 \mathrm{MPa}$ for the $0 / 90^{\circ}$ and $\pm 45^{\circ}$ fiber orientations, respectively.

The basic time-dependent allowable stress, $\mathrm{S}_{0}$, is defined as two-thirds of the $\mathrm{UTS}_{\min }$. At room temperature, the $\mathrm{S}_{0}$ values thus become

$$
\begin{aligned}
& \mathrm{S}_{0}=265 \mathrm{MPa} \text { for } 0 / 90^{\circ} ; \\
& \mathrm{S}_{0}=83 \mathrm{MPa} \text { for } \pm 45^{\circ} .
\end{aligned}
$$

Values of $\mathrm{S}_{0}$ for other temperatures can be obtained by multiplying the above roomtemperature values by the UTS factors plotted in Fig. 3.1 [the factors are taken from Chap. 7, Figs. 7.14(a) and (b)]. An additional reduction factor is applied to account for fluid effects. For tensile stresses, the appropriate bounding factors are 0.96 for the $0 / 90^{\circ}$ fiber orientation and 0.97 for the $\pm 45^{\circ}$ orientation (see Chap. 7).

Prior loadings, as discussed in Chap. 13, can also reduce subsequent short-time tensile strength. The appropriate reduction factors are 0.94 for $0 / 90^{\circ}$ and 0.96 for $\pm 45^{\circ}$. In both cases, the factors result from prior sustained loadings (creep).

Temperature cycling, within the operating range of a vehicle, lowers the subsequent $0 / 90^{\circ}$ tensile strength by $1 \%$ (see Chap. 7). It has no effect on the $\pm 45^{\circ}$ tensile strength.

The resulting allowable stresses, $\mathrm{S}_{0}$, for uniaxial tension are tabulated in Table 3.1, both with and without fluid effects and prior loading and temperature-cycling effects. Note that the allowables that incorporate fluid effects and prior load and temperature cycling effects do not include any possible synergisms. For example, fluids may have a greater effect at elevated temperatures than they do at room temperature.

\subsection{SHORT-TIME ALLOWABLE COMPRESSIVE STRESSES}

The $0 / 90^{\circ}$ tensile strength is strongly fiber dominated, whereas the compressive strength is matrix dominated. Thus, even at room temperature, the $0 / 90^{\circ}$ compressive strength is less than

\footnotetext{
*The allowable stress system, $\mathrm{S}_{0}$ and $\mathrm{S}_{\mathrm{t}}$, used here is the same as used previously for the random-glass-fiber composite design allowables. ${ }^{1,3}$
} 
Table 3.1. Allowable uniaxial tensile stresses, $\mathrm{S}_{\mathbf{0}}$ (MPa)

\begin{tabular}{|c|c|c|c|c|}
\hline & \multicolumn{4}{|c|}{ Temperature $\left({ }^{\circ} \mathrm{C}\right)$} \\
\hline & -40 & 23 & 70 & 120 \\
\hline \multicolumn{5}{|c|}{$0 / 90^{\circ}$ Fiber orientation } \\
\hline $\begin{array}{l}\text { Without fluid, temperature cycling, } \\
\text { and prior load effects }\end{array}$ & 265 & 265 & 254 & 217 \\
\hline $\begin{array}{l}\text { With fluid, temperature cycling, } \\
\text { and prior load effects }\end{array}$ & 237 & 237 & 227 & 193 \\
\hline \multicolumn{5}{|c|}{ $\pm 45^{\circ}$ Fiber orientation } \\
\hline Without fluid and prior load effects & 107 & 83 & 66 & 46 \\
\hline With fluid and prior load effects & 100 & 77 & 61 & 43 \\
\hline
\end{tabular}

the tensile strength (by a factor of 0.90), and the difference increases with increasing temperature (see Fig. 3.1). Conversely for the $\pm 45^{\circ}$ orientation, the compressive strength is greater than the tensile strength over the temperature range except near $120^{\circ} \mathrm{C}$, where it drops below the tensile strength by about $1.2 \%$. Thus, the $\pm 45^{\circ} \mathrm{S}_{0}$ values are adequate for uniaxial compression, except at $120^{\circ} \mathrm{C}$ where a slight downward adjustment is needed. Allowable compressive stresses for the $0 / 90^{\circ}$ orientation are, in contrast, significantly less than the tensile $\mathrm{S}_{0}$ values.

Table 3.2 is a tabulation of estimated allowable compressive stresses. This table is provided to give some idea of the lower allowable stress values in compression relative to the tensile $\mathrm{S}_{0}$ values. The database on which the values are based is much more limited than in the tensile case. The $\pm 45^{\circ} \mathrm{S}_{0}$ values (without fluid, temperature cycling, and prior load effects) are used for the compressive allowables, except at $120^{\circ} \mathrm{C}$, where the $\mathrm{S}_{0}$ value is reduced by $1.2 \%$. For the $0 / 90^{\circ}$ orientation, the basic room-temperature compressive allowable was obtained from the corresponding $\mathrm{S}_{0}$ value by multiplying the latter by the ratio of the average room-temperature compressive strength to the average tensile strength. The compressive temperature factors in Fig. 3.1 were then applied to this room-temperature allowable.

For the allowable compressive stresses with fluid, temperature cycling, and prior load effects, values given in Chap. 7 were used for the first two effects on compressive strength. The bounding fluid factor for the $0 / 90^{\circ}$ orientation is 0.92 ; for the $\pm 45^{\circ}$ orientation, it is 0.98 . Temperature cycling lowers the $0 / 90^{\circ}$ compressive strength by $1.1 \%$; it has no effect on the $\pm 45^{\circ}$

Table 3.2. Estimated allowable short-time uniaxial compressive stresses (MPa)

\begin{tabular}{|c|c|c|c|c|}
\hline & \multicolumn{4}{|c|}{ Temperature $\left({ }^{\circ} \mathrm{C}\right)$} \\
\hline & -40 & 23 & 70 & 120 \\
\hline \multicolumn{5}{|c|}{$0 / 90^{\circ}$ Fiber orientation } \\
\hline $\begin{array}{l}\text { Without fluid, temperature cycling, } \\
\text { and prior load effects }\end{array}$ & 283 & 238 & 186 & 98 \\
\hline $\begin{array}{l}\text { With fluid, temperature cycling, } \\
\text { and prior load effects }\end{array}$ & 242 & 203 & 159 & 84 \\
\hline \multicolumn{5}{|c|}{ $\pm 45^{\circ}$ Fiber orientation } \\
\hline Without fluid and prior-load effects & 107 & 83 & 66 & 45 \\
\hline With fluid and prior load effects & 101 & 78 & 62 & 42 \\
\hline
\end{tabular}


strength. Finally, no data are available on the effects of prior loadings on compressive strength. In the absence of such data, the tensile reduction factors -0.94 for $0 / 90^{\circ}$ and 0.96 for $\pm 45^{\circ}$ —were used in Table 3.2 .

\subsection{TIME-DEPENDENT ALLOWABLE TENSILE STRESSES, $S_{t}$}

For sustained loadings, tensile creep-rupture stress is the basis for time-dependent allowable stresses, provided that $\mathrm{S}_{0}$ is not lower than the creep-rupture-derived values. The following design margin on creep-rupture stress is used:

$$
0.8 \mathrm{~S}_{\mathrm{r}}
$$

where $\mathrm{S}_{\mathrm{r}}$ is the minimum creep-rupture strength. Equations for $0.8 \mathrm{~S}_{\mathrm{r}}$ [denoted by the maximum design allowable stress (MDAS)] are provided in Chap. 11 for both the $0 / 90^{\circ}$ and the $\pm 45^{\circ}$ fiber orientations. Stress reduction factors are given there to account for temperature, fluid exposure, and compressive loadings.

For uniaxial tension, the time-dependent allowable stress, $\mathrm{S}_{\mathrm{t}}$, is defined as

$$
\mathrm{S}_{\mathrm{t}} \leq\left\{\begin{array}{l}
\mathrm{S}_{0} \\
0.8 \mathrm{~S}_{\mathrm{r}}
\end{array} .\right.
$$

Values of $\mathrm{S}_{\mathrm{t}}$ without fluid, temperature cycling, or prior load effects are tabulated in Table 3.3 and plotted in Fig. 3.2 for the $\pm 45^{\circ}$ fiber orientation.

Three points should be made relative to Table 3.3. First, in the $0 / 90^{\circ}$ case, where creeprupture strengths are close to the short-time UTS values, $0.8 \mathrm{~S}_{\mathrm{r}}$ is always greater than $\mathrm{S}_{0}$. Creep

Table 3.3. Allowable time-dependent uniaxial

\begin{tabular}{|c|c|c|c|c|}
\hline \multirow{2}{*}{$\begin{array}{c}\text { Time } \\
\text { (h) }\end{array}$} & \multicolumn{4}{|c|}{ Temperature $\left({ }^{\circ} \mathrm{C}\right)$} \\
\hline & -40 & 23 & 70 & 120 \\
\hline \multicolumn{5}{|c|}{$0 / 90^{\circ}$ Fiber orientation } \\
\hline $\mathbf{0}$ & 265 & 265 & 254 & 217 \\
\hline 10 & & & & \\
\hline 100 & & & & \\
\hline 1,000 & & & & \\
\hline 5,000 & $\downarrow$ & $\downarrow$ & $\nabla$ & $\nabla$ \\
\hline 131,000 & & & $a$ & $a$ \\
\hline \multicolumn{5}{|c|}{ $\pm 45^{\circ}$ Fiber orientation } \\
\hline $\mathbf{0}$ & 107 & 83 & 66 & 46 \\
\hline 10 & 87 & & & 41 \\
\hline 100 & 84 & $\nabla$ & $\nabla$ & 40 \\
\hline 1,000 & 81 & 81 & 65 & 38 \\
\hline 5,000 & 79 & 79 & 63 & 37 \\
\hline 131,000 & 76 & 76 & $a$ & $a$ \\
\hline
\end{tabular}
tensile stresses, $S_{t}(\mathrm{MPa})$

$a_{\text {Not applicable. }}$ 
rupture never governs the allowable stresses. That is not the case in the $\pm 45^{\circ}$ orientation. The second point is that, for the $\pm 45^{\circ}$ case, the allowable time-dependent stresses at $70^{\circ} \mathrm{C}$ were judged to be approximately the same as those at room temperature (Chap. 11). In Table 3.3, however, the $70^{\circ} \mathrm{C}$ values have been reduced by the ratio of the $70^{\circ} \mathrm{C} \mathrm{S}$ value to the room-temperature $\mathrm{S}_{0}$ value. This seems to be more consistent. Finally, high-temperature allowable stresses are not given for times longer than $5000 \mathrm{~h}$ because high-temperatures could only exist around the engine and exhaust system.

For clarity, stresses for all of the tabulated times are not plotted in Fig. 3.2. Note that the $\mathrm{S}_{0}$ curve dips below the 10-h $0.8 \mathrm{~S}_{\mathrm{r}}$ curve in Fig. 3.2. Over that temperature range, $\mathrm{S}_{0}$ governs.

Table 3.4 is a repeat of Table 3.3 except that the allowable stresses have been reduced to account for fluid, temperature cycling, and prior load effects. Allowable $\pm 45^{\circ}$ tensile stresses reduced to account for fluid and prior load effects are plotted in Fig. 3.3.

Table 3.4. Allowable time-dependent uniaxial tensile stresses, $S_{t}(\mathrm{MPa})$, with reductions to account for fluid, temperature cycling, and prior load effects

\begin{tabular}{|c|c|c|c|c|}
\hline \multirow{2}{*}{$\begin{array}{c}\text { Time } \\
\text { (h) }\end{array}$} & \multicolumn{4}{|c|}{ Temperature $\left({ }^{\circ} \mathrm{C}\right)$} \\
\hline & -40 & 23 & 70 & 120 \\
\hline \multicolumn{5}{|c|}{ 0/90 ${ }^{\circ}$ Fiber orientation } \\
\hline 0 & 237 & 237 & 227 & 193 \\
\hline 10 & & & & \\
\hline 100 & & & & \\
\hline 1,000 & & & & \\
\hline 5,000 & & & $\downarrow$ & $\nabla$ \\
\hline 131,000 & $\nabla$ & V & $a$ & $a$ \\
\hline \multicolumn{5}{|c|}{ $\pm 45^{\circ}$ Fiber orientation } \\
\hline $\mathbf{0}$ & 100 & 77 & 61 & 43 \\
\hline 10 & 81 & & & 38 \\
\hline 100 & 78 & $\downarrow$ & $\downarrow$ & 37 \\
\hline 1,000 & 75 & 75 & 60 & 35 \\
\hline 5,000 & 73 & 73 & 59 & 34 \\
\hline 131,000 & 70 & 70 & $a$ & $a$ \\
\hline
\end{tabular}

The 0-time $\mathrm{S}_{0}$ values in Table 3.4 are taken from Table 3.1. Time-dependent values are those given in Table 3.3 reduced by the factors given in Chap. 11 to account for the standard fluid exposures -0.95 for $0 / 90^{\circ}$ and 0.93 for $\pm 45^{\circ}$ (again, the time-dependent $0 / 90^{\circ}$ values do not govern). Temperature cycling had no effect in the $\pm 45^{\circ}$ orientation, and no prior load effects factors were developed for creep rupture in Chap. 13.

\subsection{TIME-DEPENDENT ALLOWABLE COMPRESSIVE STRESSES}

As explained in Chap. 11, a limited number of compressive creep tests was performed, and only at room temperature. From these, it was estimated that the room-temperature compressive creep-rupture strength in the $0 / 90^{\circ}$ orientation is $98 \%$ of the tensile creep-rupture strength; in the $\pm 45^{\circ}$ orientation, the compressive creep-rupture strength is $97 \%$ of the tensile creep-rupture 
strength. At elevated-temperatures, these factors are likely to decrease significantly, particularly for the $0 / 90^{\circ}$ orientation.

Thus, while estimated 0-h allowable compressive stresses were tabulated in Table 3.2 for temperatures up to $120^{\circ} \mathrm{C}$, the same cannot be done for time-dependent compressive allowables. As stated in Chap. 2, compressive stresses should be avoided at elevated temperatures.

\subsection{TREATMENT OF MEMBRANE AND BENDING STRESSES}

The $\mathrm{S}_{0}$ and $\mathrm{S}_{\mathrm{t}}$ allowable stresses given in earlier sections establish limits only on in-plane membrane stresses, $\mathrm{P}$, and only when the fibers are oriented at $0 / 90^{\circ}$ or $\pm 45^{\circ}$. Allowable stresses for out-of-plane bending must be developed from flexure tests and are complicated by the material aniostropy. Even with the $0 / 90^{\circ}$ fiber orientation, bending strength depends on whether the surface fibers are parallel or perpendicular to the specimen axis. Bending tests reported in Chap. 8 for the $0 / 90^{\circ}$ fiber orientation were on specimens with the surface fibers oriented transversely to the beam axis - the weaker orientation.

Based on results of these tests, the $0 / 90^{\circ}$ elastically calculated membrane plus bending stresses, $\mathrm{P}+\mathrm{Q}$, away from geometric discontinuities are limited to

$$
\mathrm{P}+\mathrm{Q} \leq \mathrm{KS} \mathrm{S}_{\mathrm{t}}
$$

where $\mathrm{K}$ is a temperature-dependent constant, with values tabulated below:*

\begin{tabular}{cccc}
$\begin{array}{c}\mathbf{T} \\
\left({ }^{\circ} \mathbf{C}\right)\end{array}$ & & $\mathbf{K}$ \\
\cline { 1 - 1 }-40 & & 1.5 \\
23 & & 1.5 \\
70 & & 1.5 \\
120 & & 1.2
\end{tabular}

Geometric discontinuities include corners and bends. Here, the fiber distribution across the thickness of a composite plate or shell structure is likely to be less uniform. Even more importantly, when the inside surface of reentrant corners is in tension, delaminations can be introduced. In these cases, the membrane plus bending stresses are limited as follows:

$$
\mathrm{P}+\mathrm{Q} \leq 0.8 \mathrm{~S}_{\mathrm{t}} .
$$

In the $\pm 45^{\circ}$ orientation, bending response is not symmetrical because of the angle surface plies, which produce twisting. Further, the bending tests, reported later in Chap. 8, did not yield valid bending failure data because of large bending deformations that occurred prior to rupture. Thus, no allowables for bending in the $\pm 45^{\circ}$ orientation are given.

\subsection{TREATMENT OF INCREMENTS OF SUSTAINED LOADS}

For changing stress levels, the time-fraction summation method should be used to assess cumulative damage. The sum of the use fractions associated with the primary plus bending stresses for all increments of loading should not exceed a value of 1.0:

\footnotetext{
*The tabulated values are the same as those used for the previously investigated chopped-glass-fiber composite.
} 


$$
\sum_{i}\left(\frac{t}{T_{d}}\right)_{i} \leq 1.0
$$

Here, $t_{i}$ is the specified duration of a given load increment $i$, and $T_{d_{i}}$ is the allowable time for the stress associated with that load increment.

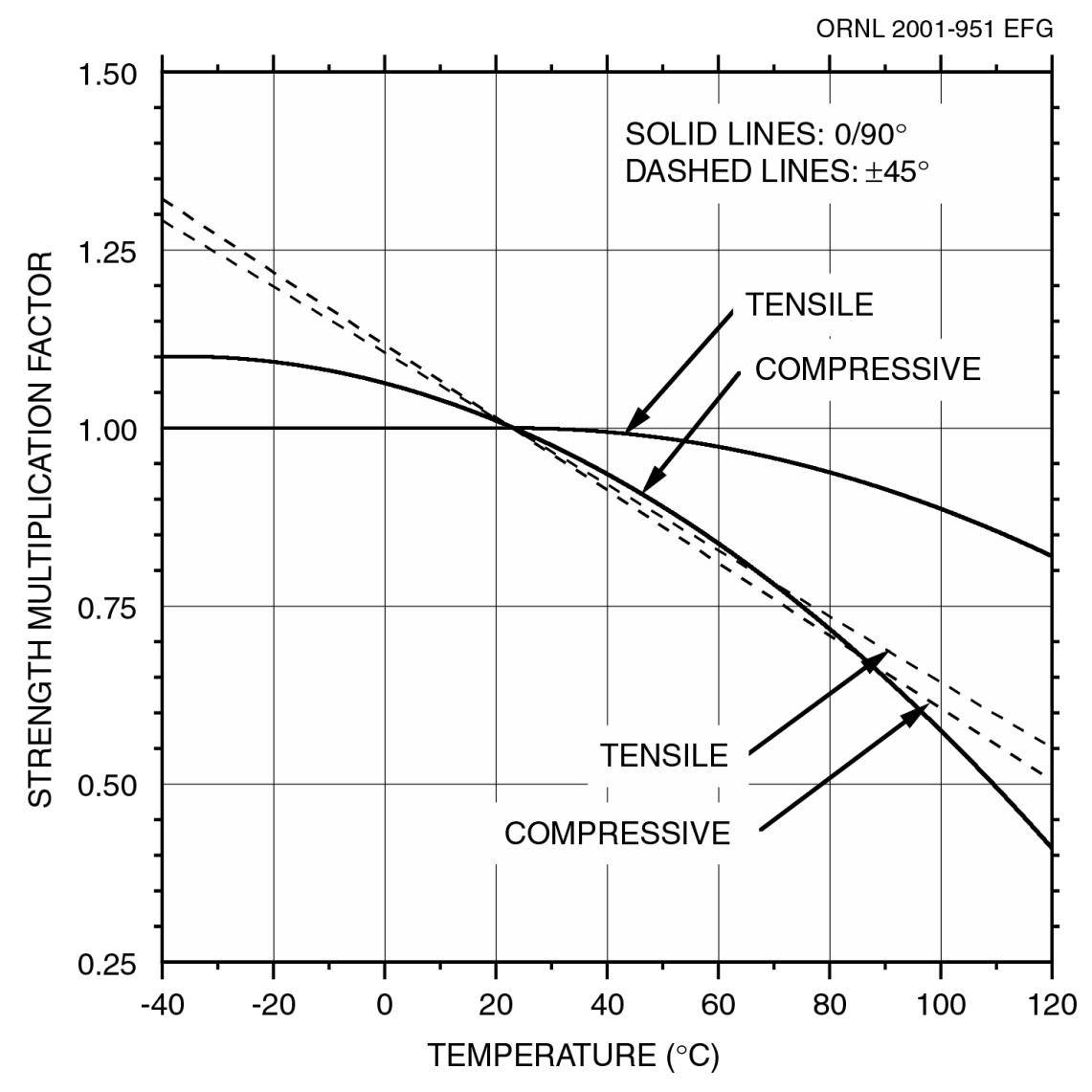

Fig. 3.1. Tensile and compressive strength multiplication factors to account for temperature. The UTS factors are applicable to $S_{0}$ values. 


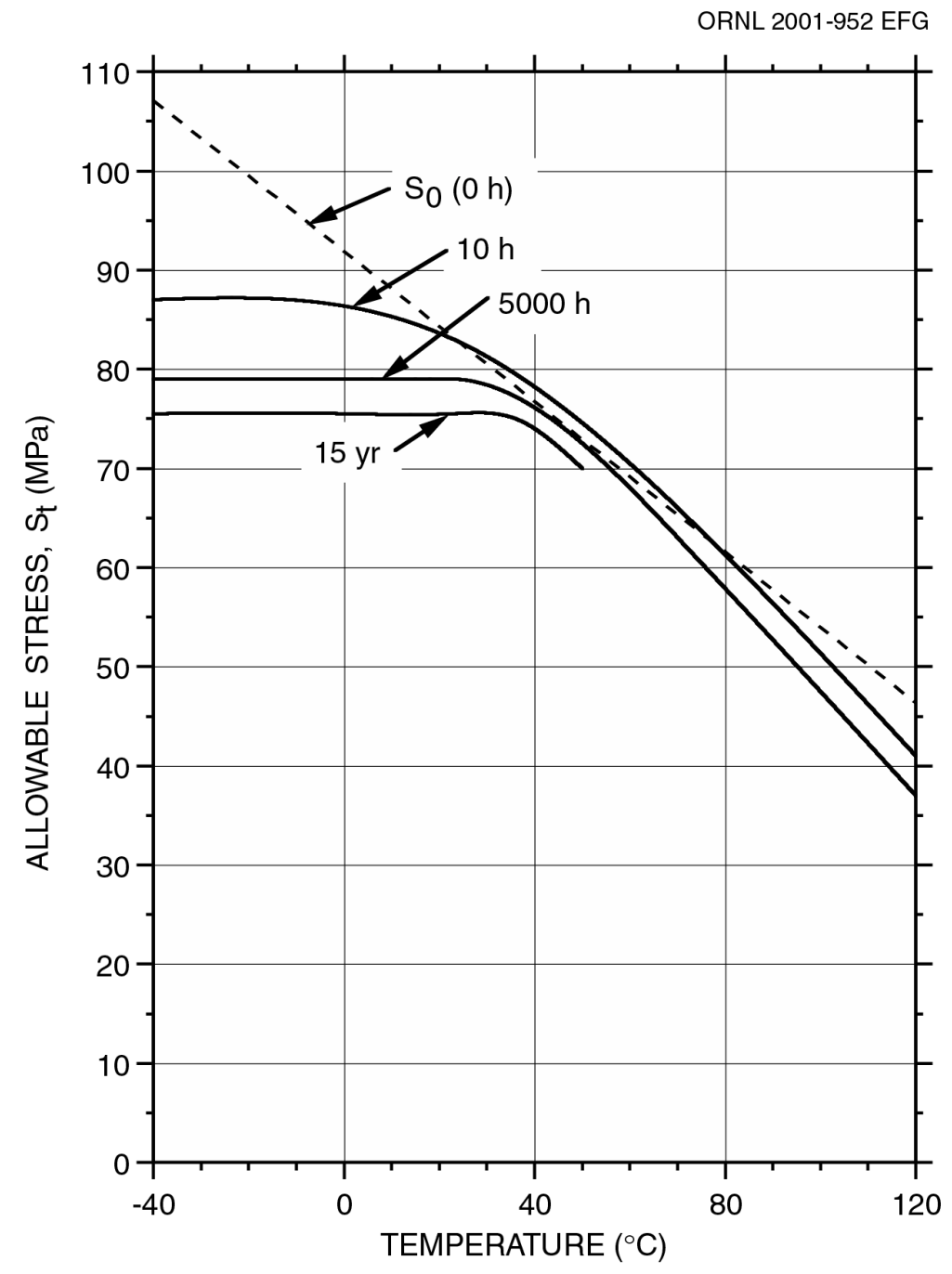

Fig. 3.2. Allowable $\pm 45^{\circ}$ tensile stresses, $S_{t}$, without fluid and prior load effects. 


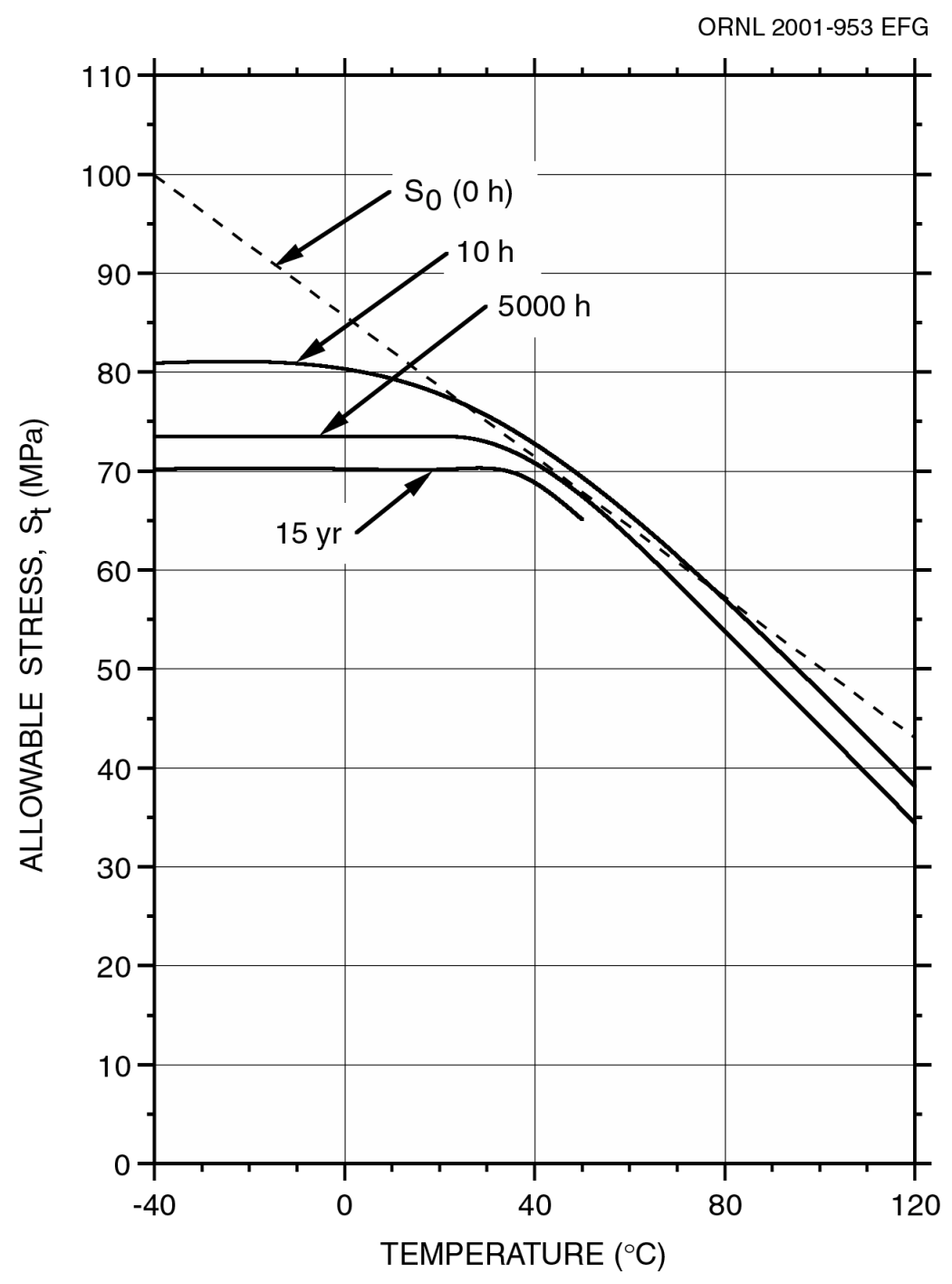

Fig. 3.3. Allowable $\pm 45^{\circ}$ tensile stresses, $S_{t}$, with reductions to account for fluid and prior load effects. 


\section{DESIGN LIMITS FOR CYCLIC LOADINGS}

\subsection{BASIC FATIGUE DESIGN CURVES}

Room-temperature, ambient-air design fatigue curves are shown in Fig. 4.1 for both 0/90 and $\pm 45^{\circ}$ fiber orientations. These curves were developed specifically to represent $R=0$ tensile cycling, where $\mathrm{R}$ is the ratio of the minimum to maximum stress in the cycle.

As described in Sect. 9.6, the 0/90 curve was derived from a fatigue failure curve by first placing a margin of 20 on cycles to failure and then multiplying stress by an additional reduction factor of 0.83 . The latter factor, which was necessary to assure adequate conservatism, is the ratio of the minimum to average ultimate tensile strength (UTS). In the case of the $\pm 45^{\circ}$ curve, only the factor of 20 on cycles was judged to be necessary. This was due, in part, to the fact that the curve was derived not from a curve representing failure by separation but from a curve representing first-ply failure, which occurs well before final failure by separation (see Chap. 9).

While the curves in Fig. 4.1 were derived to represent $\mathrm{R}=0$ tensile cycling, it is believed, based on available data presented in Chap. 9, that they can be conservatively applied to cycles with a fixed tensile mean stress, provided that the cyclic stress does not become compressive in the cycle.

In the $\pm 45^{\circ}$ case, two additional cycle types, both involving compressive stresses, were examined, as reported in Chap. 9. In the first, the cyclic stress was completely reversed $(\mathrm{R}=-1)$, while the second involved compressive cycling from 0 to a minimum (negative) stress $(\mathrm{R}=-\infty)$. While no parameter was found in Chap. 9 to adequately correlate the results for these different cycle types, they are nonetheless common ones likely to be encountered in design. Thus, for the $\pm 45^{\circ}$ case, factors are given in Table 4.1 for reducing the stresses in Fig. 4.1 to values applicable to the two compressive cycles. In using the factors in Table 4.1, the resulting stress in the reversed loading case is still the maximum cyclic stress. In the $\mathrm{R}=-\infty$ compressive cycling case, the resulting stress is the absolute value of the minimum cyclic stress. The resulting $\pm 45^{\circ}$ design fatigue curves are plotted in Fig. 4.2.

Table 4.1. Fatigue strength multiplication factors for evaluating compressive cycles for $\pm 45^{\circ}$ fiber orientation

\begin{tabular}{lcccc}
\hline \multirow{2}{*}{\multicolumn{1}{c}{ Cycle type }} & \multicolumn{4}{c}{ Cycles to failure } \\
\cline { 2 - 5 } & $\mathbf{1 0}^{\mathbf{2}}$ & $\mathbf{1 0}^{\mathbf{4}}$ & $\mathbf{1 0}^{\mathbf{6}}$ & $\mathbf{1 0}^{\mathbf{8}}$ \\
\hline Reversed loading $(\mathbf{R}=-\mathbf{1})$ & 0.68 & 0.62 & 0.57 & 0.52 \\
Compressive cycling $(\mathbf{R}=-\infty)$ & 0.84 & 0.86 & 0.88 & 0.91 \\
\hline
\end{tabular}

\subsection{EFFECTS OF TEMPERATURE}

The design fatigue curves in Figs. 4.1 and 4.2 are for room temperature. For other temperatures, fatigue strength multiplication factors, developed in Sect. 9.3, should be used. The factors are repeated here in Table 4.2.

These factors were derived from tension-tension fatigue data. In the absence of other data, it is assumed that they apply to other cycle types as well.

\footnotetext{
* Tests involving compressive stresses were not performed for the $0 / 90^{\circ}$ fiber orientation because fatigue is not likely to be a significant design problem in that case.
} 
Table 4.2. Fatigue strength factors to account for temperature

\begin{tabular}{ccccc}
\hline \multirow{5}{*}{$\begin{array}{c}\text { Temperature } \\
\left({ }^{\circ} \mathbf{C}\right)\end{array}$} & $\mathbf{1 0}^{\mathbf{2}}$ & $\mathbf{1 0}^{\mathbf{4}}$ & $\mathbf{1 0}^{\mathbf{6}}$ & $\mathbf{1 0}^{\mathbf{8}}$ \\
\cline { 2 - 4 } & \multicolumn{5}{c}{ Cycles } \\
$\mathbf{5}$ & Fiber orientation \\
$\mathbf{4 0}$ & 1.00 & 1.00 & 1.00 & 1.00 \\
$\mathbf{2 3}$ & 1.00 & 1.00 & 1.00 & 1.00 \\
$\mathbf{7 0}$ & 0.95 & 0.93 & 0.90 & 0.88 \\
$\mathbf{1 2 0}$ & 0.80 & 0.76 & 0.73 & 0.70 \\
\multicolumn{5}{c}{} \\
$\mathbf{- 4 0}$ & $\mathbf{4 4 5}$ & Fiber orientation \\
$\mathbf{2 3}$ & 1.18 & 1.22 & 1.25 & 1.29 \\
$\mathbf{7 0}$ & 0.84 & 1.00 & 1.00 & 1.00 \\
$\mathbf{1 2 0}$ & 0.49 & 0.73 & 0.63 & 0.55 \\
\end{tabular}

\subsection{ENVIRONMENTAL AND PRIOR LOAD EFFECTS}

Fluid effects on fatigue are discussed in Sect. 9.4. Just as was done for the allowable stresses for static loadings, two practical bounding fluid exposures are considered:

- 1000-h presoak in room-temperature distilled water, and

- 100-h presoak in room-temperature windshield washer fluid.

The fatigue tests were performed in the fluids in both cases.

The fatigue strength multiplication factors are tabulated in Table 4.3. Values greater than 1.00 are reduced to 1.00 in the table.

Table 4.3. Fatigue strength factors to account for two bounding fluid environments

\begin{tabular}{|c|c|c|c|c|}
\hline \multirow{2}{*}{ Environment } & \multicolumn{4}{|c|}{ Cycles } \\
\hline & $10^{2}$ & $10^{4}$ & $10^{6}$ & $10^{8}$ \\
\hline \multicolumn{5}{|c|}{$0 / 90^{\circ}$ Fiber orientation } \\
\hline Water, 1000-h presoak & 0.98 & 0.98 & 0.97 & 0.97 \\
\hline Windshield washer fluid, 100 -h presoak & 0.93 & 0.94 & 0.96 & 0.98 \\
\hline \multicolumn{5}{|c|}{ $\pm 45^{\circ}$ Fiber orientation } \\
\hline Water, 1000-presoak & 0.94 & 0.97 & 1.00 & 1.00 \\
\hline Windshield washer fluid, 100-h presoak & 1.00 & 1.00 & 1.00 & 1.00 \\
\hline
\end{tabular}

Prior creep was found to have a degrading effect on $\pm 45^{\circ}$ fatigue (see Chap. 13). A fatigue strength multiplication factor of 0.95 was recommended. 


\subsection{TREATMENT OF VARYING STRESS AMPLITUDES}

Cumulative damage under varying stress amplitudes is an important consideration in designing for cyclic loadings. For the random-glass-fiber composites previously evaluated, Miner's rule was recommended. ${ }^{1-3}$ The choice for the glass composites was based on a very limited number of block loading tests in each case and was thus not well based statistically.

For the current carbon-fiber composite block loading tests were not performed. ${ }^{*}$ It is recommended that in the absence of definitive data Miner's rule again be adopted. For a design to be acceptable, the fatigue damage should satisfy the following relation:

$$
\sum_{\mathrm{i}}\left(\mathrm{n} / \mathrm{N}_{\mathrm{d}}\right) \leq 1.0
$$

where $n_{i}$ is the number of specified cycles of type $i$, and $N_{d i}$ is the number of design-allowable cycles for cycle i determined from one of the design curves in Figs. 4.1 or 4.2. These curves should be adjusted to correspond to the maximum temperature of the cycle and to account for environment.

ORNL 2001-736 EFG

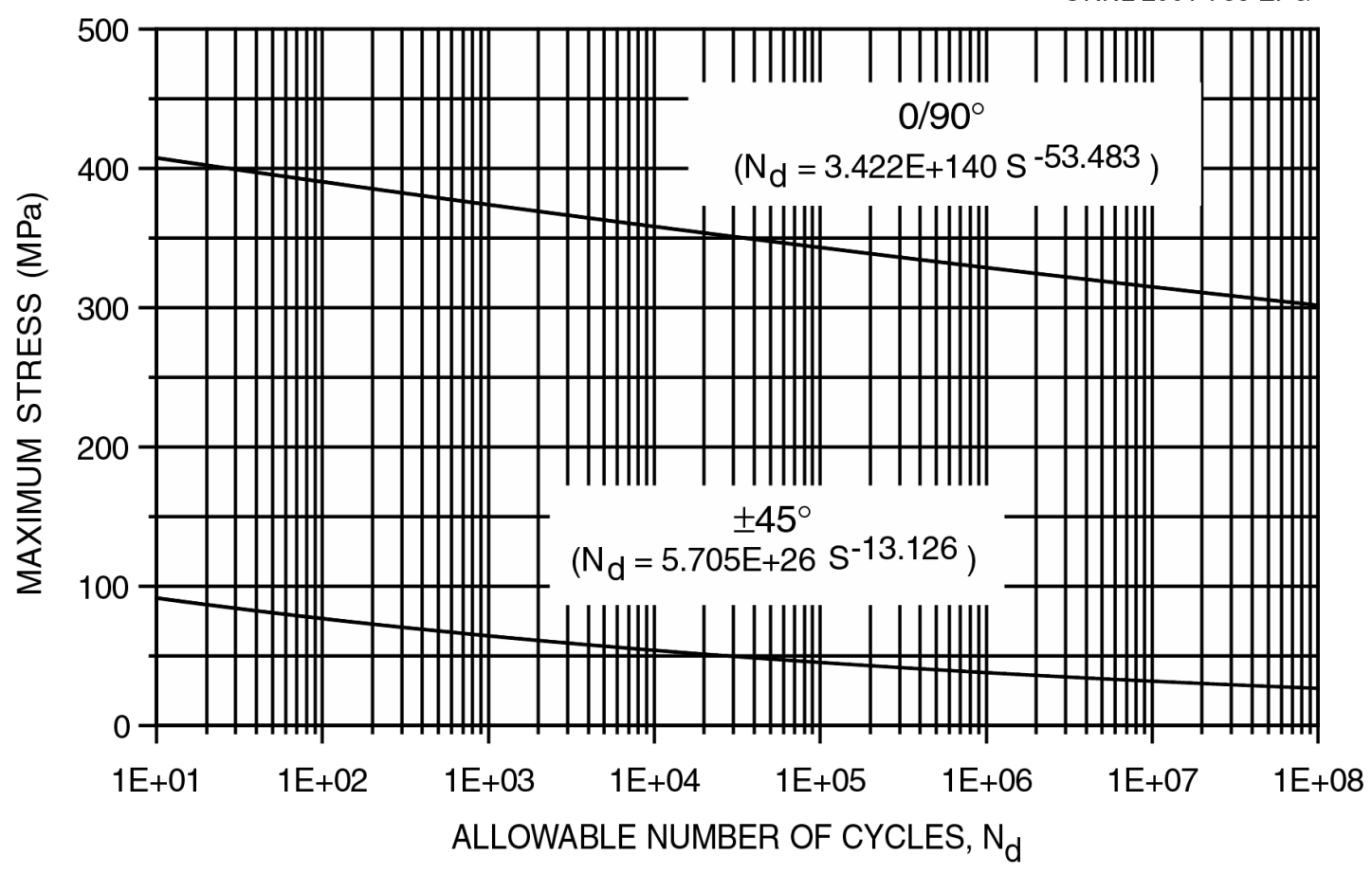

Fig. 4.1. Room-temperature design fatigue curves for tensile cycling.

* It was felt that because of the large variability in the $0 / 90^{\circ}$ data, and the need to define failure in the $\pm 45^{\circ}$ case as first-ply failure, a statistical evaluation beyond the current scope would be required. 


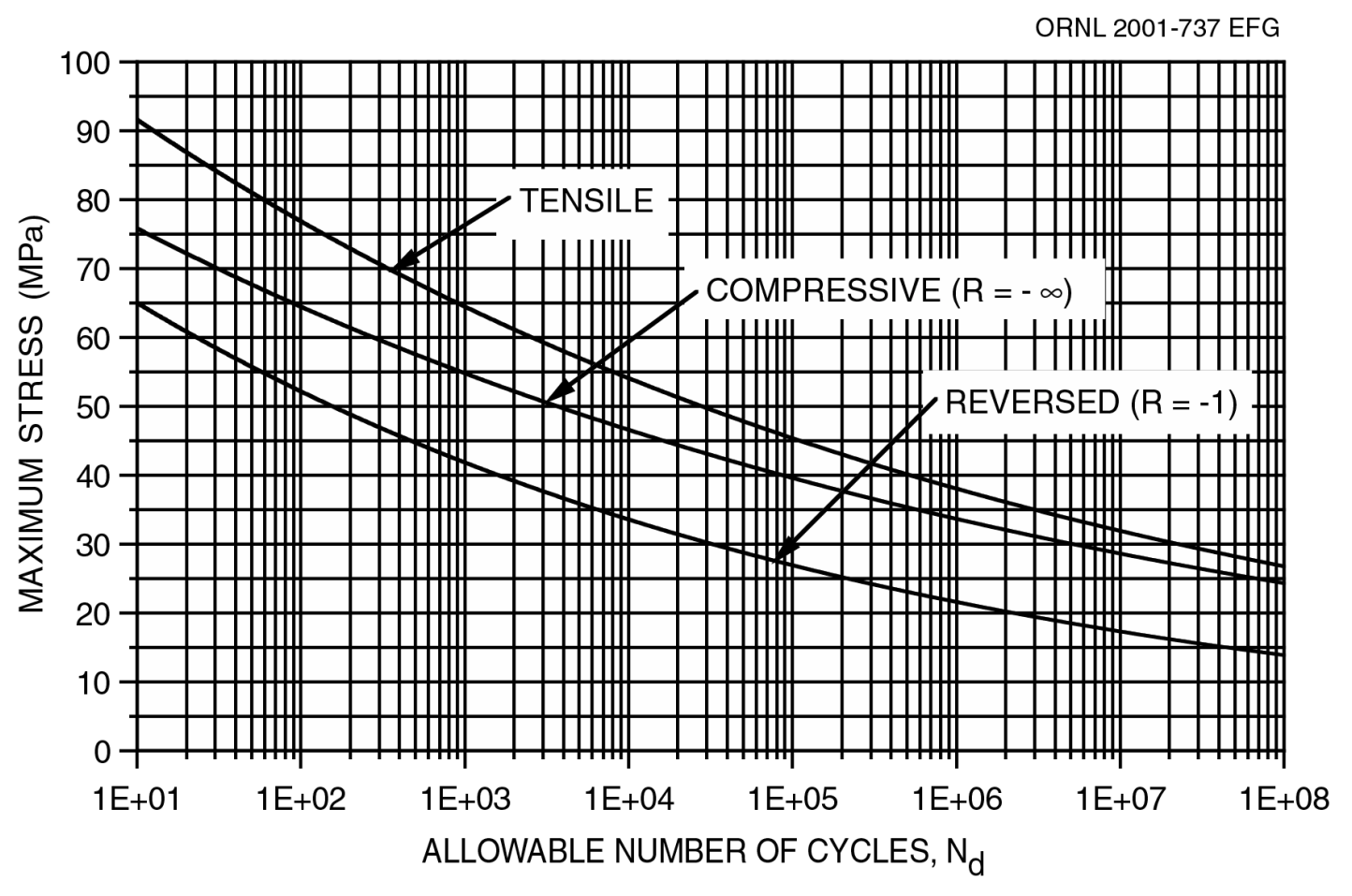

Fig. 4.2. Room-temperature $\pm 45^{\circ}$ design fatigue curves for different cycle types. 


\section{DAMAGE TOLERANCE DESIGN}

\subsection{GENERAL REQUIREMENTS}

Just as was done for the random-glass-fiber composites previously addressed, a two-part design assessment approach is recommended for the crossply carbon-fiber composite. ${ }^{1-3}$

1. Assume the presence of a 6.4-mm-diam circular hole in the worst possible location of the structure, and demonstrate, through analysis or use of experimental data and models, that the structure maintains its integrity. This evaluation will ensure that the structure can tolerate minor impacts and structural flaws at least up to a size of $6.4 \mathrm{~mm}$ in diameter or length, no matter where they are located.

2. For specific low-energy impacts such as kickups of roadway debris, tool drops, and load drops in a pickup truck box, the procedures described in Sects. 5.2 and 5.3 may be used to assess damage tolerance for damage areas larger than that corresponding to a $6.4-\mathrm{mm}$-diam hole.

\subsection{DETERMINATION OF IMPACT DAMAGE AREA}

For a given object (e.g., roadway kickup or dropped object) of mass m (kilograms) impacting a structure at a velocity $\mathrm{v}$ (meters/second) at a location away from structural discontinuities, the impact damage area can conservatively be determined from the "design" curve in Fig. 5.1. This curve is the upper bound of data generated from air-gun and pendulum impact tests on clamped 203-mm-diam by 3.2-mm-thick circular plates. Development of this design curve and its applicability to real events, such as bricks dropped in a pickup box, are discussed in Chap. 14 of Part 2. Also, it is shown in Chap. 14 that the curve covers impacts on specimens previously soaked for $1000 \mathrm{~h}$ in distilled water. The curve only applies, of course, to the particular layup and thickness of this composite.

Once the impact damage area has been estimated, the procedures recommended in Sect. 5.3 can be used to assess the likely effects on properties and structural integrity.

\subsection{DETERMINATION OF STRENGTH AND STIFFNESS DEGRADATION}

The procedures recommended here depend, to some extent, on the assumption that an impact damage area can be conservatively represented by a circular hole of equivalent area. ${ }^{*}$ Damage areas can either be factored into the structural evaluation as a circular hole or notch of equivalent size, or the degradation in strength can be estimated as specified in the following paragraph. Structural stiffness degradation can best be estimated by the equivalent circular hole method.

For a given predicted damage area, including surface ply delaminations, the degradation in tensile, compressive, and tensile fatigue strengths can be conservatively estimated using Fig. 5.2. This curve, which can be very conservative, was derived from test data obtained from 25.4-mmwide specimens cut from impacted plates (see Chap. 14). It shows the strength of $\pm 45^{\circ}$ and $0 / 90^{\circ}$ specimens containing the damage area relative to the material strength in undamaged regions.

In using Fig. 5.2 to estimate strength reductions, it should be kept in mind that the curve is only for 25.4-mm-wide specimens. To approximately convert the results to an infinitely wide plate or to other finite widths, relations for the effects of circular holes or notches in composite plates of various widths are required (e.g., see Refs. 3, 6, and 7).

\footnotetext{
* The effects of circular holes in this composite are the subject of future work.
} 


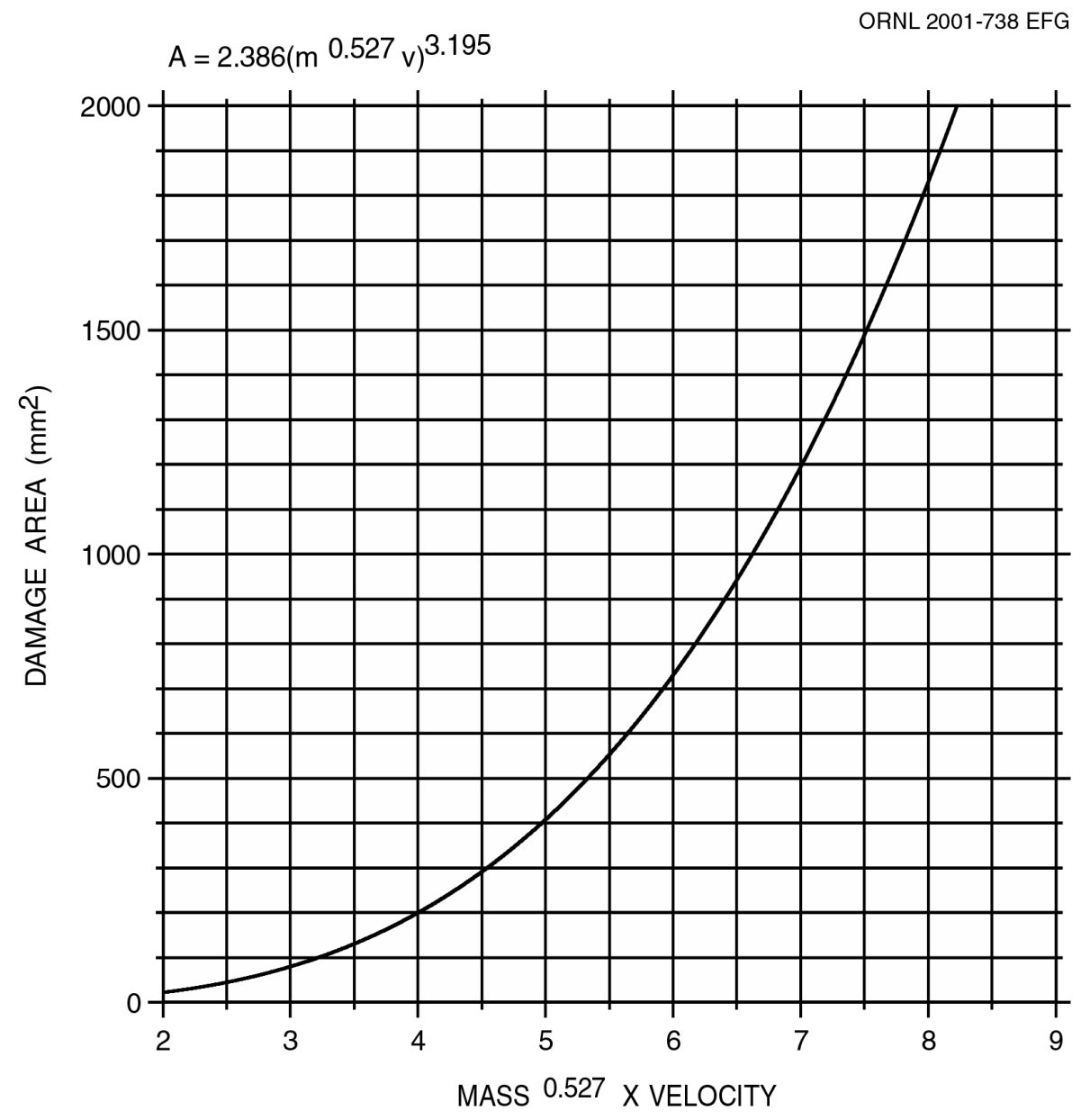

Fig. 5.1. Design curve for determining impact damage area. Mass, $m$, is in kilograms, and velocity, $v$, is in meters per second. Damage area includes possible surface-ply delaminations. 


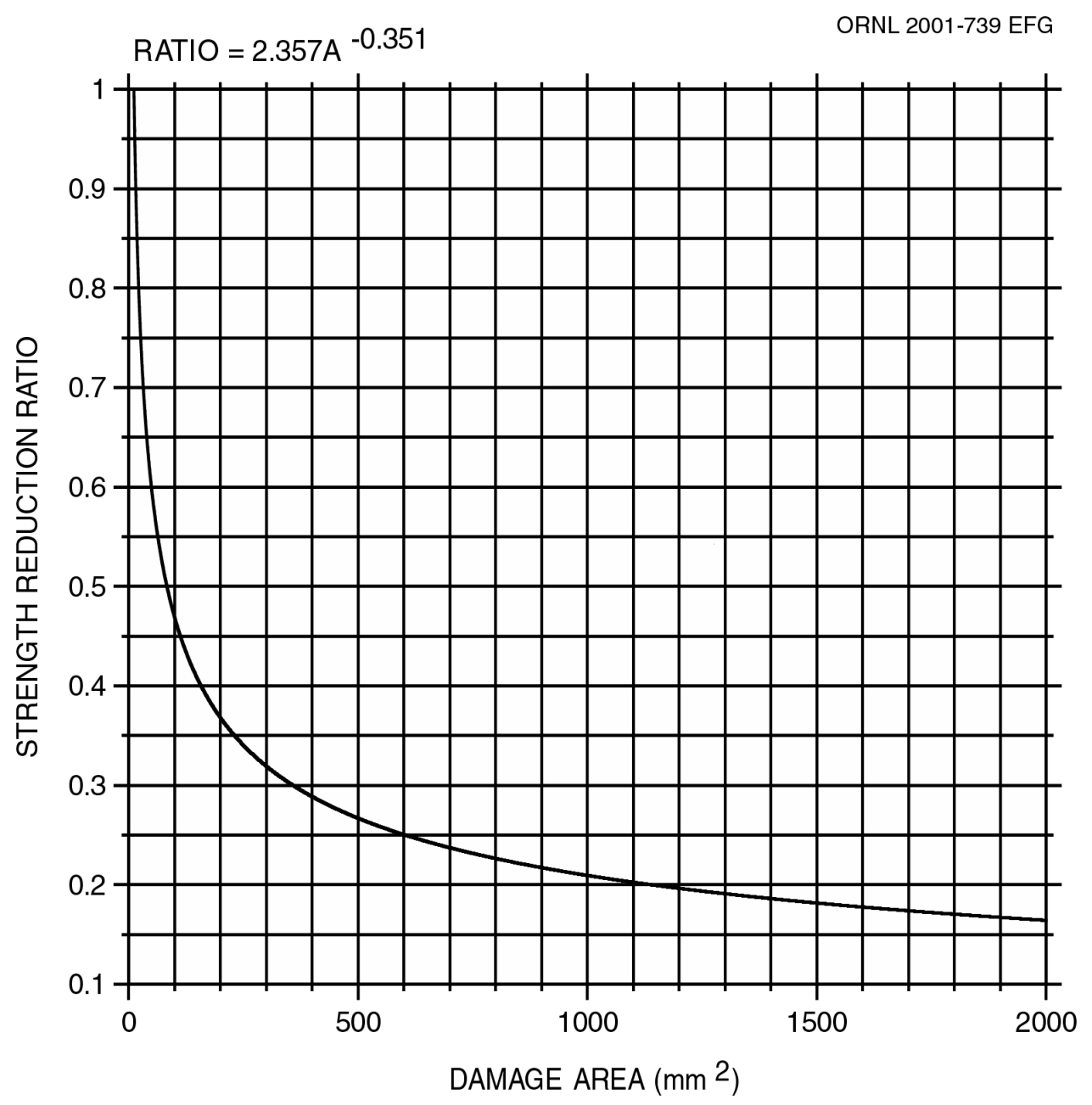

Fig. 5.2. Strength degradation as a function of damage area. This figure applies directly only to a $25.4-\mathrm{mm}$-wide specimen. 


\section{SUMMARY AND COMPARISON WITH CHOPPED- GLASS-FIBER COMPOSITE}

This chapter briefly summarizes the guidance and criteria presented in the previous four chapters for the crossply carbon-fiber composite. Major similarities and differences between the criteria for the carbon-fiber/Baydur 420 IMR material and the P4 chopped-glass-fiber/Baydur 420 IMR composite are highlighted.

In Sect. 6.3, the allowable stresses for static and cyclic loadings are reduced to a simplified table of values expressed as a percentage of the room-temperature, ambient air, UTS value. Chopped-glass-fiber composite values are shown in parentheses in the simplified table to facilitate direct comparisons between the two materials.

\subsection{ELASTIC AND CREEP PROPERTIES FOR DESIGN ANALYSIS}

Unlike the chopped-glass-fiber composite, which was essentially isotropic in the plane of the plaque, the crossply carbon-fiber composite is highly anisotropic, with a fiber-dominated $0 / 90^{\circ}$ orientation and a matrix-dominated $\pm 45^{\circ}$ orientation. Elastic constants for these two fiber orientations are compared in Table 6.1 with the glass-fiber composite elastic constants. The roomtemperature $0 / 90^{\circ}$ stiffness is more than four times the corresponding $\pm 45^{\circ}$ value. This difference increases to almost seven times at $120^{\circ} \mathrm{C}$. The $\pm 45^{\circ}$ stiffness is slightly lower than that of the glass-fiber composite at room temperature and significantly lower at $120^{\circ} \mathrm{C}$.

Table 6.1. Elastic constants

\begin{tabular}{|c|c|c|}
\hline $\begin{array}{c}\text { Temperature } \\
\left({ }^{\circ} \mathrm{C}\right)\end{array}$ & $\begin{array}{c}\text { Elastic modulus } \\
\text { (GPa) }\end{array}$ & $\begin{array}{l}\text { Poisson's } \\
\text { ratio }\end{array}$ \\
\hline \multicolumn{3}{|c|}{$0 / 90^{\circ}$ Fiber orientation } \\
\hline 23 & 46.7 & 0.05 \\
\hline 120 & 42.0 & 0.04 \\
\hline \multicolumn{3}{|c|}{ $\pm 45^{\circ}$ Fiber orientation } \\
\hline 23 & 11.3 & 0.76 \\
\hline 120 & 6.22 & 0.87 \\
\hline \multicolumn{3}{|c|}{ Glass-fiber composite } \\
\hline 23 & 11.8 & 0.32 \\
\hline 120 & 8.6 & 0.34 \\
\hline
\end{tabular}

The stiffness of the carbon-fiber composite is less affected by the standard fluid exposures$1000 \mathrm{~h}$ in distilled water or $100 \mathrm{~h}$ in windshield washer fluid - than was the glass-fiber composite. A bounding stiffness reduction factor of 0.93 holds for the carbon-fiber material, while the corresponding factor for the glass-fiber composite is 0.91 . Except for prior thermal and mechanical cycling, which has a relatively large degrading effect on $\pm 45^{\circ}$ stiffness in the carbon-fiber material, prior loads affect both materials about the same.

Room-temperature time-dependent creep strains in the carbon-fiber composite are very small for the $0 / 90^{\circ}$ fiber orientation. For the $\pm 45^{\circ}$ fiber orientation, in contrast, the time-dependent strains are more than two orders of magnitude larger. The chopped-glass-fiber composite exhibits creep strains in between these two extremes. This is illustrated by the tabulation in Table 6.2 of time-dependent creep strains predicted to result from application of a 100-MPa stress for $5000 \mathrm{~h}$ at room temperature. 
Table 6.2. Time-dependent creep strains due to $100 \mathrm{MPa}$ applied for $5000 \mathrm{~h}$

\begin{tabular}{lcc}
\hline \multicolumn{1}{c}{$\begin{array}{c}\text { Composite/ } \\
\text { orientation }\end{array}$} & $\begin{array}{c}\text { Creep strain } \\
\mathbf{( \% )}\end{array}$ & $\begin{array}{c}\text { Temperature multiplication } \\
\text { factor at } \mathbf{1 2 0}^{\circ} \mathbf{C}\end{array}$ \\
\hline Carbon fiber, $\mathbf{0} / \mathbf{9 0}^{\circ}$ & 0.02 & 6.3 \\
Carbon fiber, $\mathbf{\pm 4 5}^{\circ}$ & 3.02 & 41 \\
Glass fiber & 0.32 & 2.1 \\
\hline
\end{tabular}

As temperature is increased to $120^{\circ} \mathrm{C}$, time-dependent creep strains increase significantly more in the carbon-fiber composite than they do in the chopped-glass-fiber material. This is illustrated by the temperature multiplication factors in Table 6.2.

The standard fluid exposures also have a larger effect on time-dependent creep of the carbon-fiber composite than they do on the chopped-glass material. This is illustrated by the multiplication factors tabulated below.

\begin{tabular}{lcc}
$\begin{array}{c}\text { Composite/ } \\
\text { orientation }\end{array}$ & & $\begin{array}{c}\text { Fluid multiplication } \\
\text { factor }\end{array}$ \\
\cline { 1 - 1 } Carbon fiber, $0 / 90^{\circ}$ & & 4.0 \\
Carbon fiber, $\pm 45^{\circ}$ & & 2.5 \\
Glass fiber & & 2.2
\end{tabular}

\subsection{ALLOWABLE STRESSES FOR STATIC AND CYCLIC LOADINGS}

The basic time-dependent allowable stress quantity used in Chap. 3 for the crossply carbonfiber composite is the same as that used in Ref. 3 for the chopped-glass-fiber composite:

$$
\mathrm{S}_{\mathrm{t}} \leq\left\{\begin{array}{l}
\mathrm{S}_{0} \\
0.8 \mathrm{~S}_{\mathrm{r}}
\end{array} .\right.
$$

Here, $\mathrm{S}_{\mathrm{t}}$ is the time-dependent allowable, which in the case of the carbon-fiber composite is applicable only to uniaxial tensile stresses; $\mathrm{S}_{0}$ is the short-time (time-independent) allowable; and $\mathrm{S}_{\mathrm{r}}$ is the minimum creep-rupture strength corresponding to time $t$. Representative values of $\mathrm{S}_{\mathrm{t}}$ are tabulated in Table 6.3.

Table 6.3. $\mathrm{S}_{\mathrm{t}}$ values in air $(\mathrm{MPa})$

\begin{tabular}{|c|c|c|c|}
\hline \multirow{2}{*}{$\begin{array}{c}\text { Temperature } \\
\left({ }^{\circ} \mathrm{C}\right)\end{array}$} & \multicolumn{3}{|c|}{ Stress (MPa) } \\
\hline & $\mathbf{O} \mathbf{h}$ & $5000 \mathrm{~h}$ & 15 years \\
\hline \multicolumn{4}{|c|}{ Carbon fiber, $0 / 90^{\circ}$} \\
\hline 23 & 265 & 265 & 265 \\
\hline 120 & 217 & 217 & - \\
\hline \multicolumn{4}{|c|}{ Carbon fiber, $\pm 45^{\circ}$} \\
\hline 23 & 83 & 79 & 76 \\
\hline 120 & 46 & 37 & - \\
\hline \multicolumn{4}{|c|}{ Chopped-glass fiber } \\
\hline 23 & 99 & 91 & 87 \\
\hline 120 & 72 & 69 & - \\
\hline
\end{tabular}


Bounding fluid and prior load reduction factors for allowable stresses are summarized in Table 6.4 for both the crossply carbon-fiber composite and the chopped-glass-fiber composite.

Table 6.4. Bounding fluid and prior load reduction factors for allowable stresses at $0 \mathrm{~h}$ and $5000 \mathrm{~h}$

\begin{tabular}{lcccccc}
\hline \multirow{2}{*}{ Composite/orientation } & \multicolumn{2}{c}{ Fluids } & & \multicolumn{2}{c}{ Prior loads } \\
\cline { 2 - 3 } \cline { 5 - 6 } & $\mathbf{0 ~ h}$ & $\mathbf{5 0 0 0} \mathbf{~ h}$ & & $\mathbf{0 ~ h}$ & $\mathbf{5 0 0 0} \mathbf{~ h}$ \\
\hline Carbon fiber, $\mathbf{0} / \mathbf{9 0}^{\circ}$ & 0.96 & 0.96 & & $0.94^{a}$ & $b$ \\
Carbon fiber, $\mathbf{\pm 4 5}$ & 0.97 & 0.93 & & 0.96 & $b$ \\
Glass fiber & 0.91 & 0.60 & & 0.95 & 0.95 \\
\hline
\end{tabular}

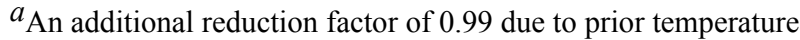
cycling is applicable for the $0 / 90^{\circ}$ orientation.

$b_{\text {Values unavailable. }}$
}

Allowable cyclic stresses were given in Chap. 4. Representative maximum stress levels for tensile cycling $(\mathrm{R}=0)$ are given in Table 6.5 for both the carbon-fiber composite and, for comparison, the chopped-glass-fiber composite.

Fluid reduction factors vary with cycles. Bounding factors (that cover both standard fluid conditions) are tabulated in Table 6.6, where they are compared with the corresponding choppedglass-fiber composite values. Prior creep conditions had a degrading effect on the $\pm 45^{\circ}$ fatigue strength. A single factor is given in Table 6.6 for this prior load effect. There was no measurable effect of prior creep in the case of the glass-fiber composite.

Table 6.5. Allowable maximum cyclic stresses for tensile cycling $(R=0)$

\begin{tabular}{|c|c|c|}
\hline \multirow{2}{*}{$\begin{array}{c}\text { Temperature } \\
\left({ }^{\circ} \mathrm{C}\right)\end{array}$} & \multicolumn{2}{|c|}{ Maximum stress (MPa) } \\
\hline & $10^{2}$ cycles & $10^{8}$ cycles \\
\hline \multicolumn{3}{|c|}{ Carbon fiber, $0 / 90^{\circ}$} \\
\hline 23 & 389 & 301 \\
\hline 120 & 311 & 211 \\
\hline \multicolumn{3}{|c|}{ Carbon fiber, $\pm 45^{\circ}$} \\
\hline 23 & 77 & 27 \\
\hline 120 & 38 & 6 \\
\hline \multicolumn{3}{|c|}{ Chopped-glass fiber } \\
\hline 23 & 90 & 22 \\
\hline 120 & 61 & 21 \\
\hline
\end{tabular}

Table 6.6. Bounding fluid and prior load reduction factors for cyclic stresses

\begin{tabular}{lccc}
\hline \multirow{2}{*}{ Composite/orientation } & \multicolumn{2}{c}{ Fluids } & Prior \\
\cline { 2 - 3 } & $\mathbf{1 0}^{\mathbf{2}}$ cycles & $\mathbf{1 0}^{\mathbf{8}}$ cycles & loads \\
\hline Carbon fiber, $\mathbf{0}^{\prime \mathbf{9 0}^{\circ}}$ & 0.93 & 0.97 & \\
Carbon fiber, $\mathbf{\pm 4 5}^{\circ}$ & 0.94 & 1.00 & 0.95 \\
Glass fiber & 0.73 & 0.97 & 1.00 \\
\hline
\end{tabular}




\subsection{SIMPLIFIED SUMMARY OF ALLOWABLE STRESSES}

As a way of further summarizing and simplifying the allowable stresses for static and cyclic loadings, Table 6.7 gives key allowable stress values for various conditions as a percentage of the average room-temperature UTS values $-477 \mathrm{MPa}$ for the $0 / 90^{\circ}$ orientation and $150 \mathrm{MPa}$ for the $\pm 45^{\circ}$ orientation. Corresponding values for the chopped-glass-fiber composite are shown in parenthesis after the $\pm 45^{\circ}$ carbon-fiber composite values in Table 6.7. The values in the table are derived from the allowable stresses given in Sect. 6.2.

Table 6.7. Key allowable tensile stresses, expressed as a percentage of average room-temperature UTS ${ }^{a}$

\begin{tabular}{|c|c|c|c|c|}
\hline \multirow[t]{2}{*}{ Stress allowable } & \multicolumn{2}{|c|}{$\begin{array}{l}\text { Without environmental } \\
\text { and prior load effects }\end{array}$} & \multicolumn{2}{|c|}{$\begin{array}{l}\text { With environmental } \\
\text { and prior load effects }\end{array}$} \\
\hline & $23^{\circ} \mathrm{C}$ & $120^{\circ} \mathrm{C}$ & $23^{\circ} \mathrm{C}$ & $120^{\circ} \mathrm{C}$ \\
\hline \multicolumn{5}{|c|}{$0 / 90^{\circ}$ Fiber orientation } \\
\hline $\mathbf{S}_{\mathbf{0}}$ & 56 & 45 & $50^{b}$ & $40^{b}$ \\
\hline $\begin{array}{l}\mathbf{S}_{\mathbf{t}} \\
\quad 5000 \mathrm{~h} \\
15 \text { years }\end{array}$ & $\begin{array}{l}56 \\
56\end{array}$ & $\begin{array}{c}45 \\
d\end{array}$ & $\begin{array}{c}50^{b, c} \\
d\end{array}$ & $\begin{array}{l}40^{b, c} \\
d\end{array}$ \\
\hline $\begin{array}{c}S_{\max }(R=0) \\
10^{2} \text { cycles } \\
10^{8} \text { cycles }\end{array}$ & $\begin{array}{l}82 \\
63\end{array}$ & $\begin{array}{l}65 \\
44\end{array}$ & $\begin{array}{l}76 \\
61\end{array}$ & $\begin{array}{l}63 \\
43\end{array}$ \\
\hline \multicolumn{5}{|c|}{ $\pm 45^{\circ}$ Fiber orientation } \\
\hline $\mathbf{S}_{\mathbf{0}}$ & $55(56)^{e}$ & $31(41)$ & $51(49)$ & $29(35)$ \\
\hline $\begin{array}{l}\mathbf{S}_{\mathbf{t}} \\
\quad 5000 \mathrm{~h} \\
\quad 15 \text { years }\end{array}$ & $\begin{array}{l}53(51) \\
51(49)\end{array}$ & $\begin{array}{c}25(39) \\
d\end{array}$ & $\begin{array}{c}47^{c}(29) \\
d\end{array}$ & $\begin{array}{c}22^{c}(22) \\
d\end{array}$ \\
\hline $\begin{array}{c}S_{\max }(R=0) \\
10^{2} \text { cycles } \\
10^{8} \text { cycles }\end{array}$ & $\begin{array}{l}51(51) \\
18(12)\end{array}$ & $\begin{array}{r}25(34) \\
4(12)\end{array}$ & $\begin{array}{l}46(38) \\
17(12)\end{array}$ & $\begin{array}{r}22(-) \\
4(-)\end{array}$ \\
\hline $\begin{array}{c}a_{0 / 90^{\circ}} \mathrm{UTS}_{\mathrm{avg}}= \\
\text { chopped-glass-fiber } \\
b_{\text {Includes } 0.99 \mathrm{re}} \\
{ }^{c} \text { Prior load effect } \\
{ }^{d_{\text {Not applicable. }}}\end{array}$ & $\begin{array}{l}477 \mathrm{MPa} ; \pm \\
\text { composite. } \\
\text { luction fact } \\
\text { factor assu }\end{array}$ & $\begin{array}{l}\mathrm{JS}_{\text {avg }}=150 \\
\text { prior tempera } \\
\text { to be the same }\end{array}$ & $\begin{array}{l}\text { a; and UTS } \\
\text { e cycling. } \\
\text { for } 0 \mathrm{~h} \text {. }\end{array}$ & $=177 \mathrm{MPa}$ \\
\hline
\end{tabular}

For glass-fiber composites, a strain limit of 0.3 to $0.4 \%$ has often been used in the past for design of automotive composite structures to cover all effects. For the chopped-glass-fiber composite, this corresponds to 20 to $27 \%$ of the average room-temperature UTS (see Ref. 3). Comparison of these values with the allowables (shown in parentheses) for the chopped-glass-fiber composite in Table 6.7 shows that the strain limits are adequate for that composite except for the extreme areas (e.g., high temperature, long times, and high cycles).

In the carbon-fiber composite case the corresponding stress levels, given as a percentage of the room-temperature UTS, are tabulated below. 


\begin{tabular}{|c|c|c|}
\hline \multirow[b]{2}{*}{ Stress level } & \multicolumn{2}{|c|}{ Strain } \\
\hline & $0.3 \%$ & $0.4 \%$ \\
\hline Percenta & 29 & 39 \\
\hline Percentage of UTS at $\pm 45^{\circ}$ & 23 & 30 \\
\hline
\end{tabular}

Comparison of these stress levels with the allowable values in Table 6.7 shows that the strain limits adequately cover all of the allowables for the $0 / 90^{\circ}$ fiber orientation. For the $\pm 45^{\circ}$ orientation, the situation is much the same as for the glass-fiber composite- the strain limits are adequate except for the extreme areas of the table.

The strain limits are overly conservative in large regions of Table 6.7. The limits given in Part 1 of this report put the design allowables on a more rational and defensible basis, and they avoid the over-and under-conservation associated with the simplified strain limit approach.

\subsection{DAMAGE TOLERANCE EVALUATION}

For specific low-energy impacts such as roadway kickups, tool drops, and load drops in a pickup box, experimentally derived correlations are given for (1) estimating the damage area from the mass and velocity of the impacting object and (2) determining, from the estimated damage area, the resulting degradation in strength. While these correlations are clearly tied to the specific sizes and geometries of the impacted plate specimens and of the specimens used for mechanical property evaluations, it is thought that they do provide useful information. This is particularly true when comparing the relative response of two different composites.

Table 6.8 gives the predicted damage for four representative combinations of impactor mass and velocity. Corresponding values for the chopped-glass-fiber composite are shown in parenthesis. The carbon-fiber composite damage areas include relatively harmless surface delaminations (see Chap. 14). Even without these, however, the carbon-fiber composite damage areas are larger than the corresponding glass-fiber composite values, particularly at the higher of the two velocities shown for each mass.

Tensile strength was most degraded by impact damage in the carbon-fiber composite. In contrast, compressive strength was most degraded for the chopped-glass-fiber composite.

Table 6.9 provides the strength reduction ratios for the two composites that correspond to the two damage areas used in Table 6.8 .

Table 6.8. Damage areas from design curve (Fig. 5.1)

\begin{tabular}{ccc}
\hline $\begin{array}{c}\text { Mass } \\
\mathbf{( k g )}\end{array}$ & $\begin{array}{c}\text { Velocity } \\
(\mathbf{m} / \mathbf{s})\end{array}$ & $\begin{array}{c}\text { Damage area } \\
\left(\mathbf{m m}^{2}\right)\end{array}$ \\
\hline $\mathbf{1 1 . 5 2}$ & 1.5 & $534(195)^{a}$ \\
$\mathbf{1 1 . 5 2}$ & 2.0 & $1339(290)$ \\
$\mathbf{0 . 0 2 2 7}$ & 40.0 & $534(251)$ \\
$\mathbf{0 . 0 2 2 7}$ & 53.3 & $1339(345)$ \\
\hline
\end{tabular}

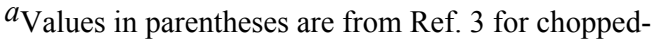
glass-fiber composite. 
Table 6.9. Strength reduction ratios caused by impact damage

\begin{tabular}{ccc}
\hline \multirow{2}{*}{$\begin{array}{c}\text { Damage area } \\
\left(\mathbf{m m}^{\mathbf{2}}\right)\end{array}$} & \multicolumn{2}{c}{ Strength reduction ratio } \\
\cline { 2 - 3 } & Carbon fiber $^{\boldsymbol{a}}$ & Glass fiber $^{\boldsymbol{b}}$ \\
\hline $\mathbf{1 0 0}$ & 0.47 & 0.90 \\
$\mathbf{3 5 0}$ & 0.30 & 0.08 \\
\hline
\end{tabular}

$a_{\text {Tensile strength loss governs. }}$

$b_{\text {Compressive strength loss governs. }}$ 
PART 2

BACKGROUND DATA AND MODELS 


\title{
7. BASIC TENSILE, COMPRESSIVE, AND SHEAR PROPERTIES
}

\author{
M. B. Ruggles
}

\subsection{TEST METHODS}

Basic properties were established from stiffness, tensile, compressive, and shear tests. Two fiber orientations were considered: $0 / 90^{\circ}$ relative to the specimen axis and $\pm 45^{\circ}$. These orientations result in two extremes of behavior. Under tensile loading, the behavior of the $0 / 90^{\circ}$ specimens is fiber dominated; for the $\pm 45^{\circ}$ fiber orientation, the behavior is matrix dominated.

Untabbed dogbone-shaped tensile specimens were used ${ }^{8}$ in all stiffness and tensile tests, which were performed according to the test method described in Ref. 8. Flat specimens with tabs were used in compression tests. ${ }^{8}$ The tab material was G-11 composite, an epoxy reinforced with woven fiberglass cloth. The adhesive used for bonding the tabs to the test specimens was Hysol's EA $93009 \mathrm{NA} \mathrm{A} / \mathrm{B}$ for the $-40^{\circ} \mathrm{C}$ and $23^{\circ} \mathrm{C}$ testing and XEA $9364 \mathrm{~A} / \mathrm{B}$ for the $120^{\circ} \mathrm{C}$ testing. Compression tests employed an IITRI fixture [Procedure B in American Society for Testing and Materials (ASTM) Standard D 341097. The test method was as described in Ref. 8. The V-notched beam (Iosipescu) shear specimens and shear test method were as described in Ref. 8. In the case of the $0 / 90^{\circ}$ fiber orientation, the tab material and adhesive used for bonding the tabs were the same as for the compression specimens. For the $\pm 45^{\circ}$ fiber orientation, the tabs were cut from the same material as the specimens. Adhesives used for tab bonding were as described above. Poisson's ratio measurements were carried out using three specimens for each fiber orientation, according to the test method described in Ref. 8.

In addition to presenting baseline properties at room temperature, this chapter provides strength and stiffness properties for $-40,70$, and $120^{\circ} \mathrm{C}$. Multiplication factors for determining elastic constants and strength properties at different temperatures from room-temperature values are developed. Furthermore, effects of thickness variations, strain rate, and thermal cycling on properties are discussed. Finally, fluid effects are considered, and fluid reduction factors for exposures in distilled water and windshield washer fluid are presented. First, however, a study of the effect of specimen width on measured properties is presented in the following section.

\subsection{SPECIMEN WIDTH EFFECTS (J. M. Corum, R. L. Battiste, and S. Deng)}

A question relative to testing of the $\pm 45^{\circ}$ crossply composite is whether the relatively narrow 20 -mm-wide specimens having a $\pm 45^{\circ}$ fiber orientation give representative properties. The concern is that specimens with fibers ending at the edges may not develop full strength. To evaluate this question, a series of tensile tests was performed on specimens of various widths.

The specimen geometries used are shown in Fig. 7.1(a). Specimen widths of 25.4, 50.8, 76.2 , and $101.6 \mathrm{~mm}$ were tested. All of the specimens were $254-\mathrm{mm}$ long with $76.2-\mathrm{mm}$ long aluminum tabs at each end. The untabbed section was 101.6-mm long. Two sets of the four specimens depicted in Fig. 7.1(a), plus one additional 25.4-mm-wide specimen were tested. All nine specimens were cut from adjacent locations in a single plaque, as shown in Fig. 7.1(b). The shaded triangular areas in Fig. 7.1 (a) depict regions where one end of the fibers in both the $+45^{\circ}$ and $-45^{\circ}$ directions is restrained at the tabs. As will be seen later, these triangular regions appeared to have less ply cracking.

Note that this study was more about end effects than width effects. Kellas, Morton, and Jackson studied true width effects in both a carbon/epoxy composite and a carbon/PEEK thermoplastic composite. ${ }^{10}$ They tested a series of tensile specimens in which all dimensions were scaled proportionally (up to a 50.8-mm-wide by 508-mm-long specimen). They also varied thickness, 
and hence number of plies, independently. They found that width had no effect. However, strength went up with thickness (the larger the ply number, the smaller the effect of the surface plies, which failed first).

In the study discussed here, as the width increased, the end tabs increasingly restrained a larger portion of the 101.6-mm length between the tabs. The 25.4-mm-wide specimen was free to neck as ply failures, and the resulting scissoring action, took place. In the wider specimens, a complex biaxial stress state developed due to the end constraint.

Three-element strain gage rosettes were installed back to back at the center of each specimen, as shown in Fig. 7.2. The two wider specimens also had rosettes at one edge. The individual gage length of the rosettes was $6.4 \mathrm{~mm}$, and the maximum strain capability of the gages was $5 \%$. Stress-strain curves developed using the resulting strain gage data help to explain the relative behavior of the specimens.

An important feature of the test results arose from the fact that the initial molded plaque and thus each specimen were bowed. This initial specimen bow is depicted in Fig. 7.3. Side 1 corresponds to the top of the molded plaque and is the side on which the A and $\mathrm{C}$ strain-gage rosettes were installed. When these bowed specimens were clamped in the hydraulic grips of the test machine, axial tensile bending stresses and strains were induced on side 2. Upon application of the test load, ply failures initially occurred on side 2 . In every test but one, the axial gage on the B rosette on side 2 failed before the maximum load was reached - indicating that either the 5\% strain capability had been exceeded or that ply failures had occurred under the gage. As ply failures occurred on side 2, that side of the narrower specimens became noticeably transversely convex. This was particularly apparent in the 50.8-mm-wide specimens. After testing, the ply failures were palpable on side 2 , while side 1 was smooth. The specimens were both transversely and axially convex on side 2 (bowed in the reverse direction from the initial bow in Fig. 7.3). This bowing was not readily apparent in the wider specimens because of the constraining effects of the end tabs.

The 25.4-mm-wide and 50.8-mm-wide specimens failed in the usual manner, with the load gradually dropping after the maximum value was reached. In contrast, the 76.2-mm-wide and 101.6-mm-wide specimens failed abruptly, with immediate loss of load.

Typical stress-strain curves for each specimen width are shown in Figs. 7.4 through 7.7. Also shown in each of the figures is an X-ray photograph of the corresponding specimen, made after failure. In each stress-strain figure, the group of axial strain curves is on the right (positive strains), the transverse strain curves (negative strains) are on the left, and the $45^{\circ}$ strains (in the direction of the fibers) are in the center. The curves are labeled A, B, or C, corresponding to the rosette designations shown in Fig. 7.2.

In Fig. 7.4 (25.4-mm-wide specimen), the axial B gage failed just below the maximum load. The transverse B gage, in contrast, had less than one-half the strain of the transverse A gage. This was a ramification of the convex cupping, which produced a transverse tensile strain component on side 2. As the specimen width, and associated constraint of the end tabs, increased, the cupping decreased; the transverse B strain became equal to the transverse A strain (see Figs. 7.5-7.7).

The X-ray photographs in the four figures each show distributed $\pm 45^{\circ}$ ply failures. Note, however, that as the width increases, the relatively undamaged triangular areas, discussed in conjunction with Fig. 7.1, became increasingly apparent.

Two cross sections cut from each of the specimens shown in Figs. 7.4-7.7 were metallographically mounted, ground, polished, and photographed at $25 \times, 40 \times$, and sometimes $100 \times{ }^{*}$

\footnotetext{
* The micrography work was carried out by Delsen Testing Laboratories, Inc.
} 
The sections were cut both perpendicular and parallel to the fibers nearest the surfaces of the composite (first and twelfth plies). The goal was to identify the typical pattern of ply cracking.

An examination of all of the photomicrographs indicates that the crack patterns are qualitatively similar for all of the specimens. Photomicrographs from two specimens, 50.8-mm-wide C48-2 and 76.2-mm-wide C48-3, were chosen to illustrate the various features and are shown in Figs. 7.8 and 7.9, respectively. The sections from $\mathrm{C} 48-2$ were cut near the middle of the specimen (see Fig. 7.5) away from the major cracking and damage. The sections from C48-3 were cut closer to the major cracking and damage (see Fig. 7.6). In all cases, the $25 \times$ photos show both surfaces, with the top surface corresponding to side 2 of the original specimen (see Fig. 7.3). The $100 \times$ photos are of selected areas in the $25 \times$ photos.

As previously explained, the ply cracking occurred predominantly on side 2 of the specimens where, due to the initial bow, the stresses and strains were the highest. The cracks occurred between fibers in the bundles; cracks in the matrix were usually arrested. Few interlaminar shear cracks were observed in Fig. 7.8 (one is visible in the lower left picture). Interlaminar shear cracks are more prevalent in Fig. 7.9. The photomicrographs illustrate one other point. The fiber bundles weave up and down and in and out of the plane of the pictures. As discussed later in this chapter, this occasionally lead to a slight stiffening of $0 / 90^{\circ}$ specimens during tensile testing due to straightening of fiber bundles. Stiffness was also observed to increase during elevatedtemperature fatigue cycling for the same reason (see Chap. 9).

Figures 7.10 and 7.11 show a definite apparent width effect on both strength and stiffness. Strength increases with width, an observation that is confirmed by results obtained earlier by Deng and Weitsman on 25.4- and 50.8-mm-wide specimens from a different plaque. ${ }^{11}$ Conversely, stiffness appears to decrease with width, although Deng and Weitsman found no change. Poisson's ratio appears to perhaps decrease very slightly with increasing width (see Fig. 7.12). With one exception, the values plotted in Fig. 7.12 agree reasonably well with the value of 0.76 reported later in this chapter from tests on 20 -mm-wide dogbone specimens.

In conclusion, it is thought that the narrower specimens give a truer measure of uniaxial tensile properties and are thus appropriate for generating data for characterization and modeling.

\subsection{PROPERTIES VS TEMPERATURE}

For the $0 / 90^{\circ}$ fiber orientation, in-air room-temperature tensile properties were established from 236 stiffness tests and 90 tensile tests; compressive properties were based on 18 tests; and shear properties were based on 21 tests on Iosipescu specimens. For the $\pm 45^{\circ}$ fiber orientation, in-air room-temperature tensile properties were established from 113 stiffness tests and 107 tensile tests; compressive properties were established based on 18 tests; and shear properties were based on 6 tests on Iosipescu specimens. All tests were performed according to the test methods

described in Ref. 1. Baseline room-temperature properties for both fiber orientations are summarized in Table 7.1 with the corresponding percent coefficients of variation (COV) given in parentheses.

Baseline tensile and compressive properties obtained for the $\pm 45^{\circ}$ fiber orientation are comparable to those obtained for the chopped-glass-fiber composite. For the chopped-glass-fiber material, tensile stiffness and strength were $11.8 \mathrm{GPa}$ and $177 \mathrm{MPa}$; compressive stiffness and strength, $11.6 \mathrm{GPa}$ and $190 \mathrm{MPa}$. In the case of shear, the chopped-glass-fiber composite produced a stiffness of $4.48 \mathrm{GPa}$, which compares better with the $0 / 90^{\circ}$ result, and a strength of $166 \mathrm{MPa}$, which is closer to that for the $\pm 45^{\circ}$ fiber orientation.

For both fiber orientations, tests conducted at $-40,23,50$ (or 70 ), and $120^{\circ} \mathrm{C}$ were employed to quantify the effects of temperature. For the $0 / 90^{\circ}$ fiber orientation, the temperature effects on tensile properties were investigated in 33 tensile tests on specimens from plaques $\mathrm{C} 1$ and $\mathrm{C} 5$ (6 tests at $-40^{\circ} \mathrm{C}$ and 9 tests at each of the other temperatures). The temperature effects on 
Table 7.1. Average in-air room-temperature baseline properties

\begin{tabular}{lcc}
\hline & \multicolumn{2}{c}{ Fiber orientation } \\
\cline { 2 - 3 } & $\mathbf{0 / 9 0}^{\circ}$ & $\mathbf{\pm 4 5 ^ { \circ }}$ \\
\hline Pensile & & \\
Modulus, GPa & $46.7(9.15)$ & $11.3(13.2)$ \\
Poisson's ratio & 0.05 & 0.76 \\
Strength, MPa & $477(10.9)$ & $150(10.8)$ \\
Failure strain, \% & $1.01(12.2)$ & $9.78(24.8)$ \\
Compressive & & \\
Modulus, GPa & $53.3(12.0)$ & $13.9(7.08)$ \\
Strength, MPa & $-429(18.1)$ & $-163(4.59)$ \\
Failure strain, \% & $-1.12(17.7)$ & $-7.25(19.7)$ \\
Shear properties & & \\
Modulus, GPa & $2.96(10.2)$ & $24.2(2.65)$ \\
Strength, MPa & $95.0(8.90)$ & $191(9.80)$ \\
Failure strain, \% & $11.9(6.08)$ & $0.88(21.2)$ \\
\hline
\end{tabular}

compressive properties were established in 36 compressive tests on specimens from plaques C2-C5 (12 tests at room temperature and 8 tests at each of the other temperatures). The temperature effects on shear properties were assessed in 33 Iosipescu shear tests on specimens from plaques $\mathrm{C} 1-\mathrm{C} 3$ ( 15 tests at room temperature and 6 tests at each of the other temperatures).

For the $\pm 45^{\circ}$ fiber orientation, the temperature effects on tensile properties were assessed in 30 tensile tests on specimens from plaques $\mathrm{C} 11$ and $\mathrm{C} 24\left(12\right.$ tests at $70^{\circ} \mathrm{C}$ and 6 tests at each of the other temperatures). The effects of temperature on compression were studied in 24 compressive tests (6 tests at each temperature) on specimens from plaque C26. The effects of temperature on shear properties were investigated in 24 Iosipescu shear tests on specimens from plaque $\mathrm{C} 21$ (6 tests at each temperature).

The average tensile, compressive, and shear properties from the temperature dependence study are summarized in Tables 7.2 and 7.3 for the $0 / 90^{\circ}$ and $\pm 45^{\circ}$ fiber orientations, respectively. Given in parentheses are the corresponding percent COVs. Typical tensile stress-strain curves at different temperatures are shown in Fig. 7.13(a) and $(b)$.

Based on data in Tables 7.2 and 7.3, percent changes from room-temperature values were calculated for each property and plotted as functions of temperature. As a result, correlations between percent changes in properties and temperature were developed. These correlations were specifically formulated to give $0 \%$ change at room temperature. Based on these correlations, properties at different temperatures and the corresponding multiplication factors were calculated. Correlations between the multiplication factors and temperature were developed, so that multiplication factors for any temperature within range can be established. Multiplication factors are presented in Tables 7.4 and 7.5 for $0 / 90^{\circ}$ and $\pm 45^{\circ}$ fiber orientations, respectively.

The multiplication factors are also plotted in Figs. 7.14(a) and $(b)$ for $0 / 90^{\circ}$ and $\pm 45^{\circ}$ fiber orientations, respectively. Note that for tension and compression, the $0 / 90^{\circ}$ behavior is fiber dominated, while the $\pm 45^{\circ}$ behavior is matrix dominated. The opposite is observed in the shear case; the $\pm 45^{\circ}$ behavior is dominated to a greater extent by the fibers. It is further observed that in the matrix-dominated cases, the multiplication factors are always the same for strength and stiffness. For the fiber-dominated cases, the strength factors at elevated temperatures are always less than the stiffness factors. For the chopped-glass-fiber composite, the stiffness multiplication factor obtained in tension could be used to cover both compression and shear. Furthermore, the shear 
Table 7.2. Average properties from temperature dependence study for $0 / 90^{\circ}$ fiber orientation

\begin{tabular}{|c|c|c|c|c|c|}
\hline \multirow{2}{*}{ Property } & \multicolumn{5}{|c|}{ Temperature } \\
\hline & $-40^{\circ} \mathrm{C}$ & $23^{\circ} \mathrm{C}$ & $50^{\circ} \mathrm{C}$ & $7^{\circ} \mathrm{C}$ & $120^{\circ} \mathrm{C}$ \\
\hline \multicolumn{6}{|l|}{ Tensile } \\
\hline Modulus, GPa & $44.7(3.98)$ & $44.5(6.51)$ & $45.0(5.07)$ & & $39.8(6.82)$ \\
\hline Poisson's ratio & 0.05 & 0.05 & & 0.04 & 0.04 \\
\hline Strength, MPa & $508(6.88)$ & $516(9.50)$ & $503(3.01)$ & & $418(8.37)$ \\
\hline \multicolumn{6}{|l|}{ Compressive } \\
\hline Modulus, GPa & $51.8(2.09)$ & $50.4(8.92)$ & $46.5(8.08)$ & & $40.0(8.47)$ \\
\hline Strength, MPa & $496(3.93)$ & $478(6.99)$ & $381(6.03)$ & & $190(13.0)$ \\
\hline \multicolumn{6}{|l|}{ Shear } \\
\hline Modulus, GPa & $3.31(3.93)$ & $2.96(11.2)$ & & $2.11(6.72)$ & $0.60(5.20)$ \\
\hline Strength, MPa & $111(3.39)$ & $92.8(8.87)$ & & $69.1(4.15)$ & $24.9(7.52)$ \\
\hline
\end{tabular}

Table 7.3. Average properties from temperature dependence study for $\pm 45^{\circ}$ fiber orientation

\begin{tabular}{ccccc}
\hline \multirow{2}{*}{ Property } & \multicolumn{4}{c}{ Temperature } \\
\cline { 2 - 4 } & $-\mathbf{4 0}^{\circ} \mathbf{C}$ & $\mathbf{2 3}^{\circ} \mathbf{C}$ & $\mathbf{7 0}^{\circ} \mathbf{C}$ & $\mathbf{1 2 0}^{\circ} \mathbf{C}$ \\
\hline Tensile & & & \\
Modulus, GPa & $13.3(7.64)$ & $10.1(5.49)$ & $8.95(6.99)$ & $3.98(6.41)$ \\
Poisson's ratio & 0.70 & 0.76 & 0.74 & 0.87 \\
Strength, MPa & $160(3.21)$ & $126(4.56)$ & $105(3.49)$ & $75.5(6.18)$ \\
Compressive & & & $10.8(6.47)$ & $6.24(7.06)$ \\
Modulus, GPa & $17.3(3.75)$ & $13.9(7.08)$ & $121(7.12)$ & $78.1(1.88)$ \\
Strength, MPa & $215(3.23)$ & $163(4.59)$ & & \\
Shear & & & $18.5(3.38)$ & $14.4(10.0)$ \\
Modulus, GPa & $30.2(7.27)$ & $24.2(2.65)$ & $111(8.42)$ & $84.3(8.51)$ \\
Strength, MPa & $248(7.30)$ & $191(9.80)$ & \\
\hline
\end{tabular}


Table 7.4. Temperature multiplication factors for determining at-temperature modulus and strength from room-temperature values for $0 / 90^{\circ}$ fiber orientation

\begin{tabular}{lcccc}
\hline & \multicolumn{4}{c}{ Multiplication factor } \\
\cline { 2 - 5 } & $\mathbf{- 4 0}^{\circ} \mathbf{C}$ & $\mathbf{2 3}^{\circ} \mathbf{C}$ & $\mathbf{7 0}^{\circ} \mathbf{C}$ & $\mathbf{1 2 0}^{\circ} \mathbf{C}$ \\
\hline Tension & & & & \\
Modulus & 1.00 & 1.00 & 0.98 & 0.90 \\
Strength & 1.00 & 1.00 & 0.96 & 0.82 \\
Compression & & & & \\
$\quad$ Modulus & 1.05 & 1.00 & 0.93 & 0.80 \\
$\quad$ Strength & 1.10 & 1.00 & 0.78 & 0.41 \\
Shear & & & & \\
$\quad$ Modulus & 1.18 & 1.00 & 0.71 & 0.26 \\
$\quad$ Strength & 1.18 & 1.00 & 0.71 & 0.26 \\
\hline
\end{tabular}

Table 7.5. Temperature multiplication factors for determining at-temperature modulus and strength from room-temperature values for $\pm 45^{\circ}$ fiber orientation

\begin{tabular}{lcccc}
\hline & \multicolumn{4}{c}{ Multiplication factor } \\
\cline { 2 - 5 } & $\mathbf{4 0}^{\circ} \mathbf{C}$ & $\mathbf{2 3}^{\circ} \mathbf{C}$ & $\mathbf{7 0}^{\circ} \mathbf{C}$ & $\mathbf{1 2 0}^{\circ} \mathbf{C}$ \\
\hline Tension & & & & \\
$\quad$ Modulus & 1.29 & 1.00 & 0.79 & 0.55 \\
$\quad$ Strength & 1.29 & 1.00 & 0.79 & 0.55 \\
Compression & & & & \\
$\quad$ Modulus & 1.32 & 1.00 & 0.76 & 0.50 \\
$\quad$ Strength & 1.32 & 1.00 & 0.76 & 0.50 \\
Shear & & & & \\
$\quad$ Modulus & 1.26 & 1.00 & 0.79 & 0.60 \\
Strength & 1.35 & 1.00 & 0.70 & 0.46 \\
\hline
\end{tabular}

strength multiplication factor was very close to that in compression and significantly below that in tension. For the $\pm 45^{\circ}$ fiber orientation, tensile, compressive, and shear stiffness as well as tensile strength are considerably more temperature sensitive than those for the chopped-glass-fiber composite. Conversely, compressive and shear strengths show a similar degree of temperature sensitivity for both materials. For the $0 / 90^{\circ}$ fiber orientation, shear stiffness is significantly more temperature sensitive than that for the chopped-glass-fiber composite. However, the remaining baseline properties exhibit comparable temperature sensitivity for both materials.

Finally, the temperature multiplication factors were applied to the baseline roomtemperature properties (Table 7.1) to obtain the at-temperature properties presented in Tables 7.6 and 7.7 for the $0 / 90^{\circ}$ and $\pm 45^{\circ}$ fiber orientations, respectively. With the exception of Poisson's ratio, all properties in Tables 7.6 and 7.7 were derived by multiplying the average 
Table 7.6. Baseline properties at different temperatures for $0 / 90^{\circ}$ fiber orientation

\begin{tabular}{lcccc}
\hline \multirow{1}{*}{ Property } & \multicolumn{4}{c}{ Temperature } \\
\cline { 2 - 5 } & $\mathbf{4 0}^{\circ} \mathbf{C}$ & $\mathbf{2 3}^{\circ} \mathbf{C}$ & $\mathbf{7 0}^{\circ} \mathbf{C}$ & $\mathbf{1 2 0}^{\circ} \mathbf{C}$ \\
\hline Tensile & & & & \\
Modulus, GPa & 46.7 & 46.7 & 45.7 & 42.0 \\
Poisson's ratio & 0.05 & 0.05 & 0.04 & 0.04 \\
Strength, MPa & 477 & 477 & 456 & 391 \\
Compressive & & & & \\
$\quad$ Modulus, GPa & 56.0 & 53.3 & 49.4 & 42.6 \\
Strength, MPa & 472 & 429 & 334 & 176 \\
Shear & & & & \\
$\quad$ Modulus, GPa & 3.49 & 2.96 & 2.10 & 0.77 \\
Strength, MPa & 112 & 95.0 & 67.5 & 24.7 \\
\hline
\end{tabular}

Table 7.7. Baseline properties at different temperatures for $\pm 45^{\circ}$ fiber orientation

\begin{tabular}{lcccc}
\hline \multirow{2}{*}{ Property } & \multicolumn{4}{c}{ Temperature } \\
\cline { 2 - 5 } & $\mathbf{4 0}^{\circ} \mathbf{C}$ & $\mathbf{2 3}^{\circ} \mathbf{C}$ & $\mathbf{7 0}^{\circ} \mathbf{C}$ & $\mathbf{1 2 0}^{\circ} \mathbf{C}$ \\
\hline Tensile & & & & \\
$\quad$ Modulus, GPa & 14.6 & 11.3 & 8.93 & 6.22 \\
Poisson's ratio & 0.70 & 0.76 & 0.74 & 0.87 \\
Strength, MPa & 194 & 150 & 119 & 82.5 \\
Compressive & & & & \\
$\quad$ Modulus, GPa & 18.3 & 13.9 & 10.6 & 6.95 \\
Strength, MPa & 215 & 163 & 124 & 81.5 \\
Shear & & & & \\
Modulus, GPa & 30.5 & 24.2 & 19.1 & 14.5 \\
Strength, MPa & 258 & 191 & 134 & 87.9 \\
\hline
\end{tabular}

room-temperature properties in Table 7.1 by the factors from Tables 7.4 and 7.5, respectively. The Poisson's ratio values are averages from actual at-temperature tests of the same specimens as used to obtain the room-temperature values. Very low loads were used to ensure that damage was not introduced at each temperature.

These baseline properties were used to determine whether classical laminated plate theory, developed for laminates formed of plies reinforced by straight unidirectional fibers, applies to the stitched-mat fabric composite. In this procedure, the basic linear-elastic properties of a unidirectionally reinforced lamina, that is, plane strain stiffnesses $\mathrm{Q}_{11}, \mathrm{Q}_{12}, \mathrm{Q}_{22}$, and $\mathrm{Q}_{66}$, are related to Young's moduli and Poisson's ratios for both fiber orientations. Thus, a system of four equations with three unknowns is formed (note that for given fiber orientations, the equations include the sum $\mathrm{Q}_{11}+\mathrm{Q}_{22}$, but not $\mathrm{Q}_{11}$ and $\mathrm{Q}_{22}$ separately). Recognizing that $\mathrm{Q}_{66}$ is equal to the shear 
modulus $\mathrm{G}_{12}$, shear moduli for both fiber orientations can be calculated. Comparison of the calculated and experimental values of shear modulus for both fiber orientations is given in Table 7.8.

Agreement between the calculated and measured shear modulus values is only fair. The largest discrepancy between calculated and experimental values of shear modulus occurs at $120^{\circ} \mathrm{C}$ for both fiber orientations. Note that calculations are sensitive to the values of Young's modulus and Poisson's ratio. Significant plaque-to-plaque and specimen-to-specimen variations in these properties were observed for the present composite. Tests at $120^{\circ} \mathrm{C}$ employed tensile and shear specimens from a number of different plaques. Thus, differences between calculated and experimental values of shear modulus may be attributed to the plaque-to-plaque variability in properties. In future work, it would be useful to cut both tensile and shear specimens for a temperature-dependence study from the same plaque.

A systematic study of variation in tensile properties with fiber orientation was conducted by Deng and Weitsman. ${ }^{11}$ Tensile tests were performed on specimens cut from a single plaque at various angles to the $0 / 90^{\circ}$ fiber orientation. Typical stress-strain curves for various orientation angles are shown in Fig. 7.15. In the nonlinear range, the stress-strain behavior is highly sensitive to orientation. Variation in strength with orientation angle is presented in Fig. 7.16. In addition, the elastic response at all orientations was predicted using laminated plate theory. ${ }^{11}$ Comparison of the predicted elastic modulus and Poisson's ratio variations with average measured values at various orientations is shown in Fig. 7.17(a) and $(b)$. The agreement is very good.

Table 7.8. Calculated and experimental values of shear modulus $G$ at different temperatures

\begin{tabular}{|c|c|c|c|c|}
\hline \multirow{2}{*}{$\begin{array}{c}\text { Temperature } \\
\left({ }^{\circ} \mathbf{C}\right)\end{array}$} & \multicolumn{2}{|c|}{ 0/90 ${ }^{\circ}$ Fiber orientation, $\mathrm{G}(\mathrm{GPa})$} & \multicolumn{2}{|c|}{ $\pm 45^{\circ}$ Fiber orientation, $G(\mathrm{GPa})$} \\
\hline & Calculated & Experimental & Calculated & Experimental \\
\hline-40 & 4.30 & 3.44 & 22.2 & 30.4 \\
\hline 23 & 3.18 & 2.92 & 22.2 & 24.2 \\
\hline 70 & 2.81 & 2.07 & 20.1 & 19.5 \\
\hline 120 & 1.63 & 0.75 & 20.3 & 14.5 \\
\hline
\end{tabular}

\subsection{EFFECTS OF PLAQUE THICKNESS VARIATIONS}

Basic room-temperature tensile stiffness and strength information was evaluated together with the plaque thickness and fiber volume content data in order to establish correlations between tensile properties and plaque thickness and/or fiber volume content. Variations in tensile stiffness and strength with thickness are presented in Figs. 7.18 and 7.19 for the two fiber orientations. Results show that for both fiber orientations tensile stiffness and strength decrease linearly with increasing specimen thickness. Adjusted fiber volume content was introduced to transition from a plaque average to a specimen-specific value. Adjusted fiber volume content was defined as the plaque average fiber volume content times the ratio of average plaque thickness to individual specimen thickness. Average plaque thickness was calculated as the average of the four corner thickness values. Note that corner thickness measurements were available only for the following plaques: $\mathrm{C} 6, \mathrm{C} 9, \mathrm{C} 11, \mathrm{C} 16, \mathrm{C} 17$, and $\mathrm{C} 34$ (specimens cut with the $\pm 45^{\circ}$ fiber orientation); and $\mathrm{C} 1-\mathrm{C} 5, \mathrm{C} 12, \mathrm{C} 13$, and $\mathrm{C} 15$ (specimens cut with the $0 / 90^{\circ}$ fiber orientation). Thus, this data set was limited. Percent relative strength and percent relative stiffness were introduced to facilitate comparison of results. Percent relative property was defined as $100 \%$ times the ratio of individual 
specimen property and the average property values. Results are presented in Figs. 7.20 and 7.21, where relative strength and stiffness are plotted vs adjusted fiber volume content for $\pm 45^{\circ}$ and $0 / 90^{\circ}$ fiber orientations, respectively. For both fiber orientations, strength and stiffness depend on fiber volume content. In all cases dependence can be approximated with a linear law. The dependence on the adjusted fiber volume content is more pronounced for stiffness than for strength. Furthermore, $0 / 90^{\circ}$ fiber orientation properties are more dependent on adjusted fiber volume content than those for the $\pm 45^{\circ}$ fiber orientation.

\subsection{EFFECT OF STRAIN RATE ON TENSILE PROPERTIES}

The effect of loading rate on tensile behavior was investigated in 32 tests conducted at the following constant strain rates: $10^{-6}, 10^{-4}, 10^{-2}$, and $10 \mathrm{~s}^{-1}$. Four tests were performed at each strain rate for each fiber orientation. Note that the displacement rate of $0.001 \mathrm{in} . / \mathrm{s}$ used in baseline tensile tests is equivalent to an average strain rate of $10^{-4} \mathrm{~s}^{-1}$ for both fiber orientations. Results are summarized in Figs. 7.22 and 7.23 for the $\pm 45^{\circ}$ and $0 / 90^{\circ}$ fiber orientations, respectively.

For the $\pm 45^{\circ}$ fiber orientation, the plot of strength vs strain rate in Fig. 7.22(a) shows a 27\% increase in strength as the strain rate increases from $10^{-6}$ to $10 \mathrm{~s}^{-1}$. The effect of strain rate on stiffness illustrated in Fig. 7.22(b) appears to be less pronounced. As the strain rate increases from $10^{-6}$ to $10 \mathrm{~s}^{-1}$, the average stiffness increases only by $6.6 \%$.

For the $0 / 90^{\circ}$ fiber orientation, the variation in stiffness shown in Fig. $7.23(b)$ follows the same pattern. The stiffness increases by $6.6 \%$ as the strain rate increases from $10^{-6}$ to $10 \mathrm{~s}^{-1}$. Conversely, the average strength shows a decrease of $11.6 \%$ as the strain rate increases from $10^{-6}$ to $10 \mathrm{~s}^{-1}$.

The stress-strain curves obtained at the different strain rates are shown in Fig. 7.24(a) and $(b)$ for the $\pm 45^{\circ}$ and the $0 / 90^{\circ}$ fiber orientations, respectively. In the case of the $\pm 45^{\circ}$ fiber orientation, the stress-strain curves support the observation of a significant increase in strength with increasing strain rate. In the case of the $0 / 90^{\circ}$ fiber orientation, the stress-strain curves indicate that variations with strain rate in both strength and stiffness may be due to data scatter. The effect of strain rate on tensile behavior for the chopped-glass-fiber composite is similar to, albeit somewhat less pronounced than, that observed for the $\pm 45^{\circ}$ fiber orientation.

\subsection{EFFECTS OF THERMAL CYCLING}

Thermal cycling is a concern because of the significant mismatch between the coefficient of thermal expansion (CTE) of the matrix and that of the fiber. ${ }^{*}$ The mismatch could lead to microstructural damage under significant temperature changes.

The effects of thermal cycling on basic tensile and compressive properties were investigated in six tensile and six compressive tests for each fiber orientation. In addition, short-beam shear specimens with a 3- by 6-mm cross-section (six for each fiber orientation) were included in this test series to establish whether a high edge-to-surface ratio serves to accelerate environmental damage. The short-beam shear specimens were tested in three-point bending with a span of $12.5 \mathrm{~mm}$. Before testing, all specimens were subjected to 20 thermal cycles. A thermal cycle between -40 and $120^{\circ} \mathrm{C}$, schematically shown in Fig. 7.25, was chosen to reflect the service temperature range.

\footnotetext{
${ }^{*}$ Unpublished ACC data indicate a CTE for Baydur 420 IMR neat resin of $79.8 \times 10^{-6} /{ }^{\circ} \mathrm{C}\left(30\right.$ to $\left.80^{\circ} \mathrm{C}\right)$. The

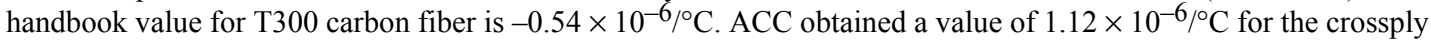
carbon-fiber composite in the $0^{\circ}$ direction.
} 
For the $0 / 90^{\circ}$ fiber orientation, prior thermal cycling had only a slight effect on tensile and compressive properties. In tension, a stiffness loss of $1.8 \%$ and a strength loss of $1.5 \%$ were observed. In compression, thermal cycling caused a stiffness drop of $0.5 \%$ and a strength drop of $1.1 \%$. Conversely, in short-beam shear, the loss of apparent shear strength was considerable, $8.5 \%$. Note that short-beam shear specimens for the $0 / 90^{\circ}$ fiber orientation failed in shear.

Microstructural investigation revealed stepwise shear cracks developing across the thickness with the largest cracks produced at midsurface, where shear is maximum.

For the $\pm 45^{\circ}$ fiber orientation, prior thermal cycling had a considerable effect on tensile stiffness, but it caused only slight changes in other tensile and compressive properties. Tensile stiffness loss was $15.5 \%$, while tensile strength improved by $1.8 \%$. In compression, stiffness dropped by $0.3 \%$ while strength increased by $6.1 \%$. In short-beam shear, apparent shear strength decreased by $2.4 \%$. Note that for the $\pm 45^{\circ}$ short-beam shear specimens, no shear cracking was observed; specimens failed in bending.

It can be concluded that thermal cycling appears to have no significant effect on properties governed by fiber strength.

\subsection{FLUID EFFECTS}

\subsubsection{Screening Tests}

Environmental screening tests were performed to establish which automotive fluids have a significant degrading effect on strength. Short-beam shear specimens were selected for this task because they have the highest edge-to-face area ratio and are therefore most susceptible to environmental damage. Nine automotive fluids were used in the screening. Details of the fluids are given in Table 7.9.

Exposure time for most of the fluids was $1000 \mathrm{~h}$. Battery acid constituted an exception with an exposure time of only $115 \mathrm{~h}$. Twelve specimens were soaked in each fluid, six for each fiber orientation. Ten unexposed specimens were tested to establish a baseline for each fiber orientation. Short-beam shear specimens were all cut from the same plaque. For the $0 / 90^{\circ}$ fiber orientation, specimens had $0^{\circ}$ fibers on the surface. All short-beam shear tests were conducted according to ASTM D 2344. ${ }^{12}$ Results are summarized in Table 7.10. Given in parentheses are COVs.

Table 7.9. Details of automotive fluids used in environmental screening

\begin{tabular}{|c|c|c|}
\hline Common name & Details & Source \\
\hline Distilled water & & Systems Scientific Laboratories, Inc. \\
\hline Saltwater & $5 \% \mathrm{NaCl} /$ distilled water & Systems Scientific Laboratories, Inc. \\
\hline Windshield washer fluid & $70 \%$ methanol, $30 \%$ distilled water & $\begin{array}{l}\text { EM Science, Systems Scientific } \\
\text { Laboratories, Inc. }\end{array}$ \\
\hline Coolant & $\begin{array}{l}\text { 90-95\% ethylene glycol, } 0-5 \% \\
\text { diethylene glycol }\end{array}$ & Old World Automotive Products, Inc. \\
\hline Motor oil & $10 \mathrm{~W} 40$ & Texaco Lubricants Company \\
\hline Gasoline & Regular, unleaded & BP Corporation \\
\hline Brake fluid & $\begin{array}{l}\text { Glycols, glycol ethers, glycol ether } \\
\text { borate esters }\end{array}$ & Castrol, Inc. \\
\hline Transmission fluid & & Exxon Company \\
\hline Battery acid & $34 \%$ sulfuric acid, $66 \%$ water & Colonial Chemical Corporation \\
\hline
\end{tabular}


Table 7.10. Effects of fluid environments on apparent shear strength in short-beam shear

\begin{tabular}{|c|c|c|}
\hline Fluid environment & $\begin{array}{l}\text { Apparent shear } \\
\text { strength } \\
\text { (MPa) }\end{array}$ & $\begin{array}{c}\text { Change in apparent } \\
\text { shear strength } \\
(\%)\end{array}$ \\
\hline \multicolumn{3}{|c|}{$0 / 90^{\circ}$ Fiber orientation } \\
\hline None & $92.1(3.76)$ & 0.00 \\
\hline Distilled water & $87.6(3.15)$ & -5.25 \\
\hline Saltwater & $85.1(2.26)$ & -7.90 \\
\hline Windshield washer fluid & $88.3(5.66)$ & -4.20 \\
\hline Coolant & $87.0(7.74)$ & -5.89 \\
\hline Motor oil & $89.6(5.05)$ & -3.29 \\
\hline Gasoline & $92.6(2.26)$ & 0.20 \\
\hline Brake fluid & $84.8(7.74)$ & -8.22 \\
\hline Transmission fluid & $86.4(5.92)$ & -6.51 \\
\hline Battery acid & $90.9(4.96)$ & -1.66 \\
\hline \multicolumn{3}{|c|}{ $\pm 45^{\circ}$ Fiber orientation } \\
\hline None & $77.1(3.35)$ & 0.00 \\
\hline Distilled water & $73.6(3.52)$ & -4.65 \\
\hline Saltwater & $74.3(5.64)$ & -3.78 \\
\hline Windshield washer fluid & $72.0(5.05)$ & -6.82 \\
\hline Coolant & $73.1(5.50)$ & -5.34 \\
\hline Motor oil & $71.1(4.48)$ & -7.94 \\
\hline Gasoline & $76.6(3.68)$ & -0.80 \\
\hline Brake fluid & $70.7(4.99)$ & -8.50 \\
\hline Transmission fluid & $72.2(6.51)$ & -6.48 \\
\hline Battery acid & $68.1(3.09)$ & -11.8 \\
\hline
\end{tabular}

It is seen in Table 7.10 that, for the $0 / 90^{\circ}$ fiber orientation, brake fluid caused the most degradation, namely a strength loss of $8.2 \%$. In the case of the $\pm 45^{\circ}$ fiber orientation, battery acid was most degrading ( $11.8 \%$ strength loss), followed by brake fluid ( $8.5 \%$ strength loss). The results in Table 7.10 are presented graphically in Fig. 7.26(a) and $(b)$. It is concluded that $1000 \mathrm{~h}$ in distilled water is likely to bound most fluid effects encountered in service, since many of the other 1000-h exposures are probably not realistic.

\subsubsection{Moisture Absorption}

Moisture absorption in the crossply carbon-fiber composite was investigated with the purpose of establishing correlations between exposure time and weight change, and subsequently with strength and stiffness. For each fiber orientation, six specimens were exposed in roomtemperature distilled water and six specimens in 70\% relative humidity $(\mathrm{RH})$ air. All specimens were initially in the "as-received" condition. The $70 \% \mathrm{RH}$ condition is of particular interest because typical meteorological year data show that humidity averages about $70 \%$ for most of the year in most places in the United States.

For the $0 / 90^{\circ}$ fiber orientation, maximum exposure times were 4241 and $3968 \mathrm{~h}$ for distilled water and $70 \% \mathrm{RH}$, respectively. In the case of the $\pm 45^{\circ}$ fiber orientation, exposure times reached 4267 and $4271 \mathrm{~h}$ for the distilled water and 70\% RH. Results are presented in Fig. 7.27, where 
weight gain is plotted vs square root of time, exhibiting classical Fickian diffusion behavior. Both fiber orientations produce very similar results for both distilled water and $70 \% \mathrm{RH}$ air exposures. As expected, moisture absorption progresses in the same fashion for both $0 / 90^{\circ}$ and $\pm 45^{\circ}$ fiber orientations. Percent weight changes for distilled water exposure were 0.84 and 0.86 for the $0 / 90^{\circ}$ and $\pm 45^{\circ}$ fiber orientations, respectively. Both fiber orientations exhibited a weight gain of $0.3 \%$ for $70 \%$ RH. Furthermore, the absorption process appears to have reached saturation at about $2000 \mathrm{~h}$ for both exposure conditions. Note that the chopped-glass-fiber composite appears to be more susceptible to moisture; the maximum weight gain there was more than $1 \%$.

The effects of exposure in room-temperature distilled water and $70 \% \mathrm{RH}$ on tensile properties are summarized in Table 7.11, where the average values of percent change in strength and stiffness are given for the different exposure conditions (each average is based on six specimens). Note that for the chopped-glass-fiber composite, moisture exposure is significantly more damaging. At saturation, stiffness loss was about $13 \%$, and strength loss was about $35 \%$.

Prolonged exposure in room-temperature distilled water represents a bounding condition, which was studied to gain a better understanding of environmental material and property degradation. However, a 4000-h exposure in water does not represent a typical service condition for an automotive composite. A 1000-h exposure in room-temperature water, while sufficiently near saturation, is considered to be a more representative bounding moisture exposure likely to be encountered under normal operating conditions. Thus, throughout this report, a 1000-h exposure in room-temperature distilled water is chosen as the most representative bounding condition (standard exposure). For the $0 / 90^{\circ}$ fiber orientation, a 1000 -h distilled water exposure bounds exposure in $70 \% \mathrm{RH}$ more than adequately. The same can be concluded for tensile stiffness for the $\pm 45^{\circ}$ fiber orientation. However, a 1000 -h distilled water exposure does not bound tensile strength degradation due to prolonged exposure in $70 \% \mathrm{RH}$ air.

In addition to the these conditions, the effects of exposure to freezing temperatures on stiffness and strength of the material when saturated or nearly saturated with water were considered. Twelve tensile specimens for each fiber orientation were soaked in room-temperature distilled water for $1000 \mathrm{~h}$. Six of the twelve specimens were tested after exposure. The remaining six specimens were exposed overnight to a temperature of $-15^{\circ} \mathrm{C}$ and then tested. Changes in stiffness and strength due to exposure to distilled water, as well as to the water exposure followed by subfreezing overnight, were assessed and compared. As before, changes in stiffness were calculated with reference to the virgin stiffness for each specimen, while changes in strength

Table 7.11. Effects of exposure in $23^{\circ} \mathrm{C}$ distilled water and in $70 \%$ RH air on tensile strength and stiffness

\begin{tabular}{|c|c|c|}
\hline Exposure condition & $\begin{array}{c}\text { Change in } \\
\text { stiffness } \\
(\%)\end{array}$ & $\begin{array}{c}\text { Change in } \\
\text { strength } \\
(\%)\end{array}$ \\
\hline \multicolumn{3}{|c|}{$0 / 90^{\circ}$ Fiber orientation } \\
\hline Distilled water, $1000 \mathrm{~h}$ & -6.09 & -3.94 \\
\hline Distilled water, $4241 \mathrm{~h}$ & -7.63 & -6.38 \\
\hline $70 \%$ RH, 3968 h & -0.78 & -0.22 \\
\hline \multicolumn{3}{|c|}{ $\pm 45^{\circ}$ Fiber orientation } \\
\hline Distilled water, $1000 \mathrm{~h}$ & -4.09 & -3.47 \\
\hline Distilled water, $4267 \mathrm{~h}$ & -4.88 & -8.27 \\
\hline $70 \%$ RH, 4271 h & -2.30 & -6.78 \\
\hline
\end{tabular}


were referenced to the plaque average strength. Results are summarized in Table 7.12. Note that all $0 / 90^{\circ}$ specimens came from a single plaque $(\mathrm{C} 15)$, as did the $\pm 45^{\circ}$ specimens $(\mathrm{C} 17)$.

Freezing does not appear to have a significant effect on stiffness and strength.

Table 7.12. Effects on stiffness and strength of exposure to moisture followed by freezing

\begin{tabular}{|c|c|c|c|c|}
\hline $\begin{array}{l}\text { Exposure } \\
\text { condition }\end{array}$ & $\begin{array}{c}\text { Change in } \\
\text { stiffness } \\
(\%)\end{array}$ & $\begin{array}{l}\text { Stiffness } \\
\text { reduction } \\
\text { factor }\end{array}$ & $\begin{array}{l}\text { Change in } \\
\text { strength } \\
(\%)\end{array}$ & $\begin{array}{l}\text { Strength } \\
\text { reduction } \\
\text { factor }\end{array}$ \\
\hline \multicolumn{5}{|c|}{$0 / 90^{\circ}$ Fiber orientation } \\
\hline $\begin{array}{l}1000 \mathrm{~h} \text { in distilled } \\
\text { water }\end{array}$ & -5.12 & 0.95 & 1.26 & 1.01 \\
\hline $\begin{array}{l}1000 \mathrm{~h} \text { in distilled } \\
\text { water followed by } \\
\text { freezing }\end{array}$ & -3.97 & 0.96 & 1.66 & 1.02 \\
\hline \multicolumn{5}{|c|}{ $\pm 45^{\circ}$ Fiber orientation } \\
\hline $\begin{array}{l}1000 \mathrm{~h} \text { in distilled } \\
\text { water }\end{array}$ & -6.22 & 0.94 & -2.40 & 0.98 \\
\hline $\begin{array}{l}1000 \mathrm{~h} \text { in distilled } \\
\text { water followed by } \\
\text { freezing }\end{array}$ & -4.87 & 0.95 & -3.25 & 0.97 \\
\hline
\end{tabular}

\subsubsection{Windshield Washer Fluid}

The effects of exposure in windshield washer fluid (30\% distilled water and $70 \%$ methanol) were investigated. Windshield washer fluid was chosen as a practical exposure condition because methanol in windshield washer fluid is a "lighter molecule." Exposure times were 50, 100, and $1000 \mathrm{~h}$. Results are summarized in Table 7.13. All reduction factors are based on at least six tests.

Table 7.13. Effects on stiffness and strength of exposure in windshield washer fluid

\begin{tabular}{|c|c|c|c|c|}
\hline $\begin{array}{l}\text { Exposure } \\
\text { time } \\
\text { (h) }\end{array}$ & $\begin{array}{c}\text { Change in } \\
\text { stiffness } \\
(\%)\end{array}$ & $\begin{array}{c}\text { Stiffness } \\
\text { reduction } \\
\text { factor }\end{array}$ & $\begin{array}{c}\text { Change in } \\
\text { strength } \\
(\%)\end{array}$ & $\begin{array}{c}\text { Strength } \\
\text { reduction } \\
\text { factor }\end{array}$ \\
\hline \multicolumn{5}{|c|}{$0 / 90^{\circ}$ Fiber orientation } \\
\hline 50 & -0.72 & 0.99 & -0.39 & 0.99 \\
\hline 100 & -0.76 & 0.99 & -2.28 & 0.98 \\
\hline 1000 & -1.95 & 0.98 & 14.5 & 1.15 \\
\hline \multicolumn{5}{|c|}{ $\pm 45^{\circ}$ Fiber orientation } \\
\hline 50 & -0.68 & 0.99 & -0.84 & 0.99 \\
\hline 100 & -4.24 & 0.96 & -2.80 & 0.97 \\
\hline 1000 & -9.36 & 0.91 & -2.99 & 0.97 \\
\hline
\end{tabular}


Stiffness reductions were established with reference to the virgin stiffness for each specimen. Strength reductions were established relative to plaque average UTS values.

For both fiber orientations, stiffness decreases with increasing exposure times, with the $\pm 45^{\circ}$ fiber orientation showing the larger effect (a $9 \%$ drop at $1000 \mathrm{~h}$ as opposed to a $2 \%$ drop for the $0 / 90^{\circ}$ orientation). With one exception, strength is little affected in either case. The indicated increase in the $90^{\circ}$ strength may be just an artifact, reflecting scatter from plaque to plaque and within each plaque. The chopped-glass-fiber composite appears to be more sensitive to windshield washer fluid exposure. For the chopped-glass-fiber material, $1000 \mathrm{~h}$ in windshield washer fluid caused a stiffness loss of $12 \%$ and a strength loss of $11 \%$.

Just as in the case of moisture exposure, it is recognized that a 1000-h exposure in windshield washer fluid does not represent a realistic service condition for an automotive composite. Thus, $100 \mathrm{~h}$ was chosen as the bounding condition (or standard exposure) for windshield washer fluid.

\subsubsection{Fluid Reduction Factors for Standard Exposures}

Fluid reduction factors for standard exposures in room-temperature distilled water $(1000 \mathrm{~h})$ and in windshield washer fluid $(100 \mathrm{~h})$ are summarized in Tables 7.14 and 7.15, respectively.

Table 7.14. Fluid reduction factors for 1000-h exposure in room-temperature distilled water

\begin{tabular}{lcc}
\hline & $\begin{array}{c}\text { Stiffness reduction } \\
\text { factor }\end{array}$ & $\begin{array}{c}\text { Strength reduction } \\
\text { factor }\end{array}$ \\
\hline & $\mathbf{0 / 9 0}^{\circ}$ Fiber orientation & \\
Tension & 0.94 & 0.96 \\
Compression & 0.94 & 0.98 \\
Shear & 0.99 & 0.97 \\
& $\mathbf{\pm 4 5}$ Fiber orientation & \\
Tension & 0.96 & 0.97 \\
Compression & 0.95 & 0.98 \\
Shear & 0.93 & 0.96 \\
\hline
\end{tabular}

Table 7.15. Fluid reduction factors for 100-h exposure in windshield washer fluid

\begin{tabular}{lcc}
\hline & $\begin{array}{c}\text { Stiffness reduction } \\
\text { factor }\end{array}$ & $\begin{array}{c}\text { Strength reduction } \\
\text { factor }\end{array}$ \\
\hline & $\mathbf{0 / 9 0}^{\circ}$ Fiber orientation \\
Tension & 0.99 & 0.98 \\
Compression & & 0.92 \\
Shear & & 0.97 \\
& & \\
Tension & $\mathbf{4 5 ^ { \circ }}$ Fiber orientation \\
Compression & 0.96 & 0.97 \\
Shear & & 0.99 \\
\hline
\end{tabular}


Note that for the $0 / 90^{\circ}$ fiber orientation, the strength reduction factor of 0.92 obtained for windshield washer fluid can be used to represent the effects of the standard exposure in either fluid. Likewise, for the $\pm 45^{\circ}$ fiber orientation, a single factor of 0.93 bounds realistic environmental effects on strength and stiffness. Both of these reduction factors are comparable to the reduction factor of 0.91 used to bound standard exposures for the chopped-glass-fiber composite.

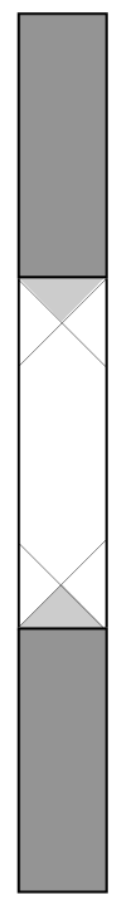

$25.4 \mathrm{~mm}$

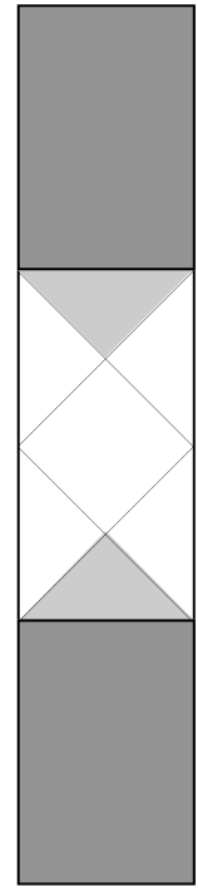

$50.8 \mathrm{~mm}$

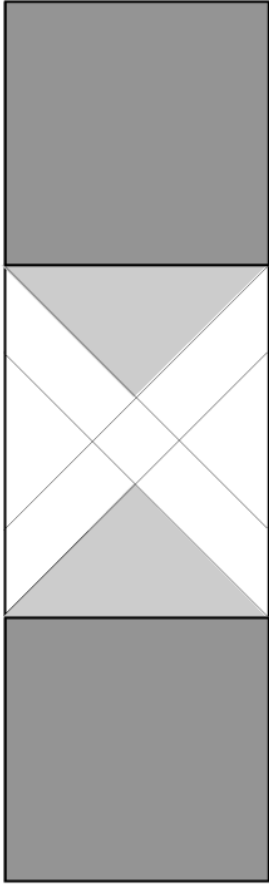

$76.2 \mathrm{~mm}$
ORNL 2001-740 EFG

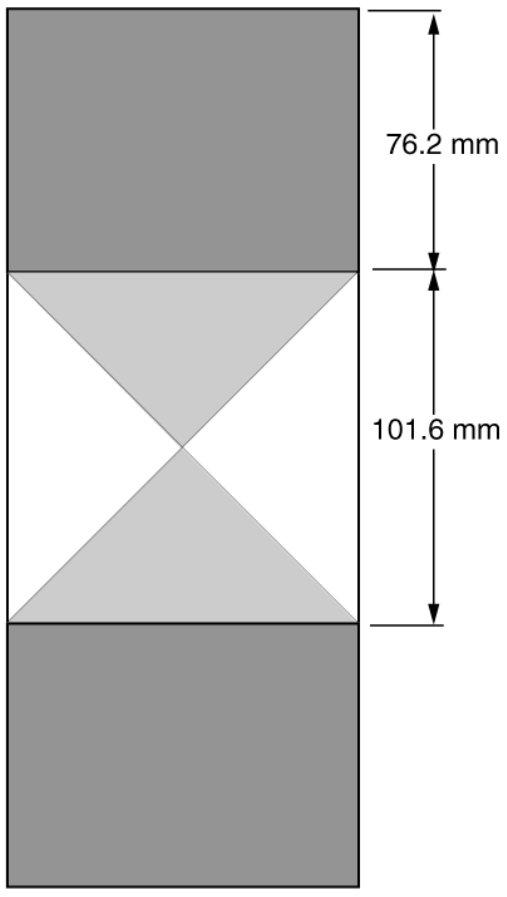

$101.6 \mathrm{~mm}$

(a)

(b)

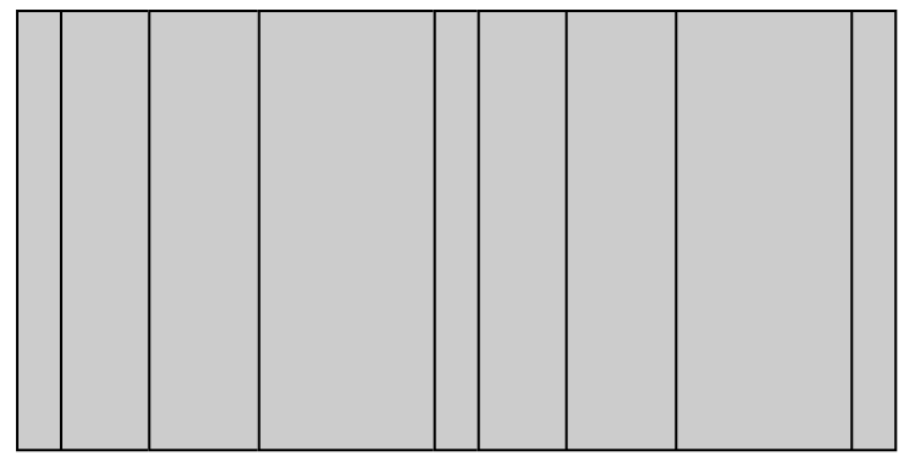

Fig. 7.1. Specimens used in width study, $(a)$ specimens and $(b)$ cutting plan. 


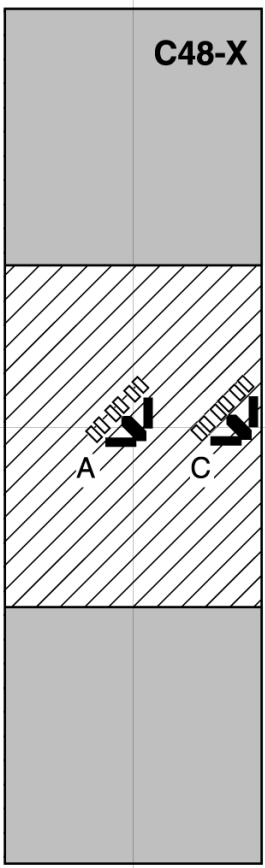

SIDE 1

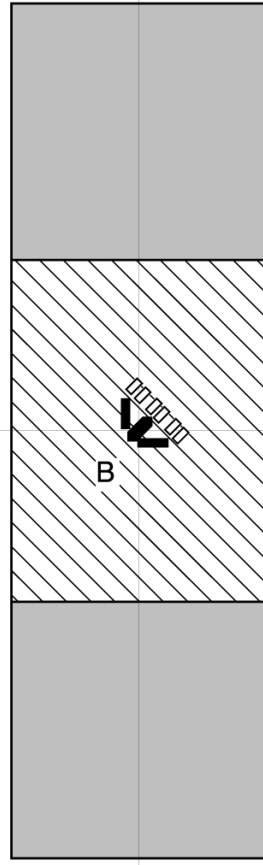

SIDE 2

Fig. 7.2. Strain-gage layout used for width effect specimens. Only 76.2- and 101.6-mm-wide specimens had rosette $\mathrm{C}$.

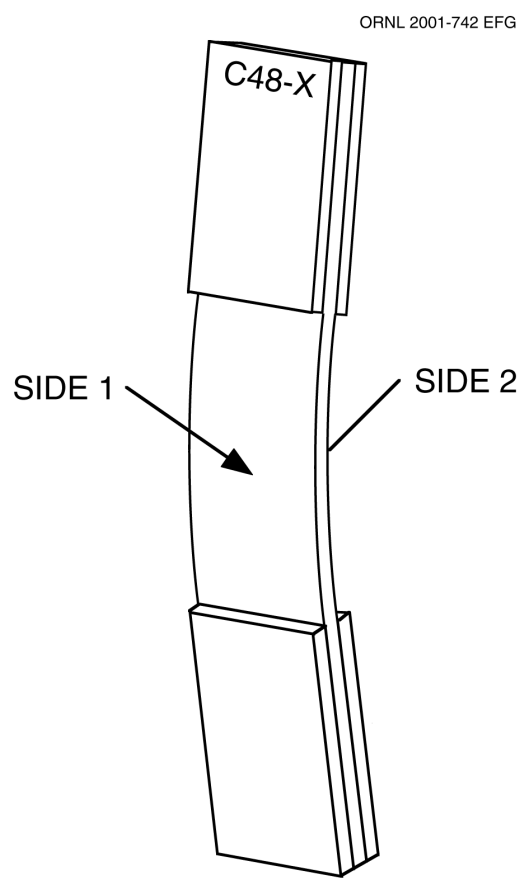

Fig. 7.3. Initial bowed configuration of specimens. 


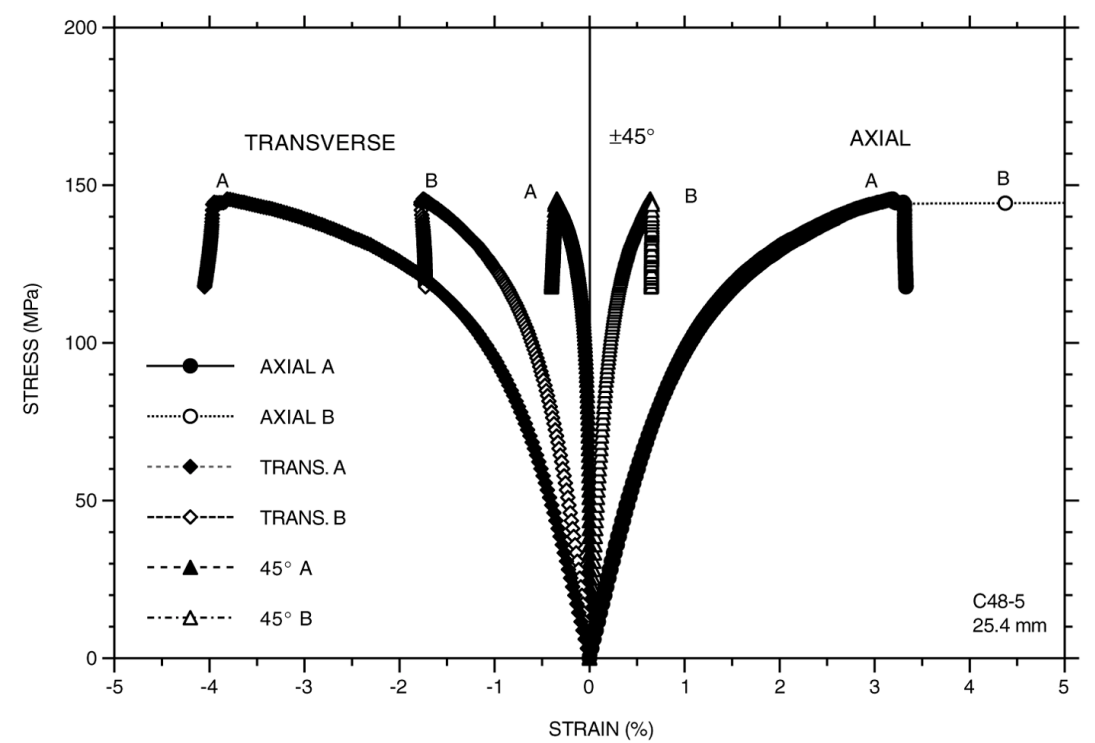

Fig. 7.4. Stress-strain curves and X-ray photograph of 25.4-mm-wide specimen C48-5. 

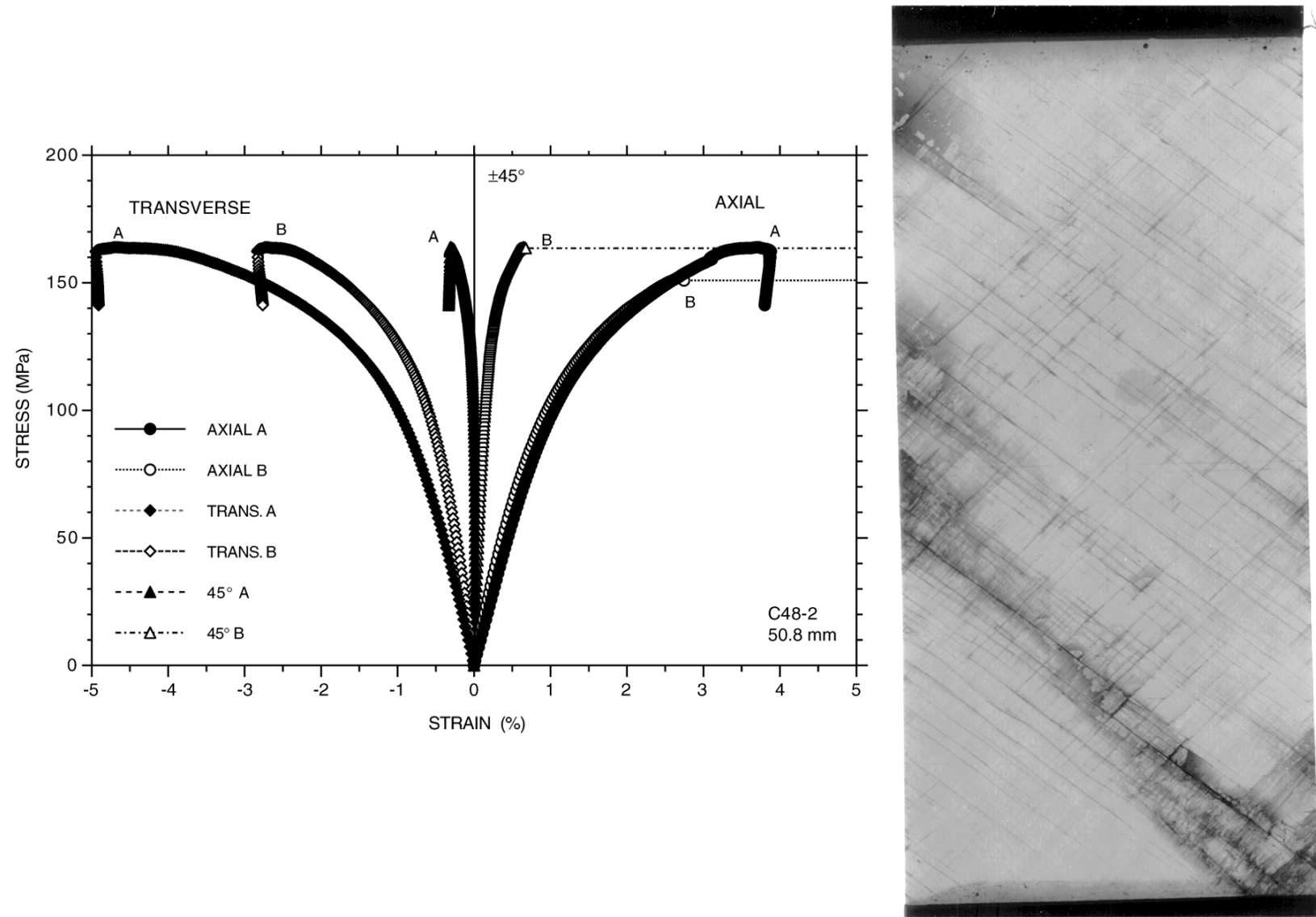

Fig. 7.5. Stress-strain curves and X-ray photograph of 50.8-mm-wide specimen C48-2. 
ORNL 2001-745 EFG
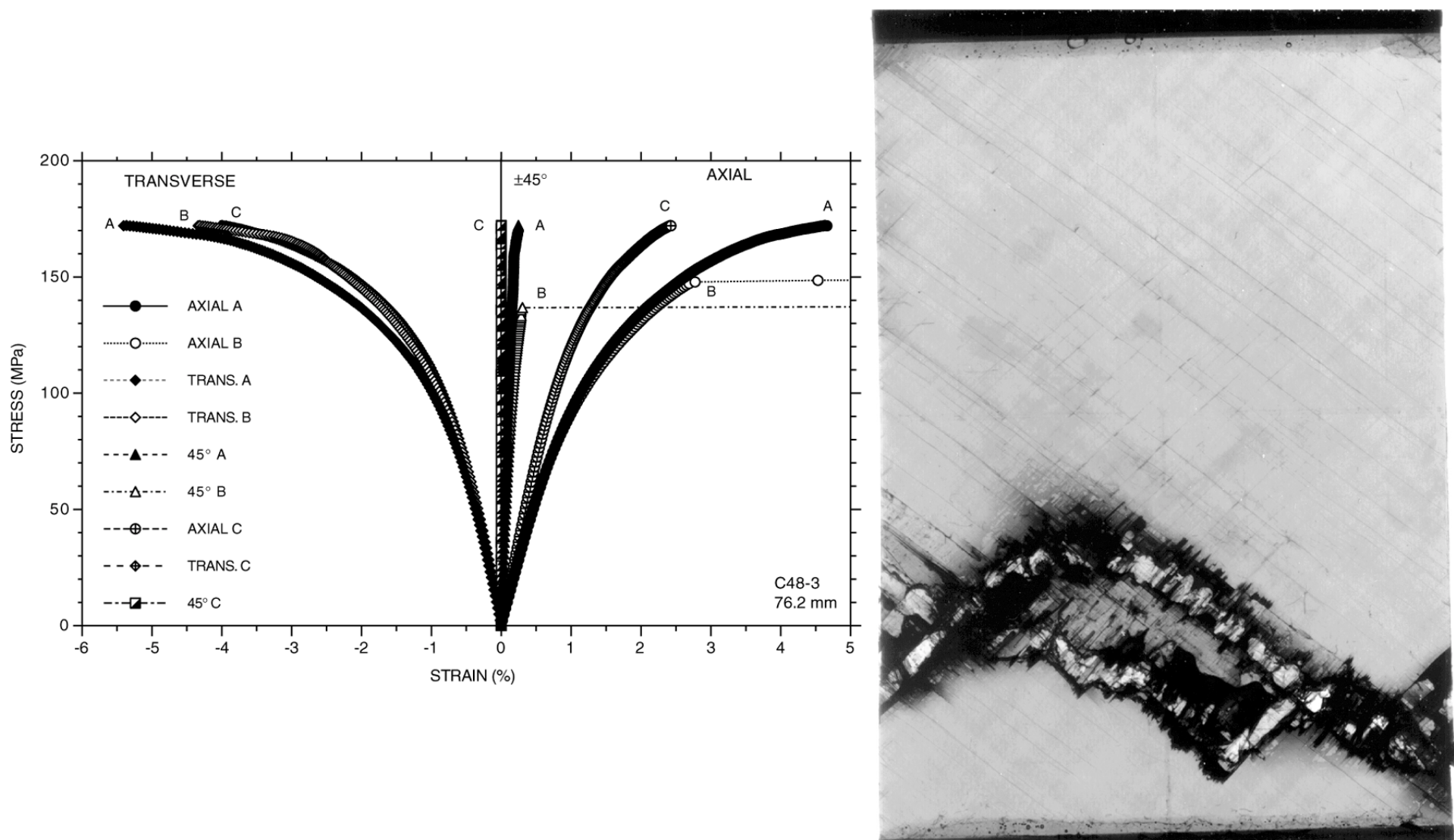

Fig. 7.6. Stress-strain curves and X-ray photograph of 76.2-mm-wide specimen C48-3. 
ORNL 2001-746 EFG
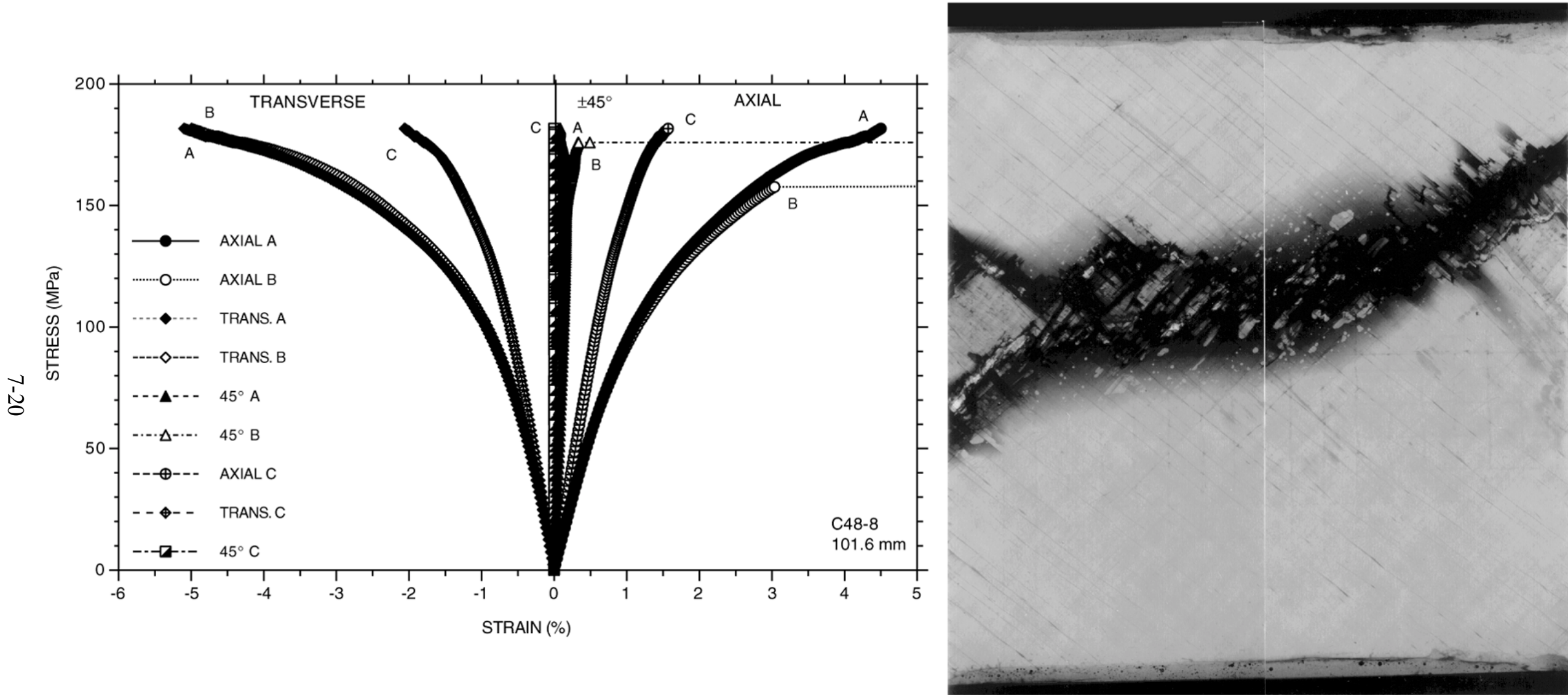

Fig. 7.7. Stress-strain curves and X-ray photograph of 101.6-mm-wide specimen C48-8. 


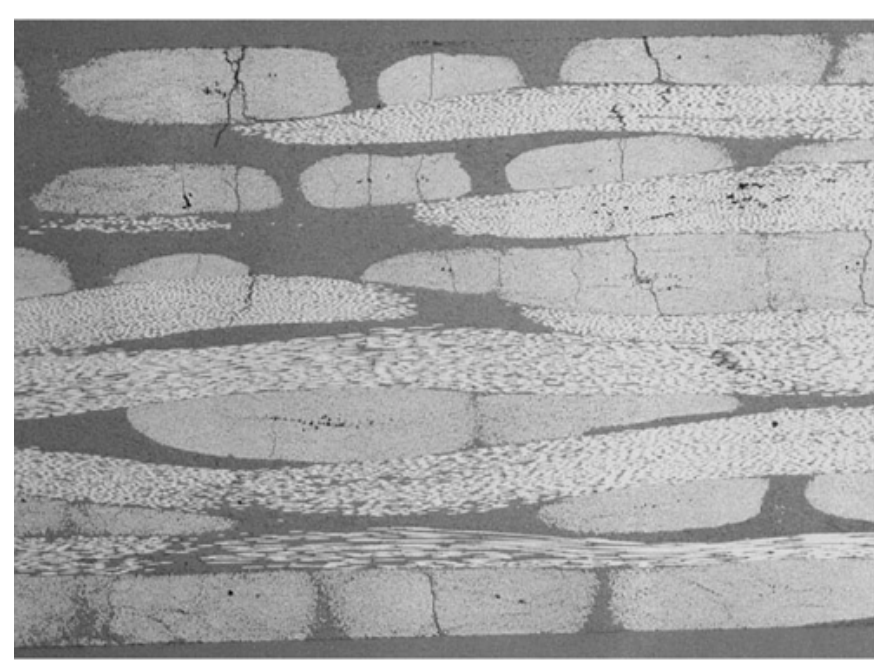

Perpendicular to surface fibers 25X magnification

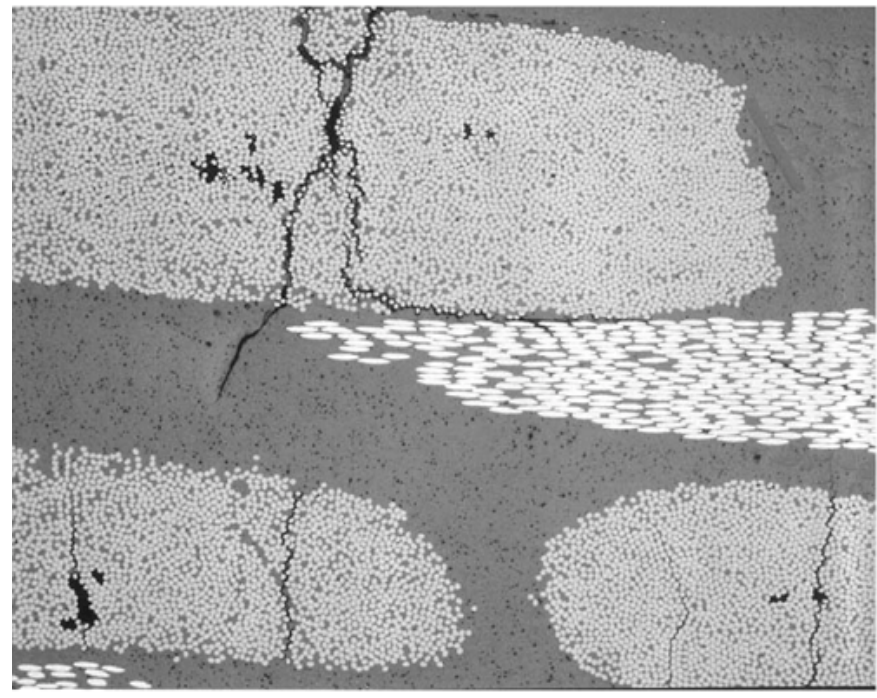

Perpendicular to surface fibers 100X magnification

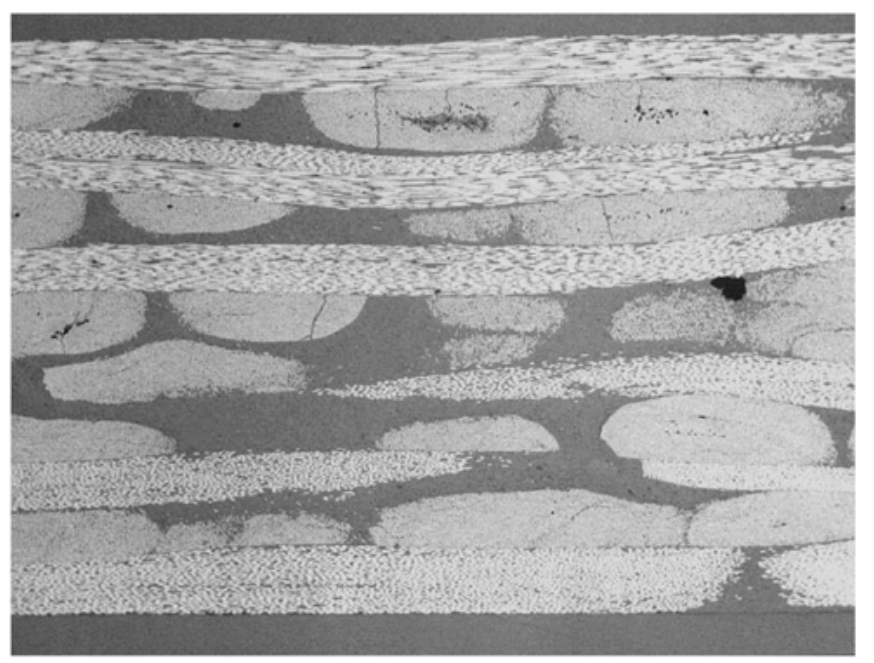

Parallel to surface fibers 25X magnification

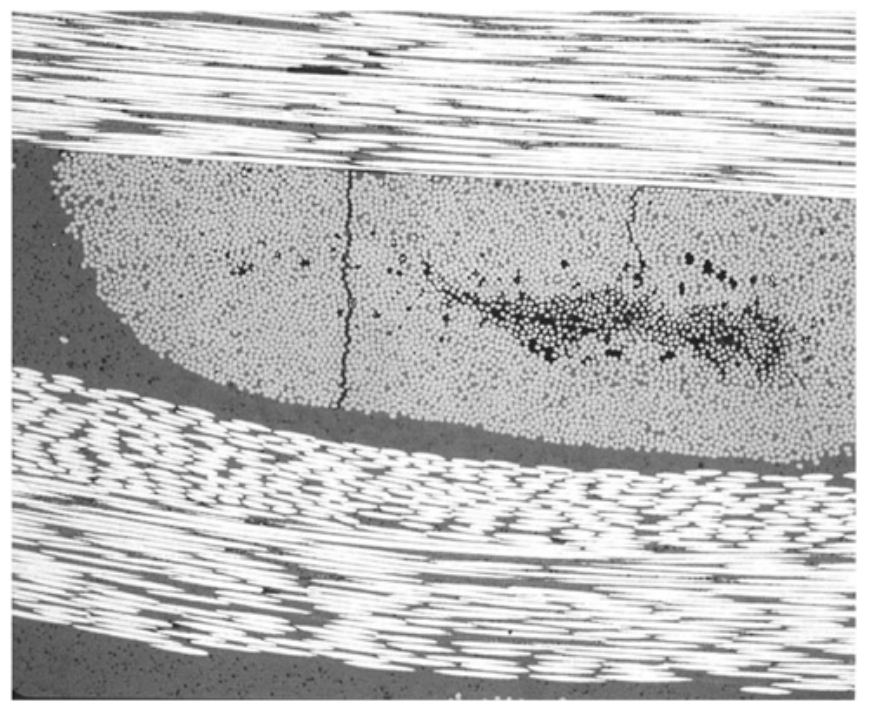

Parallel to surface fibers 100X magnification

Fig. 7.8. Photomicrographs of sections from 50.8-mm-wide specimen C48-2. Pictures are reduced approximately $15 \%$ from original magnification. The horizontal crack between bundles in the lower left figure is likely evidence of interlaminar shear cracking. 


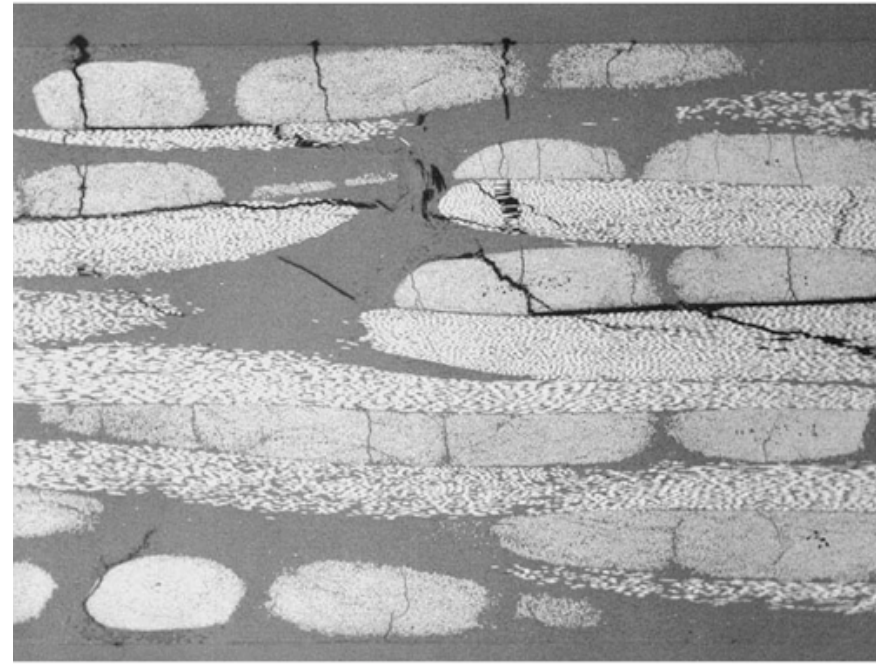

Perpendicular to surface fibers 25X magnification

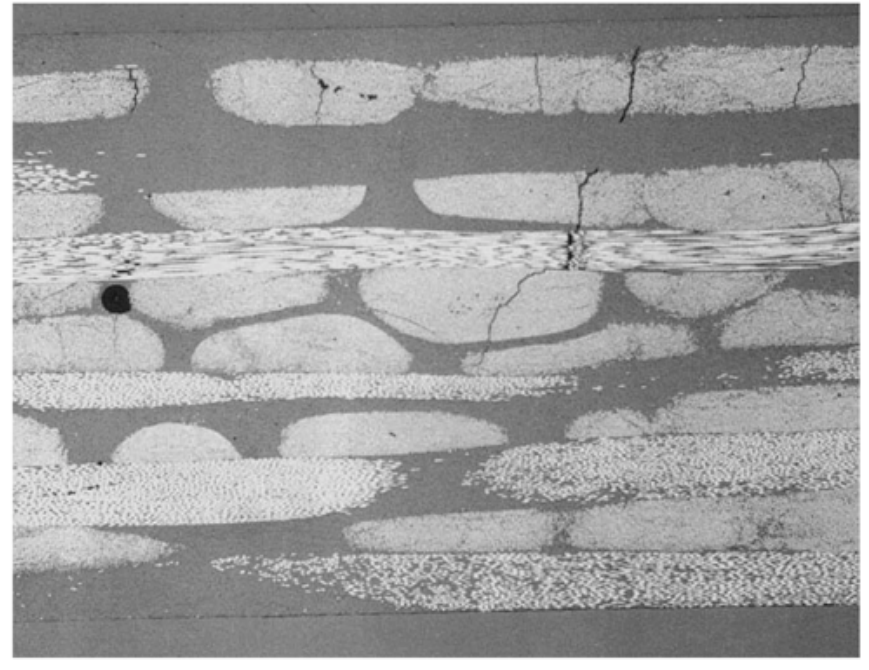

Parallel to surface fibers 25X magnification

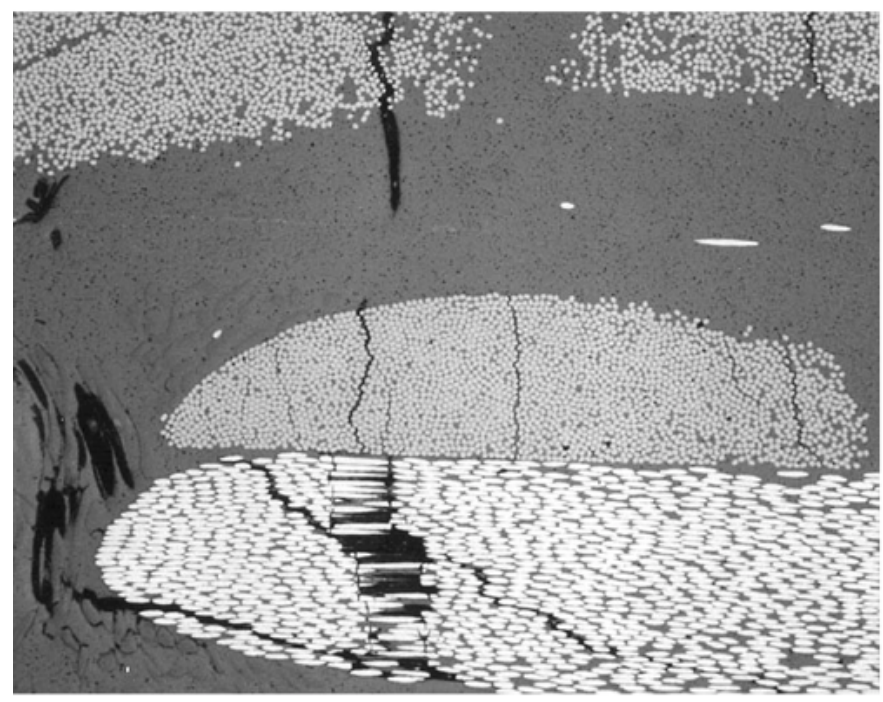

Perpendicular to surface fibers 100X magnification

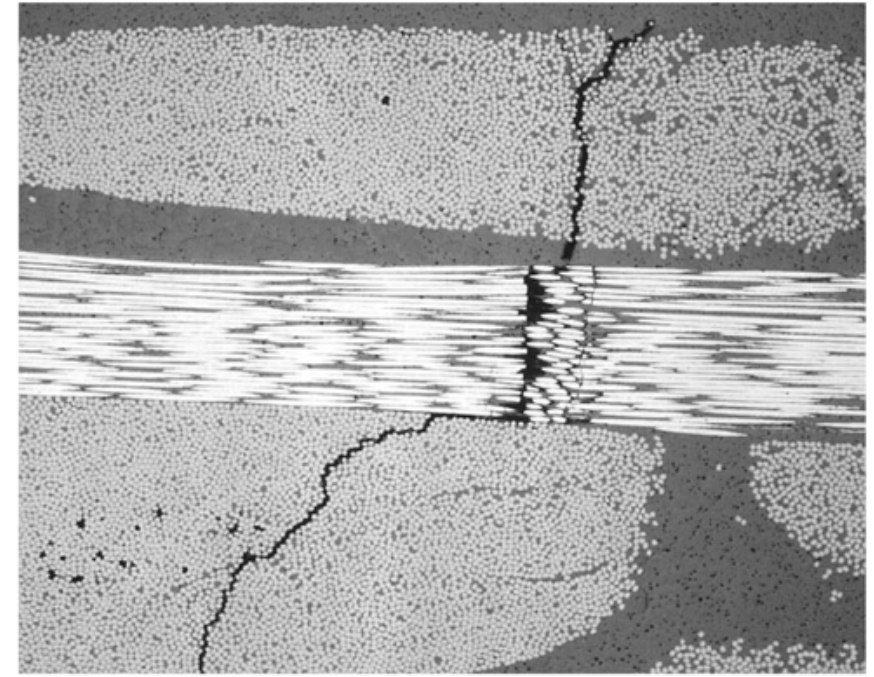

Parallel to surface fibers 100X magnification

Fig. 7.9. Photomicrographs of sections from 76.2-mm-wide specimen C48-3. Pictures are reduced approximately $15 \%$ from original magnification. Several horizontal cracks, indicating interlaminar shear cracking, are visible in these figures. 
- WIDTH STUDY, PLAQUE C48

O PLAQUE C48 REFERENCE AVERAGE

$\triangle$ DENG/WEITSMAN AVERAGES, PLAQUE C54

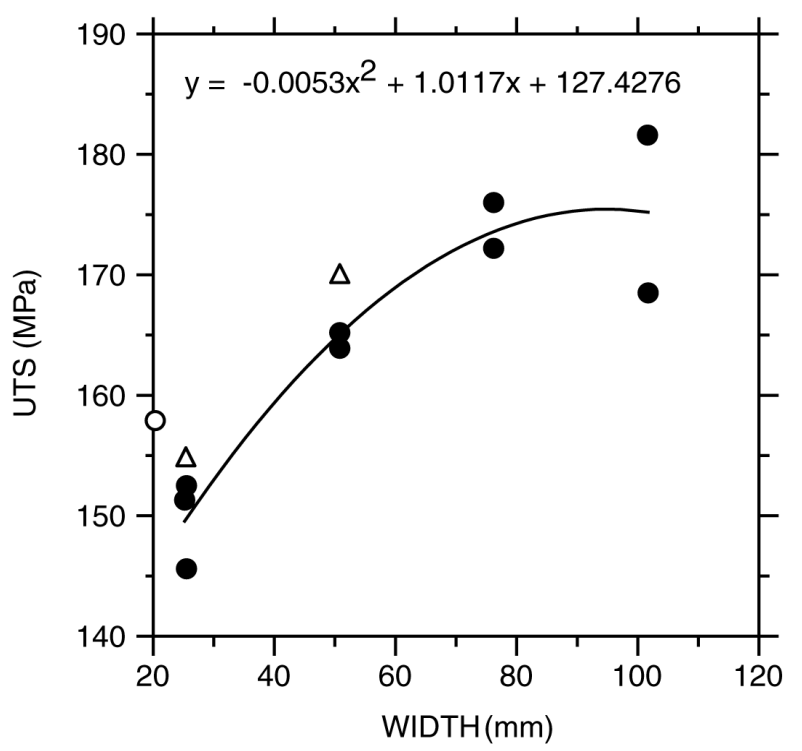

Fig. 7.10. UTS vs specimen width.

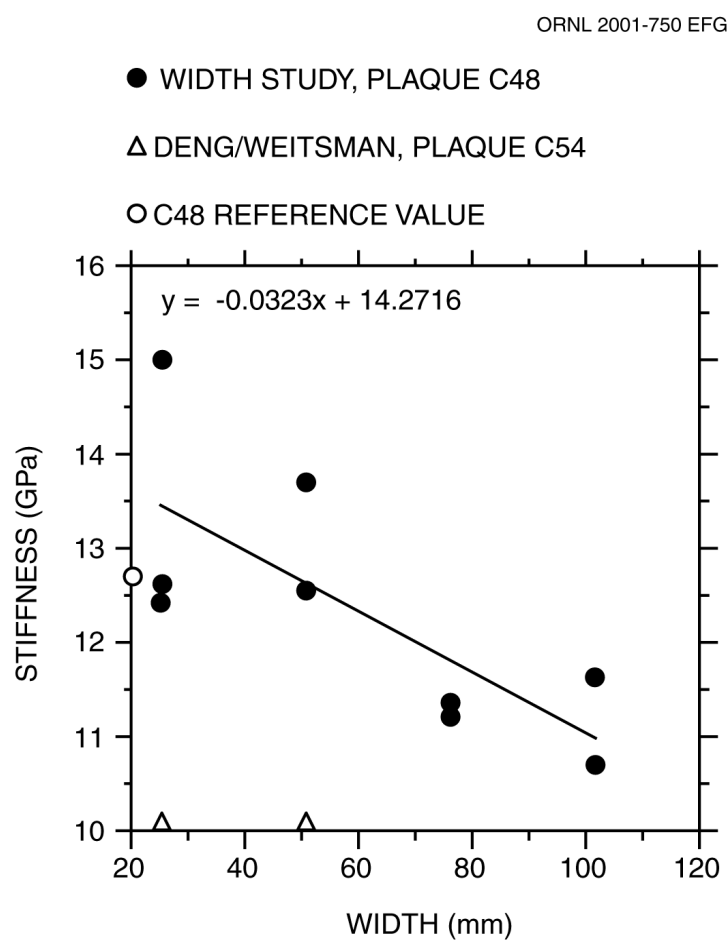

Fig. 7.11. Stiffness (apparent modulus of elasticity) vs specimen width. 

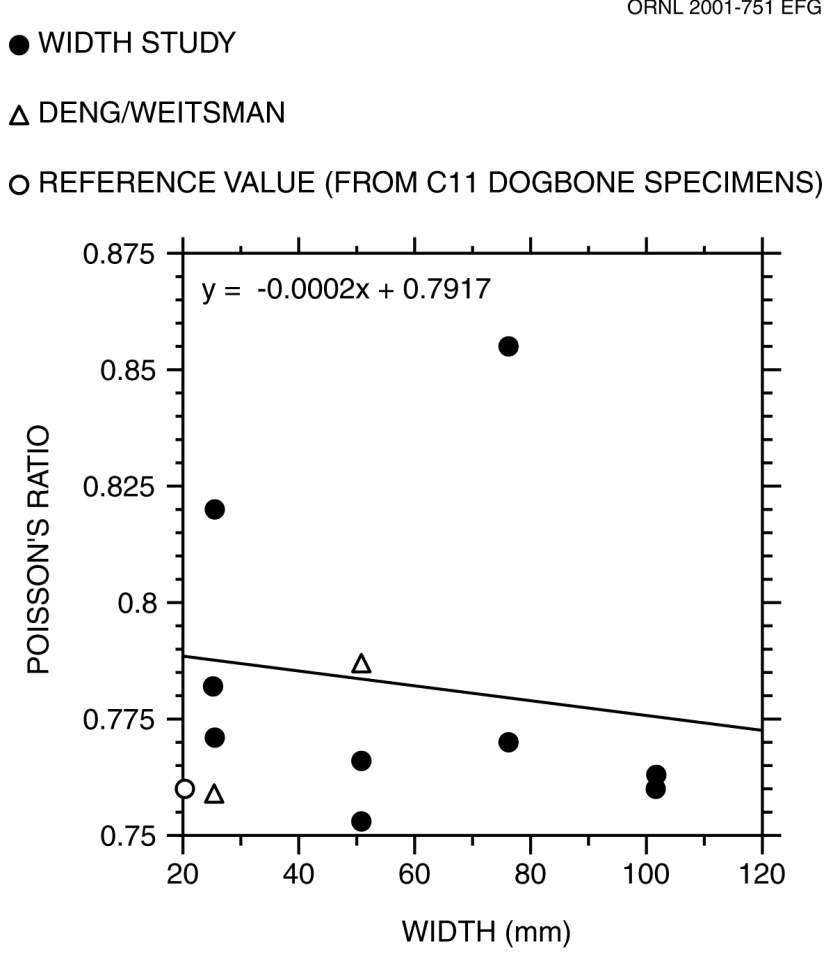

Fig. 7.12. Poisson's ratio vs specimen width. 
ORNL 2001-752 EFG
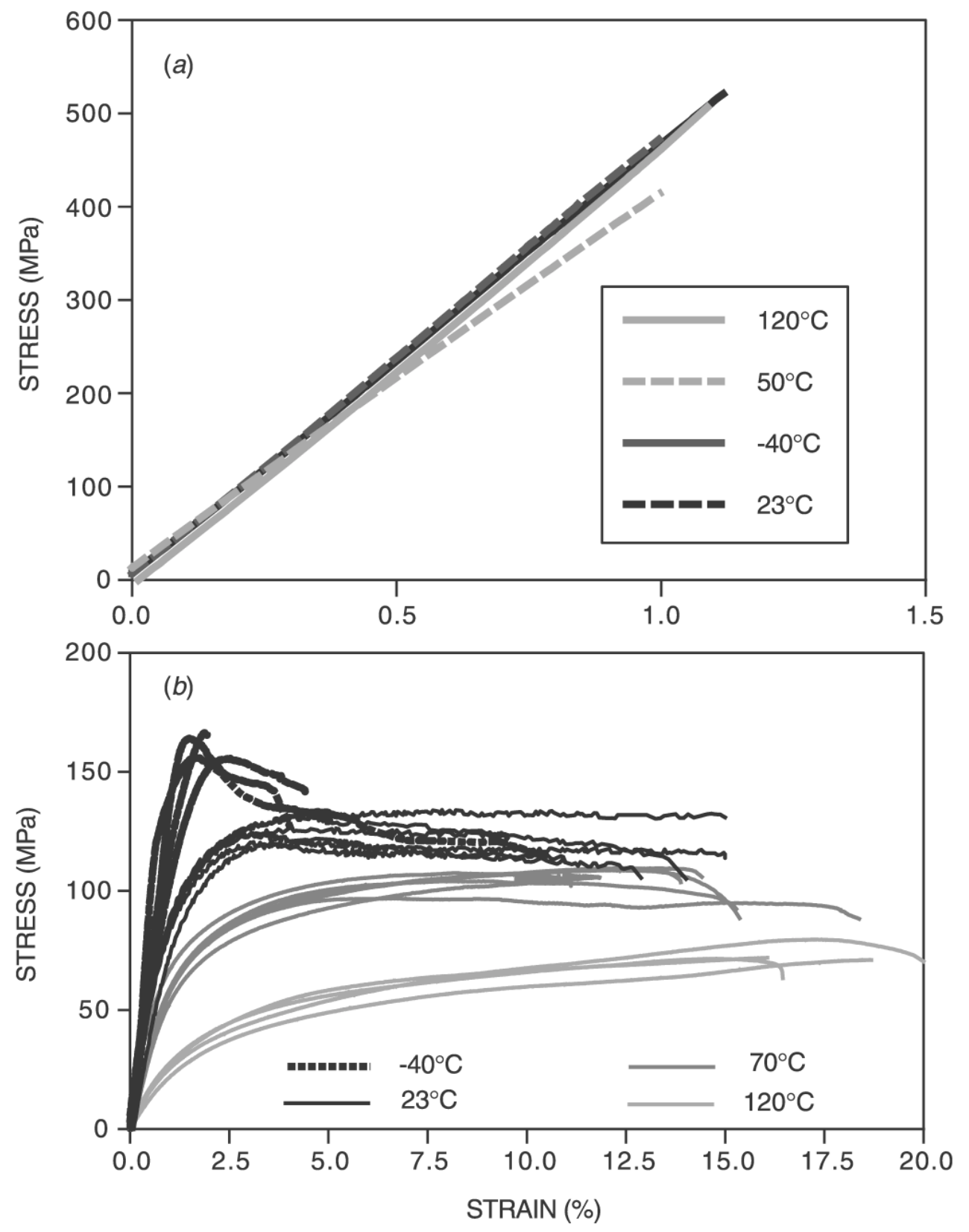

Fig. 7.13. Typical stress-strain curves: (a) $0 / 90^{\circ}$ fiber orientation and $(b) \pm 45^{\circ}$ fiber orientation. 


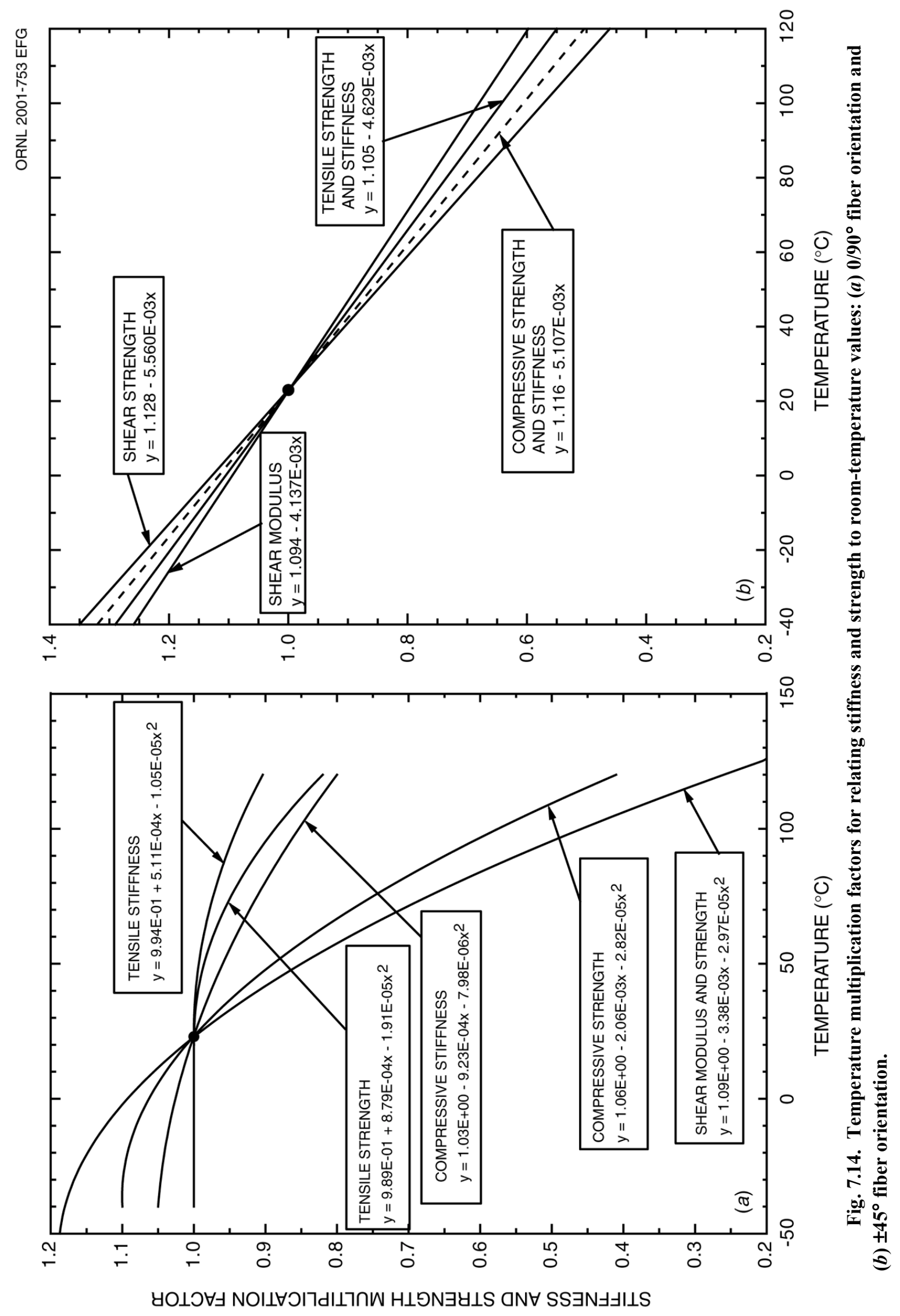


ORNL 2001-754 EFG

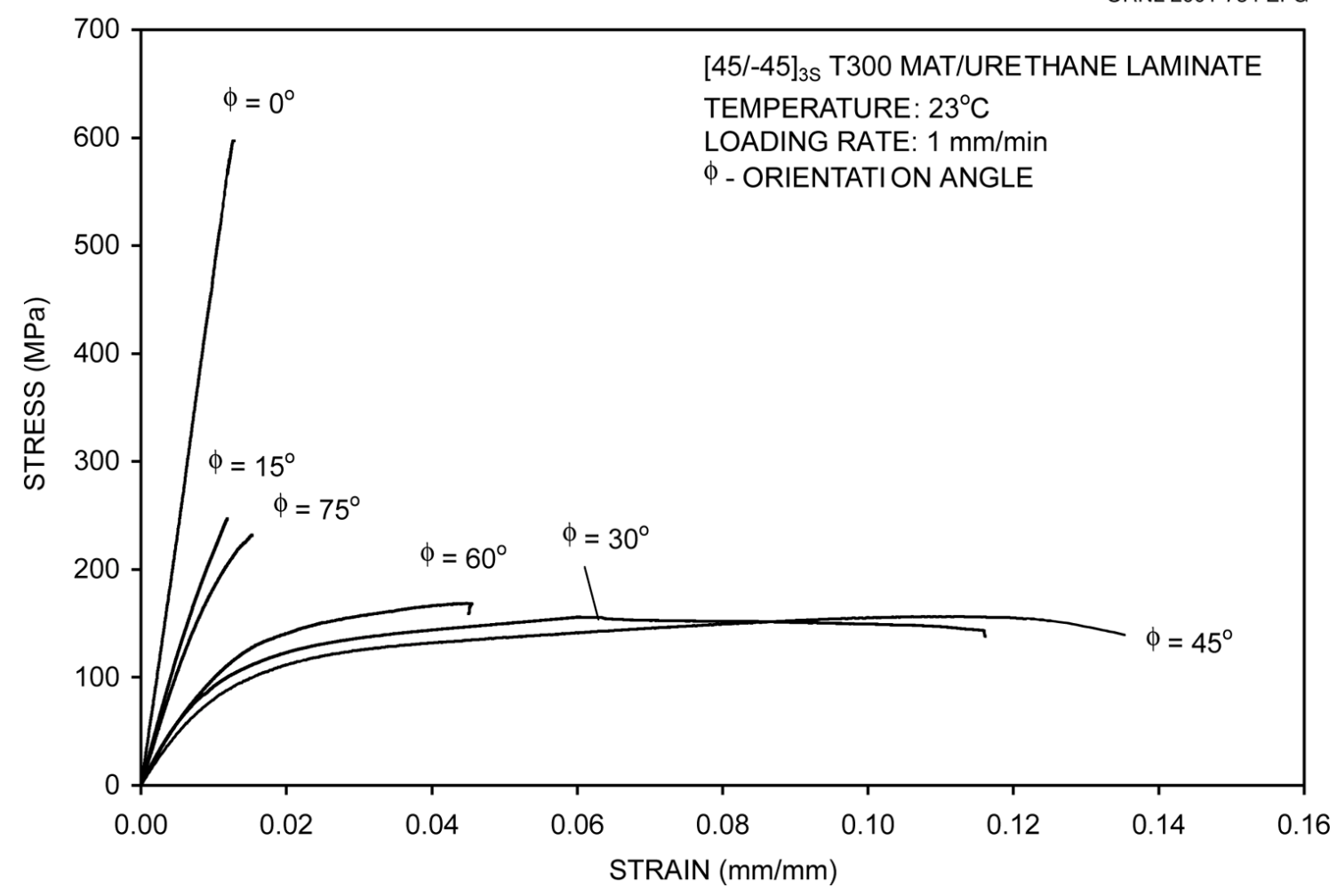

Fig. 7.15. Typical stress-strain response to failure at various orientation angles. Source: Ref. 11.

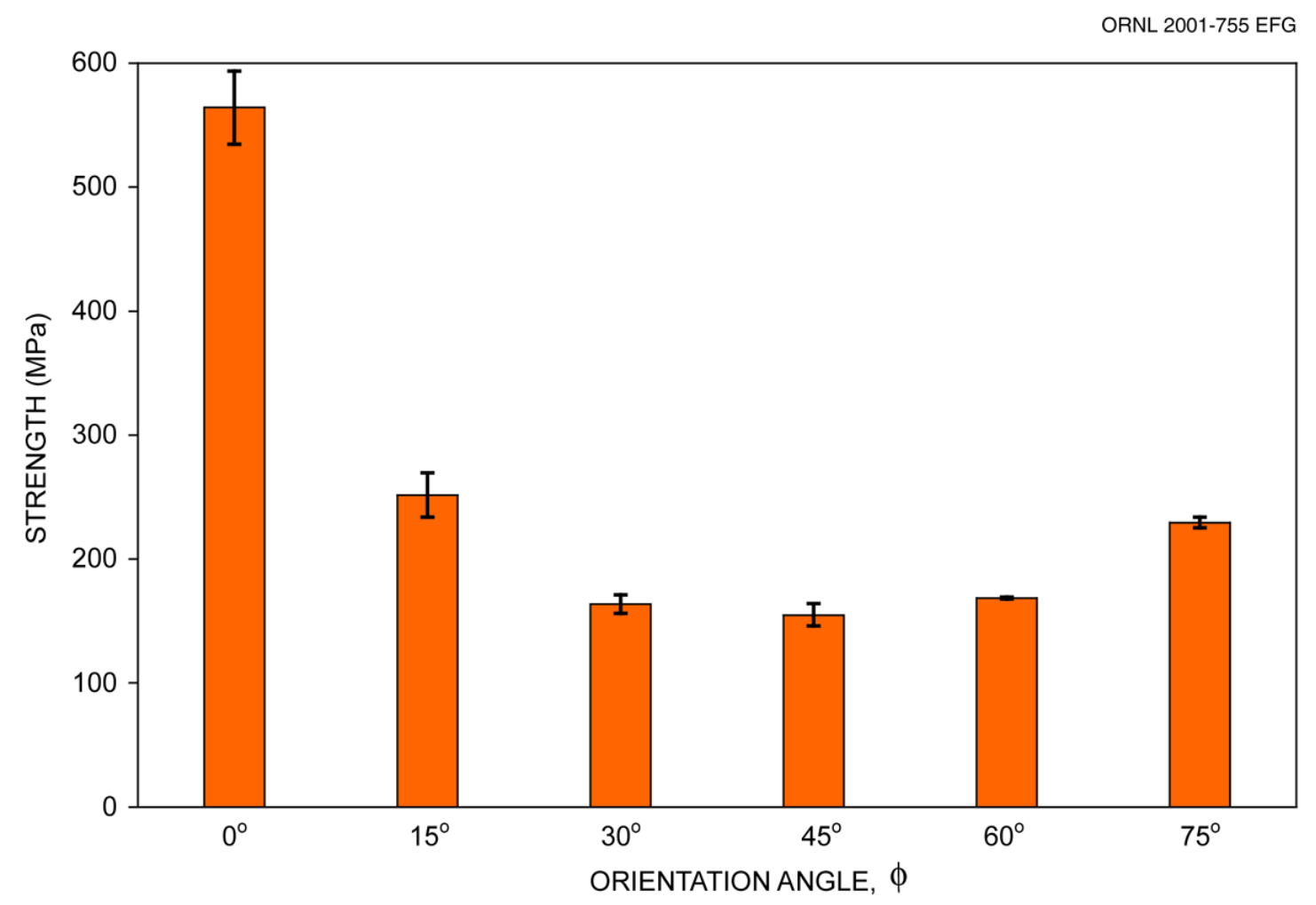

Fig. 7.16. Tensile strength vs orientation angle. Source: Ref. 11. 

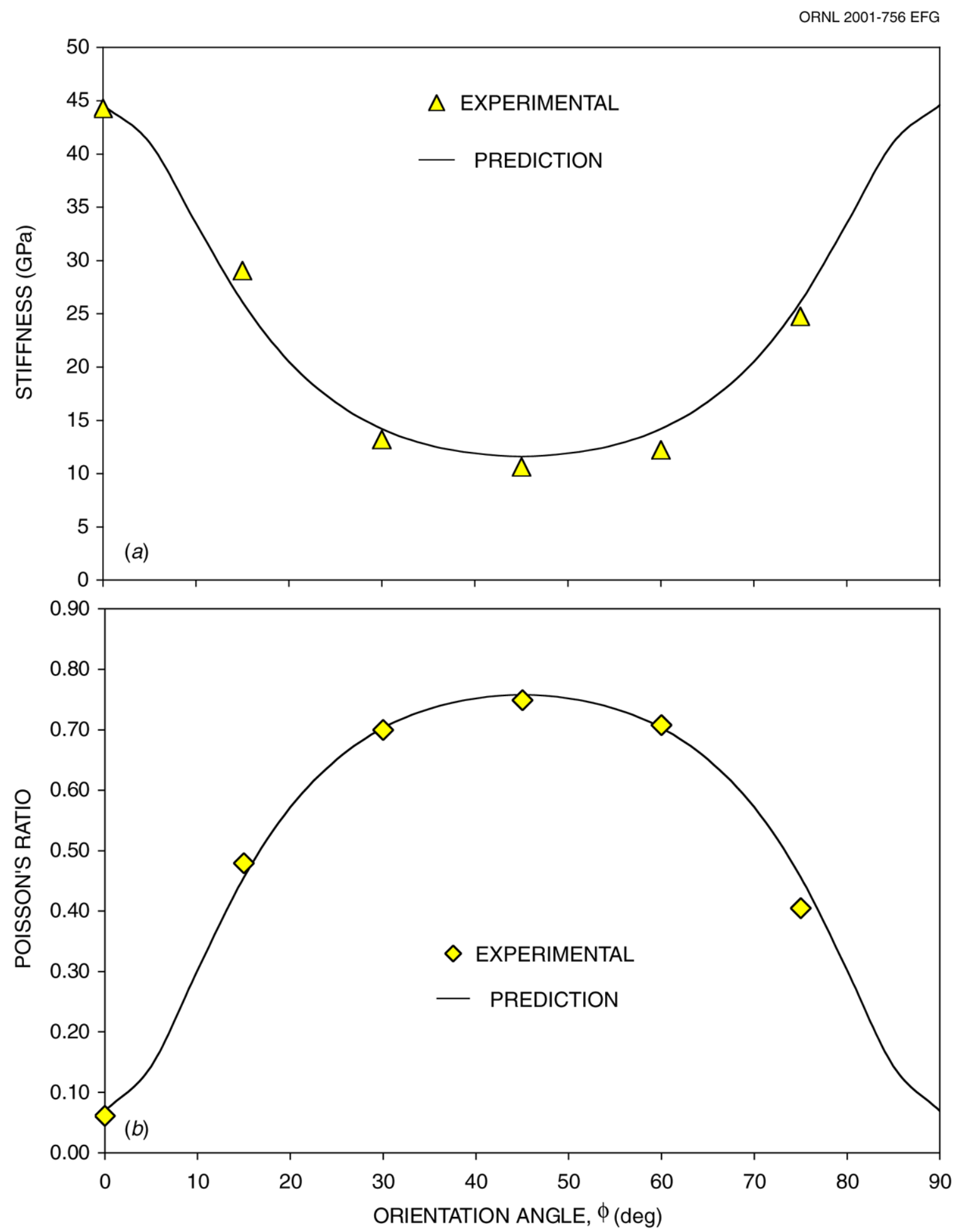

Fig. 7.17. Measured and predicted variation of elastic properties with orientation: $(a)$ stiffness and (b) Poisson's ratio. Source: Ref. 11. 
ORNL 2001-757 EFG

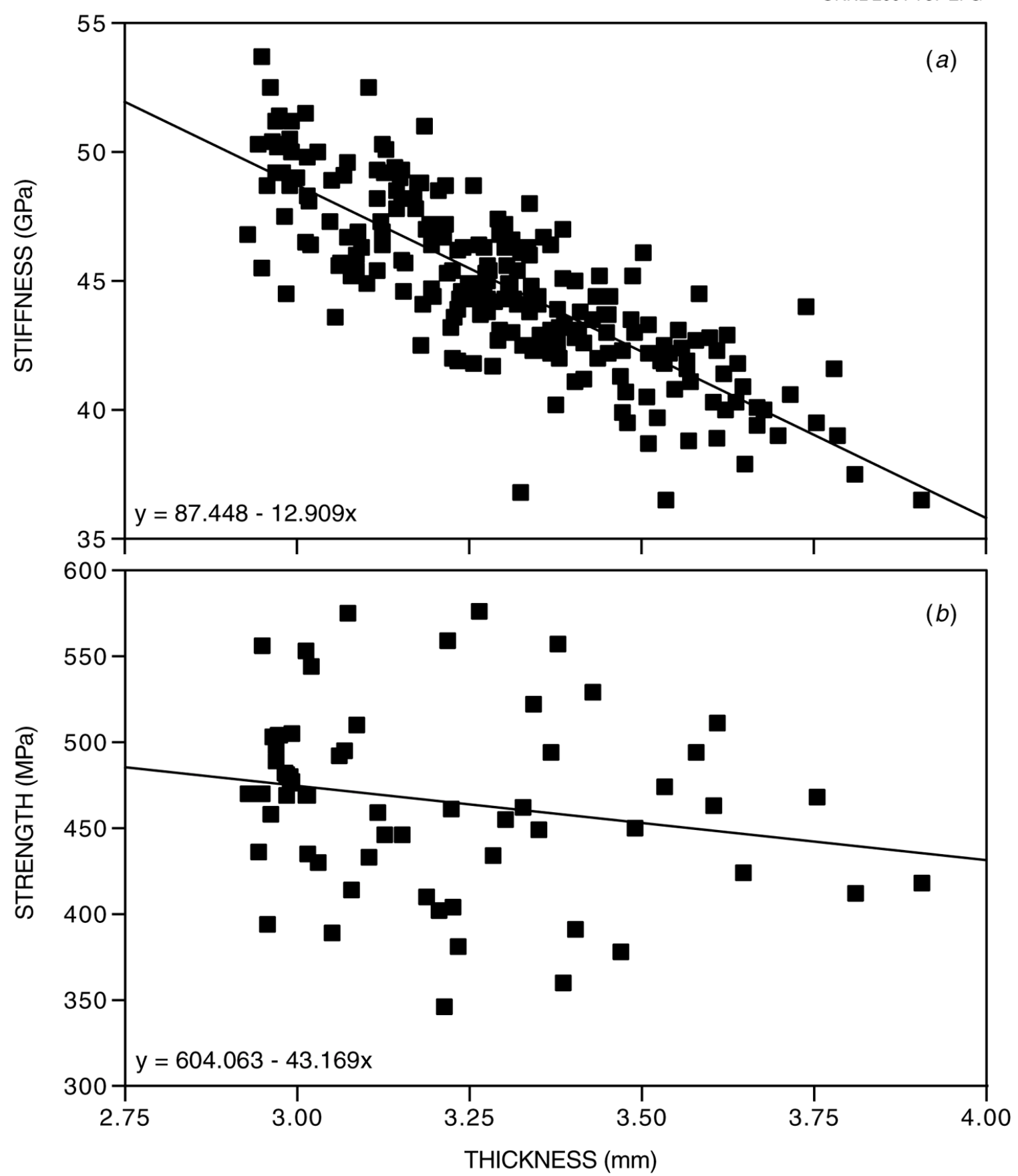

Fig. 7.18. Variation in tensile properties with specimen thickness for $0 / 90^{\circ}$ fiber orientation: (a) stiffness and $(b)$ strength. 
ORNL 2001-758 EFG
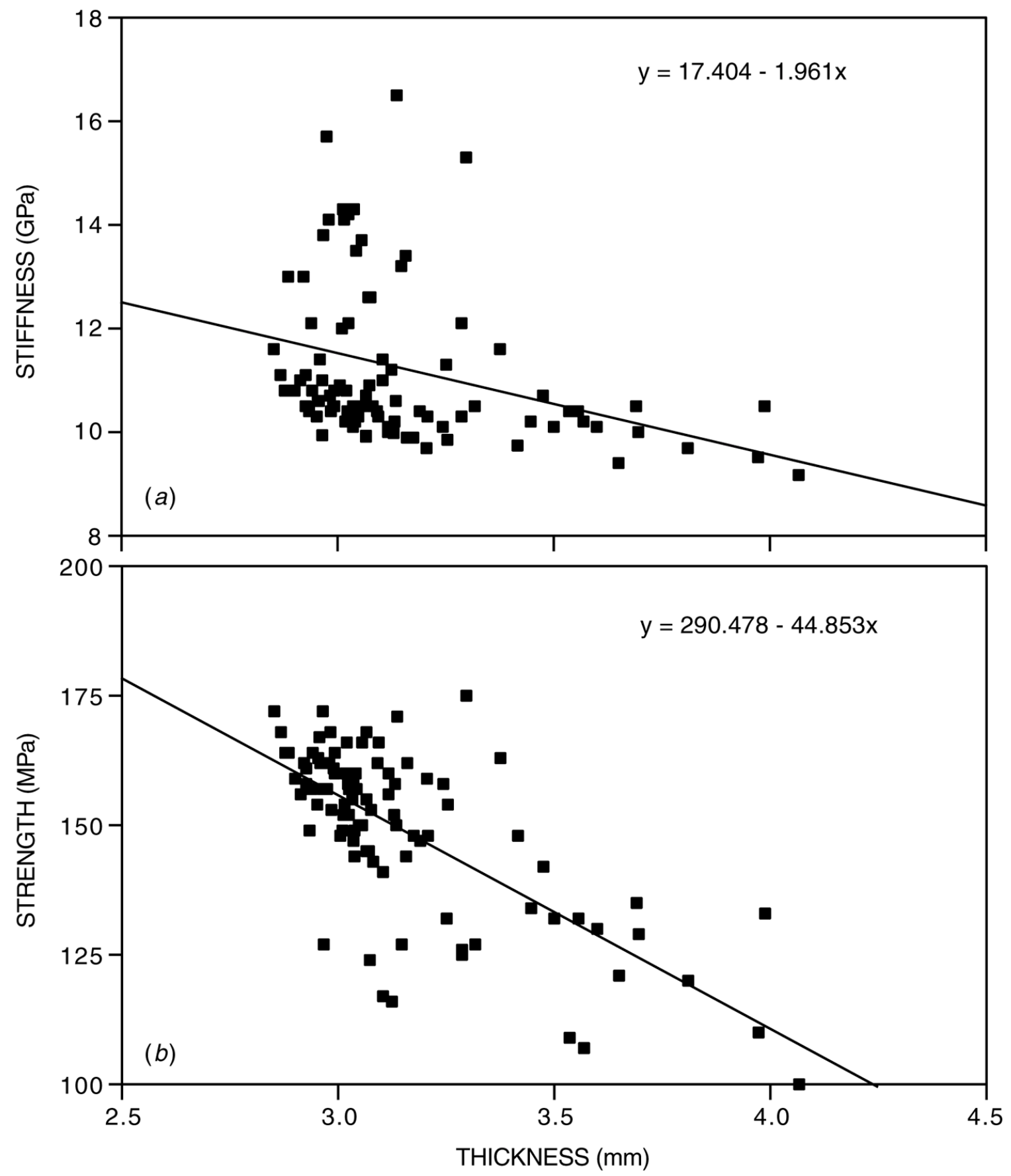

Fig. 7.19. Variation in tensile properties with specimen thickness for $\pm 45^{\circ}$ fiber orientation: (a) stiffness and $(b)$ strength. 
ORNL 2001-759 EFG
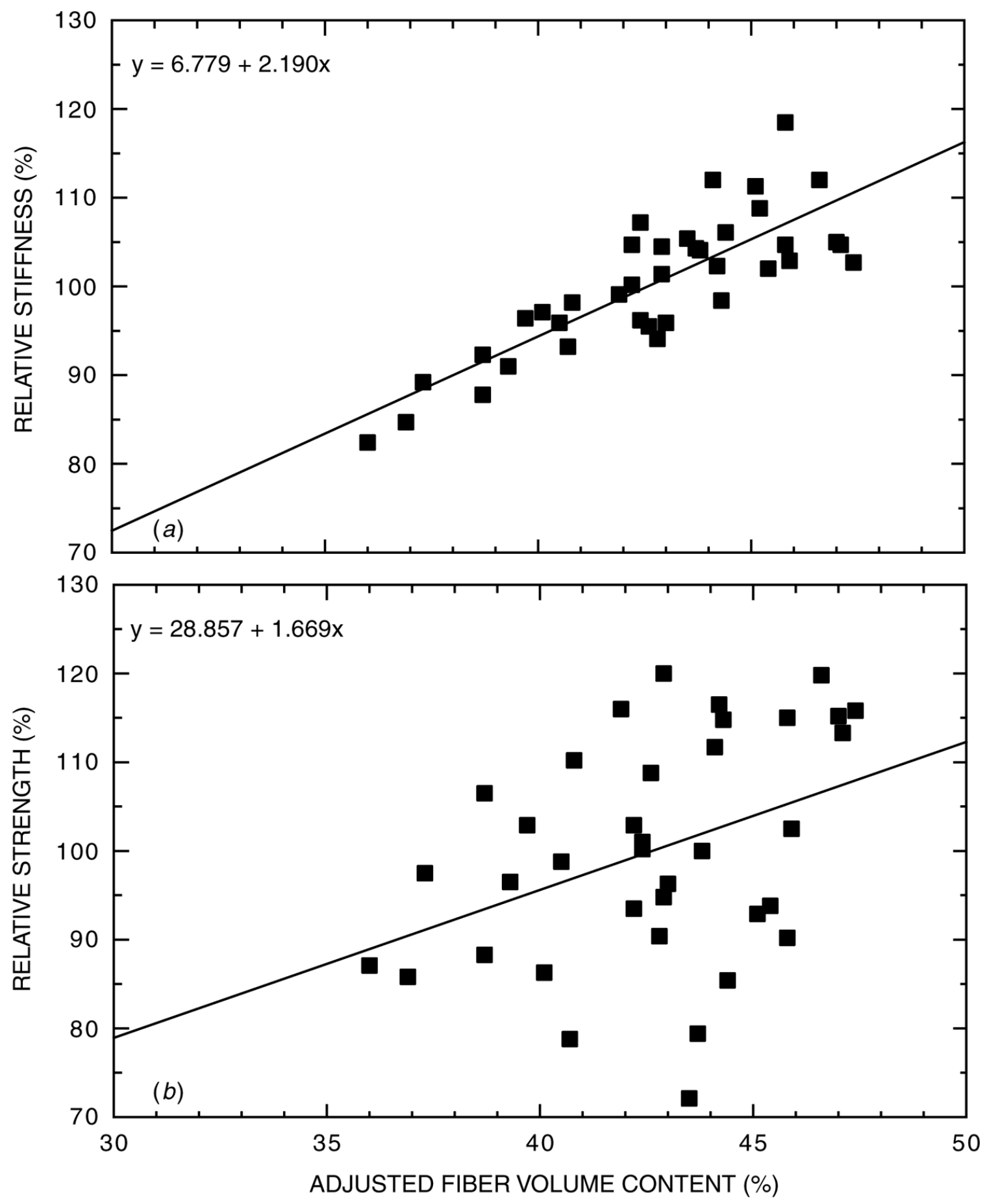

Fig. 7.20. Relative stiffness and strength vs adjusted fiber volume content for $0 / 90^{\circ}$ fiber orientation: $(a)$ relative stiffness and $(b)$ relative strength. 


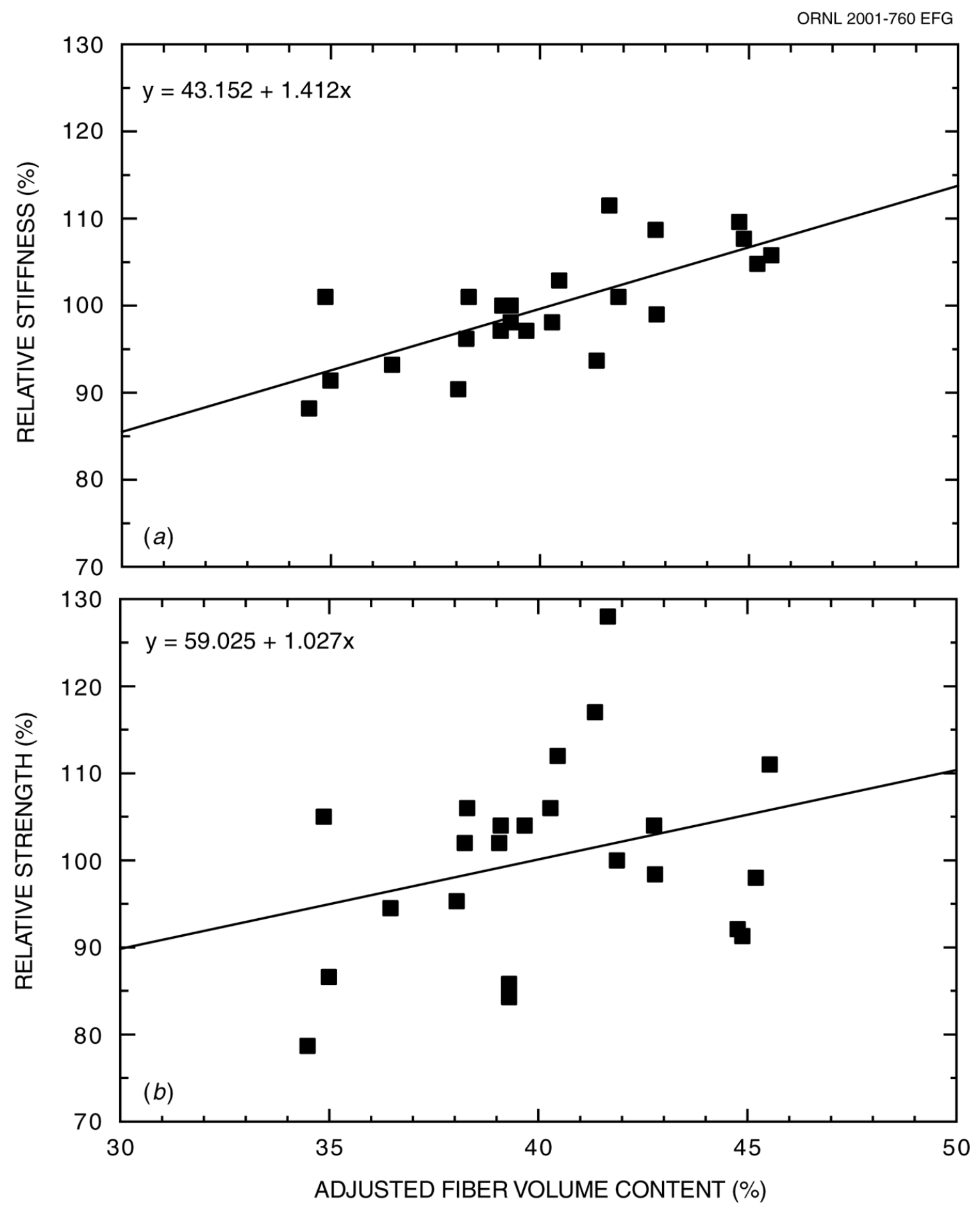

Fig. 7.21. Relative stiffness and strength vs adjusted fiber volume content for $\pm 45^{\circ}$ fiber orientation: $(a)$ relative stiffness and $(b)$ relative strength. 


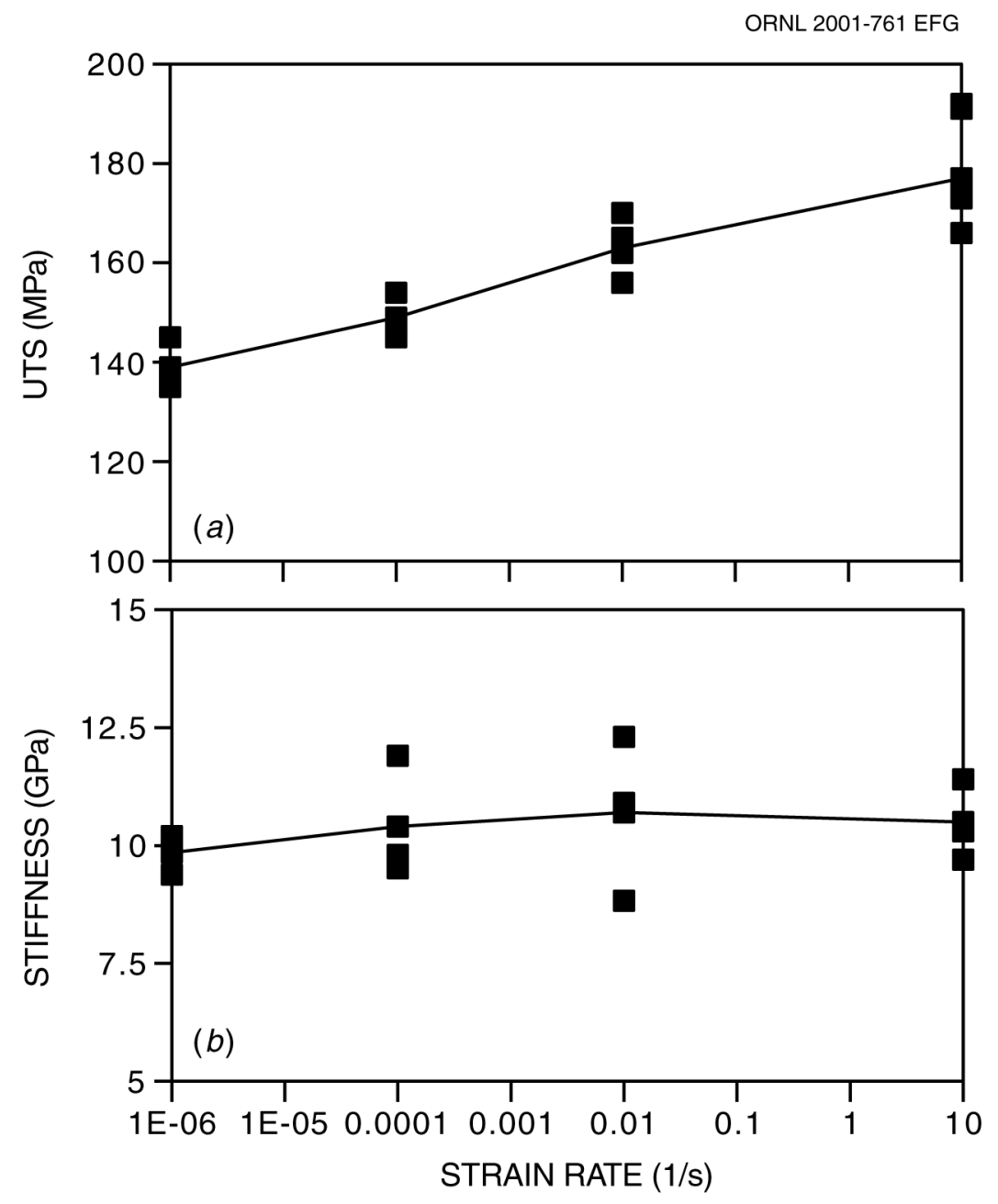

Fig. 7.22. Effect of rate on $\pm 45^{\circ}$ tensile properties: (a) strength and (b) stiffness. 


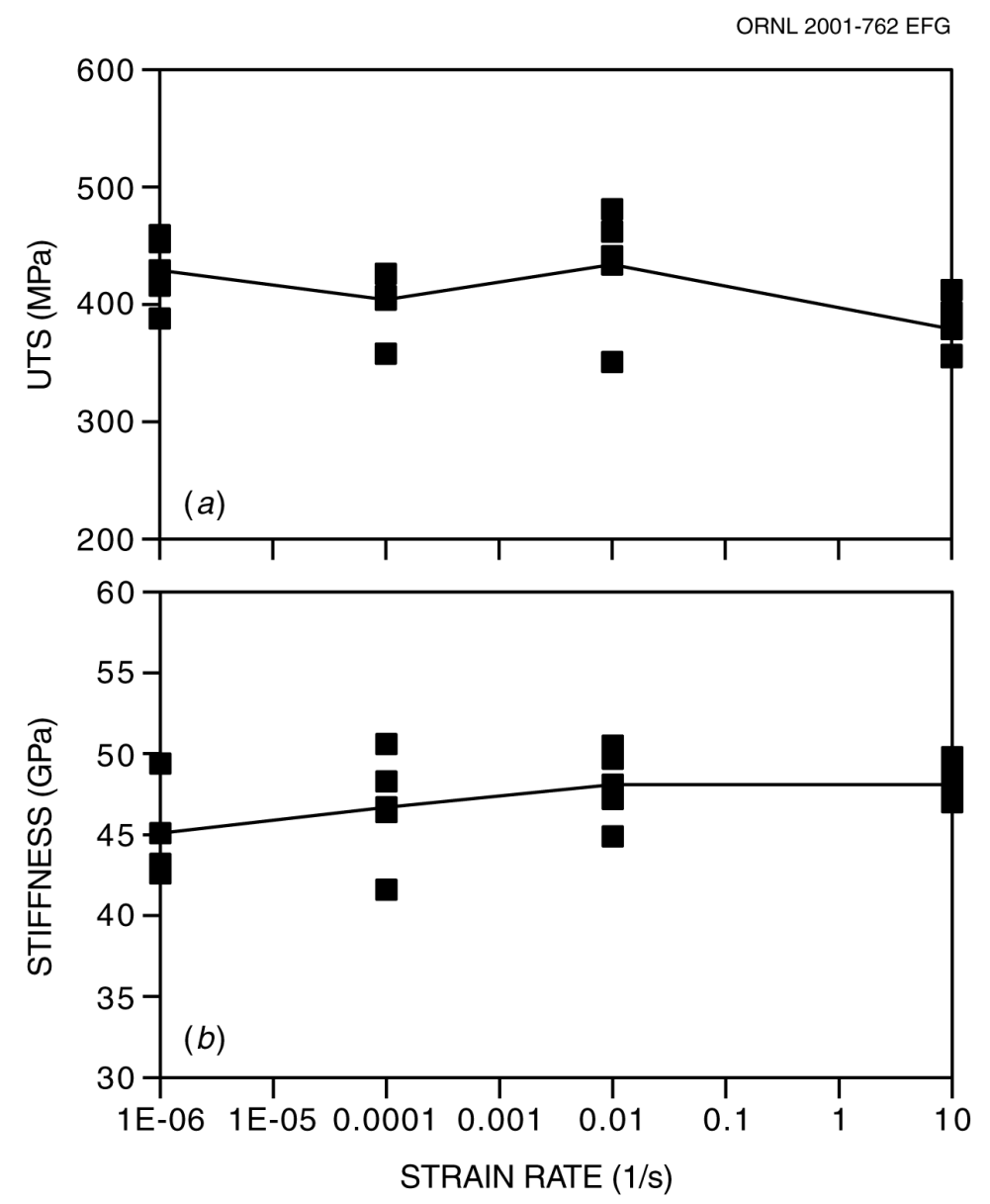

Fig. 7.23. Effect of rate on $0 / 90^{\circ}$ tensile properties: (a) strength and $(b)$ stiffness. 

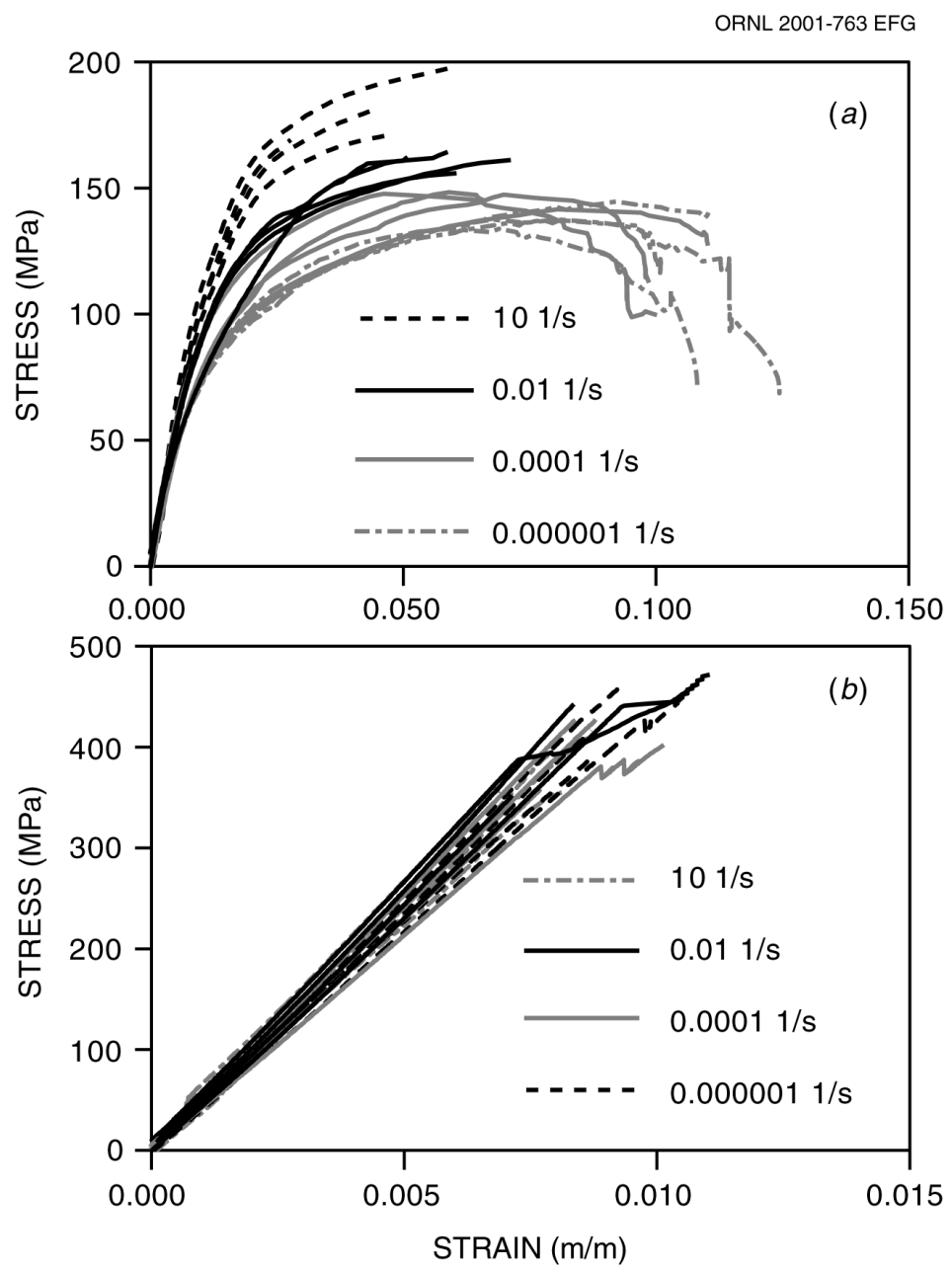

Fig. 7.24. Stress-strain curves at different strain rates: $(a) \pm 45^{\circ}$ and $(b) 0 / 90^{\circ}$.

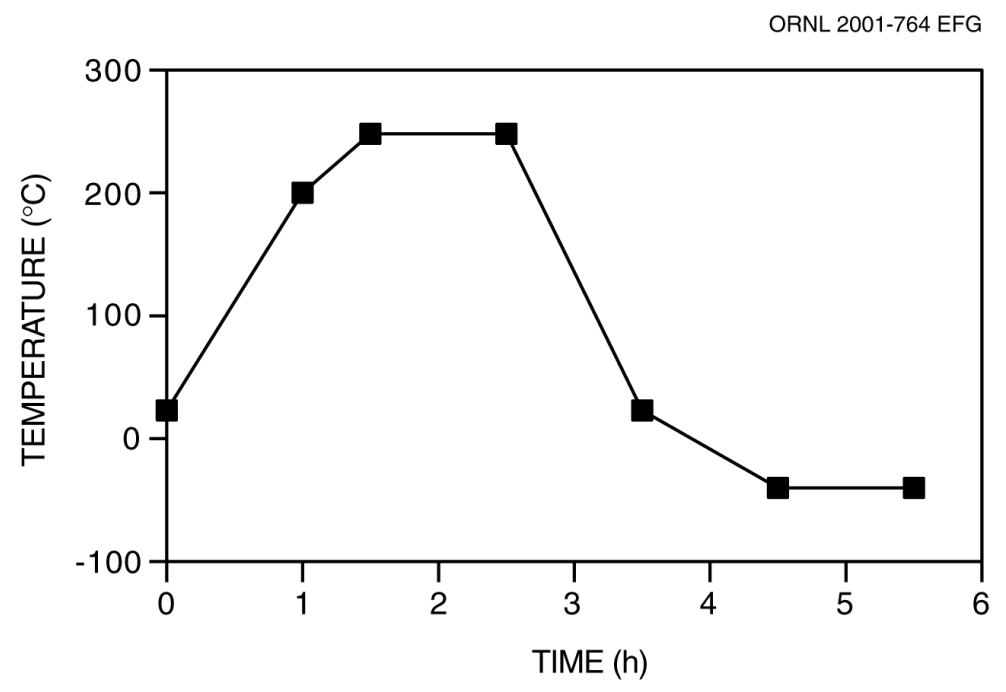

Fig. 7.25. Thermal cycle. 
ORNL 2001-765 EFG
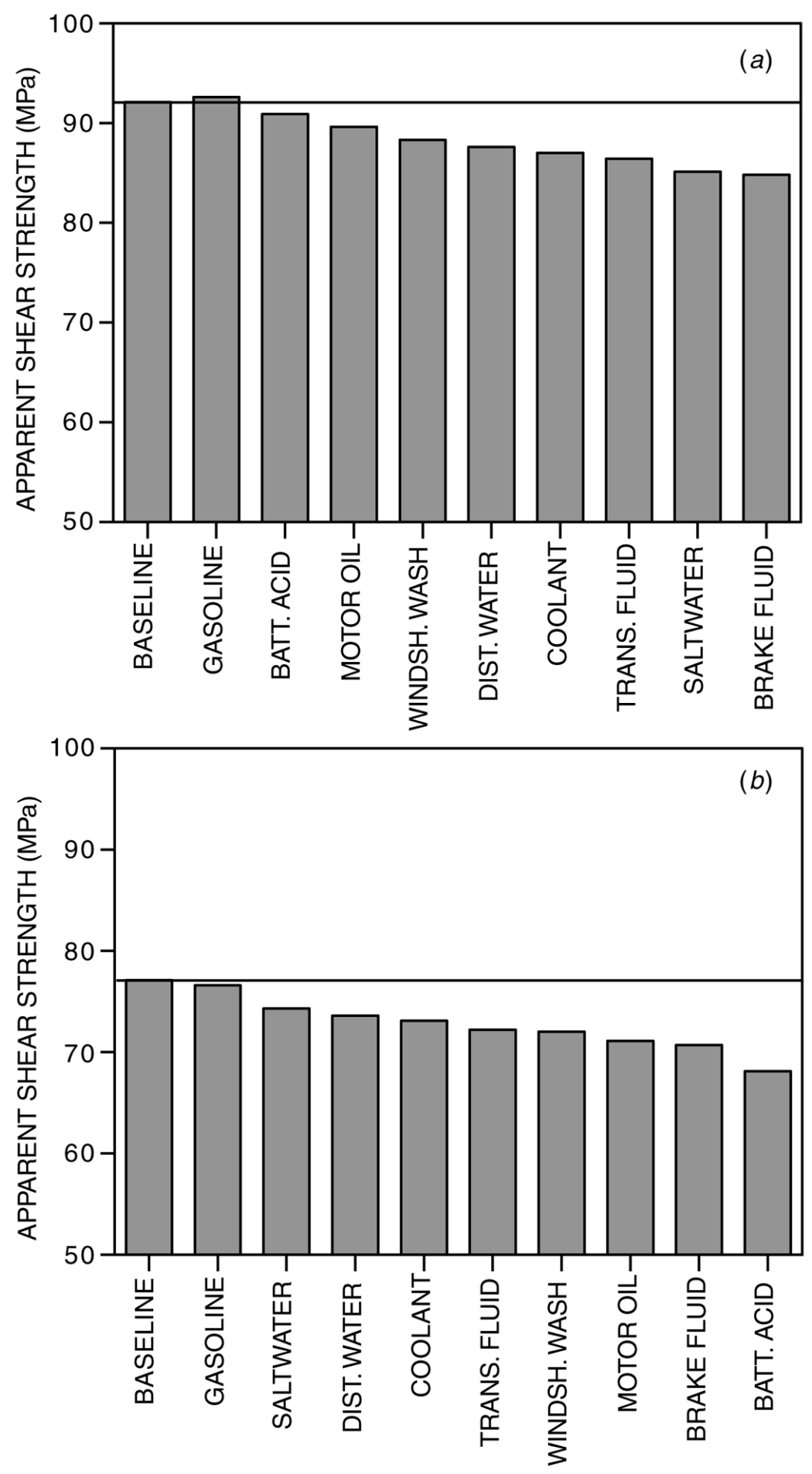

Fig. 7.26. Effects of automotive fluids on apparent shear strength: (a) $0 / 90^{\circ}$ and $(b) \pm 45^{\circ}$. 
ORNL 2001-766 EFG

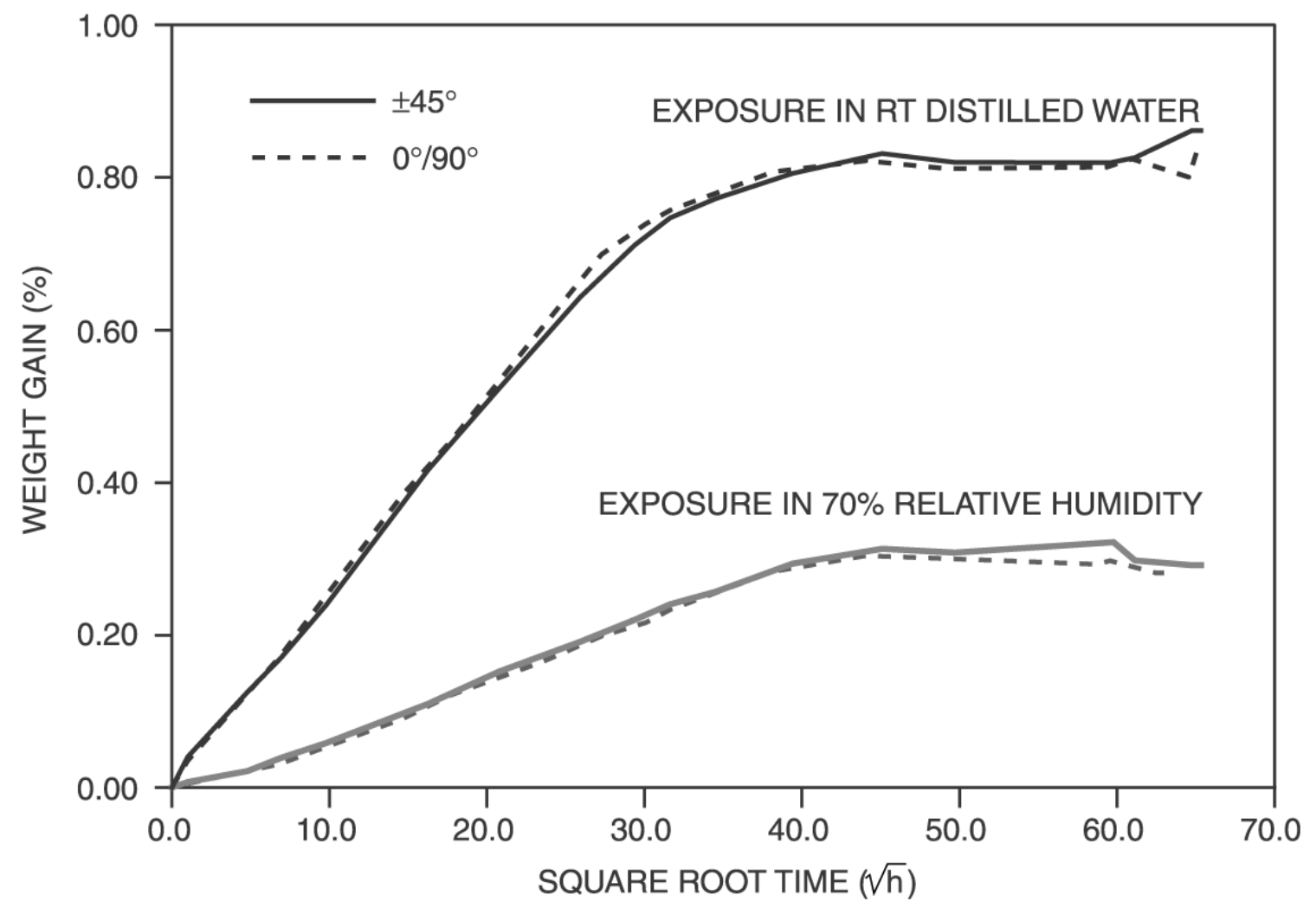

Fig. 7.27. Percent weight change due to exposure in room-temperature distilled water and in $70 \%$ RH air. 
7-38 


\title{
8. UNIAXIAL AND BIAXIAL FLEXURE PROPERTIES
}

\author{
M. B. Ruggles
}

\subsection{INTRODUCTION}

Because it is almost impossible to avoid bending in composite sections, there is a need to determine the flexural properties experimentally. According to the ASTM Standard D $790^{13}$ test method, a three-point bend test was used to measure the apparent bending strength and stiffness. The specimen width was $25.4 \mathrm{~mm}$, and the support span was $50.8 \mathrm{~mm}$. The loading rollers had a radius of $12.7 \mathrm{~mm}$. For the specimens with a $0 / 90^{\circ}$ fiber orientation, these dimensions are generally consistent with ASTM Standard D 790 . The surface fibers in the $0 / 90^{\circ}$ beams were at $90^{\circ}$ to the beam axis, thus placing a weaker ply at the specimen surface. For the $\pm 45^{\circ}$ specimens, the span should have been $192 \mathrm{~mm}$ to minimize shear effects. However, even at the smaller span, the $\pm 45^{\circ}$ specimens produced very large deflections prior to failure. Thus, the maximum bending strain significantly exceeded the $5 \%$ limit for applicability of the test procedure, as specified in the standard. However, results obtained in the $\pm 45^{\circ}$ tests, albeit purely qualitative, may be used to establish environmental and temperature reduction factors. Uniaxial flexure results are presented in Sect. 8.2.

Biaxial flexure tests on simply supported, ring-loaded circular disks were performed to investigate failure under biaxial tensile stress. In the case of in-plane isotropy, small-deflection, elastic plate bending theory predicts that the maximum stresses on the bottom surface of the specimen are inside the load ring and are everywhere equibiaxial tension. However, large deflections develop long before failure, and the nonlinear stress-strain response of the composite must be considered. At the large deflections, the maximum stresses shift to a location opposite the load ring. A nonlinear, inelastic, large-deflection, finite-element analysis would be required to predict stresses at failure. Further complicating the situation is the fact that the current crossply composite is highly anisotropic. Results presented here are not supported by analysis and are, therefore, purely qualitative. However, just as in the case of $\pm 45^{\circ}$ uniaxial flexure tests, these results can be used to establish environmental and temperature reduction factors. Biaxial flexure results are summarized in Sect. 8.3.

\subsection{UNIAXIAL FLEXURE}

Flexure properties at $23^{\circ} \mathrm{C}$ and $120^{\circ} \mathrm{C}$ were established based on six tests at each temperature for each fiber orientation. Results are presented in Table 8.1. Note that the modulus of

Table 8.1. Flexure properties at $23^{\circ} \mathrm{C}$ and $120^{\circ} \mathrm{C}$

\begin{tabular}{|c|c|c|}
\hline Property & $23^{\circ} \mathrm{C}$ & $120^{\circ} \mathrm{C}$ \\
\hline \multicolumn{3}{|l|}{$0 / 90^{\circ}$ Fiber orientation } \\
\hline Modulus of elasticity, GPa & 23.5 & 14.0 \\
\hline Modulus of rupture, MPa & 797 & 486 \\
\hline \multicolumn{3}{|l|}{ $\pm 45^{\circ}$ Fiber orientation } \\
\hline Modulus of elasticity, GPa & 2.63 & 0.73 \\
\hline Modulus of rupture, $\mathrm{MPa}^{a}$ & $566^{a}$ & $262^{a}$ \\
\hline Maximum bending stress at $5 \%$ strain, MPa & 311 & 154 \\
\hline
\end{tabular}

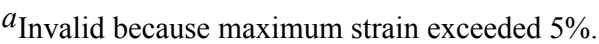


rupture and maximum bending stress values in Table 8.1 were calculated using the expression $\sigma_{\max }=\mathrm{Mc} / \mathrm{I}$, which is clearly invalid for a laminated composite. Likewise the "modulus of elasticity" values tabulated are just apparent values based on the assumption that the composite is homogeneous, isotropic, and elastic. In other words, all of the values in Table 8.1 are based on simple elastic beam theory.

For the $0 / 90^{\circ}$ fiber orientation, the ratio of the MOR (elastically calculated maximum bending stress at rupture) to the UTS is 1.7 at room temperature and 1.2 at $120^{\circ} \mathrm{C}$. The apparent elastic moduli are lower than the tensile moduli, particularly for the $\pm 45^{\circ}$ fiber orientation, where the tensile moduli are 11.2 and $6.16 \mathrm{GPa}$ at $23^{\circ} \mathrm{C}$ and $120^{\circ} \mathrm{C}$, respectively. No MOR could be calculated from the $\pm 45^{\circ}$ tests. However, the elastically calculated stress at $5 \%$ strain, may be employed in a comparative study to assess effects of temperature and fluid environment and to develop corresponding reduction factors. Note that for the chopped-glass-fiber composite, the load-carrying capacity in bending at $23^{\circ} \mathrm{C}$ and $50^{\circ} \mathrm{C}$ was found to be almost twice that which would be indicated by limiting the elastically calculated maximum stress to the UTS. However, at $120^{\circ} \mathrm{C}$ the load-carrying capacity in bending was only 1.4 times that indicated by the UTS.

Two fluids and different exposure times were used to assess the effects of environment on flexure properties. Exposure in windshield washer fluid was investigated using specimens presoaked for $50 \mathrm{~h}$ and $100 \mathrm{~h}$. Exposure in room-temperature distilled water was explored using specimens presoaked for $1000 \mathrm{~h}$. For each fiber orientation, six specimens were tested per condition. Resulting environmental strength reduction factors are presented in Table 8.2 together with the corresponding environmental strength reduction factors for tension and compression. Results in Table 8.2 demonstrate that for both fiber orientations, the environmental reduction factor obtained in uniaxial tension for a 1000-h exposure in distilled water may be used to represent the effects of $1000 \mathrm{~h}$ in distilled water or $100 \mathrm{~h}$ in windshield washer fluid on flexure.

As noted in Sect. 7.7.1, ten short-beam shear specimens for each fiber orientation were tested according to ASTM Standard D 2344. ${ }^{12}$ All specimens were cut from a single plaque. The $0 / 90^{\circ}$ specimens had $0^{\circ}$ fibers on the surface. Apparent shear strengths were $92.1 \mathrm{MPa}$ and 77.1 $\mathrm{MPa}$ for the $0 / 90^{\circ}$ and the $\pm 45^{\circ}$ fiber orientations, respectively. Short-beam shear failures were assessed based on microscopic examination. For the $0 / 90^{\circ}$ fiber orientation, stepwise shear cracks developed across the thickness, with the largest crack at midsurface where shear is highest. The $0 / 90^{\circ}$ specimens thus failed in shear. For the $\pm 45^{\circ}$ fiber orientation, no shear cracking was apparent. The $\pm 45^{\circ}$ specimens failed in bending. Note, that for the chopped-glass-fiber composite, all short-beam shear specimens failed in bending. Microstructural examination revealed no evidence of interlaminar shear.

Table 8.2. Effects of environment on flexure properties

\begin{tabular}{|c|c|c|c|}
\hline Environment & $\begin{array}{l}\text { MOR reduction } \\
\text { factor }\end{array}$ & $\begin{array}{l}\text { Tensile strength } \\
\text { reduction factor }\end{array}$ & $\begin{array}{c}\text { Compressive } \\
\text { strength reduction } \\
\text { factor }\end{array}$ \\
\hline \multicolumn{4}{|c|}{$0 / 90^{\circ}$ Fiber orientation } \\
\hline $1000 \mathrm{~h}$ in distilled water & 0.96 & 0.96 & 0.98 \\
\hline $50 \mathrm{~h}$ in windshield washer fluid & 0.98 & 0.99 & 0.98 \\
\hline $100 \mathrm{~h}$ in windshield washer fluid & 0.97 & 0.98 & 0.92 \\
\hline \multicolumn{4}{|c|}{ $\pm 45^{\circ}$ Fiber orientation } \\
\hline $1000 \mathrm{~h}$ in distilled water & 0.98 & 0.97 & 0.98 \\
\hline $50 \mathrm{~h}$ in windshield washer fluid & 0.99 & 0.99 & 0.99 \\
\hline $100 \mathrm{~h}$ in windshield washer fluid & 0.97 & 0.97 & 0.99 \\
\hline
\end{tabular}


Results of the short-beam shear tests were compared with those obtained in the flexure tests. The $0 / 90^{\circ}$ short-beam shear tests produced an apparent shear strength of $92.1 \mathrm{MPa}$, corresponding to the maximum bending stress of $768 \mathrm{MPa}$, which constitutes $161 \%$ of the UTS. The $0 / 90^{\circ}$ flexure tests produced an MOR of $797 \mathrm{MPa}$, which constitutes $167 \%$ of the UTS.

\subsection{BIAXIAL FLEXURE}

Failure under biaxial bending stress states was investigated in 22 biaxial flexure tests on simply supported, ring-loaded circular disks as illustrated in Fig. 8.1. The specimen outside diameter was $94 \mathrm{~mm}$, and the nominal thickness was $3.2 \mathrm{~mm}$. The load-ring diameter was $38.1 \mathrm{~mm}$, while the support-ring diameter was $88.9 \mathrm{~mm}$.

Tests were performed with the purpose of determining environmental (temperature and fluids) stress reduction factors for biaxial bending stress states. Six "as-received" specimens were tested in air at room temperature. In addition, four tests were performed at $120^{\circ} \mathrm{C}$. To explore fluid effects, six specimens presoaked for $100 \mathrm{~h}$ in windshield washer fluid and six specimens presoaked for $1000 \mathrm{~h}$ in room-temperature distilled water were also tested. Results are summarized in Table 8.3, where reduction factors are the ratios of the average failure load, for each set of tests, to the average for the as-received room-temperature tests. Load-deflection curves obtained in biaxial flexure tests are shown in Fig. 8.2.

Note that the maximum load produced at room temperature was somewhat higher than that for the chopped-glass-fiber composite $(11,403 \mathrm{~N})$. However, the reduction factors in Table 8.3 follow the same trend as those obtained for the chopped-glass-fiber composite, with the lowest reduction factor corresponding to $120^{\circ} \mathrm{C}(0.42$ for the chopped-glass-fiber composite).

Strength reduction factors obtained in biaxial flexure tests are further compared with those obtained under various other stress states in Table 8.4. It is seen that at $120^{\circ} \mathrm{C}$ the biaxial flexure strength reduction factor $(0.55)$ compares well with the uniaxial flexure strength reduction factors of 0.61 (for the $0 / 90^{\circ}$ fiber orientation) and 0.49 (for the $\pm 45^{\circ}$ fiber orientation). In the case of the 1000 -h distilled water soak, biaxial flexure strength was reduced by $2 \%$, while uniaxial flexure strengths were reduced by $4 \%$ and $2 \%$ for $0 / 90^{\circ}$ and $\pm 45^{\circ}$ fiber orientations, respectively. In the case of a 100-h soak in windshield washer fluid, both biaxial (0.99) and uniaxial (0.97) flexure strength reduction factors indicated that the effects were small for the $0 / 90^{\circ}$ and $\pm 45^{\circ}$ fiber orientations. It is further seen that the fluid effects are similar for all states of stress considered, with reduction factors ranging from 0.92 to 0.99 . (The lowest strength reduction factor of 0.92 was produced in compression on specimens presoaked for $100 \mathrm{~h}$ in windshield washer fluid).

Effects of temperature on strength appear to be more uniform for various states of stress for the $\pm 45^{\circ}$ fiber orientation than for the $0 / 90^{\circ}$ orientation. For the $\pm 45^{\circ}$ fiber orientation, strength reduction factors at $120^{\circ} \mathrm{C}$ range from 0.46 for shear to 0.55 for biaxial flexure. Conversely, for the $0 / 90^{\circ}$ fiber orientation, strength reduction factors at $120^{\circ} \mathrm{C}$ range from 0.25 for shear (matrixdominated behavior) to 0.82 for tension (fiber-dominated response).

Table 8.3. Biaxial flexure strength results

\begin{tabular}{lccc}
\hline \multicolumn{1}{c}{ Specimen and test condition } & $\begin{array}{c}\text { Maximum } \\
\text { load (N) }\end{array}$ & $\begin{array}{c}\text { COV } \\
(\%)\end{array}$ & $\begin{array}{c}\text { Reduction } \\
\text { factor }\end{array}$ \\
\hline As-received, room temperature & 12,380 & 3.03 & 1.00 \\
As-received, $\mathbf{1 2 0}^{\circ} \mathbf{C}$ & 6,757 & 9.59 & 0.55 \\
$\mathbf{1 0 0}_{\mathbf{h} \text { in windshield washer fluid }}$ & 12,344 & 4.69 & 0.99 \\
$\mathbf{1 0 0 0} \mathbf{h}$ in distilled water & 12,170 & 2.00 & 0.98 \\
\hline
\end{tabular}


Table 8.4. Strength reduction factors relative to in-air room-temperature values

\begin{tabular}{|c|c|c|c|}
\hline Stress state & $\begin{array}{c}1000 \mathrm{~h} \text { in } \\
\text { distilled water }\end{array}$ & $\begin{array}{l}100 \mathrm{~h} \text { in windshield } \\
\text { washer fluid }\end{array}$ & $120^{\circ} \mathrm{C}$ \\
\hline \multicolumn{4}{|c|}{$0 / 90^{\circ}$ Fiber orientation } \\
\hline Tension & 0.96 & 0.98 & 0.82 \\
\hline Compression & 0.98 & 0.92 & 0.41 \\
\hline Shear & 0.97 & 0.97 & 0.25 \\
\hline Biaxial flexure & 0.98 & 0.99 & 0.55 \\
\hline Uniaxial flexure & 0.96 & 0.97 & 0.61 \\
\hline \multicolumn{4}{|c|}{ $\pm 45^{\circ}$ Fiber orientation } \\
\hline Tension & 0.97 & 0.97 & 0.55 \\
\hline Compression & 0.98 & 0.99 & 0.50 \\
\hline Shear & 0.96 & 0.93 & 0.46 \\
\hline Biaxial flexure & 0.98 & 0.99 & 0.55 \\
\hline Uniaxial flexure & 0.98 & 0.97 & 0.49 \\
\hline
\end{tabular}

Results in Table 8.4 demonstrate that at $120^{\circ} \mathrm{C}$ the governing temperature reduction factor corresponds to shear for both fiber orientations. For the chopped-glass-fiber composite, the compression reduction factor was the governing parameter.

Also, for the chopped-glass-fiber composite, maximum stresses in the disks at failure were predicted by a nonlinear finite-element analysis. This permitted the use of the biaxial test results, along with tensile, compressive, and shear in evaluating candidate biaxial strength criteria. Biaxial test results presented here cannot be employed in a similar manner. 


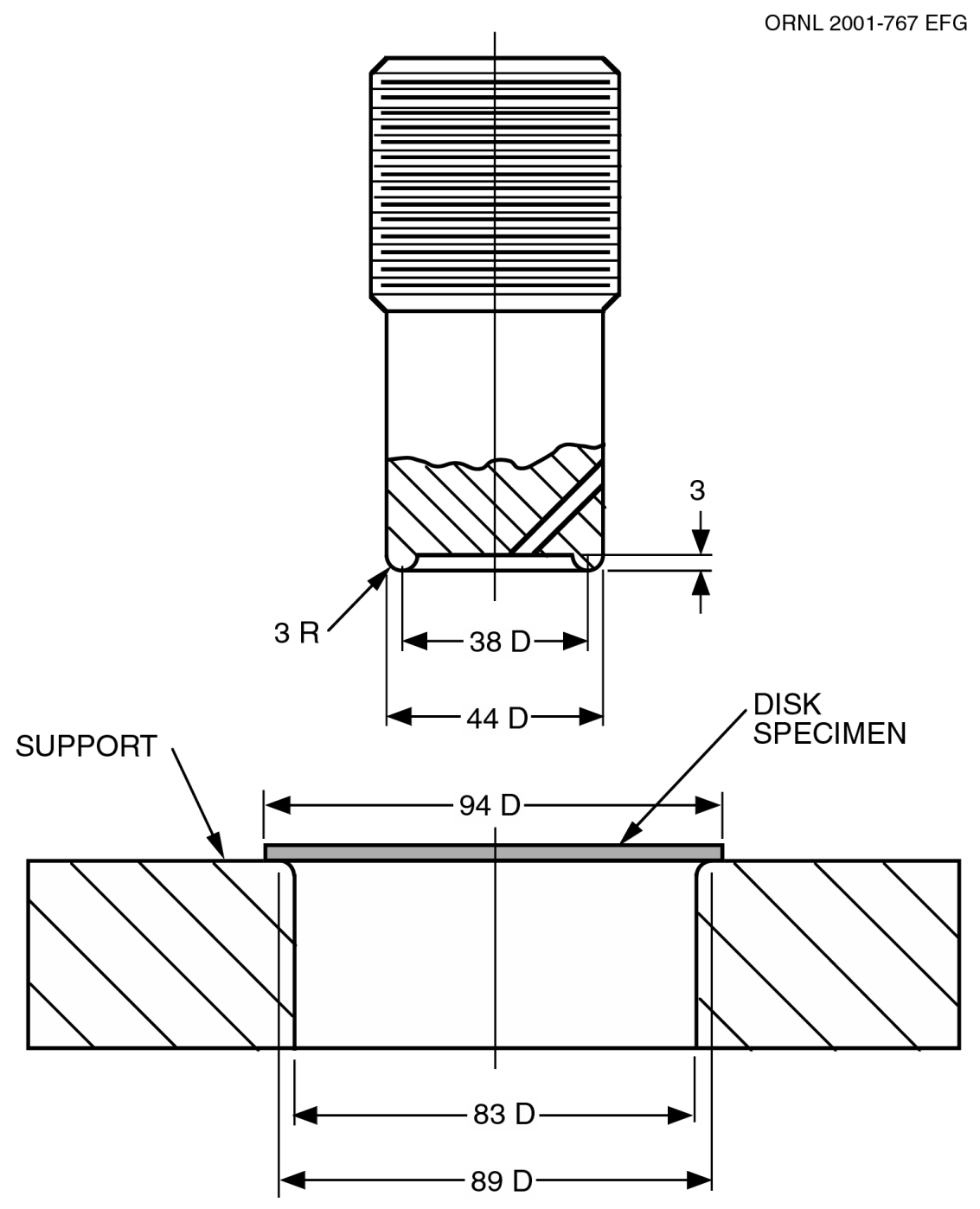

Fig. 8.1. Fixture for biaxial flexure tests. Dimensions are in millimeters. 
ORNL 2001-768 EFG

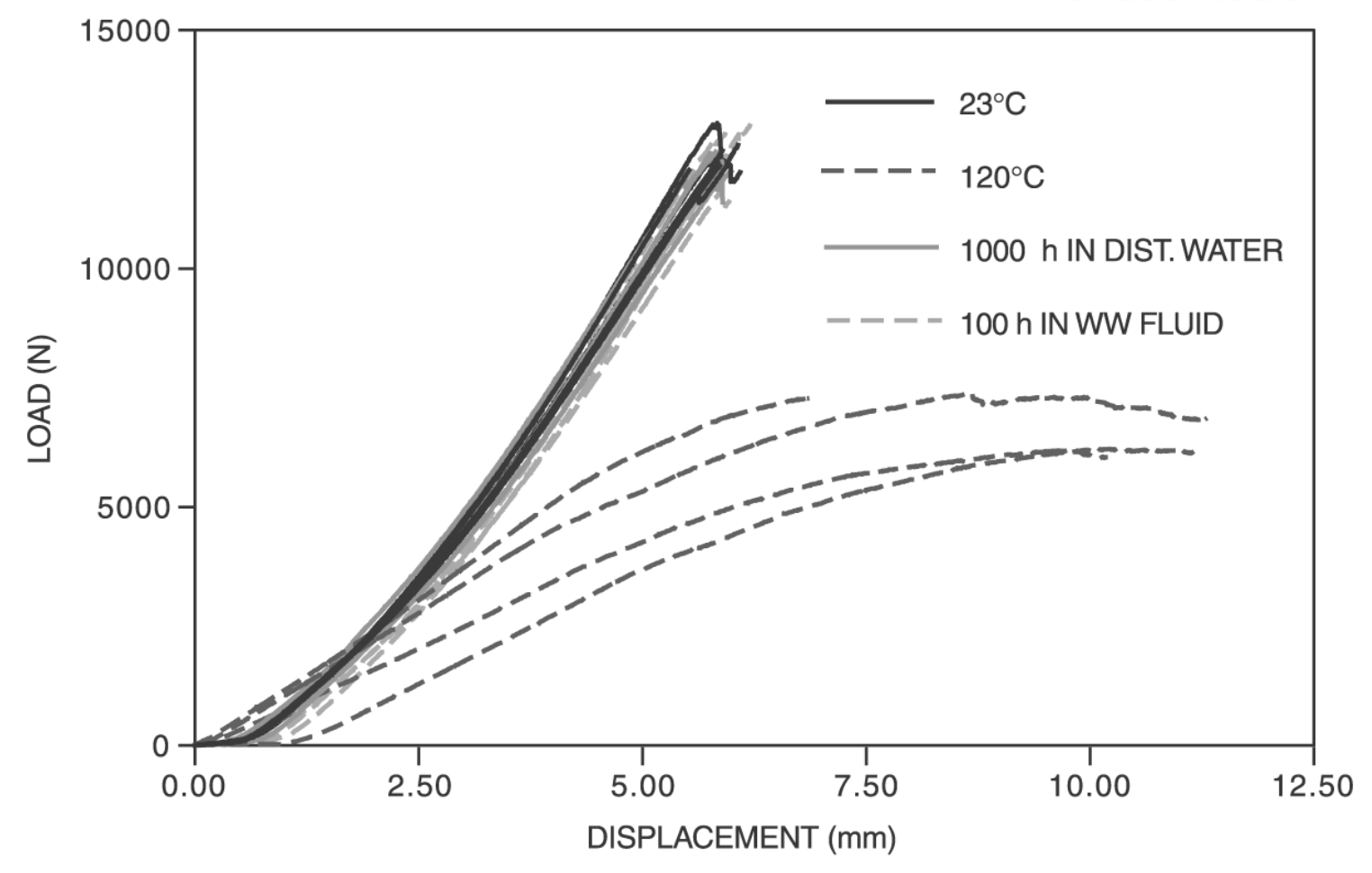

Fig. 8.2. Load vs deflection curves for biaxial flexure tests. 


\title{
9. CYCLIC FATIGUE BEHAVIOR
}

\author{
J. M. Corum and R. L. Battiste
}

\subsection{INTRODUCTION}

Several series of cyclic fatigue tests, leading to stress vs cyclic life curves, were carried out for both the $\pm 45^{\circ}$ and $0 / 90^{\circ}$ fiber orientations. In most cases, maximum and minimum cyclic strains and cyclic stiffness (elastic modulus) values were monitored and recorded. The test series included the following:

- baseline in-air tests at $23^{\circ} \mathrm{C}$ and $120^{\circ} \mathrm{C}$ on specimens from several different plaques;

- tests at $-40,23,70$, and $120^{\circ} \mathrm{C}$, for each fiber orientation, on specimens from a single plaque to establish how fatigue strength varies with temperature;

- tests on presoaked specimens in distilled water (100- and 1000-h presoaks) and windshield washer fluid (100-h presoak) to establish fluid effects; and

- mean stress effects tests using several different cycle types.

Relatively large numbers of baseline tests were performed. In the other series a minimum of eight tests per condition was generally conducted.

All of the tests, except the mean stress ones, used the standard dogbone tensile-type specimen and a tensile cycle in which the ratio, $\mathrm{R}$, of minimum to maximum stress was $0.1 .^{8}$ The mean stress tests used the hourglass specimen design previously employed for glass-fiber composite mean stress tests. ${ }^{8}$ The specimens for the various fatigue series came from a total of 11 plaques (see Appendix B).

Each of the above test series is discussed in the following sections. Conclusions and recommendations for developing fatigue design curves are presented in the last section of the chapter.

\subsection{BASELINE TENSILE FATIGUE $(\mathrm{R}=0.1)$}

Baseline in-air tests were performed at $23^{\circ} \mathrm{C}$ and $120^{\circ} \mathrm{C}$. The plaques from which the specimens came are shown below for each fiber orientation.

$\pm 45^{\circ} \begin{cases}23^{\circ} \mathrm{C} & \mathrm{C} 19, \mathrm{C} 16, \mathrm{C} 17, \text { and } \mathrm{C} 20 \\ 120^{\circ} \mathrm{C} & \mathrm{C} 9, \mathrm{C} 16, \text { and } \mathrm{C} 17\end{cases}$

$0 / 90^{\circ} \begin{cases}23^{\circ} \mathrm{C} & \mathrm{C} 3, \mathrm{C} 15, \text { and } \mathrm{C} 18 \\ 120^{\circ} \mathrm{C} & \mathrm{C} 3, \mathrm{C} 15, \text { and } \mathrm{C} 18\end{cases}$

A haversine waveform was used. The frequency varied with stress in accordance with the following relation, recommended by ACC: 8

$$
\mathrm{f}=\left(\mathrm{k} \mathrm{S}_{\mathrm{ult}}\right) /\left(\mathrm{S}_{\max }-\mathrm{S}_{\min }\right),
$$


where $\mathrm{k}=3 \mathrm{~Hz}$ was used, $\mathrm{S}_{\mathrm{ult}}$ is the at-temperature UTS of the material, $\mathrm{S}_{\max }$ is the maximum stress in the cycle, and $\mathrm{S}_{\min }$ is the minimum cyclic stress $\left(\mathrm{S}_{\min }=0.1 \mathrm{~S}_{\max }\right)$. Heated air was used to maintain specimen temperature in the $120^{\circ} \mathrm{C}$ tests. ${ }^{8}$

The baseline results are plotted in Fig. 9.1, which shows cycles to failure as a function of the maximum cyclic stress. Power law curves were fit to each set of data. The coefficient of determination, $\mathrm{r}^{2}$, is listed after each equation. Note that in the case of the $0 / 90^{\circ}$ fiber orientation, the low-cycle data points at room temperature are all close to the ultimate strength of the composite (average UTS $=499 \mathrm{MPa}$ ). Thus, the scatter is large, as reflected by the low coefficient of determination for the curve fit, and the resistance to cyclic fatigue is very high. For the $\pm 45^{\circ}$ fiber orientation, fatigue resistance is much lower, but it is higher than for the chopped-glass-fiber composite characterized earlier. ${ }^{3}$ At $2 \times 10^{5}$ cycles, the fatigue strengths of the chopped-glass-fiber composite and the current carbon-fiber composite with the $\pm 45^{\circ}$ fiber orientation are about the same. ${ }^{*}$ At $120^{\circ} \mathrm{C}$, the carbon-fiber composite with the $\pm 45^{\circ}$ fiber orientation has a significantly lower fatigue strength than does the chopped-glass-fiber composite.

The tick marks labeled " $\mathrm{S}_{0}$ " in Fig. 9.1 represent the basic allowable stress values determined earlier for $23^{\circ} \mathrm{C}$ and $120^{\circ} \mathrm{C}$ (see Sect. 3.1 of Part 1). For the $0 / 90^{\circ}$ fiber orientation, there is not likely to be a fatigue problem with the carbon-fiber composite; the fatigue curves are above the basic allowable stresses, even with a design margin placed on cycles to failure. In contrast, the $\mathrm{S}_{0}$ values in the $\pm 45^{\circ}$ case are the same magnitude as the fatigue strength, so fatigue is a significant consideration.

Contrary to fatigue failures in the $0 / 90^{\circ}$ case, the $\pm 45^{\circ}$ specimens exhibit very large strains prior to specimen breakage. In fact, the $120^{\circ} \mathrm{C}$ specimens did not break. "Failure" was defined as the point at which the strains became unstable. The source of the large unstable deformations is illustrated by the failed specimen in Fig. 9.2. Starting with the surface plies, mixed-mode ply failures occur, followed by interlaminar shear cracking. This leads to a scissoring action, large deformations, and a significant specimen temperature increase. These ply failures and interlaminar cracks can be seen in Fig. 9.2.

The failure process in $\pm 45^{\circ}$ specimens is reflected in Fig. 9.3, where the maximum cyclic strain in selected tests is plotted as a function of cycle number. The initial linear increase of strain with cycle number probably reflects the buildup of some microstructural damage and also some time-dependent creep strain (due to the positive tensile mean stress). Once ply failures occur, the curves begin to turn upward.

Figures 9.4 and 9.5 show the results of a couple of room-temperature tests on $\pm 45^{\circ}$ specimens in which specimen temperature was measured. The first figure is for a low-stress $(49 \%$ UTS) test. Here, neither maximum strain nor temperature increases significantly until near the end of life. The second figure is for a higher stress (68\% of UTS). Both strain and temperature begin an upturn relatively early in the cyclic life. The abrupt change in slope of the temperature curve in Fig. 9.5 at 300 cycles has the following explanation. The cycling was periodically stopped in these tests to allow for a static stiffness check to be performed. This allowed some specimen cooling to take place during the brief pause. At 300 cycles, the stiffness check interval was increased to 100 cycles, which was too infrequent to have an overall cooling effect.

To avoid the accumulation of large strains over a relatively large part of the cyclic life, an alternative definition of "failure" is needed. To quantify the threshold at which the upturn in strain begins, a $0.2 \%$-offset procedure, similar to the $0.2 \%$-offset yield point definition used for metals, is proposed. The procedure is illustrated in both Figs. 9.4 and 9.5. A straight line, vertically offset by a strain of $0.2 \%$, is drawn parallel to the line representing the initial linear increase in strain. The point at which this offset line intersects the curve defines "failure."

\footnotetext{
*At lower cycles, the glass-fiber-composite is stronger, and at higher cycles the carbon-fiber composite is stronger.
} 
Figure 9.6 shows maximum strain curves from tests of plaque $\mathrm{C} 17$ specimens at $120^{\circ} \mathrm{C}$. As mentioned earlier, these specimens did not break into two pieces. Quantitatively, these maximum strain curves are similar to the ones obtained at room temperature, and it was possible to use the $0.2 \%$-offset procedure illustrated in Figs. 9.4 and 9.5 to determine functional failure. The noticeable drop in each of the Fig. 9.6 curves between cycles 10 and 11 is again an artifact of the way the tests were interrupted for stiffness checks. The drop was graphically removed in applying the $0.2 \%$-offset procedure.

The effect of adopting the alternative failure definition is illustrated in Fig. 9.7, where $\pm 45^{\circ}$ $\mathrm{S}-\mathrm{N}$ curves at $23^{\circ} \mathrm{C}$ and $120^{\circ} \mathrm{C}$ with failure determined by the $0.2 \%$-offset procedure are compared with the original curves from Fig. 9.1. The difference at $120^{\circ} \mathrm{C}$ is particularly significant. The $0.2 \%$-offset procedure for determining functional failure in specimens with the $\pm 45^{\circ}$ fiber orientation is used throughout the remainder of this chapter.

In the case of specimens with the $0 / 90^{\circ}$ fiber orientation, there is little change in maximum strain throughout the cyclic life. This is illustrated in Fig. 9.8(a) for room temperature and in Fig. $9.8(b)$ for $120^{\circ} \mathrm{C}$.

Of particular importance in cyclic fatigue is the reduction in stiffness, reflecting the accumulation of damage with cycling. Ideally, this loss should not exceed $10 \%$ during the design allowable life. The loss for specimens with the $\pm 45^{\circ}$ fiber orientation is shown in Fig. 9.9(a) for room temperature and in Fig. $9.9(b)$ for $120^{\circ} \mathrm{C}$. With the factor of 20 design margin $\left(\mathrm{n} / \mathrm{N}_{\mathrm{f}}=0.05\right)$ on cyclic life that is recommended later in this chapter, the room-temperature stiffness loss is seen to be less than $10 \%$. Note that the original definition of failure, $\mathrm{N}_{\mathrm{f}}$, was used in Fig. 9.9. If the $0.2 \%$-offset definition were used, the curves would shift to the right, so the room-temperature stiffness drop would be even lower. In contrast to the room-temperature case, the stiffness at $120^{\circ} \mathrm{C}$ drops more than $10 \%$ almost immediately. Adoption of the $0.2 \%$-offset definition would lower the stiffness drop significantly in the design range. Still, cyclic loadings should be scrutinized carefully at $120^{\circ} \mathrm{C}$ when the fiber orientation is $\pm 45^{\circ}$. One further point should be made regarding the curves in Fig. 9.9. The scatter appears to be just that; there is no apparent trend between the magnitude of the stiffness loss and the cyclic stress levels.

Figure $9.10(a)$ and $(b)$ shows the measured stiffness loss for $0 / 90^{\circ}$ specimens at room temperature and $120^{\circ} \mathrm{C}$. While there is some loss at room temperature, it is small. At $120^{\circ} \mathrm{C}$ the scatter is greater, but stiffness appears to generally increase with cycling. The presumed explanation for this observation is that the softer matrix allows for some straightening of fibers during cycling.

\subsection{QUANTIFICATION OF TEMPERATURE EFFECTS}

The following procedure was used to develop a consistent set of failure curves over the $-40^{\circ} \mathrm{C}$ to $120^{\circ} \mathrm{C}$ temperature range for each fiber orientation. For each orientation, specimens from a single plaque $\left(\mathrm{C} 17\right.$ for $\pm 45^{\circ}$ and $\mathrm{C} 18$ for $\left.0 / 90^{\circ}\right)$ were used to generate tensile $(\mathrm{R}=0.1)$ S-N curves at $-40,23,70$, and $120^{\circ} \mathrm{C}$. In each case, factors were developed relating each curve to the corresponding room-temperature curve. These factors were then applied to the baseline roomtemperature curves to obtain the final sets of curves. ${ }^{*}$

Figure 9.11 shows the $\pm 45^{\circ} \mathrm{S}-\mathrm{N}$ curves obtained using specimens from plaque $\mathrm{C} 17$. The original data using specimen breakage or strain instability to define failure, are shown in Fig. 9.11(a); while Fig. 9.11(b) shows data and curves based on the $0.2 \%-$ offset procedure. The equations for the latter curves were the basis for determining temperature factors for the $\pm 45^{\circ}$ orientation.

\footnotetext{
* As will be explained later, some deviation from this procedure was necessary in the $0 / 90^{\circ}$ case.
} 
In the $0 / 90^{\circ}$ case, data scatter at $-40,23$, and $70^{\circ} \mathrm{C}$ made completely satisfactory curve fitting difficult, especially using the conventional approach of expressing the dependent variable, $\mathrm{N}_{\mathrm{f}}$, as a function of stress. Expressing stress as a function of cycles to failure, though not recommended practice, did lead to more reasonable curve fits; thus, the equations for those curves were used to determine factors at $-40,23$, and $70^{\circ} \mathrm{C}$. For $120^{\circ} \mathrm{C}$, the baseline $0 / 90^{\circ}$ curve that was shown in Fig. 9.1 was used.

The resulting tensile fatigue curves are shown in Fig. 9.12. The corresponding fatigue strength multiplication factors are tabulated in Table 9.1. The factors are those used in Sect. 4.2 of Part 1.

Table 9.1. Fatigue strength multiplication factors for temperature

\begin{tabular}{|c|c|c|c|c|}
\hline \multirow{2}{*}{$\begin{array}{c}\text { Temperature } \\
\left({ }^{\circ} \mathrm{C}\right)\end{array}$} & \multicolumn{4}{|c|}{ Cycles to failure } \\
\hline & $10^{2}$ & $10^{4}$ & $10^{6}$ & $10^{8}$ \\
\hline & \multicolumn{4}{|c|}{$0 / 90^{\circ}$ Fiber orientation } \\
\hline-40 & 1.00 & 1.00 & 1.00 & 1.00 \\
\hline 23 & 1.00 & 1.00 & 1.00 & 1.00 \\
\hline 70 & 0.95 & 0.93 & 0.90 & 0.88 \\
\hline \multirow[t]{2}{*}{120} & 0.80 & 0.76 & 0.73 & 0.70 \\
\hline & \multicolumn{4}{|c|}{ $\pm 45^{\circ}$ Fiber orientation } \\
\hline-40 & 1.18 & 1.22 & 1.25 & 1.29 \\
\hline 23 & 1.00 & 1.00 & 1.00 & 1.00 \\
\hline 70 & 0.84 & 0.73 & 0.63 & 0.55 \\
\hline 120 & 0.49 & 0.39 & 0.31 & 0.24 \\
\hline
\end{tabular}

\subsection{FLUID EFFECTS}

Fatigue strength multiplication factors to account for fluid effects were developed in a similar manner to the temperature factors. The following three fluid conditions were examined for each fiber orientation:

- specimens soaked for $100 \mathrm{~h}$ and then tested in distilled water,

- $\quad$ specimens soaked for $1000 \mathrm{~h}$ and then tested in distilled water, and

- $\quad$ specimens soaked for $100 \mathrm{~h}$ and then tested in windshield washer fluid $(70 \%$ methanol $/ 30 \%$ distilled water).

Room-temperature tensile fatigue $(\mathrm{R}=0.1)$ tests were for each fiber orientation, carried out on specimens from a single plaque $\left(\mathrm{C} 16\right.$ for $\pm 45^{\circ}, \mathrm{C} 19$ for $\left.0 / 90^{\circ}\right)$. In addition to the three fluid exposures, a baseline in-air fatigue curve was also developed for each orientation. The ratio of the fatigue strength from the curve for one of the fluid conditions to the corresponding strength from the in-air curve provided the fluid reduction factors.

The various $\pm 45^{\circ}$ fluid effects results are plotted in Fig. 9.13(a). and $(b)$. In these curves, failure is based on the usual definition of specimen separation. Results for the two standard exposures - $1000 \mathrm{~h}$ in distilled water and $100 \mathrm{~h}$ in windshield washer fluid - are replotted in Fig. 9.14 with failure defined by the $0.2 \%$-offset procedure. The curve-fit equations shown above the plots were used to calculate the fluid multiplication factors for the $\pm 45^{\circ}$ case. 
The $0 / 90^{\circ}$ results are plotted in Fig. 9.15. Just as was the case for the $0 / 90^{\circ}$ tests at various temperatures, data scatter made it difficult to obtain reliable curve fits. Two things were done to improve the situation. First, because little overall difference was observed between the effects of the 100-h and 1000-h preexposures in distilled water, the two data sets were "combined" to obtain the curve fit shown by the dashed line in Fig. 9.15. Second, stress was again expressed as a function of cycles to failure. Even with these steps, the coefficient of determination, $\mathrm{r}^{2}$, for the distilled water data is quite low. Nonetheless, the curve-fit equations shown in the figure were used to calculate the fluid multiplication factors for the $0 / 90^{\circ}$ case.

The resulting fluid factors are tabulated in Table 9.2 for the $0 / 90^{\circ}$ and the $\pm 45^{\circ}$ fiber orientations. At the higher cycles, the $\pm 45^{\circ}$ strength actually appears to be enhanced by the presence of fluid. This was also the case for the chopped-glass-fiber composite, with the same matrix, tested previously. ${ }^{3}$ With the exception of the $0 / 90^{\circ}$ case in windshield washer fluid, all of the factors in Table 9.2 are higher than the corresponding factors for the chopped-glass-fiber composite.

Table 9.2. Fatigue strength multiplication factors to account for fluid effects

\begin{tabular}{|c|c|c|c|c|}
\hline \multirow{2}{*}{ Fluid condition } & \multicolumn{4}{|c|}{ Cycles to failure } \\
\hline & $10^{2}$ & $10^{4}$ & $10^{6}$ & $10^{8}$ \\
\hline & \multicolumn{4}{|c|}{$0 / 90^{\circ}$ Fiber orientation } \\
\hline 1000-h presoak in distilled water & 0.98 & 0.98 & 0.97 & 0.97 \\
\hline \multirow[t]{2}{*}{$100-h$ presoak in windshield washer fluid } & 0.93 & 0.94 & 0.96 & 0.98 \\
\hline & \multicolumn{4}{|c|}{ $\pm 45^{\circ}$ Fiber orientation } \\
\hline 1000-h presoak in distilled water & 0.94 & 0.97 & 1.01 & 1.05 \\
\hline 100-h presoak in windshield washer fluid & 1.00 & 1.03 & 1.06 & 1.09 \\
\hline
\end{tabular}

\subsection{MEAN STRESS EFFECTS}

While tensile cycling with $\mathrm{R}=0$, which leads to fatigue lives similar to those with $\mathrm{R}=0.1$, is likely to be common in automotive components, other types of cycles are equally likely. Thus, cyclic fatigue data are needed for other cycle types. Ideally, some method can also be identified for correlating the various sets of data.

Here, data were generated for four different cycle types, as depicted in Fig. 9.16. For the $\pm 45^{\circ}$ fiber orientation, data ( $\mathrm{S}-\mathrm{N}$ curves, maximum and minimum strains vs cycles, and stiffness reduction vs cycles) were generated for all four cycle types. In the $0 / 90^{\circ}$ case, only the $\mathrm{R}=0$ and $50 \%$ UTS mean stress cycles, which involved only tensile stresses, were examined.

Whereas a dogbone specimen was used for all of the tests reported earlier in this chapter, an hourglass specimen, shown in Fig. 9.17, was used for the mean stress cycles shown in Fig. 9.16. The hourglass specimen, which was developed for the glass-fiber composite tested earlier, is intended to resist buckling under compressive loadings. For the glass-fiber composites, the specimens were clamped down slightly into the hourglass section, as shown in Fig. 9.17. For the carbon-fiber composite, the specimens could be clamped only to the beginning of the hourglass section. Thus, the unsupported length was greater than originally intended. An extensometer with a 12.7-mm gage length was used.

All of the specimens for the mean stress tests came from two plaques $-\mathrm{C} 28$ and C46. Both specimens with $\mathrm{a} \pm 45^{\circ}$ fiber orientation and with a $0 / 90^{\circ}$ orientation were cut from each plaque. 
These two plaques were molded sequentially and had identical fiber volume contents (see Appendix B), so the mean stress data should be reasonably comparable.

Prior to running the tests depicted in Fig. 9.16, a series of tensile fatigue tests using $\mathrm{R}=0.1$ was performed on $\pm 45^{\circ}$ hourglass specimens. The results were then compared with the $\mathrm{R}=0.1$ results from dogbone specimens to determine if data from the two specimen types were comparable. As shown in Fig. 9.18, they were not. Even when stress levels were adjusted by specimen thickness to approximately account for differing fiber-volume contents, the hourglass specimens produced higher fatigue strength values.

\subsubsection{The $\pm 45^{\circ}$ Fiber Orientation}

Maximum and/or minimum cyclic strains for all four cycle types are plotted in Figs. 9.19 and 9.20. Figure 9.19 shows the two tensile cycling cases $-\mathrm{R}=0$ and $50 \%$ UTS mean stress. Figure 9.20 shows the two cases involving compressive stress in the cycle-completely reversed $\left(\mathrm{R}=-1, \sigma_{\text {mean }}=0\right)$ and compressive cycling $(\mathrm{R}=-\infty)$. In all cases, the percentages shown in the legends and as curve labels are the maximum cyclic stress (or absolute value of the minimum) in terms of the plaque average UTS.

The $\mathrm{R}=0$ results are qualitatively similar to the $\mathrm{R}=0.1$ data plotted in Fig. 9.3. The data for the two cycle types involving compression turned up more abruptly near the end of life than did the $\mathrm{R}=0$ tensile data. Note also that the completely reversed cycle (mean stress of zero) showed relatively little strain increase prior to the abrupt upturn. This is likely a reflection of the absence of a net creep strain. The cycle type that stands out from the others, however, is the 50\% UTS mean stress case in Fig. 9.19(b). Here, the strain curves turn up noticeably earlier in life, implying that ply failures and the scissoring action occur earlier.

The $0.2 \%$-offset procedure was applied to all of the curves in Figs. 9.19 and 9.20 to determine failure. As would be expected, the number of cycles to failure was reduced most in the $50 \%$ UTS mean stress case.

Figures 9.21 and 9.22 depict the reduction of stiffness with cycles for the two tensile and two compressive stress cycles, respectively. The cycles to failure, $\mathrm{N}_{\mathrm{f}}$, in these plots are based on specimen separation or large unstable straining. With a few exceptions, the reduction in stiffness at $\mathrm{n} / \mathrm{N}_{\mathrm{f}}=0.05$ is less than $10 \%$ except in the $\mathrm{R}=0$ tensile cycling case. There, several curves show a reduction as high as $13 \%$.

Fatigue curves developed from the four cycle types are plotted in Fig. 9.23. Here, the stress parameter is the maximum stress, or absolute value of the minimum stress, in the cycle. Curves for both relevant definitions of failure - complete separation or large straining (solid points and curves) and failure defined by the $0.2 \%$-offset procedure - are shown. Three observations should be made relative to Fig. 9.23. First, maximum stress does not generally correlate the data well, although it does a fair job of correlating the tensile stress results $(\mathrm{R}=0$ and $50 \%$ UTS mean stress) when failure is defined by the $0.2 \%$-offset procedure. The second point is that defining failure using the $0.2 \%$-offset method has a large effect only on the $50 \%$ UTS tensile mean stress case, as previously noted. The third point is that the solid $\mathrm{R}=0$ tensile curve in Fig. 9.23 is essentially identical to the $\mathrm{R}=0.1$ curve, also developed from hourglass specimens, that was presented in Fig. 9.18.

Figure 9.24 shows the same data as the solid points in Fig. 9.23 except that the stress parameter is the alternating stress, $\mathrm{S}_{\mathrm{a}}$, in each cycle type. The solid lines represent the two tensile cases, and the dashed lines, the compressive cases. Alternating stress does not correlate the data.

Another stress parameter, which was used for the chopped-glass-fiber composite with some success, was first suggested by Conle and Ingall ${ }^{14}$ for composites. The stress parameter, which simply combines the maximum cyclic stress and the stress amplitude, is 


$$
\sqrt{\mathrm{S}_{\max } \times \mathrm{S}_{\mathrm{a}}}
$$

Conle and Ingall reviewed data from the literature as well as their own data on an automotive glass-fiber composite. They found that to use the stress parameter, failure results must be grouped according to failure mode - tension or compression. A separate parameter is needed for each.

Figure 9.25 shows the four sets of data from the previous two figures replotted against the parameter $\sqrt{\mathrm{S}_{\max } \times \mathrm{S}_{\mathrm{a}}}$ or, in the case of compression cycling, $\sqrt{\left|\mathrm{S}_{\max }\right| \times \mathrm{S}_{\mathrm{a}}}$. The parameter does an excellent job of pulling the two tensile cycle results together, and it does a fair job of pulling the two compressive cycle results together, although the slopes do not match well. ${ }^{*}$

Failure in Fig. 9.25 is based on the usual definition (separation or large unstable strains). What happens if the $0.2 \%$-offset definition is used? Figure 9.26 shows that the good tensile correlation is lost. This would be expected because the peak strains in the 50\% UTS mean stress case began to turn up so early in life.

\subsubsection{The $0 / 90^{\circ}$ Fiber Orientation}

Only the two tensile cycles ( $\mathrm{R}=0$ and $50 \%$ UTS mean stress) were assessed in the $0 / 90^{\circ}$ tests. The best correlation was provided by the alternating stress, which is shown in Fig. 9.27. The relatively good correlation between these two cases is not surprising. Because the $0 / 90^{\circ}$ curves are relatively flat, the alternating stress components do not differ much in the two cycles (refer back to Fig. 9.16). Results using the other two parameters $-S_{\max }$ and $\sqrt{S_{\max } \times S_{a}}$ are shown in Fig. 9.28(a) and (b). Neither does a very good job.

\subsection{CONCLUSIONS AND RECOMMENDATIONS}

The purpose of this section is to summarize and draw conclusions from the cyclic fatigue information that has been presented and to develop recommendations on which the fatigue design guidance is based in Chap. 4 of Part 1 .

As has been shown in this chapter, the fatigue behavior of specimens with a $0 / 90^{\circ}$ fiber orientation is very different from that of specimens with a $\pm 45^{\circ}$ fiber orientation. In the $0 / 90^{\circ}$ case, resistance to cycling is high, and fatigue strengths are very near the UTS values over the temperature range of interest. Even with design margins imposed, fatigue strengths are above the basic allowable stress values, $\mathrm{S}_{0}$. Failure in the $0 / 90^{\circ}$ case occurs abruptly, and peak cyclic strains remain relatively constant throughout the cyclic life. Any stiffness loss with cycling is well below the desired limit of $10 \%$.

The superior fatigue strength and resistance of the carbon-fiber composite is lost with the $\pm 45^{\circ}$ fiber orientation. In the latter case, the fatigue properties are similar to those observed for the chopped-glass-fiber composite previously characterized. ${ }^{3}$ At room temperature, the fatigue strength of the carbon-fiber composite is somewhat less than that of the glass-fiber composite at low cycles; at high cycles it is slightly higher when the ordinary definition of failure is used and slightly lower when the $0.2 \%$-offset definition is used. At $120^{\circ} \mathrm{C}$, the carbon-fiber composite fatigue strength is below that of the glass-fiber composite. In any event, the $\pm 45^{\circ}$ fatigue strength values are below the $\mathrm{S}_{0}$ values over most of the cyclic life, so fatigue must be a definite design concern.

\footnotetext{
*The slope mismatch may simply reflect the limited amount of data available for the two compressive cases.
} 
The distinguishing characteristic of the fatigue behavior when the fibers are oriented at $\pm 45^{\circ}$ is the early ply failures that occur well before first specimen separation and that lead to a scissoring action and resulting large deformations. To preclude this kind of functional failure, an alternative failure definition (the $0.2 \%$-offset method) based on limiting the increase in peak strains is recommended and used in the design guidance for the $\pm 45^{\circ}$ fiber orientation. Cyclic stiffness data presented in this chapter indicate that a design margin of 20 on cycles is sufficient to limit stiffness loss to about $10 \%$ or less (up to $13 \%$ in one case) at room temperature. At $120^{\circ} \mathrm{C}$, however, this was not the case, so caution should be used in allowing cyclic loadings at elevated temperatures for the $\pm 45^{\circ}$ fiber orientation.

Multiplication factors on the room-temperature fatigue strength values were developed to handle both temperature and fluid effects. For the $0 / 90^{\circ}$ case, the fatigue strength reduction at $120^{\circ} \mathrm{C}$ is less than for the glass-fiber composite at low cycles but significantly greater at high cycles. For the $\pm 45^{\circ}$ case, the reduction at $120^{\circ} \mathrm{C}$ is significantly greater than for the choppedglass-fiber composite. In the case of fluid effects, the carbon-fiber composite generally exhibited greater resistance than did the glass-fiber composite.

The design approach recommended in Chap. 4 of Part 1 makes use of room-temperature design curves for each fiber orientation based on tensile $(\mathrm{R}=0$, or $\mathrm{R}=0.1)$ cycling. The construction of those curves is shown in Fig. 9.29. The baseline data are shown in each case (the $0.2 \%$-offset failure definition was used in the $\pm 45^{\circ}$ case). In the $0 / 90^{\circ}$ case, where the curve is relatively flat, a margin of 20 on cycles to failure alone is seen to be insufficient. An additional multiplication factor of $\mathrm{UTS}_{\min } / \mathrm{UTS}_{\mathrm{avg}}=0.83$ was thus applied to stress to obtain the final design curve. This same procedure was used for the chopped-glass-fiber composite. In the $\pm 45^{\circ}$ case, where the fatigue curve is steeper, the factor of 20 on cycles alone was judged to be adequate. A curve corresponding to imposition of the additional factor $\mathrm{UTS}_{\min } / \mathrm{UTS}_{\mathrm{avg}}$, which was 0.83 for both fiber orientations, is shown for reference only.

As was shown in the previous section, no apparent parameter was identified for correlating results for the various mean stress cycle types, especially with the $0.2 \%$-offset failure definition used in the $\pm 45^{\circ}$ case. Consequently, the following approaches were adopted to account for the common cycle types that were examined.

- For both the $0 / 90^{\circ}$ and $\pm 45^{\circ}$ fiber orientations, the $\mathrm{R}=0$ tensile curves in Fig. 9.29 can be conservatively applied to the $50 \%$ UTS mean stress tensile results. Hence, in the absence of other data, those curves are recommended for cycles involving only tensile stresses.

- In the $\pm 45^{\circ}$ case, multiplication factors on fatigue strength were developed to apply the tensile design curve to the case of completely reversed loadings $(\mathrm{R}=-1)$ and compression cycling $(\mathrm{R}=-\infty)$.

The aforementioned factors were developed from the dashed curves in Fig. 9.23 and are tabulated in Table 9.3. In using the factors in Table 9.3, the stress parameter is the maximum stress in the cycle or, in the compressive cycling case, the absolute value of the minimum stress.

Table 9.3. Fatigue strength multiplication factors for the $\pm 45^{\circ}$ fiber orientation to account for cycle type

\begin{tabular}{lcccc}
\hline \multirow{2}{*}{ Cycle type } & \multicolumn{4}{c}{ Cycles to failure } \\
\cline { 2 - 5 } & $\mathbf{1 0}^{\mathbf{2}}$ & $\mathbf{1 0}^{\mathbf{4}}$ & $\mathbf{1 0}^{\mathbf{6}}$ & $\mathbf{1 0}^{\mathbf{8}}$ \\
\hline Reversed loading $(\mathbf{R}=-\mathbf{1})$ & 0.68 & 0.62 & 0.57 & 0.52 \\
Compressive cycling $(\mathbf{R}=-\infty)$ & 0.84 & 0.86 & 0.88 & 0.91 \\
\hline
\end{tabular}




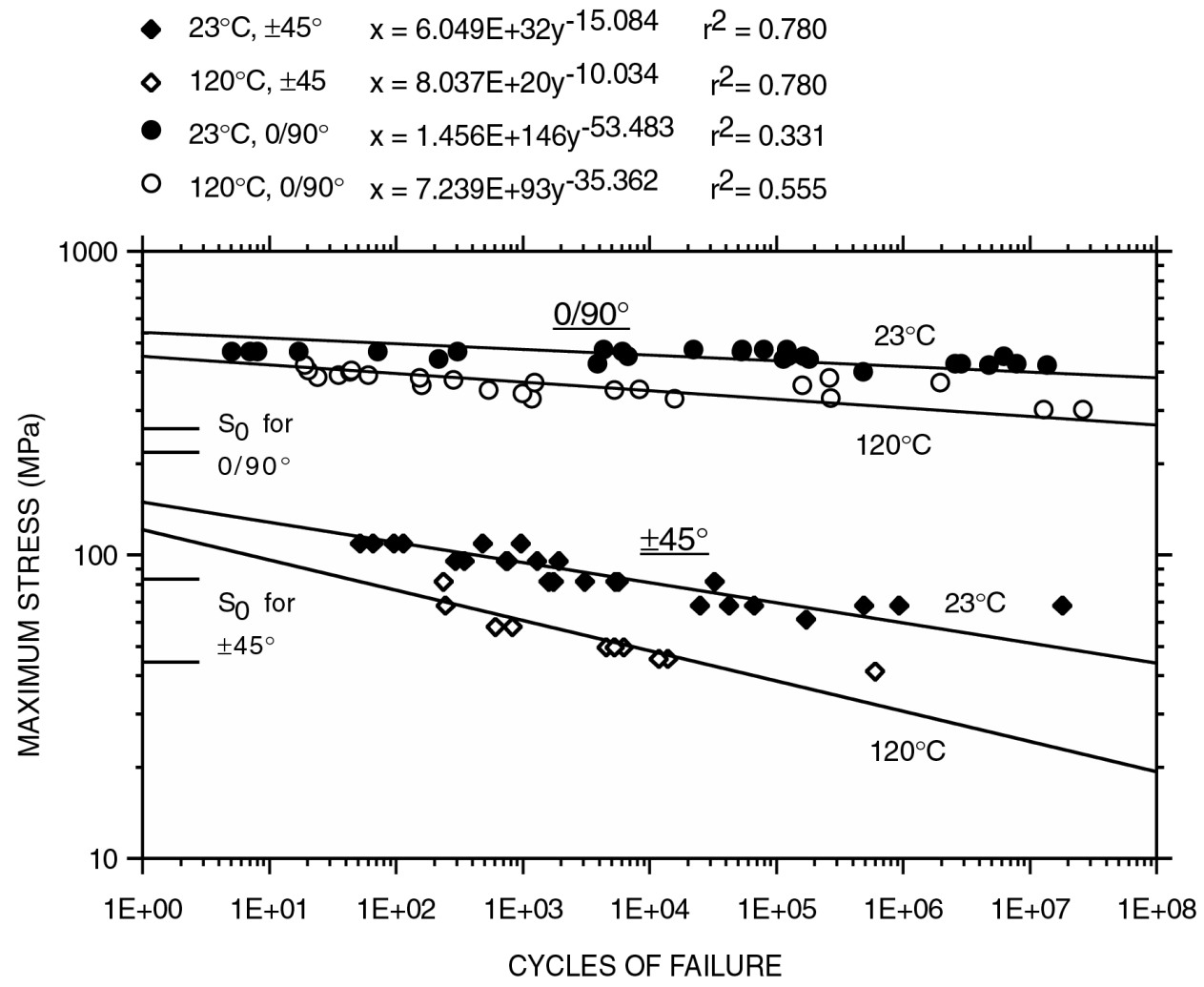

Fig. 9.1. Tensile fatigue $(R=0.1)$ curves at $23^{\circ} \mathrm{C}$ and $120^{\circ} \mathrm{C}$. The ticks labeled $\mathrm{S}_{0}$ are allowable stress values at the two temperatures.

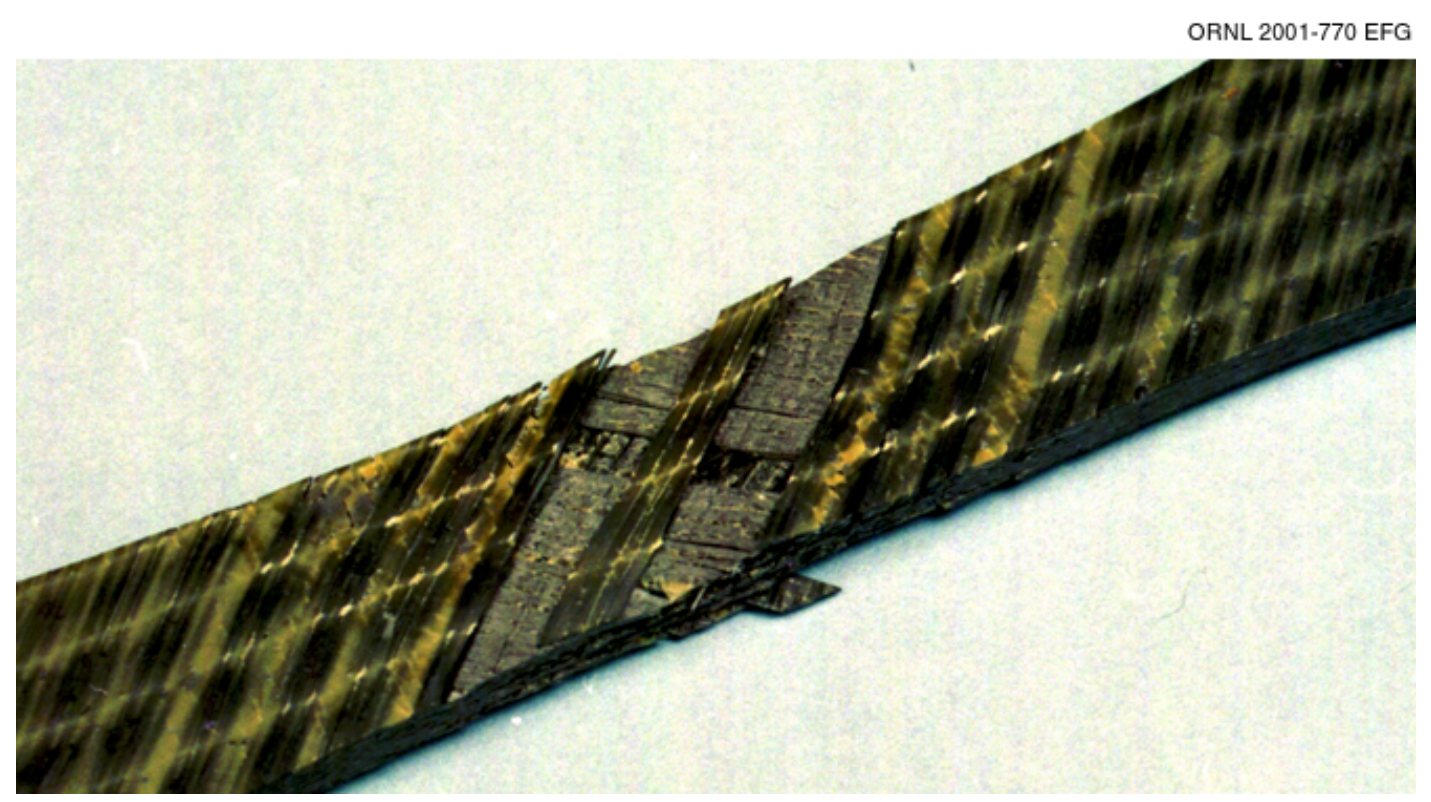

Fig. 9.2. Mixed-mode ply failures and interlaminar shear failures exhibited by specimens with $\pm 45^{\circ}$ fiber orientation. 


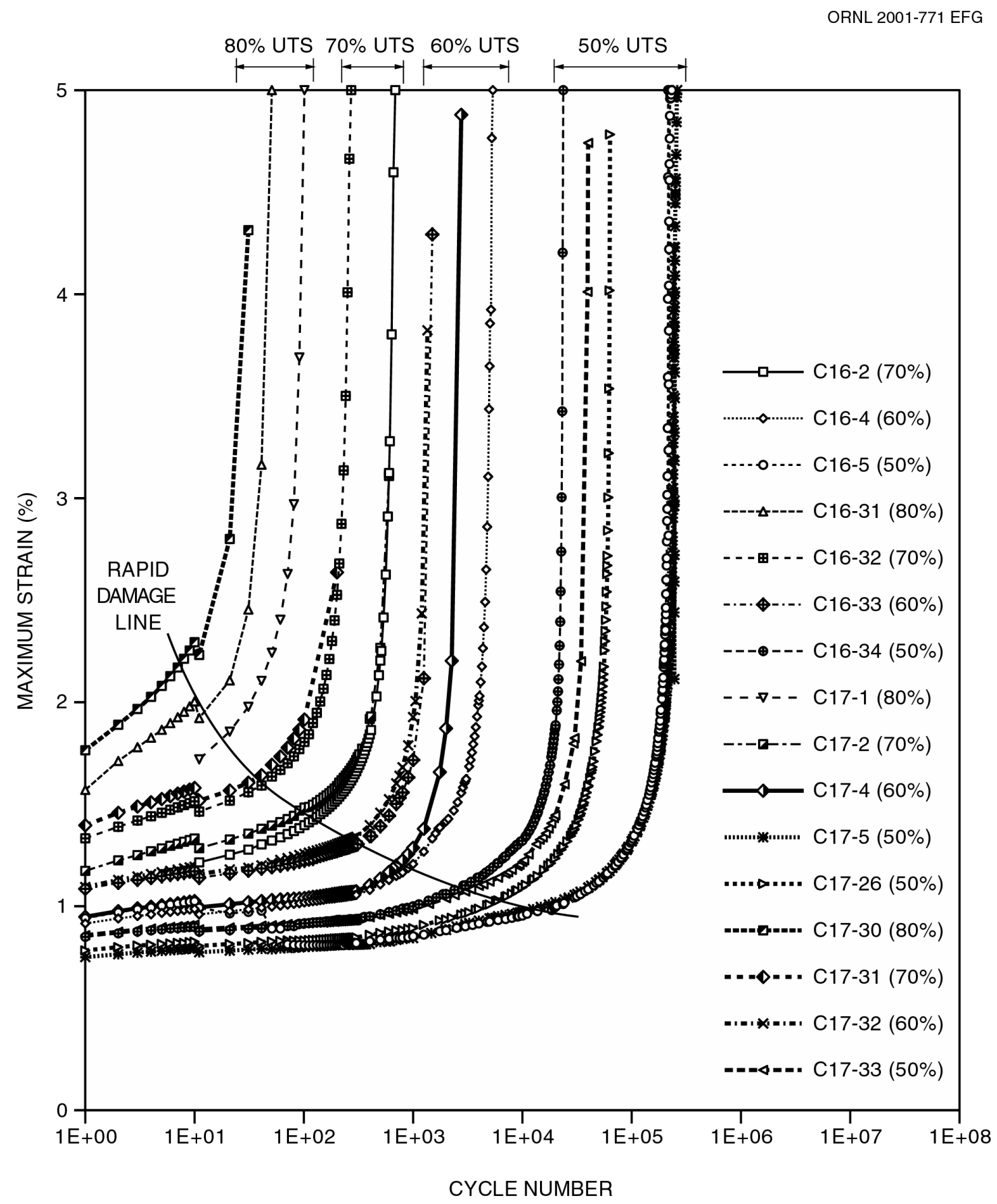

Fig. 9.3. Maximum strain behavior at room temperature in specimens with $\pm 45^{\circ}$ fiber orientation. The numbers in percent denote the maximum cyclic stress as a percentage of the UTS. The curves are labeled with these percentages. 


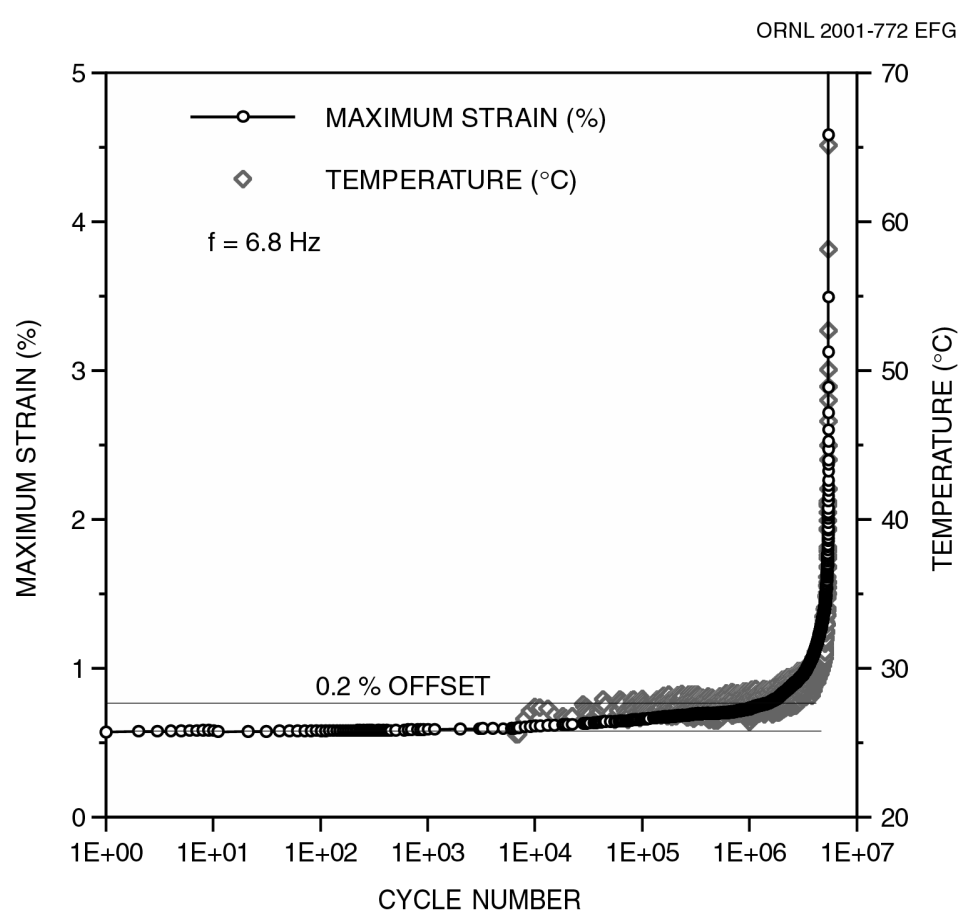

Fig. 9.4. Maximum strain and temperature vs cycle number for $\pm 45^{\circ}$ specimen with maximum stress of $49 \%$ UTS.

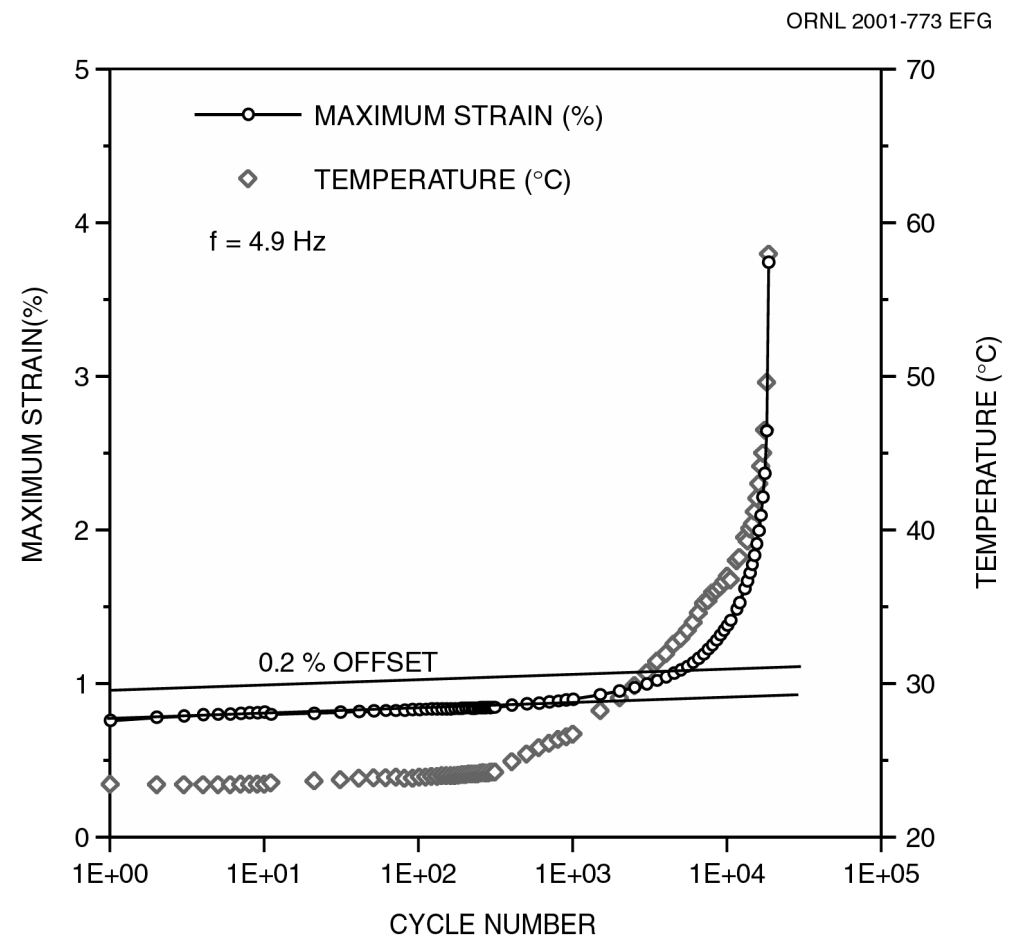

Fig. 9.5. Maximum strain and temperature vs cycle number for $\pm 45^{\circ}$ specimen with maximum stress of $68 \%$ UTS. 


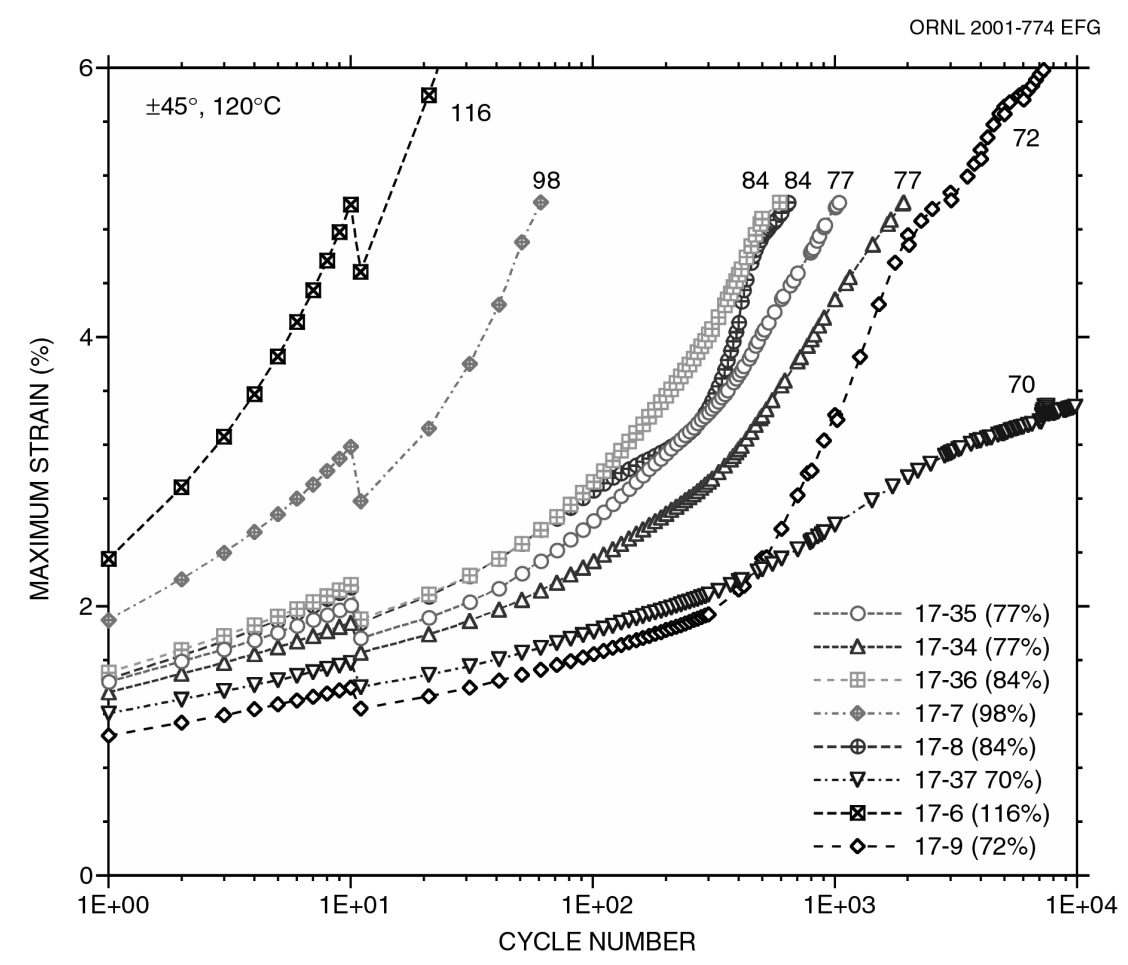

Fig. 9.6. Maximum strain behavior at $120^{\circ} \mathrm{C}$ in specimens with $\pm 45^{\circ}$ fiber orientation.

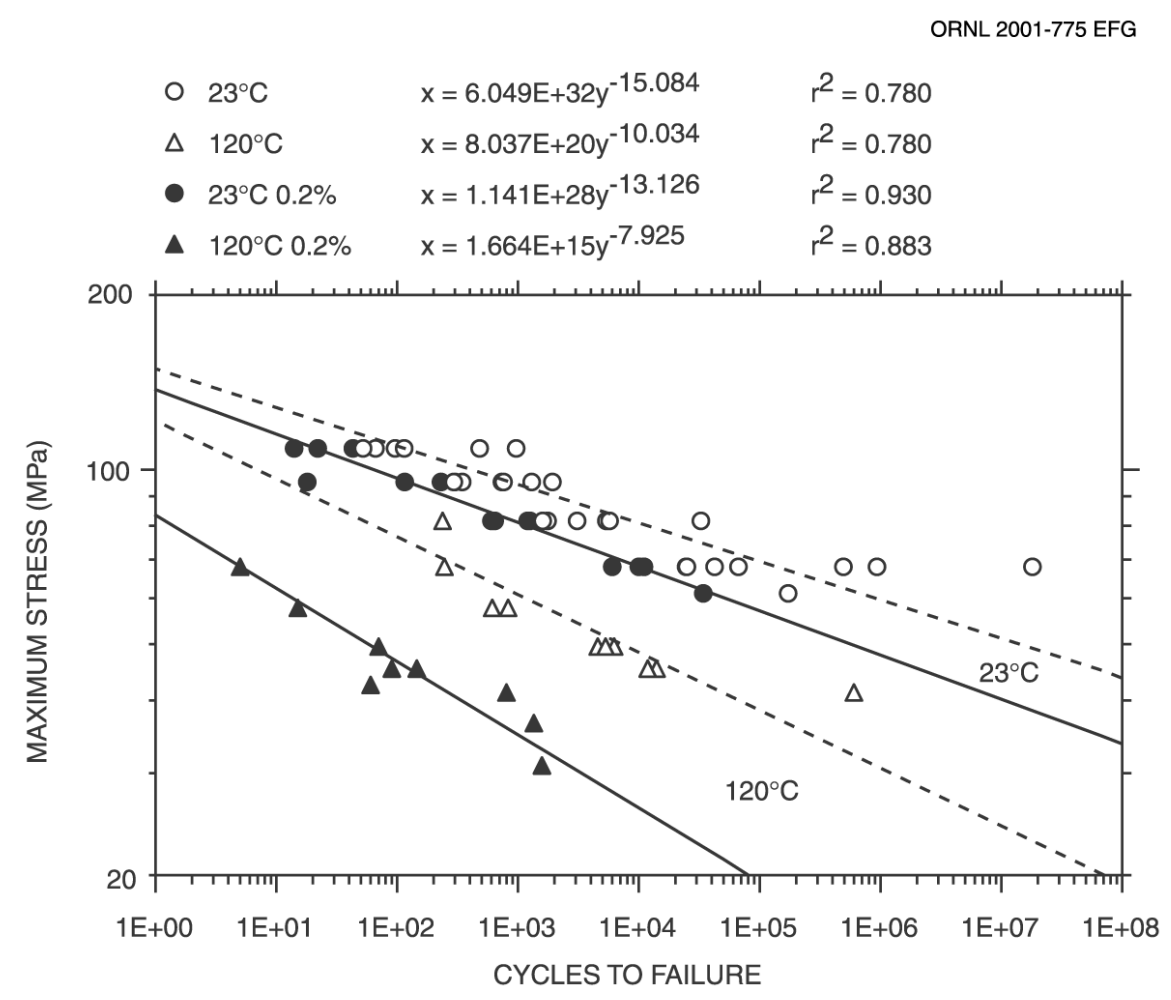

Fig. 9.7. Tensile fatigue $(R=0.1)$ curves for $\pm 45^{\circ}$ specimens at $23^{\circ} \mathrm{C}$ and $120^{\circ} \mathrm{C}$ based on $0.2 \%-0$ ffset definition (solid curves and filled points). 
ORNL 2001-776 EFG

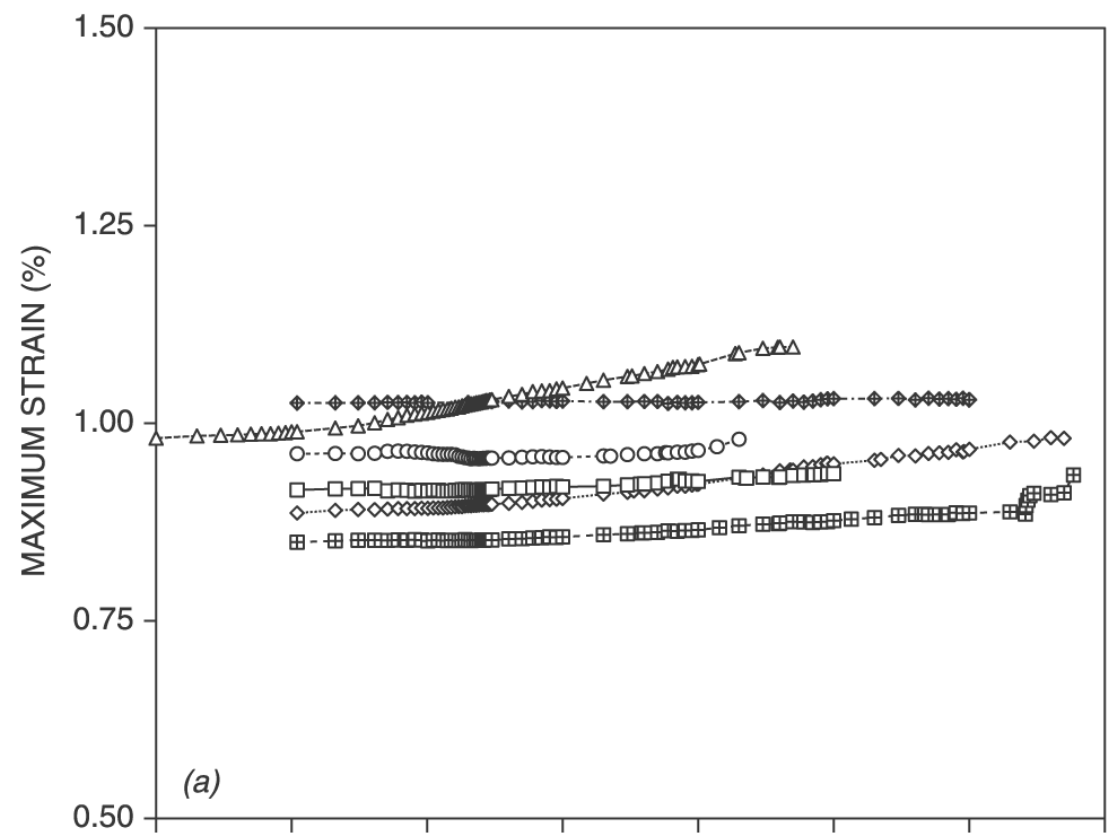

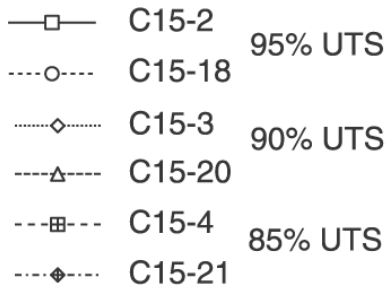

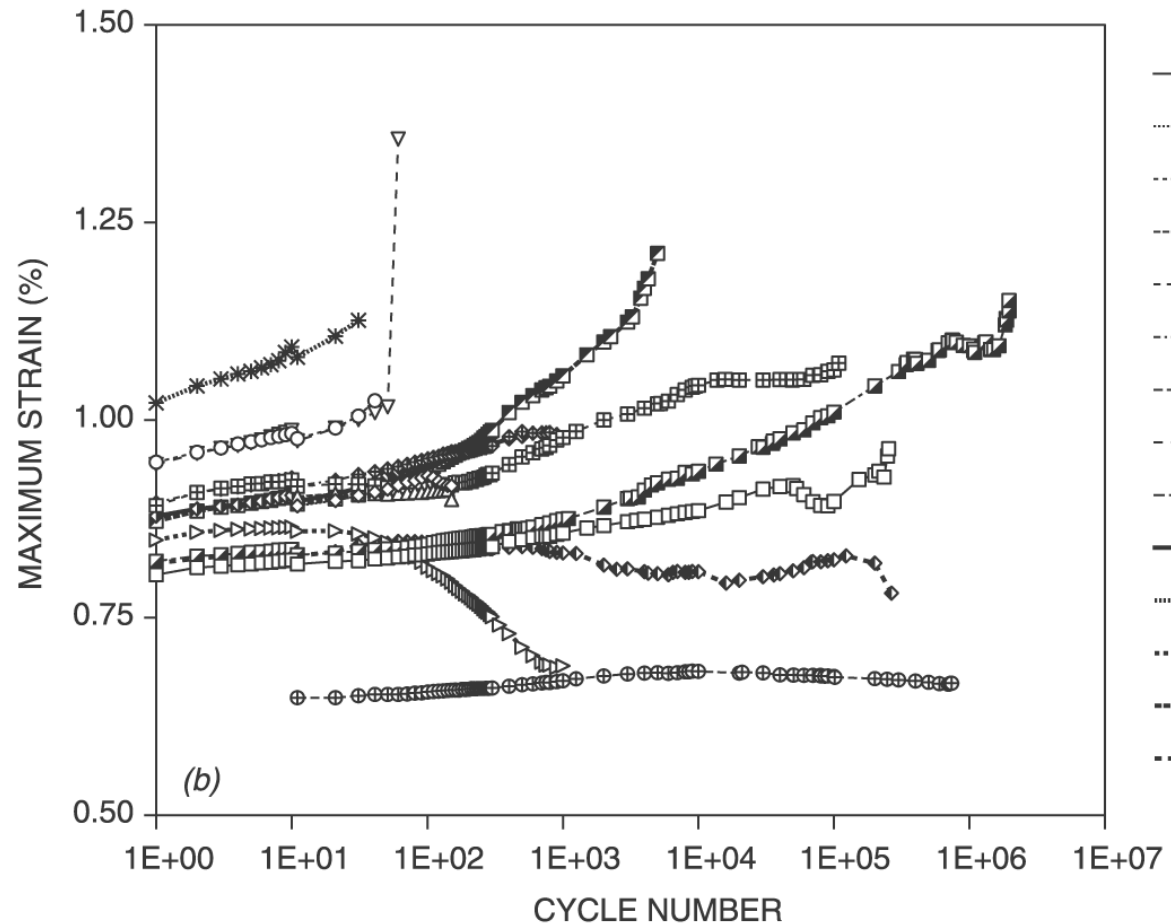

$\longrightarrow$ - 15-7 (101\%)

…… $\diamond \cdots \cdots \cdots . . \quad 15-8$ (96\%)

…-.... 15-23 (107\%)

------- 15-24 (101\%)

---田-- 15-25 (96\%)

$\cdots \leftrightarrow \cdots$ 15-26 (90\%)

--๑--- 18-10 (91\%)

- - $\nabla$ - - 18-6 (108\%)

--- 18-7 (102\%)

$\longrightarrow \quad 18-8$ (96\%)

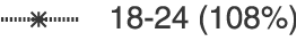

.... .... 18-25 (102\%)

----v--.. 18-26 (96\%)

....... 18-27 (91\%)

Fig. 9.8. Maximum strain behavior in specimens with $0 / 90^{\circ}$ fiber orientation: (a) $23^{\circ} \mathrm{C}$ and (b) $120^{\circ} \mathrm{C}$. 

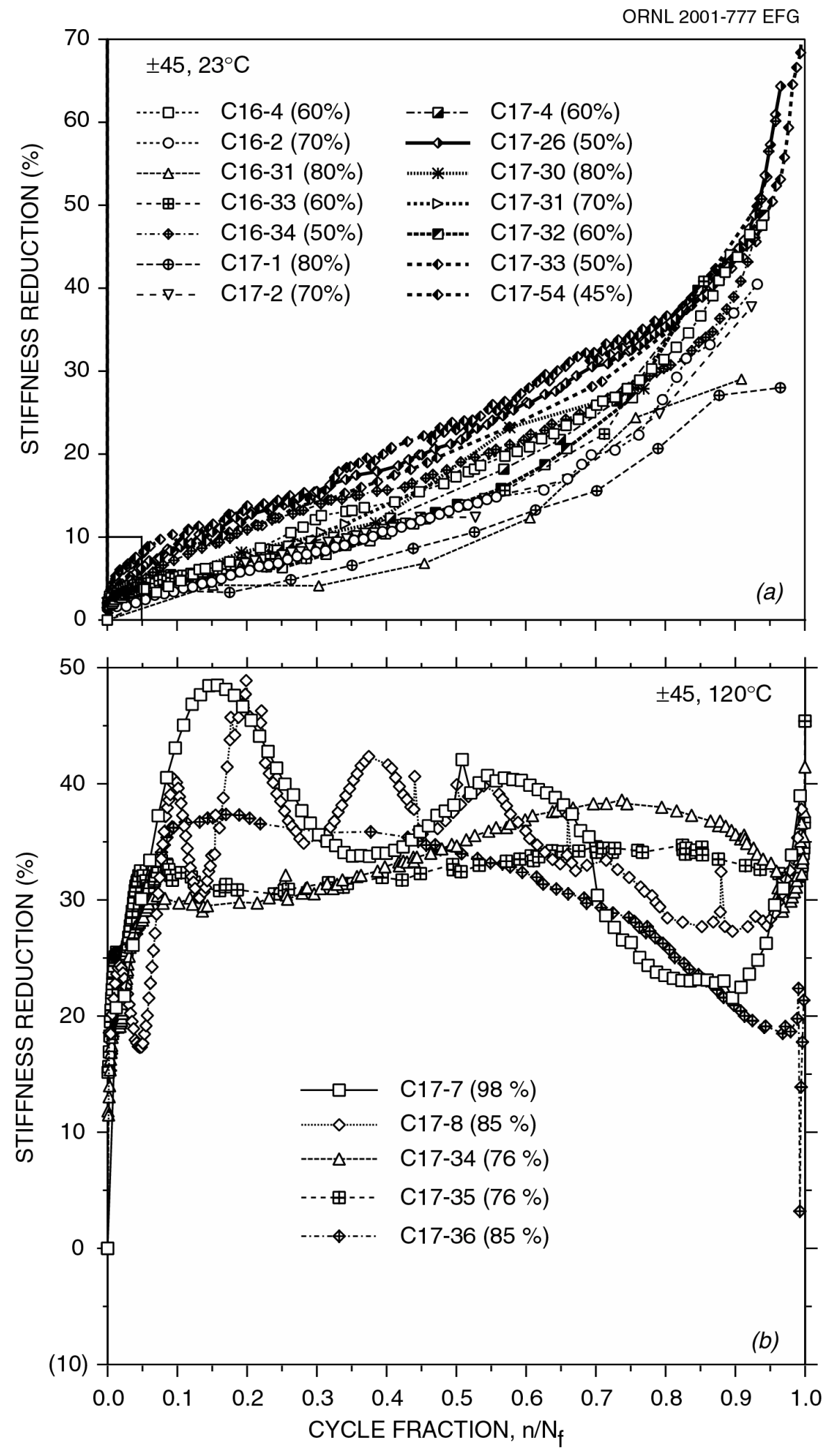

Fig. 9.9. Stiffness loss vs cycle fraction, $n / N_{f}$, in $\pm 45^{\circ}$ specimens: (a) $23^{\circ} \mathrm{C}$ and $(b) 120^{\circ} \mathrm{C}$. 
ORNL 2001-778 EFG
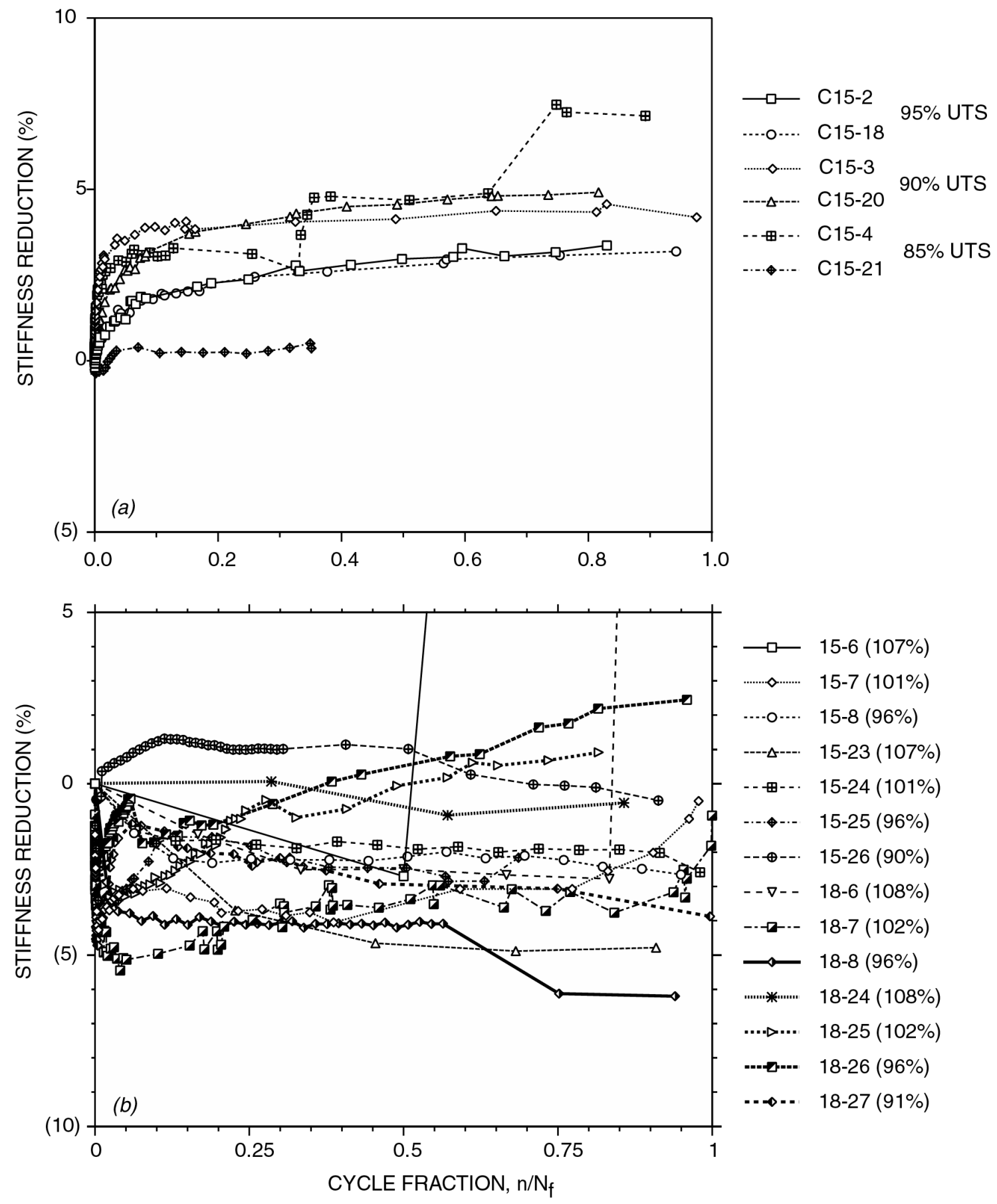

Fig. 9.10. Stiffness loss vs cycle fraction, $n / \mathbf{N}_{f}$, in $0 / 90^{\circ}$ specimens: $(a) 23^{\circ} \mathrm{C}$ and $(b) 120^{\circ} \mathrm{C}$. 


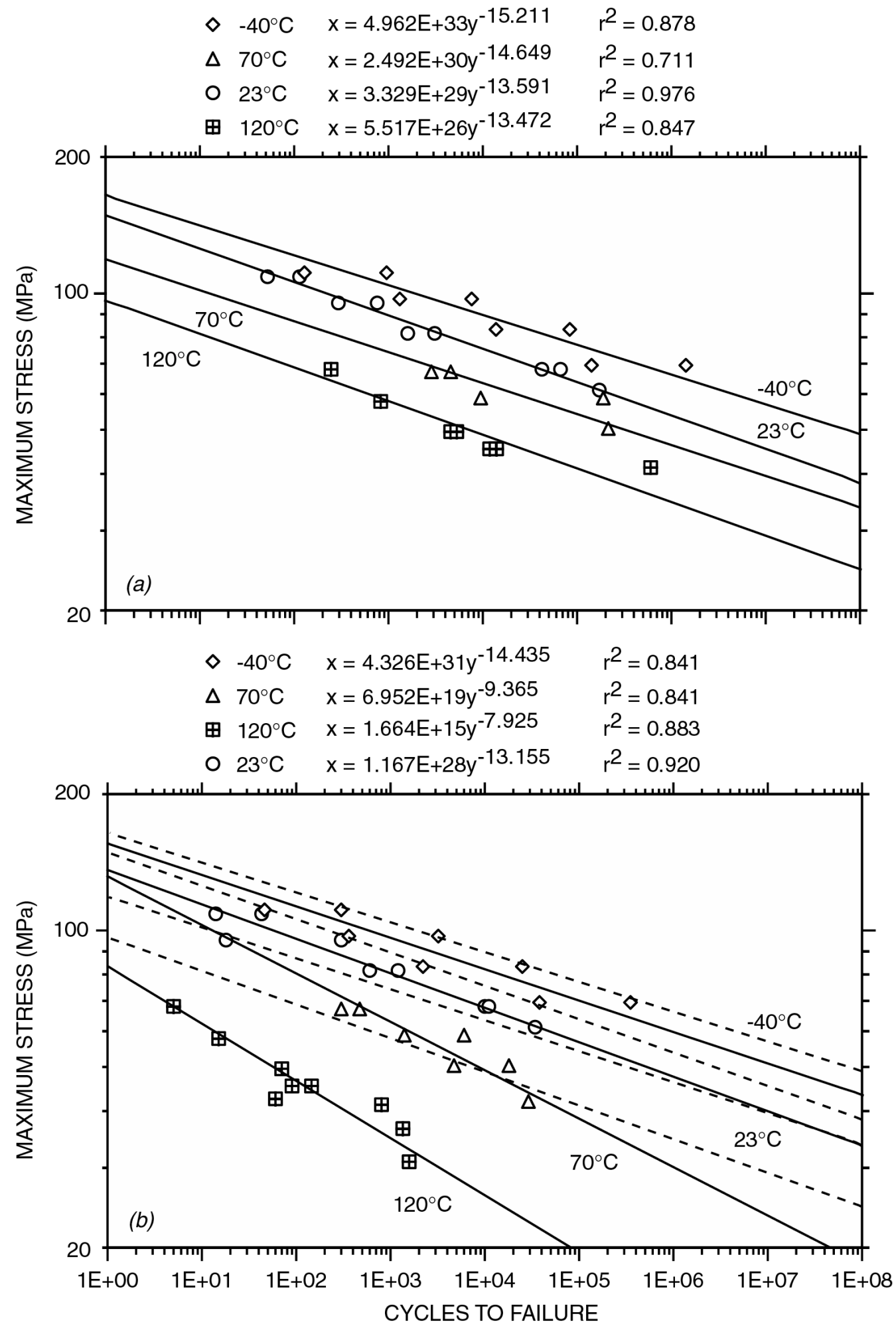

Fig. 9.11. Tensile fatigue curves for $\pm 45^{\circ}$ specimens (plaque C17) for various temperatures: (a) failure based on specimen separation or instability and $(b)$ failure based on $0.2 \%-$ offset definition (solid curves). The dashed curves are from $(a)$. 
ROOM-TEMPERATURE CURVES:

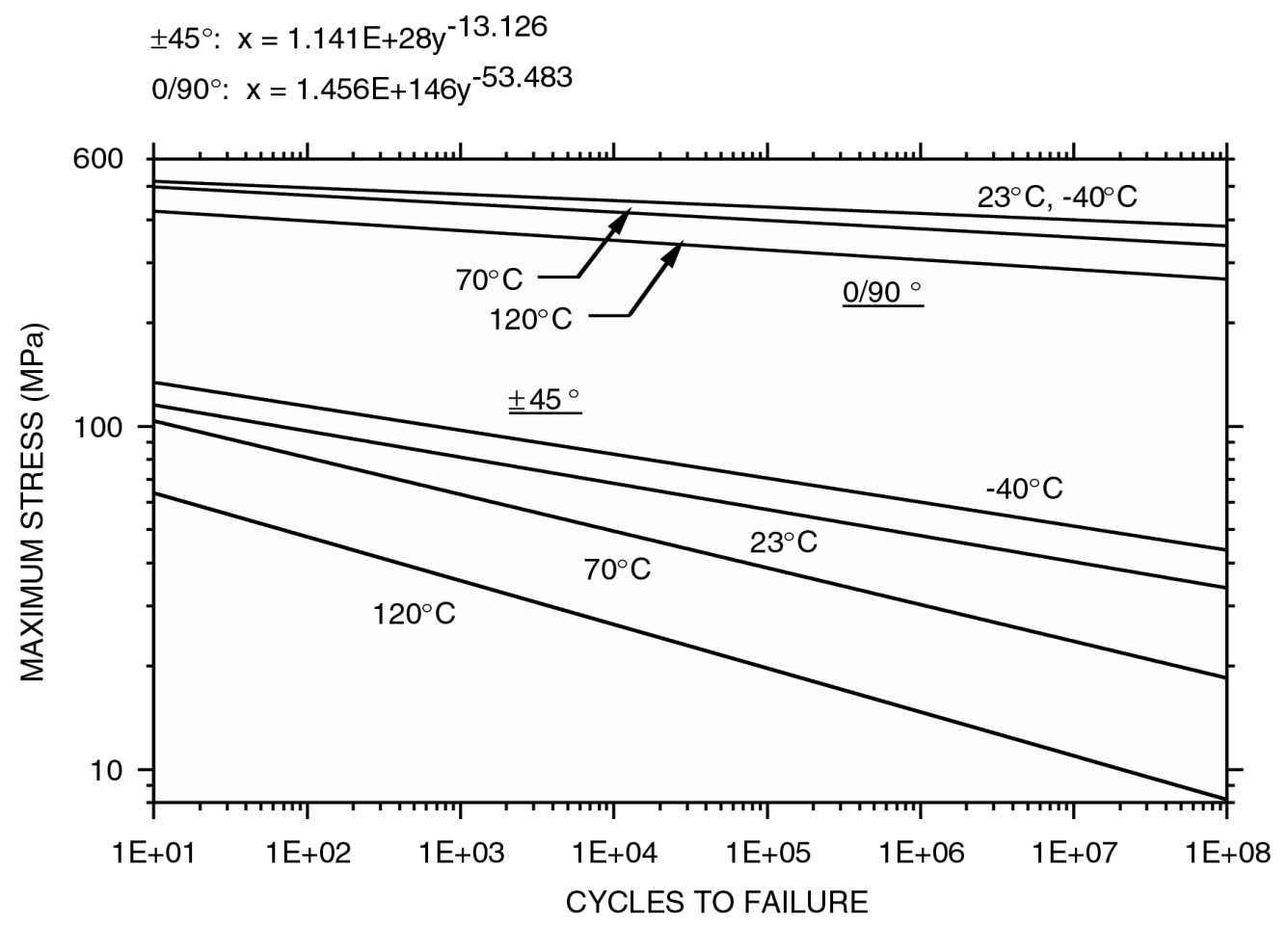

Fig. 9.12. Final tensile fatigue curves. The $\pm 45^{\circ}$ curves are based on the $0.2 \%$-offset procedure for determining failure [the $23^{\circ} \mathrm{C}$ curve is taken from Fig. 9.11(b)]. 

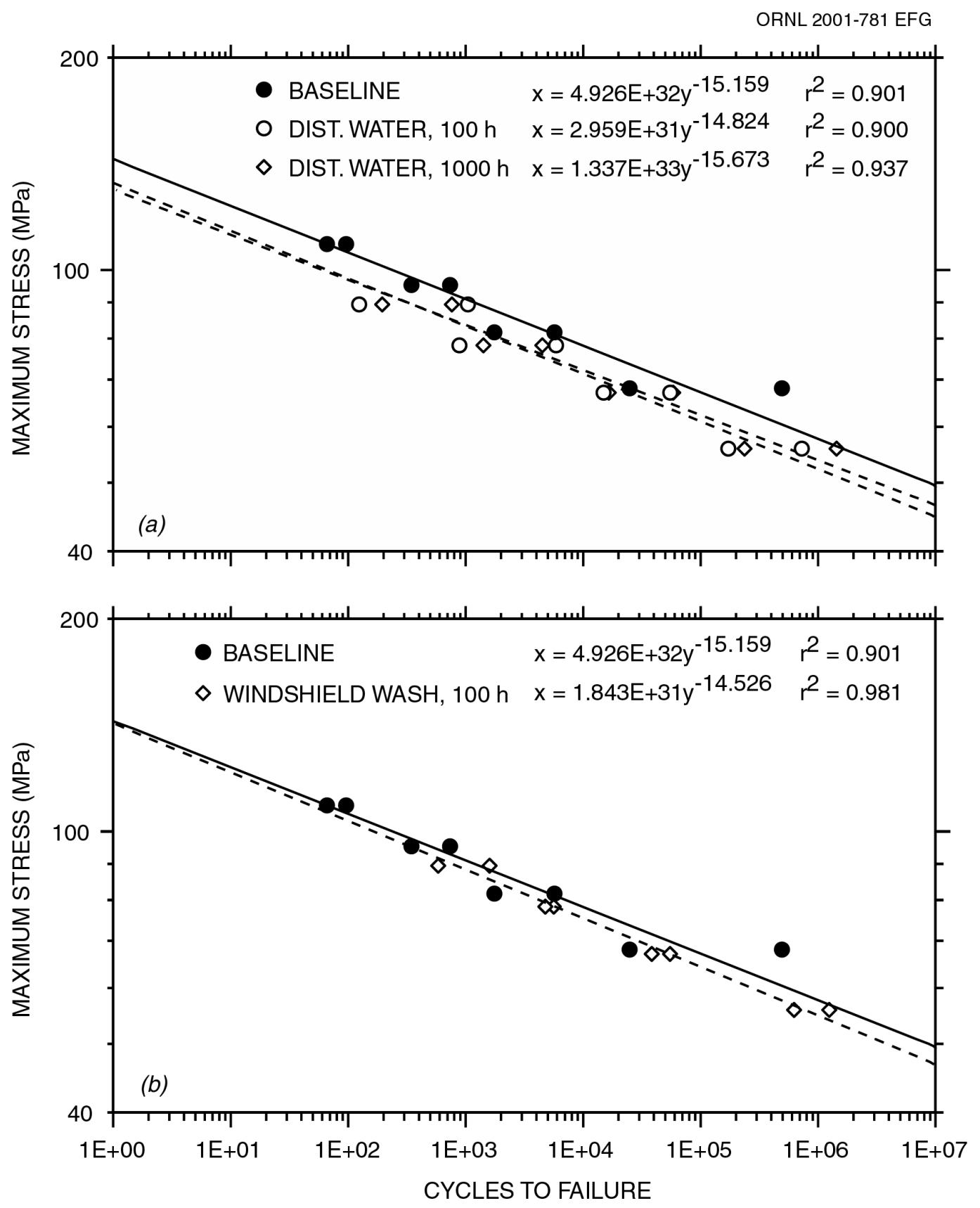

Fig. 9.13. Effects of fluids on room-temperature tensile fatigue strength of $\pm 45^{\circ}$ specimens. Failure is based on specimen separation: $(a)$ distilled water and $(b)$ windshield washer fluid. 


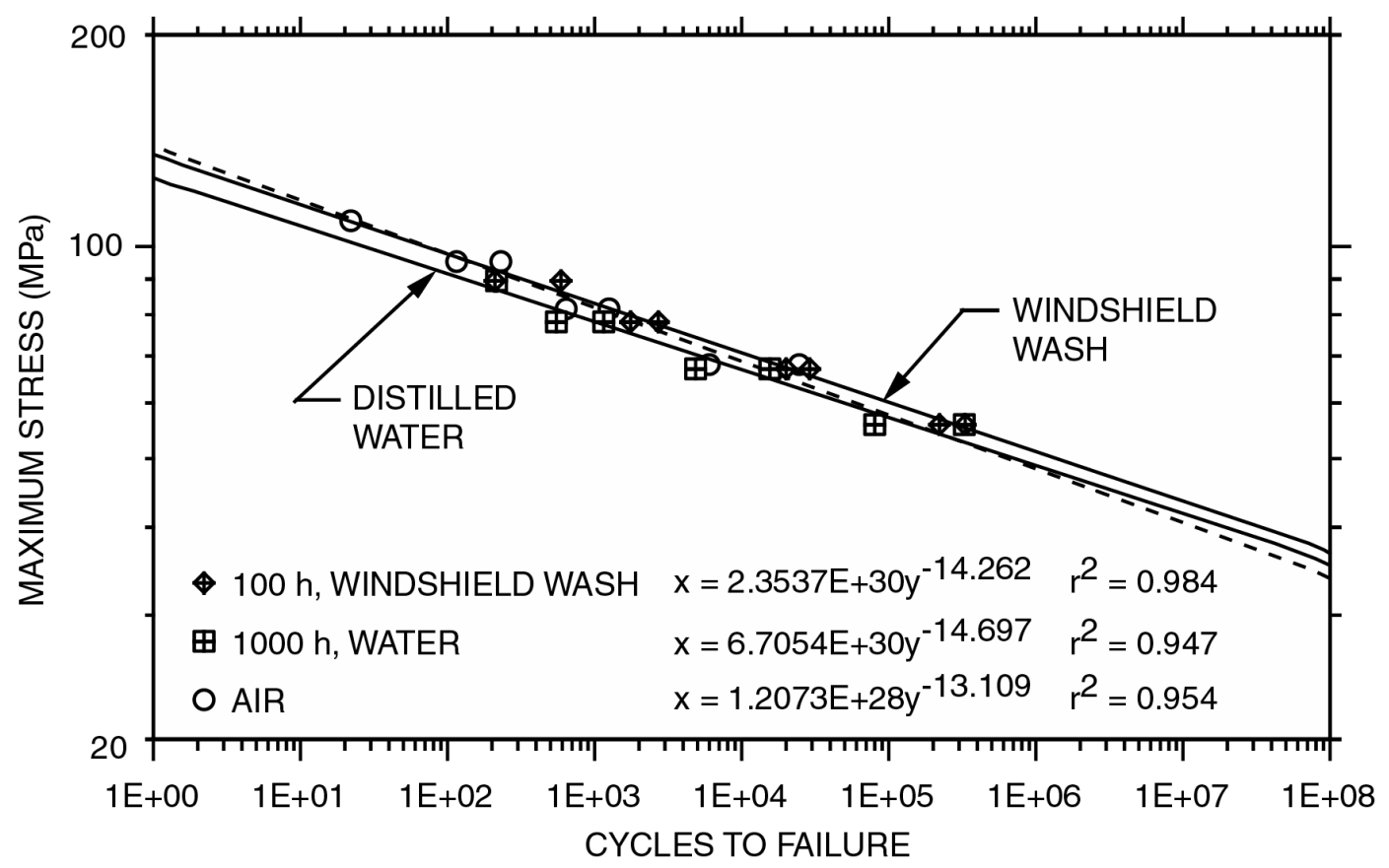

Fig. 9.14. Fluid effects in $\pm 45^{\circ}$ specimens based on $0.2 \%-$ offset failure definition.

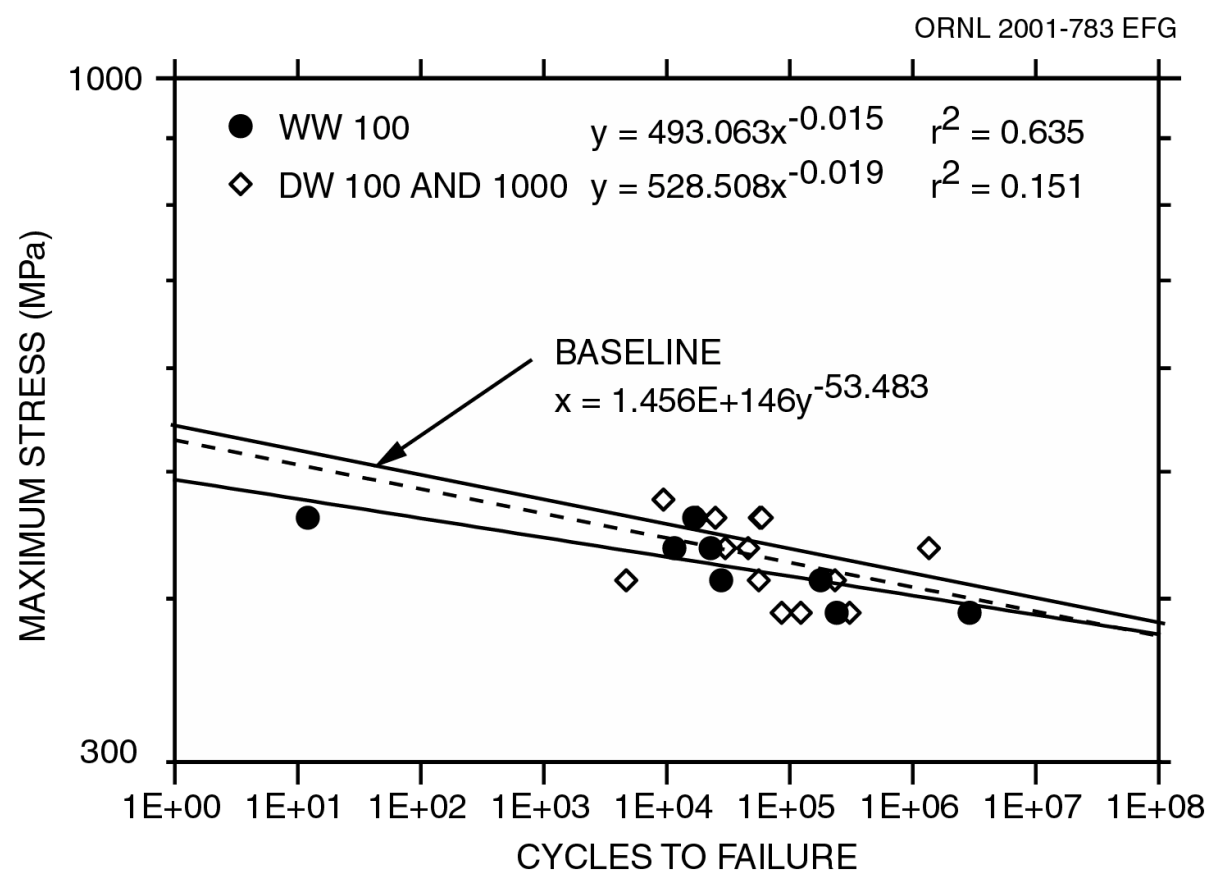

Fig. 9.15. Fluid effects in $\mathbf{0 / 9 0}{ }^{\circ}$ specimens. The dashed line represents distilled water, and the lower solid line represents windshield washer fluid. 
ORNL 2001-784 EFG
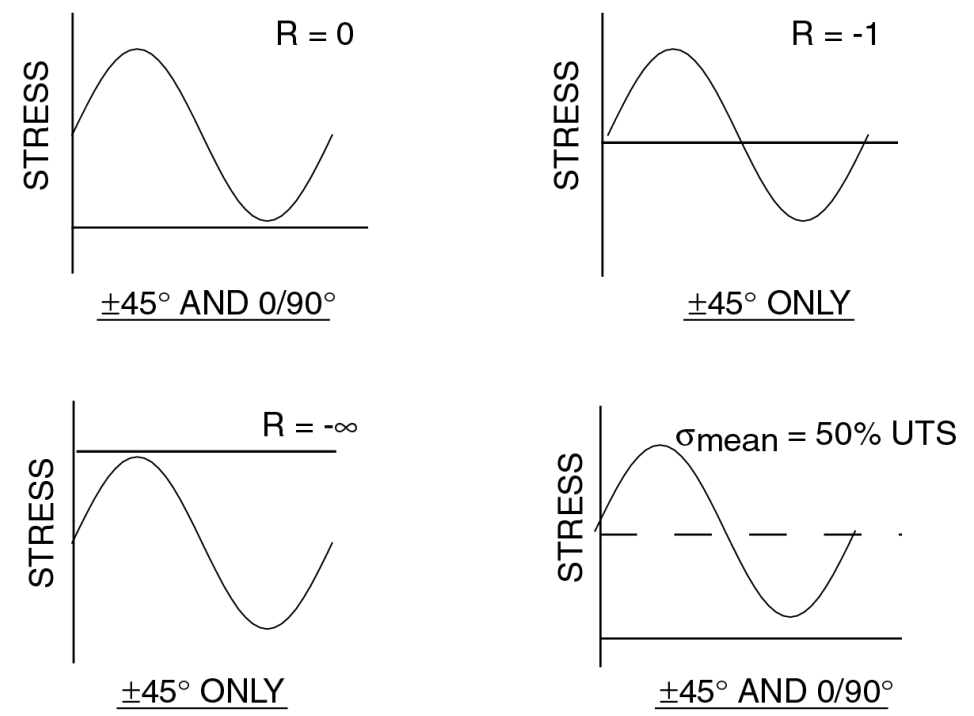

Fig. 9.16. Four cyclic stress histories used to examine mean stress effects. In the $\mathrm{R}=-\infty$ case, a few compression-compression tests with $\mathrm{R}=10$ were performed.

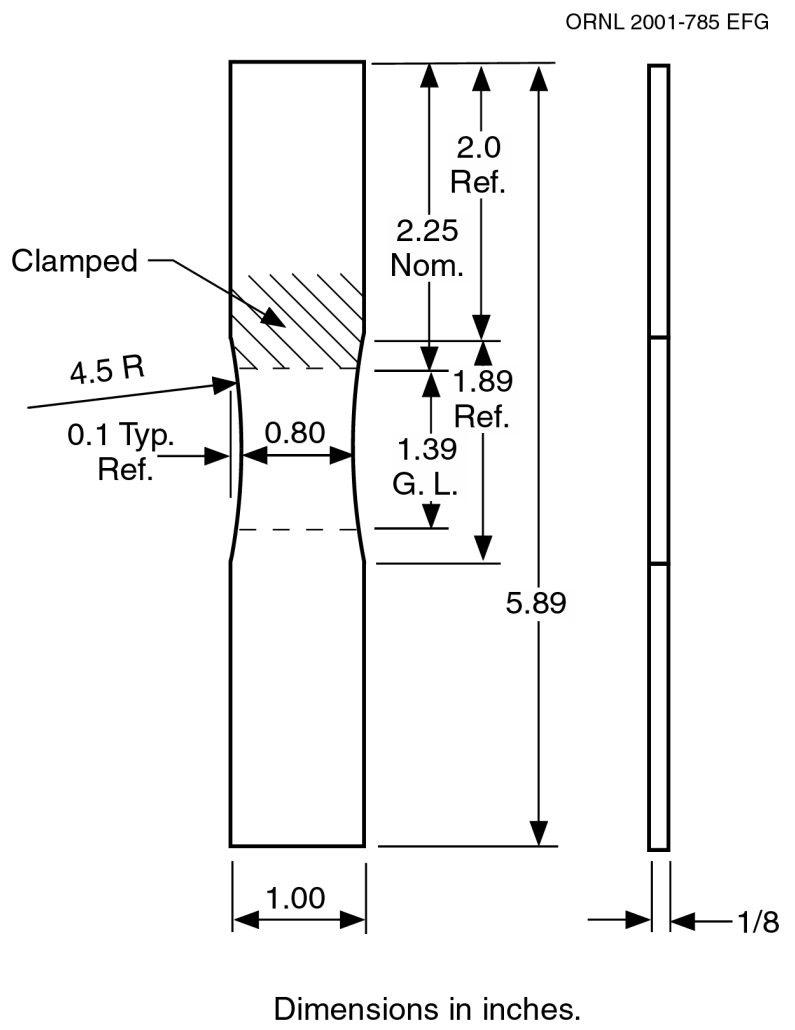

Fig. 9.17. Hourglass specimen configuration used for mean stress tests $(1 \mathrm{in} .=25.4 \mathrm{~mm})$. 


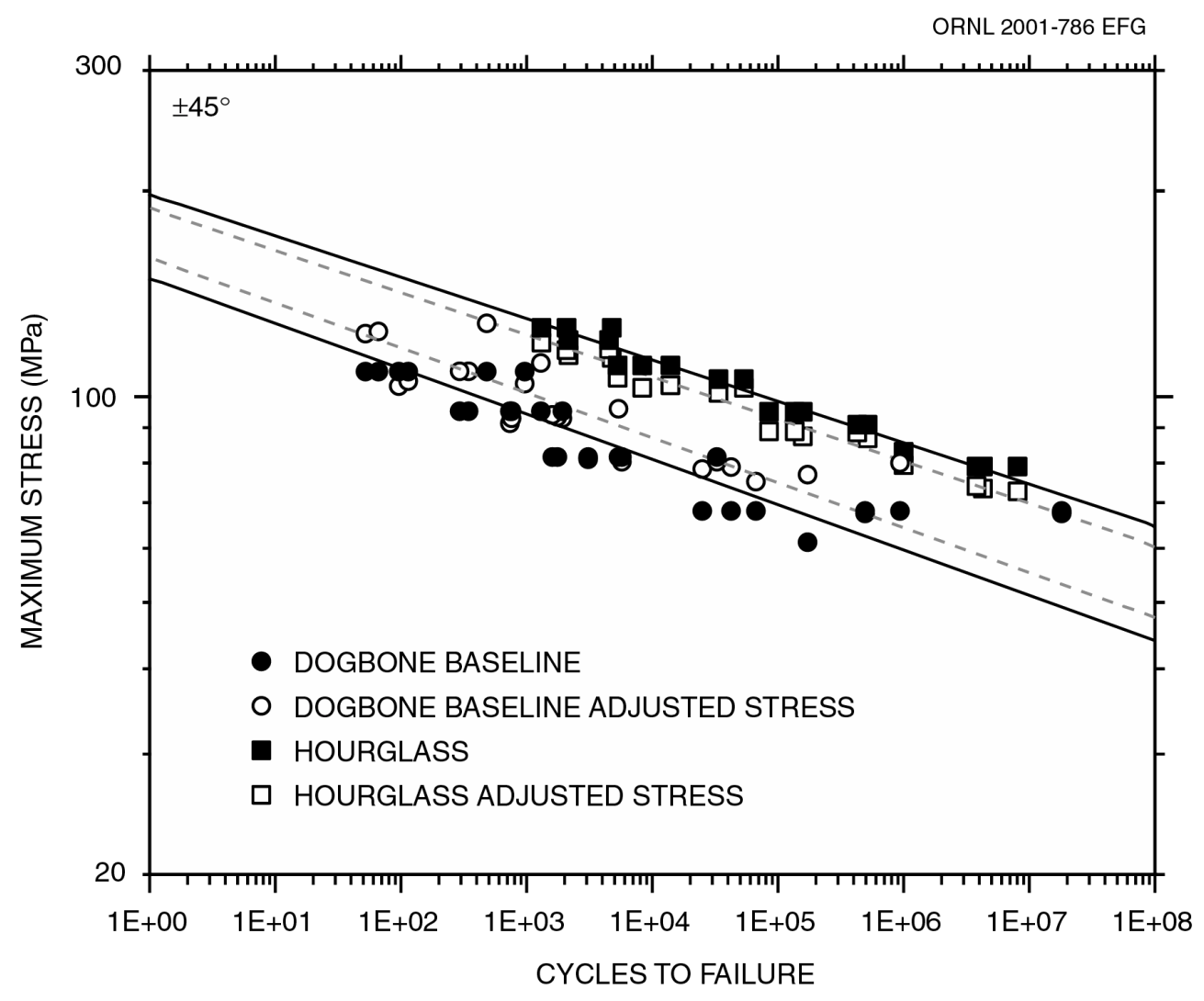

Fig. 9.18. Comparison of tensile fatigue curves $(R=0.1)$ generated using $\pm 45^{\circ}$ dogbone specimens and hourglass specimens. The dashed lines represent thicknessadjusted results. 


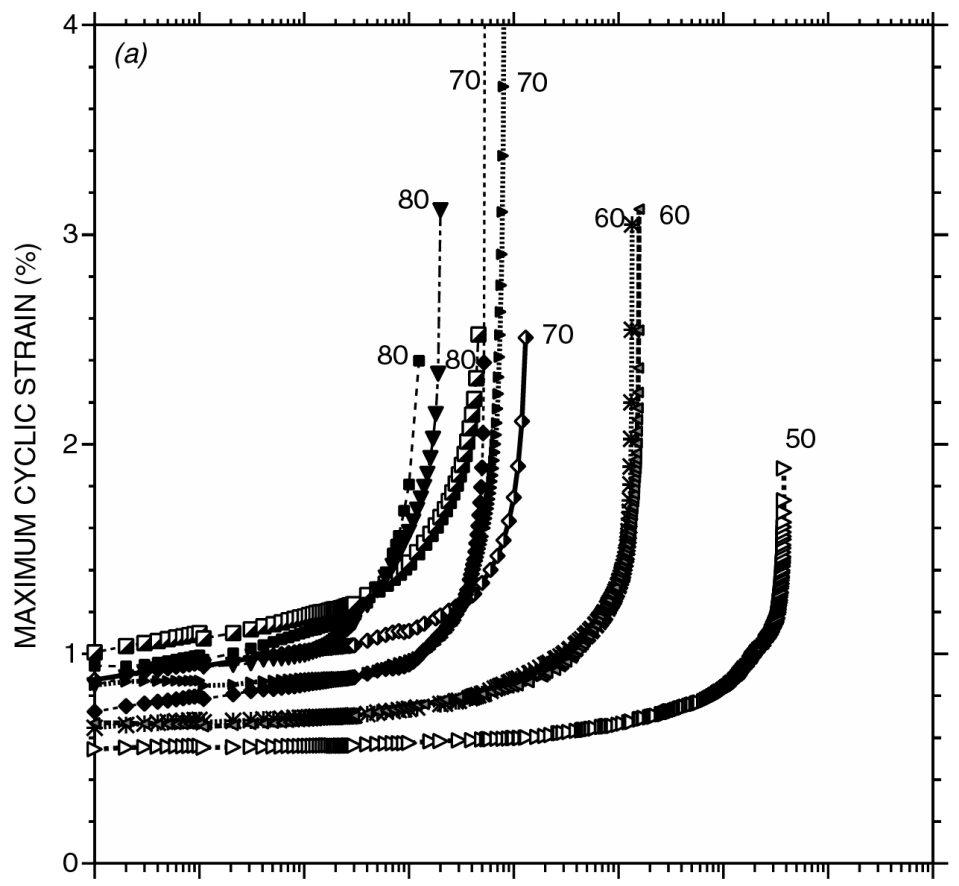

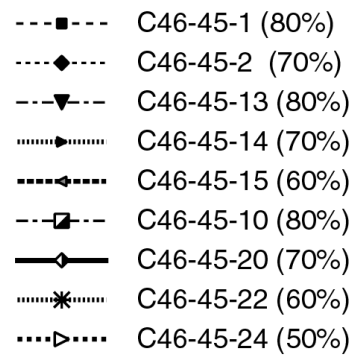

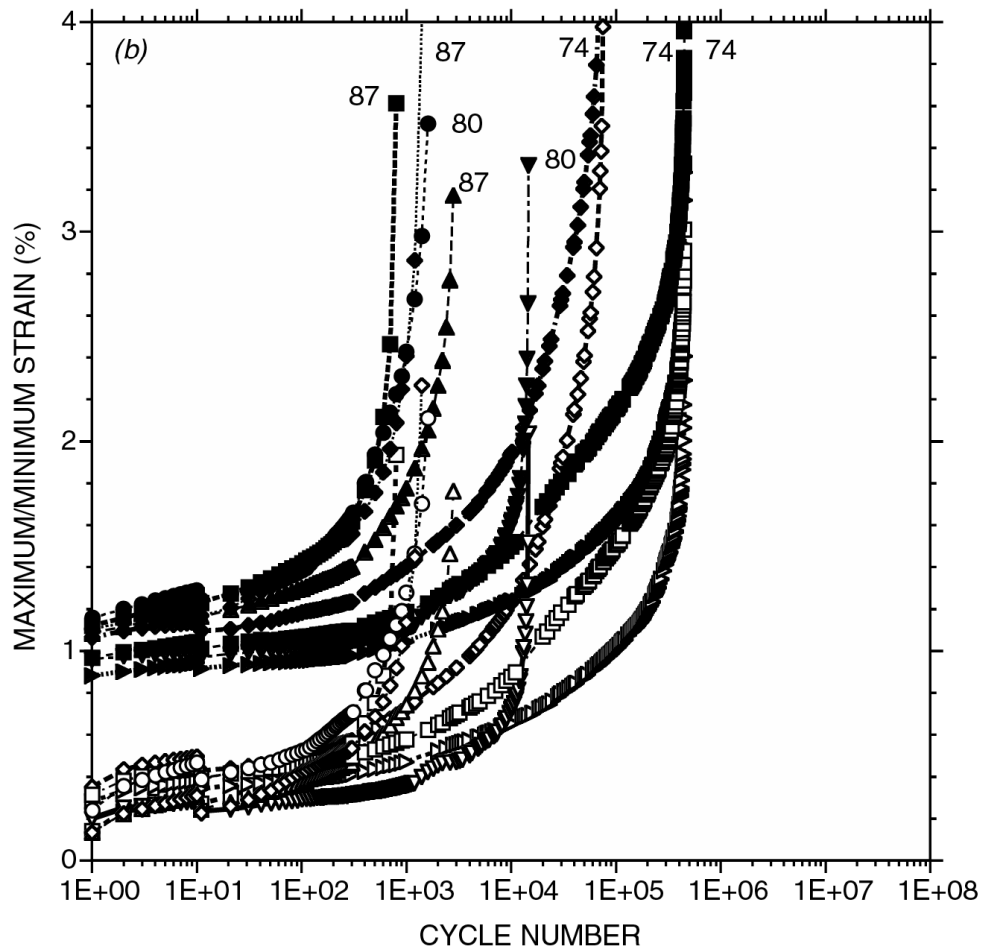

……… C46-45-5 MAX (87\%)

............... C46-45-5 MIN

...-.... C46-45-6 MAX (80\%)

....-... C46-45-6 MIN

---n--- C46-45-7 MAX (74\%)

-...-... C46-45-7 MIN

---A--- C46-45-17 MAX (87\%)

- - $\Delta$ - - C46-45-17 MIN

---7-- C46-45-18 MAX (80\%)

$\longrightarrow$ C46-45-18 MIN

C46-45-19 MAX (74\%)

........ C46-45-19 MIN

-.--n-... C46-45-21 MAX (87\%)

...-... C46-45-21 MIN

-..-... C46-45-11 MAX (74\%)

- $\diamond-. . \quad$ C46-45-11 MIN

Fig. 9.19. Maximum strain vs cycle number for $\pm 45^{\circ}$ specimens undergoing tensile cycling: (a) $\mathrm{R}=\mathbf{0}$, and (b) $50 \%$ UTS mean stress. 


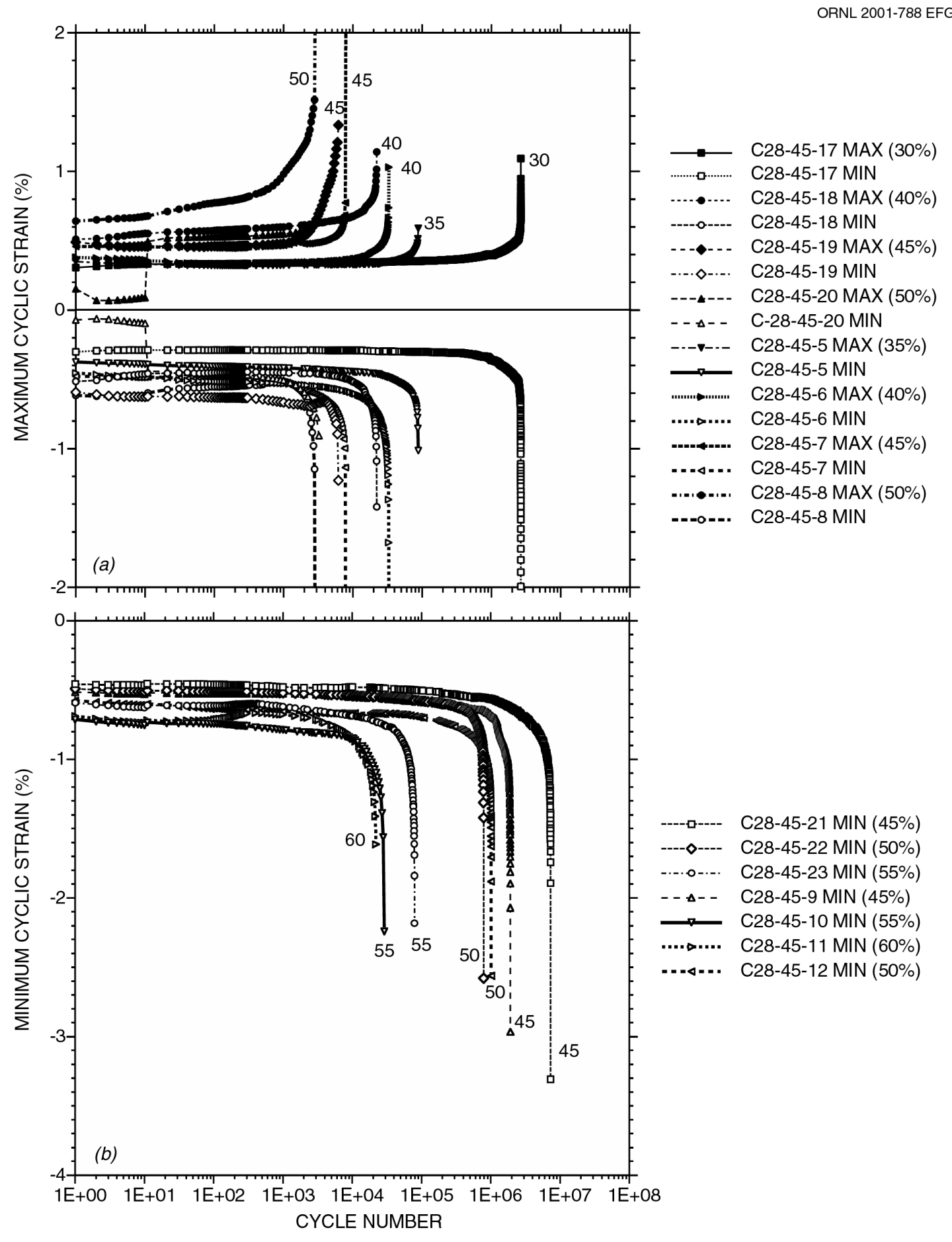

Fig. 9.20. Maximum strain vs cycle number for $\pm 45^{\circ}$ specimens undergoing cycling involving compressive stresses: (a) reversed fatigue $R=-1$, and (b) $R=-\infty$ and 10 . 

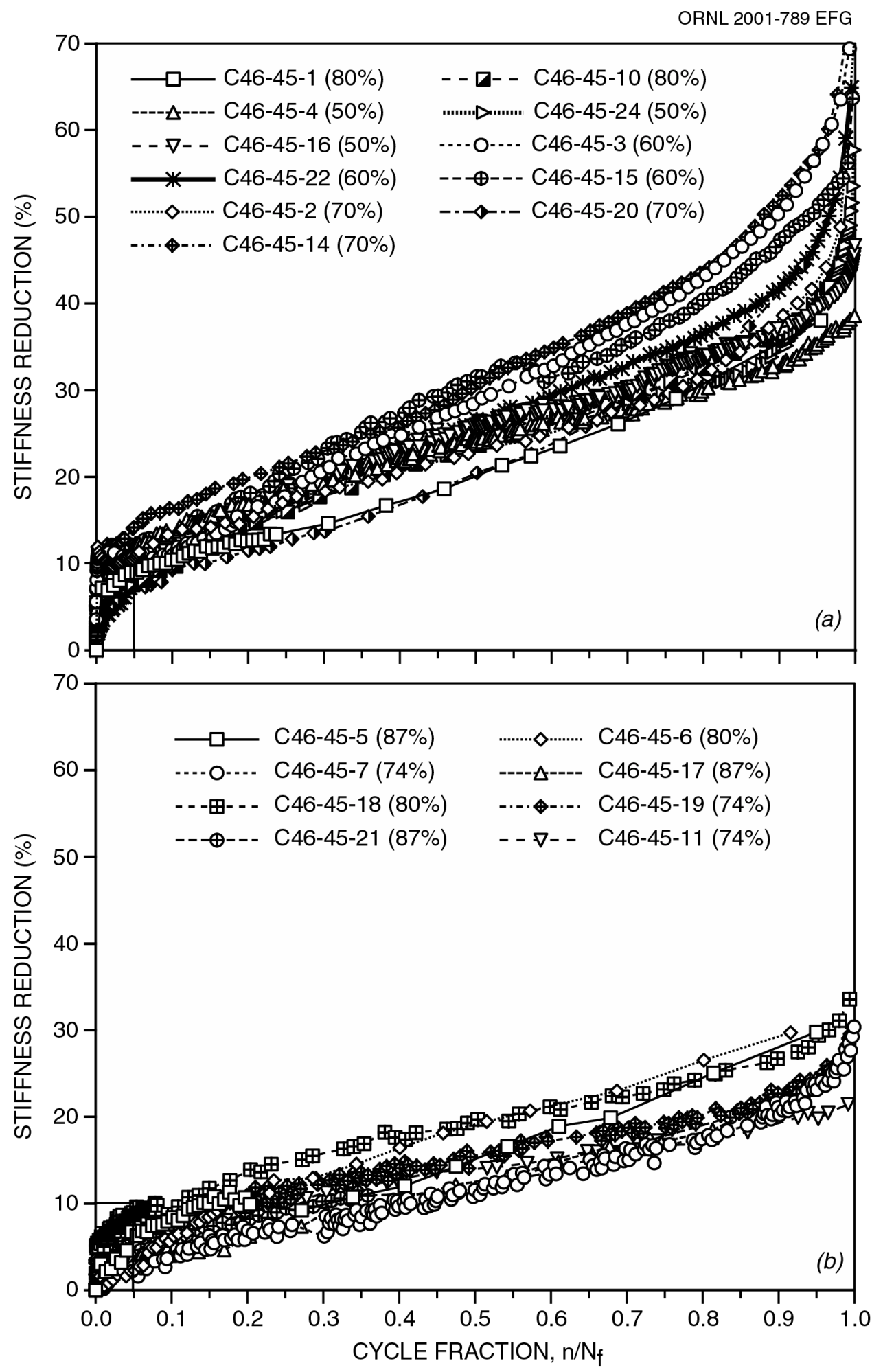

Fig. 9.21. Stiffness loss vs cycle fraction, $n / \mathbf{N}_{f}$, in $\pm 45^{\circ}$ specimens undergoing tensile cycling: (a) $\mathrm{R}=\mathbf{0}$, and (b) $50 \%$ UTS mean stress. 

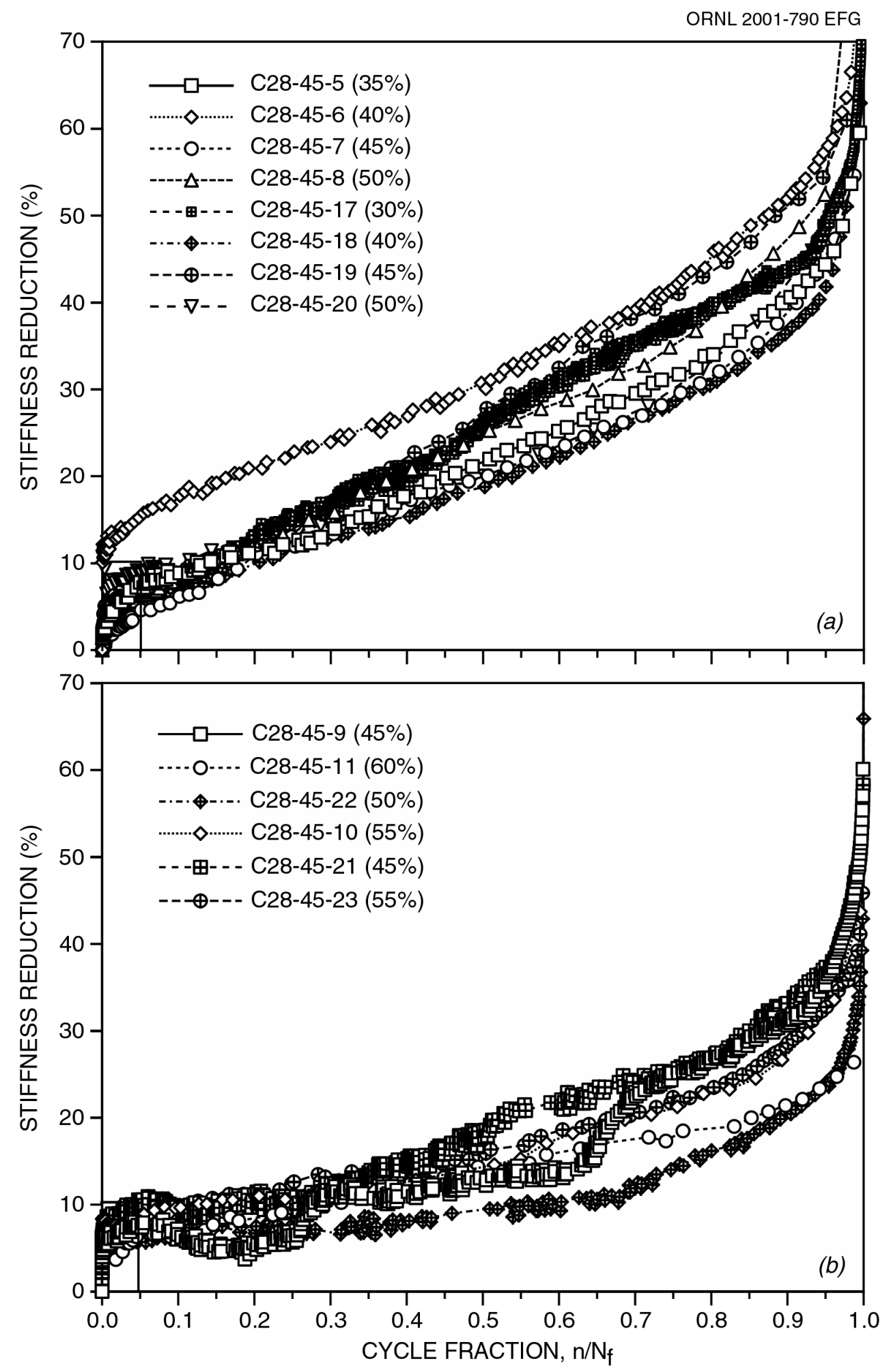

Fig. 9.22. Stiffness loss vs cycle fraction, $n / \mathbf{N}_{\mathbf{f}}$, in $\pm 45^{\circ}$ specimens undergoing cycling involving compressive stresses: $(a) R=-1$, and $(b) R=-\infty$ or 10 . 


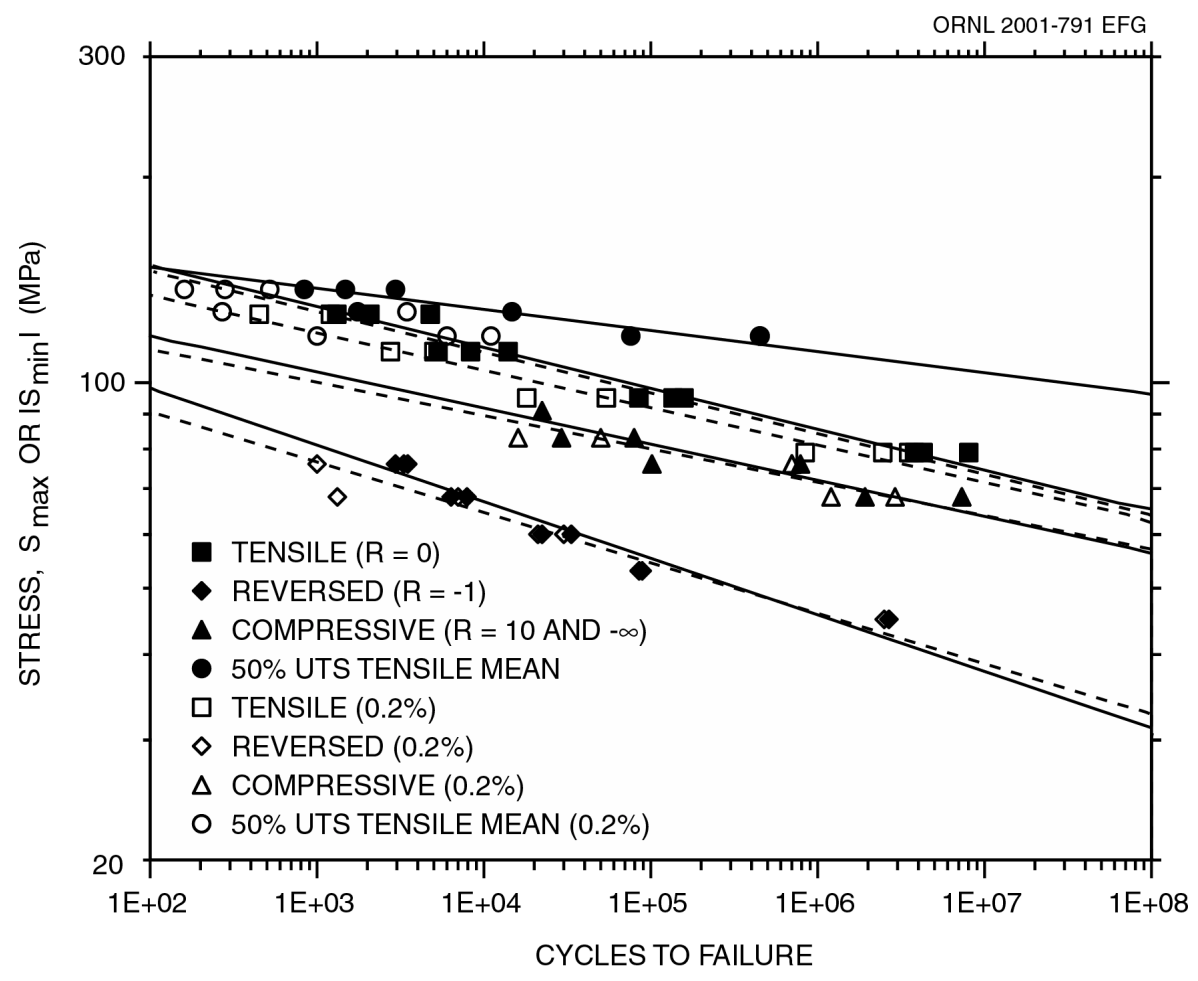

Fig. 9.23. Mean stress fatigue results for $\pm 45^{\circ}$ specimens correlated using maximum (or absolute value of minimum) stress in cycle.

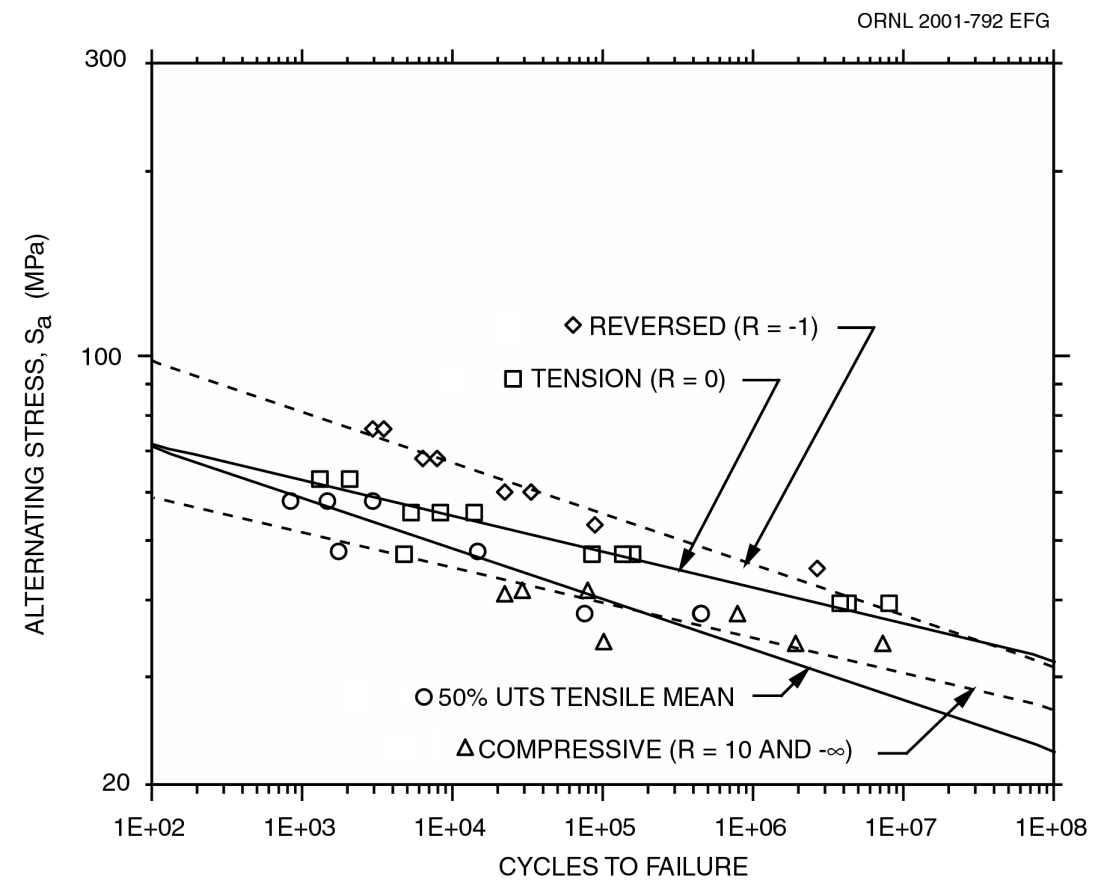

Fig. 9.24. Mean stress fatigue results for $\pm 45^{\circ}$ specimens correlated using alternating stress component. The usual definition of failure (instability or separation) is employed. 


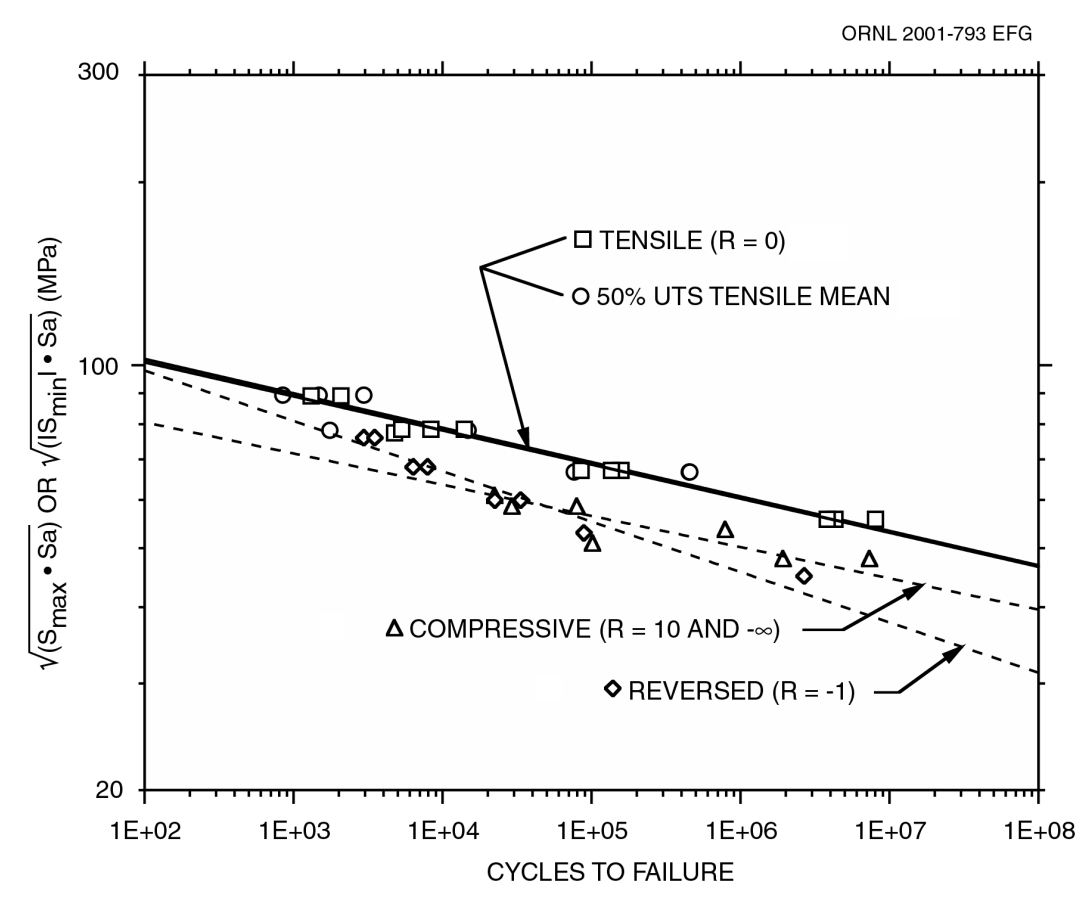

Fig. 9.25. Mean stress fatigue results for $\pm 45^{\circ}$ specimens correlated using stress parameter $\sqrt{S_{\max } \times S_{a}}$ or $\sqrt{\left|S_{\max }\right| \times S_{a}}$. The usual definition of failure (instability or separation) is employed.

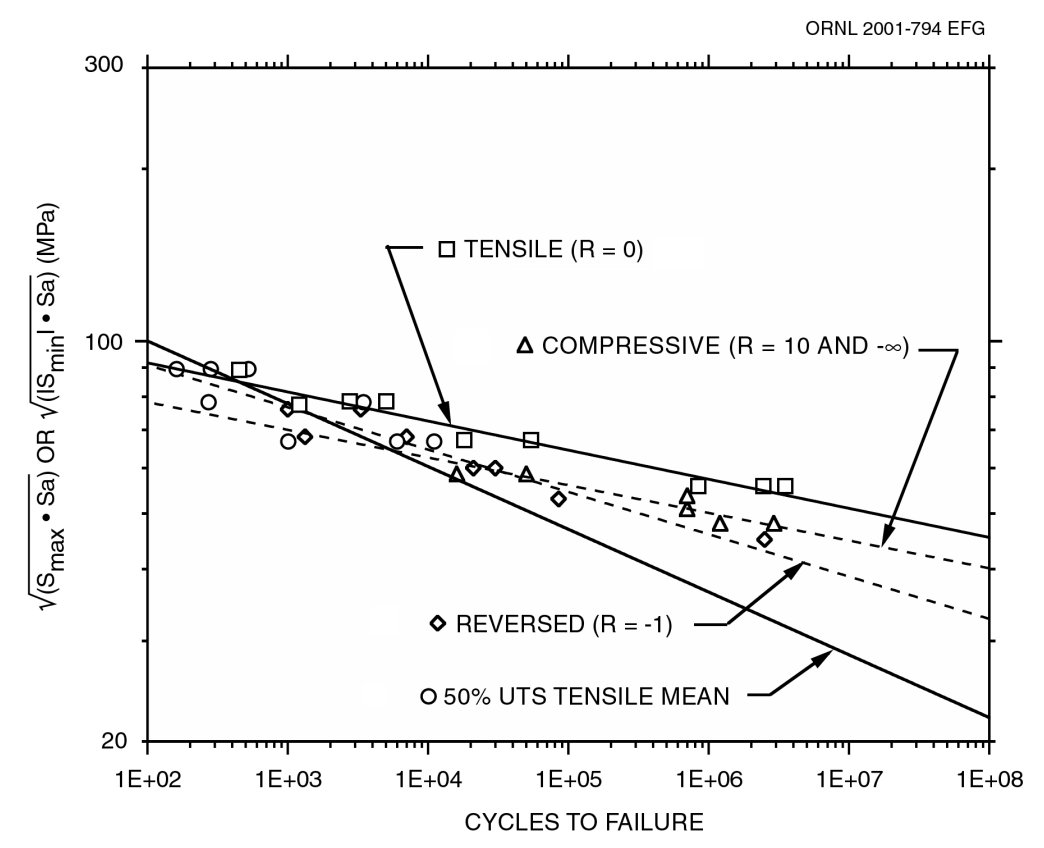

Fig. 9.26. Mean stress fatigue results for $\pm 45^{\circ}$ specimens

correlated using stress parameter $\sqrt{S_{\max } \times S_{a}}$ or $\sqrt{\left|S_{\max }\right| \times S_{a}}$ with failure defined by the $0.2 \%-$ offset method. 


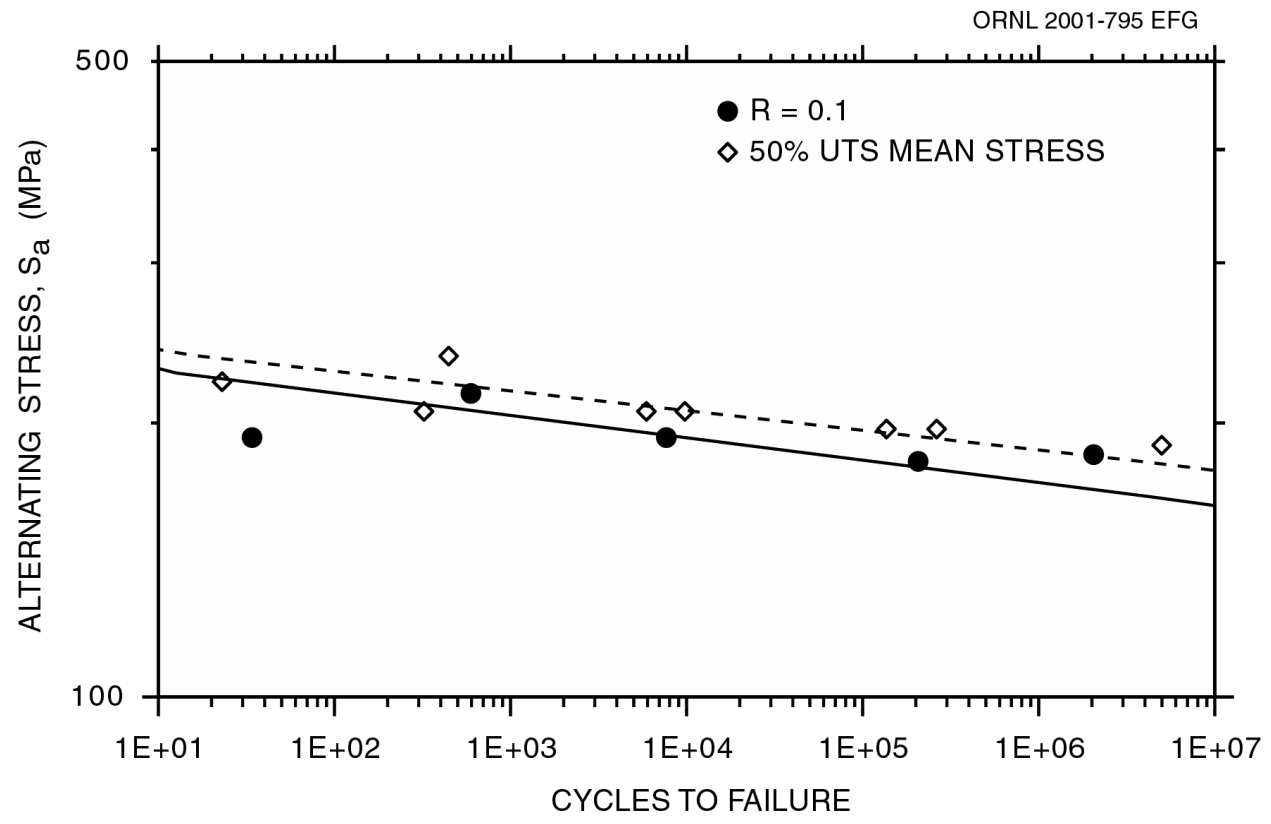

Fig. 9.27. Mean stress fatigue results for $0 / 90^{\circ}$ specimens correlated using alternating stress component $S_{\mathbf{a}}$. 


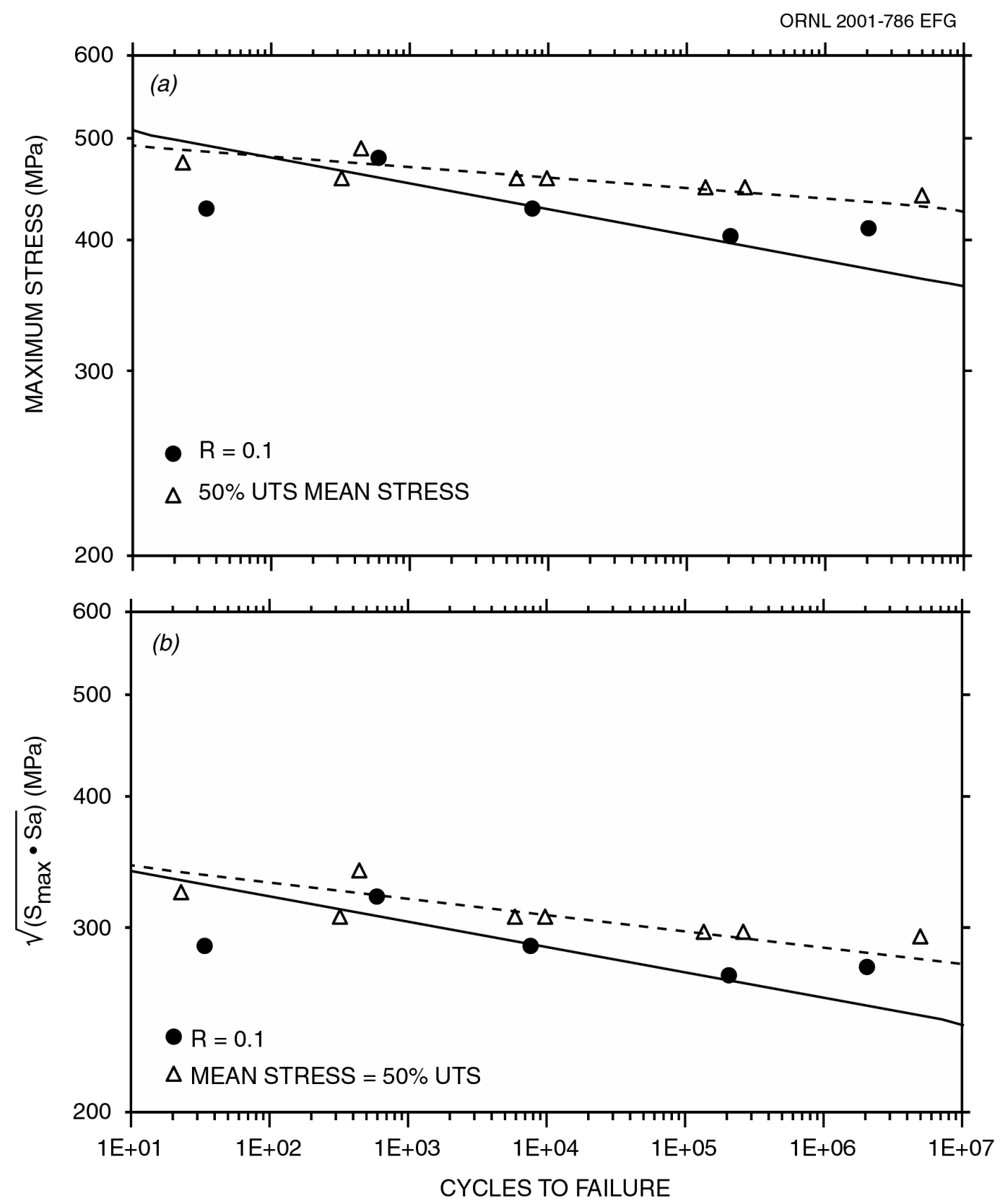

Fig. 9.28. Mean stress fatigue results for $0 / 90^{\circ}$ specimens correlated using other stress parameters: (a) $S_{\max }$ and (b) $\sqrt{S_{\max } \times S_{a}}$. 


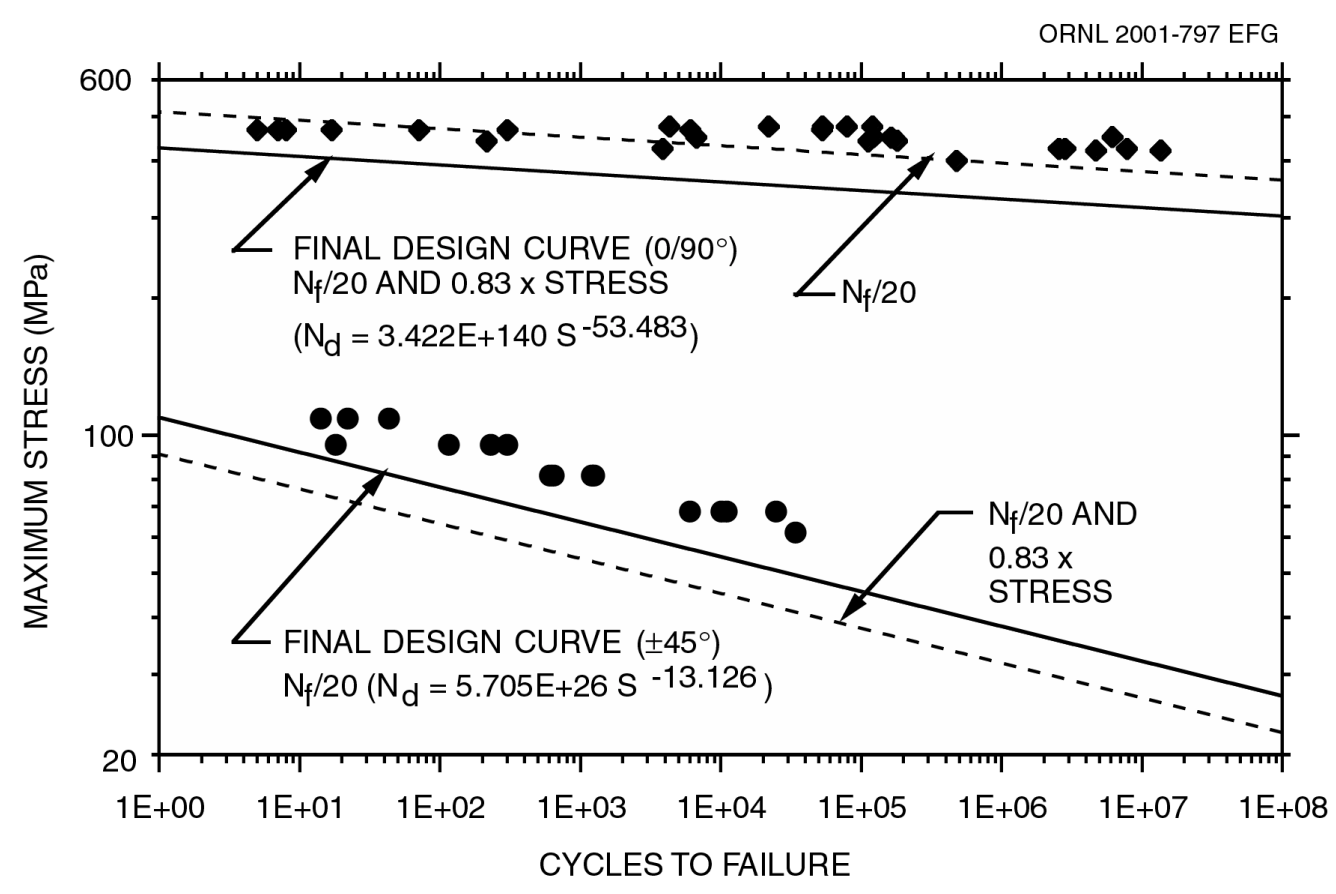

Fig. 9.29. Room-temperature fatigue design curves for tension $(R=0)$ cycling. 


\title{
10. CREEP DEFORMATION
}

\author{
K. C. Liu
}

This is a summary of two series of tensile creep tests on the reference carbon-fiber composite. Results of the first series, although limited in scope and exploratory in nature, were reported previously, and baseline information was established. ${ }^{15}$ In the second series, several of the previous tests were duplicated for examining the reproducibility of the data using specimens from a different plaque mold run and for identifying problem areas that needed effective remedies. Details of the tests performed in each series are tabulated in Tables 10.1 and 10.2.

Two fiber orientations are addressed: $0 / 90^{\circ}$ relative to the specimen axis and $\pm 45^{\circ}$. These orientations result in two extremes in behavior.

Table 10.1. Summary of test parameters and results of creep and creep-rupture tests in first test series (mold-run TBC)

\begin{tabular}{|c|c|c|c|c|c|c|c|}
\hline $\begin{array}{c}\text { Specimen } \\
\text { No. }\end{array}$ & $\begin{array}{l}\text { Stress } \\
\text { (MPa) }\end{array}$ & $\begin{array}{c}\text { Thickness } \\
\text { (mm) }\end{array}$ & $\begin{array}{c}\text { Loading } \\
\text { strain } \\
(\%)\end{array}$ & $\begin{array}{c}\text { Creep } \\
\text { strain } \\
(\%)\end{array}$ & $\begin{array}{c}\text { Time } \\
\text { tested } \\
\text { (h) }\end{array}$ & $\begin{array}{c}\text { Rupture } \\
\text { life } \\
\text { (h) }\end{array}$ & Notes \\
\hline \multicolumn{8}{|c|}{$0 / 90^{\circ}$ Fiber orientation } \\
\hline C2-5 & 100 & 3.157 & 0.2 & 0.0247 & 6290 & & Test discontinued \\
\hline C2-31 & 100 & 3.18 & 0.19 & 0.025 & 5636 & & Test discontinued \\
\hline C2-30 & 200 & 3.152 & 0.38 & 0.0383 & 5763 & & Test discontinued \\
\hline C2-33 & 200 & 3.249 & 0.419 & 0.0226 & 5621 & & Test discontinued \\
\hline C2-15 & 300 & 3.101 & 0.56 & 0.0677 & 6248 & & Test discontinued \\
\hline C2-34 & 300 & 3.265 & 0.61 & 0.065 & 5617 & & Test discontinued \\
\hline C2-6 & 400 & 3.173 & 0.78 & 0.1 & & 7.74 & Failed $^{a}$ \\
\hline C2-7 & 400 & 3.18 & 0.786 & 0.0681 & 8835 & & Test discontinued \\
\hline C2-8 & 400 & 3.197 & 0.825 & 0.093 & & 4641 & Failed $^{a}$ \\
\hline C2-35 & 400 & 3.302 & 0.787 & 0.0862 & 5214 & & Test discontinued \\
\hline C2-13 & 450 & 3.048 & 0.8 & 0.11 & 6914 & & Test discontinued \\
\hline C2-14 & 450 & 3.073 & 0.86 & 0.067 & & 87.01 & Failed $^{a}$ \\
\hline C2-16 & 470 & 3.124 & 0.83 & 0.07 & & 2597.5 & Failed $^{a}$ \\
\hline \multicolumn{8}{|c|}{ $\pm 45^{\circ}$ Fiber orientation } \\
\hline C6-9 & 25 & 3.302 & 0.208 & 0.1079 & 5718 & & Test discontinued \\
\hline C6-28 & 25 & 3.556 & 0.227 & 0.1153 & 3173 & & Test discontinued \\
\hline C6-48 & 25 & 3.962 & 0.25 & 0.2332 & 4855 & & Test discontinued \\
\hline C6-8 & 50 & 3.277 & 0.42 & 0.4717 & 2712 & & Test discontinued \\
\hline C6-38 & 50 & 3.708 & 0.46 & 0.67 & 5810 & & Test discontinued \\
\hline C6-7 & 75 & 3.251 & 0.67 & 1.95 & 4905 & & Test discontinued \\
\hline C6-39 & 75 & 3.759 & 0.913 & 2.015 & 5791 & & Test discontinued \\
\hline C6-5 & 100 & 3.20 & 1.41 & $>4.7$ & 6241 & & Test discontinued \\
\hline C6-27 & 100 & 3.531 & & & & 146.4 & Rupture test only $a, b$ \\
\hline C6-40 & 100 & 3.81 & 1.53 & 2.78 & & 4.61 & Failed $^{a}$ \\
\hline C6-41 & 100 & 3.81 & 1.62 & 4.54 & & 20.2 & Failed $^{a}$ \\
\hline C6-25 & 103 & 3.531 & & & & 27.1 & Rupture test only $a, b$ \\
\hline C6-24 & 107 & 3.505 & & & & 0.22 & Rupture test only $a, b$ \\
\hline
\end{tabular}

$a_{\text {Data used in Chap. } 11 .}$

$b_{\text {No strain measurement. }}$ 
Table 10.2. Summary of test parameters and results of creep and creep-rupture tests in second test series (mold-run DEV)

\begin{tabular}{|c|c|c|c|c|c|c|c|c|}
\hline $\begin{array}{c}\text { Specimen } \\
\text { No. }\end{array}$ & $\begin{array}{l}\text { Stress } \\
(\mathrm{MPa})\end{array}$ & $\begin{array}{c}\text { Temperature/ } \\
\text { environment/ } \\
\text { loading }\end{array}$ & $\begin{array}{c}\text { Thickness } \\
\text { (mm) }\end{array}$ & $\begin{array}{c}\text { Loading } \\
\text { strain } \\
\text { (\%) }\end{array}$ & $\begin{array}{c}\text { Creep } \\
\text { strain } \\
(\%)\end{array}$ & $\begin{array}{l}\text { Time } \\
\text { tested } \\
\text { (h) }\end{array}$ & $\begin{array}{c}\text { Rupture } \\
\text { life } \\
\text { (h) }\end{array}$ & Notes \\
\hline \multicolumn{9}{|c|}{ 0/90 ${ }^{\circ}$ Fiber orientation } \\
\hline C22-20 & 100 & $23^{\circ} \mathrm{C}$ & 2.946 & 0.191 & 0.0083 & 7445 & & Test discontinued \\
\hline C22-21 & 200 & $23^{\circ} \mathrm{C}$ & 2.972 & 0.362 & 0.0178 & 7654 & & Test discontinued \\
\hline C22-18 & 300 & $23^{\circ} \mathrm{C}$ & 2.946 & 0.567 & 0.0338 & 7156 & & Test discontinued \\
\hline C22-22 & 400 & $23^{\circ} \mathrm{C}$ & 2.946 & 0.711 & 0.0484 & 7484 & & $\begin{array}{l}\text { Not ruptured but } \\
\text { cracks visible }^{a}\end{array}$ \\
\hline C22-23 & 430 & $23^{\circ} \mathrm{C}$ & 2.972 & 0.718 & 0.1060 & 1672 & & $\begin{array}{l}\text { Not ruptured but } \\
\text { cracks visible }^{a}\end{array}$ \\
\hline C22-17 & 450 & $23^{\circ} \mathrm{C}$ & 2.946 & 0.819 & 0.0164 & & 0.042 & $\begin{array}{l}\text { Ruptured by } \\
\text { separation }^{a}\end{array}$ \\
\hline C22-15 & 200 & $70^{\circ} \mathrm{C}$ & 2.946 & 0.354 & 0.0227 & 3906 & & Test discontinued \\
\hline C22-13 & 300 & $70^{\circ} \mathrm{C}$ & 2.946 & 0.550 & 0.0367 & 4200 & & Test discontinued \\
\hline C22-12 & 400 & $70^{\circ} \mathrm{C}$ & 2.946 & 0.738 & 0.0650 & & 693 & $\begin{array}{l}\text { Ruptured by } \\
\text { separation }^{a}\end{array}$ \\
\hline C22-34 & 200 & $120^{\circ} \mathrm{C}$ & 2.972 & 0.396 & 0.1050 & 1799 & & Test discontinued \\
\hline C22-35 & 300 & $120^{\circ} \mathrm{C}$ & 2.946 & 0.572 & 0.5190 & & 0.391 & $\begin{array}{l}\text { Ruptured by } \\
\text { separation }\end{array}$ \\
\hline \begin{tabular}{|l|}
$\mathrm{C} 22-31$ \\
\end{tabular} & 200 & $23^{\circ} \mathrm{C}-\mathrm{H}_{2} \mathrm{O}$ & 2.946 & 0.329 & \begin{tabular}{|l|}
0.0467 \\
\end{tabular} & 4902 & & Test discontinued \\
\hline C22-30 & 300 & $23^{\circ} \mathrm{C}-\mathrm{H}_{2} \mathrm{O}$ & 2.946 & 0.582 & 0.1050 & 2916 & & Test discontinued \\
\hline C22-32 & 300 & $23^{\circ} \mathrm{C}-\mathrm{H}_{2} \mathrm{O}$ & 2.946 & 0.565 & 0.0752 & 1706 & & Test discontinued \\
\hline C22-16 & 300 & $23^{\circ} \mathrm{C}-\mathrm{WWF}$ & 2.946 & 0.541 & 0.1090 & 1516 & & Test discontinued \\
\hline C23-17 & 200 & $23^{\circ} \mathrm{C}$ & 3.150 & 0.420 & 0.0143 & 7078 & & Test discontinued \\
\hline C23-16 & 300 & $23^{\circ} \mathrm{C}$ & 3.124 & 0.590 & 0.0371 & 7922 & & Test discontinued \\
\hline C23-18 & 400 & $23^{\circ} \mathrm{C}$ & 3.124 & 0.726 & 0.0481 & & 766 & $\begin{array}{l}\text { Ruptured by } \\
\text { separation }^{a}\end{array}$ \\
\hline C23-20D & -250 & $23^{\circ} \mathrm{C}-\mathrm{Comp}$ & 3.124 & 0.503 & 0.0196 & & 133 & $\begin{array}{l}\text { Delaminated and } \\
\text { fractured }\end{array}$ \\
\hline C23-20C & -300 & $23^{\circ} \mathrm{C}-\mathrm{Comp}$ & 3.124 & 0.641 & 0.0155 & & 0.0017 & $\begin{array}{l}\text { Specimen } \\
\text { buckled }\end{array}$ \\
\hline C23-21D & -300 & $23^{\circ} \mathrm{C}-$ Comp & 3.099 & & & & & $\begin{array}{l}\text { Delaminated and } \\
\text { fractured }\end{array}$ \\
\hline C23-20E & -350 & $23^{\circ} \mathrm{C}-\mathrm{Comp}$ & 3.099 & 0.764 & \begin{tabular}{|l|}
0.0410 \\
\end{tabular} & & 0.014 & $\begin{array}{l}\text { Specimen } \\
\text { buckled }\end{array}$ \\
\hline \multicolumn{9}{|c|}{ $\pm 45^{\circ}$ Fiber orientation } \\
\hline \begin{tabular}{|l|} 
C24-7 \\
\end{tabular} & 50 & $23^{\circ} \mathrm{C}$ & 2.921 & 0.350 & 0.3180 & 4007 & & Test discontinued \\
\hline C24-2 & 75 & $23^{\circ} \mathrm{C}$ & 2.870 & 0.670 & 0.9370 & 8291 & & Test discontinued \\
\hline C24-27 & 87.5 & $23^{\circ} \mathrm{C}$ & 2.896 & 0.763 & 1.3640 & 7086 & & Test discontinued \\
\hline C24-4 & 100 & $23^{\circ} \mathrm{C}$ & 2.921 & 0.862 & 2.0530 & 6362 & & $\begin{array}{r}\text { Specimen } \\
\text { cracked }^{a}\end{array}$ \\
\hline C24-26 & 125 & $23^{\circ} \mathrm{C}$ & 2.921 & 1.481 & 1.0930 & & 0.0147 & $\begin{array}{r}\text { Ruptured by } \\
\text { separation }\end{array}$ \\
\hline C24-28 & 50 & $70^{\circ} \mathrm{C}$ & 2.896 & 0.520 & 1.3900 & 4239 & & Test discontinued \\
\hline C24-50 & 75 & $70^{\circ} \mathrm{C}$ & 2.921 & 0.926 & 2.6800 & 3026 & & $\begin{array}{l}\text { Not ruptured but } \\
\text { cracked }\end{array}$ \\
\hline
\end{tabular}


Table 10.2. (continued)

\begin{tabular}{|l|c|l|c|c|c|c|c|c|}
\hline $\begin{array}{l}\text { Specimen } \\
\text { No. }\end{array}$ & $\begin{array}{c}\text { Stress } \\
\mathbf{( M P a})\end{array}$ & $\begin{array}{c}\text { Temperature/ } \\
\text { environment/ } \\
\text { loading }\end{array}$ & $\begin{array}{c}\text { Thickness } \\
\mathbf{( m m )}\end{array}$ & $\begin{array}{c}\text { Loading } \\
\mathbf{s t r a i n} \\
\mathbf{( \% )}\end{array}$ & $\begin{array}{c}\text { Creep } \\
\text { strain } \\
\mathbf{( \% )}\end{array}$ & $\begin{array}{c}\text { Time } \\
\text { tested } \\
\mathbf{( h )}\end{array}$ & $\begin{array}{c}\text { Rupture } \\
\text { life } \\
\mathbf{( h )}\end{array}$ & Notes \\
\hline \multicolumn{7}{|c|}{$\mathbf{\pm 4 5}$ Fiber orientation } \\
\hline $\mathbf{C 2 4 - 1 2}$ & 87.5 & $70^{\circ} \mathrm{C}$ & 2.997 & 1.384 & 0.8900 & 3386 & & $\begin{array}{c}\text { Not ruptured but } \\
\text { delaminated }\end{array}$ \\
\hline $\mathbf{C 2 4 - 4 8}$ & 37.5 & $120^{\circ} \mathrm{C}$ & 2.946 & 1.030 & 2.9000 & 1707 & & Test discontinued \\
\hline $\mathbf{C 2 4 - 8}$ & 50 & $120^{\circ} \mathrm{C}$ & 2.946 & 2.216 & & & 111.5 & $\begin{array}{l}\text { Severely } \\
\text { delaminated }\end{array}$ \\
\hline $\mathbf{C 2 4 - 4 9}$ & 75 & $120^{\circ} \mathrm{C}$ & 2.921 & & 0.0000 & & 0 & $\begin{array}{c}\text { Failed just after } \\
\text { loading } a\end{array}$ \\
\hline $\mathbf{C 2 4 - 6}$ & 50 & $23^{\circ} \mathrm{C}-\mathrm{H}_{2} \mathrm{O}$ & 2.921 & 0.372 & 0.8340 & 4492 & & Test discontinued \\
\hline $\mathbf{C 2 4 - 9}$ & 75 & $23^{\circ} \mathrm{C}-\mathrm{WWF}$ & 2.946 & 0.679 & 1.7250 & 1388 & & Test discontinued \\
\hline $\mathbf{C 2 4 - 2 7 C}$ & 87.5 & $23^{\circ} \mathrm{C}-\mathrm{Comp}$ & 2.896 & 0.802 & 1.7000 & 3570 & & Test discontinued \\
\hline $\mathbf{C 2 4 - 2 7} \mathbf{E}$ & 100 & $23^{\circ} \mathrm{C}-\mathrm{Comp}$ & 2.896 & 1.217 & 2.2100 & 3602 & & Test discontinued \\
\hline
\end{tabular}

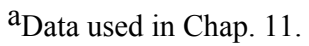

Specimens having the same fiber orientation but fabricated from plaques of different mold runs exhibited significant differences in creep behavior. Therefore, two creep models were proposed for each fiber orientation, differing only by a mold-run factor (MRF). Most of the tests were performed in tension, but a limited number of tests were performed in compression. Specimens were also tested at elevated temperatures $\left(70^{\circ} \mathrm{C}\right.$ and $120^{\circ} \mathrm{C}$ in air) and in distilled water or in windshield washer fluid ( $70 \mathrm{vol} \%$ alcohol $/ 30 \mathrm{vol} \%$ water). Changes in relative humidity (RH) in the test laboratory were found to have strong influences on the as-acquired small creep strains in the $0 / 90^{\circ}$ direction. Therefore, the $0 / 90^{\circ}$ data from the series 2 tests were normalized to a $50 \%$ $\mathrm{RH}$ condition. To facilitate understanding of the creep deformation, a method is introduced to take into account the effects of variation in fiber volume and specimen thickness on creep data.

\subsection{SPECIMENS AND TEST PROCEDURE}

\subsubsection{Material and Specimens}

As previously discussed, the material was supplied by ACC in the nominal size of $610 \times$ $610 \times 3$-mm-thick plaques. However, some variations in plaque thickness were found, leading to complicated variations in creep responses. The plaques used in the creep experiments came from two different molding runs, designated by ACC as TBC and DEV with average fiber volume contents of $41.1 \%$ and $39.0 \%$, respectively. The first series of tests used TBC specimens; the second series, DEV specimens. The fiber misalignment was measured to be about $2^{\circ}$ to $3^{\circ}$ in the $\mathrm{TBC}$ plaques and $7^{\circ}$ to $8^{\circ}$ in the DEV plaques. It is not clear whether the stacking order of the fiber reinforcement had a significant effect on the in-plane creep properties. However, it may be of some value to note that a symmetric stacking order of the reinforcement, $\left( \pm 45^{\circ}\right)_{3 \mathrm{~S}}$, was used in the DEV plaques, and an unsymmetrical one, $\left( \pm 45^{\circ}\right)_{6 \mathrm{~T}}$, was used in the TBC plaques.

Tensile creep specimens were fabricated from the plaques in a dogbone-shape having a nominal 25.4-mm width and 203-mm length with a $20.3-\mathrm{mm}$ wide reduced gage section and a 42-mm uniform length. Two types of specimens were made, with the longitudinal axis aligned either in the $0 / 90^{\circ}$ or in the $\pm 45^{\circ}$ fiber orientation. Specimens from TBC plaques with a $\mathrm{C} 2$ prefix 
(ORNL designation) have the $0 / 90^{\circ}$ fiber orientation, and those with a C6 prefix, the $\pm 45^{\circ}$ orientation. No end tabs were bonded on the specimens for reinforcement. Tabbed specimens, as shown in Fig. 10.1, were made from the DEV plaques and used in the second series of tests to avoid gripping failures. Tabs were bonded with a high-temperature adhesive for $120^{\circ} \mathrm{C}$ testing. Specimens from DEV plaques with a C22 or C23 prefix have the $0 / 90^{\circ}$ fiber orientation, and $\mathrm{C} 24$, the $\pm 45^{\circ}$ orientation.

Short rectangular specimens, 25.4-mm wide by $32-\mathrm{mm}$ long, were used in compressive creep testing. They were sectioned from straight-sided specimen blanks cut from the C23 and C24 plaques with the fibers oriented in the $0 / 90^{\circ}$ and $\pm 45^{\circ}$ directions, respectively.

\subsubsection{Experiments}

Creep tests were performed on lever-arm type creep machines. To transmit the tensile load to the specimen, the specimen ends were sandwiched between a set of steel shackles and clamped with steel bolts. A short section of steel file with ripple-shaped teeth was inserted between the specimen and shackles to prevent slippage when the specimen was loaded. The far ends of the shackles were drilled to receive a pin to make a pin-clevis linkage for connection to the pull rod assembly. A complete gripping assembly is shown in Fig. 10.2.

In the first series of tests, creep strain was measured using a single strain gage mounted on one side of the specimen. As stated earlier, the fiber reinforcement was unsymmetrical in plaques $\mathrm{C} 2$ and $\mathrm{C} 6$. For $0 / 90^{\circ}$ specimens, the single strain gage was generally bonded on the surface where the first fiber layer was in the $0^{\circ}$ direction. Thus, the gage and the closest fibers to the surface were parallel. In a few cases, the single strain gage was attached to the surface where the first fiber layer was in the $90^{\circ}$ direction. This may have had some effect on the indicated strain.

Effort was made to load every specimen at a preset strain rate of $0.04 / \mathrm{min}$, but this was not always achieved in the first test series due to the limitations of the mechanical load elevator used to lower the deadweights onto the load pans of the lever-arm creep machines. This problem was rectified, and the loading strain rate was controlled within $\pm 5 \%$ of $0.04 / \mathrm{min}$ in the second series with the use of an electrohydraulic feedback-controlled elevator.

In the second series of tests, all tensile specimens were fabricated from the DEV plaques, which have a lower average fiber content. A few compressive creep specimens were fabricated from the $\mathrm{C} 24$ plaques in the $\pm 45^{\circ}$ orientation. The DEV plaques were not very flat. Most of the C24 tensile specimens showed a bow of as much as $3 \mathrm{~mm}$ off the midplane, but the C22 specimens were not as bowed. Two strain gages were bonded back to back on the specimen surfaces at midlength. The half bridge circuit cancels the bending effect due to the load column misalignment and the initial loading. The dual strain gages were used in the compressive creep tests also.

Tests at elevated temperatures were accomplished with heating tape, which heated the specimen indirectly via a pair of thin aluminum plates $(25 \mathrm{~mm}$ by $80 \mathrm{~mm})$, facing parallel to each side of the specimen with a clearance of about $4 \mathrm{~mm}$ (see Fig. 10.2). A thin, flat-headed, type $\mathrm{K}$ thermocouple was attached to the gage section of the specimen with a fiberglass patch.

Figure 10.3 shows a heating tape coiling around the aluminum plates. To minimize the heat loss and maintain a steady test temperature for the specimen, the whole heating assembly was wrapped with three layers of fiberglass cloth. For elevated temperature testing, strain gages having a zero self-temperature compensation (STC) were used and bonded with a hightemperature epoxy adhesive.

A special Plexiglas cup (40-mm ID by $80-\mathrm{mm}$ long) with a narrow slit opening in a silicon rubber bottom was built around the specimen gage section for testing in fluid, as shown in Fig. 10.4. A silicon rubber lid kept the container full with only infrequent refills. The strain gages were waterproofed with a thin coat of soft rubber. 
To perform compression creep tests in the lever-arm creep machines, the test fixture shown in Fig. 10.5 was used. It consists of two heavy circular platens as a pair of compression anvils, connected to upper and lower pull rods. This fixture has been successfully used to test short cylindrical specimens in compression. However, some difficulties were experienced in keeping the thin-walled specimen from buckling, especially at high temperature. To improve the specimen stability, each end of the specimen was held in a grooved supporting block. Nevertheless, specimen buckling continued to be a problem at high compressive loads.

\subsection{BASELINE CREEP}

\subsubsection{Room-Temperature, In-Air Tensile Deformation}

The creep data are complicated due to the variations in fiber volume, specimen thickness, and fiber orientation. Without a rational physically based benchmark for reference, fair and meaningful comparisons of creep properties cannot be achieved. First, note that applied loads used in the experiments were based on the minimum cross section of the specimen, with no consideration of the proportion of individual constituents. Therefore, for a given stress level, a lower applied load yielded lower creep strains for a thinner specimen than did the higher load required for a thicker specimen having the same fiber content. A good normalization value should be based on applied load per number of fibers.

Because a relative value of applied load per number of fibers for a given specimen with respect to that of a selected reference specimen is of interest, the product of the thickness and fiber-volume percentage will be used because the applied load is proportional to the respective specimen thickness.

Derivation of Table 10.3 is self-explanatory. It shows normalization ratios of $\mathrm{L} / \mathrm{F}_{\mathrm{n}}$ with respect to plaque $\mathrm{C} 22$. The value was used to normalize the as-acquired creep data from C6-specimens. The ratios for $\mathrm{C} 23$ and $\mathrm{C} 24$ were judged to be sufficiently close to a value of 1.00 , which did not warrant normalization.

Figure 10.6 shows creep data reported previously for plaque $\mathrm{C} 2^{16}$ and those for plaque $\mathrm{C} 22$ and $\mathrm{C} 23$ specimens tested at room temperature in air. Plaques $\mathrm{C} 22$ and $\mathrm{C} 23$ are seen to be more creep resistant than plaque $\mathrm{C} 2$. At first look, it was noticed that the $\mathrm{C} 22$ specimens were in general thinner than the $\mathrm{C} 2$ specimens by about 7\%; therefore, less load was applied to the former than to the latter, and less applied load in turn yielded less creep strain. However, that theory was quickly discounted because the applied load per number of fibers was the same for both plaques, according to Table 10.3. On the basis of the ratio of applied load per number of fibers, the $\mathrm{C} 22$

Table 10.3. Interplaque normalization ratios

\begin{tabular}{|c|c|c|c|c|c|c|}
\hline Plaques & $\begin{array}{c}\begin{array}{c}\text { Average } \\
\text { thickness, } t \\
(\mathbf{m m})\end{array} \\
\end{array}$ & $\begin{array}{c}\text { Fiber } \\
\text { volume, } \mathbf{F}_{\mathbf{v}} \\
(\%)\end{array}$ & $\begin{array}{c}\text { Fiber } \\
\text { content } \\
\mathbf{F}_{\mathbf{n}}=\mathbf{t} \times \mathbf{F}_{\mathbf{V}}\end{array}$ & $\operatorname{Load}^{a} \mathbf{L}$ & $\begin{array}{c}\mathbf{L o a d} / \mathbf{F}_{\mathbf{n}} \\
\mathbf{L} / \mathbf{F}_{\mathbf{n}}\end{array}$ & $\begin{array}{c}\text { Ratio } \\
\left(\mathbf{L} / \mathbf{L}_{\mathbf{n}}\right) /\left(\mathbf{L} / \mathbf{L}_{n}\right)_{\mathbf{C} 22}\end{array}$ \\
\hline $\mathrm{C} 2\left(0 / 90^{\circ}\right)$ & 3.18 & 44.1 & 140.0 & 317.5 & 2.268 & 1 \\
\hline $\operatorname{C22}\left(0 / 90^{\circ}\right)$ & 2.95 & 44.1 & 129.9 & 294.6 & 2.268 & 1 \\
\hline $\operatorname{C23}\left(0 / 90^{\circ}\right)$ & 3.12 & 41.8 & 130.6 & 312.4 & 2.392 & 1.055 \\
\hline C6 $\left( \pm 45^{\circ}\right)$ & 3.56 & 39.1 & 139.0 & 355.6 & 2.558 & 1.128 \\
\hline $\mathrm{C} 24\left( \pm 45^{\circ}\right)$ & 2.92 & 44.7 & 130.6 & 292.1 & 2.237 & 0.986 \\
\hline
\end{tabular}

$a_{\text {Load is }}$ based on $100 \mathrm{MPa}$. 
and C2 specimens should have performed approximately the same, but they did not. Table 10.3 shows that in terms of load per number of fibers, the C23 specimens were slightly overloaded by about 5.5\% compared to the $\mathrm{C} 22$ specimens, and the test results confirmed that the former yielded slightly higher creep strain than the latter. This observation led to speculation that the discrepancies in creep performance may be attributed to such things as the difference in carbon-fiber stacking order, fiber mat characteristics, mold run, and process methods.

In addition to the obvious differences in creep behavior due to plaque variations, an unusual creep behavioral feature was observed in all the C22 and C23 creep curves. Each had a creep strain peak occurring approximately between test time 4000 and $5000 \mathrm{~h}$. Because the tests on the C22 and C23 specimens were all initiated within a month, the creep strain peaks were suspected to relate to the change of RH in the laboratory as the season changed. Figure 10.7 shows the correlation between weekly average lab RH and creep data as acquired for specimen C22-18 tested with an applied stress of $300 \mathrm{MPa}$. It would appear from an assessment of Fig. 10.7 that an increment of $1 \% \mathrm{RH}$ contributed approximately $0.0002 \%$ to the as-acquired creep data. ${ }^{*}$ A creep curve normalized to the $50 \% \mathrm{RH}$ reference condition is illustrated in Fig. 10.7. A reasonably well-defined steady-state creep regime can now be recognized following the primary creep. The apparent creep strain change per 1\% change of RH appeared to be independent of applied stress, but more data would be required to reach a firm conclusion.

The creep strains in the $0 / 90^{\circ}$ direction are extremely small. Therefore, laboratory $\mathrm{RH}$ swings can significantly distort the creep curves as illustrated in Figs. 10.6 and 10.7. The differences in creep strain between the as-acquired creep curves for the C22 and C23 specimens tested at 200 and $300 \mathrm{MPa}$ are also attributed to the laboratory RH because all the tests were not started on the same day. To eliminate the RH influence, all the C22 and C23 creep curves were normalized to the 50\% RH reference condition, as shown in Fig. 10.8. Generally, the C23 specimens yielded slightly higher creep strain than the $\mathrm{C} 22$ specimens, but the $5.5 \%$ extra load on the $\mathrm{C} 23$ specimens did not significantly influence the creep performance because the specimens are fiber dominated. However, the situation changed dramatically for the C23 specimen tested at $400 \mathrm{MPa}$, where the short creep-rupture life may be attributed to the $5.5 \%$ extra load.

\subsubsection{Creep Equation Development}

An interim creep equation given below was suggested previously to describe the creep behavior of plaque $\mathrm{C} 2$ in the $0 / 90^{\circ}$ direction: ${ }^{15}$

$$
\varepsilon_{\mathrm{c}}=\mathrm{A} \sigma \mathrm{t}^{\mathrm{n}}
$$

\footnotetext{
*Actually, the rate of moisture weight gain, and the subsequent expansion strain, depends on both the RH level and the applied stress. A change from $60 \%$ to $70 \% \mathrm{RH}$ results in a greater expansion strain than does one from $30 \%$ to $40 \%$ RH. Likewise, the weight gain and expansion strain would be greater the higher the applied stress.

To check on the reasonableness of the $0.0002 \%$ strain $/ 1 \%$ RH change as an approximation, laminated plate theory and moisture expansion coefficients values for a carbon-fiber/epoxy composite were used. The moisture-induced expansion strain in a crossply composite is isotropic in the plane and depends on the moisture content, the ply-level expansion coefficients, and the laminate stiffness values $\mathrm{Q}_{\mathrm{ij}}$ (see Chap. 12). When the RH was cycled from $50 \%$ to $80 \%$. the moisture content in a carbon-fiber/epoxy composite varied by approximately $0.5 \%$. Using this value along with the aforementioned expansional coefficients for the carbon-fiber/epoxy material but the $\mathrm{Q}_{\mathrm{ij}}$ values for the carbonfiber/urethane composite addressed here, the expansion strain in the latter was estimated to be $0.0045 \%$ for the $50 \%$ to $80 \%$ RH change. Assuming the rate of change to be independent of humidity level, a value of $0.00015 \%$ strain per $1 \%$ $\mathrm{RH}$ is obtained, which closely matches the $0.0002 \%$ estimate.

It should be pointed out that fluctuations in moisture content also affect the mechanically induced strain due to the well-known phenomenon of moisture-enhanced creep response in polymers and polymeric composites. However, this enhancement is expected to be minimal in the $0 / 90^{\circ}$ fiber orientation.
} 
where $\varepsilon_{\mathrm{c}}$ is the time-dependent tensile creep strain in percent, $\sigma$ is the applied stress in megapascals, $\mathrm{t}$ is time in hours, and $\mathrm{A}$ and $\mathrm{n}$ are constants. Because the creep strains yielded by plaques $\mathrm{C} 2$ and $\mathrm{C} 22$ (or C23) were significantly different in magnitude, the overall creep behavior from the two sets of specimens cannot be adequately represented by Eq. (10.1) with a single value of the constant A. However, a single value of the exponent $\mathrm{n}$ can be used. Once past the primary creep stage, the creep strain changes were not so much larger than the strain gage resolution and were reasonably steady. Behavior beyond the maximum test time however is uncertain.

To best fit the creep curves for stresses of $400 \mathrm{MPa}$ and below for both sets of data derived from the TBC plaque (C2) and DEV plaques (C22 and C23), an " $\mathrm{M}$ " factor defined as a mold-run index is introduced to distinguish two creep models having the same basic form as shown below.

$$
\varepsilon_{\mathrm{c}}=0.4152 \times 10^{-4} \mathrm{M} \sigma \mathrm{t}^{0.112} \text {. }
$$

Then $\mathrm{M}=1$ is assigned for DEV plaques, and $\mathrm{M}=2$ for TBC plaques. Agreement between predictions and experimental data shown in Figs. 10.8 and 10.9 is respectable in view of the small creep strains exhibited.

Although the creep behavior of $\pm 45^{\circ}$ specimens is not fully dominated by fiber content, the ratio of applied load per number of fibers as a parameter should still play a key role. An examination indicates that $\mathrm{C} 22$ and $\mathrm{C} 24$ specimens are physically comparable on the basis of the parameter because the specimen thickness and fiber volume percent are virtually identical, and both are fabricated from DEV plaques. However, the creep model for representing the behavior in the $\pm 45^{\circ}$ direction will remain independent from Eq. (10.2) because of the absence of information in the other directions. To make a meaningful comparison of creep data for the C6 and C24 specimens, the C6 stress levels were normalized downward according to the load/fiber parameter by $12.8 \%$. Note that the $\pm 45^{\circ}$ creep model is not a linear function of applied stress.

The normalized creep curves for C6 specimens and the as-acquired creep curves for C24 $\left( \pm 45^{\circ}\right)$ specimens are shown in Fig. 10.10. Test results for the C24 specimens also indicated that they are more creep resistant compared to C6 specimens. This finding is consistent with the earlier observation in the $0 / 90^{\circ}$ direction. Because the creep deformation exhibited in Fig. 10.10 is much higher than that for the $0 / 90^{\circ}$ specimens, the influence of the laboratory RH was completely obscured. Because the creep deformation in the $\pm 45^{\circ}$ direction is not a linear function of applied stress, the following equation was used to represent the creep behavior of the C6 specimens:

$$
\varepsilon_{\mathrm{c}}=\mathrm{A} \sigma^{\mathrm{m}} \mathrm{t}^{\mathrm{n}}
$$

where $\mathrm{m}$ is a material constant. The explicit form of Eq. (10.3) shown below was derived to fit the curves for the $\mathrm{C} 24$ specimens tested at $100 \mathrm{MPa}$ and below:

$$
\varepsilon_{\mathrm{c}}=2.037 \times 10^{-6} \mathrm{M \sigma}^{2.634} \mathrm{t}^{0.20},
$$

where $\mathrm{M}=1$ is assigned for the DEV (C24) creep model, and $\mathrm{M}=1.46$ for the TBC (C6) creep model. ${ }^{*}$ Comparison of predictions and experimental data in Fig. 10.11 shows good agreement. The equation overpredicted the creep strains at 75 and $87.5 \mathrm{MPa}$ by about $16 \%$, which is again respectable.

\footnotetext{
${ }^{*}$ The $\mathrm{M}=1.46$ factor includes the stress reduction mentioned earlier for the $\mathrm{C} 6$ specimens.
} 


\subsection{TEMPERATURE EFFECTS}

A limited number of $0 / 90^{\circ} \mathrm{C} 22$ specimens was tested at $70^{\circ} \mathrm{C}$ and $120^{\circ} \mathrm{C}$. The results are shown in Fig. 10.12. Creep resistance at $70^{\circ} \mathrm{C}$ was not significantly degraded in terms of cumulative creep strain and creep-strain rate, but the degradation accelerated rapidly as the temperature increased to $120^{\circ} \mathrm{C}$. Because of the paucity of data, a rather conservative $0 / 90^{\circ}$ temperature model, shown below, is proposed for design applications:

$$
\varepsilon_{\mathrm{c}}=0.4152 \times 10^{-4} \mathrm{M} \sigma \mathrm{t}^{0.112} \exp \left\{-4.7\left(\mathrm{~T}-\mathrm{T}_{0}\right) /\left[-345+\left(\mathrm{T}-\mathrm{T}_{0}\right)\right]\right\} \text {, }
$$

where $\sigma \leq 400 \mathrm{MPa}, \mathrm{T}$ is in degrees Celsius, and $\mathrm{T}_{0}=23^{\circ} \mathrm{C}$. Model predictions and experimental data are compared in Fig. 10.12. Conservatism is clearly illustrated in the low stress region, but the data trend shows this may not be the case at high stress and high temperature. The creep curve at $70^{\circ} \mathrm{C}$ and $400 \mathrm{MPa}$ hints at the possibility of tertiary creep, but that cannot be confirmed with the limited information.

Results of three tests on $\pm 45^{\circ} \mathrm{C} 24$ specimens at $70^{\circ} \mathrm{C}$ are shown in Fig. 10.13. Unlike the situation in the $0 / 90^{\circ}$ direction, the creep resistance of the $\mathrm{C} 24$ specimens decreased rather dramatically by about a factor of 4 in terms of cumulative creep strain. Results of a test with an applied stress of $87.5 \mathrm{MPa}$ showed that the specimen crept about $1.8 \%$ in $15 \mathrm{~min}$. Although the specimen did not fail by separation, the material was severely damaged beyond the useful condition. In the practical sense, the material should be considered as failed.

Three $\pm 45^{\circ} \mathrm{C} 24$ specimens were tested at $120^{\circ} \mathrm{C}$, at stress levels of $37.5,50$, and $75 \mathrm{MPa}$. No creep curves are available from the two highest stress tests due to the excessive deformation occurring beyond the measurable range of the strain gages. The test for the specimen at $37.5 \mathrm{MPa}$ was discontinued after completing $1707 \mathrm{~h}$ due to a power failure and subsequent overheating. The second specimen tested at $50 \mathrm{MPa}$ ruptured at $111.5 \mathrm{~h}$, and the third specimen ruptured on loading to $75 \mathrm{MPa}$. In the absence of more data, a multiplication factor of 3.5 to Eq. (10.4) is suggested for modeling the $70^{\circ} \mathrm{C}$ behavior, but no factor can be recommended for $120^{\circ} \mathrm{C}$. ${ }^{*}$ The results indicate that creep conditions in the $\pm 45^{\circ}$ direction should be avoided near $120^{\circ} \mathrm{C}$.

\subsection{FLUID EFFECTS}

Creep curves of $0 / 90^{\circ} \mathrm{C} 22$ specimens in distilled water and in the windshield washer fluid (WWF) are plotted in Fig. 10.14. Specimens were subjected to 100-h preexposures prior to testing. The fluids are clearly detrimental to the creep resistance of the composite in terms of causing higher creep strain compared to the ambient-air test results. Although WWF appeared more deleterious than distilled water, all creep data for $300 \mathrm{MPa}$ are well within the data scatter. Therefore, no distinction between the two will be made. Figure 10.14 indicates that a multiplication factor of four is adequate to conservatively bound the creep behavior.

Two $\pm 45^{\circ} \mathrm{C} 24$ specimens were tested in the fluids, one in the distilled water and another in the WWF. Again, no distinction is made between the effects of the two fluids. However, the fluid effect on creep behavior is clearly discernible, as shown in Fig. 10.15. Comparison with the air test data indicates that a multiplication factor of 2.5 should suffice.

* Deng and Weitsman, in unpublished results, ran short (5-h) creep tests on $\pm 45^{\circ}$ specimens at $120^{\circ} \mathrm{C}$. Stress levels of $31,46.5$, and $62 \mathrm{MPa}$ were used. Time-dependent creep at $120^{\circ} \mathrm{C}$ was, on average, 41 times that at room temperature! 


\subsection{COMPRESSIVE CREEP}

Three compressive creep tests were performed on $0 / 90^{\circ}$ plaque $\mathrm{C} 22$ specimens under stresses of $-250,-300$, and $-350 \mathrm{MPa}$. The results are shown in Fig. 10.16. No significant information was gleaned from the two tests under high compressive stresses because the specimens buckled within a minute of testing. Nevertheless, useful information was obtained. Results of the test under low compressive stress showed that creep in compression yielded a higher strain in comparison with that in tension by about $30 \%$. For the purpose of modeling, a multiplication factor of 1.5 is recommended for applications at or below $300 \mathrm{MPa}$. The model appears to cover the low-stress region well, but it significantly underpredicts the situation above $-300 \mathrm{MPa}$.

Compressive creep tests were performed in air for two $\pm 45^{\circ} \mathrm{C} 24$ specimens under -87.5 and $-100 \mathrm{MPa}$. The results are shown in Fig. 10.17. Creep in tension and compression was shown to be unsymmetrical in the $\pm 45^{\circ}$ direction also, and compression yielded higher creep strains than tension by $50 \%$ in both tests. Therefore, the same multiplication factor of 1.5 is recommended for the sake of consistency. Figure 10.17 indicates that compressive creep data are well represented by the model.

\subsection{SUMMARY}

Room-temperature, in-air, time-dependent creep strains are predicted by Eqs. (10.2) and (10.4) for the $0 / 90^{\circ}$ and $\pm 45^{\circ}$ fiber orientations, respectively. Each equation contains a mold-run multiplier, M. Values of $\mathrm{M}$ are given below.

$\begin{array}{ccccc}\text { Molding run } & & \mathbf{0 / 9 0}^{\circ} & & \mathbf{t 4 5}^{\circ} \\ \text { TBC } & & 2.0 & & 1.46 \\ \text { DEV } & & 1.0 & & 1.0\end{array}$

The TBC M factors were chosen for recommended design analysis use in Chap. 2 of Part 1. There were two reasons for that choice. First, the TBC factors are more conservative (lead to greater predicted creep deformations), and second, at least from a tensile stiffness standpoint, the TBC plaque properties are more typical of the overall average properties for all plaques than are the DEV plaque values. This can be seen by comparing the stiffness values for the individual plaques used in the creep studies with the overall average value for all plaques (see Table B.1 in Appendix B). These values are tabulated below.

\begin{tabular}{|c|c|c|}
\hline \multirow[b]{2}{*}{ Plaque } & \multicolumn{2}{|c|}{$\begin{array}{c}\text { Stiffness } \\
\text { (GPa) }\end{array}$} \\
\hline & $0 / 90^{\circ}$ & $\pm 45^{\circ}$ \\
\hline $\mathrm{C} 2$ (TBC) & 46.2 & \\
\hline C22 (DEV) & 48.5 & \\
\hline C23 (DEV) & 48.4 & \\
\hline C6 (TBC) & & 10.7 \\
\hline C24 (DEV) & & 12.7 \\
\hline Average (all plaques) & 46.8 & 11.3 \\
\hline
\end{tabular}

The various K factors for use with Eqs. (10.2) and (10.4) are summarized in Table 10.4. These values were used in Chap. 2. 
Table 10.4. Creep strain multiplication factors, $K$, for various environmental and loading conditions

\begin{tabular}{lcc}
\hline \multicolumn{1}{c}{ Environment/loading } & $\begin{array}{c}\text { K for } \\
\text { Eq. (10.2) } \\
\mathbf{0 / 9 0}\end{array}$ & $\begin{array}{c}\text { K for } \\
\text { Eq. (10.4) } \\
\mathbf{\pm 4 5}^{\circ}\end{array}$ \\
\hline $\mathbf{7 0}^{\circ} \mathbf{C}$ & 2.1 & 3.5 \\
$\mathbf{1 2 0}^{\circ} \mathbf{C}$ & 6.3 & \\
Water/windshield washer fluid & 4.0 & 2.5 \\
Compression & 1.5 & 1.5 \\
\hline
\end{tabular}

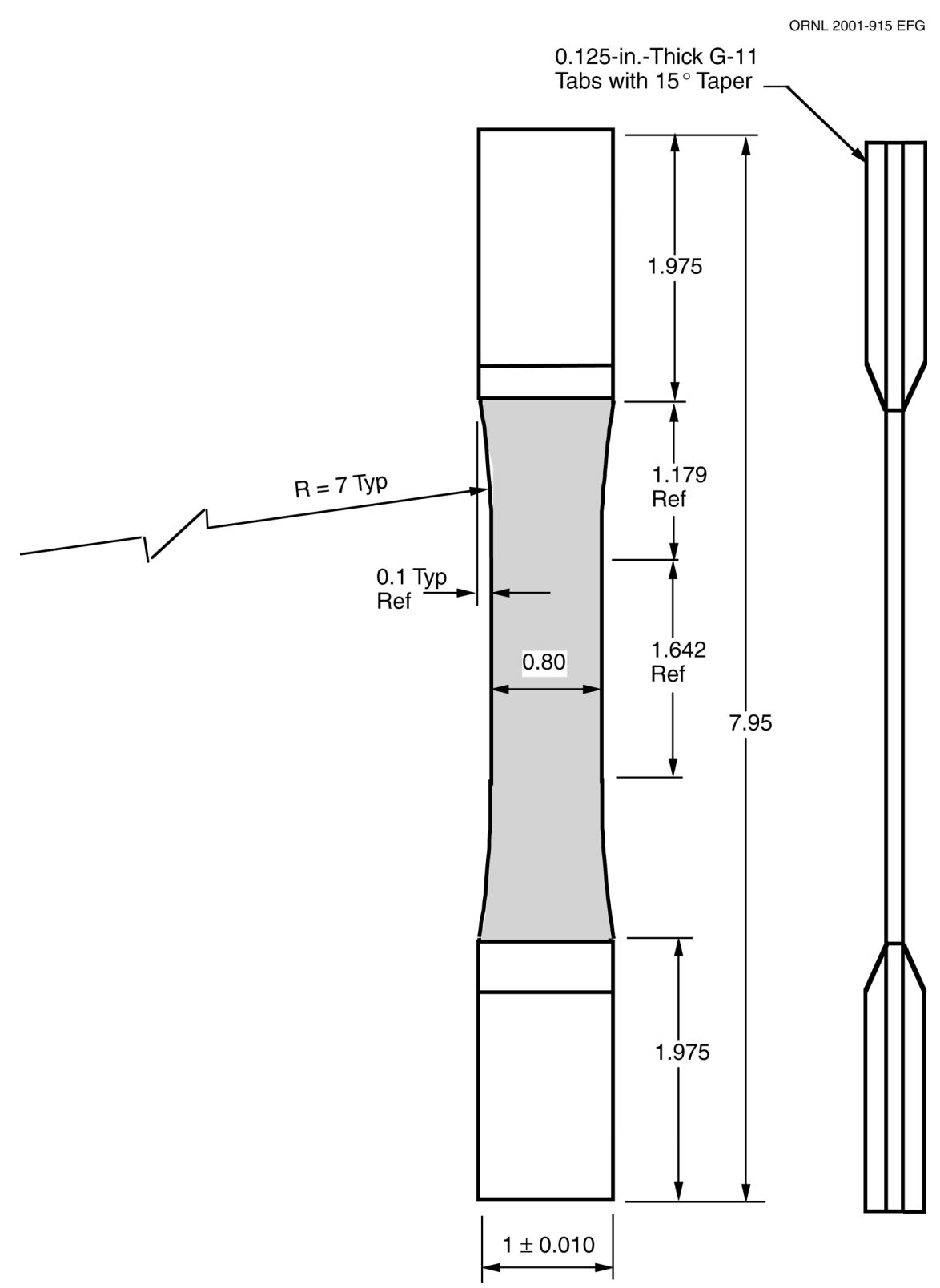

Fig. 10.1. Tabbed dogbone tensile specimens used for creep tests. Dimensions are in inches $(1$ in. $=25.4 \mathrm{~mm})$. 


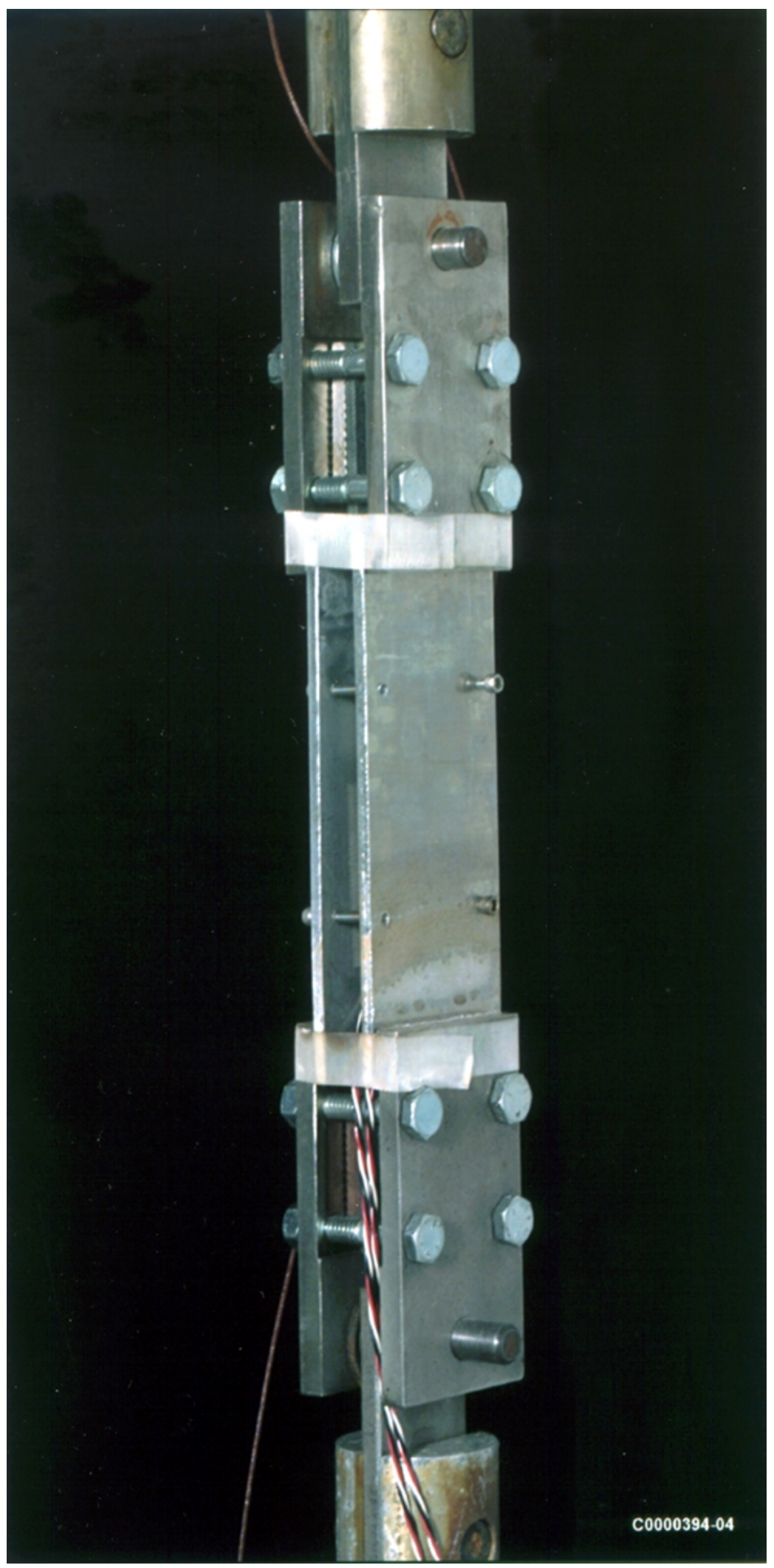

Fig. 10.2. Specimen assembly for creep test. Thin aluminum plates are shown adjacent to the specimen for heating purposes. 


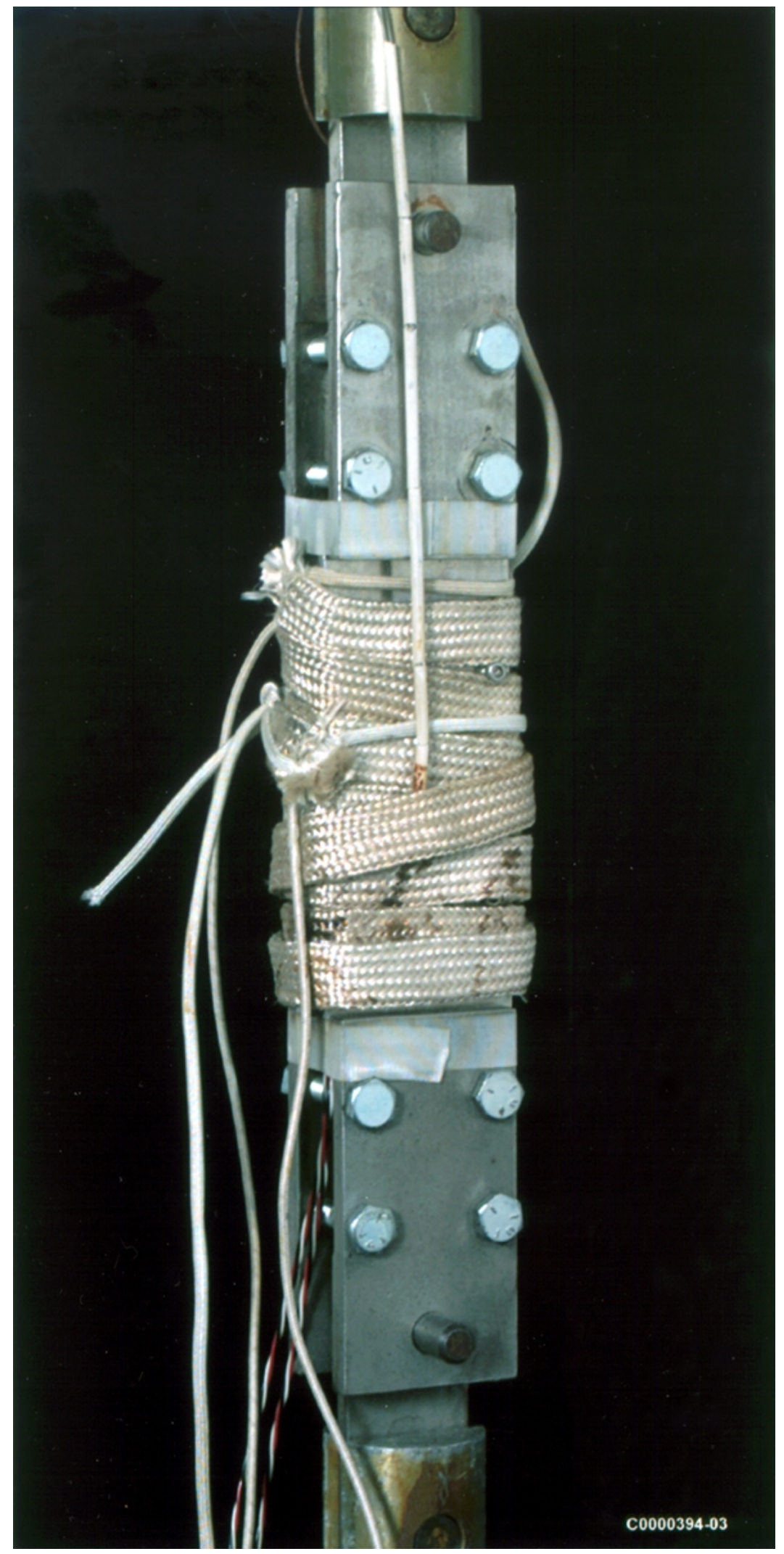

Fig. 10.3. Heating tape arrangement used to heat specimen. 


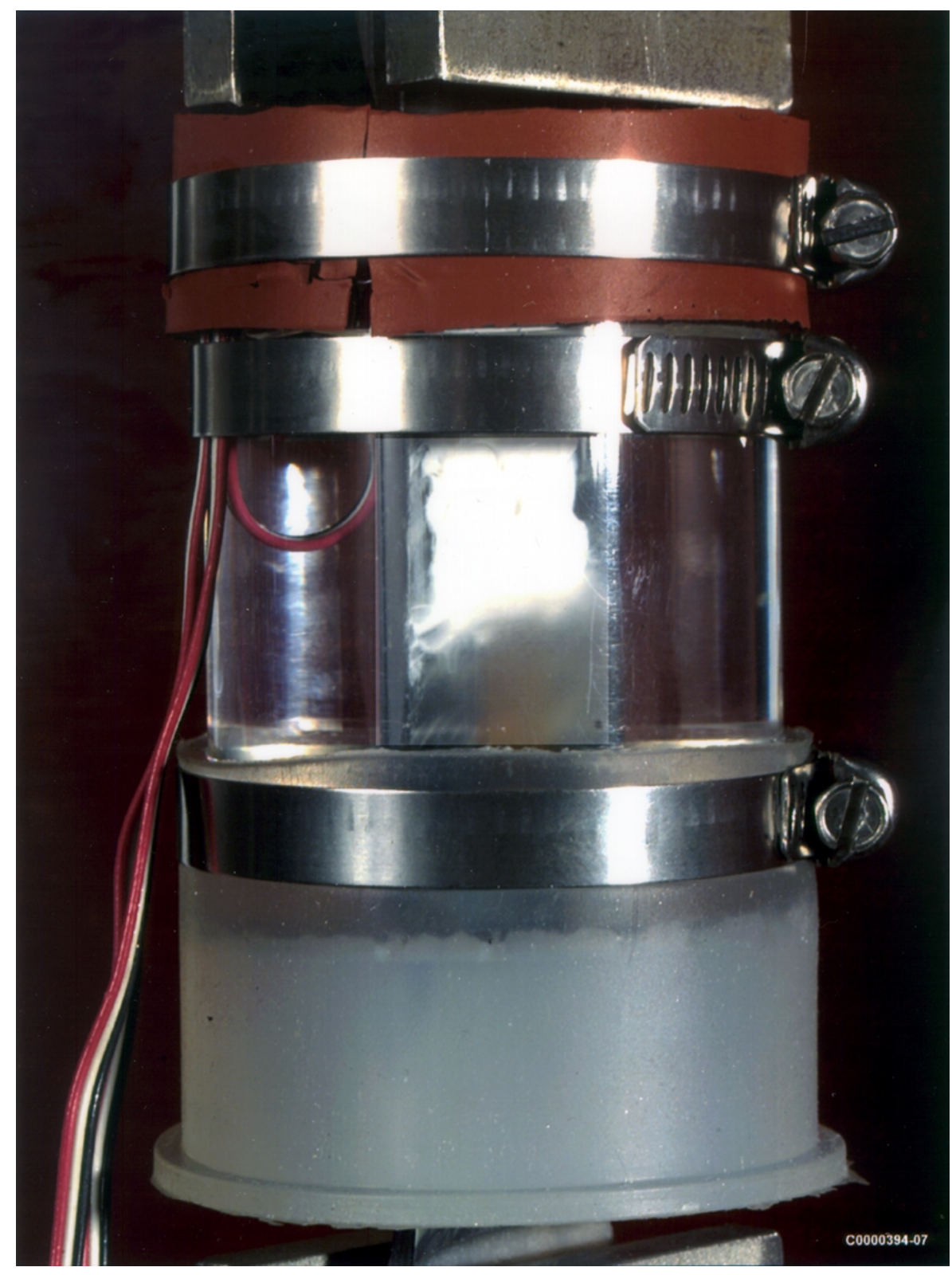

Fig. 10.4. Plexiglass cup surrounding specimens for fluid tests. 


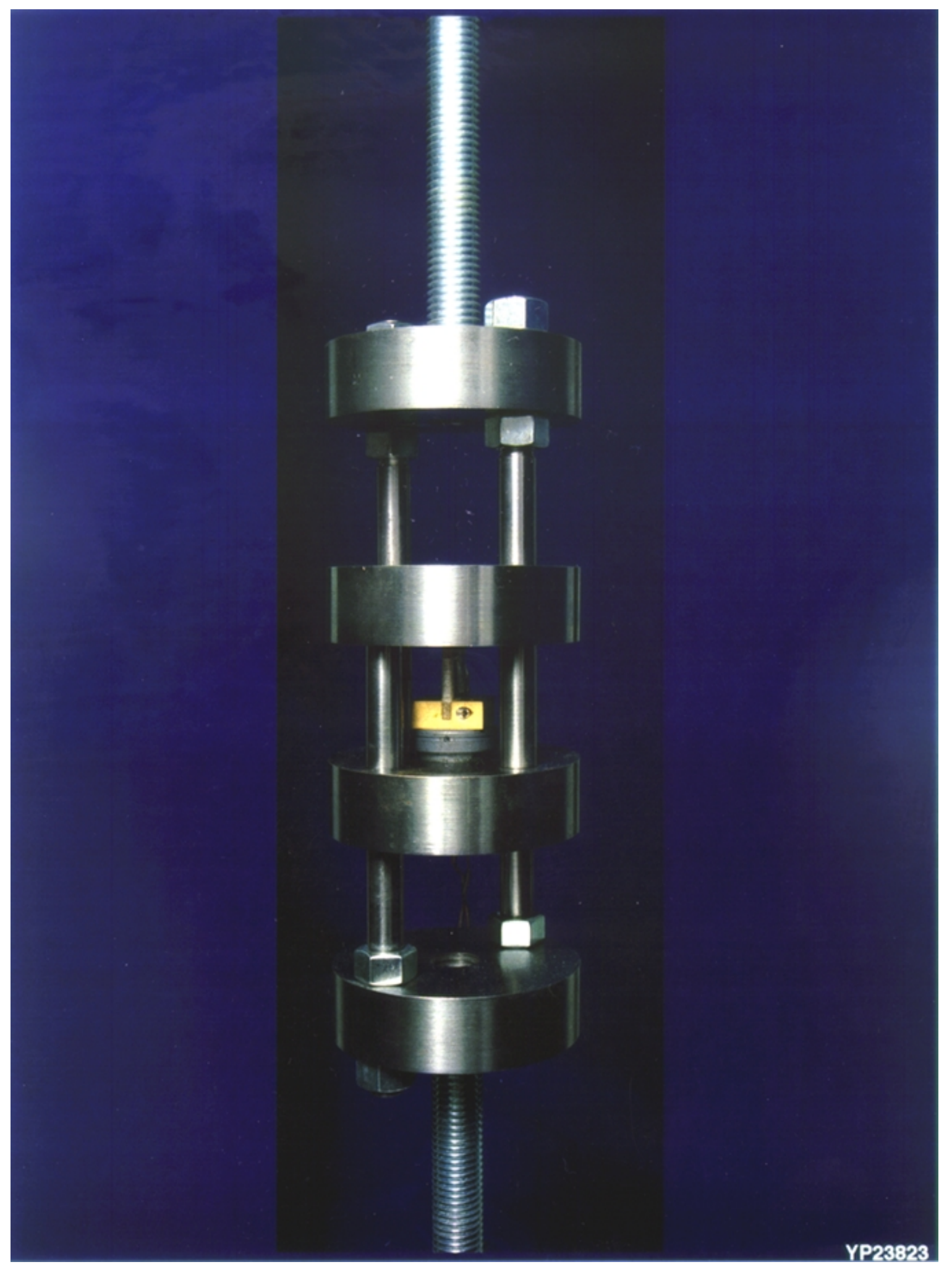

Fig. 10.5. Compressive creep-test fixture.

$10-14$ 
ORNL 2001-920 EFG

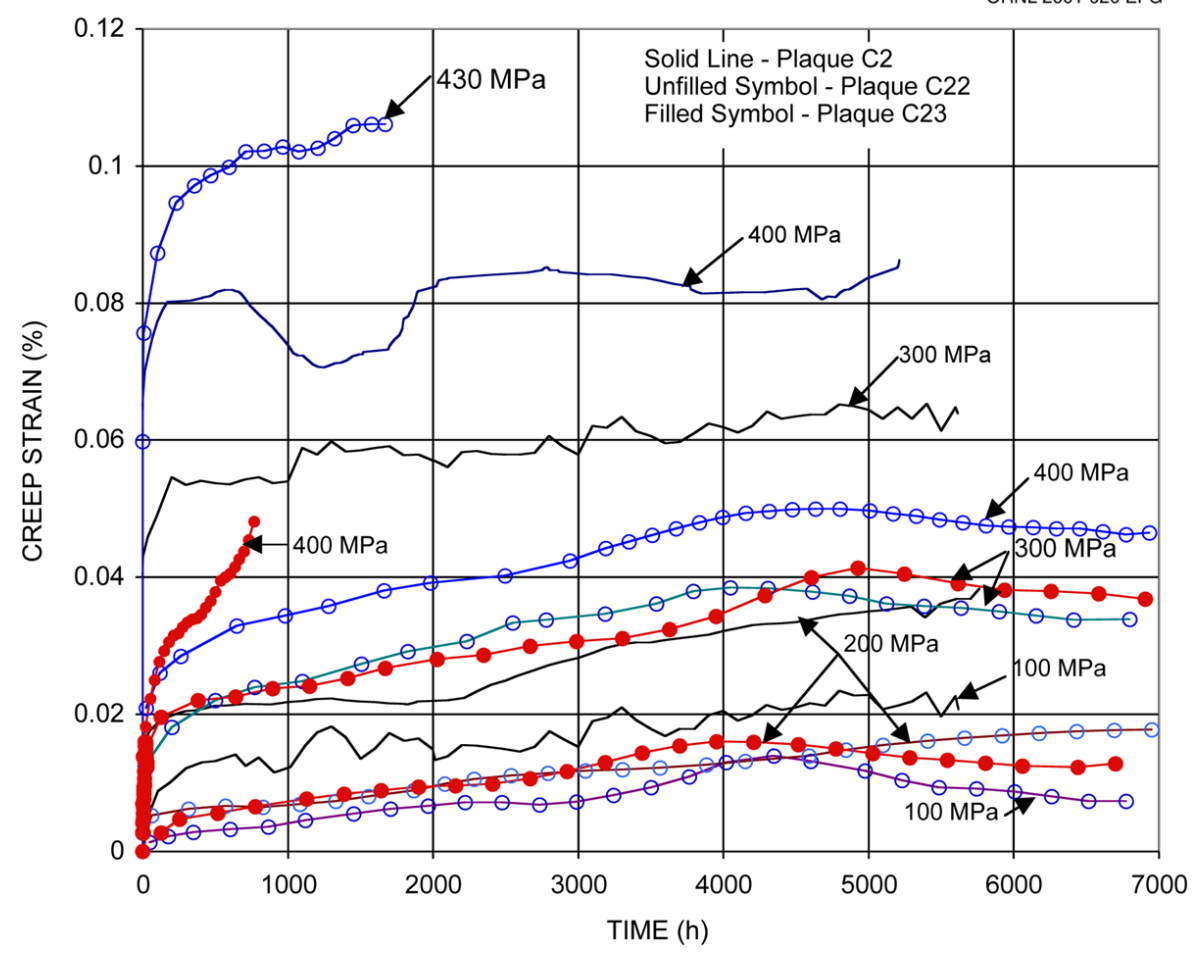

Fig. 10.6. Summary of time-dependent creep data for plaques $\mathrm{C} 22$ and $\mathrm{C} 23$ (DEV) and plaque $\mathrm{C} 2$ (TBC) in the $0 / 90^{\circ}$ direction.

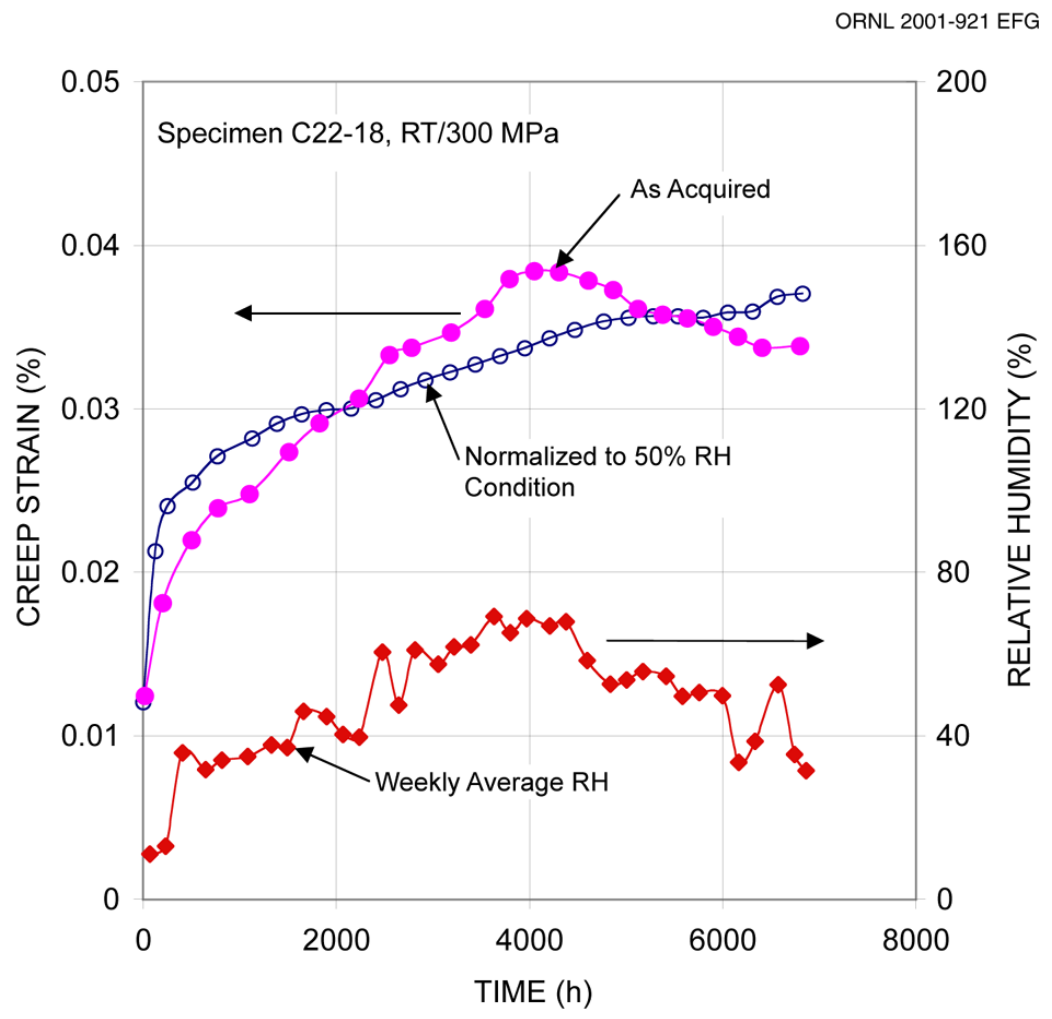

Fig. 10.7. Time-dependent deformation in the $0 / 90^{\circ}$ direction showing sensitivity to changes in laboratory RH. 


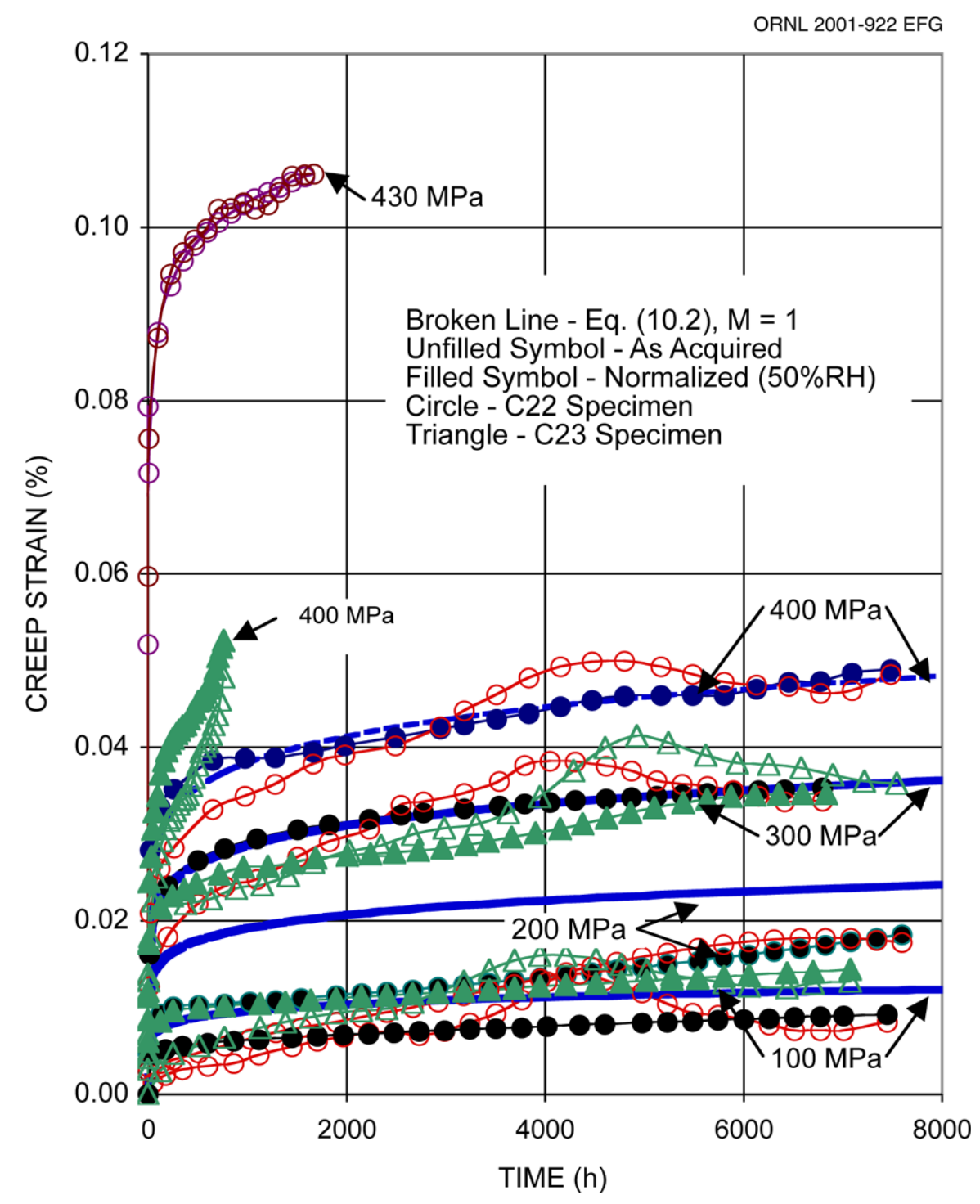

Fig. 10.8. Comparison of $0 / 90^{\circ}$ model predictions $(M=1)$ with the asacquired and normalized (50\% $\mathrm{RH})$ time-dependent creep data of $\mathrm{C22}$ and $\mathrm{C} 23$ specimens tested at room temperature. 
ORNL 2001-923 EFG

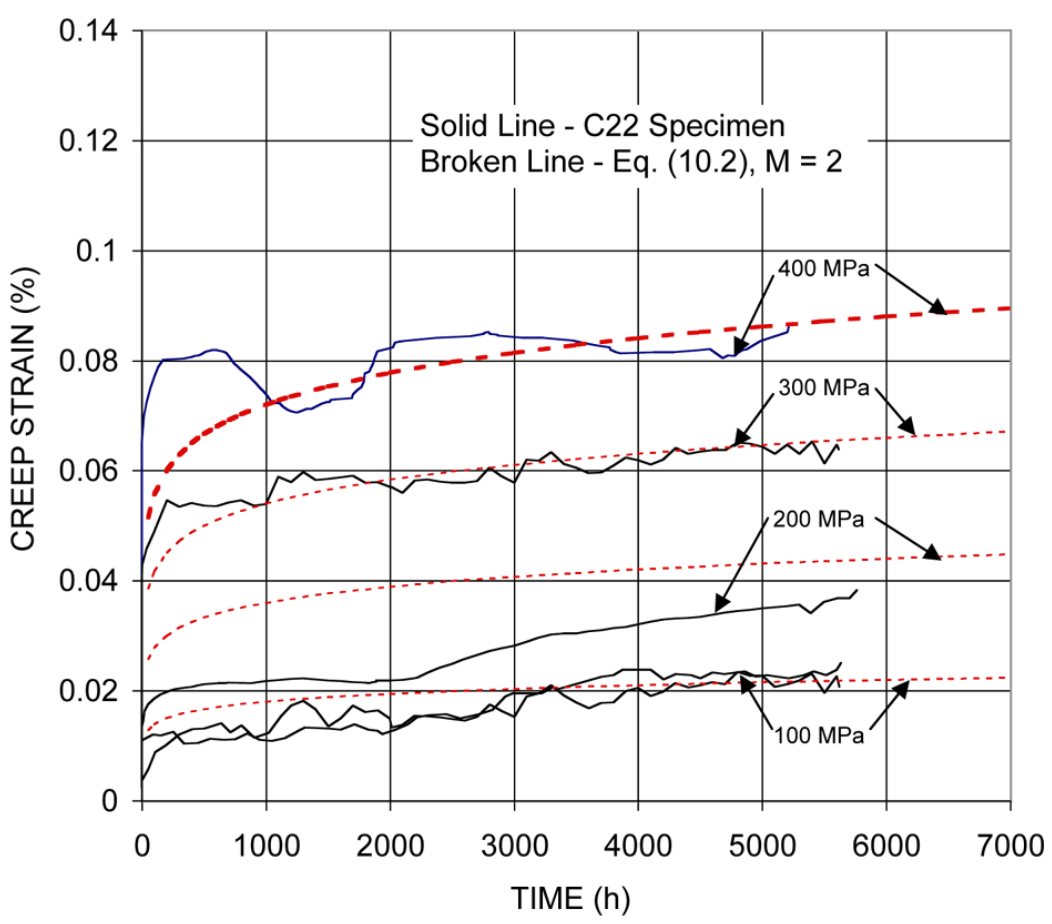

Fig. 10.9. Comparison of $0 / 90^{\circ}$ predictions $(M=2)$ and timedependent creep data from $\mathrm{C} 2$ specimens tested at room temperature.

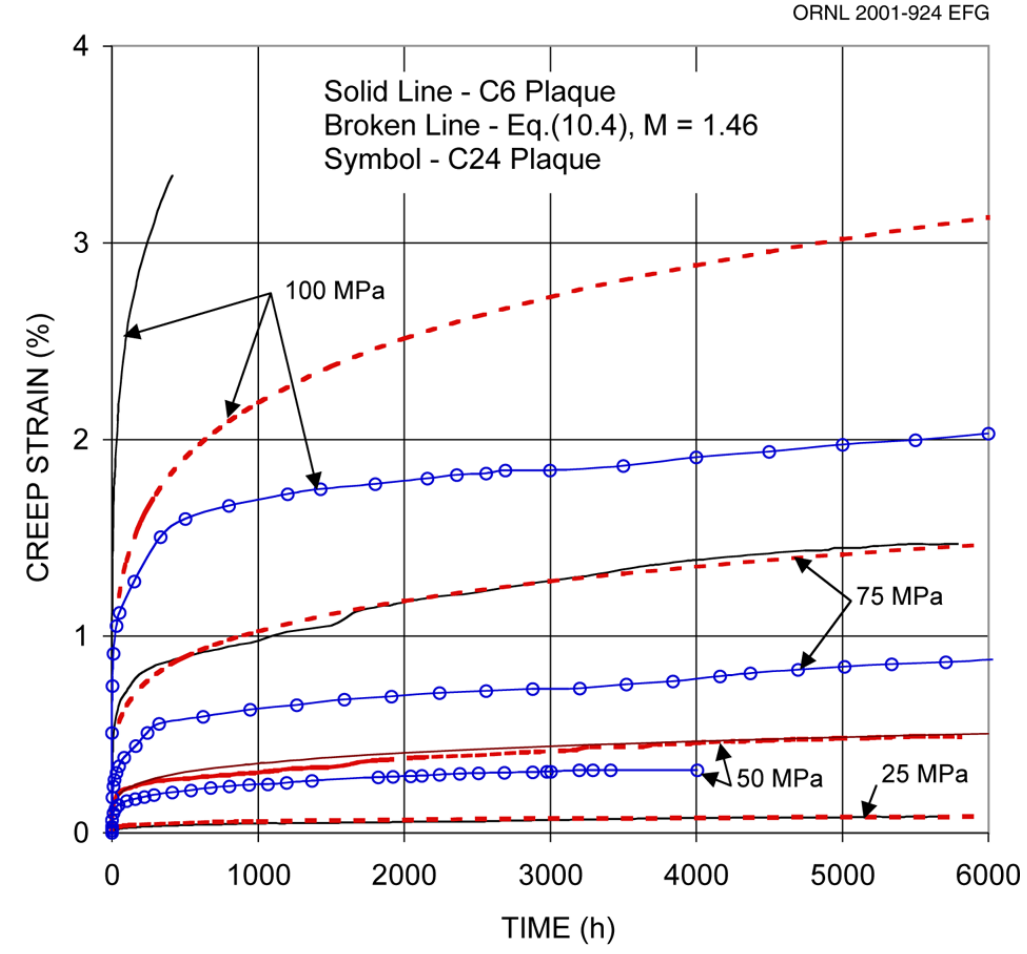

Fig. 10.10. Comparison of $\pm 45^{\circ}$ model predictions and timedependent creep data for $\mathrm{C} 6$ and $\mathrm{C} 24$ specimens tested at room temperature. The predictions $(\mathrm{M}=1.46)$ are for plaque $\mathrm{C} 6$. 


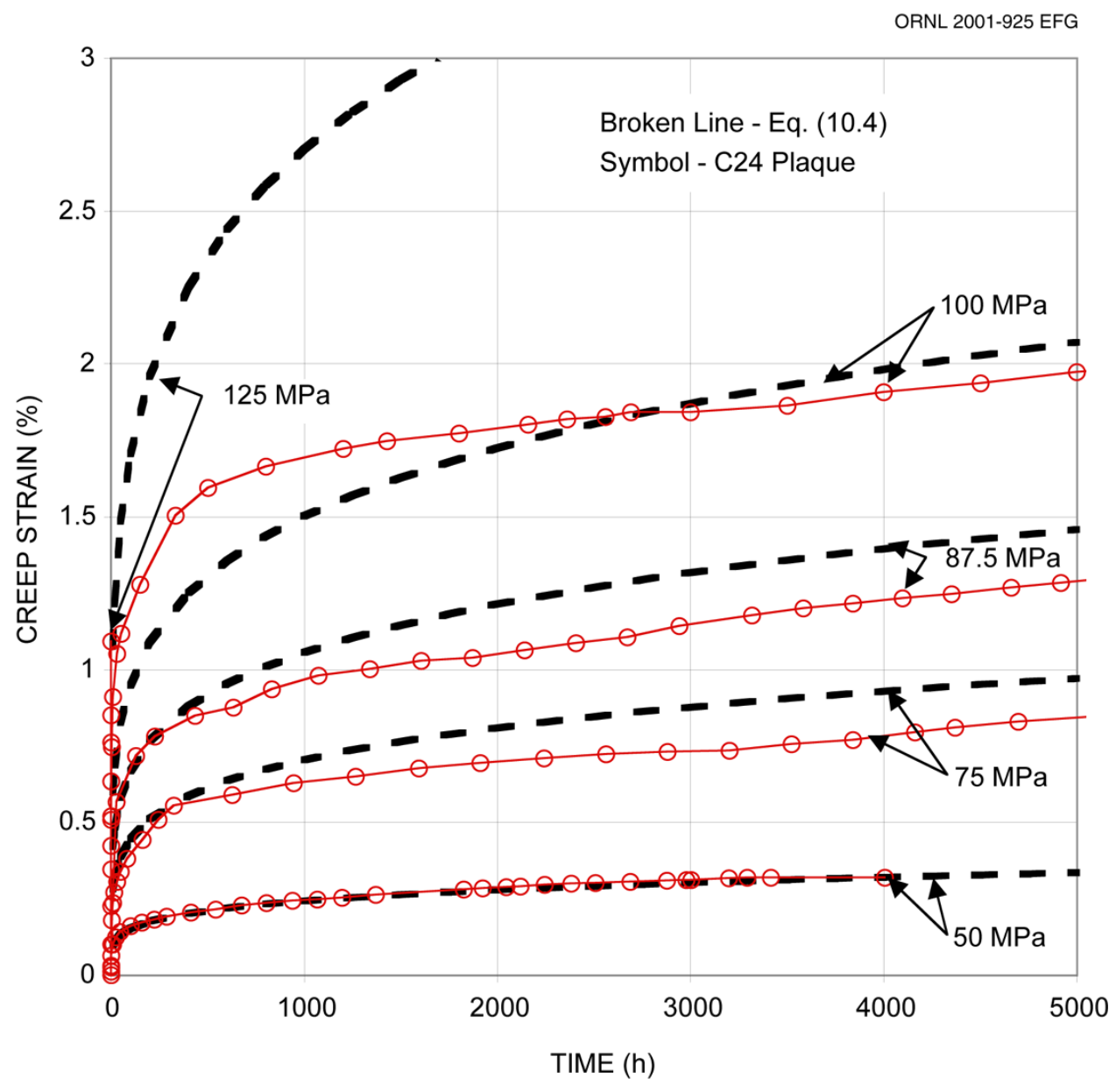

Fig. 10.11. Comparison of creep model predictions and time-dependent creep data for $\mathrm{C} 24$ specimens tested at room temperature. 


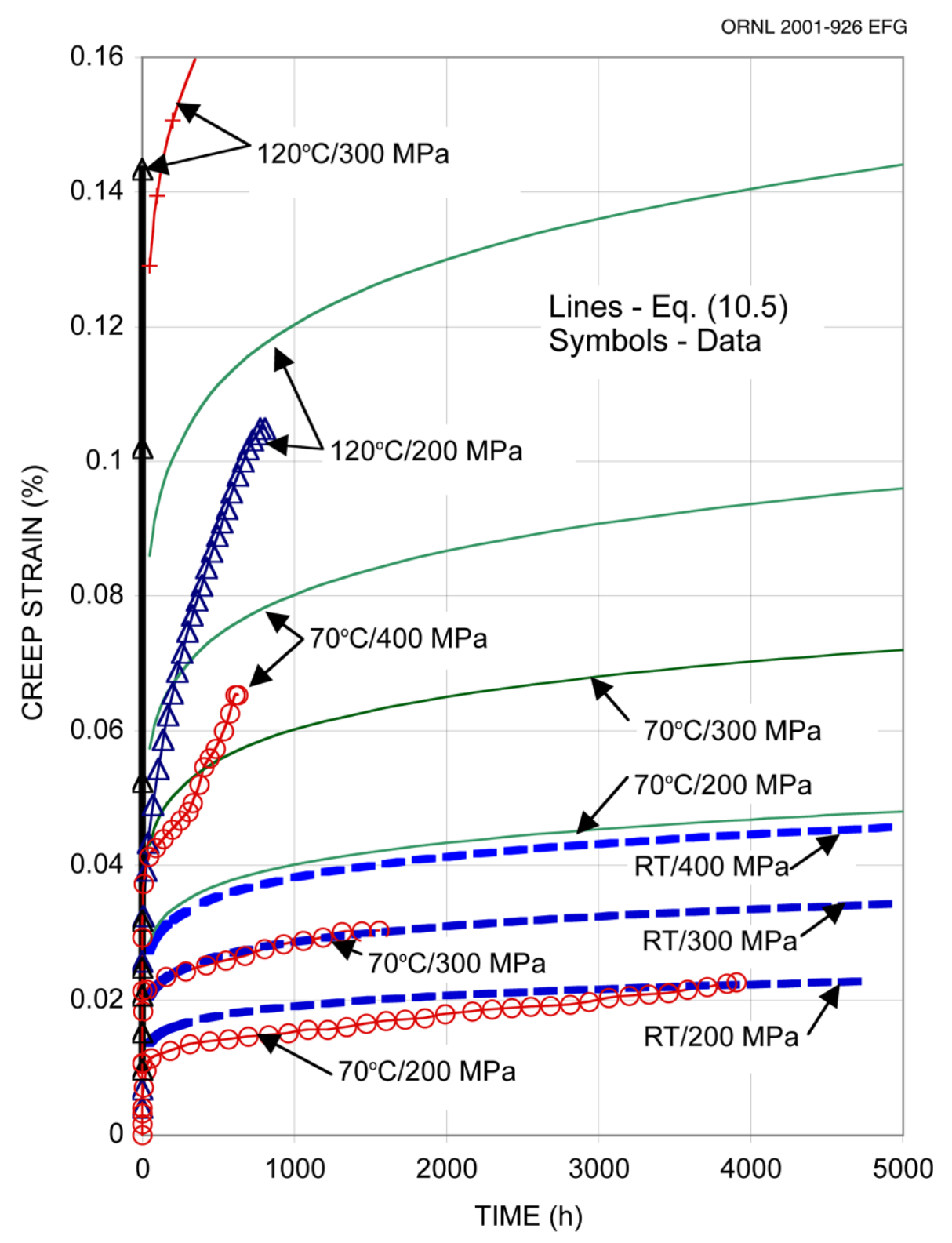

Fig. 10.12. Comparison of $0 / 90^{\circ}$ model predictions and time-dependent creep data for $\mathrm{C22}$ specimens tested at elevated temperatures. 
ORNL 2001-927 EFG

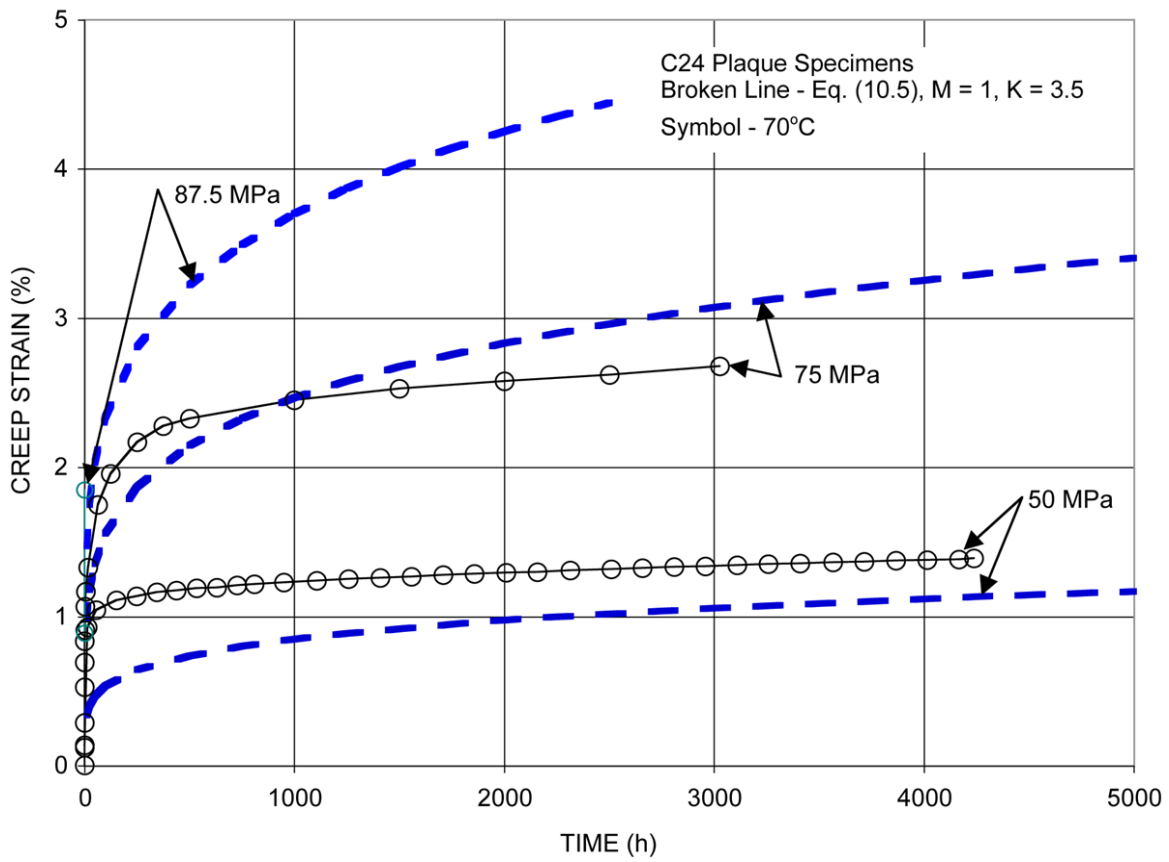

Fig. 10.13. Comparison of $\pm 45^{\circ}$ model predictions and time-dependent creep data for $\mathrm{C} 24$ specimens tested at $70^{\circ} \mathrm{C}$.

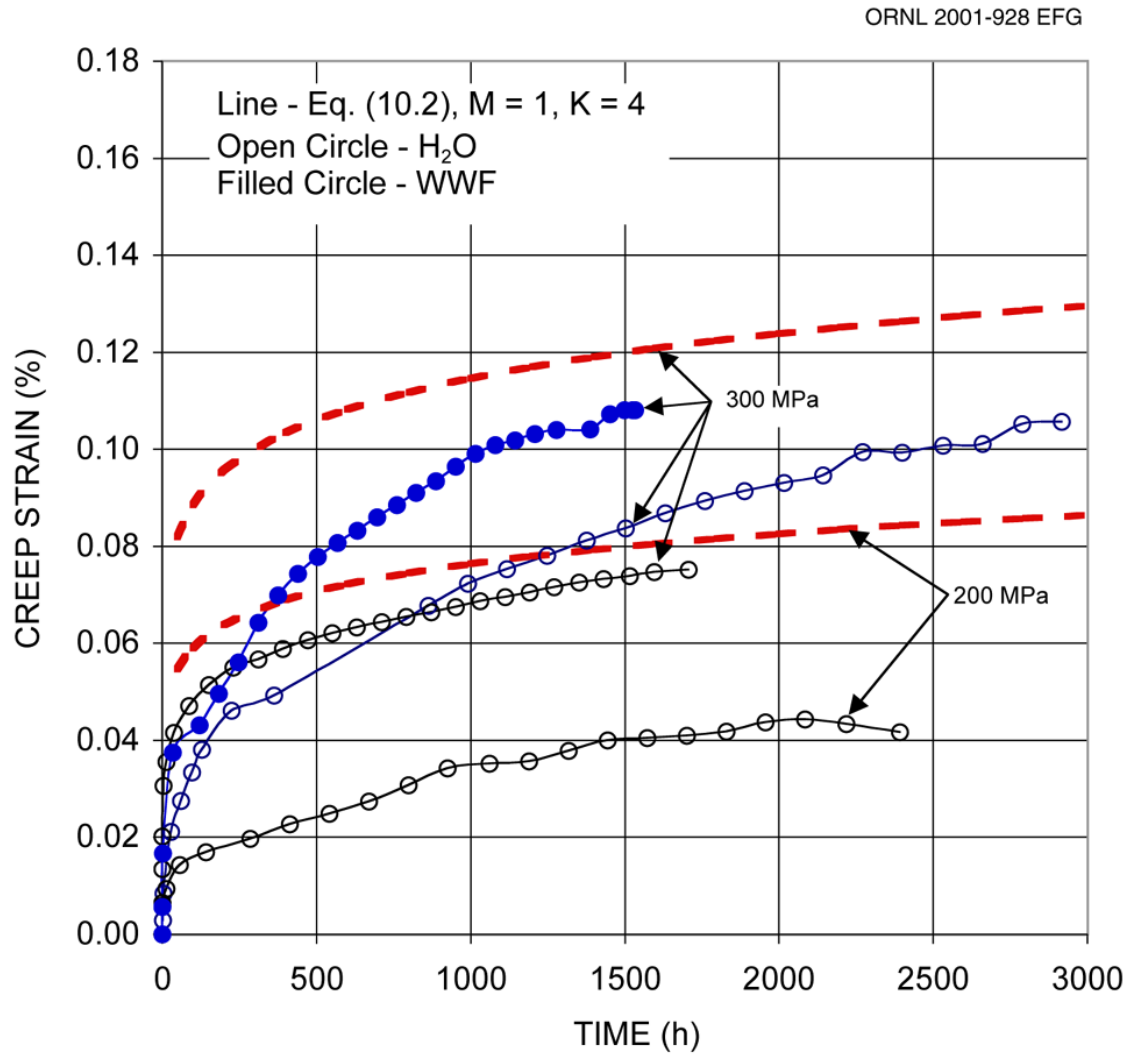

Fig. 10.14. Comparison of $0 / 90^{\circ}$ model predictions $(M=1, K=4)$ and time-dependent creep data from $\mathrm{C22}$ specimens tested in distilled water and windshield washer fluid. 


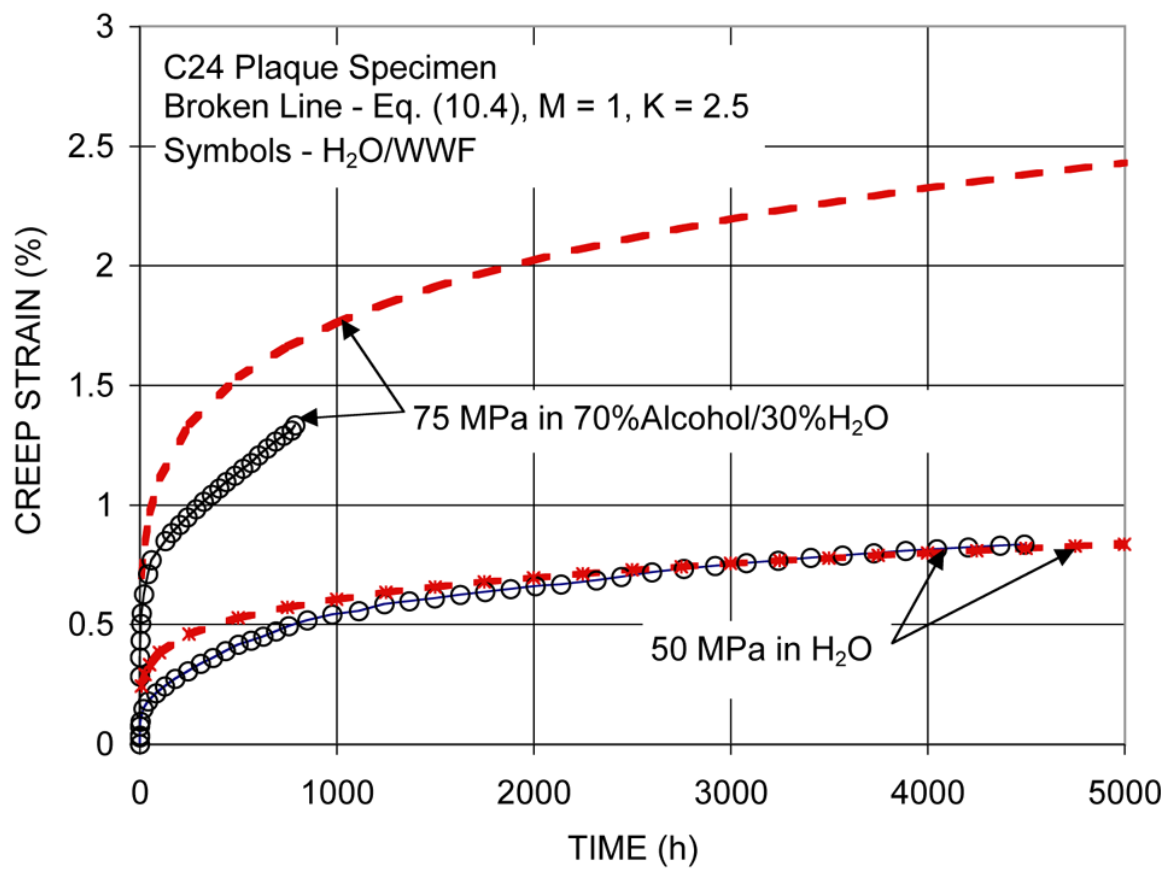

Fig. 10.15. Comparison of $\pm 45^{\circ}$ model predictions $(M=1, K=2.5)$ and time-dependent creep data from $\mathrm{C} 24$ specimens tested in water and windshield washer fluid.

ORNL 2001-930 EFG

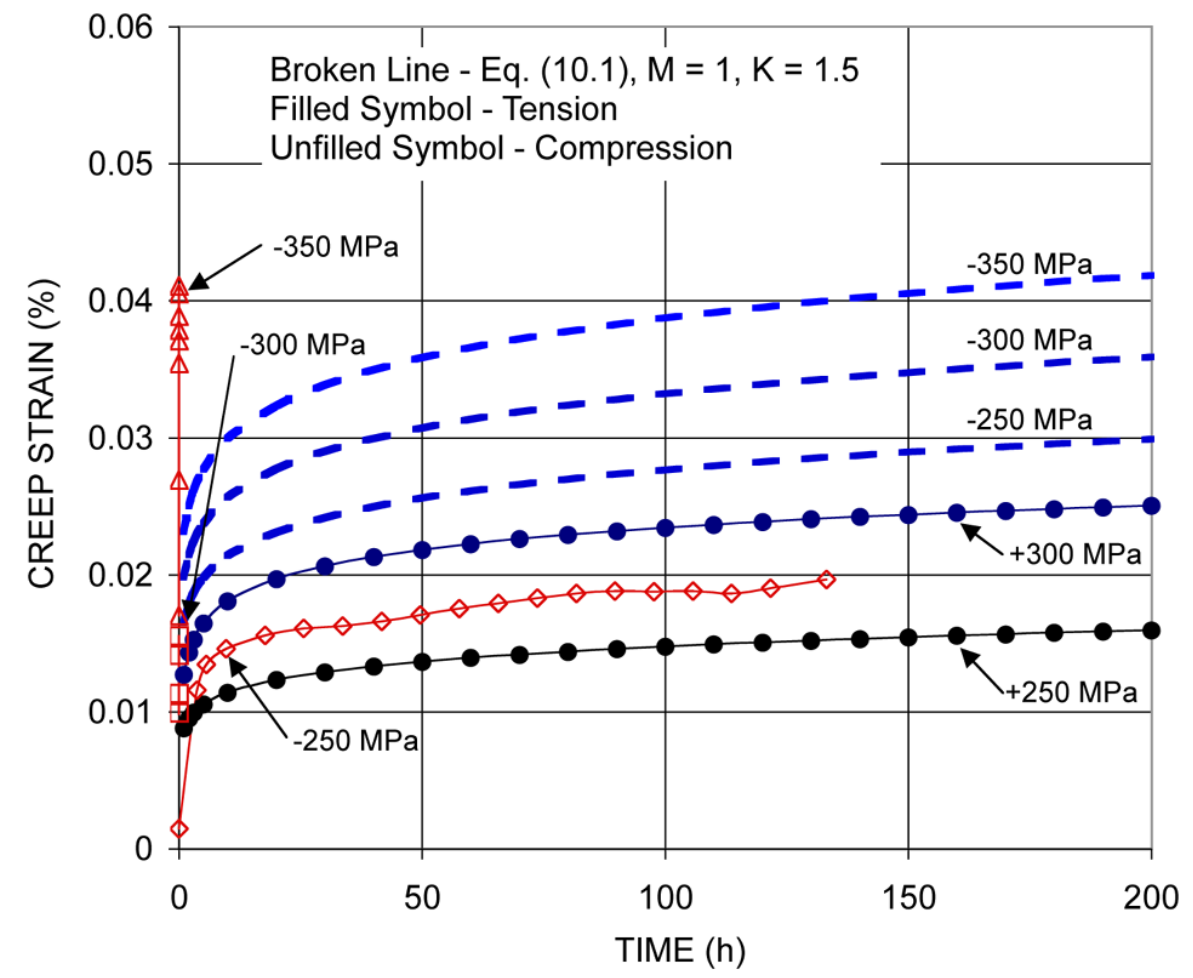

Fig. 10.16. Comparison of simulated $0 / 90^{\circ}$ compressive creep curves $(M=1$, $K=1.5$ ) and creep data from $\mathrm{C} 23$ specimens tested in either tension or compression. 


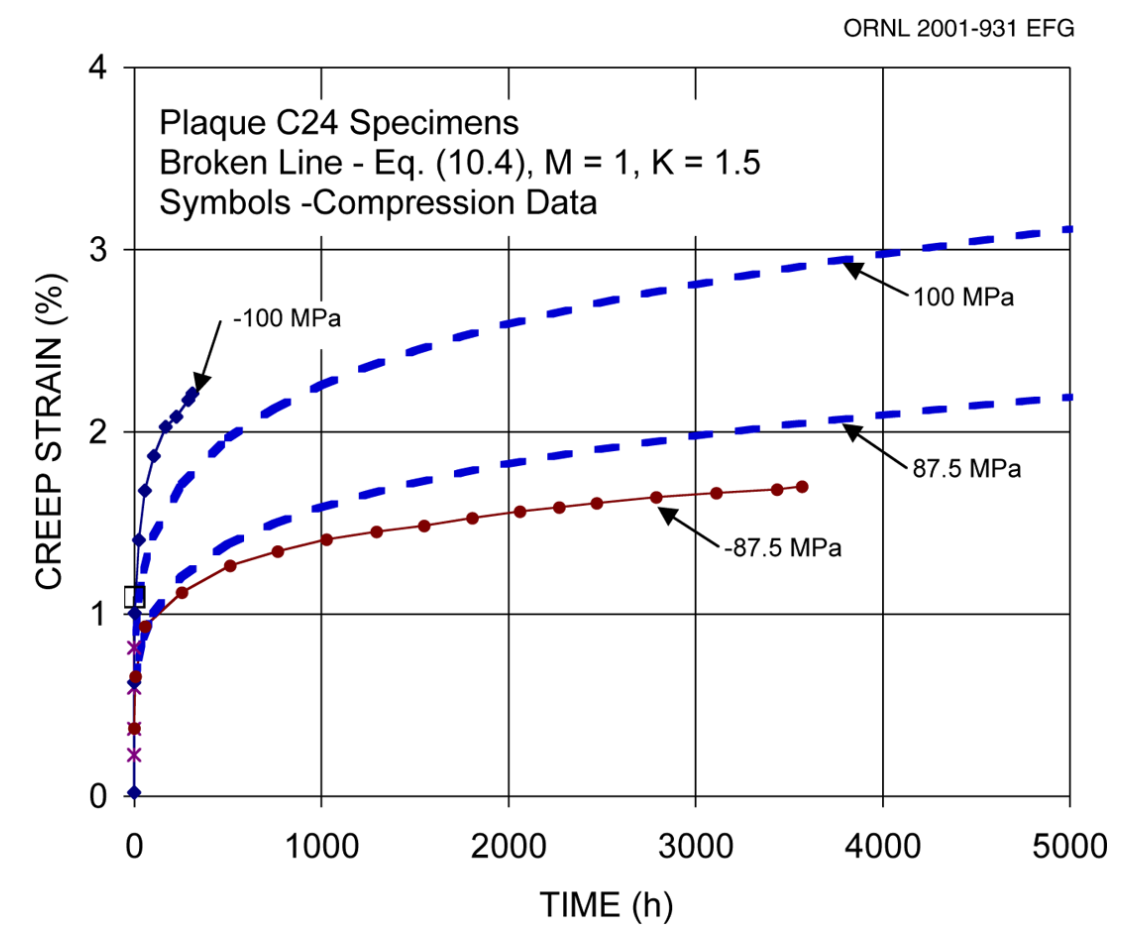

Fig. 10.17. Comparison of $\pm 45^{\circ}$ model predictions $(M=1, K=1.5)$ and time-dependent creep data from $\mathrm{C} 24$ specimens tested in compression. 


\title{
11. CREEP RUPTURE
}

\author{
K. C. Liu
}

The creep tests that were listed in Tables 10.1 (first test series) and Table 10.2 (second test series) included those tests that resulted in failures and were thus used in this chapter. Those tests are denoted in the tables. Nineteen tensile tests resulted in failures, including three in Table 10.2 that did not result in separation but were so damaged by cracks that they were considered to have failed. Several compressive creep tests also failed, usually with an element of buckling included in the failure mode. Results from the compressive tests are also included in this chapter.

\subsection{IN-AIR RESULTS}

The 19 tensile rupture points, including results from tests at $70^{\circ} \mathrm{C}$ and $120^{\circ} \mathrm{C}$ and tests in fluids, are plotted in Figs. 11.1 and 11.2, where rupture stress is shown vs rupture time. Note that all the stress-rupture data points for the $\pm 45^{\circ}$ specimens were normalized with respect to the load per number of fibers of the $\mathrm{C} 24$ plaque in accordance with the ratios given in Table 10.3. A stress vs rupture-time relationship was derived in a power-law form:

$$
\sigma=\mathrm{Bt}^{\mathrm{m}} \text {. }
$$

Here, $\sigma$ is the rupture stress, $\mathrm{t}$ is the rupture time, and $\mathrm{B}$ and $\mathrm{m}$ are constants. The baseline rupture equations representing the average stress-rupture behavior were derived using the least-squares regression method. The explicit forms of the average (Avg) and minimum stress-rupture (Min) and maximum design allowable stress (MDAS) equations for the $0 / 90^{\circ}$ direction and their curves are presented and labeled accordingly in Fig. 11.1, and those for the $\pm 45^{\circ}$ direction are in Fig. 11.2. The minimum curves represent the lower bound of the respective data group, and the MDAS curves represent $80 \%$ of the minimum rupture strength. All curves in each case were assumed to be parallel.

Cursory comparisons were made between the room-temperature stress-rupture strength of the crossply carbon-fiber composite and that of the chopped-glass-fiber composite, which used the same polymeric matrix. ${ }^{3}$ Results indicate that the former in the $0 / 90^{\circ}$ direction is higher than the latter by about $300 \%$ at room temperature (RT), but lower by about $15 \%$ in the $\pm 45^{\circ}$ direction. At $120^{\circ} \mathrm{C}$, the rupture strength relationship in the $0 / 90^{\circ}$ direction remained about the same as at RT, but decreased to about $50 \%$ in the $\pm 45^{\circ}$ direction.

\subsection{TEMPERATURE EFFECTS}

\subsubsection{The $0 / 90^{\circ}$ Fiber Orientation}

Creep deformation data for the $0 / 90^{\circ}$ specimens tested at elevated temperatures are summarized in Figs. 11.3-11.5. The figures include data for those specimens tested in fluid environments. The data show that the creep behavior at $70^{\circ} \mathrm{C}$ virtually followed the RT curves until the applied stress increased to $400 \mathrm{MPa}$. The two RT creep curves shown in Fig. 11.5 suggest that the behavior at the 400-MPa stress level may be rather unpredictable and plaque dependent. The $70^{\circ} \mathrm{C}$ curve for the $\mathrm{C} 22$ specimen at $400 \mathrm{MPa}$ is parallel to the RT curve of the $\mathrm{C} 23$ specimen, exhibiting similar behavior. Both of the specimens ruptured at or shortly after $700 \mathrm{~h}$ of testing, so that the tertiary creep being hinted at by the curves may be real behavior. Because the creep rates 
at $70^{\circ} \mathrm{C}$ are virtually the same as those at RT and the rupture point fell above the RT minimum curve shown in Fig. 11.1, the RT stress-rupture criteria are recommended for $70^{\circ} \mathrm{C}$ applications.

Creep resistance decreased dramatically as the temperature was increased to $120^{\circ} \mathrm{C}$, as the data in Figs. 11.3 and 11.4 indicate. Two $120^{\circ} \mathrm{C}$ data points were shown in Fig. 11.1—one rupture at $300 \mathrm{MPa}$ and another data point at $200 \mathrm{MPa}$ with an arrow indicating no rupture. The minimum stress-rupture curve was determined based on the sole rupture point at $120^{\circ} \mathrm{C}$ with respect to the RT curve. The minimum stress-rupture and MDAS equations and associated curves are illustrated in Fig. 11.1.

\subsubsection{The $\pm 45^{\circ}$ Fiber Orientation}

Three $\pm 45^{\circ}$ specimens ( $\mathrm{C} 24$ plaque) were tested at $70^{\circ} \mathrm{C}$, and the creep deformation results are plotted and compared with the RT data in Fig. 11.6. None of the three tests at $70^{\circ} \mathrm{C}$ reached rupture. The acquisition of the data for the test at $87.5 \mathrm{MPa}$ ceased due to strain gage failure shortly after the specimen was fully loaded, but the test was not discontinued until after completing $3400 \mathrm{~h}$ of testing. Because no stress-rupture data at $70^{\circ} \mathrm{C}$ are available, a tentative stressrupture criterion was deduced from the creep deformation behavior. The data show that the primary creep strains at $70^{\circ} \mathrm{C}$ are about four to six times those for the corresponding tests at RT. However, the creep rates after $100 \mathrm{~h}$ of testing at $70^{\circ} \mathrm{C}$ are about the same as at RT. If the total cumulative creep strains at $70^{\circ} \mathrm{C}$ and RT differ only by the initial primary creep strain, the RT stress-rupture criteria may be tentatively used.

As was demonstrated in Chap. 10, creep resistance in the $\pm 45^{\circ}$ direction decreased dramatically as the temperature was increased to $120^{\circ} \mathrm{C}$. Two stress-rupture data points at $120^{\circ} \mathrm{C}$ were plotted in Fig. 11.2, and the minimum stress-rupture curve was estimated based on the lower stress point with respect to the RT baseline curve.

\subsection{FLUID EFFECTS}

None of the creep tests in fluids resulted in rupture. Thus, an attempt was made to again determine reduction factors for stress-rupture curves based on creep deformation behavior. To this end, it was assumed that stress-rupture life is limited by the maximum creep strain that the composite can sustain under a given stress, temperature, and fluid environment. The reduction factors, which are relative to the RT baseline, were derived based on the creep-strain multiplication factors $\mathrm{K}$, given in Table 10.4. No tertiary creep was assumed to occur before specimen rupture.

When two time-dependent creep curves have the same basic form as shown in either Eq. (10.1) or (10.3) but differ only by a creep strain multiplication factor, the rupture times for the two specimens to reach the same rupture creep strain can be related to each other as

$$
\mathrm{t}_{0}=\mathrm{K}^{1 / \mathrm{n}} \mathrm{t}_{1}
$$

where $t_{0}$ is the reference rupture time, $t_{1}$ is the rupture time to be estimated, and $\mathrm{K}$ is the creep strain multiplication factor. Substitution of Eq. (11.2) into Eq. (11.1) with $t=t_{0}$ yields

$$
\sigma=\mathrm{B} \mathrm{R} \mathrm{t}
$$

where $\mathrm{R}=\mathrm{K}^{\mathrm{m} / \mathrm{n}}$ is the stress reduction factor. The stress reduction factors for the two standard fluid exposures are given in Table 11.1 and the equations and associated curves are shown in Figs. 11.7 and 11.8 for comparison. 
Table 11.1. Stress reduction factors to account for fluids and compression

\begin{tabular}{lcc}
\hline \multirow{2}{*}{ Condition } & \multicolumn{2}{c}{$\mathbf{R}$} \\
\cline { 2 - 3 } & $\mathbf{0 / 9 0 ^ { \circ }}$ & $\mathbf{\mathbf { 4 4 5 } ^ { \circ }}$ \\
\hline Water/windshield washer fluid & 0.95 & 0.93 \\
Compression & 0.98 & 0.97 \\
\hline
\end{tabular}

\subsection{COMPRESSION EFFECTS}

A number of specimens tested in compression failed due to buckling, usually occurring in less than a minute after the specimen was fully loaded (see Table 10.2). Therefore, the resulting data do not represent true stress-rupture life because the failure was the consequence of a synergy with bending. Thus, the same technique discussed in the preceding section was employed to estimate the stress reduction factors for stress rupture in compression. Results are included in Table 11.1, and the stress-rupture equations and associated curves are included in Figs. 11.7 and 11.8.

\subsection{SUMMARY}

The baseline maximum design allowable stress (MDAS) curves to guard against creep rupture were developed from the RT in-air creep-rupture data by taking $80 \%$ of the minimum creep-rupture curves. The $80 \%$ factor is commonly used for metals and has been judged to be appropriate for automotive composites. ${ }^{1,3}$ The minimum curves for each fiber orientation were established by bounding the lower data points with a curve parallel to the average creep-rupture curve. The resulting MDAS curves are represented by the following equations. In these equations, $\mathrm{S}_{\mathrm{r}}$ denotes the minimum stress to rupture in $\mathrm{MPa}$, and $\mathrm{t}$ is time in hours.

$$
\begin{aligned}
& \text { For } 0 / 90^{\circ}: \text { MDAS }=0.8 \mathrm{~S}_{\mathrm{r}}=322.58 \mathrm{t}^{-0.00457} . \\
& \text { For } \pm 45^{\circ}: \mathrm{MDAS}=0.8 \mathrm{~S}_{\mathrm{r}}=90.64 \mathrm{t}^{-0.0155} .
\end{aligned}
$$

Because of the limited amount of rupture data available at elevated temperatures, in fluids and under compressive loadings, it was necessary to assume that the creep-rupture curves for each of these various conditions were, for each fiber orientation, parallel to the RT, in-air baseline curve. A single stress reduction factor could then be specified for each condition. Table 11.2 summarizes the factors.

While these factors are recognized as approximations, it is thought that they capture the essence of the effects, and they were used in developing the time-dependent allowable stresses in Chap. 3.

Table 11.2. Creep-rupture stress reduction factors

\begin{tabular}{lll}
\hline \multirow{2}{*}{ Condition } & \multicolumn{2}{c}{ Fiber orientation } \\
\cline { 2 - 3 } & $\mathbf{0 / 9 0}^{\circ}$ & $\mathbf{\pm 4 5}^{\circ}$ \\
\hline $\mathbf{7 0}^{\circ} \mathbf{C}$ & 1.0 & 1.0 \\
$\mathbf{1 2 0}^{\circ} \mathbf{C}$ & 0.92 & 0.47 \\
Fluid exposure & 0.95 & 0.93 \\
Compressive loading & 0.98 & 0.97 \\
\hline
\end{tabular}

11-3 
ORNL 2001-932 EFG

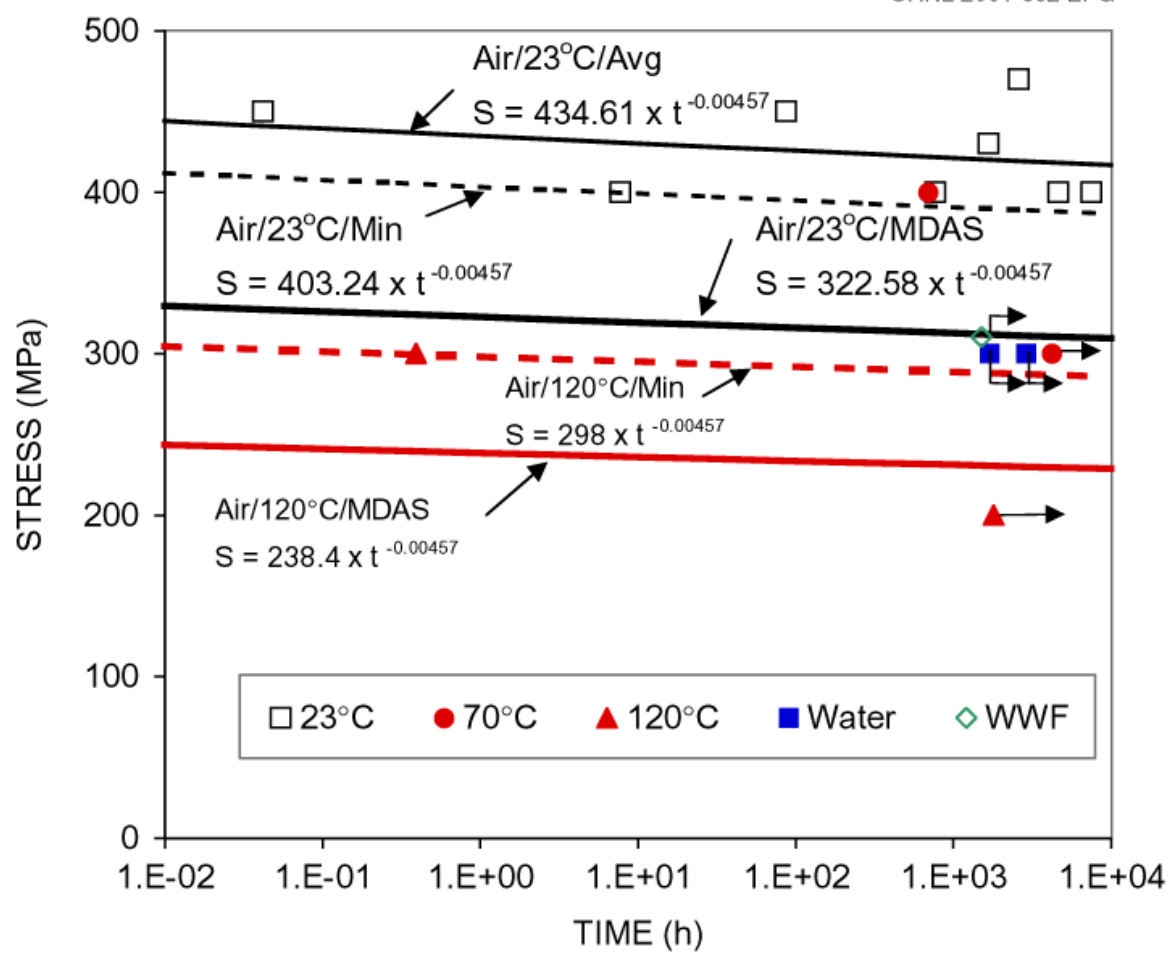

Fig. 11.1. Stress-rupture data and relationships for $0 / 90^{\circ}$ specimens.

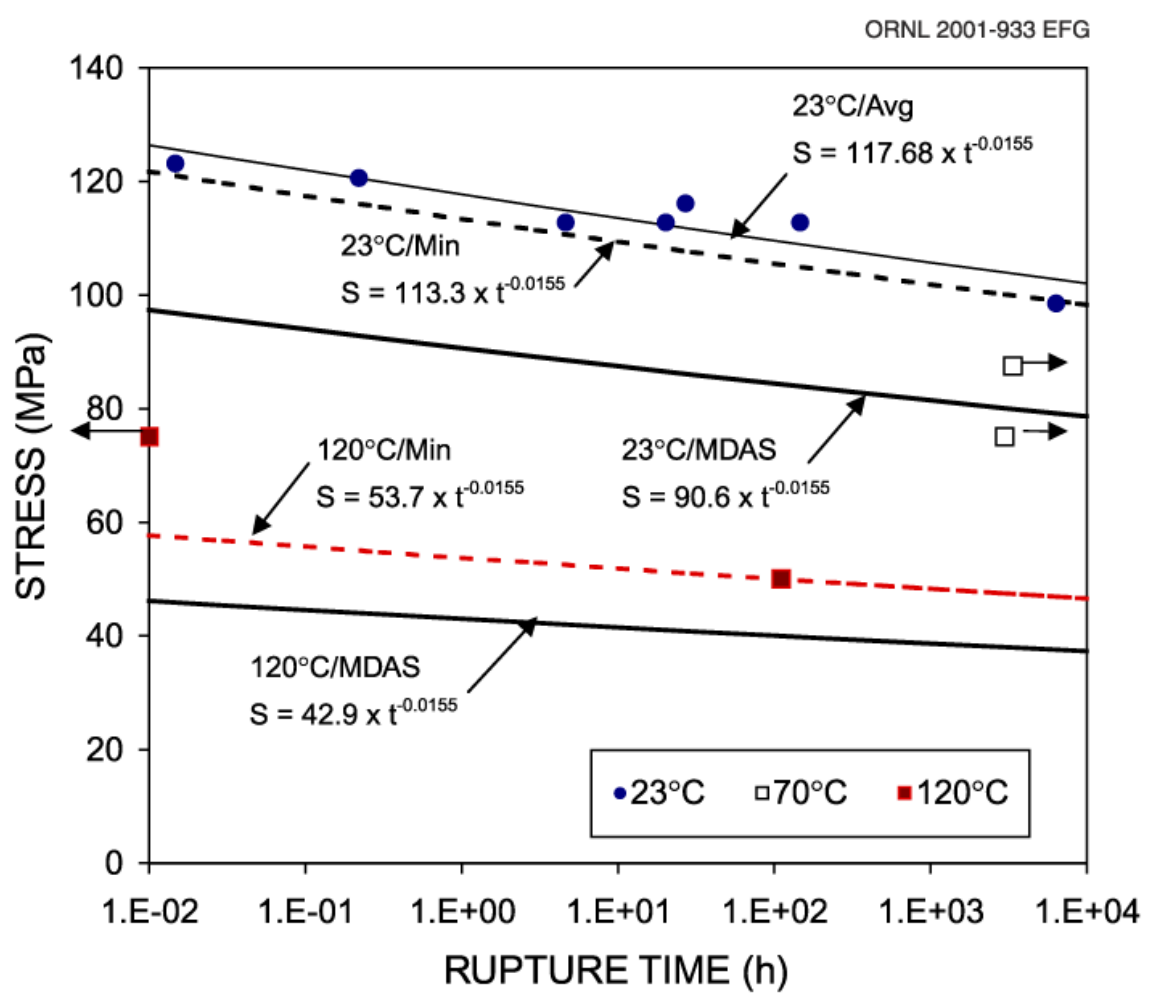

Fig. 11.2. Stress-rupture data and relationships for $\pm 45^{\circ} \mathrm{C} 24$ specimens. 
ORNL 2001-934 EFG

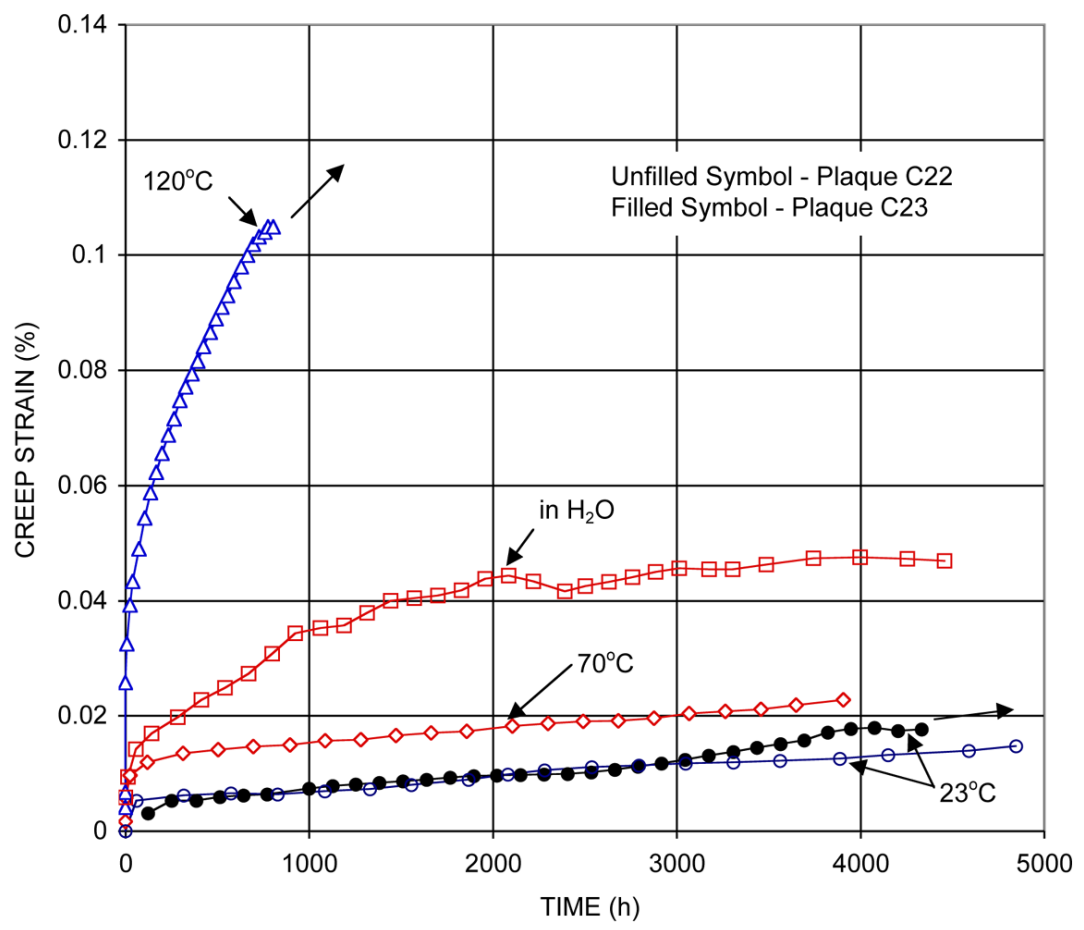

Fig. 11.3. Comparison of creep behavior of $0 / 90^{\circ}$ specimens tested at $200 \mathrm{MPa}$ at elevated temperatures and in distilled water.

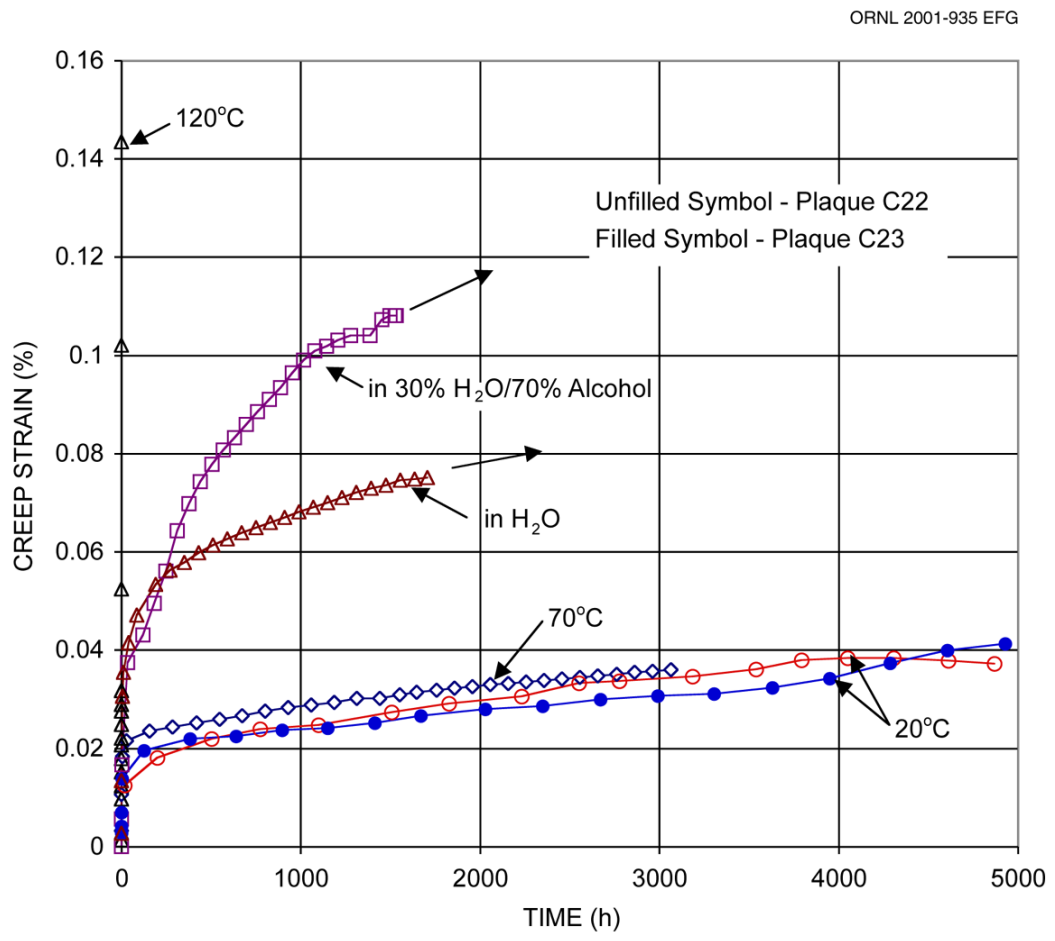

Fig. 11.4. Comparison of creep behavior of $0 / 90^{\circ}$ specimens tested at $300 \mathrm{MPa}$ at elevated temperatures and in distilled water and windshield washer fluid. 


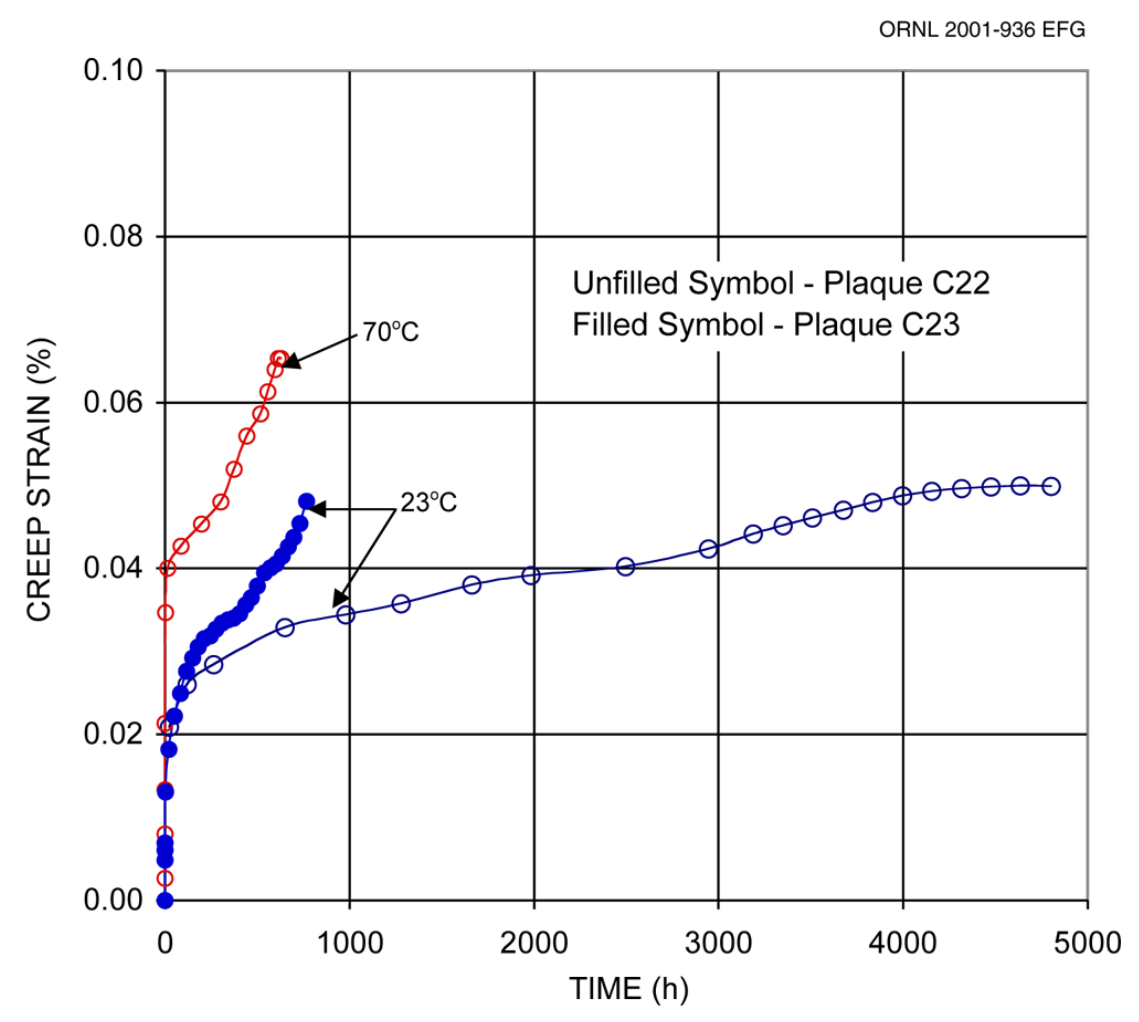

Fig. 11.5. Comparison of creep behavior of $0 / 90^{\circ}$ specimens tested at $400 \mathrm{MPa}$ at $23^{\circ}$ and $70^{\circ} \mathrm{C}$.

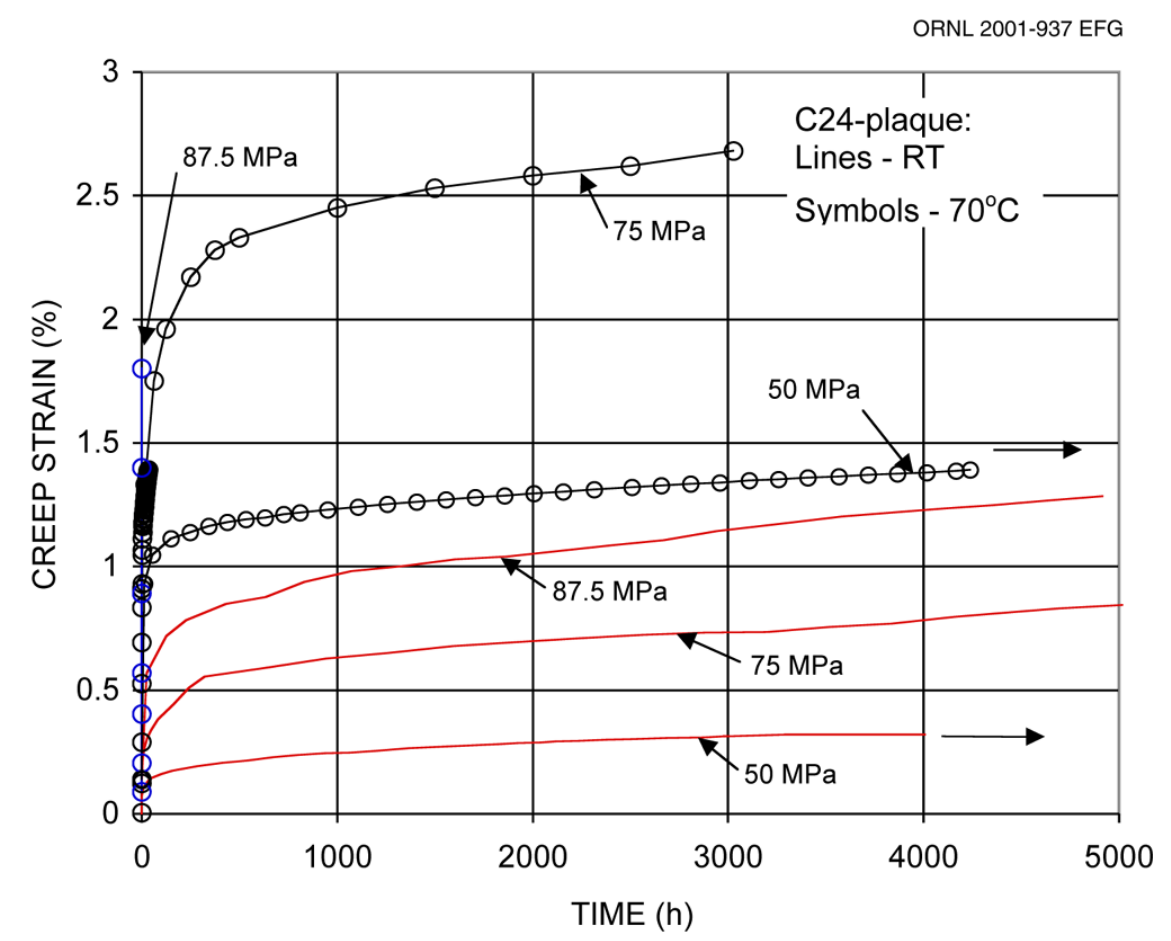

Fig. 11.6. Creep data for $\pm 45^{\circ} \mathrm{C} 24$ specimens at room temperature and $70^{\circ} \mathrm{C}$. 


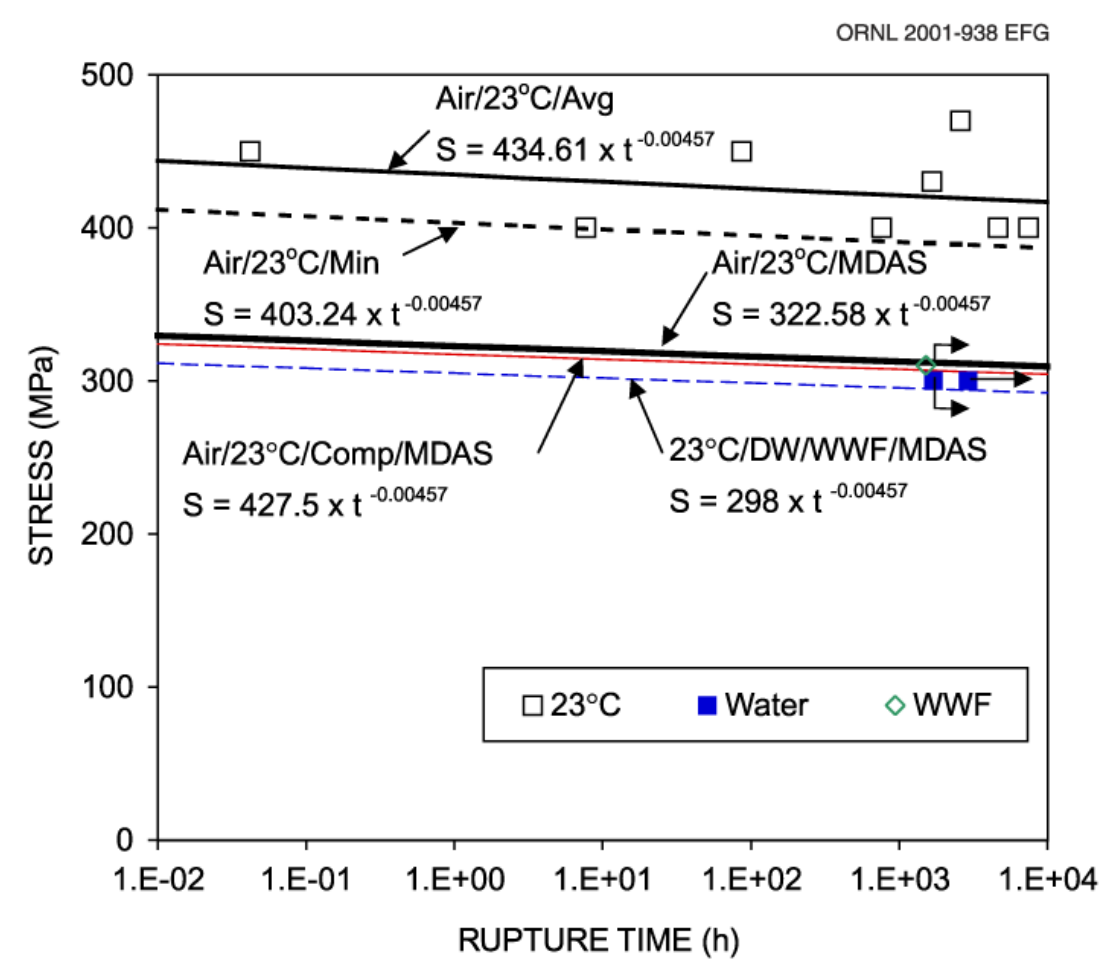

Fig. 11.7. MDAS curves for plaques $\mathrm{C} 22$ and $\mathrm{C} 23\left(0 / 90^{\circ}\right)$ for fluid environments and for compressive loading.

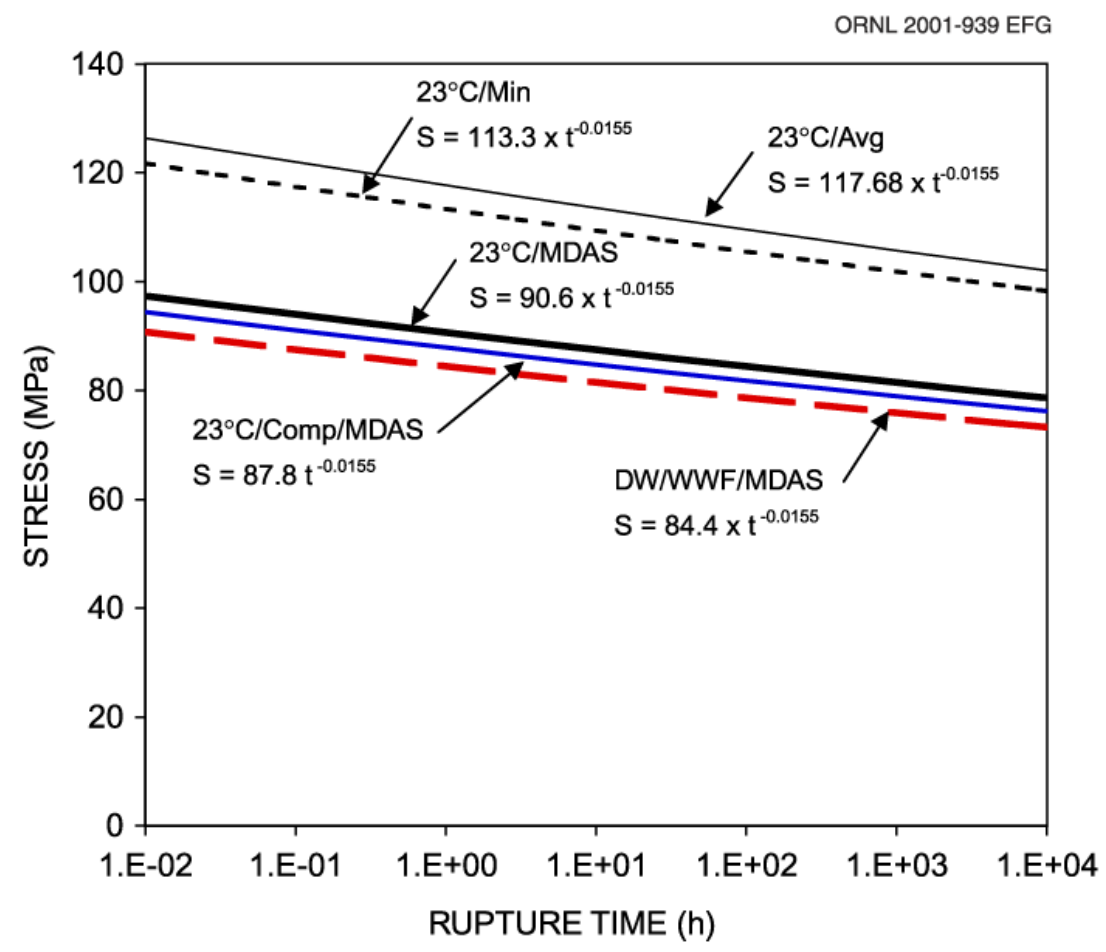

Fig. 11.8. MDAS curves for plaque $\mathrm{C} 24\left( \pm 45^{\circ}\right)$ for fluid environments and for compressive loading. 


\title{
12. TIME-DEPENDENT DEFORMATION RESPONSE: DATA AND MODELING
}

\author{
S. Deng and Y. J. Weitsman
}

\subsection{INTRODUCTION}

The purpose of this chapter is to develop a predictive method for the time-dependent deformation behavior of stitched T300 mat/urethane IMR resin crossply laminates subjected to mechanical loading. This objective is achieved by evaluating the material parameters that govern the shear and transverse compliances $Q_{66}$ and $Q_{22}$ of the individual plies. In the absence of uniaxially reinforced composite specimens, all experiments were performed with coupons cut at various orientations from symmetrically laid-up crossply plaques. The experiments consisted of collecting creep and recovery data for a wide range of stress levels, and with load durations ranging between 1 and $24 \mathrm{~h}$.

Employing classical lamination and viscoelasticity theories, it was possible to extract the basic time-dependent properties from data collected on crossply specimens where the load was oriented at $45^{\circ}$ to the fiber directions. Subsequently, the aforementioned properties were used within the general theoretical framework to predict the deformation of coupons oriented at $15^{\circ}$ and $34^{\circ}$ to the load directions, resulting in a good agreement with experimental data.

Note that the predictive model is confined to the linear range of material response, where strains are proportional to stresses.

The results and analysis presented here extend previously reported information.

\subsection{CREEP AND RECOVERY STRAINS OF $\left( \pm 45^{\circ}\right)_{3 S}$ COUPONS AT ROOM TEMPERATURE}

Creep and recovery data were collected under the application of several levels of constant stress $\sigma_{\mathrm{o}}$ for a time interval $0 \leq t \leq t_{\mathrm{O}}$ and following stress removal. Three load durations $t_{\mathrm{o}}$ were employed, namely, 1,5 , and $24 \mathrm{~h}$, which were followed by the monitoring of recovery strains for additional periods of 15,15 , and $48 \mathrm{~h}$, respectively. At least three replicate specimens were employed for each circumstance. The lay-up and load orientation, taken about the fiber direction in the outer plies, are shown in Fig. 12.1.

Results are exhibited in Figs. 12.2-12.7, where average values are shown together with scatter bands that correspond to standard deviations. Note that no complete recovery was achieved for stresses that exceeded approximately $40 \mathrm{MPa}$. The presence of nonrecoverable strain, which persisted long after stress removal, was attributed to the onset of irreversible damage that occurred at stresses larger than $40 \mathrm{MPa} .{ }^{11}$

The above data were fitted into a power-law creep form expressed by

$$
\varepsilon(t)=\left(D_{\mathrm{o}}+D_{1} t^{n}\right) \sigma_{\mathrm{o}} \text { for } 0 \leq t \leq t_{\mathrm{o}}
$$

which leads to the following expression for the recovery strain

$$
\varepsilon(t)=D_{1}\left[t^{n}-\left(t-t_{o}\right)^{n}\right] \sigma_{o}+\varepsilon_{p} \text { for } t>t_{\mathrm{o}} .
$$

In Eq. (12.2), $\varepsilon_{p}$ denotes the nonrecoverable permanent portion of strain. 
The resulting values for the fitting parameters $D_{\mathrm{o}}, D_{1}$, and $n$ are listed in Table 12.1. These values represent the averages obtained from the three or more replicate tests for each circumstance listed.

Note that on averaging the values of $D_{\mathrm{o}}, D_{1}$, and $n$ for each stress level, $\bar{D}_{o}$ and $\bar{n}$ increase moderately with $\sigma_{\mathrm{o}}\left(\bar{D}_{o}\right.$ by about $64 \%$ and $\bar{n}$ by $\left.20 \%\right) ; \bar{D}_{1}$ increases more than tenfold. Also note that $D_{1}$ tends to increase, while $n$ tends to decrease with creep duration. In fact the average value of $n$ for all 24-h creep data is $n=0.202$, which agrees remarkably well with $n=0.2$ for the long-term data, as expressed in Chap. 10 [Eq. (10.4)]. This suggests that early stage creep mechanisms may differ from those that occur at later times. Alternately, the above observation suggests that power-law creep cannot account for all the internal mechanisms that cause the timedependent response of the material at hand; it is therefore limited in its ability to predict long-tem deformation on the basis of short-term data. Nevertheless, the foregoing data are still useful for interpreting material behavior within the linear range of response.

Table 12.1. Parameters used for fitting the creep and recovery data of $45^{\circ}$ coupons

\begin{tabular}{|c|c|c|c|c|c|}
\hline $\begin{array}{c}\sigma_{\mathbf{0}} \\
(\mathrm{MPa})\end{array}$ & $\begin{array}{l}\text { Creep time } \\
\text { (h) }\end{array}$ & $\begin{array}{l}\text { Recovery time } \\
\text { (h) }\end{array}$ & $\begin{array}{c}\mathrm{D}_{\mathrm{o}} \\
10^{-5}\left(\mathrm{MPa}^{-1}\right)\end{array}$ & $\begin{array}{c}\mathrm{D}_{1} \\
10^{-6}\left(\mathrm{MPa}^{-\mathrm{n}_{\min ^{-n}}}\right)\end{array}$ & n \\
\hline 31.0 & 1 & 15 & 8.07 & 2.85 & 0.245 \\
\hline 31.0 & 5 & 15 & 7.94 & 2.27 & 0.283 \\
\hline 31.0 & 24 & 48 & 8.37 & 2.35 & 0.187 \\
\hline Average & & & 8.13 & 2.49 & 0.238 \\
\hline 46.5 & 1 & 15 & 9.24 & 3.28 & 0.285 \\
\hline 46.5 & 5 & 15 & 8.75 & 2.54 & 0.299 \\
\hline 46.5 & 24 & 48 & 8.18 & 3.89 & 0.224 \\
\hline Average & & & 8.78 & 3.01 & 0.277 \\
\hline 62.0 & 1 & 15 & 8.47 & 5.09 & 0.271 \\
\hline 62.0 & 5 & 15 & 8.83 & 6.13 & 0.277 \\
\hline 62.0 & 24 & 48 & 8.67 & 7.57 & 0.211 \\
\hline Average & & & 8.66 & 6.26 & 0.253 \\
\hline 77.5 & 1 & 15 & 9.52 & 8.43 & 0.298 \\
\hline 77.5 & 5 & 15 & 10.2 & 7.97 & 0.289 \\
\hline 77.5 & 24 & 48 & 8.63 & 11.6 & 0.195 \\
\hline Average & & & 9.45 & 9.33 & 0.261 \\
\hline 93.0 & 1 & 15 & 9.84 & 11.6 & 0.290 \\
\hline 93.0 & 5 & 15 & 9.44 & 16.4 & 0.223 \\
\hline 93.0 & 24 & 48 & 9.46 & 18.2 & 0.179 \\
\hline Average & & & 9.58 & 15.4 & 0.230 \\
\hline 108.5 & 1 & 15 & 11.9 & 22.8 & 0.251 \\
\hline 108.5 & 5 & 15 & 13.7 & 28.5 & 0.237 \\
\hline 108.5 & 24 & 48 & 14.3 & 25.6 & 0.220 \\
\hline Average & & & 13.3 & 25.6 & 0.236 \\
\hline
\end{tabular}


The power-law fit parameters, listed in Table 12.1, were employed to match the data shown in Figs. 12.2-12.7. These "best parameter fit" curves are given by the solid lines shown there. Note that recovery strains exhibited in Figs. 12.3, 12.5, and 12.7 could be predicted rather well for stress levels below 46.5 MPa, while even larger deviations between Eq. (12.2) and actual data occurred with increasing stress.

The substantial increase in data scatter with stress amplitude, exhibited in Figs. 12.2-12.7, is attributable to the onset and growth of internal damage. Because this damage, mainly in the form

of fiber/matrix debondings, ${ }^{17}$ is distributed nonuniformly along the coupon's length, it results in a wide scatter in the recordings of creep strain as best demonstrated by the deformation data collected in a multigaged sample subjected to an elevated stress shown in Fig. 12.8. Strain gages that happened to straddle regions of localized damage record much higher strains than those located above undamaged zones. This wide scatter in creep data precluded the establishment of a predictive model, based on continuum concepts, in those circumstances when damage becomes of paramount importance. Consequently, the predictive model formulated below is restricted to the linear range of material behavior or, at most, to the cases when damage is inconsequential, namely, for "limited" nonlinearity.

\subsection{MODEL DEVELOPMENT}

\subsubsection{Linear-Elastic Behavior of Crossply Laminates}

Linear-elastic laminated plate theory ${ }^{18}$ gives the following expression for the longitudinal strain $\varepsilon_{x}$ in a $[\phi /(\phi+\pi / 2)]_{3 S}$ crossply coupon subjected to a uniaxial stress $\sigma_{x}$ :

$$
\varepsilon_{x}=12 h\left[\frac{A_{11} A_{66}-A_{16}^{2}}{A_{66}\left(A_{11}^{2}-A_{12}^{2}\right)-2 A_{16}^{2}\left(A_{11}+A_{22}\right)}\right] \sigma_{x},
$$

where

$$
\begin{aligned}
& A_{11}=A_{22}=6 h\left[\left(m^{4}+n^{4}\right)\left(Q_{11}+Q_{22}\right)+4 m^{2} n^{2}\left(Q_{12}+2 Q_{66}\right)\right], \\
& A_{12}=6 h\left[2 m^{2} n^{2}\left(Q_{11}+Q_{22}\right)+2\left(m^{4}+n^{4}\right) Q_{12}-8 m^{2} n^{2} Q_{66}\right], \\
& A_{16}=-A_{26}=6 h\left[\left(m^{3} n-m n^{3}\right)\left(Q_{11}+Q_{22}\right)+2\left(m n^{3}-m^{3} n\right)\left(Q_{12}+2 Q_{66}\right)\right], \\
& A_{66}=6 h\left[2 m^{2} n^{2}\left(Q_{11}+Q_{22}\right)-4 m^{2} n^{2} Q_{12}+2\left(m^{2}-n^{2}\right)^{2} Q_{66}\right] .
\end{aligned}
$$

In Eqs. (12.3) and (12.4), $h$ denotes ply thickness, $m=\cos \phi$, and $\mathrm{n}=\sin \phi$. For the material at hand $h=0.25 \mathrm{~mm}$, and $Q_{11}+Q_{22}=89.7 \mathrm{GPa}, Q_{12}=3.1 \mathrm{GPa}$, and $Q_{66}=3.3 \mathrm{GPa} .{ }^{* 19}$

Note that Eq. (12.4) involves only the lumped sum of $Q_{11}+Q_{22}$ rather than their individual values. Employing micromechanical analysis, ${ }^{19}$ these individual values were estimated to be $Q_{11}=89 \mathrm{GPa}$ and $Q_{22}=0.7 \mathrm{GPa}$.

For $\phi= \pm 45^{\circ}$, Eq. (12.3) reduces to

$$
\varepsilon_{x}=\frac{1}{4}\left(\frac{4}{Q_{00}}+\frac{1}{Q_{66}}\right) \sigma_{x},
$$

where $Q_{00}=Q_{11}+Q_{22}+2 Q_{12}$.

\footnotetext{
*Note that these values exhibit data scatter of about $\pm 3 \%$.
} 


\subsubsection{Time-Dependent Behavior}

Of the four lamina stiffness components $Q_{11}, Q_{12}, Q_{22}$, and $Q_{66}$, the latter two, namely the transverse stiffness $Q_{22}$ and the shear stiffness $Q_{66}$, depend significantly on the properties of the polymeric resin phase. Because polymers are known to creep under imposed stresses, it is reasonable to associate the creep of crossply laminates with the time-dependence of $Q_{22}$ and $Q_{66}$.

As noted earlier, $Q_{22}$ appears in Eqs. (12.3) and (12.4) only in conjunction with $Q_{11}$, namely as part of the sum of $Q_{11}+Q_{22}$. Previously obtained data on neat urethane resin ${ }^{20}$ showed that its stiffness could decrease by up to $25-30 \%$ with time. Assuming that $Q_{22}$ decreases by approximately the same amount, one obtains that $Q_{11}+Q_{22}$ would vary between 89.5 and 89.7 $\mathrm{GPa}$, namely by less than $0.2 \%$. This miniscule amount of time-dependence is indeed observed for the $0^{\circ} / 90^{\circ}$ case $\left[\phi=0^{\circ}\right.$ in Eq. (12.3), in which case $Q_{66}$ is absent in the stress-strain relation]. However, the foregoing amount is too insignificant to account for the recorded amount of creep in $\pm 45^{\circ}$ lay-ups $\left(\phi=45^{\circ}\right)$, as exhibited in Figs. 12.2-12.7.

It is thus concluded that creep in the $\pm 45^{\circ}$ fiber orientation case is caused by the timedependence of the shear stiffness $Q_{66}$ in Eq. (12.5), namely due to $Q_{66}(t)$.

\subsubsection{Calibration of Creep Data at $\phi=4^{\circ}$ to Determine the Time-Dependent Shear Stiffness $Q_{66}(t)$}

It is possible to use the creep data for the $\pm 45^{\circ}$ fiber orientations, which are shown in larger detail in Figs. 12.9 and 12.10, to "calibrate" the expression for $Q_{66}(t)$. This is accomplished by equating the empirical data-fit Eq. (12.1) with the laminated plate Eq. (12.5) in which

$$
Q_{66}=Q_{66}(t)=Q_{66}(0)+\Delta Q_{66}(t)
$$

The aforementioned equality yields

$$
\frac{1}{4}\left(\frac{4}{\mathrm{Q}_{00}}+\frac{1}{\mathrm{Q}_{66}(0)}\right)=\mathrm{D}_{\mathrm{o}},
$$

and

$$
\frac{1}{Q_{66}(t)}=\frac{1}{Q_{66}(0)}+4 D_{1} t^{n}
$$

where $D_{\mathrm{o}}=8.13 \times 10^{-5} \mathrm{MPa}^{-1}, D_{1}=2.49 \times 10^{-6} \mathrm{MPa}^{-\mathrm{n}} \min ^{-\mathrm{n}}, n=0.238$, and $t$ is time in minutes.*

\subsection{PREDICTIONS FOR OTHER ORIENTATIONS}

With $Q_{66}(t)$ determined by Eq. (12.8) it is now possible to compute the time-dependent strain at other orientations $\phi$ by means of Eqs. (12.3) and (12.4). Direct substitution of numerical values for $\phi=15^{\circ}$ and $34^{\circ}$ as well as for various times $t$ results in the predictive curves for $\varepsilon(t)$ shown in Figs. 12.11-12.14. These predictive values are compared against experimental creep

\footnotetext{
*Note again that Eq. (12.7) requires $D_{\mathrm{O}}=7.85 \times 10^{-5} \mathrm{MPa}^{-1}$, rather than the experimental-fit value of $8.13 \times$ $10^{-5} \mathrm{MPa}^{-1}$. However, this discrepancy falls within the scatter range of $Q_{00}$ and $Q_{66}$.
} 
results obtained with at least three replicate specimens for each circumstance. Note the very good agreement between predicted and recorded creep behavior exhibited in the latter four figures.

As remarked earlier, for $\phi=0$, Eqs. (12.3) and (12.4) give

$$
\varepsilon_{x}=\frac{2\left(Q_{11}+Q_{22}\right)}{\left(Q_{11}+Q_{22}\right)^{2}-4 Q_{12}^{2}} \sigma_{x} .
$$

Thus, the expected amount of creep, all due to the time dependence of $Q_{22}$, should cause $\varepsilon_{x}$ to increase by about $0.2 \%$ over time. Results shown in Fig. 12.15 tend to confirm this prediction even at the relatively high stress level of $350 \mathrm{MPa}$.

\subsection{NONLINEAR CREEP OF $\pm 45^{\circ}$ COUPONS}

As noted earlier, it is impossible to predict behavior under excessively high stresses by means of a continuum model in view of the presence of randomly localized damage within the test specimens. However, when such damage is absent, it is possible to predict creep behavior under limited excursions into the nonlinear range of response.

For this purpose, consider the case of a two-step stress history applied to a $\left( \pm 45^{\circ}\right)_{3 \mathrm{~S}}$ sample, namely:

$$
\sigma=\sigma_{o}\left[H(t)-H\left(t_{1}\right)\right]+\left(\sigma_{1}-\sigma_{o}\right)\left[H\left(t_{o}\right)-H\left(t_{1}\right)\right]
$$

where $\mathrm{H}(\cdot)$ denotes the unit step function.

The following specific values were employed in the test program: $\sigma_{\mathrm{o}}=31 \mathrm{MPa}, \sigma_{1}=$ $46.5 \mathrm{MPa}, t_{\mathrm{O}}=300 \mathrm{~min}$, and $t_{1}=600 \mathrm{~min}$. The above stress history is shown by the dotted line in Fig. 12.16.

As noted from Table 12.1, the creep parameters $D_{0}, D_{1}$, and $n$ vary with the stress level $\sigma$. Specifically, for $\sigma=31 \mathrm{MPa}, D_{\mathrm{o}}=7.85 \times 10^{-5} \mathrm{MPa}^{-1}, D_{1}=2.49 \times 10^{-6} \mathrm{MPa}^{-\mathrm{n}} \mathrm{min}^{-\mathrm{n}}$, and $n=$ 0.238 ; while for $\sigma=46.5 \mathrm{MPa}, D_{\mathrm{o}}=8 \times 10^{-5} \mathrm{MPa}^{-1}, D_{1}=3.24 \times 10^{-6} \mathrm{MPa}^{-\mathrm{n}} \mathrm{min}^{-\mathrm{n}}$, and $n=$ 0.269 . (The average numerical values of the above parameters are $7.93 \times 10^{--5}, 2.87 \times 10^{-6}$, and 0.253 , respectively.)

A good prediction for the creep and recovery under the above two-step stress history is obtained by superimposing the creep and recovery strains that result from $\sigma(t)=\sigma_{\mathrm{o}}\left[H(t)-H\left(t_{\mathrm{o}}\right)\right]$ with values of $D_{\mathrm{o}}, D_{1}$, and $n$ that correspond to $\sigma_{\mathrm{o}}=31 \mathrm{MPa}$ and the creep and recovery strains caused by $\sigma(t)=\sigma_{1}\left[H\left(t_{0}\right)-H\left(t_{1}\right)\right]$ with values of $D_{0}, D_{1}$, and $n$ associated with $\sigma_{1}=46.5 \mathrm{MPa}$. This "piecewise superposition" that uses stress-varying creep parameters ${ }^{21}$ provides a far better agreement with creep data than linear superposition employing average values of creep parameters $D_{\mathrm{o}}, D_{1}$, and $n$. Results are shown in Fig. 12.16 .

\subsection{POISSON'S RATIO FOR $\left( \pm 45^{\circ}\right)_{3 S}$ COUPONS}

Lamination theory provides the following general expression for the Poisson's ratio $v_{x y}$ of a crossply laminate due to a uniaxial stress $\sigma_{x}$ :

$$
v_{x y}=-\frac{\varepsilon_{y}}{\varepsilon_{x}}=\frac{A_{12} A_{66}-A_{16} A_{26}}{A_{22} A_{66}-A_{26}^{2}}
$$


which, for the special case of $\left( \pm 45^{\circ}\right)_{3 \mathrm{~S}}$, yields

$$
v_{x y}=\frac{\frac{1}{2}\left(Q_{11}+Q_{22}+2 Q_{12}\right)-2 Q_{66}(t)}{\frac{1}{2}\left(Q_{11}+Q_{22}+2 Q_{12}\right)+2 Q_{66}(t)}
$$

In Eq. (12.12), $Q_{66}$ was taken to be time-dependent according to Eq. (12.8).

Substituting the previously listed values for $Q_{11}+Q_{22}, Q_{12}$, and $Q_{66}(t)$ into Eq. (12.12), one concludes that $v_{x y}$ decreases from 0.751 to 0.748 as time increases from 0 to $300 \mathrm{~min}$. Experimental results collected from multigaged specimens are shown in Fig. 12.17. Although these results exhibit a wide scatter of values, they confirm the prediction that the $v_{x y}$ is essentially time-independent.

\subsection{CONCLUDING REMARKS}

It was shown that the creep behavior of crossply stitched T300 mat/urethane 420 IMR resin composite laminates can be explained and predicted on the basis of classical lamination theory and basic concepts of viscoelasticity theory. Although these predictions are limited to the linear or "slightly" nonlinear range of response, they provide an effective design tool for the stress range of practical significance. It was also noted that predictions based on relatively short-time creep data, namely up to $24 \mathrm{~h}$, may overestimate the actual levels of long-term deformation. However, this uncertainty errs on the safe side; in any event, such errors may well fall within the range of sample-to-sample scatter of data. Within the linear range, the current model predicts reasonably well the long-term creep data presented in Chap. 11. Nevertheless, this prediction is less satisfactory than in the case of chopped-glass strand mat reinforcement.

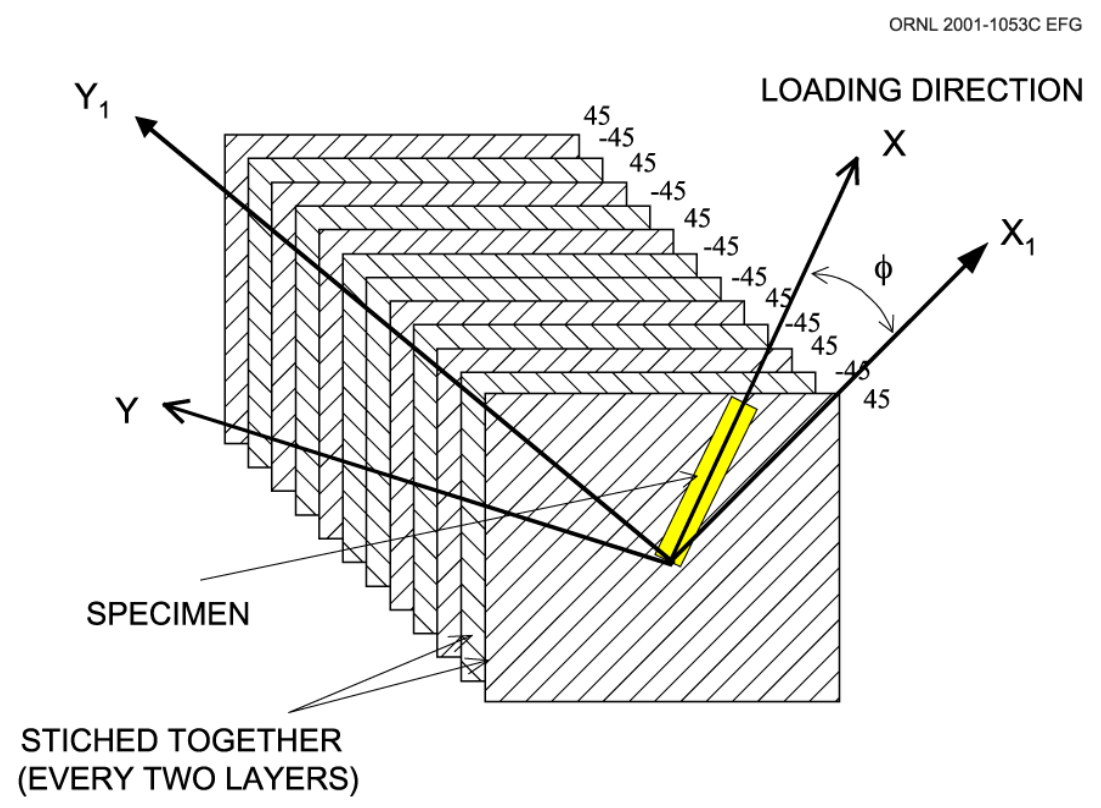

Fig. 12.1. Schematic drawing of crossply-stitched T300 mat/urethane 420 IMR resin composite laminate $\left( \pm 45^{\circ}\right) 3 \mathrm{~S}$, showing load orientation angle $\phi$.

\footnotetext{
"The data scatter is most likely because the test coupons were not flat.
} 


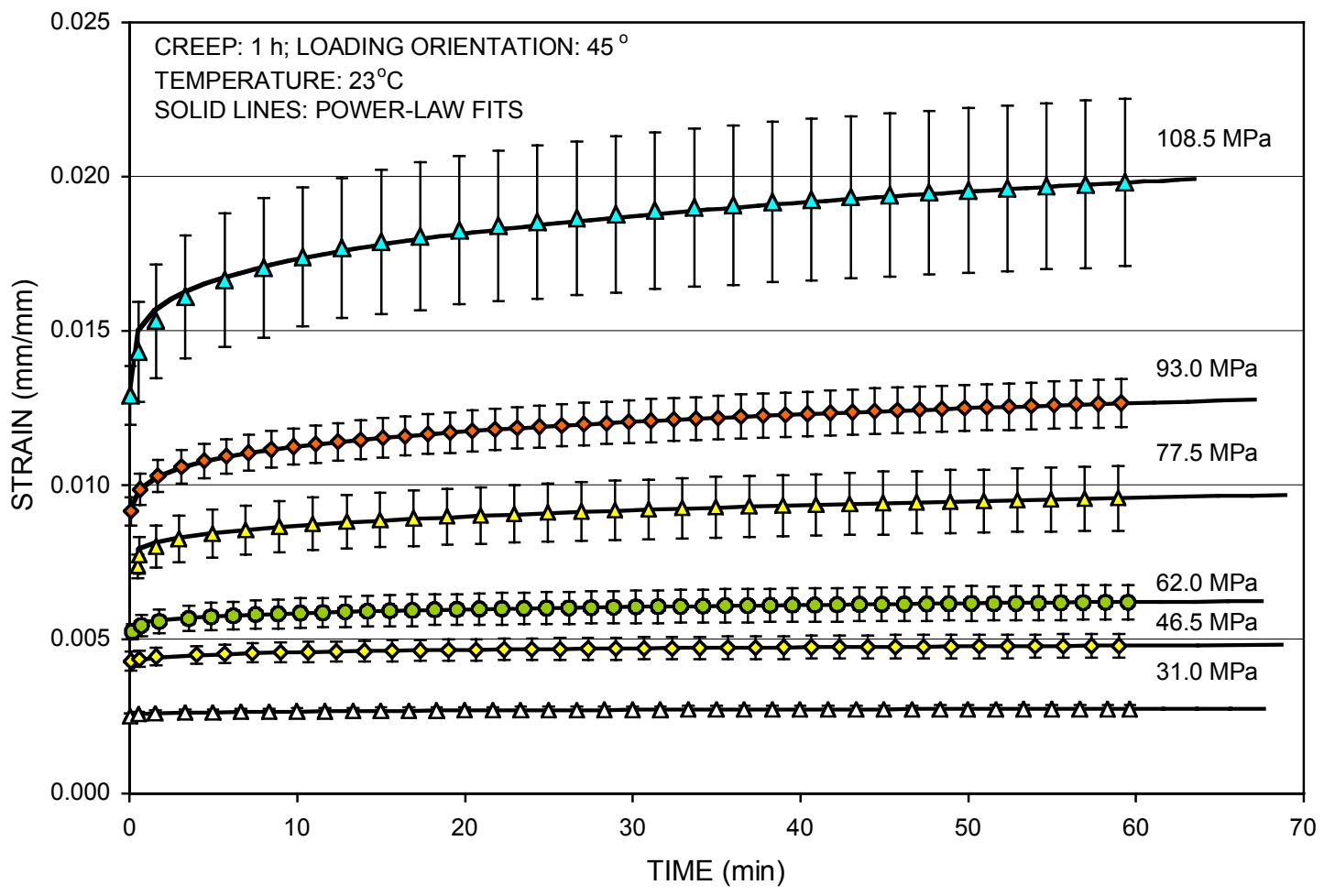

Fig. 12.2. Average values and standard deviations for 1-h creep data of $45^{\circ}$ coupons at $23^{\circ} \mathrm{C}$ and their power-law fits for various stress levels.

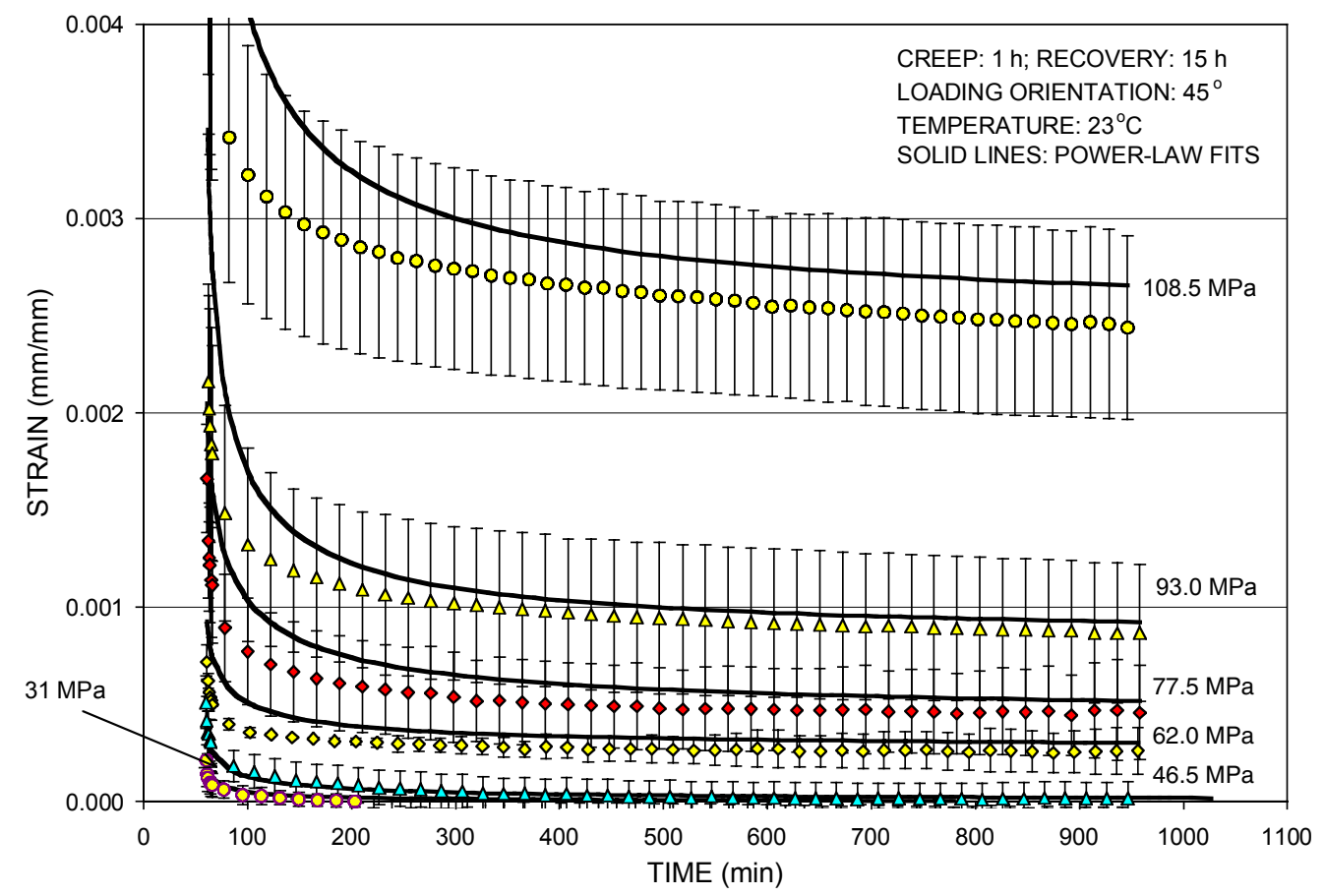

Fig. 12.3. Average values and standard deviations during 15-h recovery, following 1-h creep, and their power-law predictions under various stress levels for $45^{\circ}$ coupons at $23^{\circ} \mathrm{C}$. 


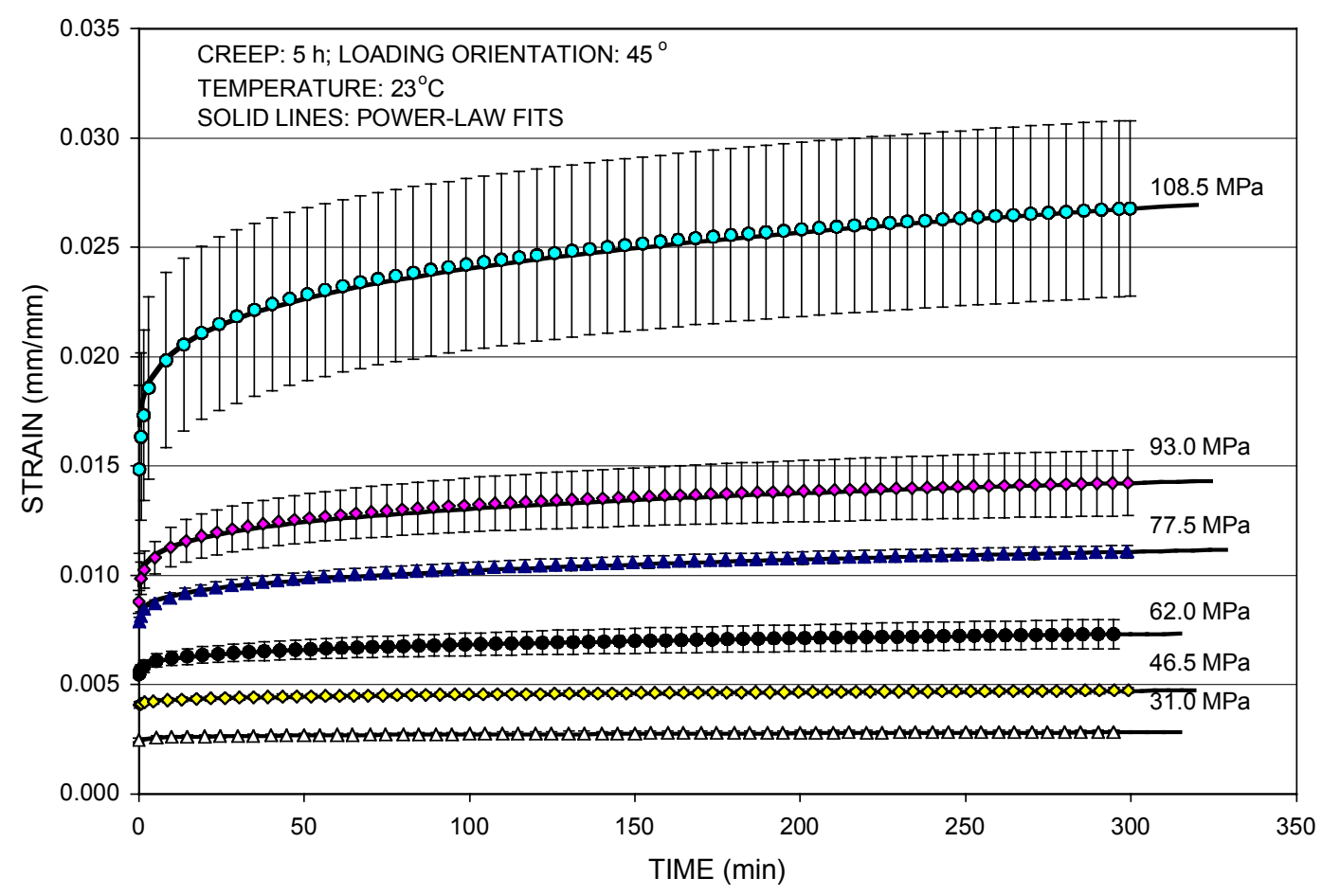

Fig. 12.4. Average values and standard deviations for 5-h creep data of $45^{\circ}$ coupons at $23^{\circ} \mathrm{C}$ and their power-law fits for various stress levels.

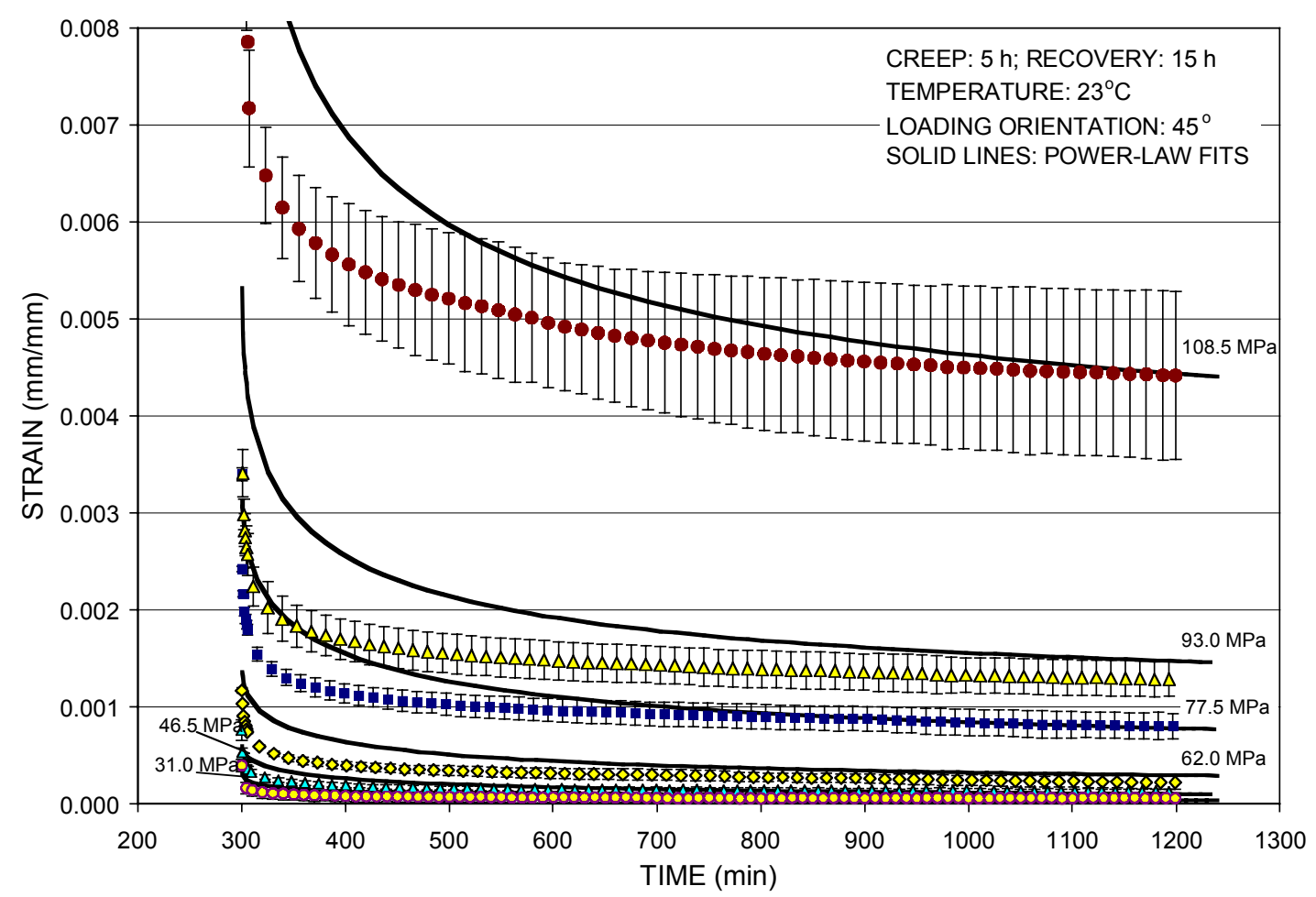

Fig. 12.5. Average values and standard deviations during 15-h recovery, following 5-h creep, and their power-law predictions under various stress levels for $45^{\circ}$ coupons at $23^{\circ} \mathrm{C}$. 


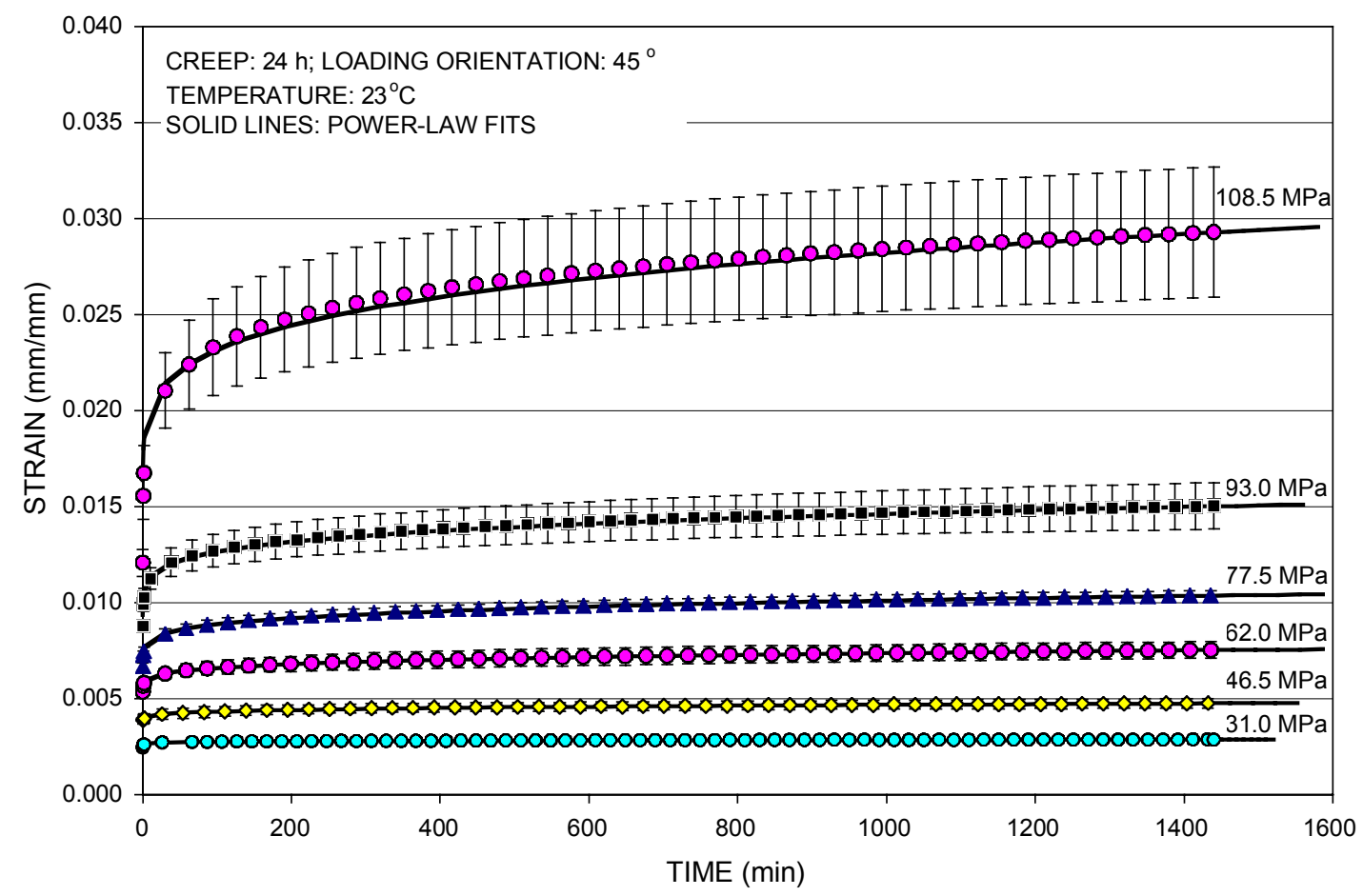

Fig. 12.6. Average values and standard deviations for $24-\mathrm{h}$ creep data of $45^{\circ}$ coupons at $23^{\circ} \mathrm{C}$ and their power-law fits for various stress levels.

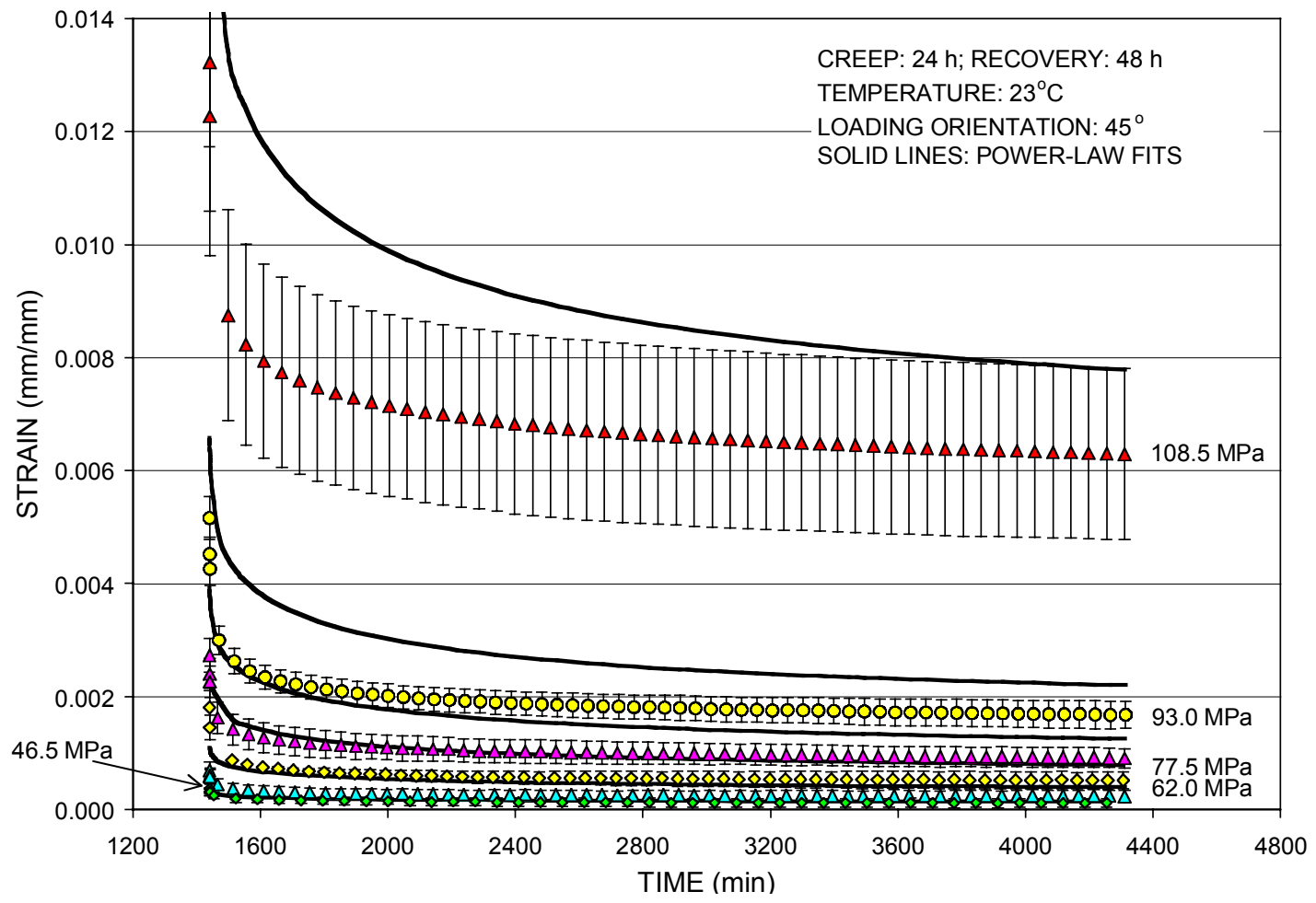

Fig. 12.7. Average values and standard deviations during 48-h recovery, following $24-\mathrm{h}$ creep, and their power-law predictions under various stress levels for $45^{\circ}$ coupons at $23^{\circ} \mathrm{C}$. 


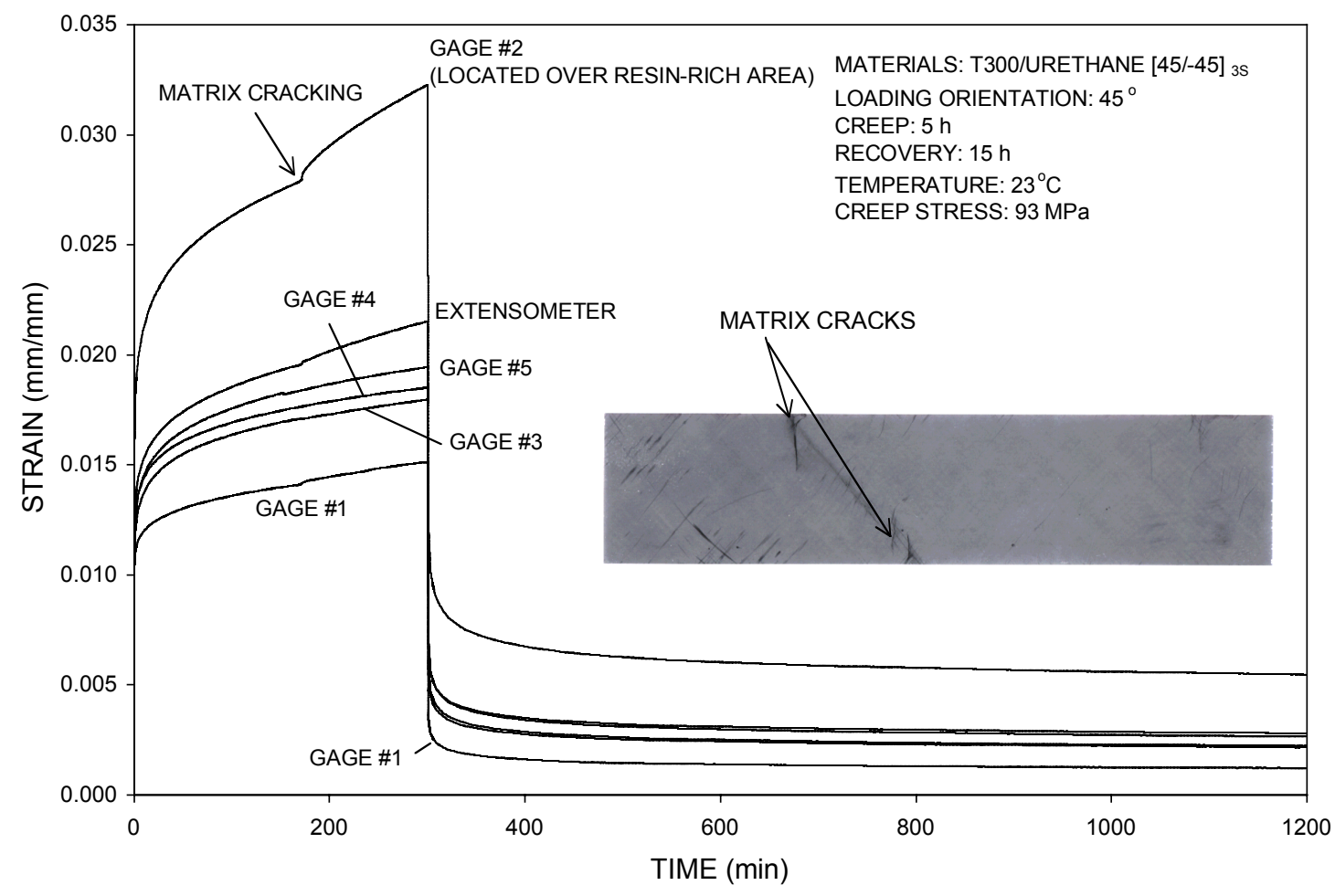

Fig. 12.8. Creep and recovery data collected on a multigaged $45^{\circ}$ coupon exhibiting nonuniform deformation within a test specimen.

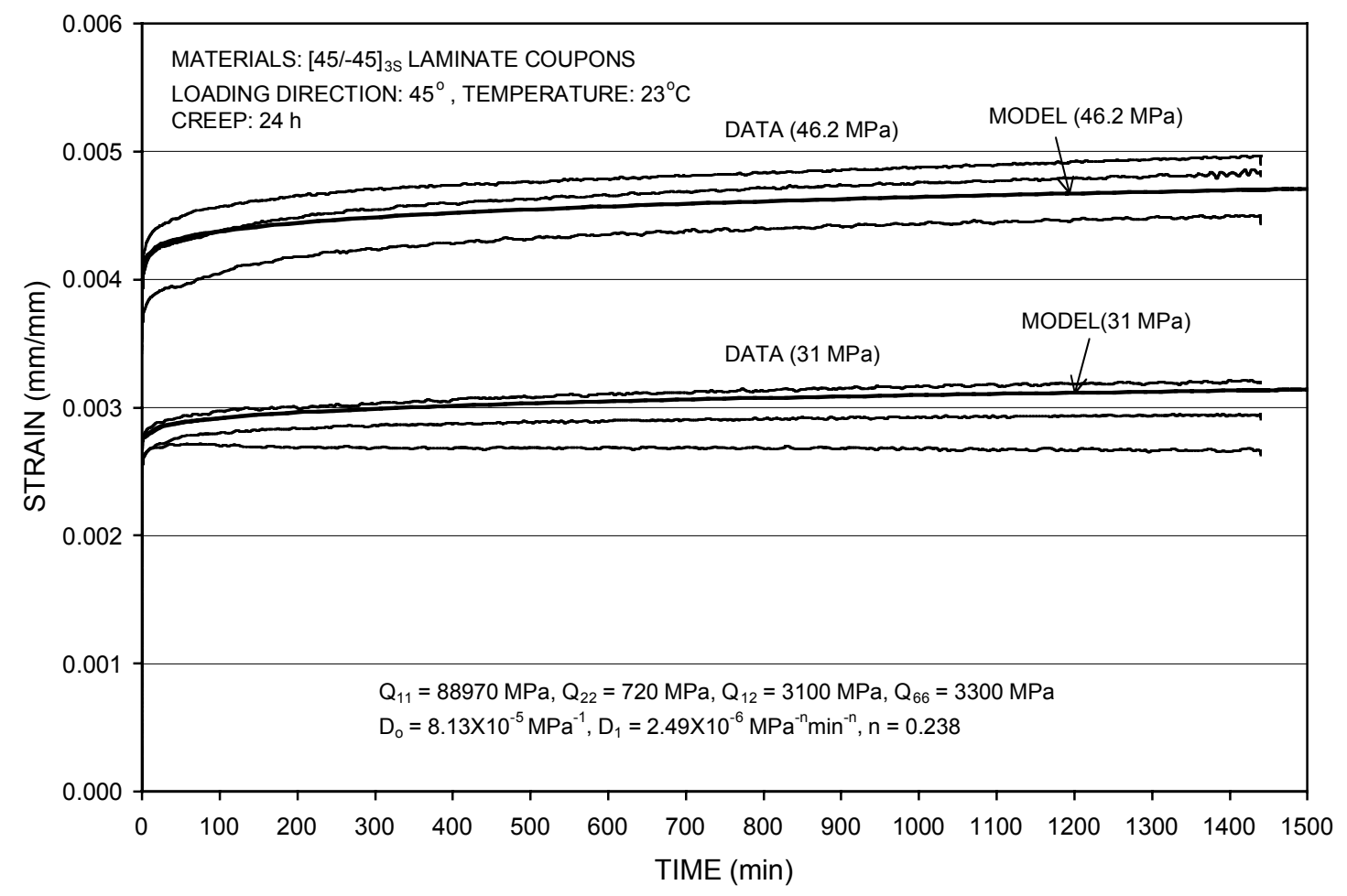

Fig. 12.9. Baseline creep data to establish power-law stress-strain parameters within the linear range $\left(\phi=4^{\circ}, 24-\mathrm{h}\right.$ creep, and $\left.23^{\circ} \mathrm{C}\right)$. 


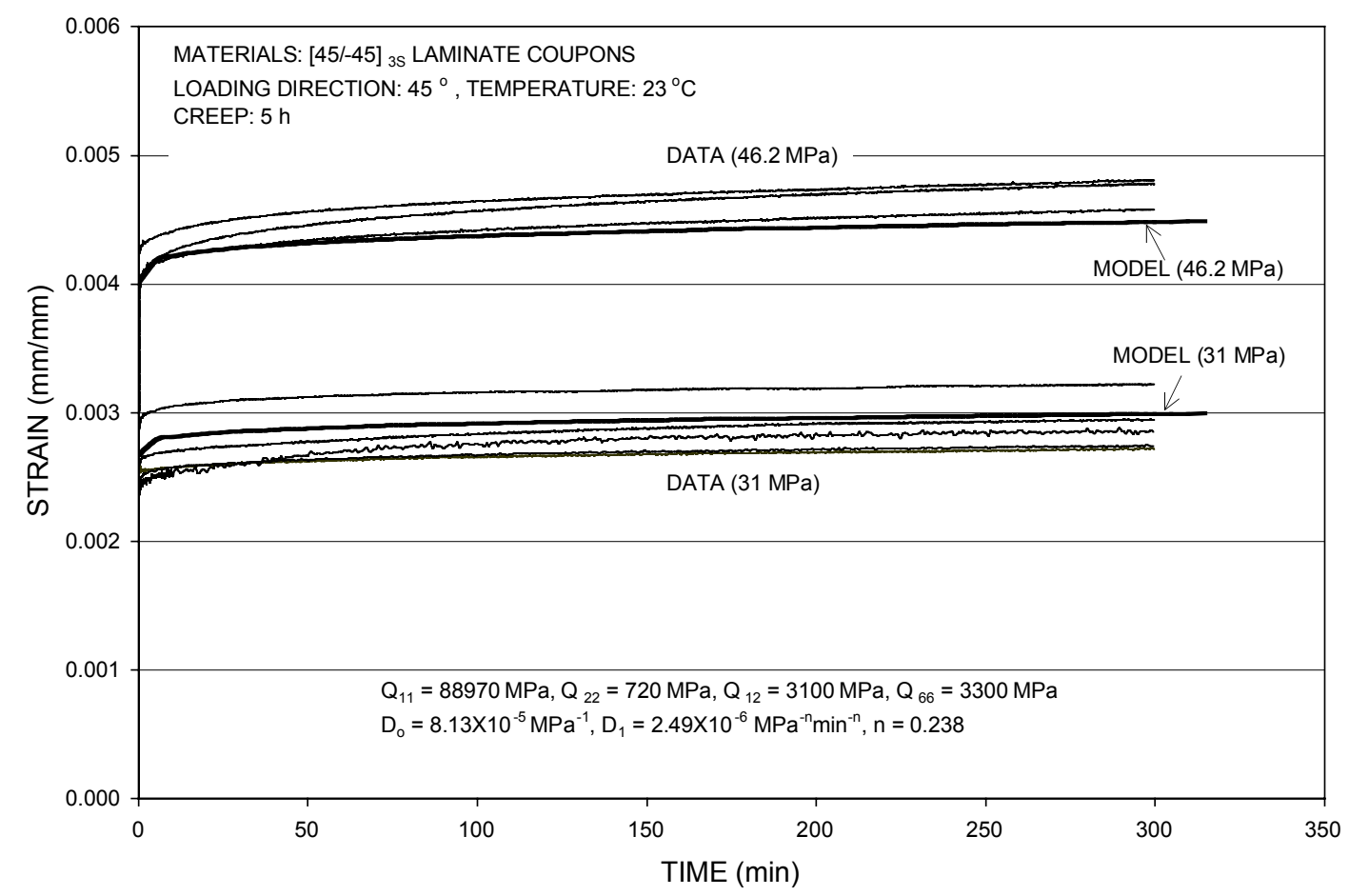

Fig. 12.10. Use of baseline creep data for predicting the short-term stress-strain response within the linear range $\left(\phi=45^{\circ}, 5\right.$-h creep, and $\left.23^{\circ} \mathrm{C}\right)$.

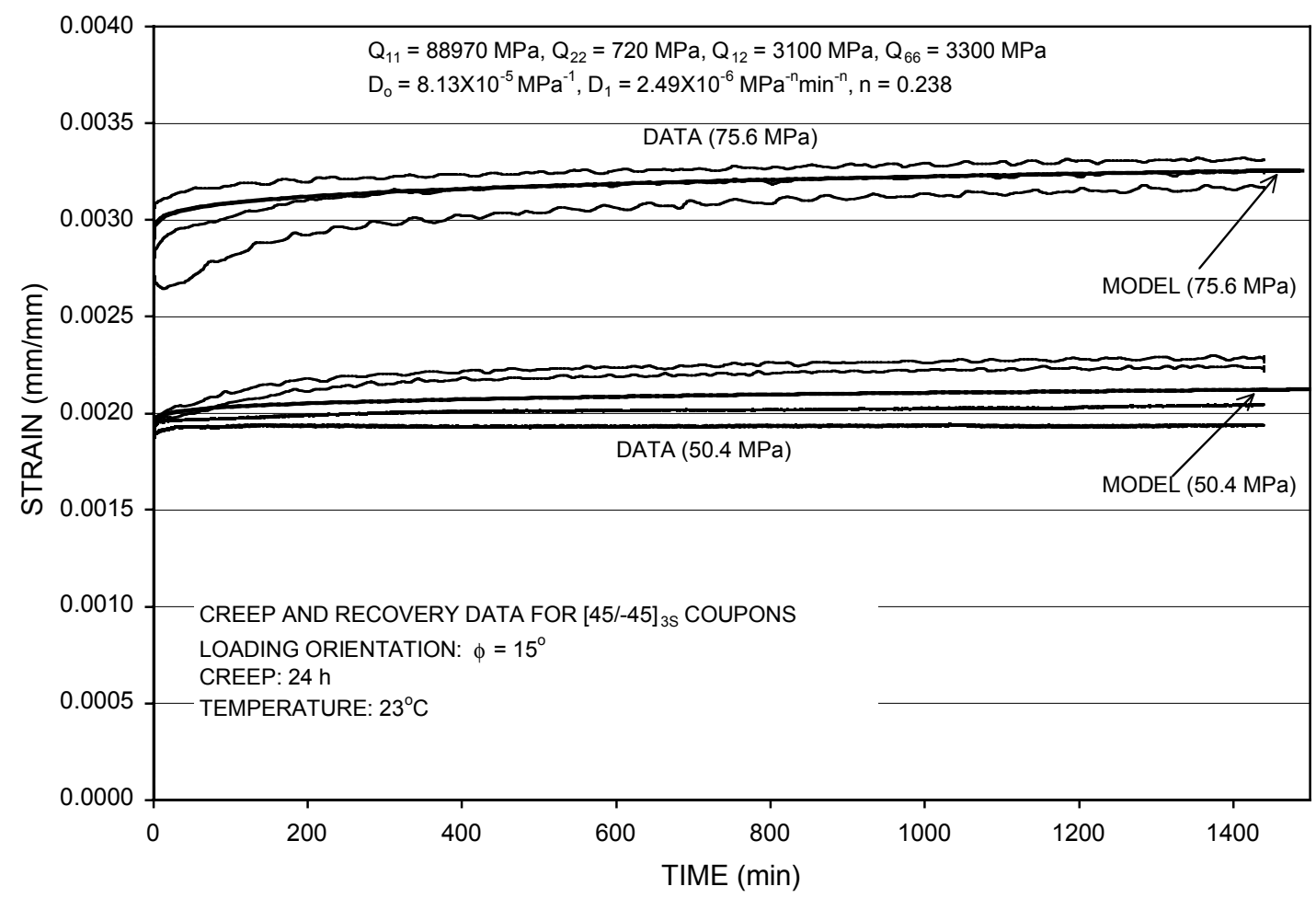

Fig. 12.11. Comparison of creep data with theoretical predictions for stress-strain response within linear range $\left(\phi=15^{\circ}, 24-\mathrm{h}\right.$ creep, and $\left.23^{\circ} \mathrm{C}\right)$. 


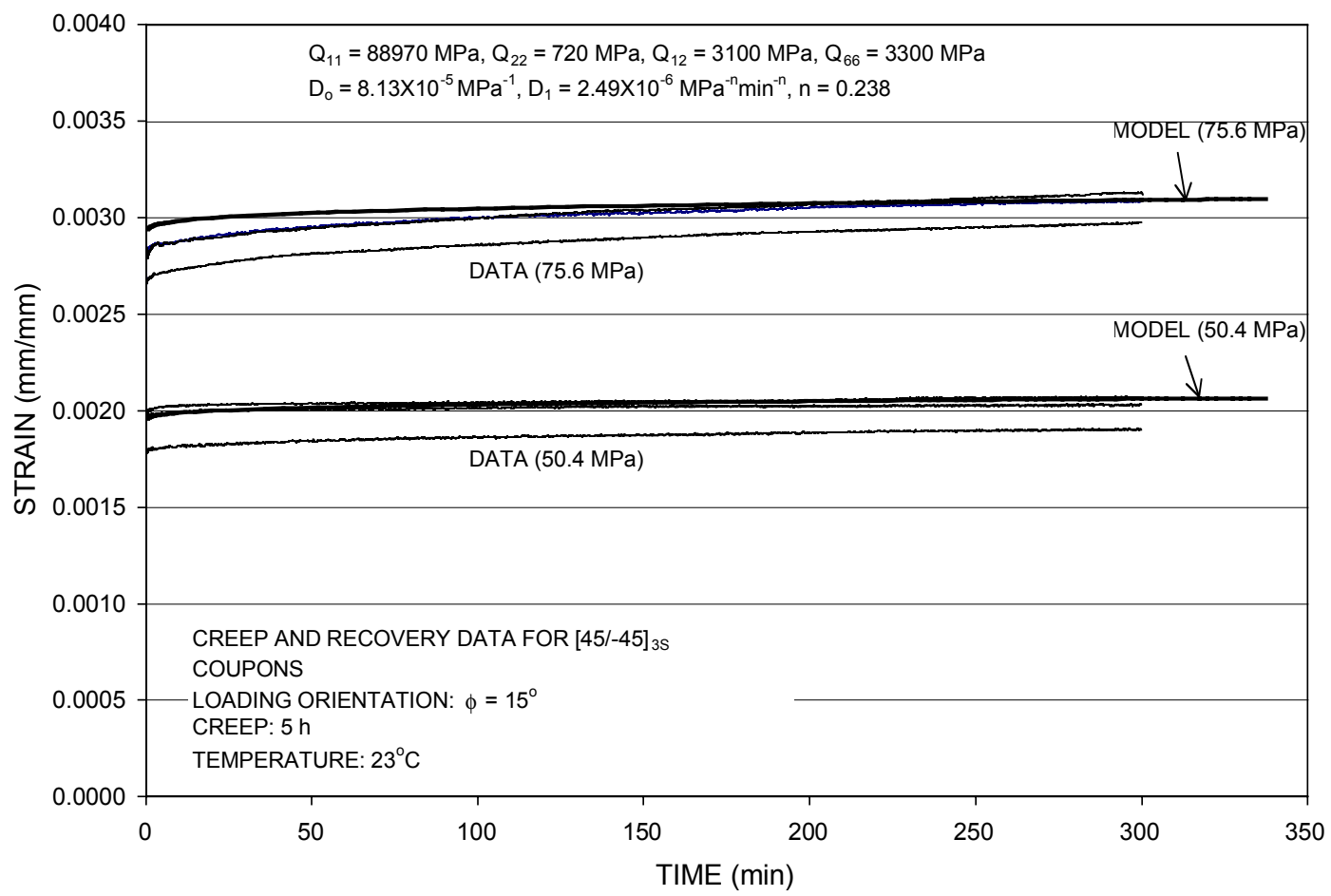

Fig. 12.12. Comparison of creep data with theoretical predictions for stress-strain response within the linear range $\left(\phi=15^{\circ}, 5-h\right.$ creep, and $\left.23^{\circ} \mathrm{C}\right)$.

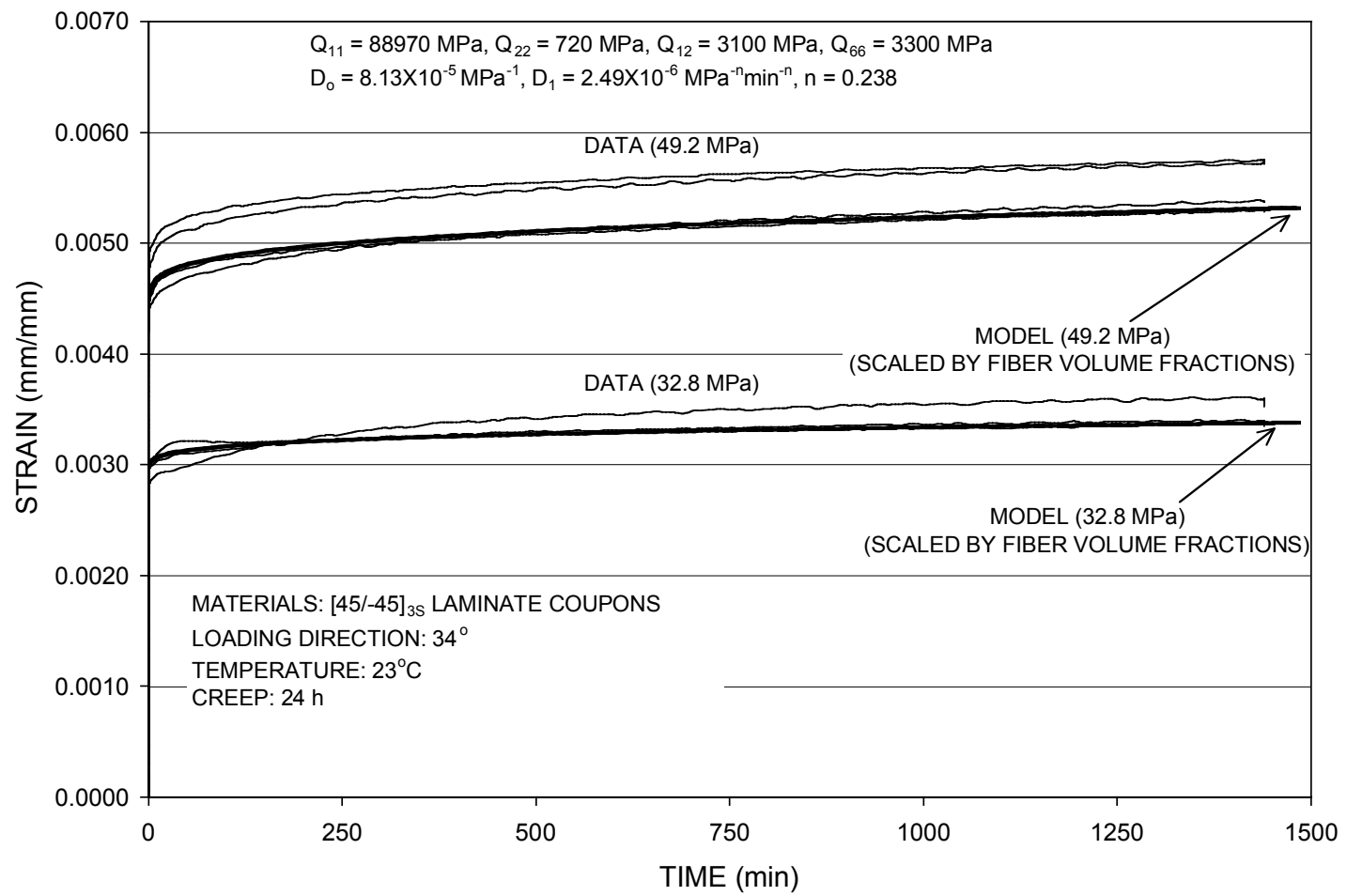

Fig. 12.13. Comparison of creep data with theoretical predictions for stress-strain response within the linear range $\left(\phi=34^{\circ}, 24-h\right.$ creep, and $\left.23^{\circ} \mathrm{C}\right)$. 


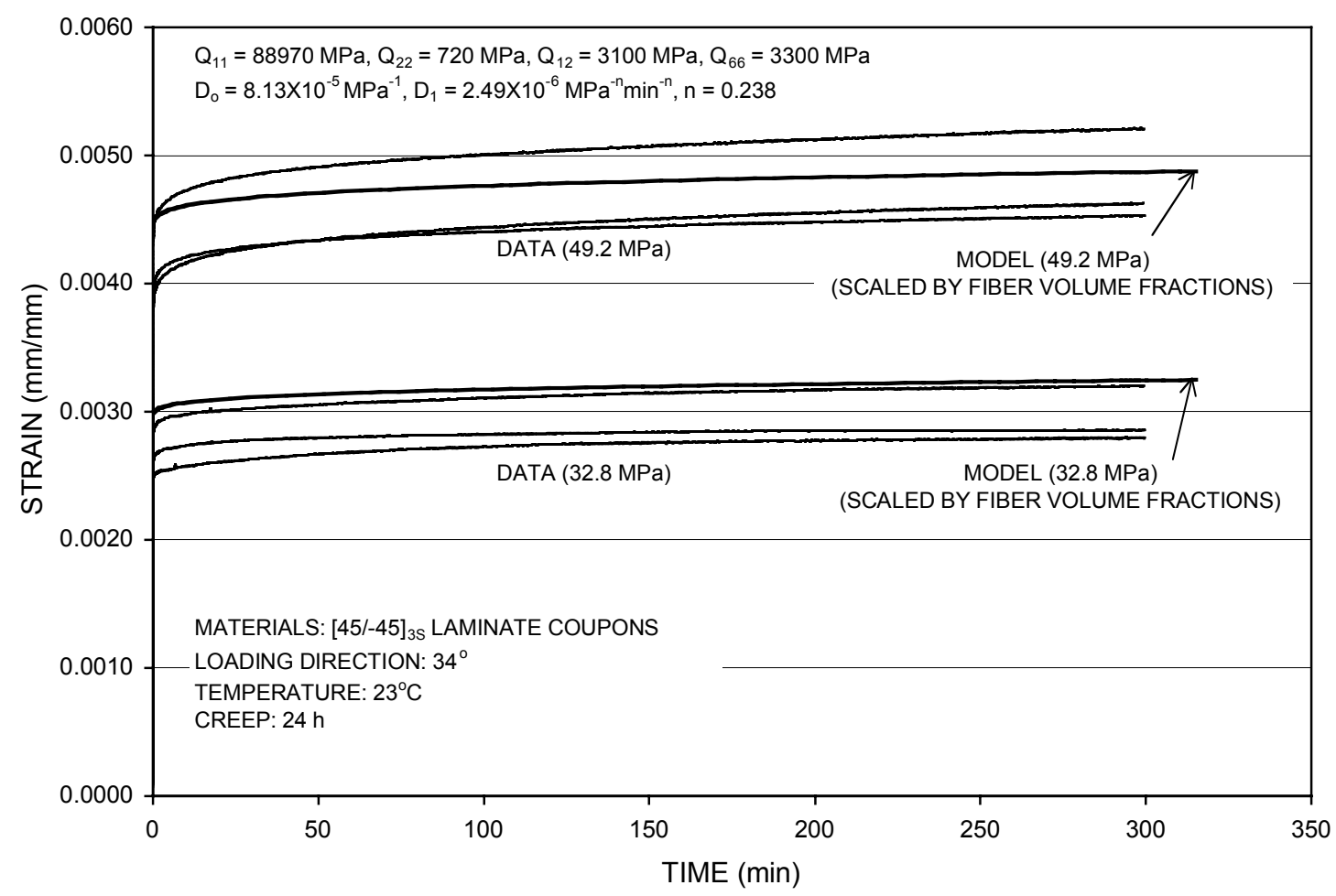

Fig. 12.14. Comparison of creep data with theoretical predictions for stress-strain response within the linear range $\left(\phi=34^{\circ}, 5-h\right.$ creep, and $\left.23^{\circ} \mathrm{C}\right)$.

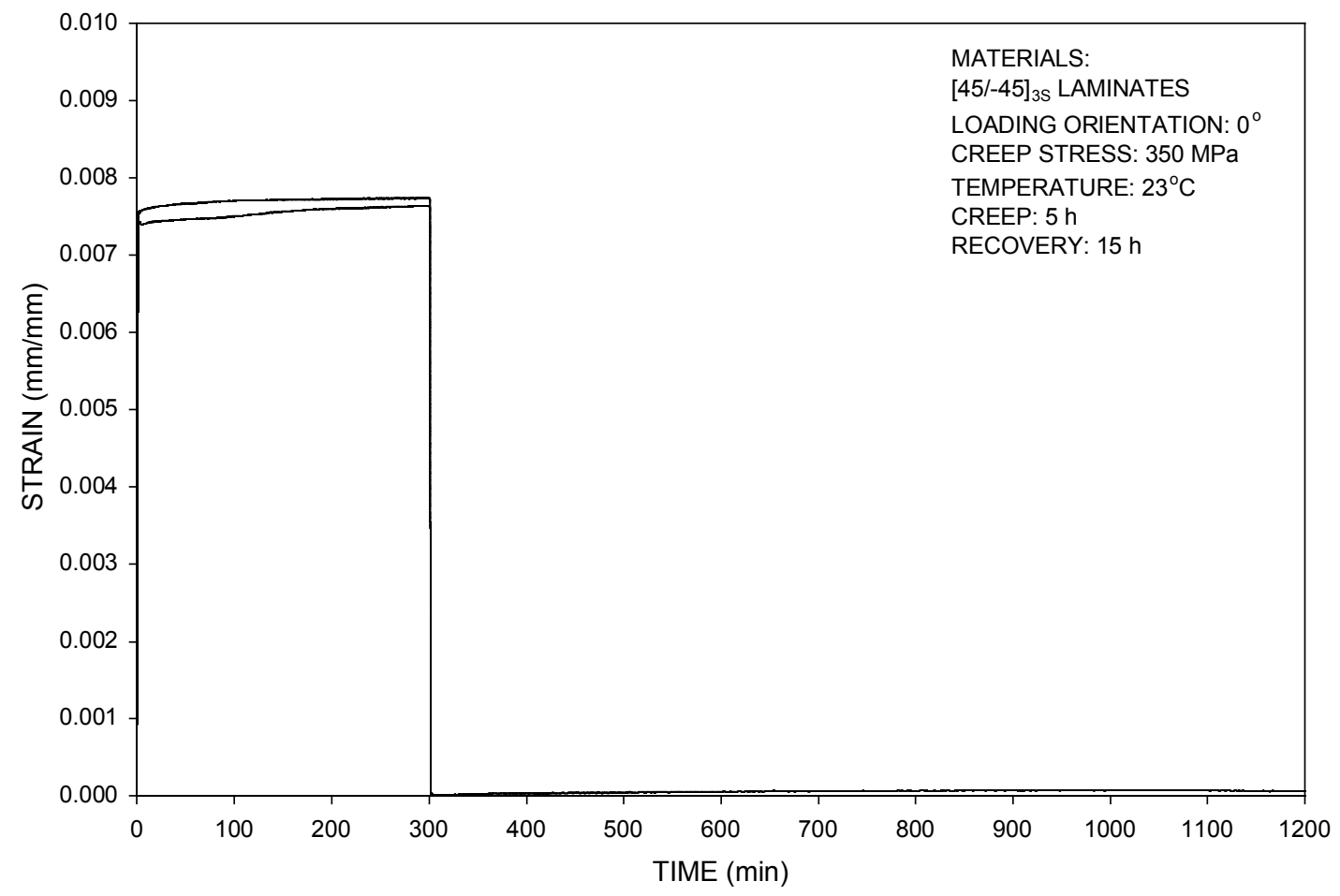

Fig. 12.15. Creep and recovery data of $0^{\circ}$ coupons under a stress level of $350 \mathrm{MPa}\left(\phi=0^{0}\right.$, 5-h creep, 15-h recovery, and $23^{\circ} \mathrm{C}$ ). 


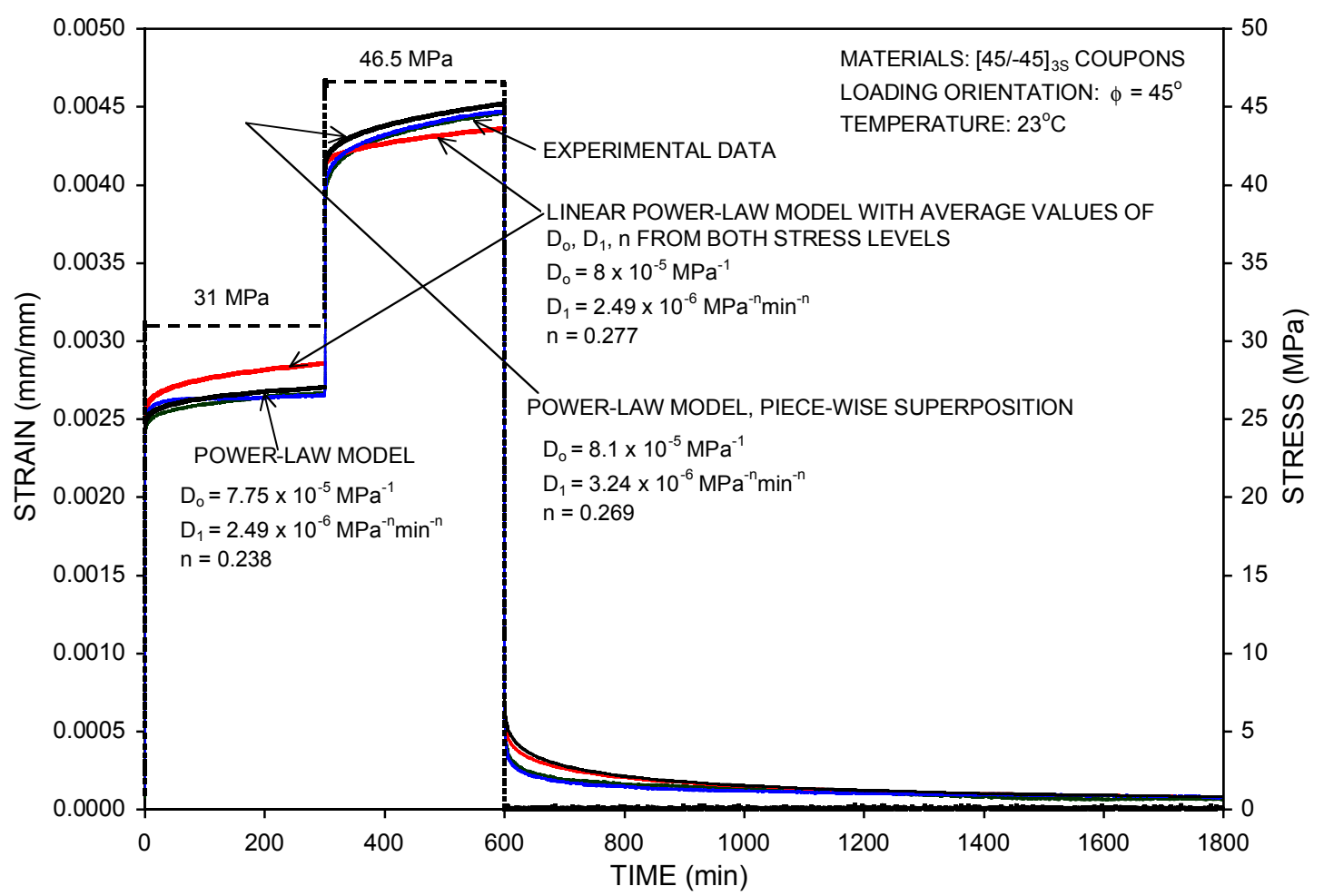

Fig. 12.16. Experimental data and model prediction under a two-step load history for $45^{\circ}$ coupons at $23^{\circ} \mathrm{C}$.

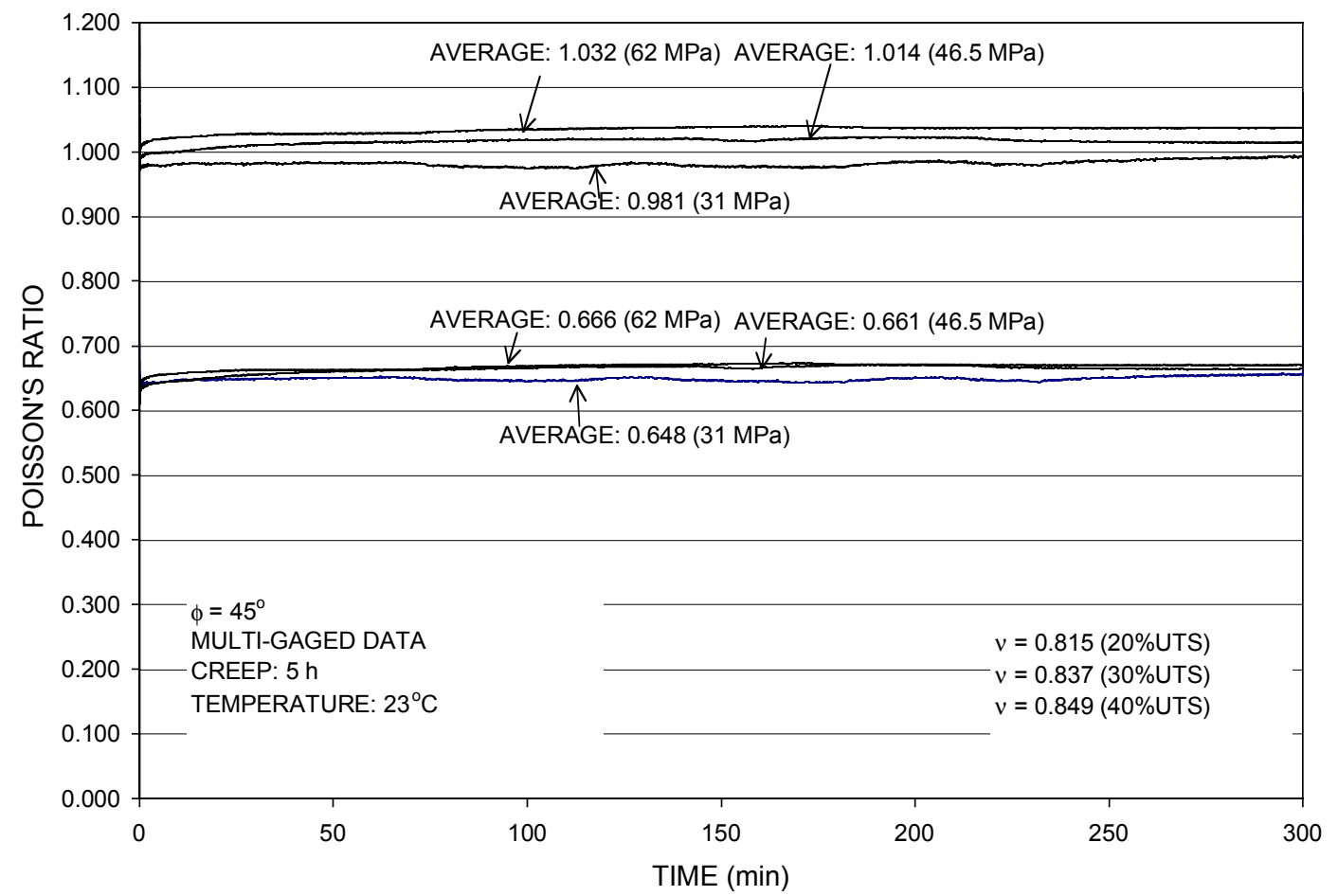

Fig. 12.17. Relationship between Poisson's ratio and creep time for a multigaged coupon $\left(\phi=45^{\circ}, 5\right.$-h creep, and $23^{\circ} \mathrm{C}$ ). 


\title{
13. PRIOR LOAD EFFECTS
}

\author{
J. M. Corum, R. L. Battiste, K. C. Liu, and M. B. Ruggles
}

\subsection{INTRODUCTION}

Prior loadings, whether short-time static, cyclic, or long-term, can potentially have a degrading effect on residual strength and, especially, stiffness. To quantify these effects for the crossply carbon-fiber composite, a series of prior load effects studies was carried out. These addressed the following:

- effects of prior short-time static loadings on stiffness and UTS;

- effects of prior fatigue cycles on stiffness, UTS, and creep; and

- effects of prior creep deformation on stiffness, UTS, and fatigue strength.

Each of these effects is discussed in the following sections.

\subsection{EFFECT OF PRIOR SHORT-TIME STATIC LOADINGS}

Subjecting a specimen to a short-time tensile load can cause microstructural damage that is subsequently reflected in a loss in residual stiffness. To quantify this effect, 16 specimens for each fiber orientation $\left( \pm 45^{\circ}\right.$ and $\left.0 / 90^{\circ}\right)$ were subjected to sequentially increasing loadings followed by unloadings. For each fiber orientation, four specimens were each subjected to sequential loads of $20,40,60$, and $80 \%$ of the UTS. After each target load was reached, the specimen was unloaded, and the stiffness was checked. Finally, each specimen was loaded to failure. For each fiber orientation, additional groups of four specimens were subjected to load sequences starting with 40,60 , and $80 \%$ of the UTS. The $\pm 45^{\circ}$ specimens all came from plaque C57, while the $0 / 90^{\circ}$ specimens all came from plaque C56. Results are summarized in Fig. 13.1 $(a)$ and $(b)$ for the $\pm 45^{\circ}$ and $0 / 90^{\circ}$ fiber orientations, respectively. Changes in stiffness were calculated with respect to the virgin stiffness of individual specimens.

For the $\pm 45^{\circ}$ fiber orientation, the loss in stiffness appears to be unaffected by the prior loading history. Specimens subjected to sequential loads of $20,40,60$, and $80 \%$ and those loaded directly to $80 \%$ of the UTS exhibit similar stiffness loss. The same observation can be made for other target loads. However, more scatter is observed for higher prior loads. Results in Fig. 13.1 $(a)$ indicate that a threshold of about $30 \%$ of the UTS exists, below which prior loads cause no stiffness loss. Stiffness loss at the $\pm 45^{\circ} \mathrm{S}_{0}$ stress level, which is equal to $83 \mathrm{MPa}$ and constitutes $55 \%$ of the UTS, was approximately $4 \%$. The average stiffness loss corresponding to the maximum prior load of $80 \%$ of UTS was $18.1 \%$.

For the $0 / 90^{\circ}$ fiber orientation, no significant loss of stiffness was observed, regardless of the prior loading history. All reductions in stiffness, including stiffness loss at the $\mathrm{S}_{0}$ stress level of $265 \mathrm{MPa}$, were less that $1 \%$.

For the chopped-glass-fiber composite, the maximum stiffness reduction was $9.1 \%$. It is interesting that for the swirled-glass-mat composite, a similar threshold of about $30 \%$ of the UTS was observed. ${ }^{2}$ Below this value prior loads resulted in no stiffness loss, presumably because no damage was produced. It was unclear whether a threshold exists for the chopped-glass-fiber composite. If it does, it is considerably less than $30 \%$ of the UTS.

As stated above, each specimen in each group of four replicate tests was ultimately tested to failure. Comparison of the average UTS values from these groups with the averages from tests of virgin specimens from the same plaques provides insight into the effects of prior short-time loads 
on the UTS. These average values are tabulated in Table 13.1. It appears that, if anything, the prior loadings result in a higher UTS, especially in the $0 / 90^{\circ}$ case. In any event, it can be concluded that prior short-time static loads do not degrade the UTS.

Table 13.1. Average UTS values from groups of specimens subjected to prior short-time static loads

\begin{tabular}{|c|c|}
\hline $\begin{array}{c}\text { Prior loads } \\
\text { (\% UTS) }\end{array}$ & $\begin{array}{c}\text { Average subsequent } \\
\text { UTS (MPa) }\end{array}$ \\
\hline \multicolumn{2}{|c|}{ $\pm 45^{\circ}$ Fiber orientation } \\
\hline 0 (virgin) $^{a}$ & 159 \\
\hline $20,40,60,80$ & 170 \\
\hline $40,60,80$ & 169 \\
\hline 60,80 & 171 \\
\hline 80 & 170 \\
\hline \multicolumn{2}{|c|}{$0 / 90^{\circ}$ Fiber orientation } \\
\hline 0 (virgin $)^{a}$ & 386 \\
\hline $20,40,60,80$ & 429 \\
\hline $40,60,80$ & 410 \\
\hline 60,80 & 432 \\
\hline 80 & 425 \\
\hline
\end{tabular}

\subsection{EFFECT OF PRIOR FATIGUE CYCLES}

The effects of fatigue cycles on stiffness were reported in Chap. 9 for both fiber orientations and for a variety of cycle types and environments. For the $0 / 90^{\circ}$ fiber orientation, it was shown that the stiffness loss remains well below the desired $10 \%$ throughout the cyclic life. Conversely for the $\pm 45^{\circ}$ orientation, the loss becomes larger than $10 \%$ during life, but, at least at room temperature, the recommended design margin of $20\left(\mathrm{n} / \mathrm{N}_{\mathrm{f}}=0.05\right)$ on cycles ensures that the stiffness loss is about $10 \%$ or less for the allowable number of cycles.

To evaluate the effects of prior fatigue cycles on UTS and subsequent creep, twenty $\pm 45^{\circ}$ specimens from plaque $\mathrm{C} 20$ were cycled in tension $(\mathrm{R}=0.1)$ at one of two stress levels and to one of three cycle fractions. The various combinations and number of replicate specimens are provided in Table 13.2. Three of the 86-MPa specimens cycled to $\mathrm{n} / \mathrm{N}_{\mathrm{f}}=0.25$ plus the one specimen cycled to 0.75 were subsequently creep tested. The remainder were tensile tested to determine if there is any effect on UTS that needs to be accounted for.

No tests were carried out for the $0 / 90^{\circ}$ fiber orientation because (1) any effects there are expected to be very small and (2) the wide scatter in fatigue lives would make life fraction values tenuous.

\subsubsection{Effect on Tensile Properties}

Figure 13.2 shows the measured effect of the prior fatigue cycles on UTS and stiffness. Each of the four points in the two figures represents the average of four tests (Table 13.2). 
Table 13.2. Prefatigue tests

\begin{tabular}{ccc}
\hline $\begin{array}{c}\text { Stress } \\
(\mathbf{M P a})\end{array}$ & $\mathbf{n} / \mathbf{N}_{\mathbf{f}} \boldsymbol{a}^{\mathbf{a}}$ & Replicates \\
\hline $\mathbf{6 2}$ & 0.25 & 4 \\
$\mathbf{6 2}$ & 0.75 & 4 \\
$\mathbf{8 6}$ & 0.25 & 7 \\
$\mathbf{8 6}$ & 0.50 & 4 \\
$\mathbf{8 6}$ & 0.75 & 1 \\
\hline
\end{tabular}

${ }^{a} \mathrm{~N}_{\mathrm{f}}$ is the expected number of cycles to failure for plaque $\mathrm{C} 20-10^{6}$ for $62 \mathrm{MPa}$ and $10^{4}$ for $86 \mathrm{MPa}$.

In the case of stiffness [Fig. 13.2(b)] the reduction for each individual specimen was calculated relative to the virgin stiffness of that specimen measured prior to the fatigue cycles. Even so, the scatter was significant. In the worse case of $86 \mathrm{MPa}$ and $\mathrm{n} / \mathrm{N}_{\mathrm{f}}=0.5$, the changes ranged from small to more than $17 \%$. Almost the same degree of scatter was observed in Fig. 9.9(a), where the change in stiffness for several $\pm 45^{\circ}$ fatigue specimens was plotted as a function of $n / \mathrm{N}_{\mathrm{f}}$.

The points and solid lines in Fig. 13.2(a) depict the apparent change in UTS with cyclic life fraction. In an attempt to reduce scatter, all of the original UTS values were adjusted by the ratio of the specimen thickness to the plaque average thickness. Here the change was determined relative to the average UTS from tests of three reference tensile specimens from plaque C20. Thus, while the magnitude of the changes may be biased, the slope of the solid curves should be more reliable. The curves should pass through zero, so they were shifted, as represented by the dashed curves. From the dashed curves, it is seen that for the allowable number of design cycles $\left(\mathrm{n} / \mathrm{N}_{\mathrm{f}}=\right.$ $0.05)$, the corresponding reduction in expected residual strength is negligible. For the choppedglass-fiber composite, the corresponding reduction was just $1.6 \%$.

\subsubsection{Effect on Creep}

The four precycled specimens that were tested under creep conditions were all subjected to a stress of $91 \mathrm{MPa}$, which was estimated to produce creep-rupture failure in about $1000 \mathrm{~h}$. Three of the specimens were tested well beyond $1000 \mathrm{~h}$ without failure, although they all exhibited the usual ply cracking and delaminations typical of $\pm 45^{\circ}$ specimens. These tests were discontinued.

Time-dependent creep curves from the four tests are plotted in Fig. 13.3, where they are compared with typical curves from virgin specimens tested at stress levels bracketing $91 \mathrm{MPa}$. Recall that in all four cases the prefatigue cycles were conducted at a maximum stress of $86 \mathrm{MPa}$. Clearly, the scatter is large in Fig. 13.3, and there does not appear to be any logical correlation with the number of cycles imposed. Interestingly, what does correlate with creep strain is the loading strain in the creep tests, which is a measure of the prior cyclic damage incurred. ${ }^{*}$ The loading strains are tabulated in the order (top to bottom) of the curves in Fig. 13.3. While the data are far too limited to draw quantitative conclusions, it does appear that just as prior cycling lowers stiffness, and thus increases loading strains, it increases creep strain. The affect that this might have on creep rupture is unknown.

\footnotetext{
* The loading strains in the tests varied by $35 \%$, whereas the specimen thickness, which is the source of much of the usual variation, varied by only $4.8 \%$.
} 


\begin{tabular}{|c|c|}
\hline Specimen & $\begin{array}{c}\text { Loading strain } \\
(\%)\end{array}$ \\
\hline C20-41 & 1.22 \\
\hline C20-39 & 1.01 \\
\hline C20-37 & 0.96 \\
\hline C20-38 & 0.86 \\
\hline
\end{tabular}

\subsection{EFFECT OF PRIOR CREEP DEFORMATION}

Six $\pm 45^{\circ}$ specimens from plaque $\mathrm{C} 24\left(\mathrm{UTS}_{\mathrm{avg}}=161 \mathrm{MPa}\right)$ and six $0 / 90^{\circ}$ specimens from plaque $\mathrm{C} 23\left(\mathrm{UTS}_{\mathrm{avg}}=399 \mathrm{MPa}\right)$ were initially subject to creep stresses of $68 \mathrm{MPa}$ and $261 \mathrm{MPa}$, respectively, for $1000 \mathrm{~h}$. These stress levels were chosen to correspond to preliminary estimates of the allowable stresses, $\mathrm{S}_{t}$, at $1000 \mathrm{~h}$. Three of the precrept specimens in each group were subsequently tensile tested to determine the effect of the creep period on stiffness and UTS. The intent was to test the other precrept specimens in each group in fatigue. Only the three $\pm 45^{\circ}$ specimens were actually tested, however, because of the large inherent scatter in $0 / 90^{\circ}$ fatigue test results and the fact that fatigue resistance is so high for the $0 / 90^{\circ}$ fiber orientation that it would not likely be a problem in design.

\subsubsection{Effect on Tensile Properties}

The change in stiffness for each tensile specimen was calculated relative to the virgin stiffness (measured prior to the creep test) of the specimen. Changes in UTS were calculated relative to the average values determined for each plaque. The average results are given in Table 13.3. Note that about one-half of the $\pm 45^{\circ}$ stiffness loss is attributable to the initial loading to the creep stress level ( $68 \mathrm{MPa}=42 \%$ of UTS). This can be seen in Fig. 13.1(a). In the $0 / 90^{\circ}$ case, very little change due to loading would be expected [see Fig. 13.1(b)].

In the case of the chopped-glass-fiber composite, the same creep test conditions $(1000 \mathrm{H}$ at the allowable time-dependent stress) resulted in a stiffness loss of $13.1 \%$ and a $3.6 \%$ reduction in the UTS. Thus, the stiffness losses in the carbon-fiber composite are significantly less. The UTS loss for the $\pm 45^{\circ}$ carbon-fiber orientation is about the same as for the chopped-glass-fiber composite; the apparent $0 / 90^{\circ}$ UTS loss is greater than for the glass-fiber composite.

Table 13.3. Results of tensile tests on precrept specimens

\begin{tabular}{|c|c|c|c|c|}
\hline $\begin{array}{c}\text { Fiber } \\
\text { orientation }\end{array}$ & $\begin{array}{c}\text { Stiffness } \\
\text { (GPa) }\end{array}$ & $\begin{array}{c}\text { Change in } \\
\text { stiffness (\%) }\end{array}$ & UTS (MPa) & $\begin{array}{l}\text { Change in } \\
\text { UTS (\%) }\end{array}$ \\
\hline $\pm 45^{\circ}(\mathrm{C} 24)$ & 12.3 & -4.4 & 155 & -3.7 \\
\hline $0 / 90^{\circ}(\mathrm{C} 23)$ & 47.3 & -4.8 & 375 & -6.0 \\
\hline
\end{tabular}

\subsubsection{Effect on Fatigue Strength}

Each of the three fatigue tests on the precrept $\pm 45^{\circ}$ specimens from plaque $\mathrm{C} 24$ were performed at a maximum tensile stress of $105 \mathrm{MPa}$, with $\mathrm{R}=0.1$. The results were compared with the baseline tensile fatigue data and correlation that were shown in Fig. 9.1 to determine the resulting reduction in fatigue strength caused by the precreep.

The $\pm 45^{\circ}$ test data plotted in Fig. 9.1 were generated on specimens from four plaques $-\mathrm{C}$, $\mathrm{C} 16, \mathrm{C} 17$, and $\mathrm{C} 20$. With an average UTS of $120 \mathrm{MPa}$, these were all weak plaques relative to 
C24, which had a UTS of $161 \mathrm{MPa}$. In an attempt to account for this difference, the 105-MPa stress used in the three fatigue tests was adjusted downward by the UTS ratio:

$$
\text { Stress }=\frac{120}{161} \times 105=78 \mathrm{MPa}
$$

Figure 13.4 compares the results of the three fatigue tests, plotted at $78 \mathrm{MPa}$, with the baseline data on virgin specimens. The plotted values are 3,182;6,686; and 13,400 cycles with an average value of 7,756 cycles. While the fatigue lives of the precrept specimens do appear to be reduced, they are within the scatter band of the virgin specimen data.

To estimate the apparent reduction in fatigue strength, it was assumed that a fatigue curve for the precrept specimens would be parallel to the baseline curve and pass through the point ( $78 \mathrm{MPa}, 7756$ cycles). With this assumption, the strength reduction multiplication factor is 0.95 , or a reduction of $5 \%$. This compares with the $3.7 \%$ UTS reduction that was tabulated in Table 13.3.

In the case of the chopped-glass-fiber composite, similar tests led to the conclusion that there was no apparent effect of prior creep on subsequent fatigue strength.

\subsection{SUMMARY}

The various reductions that have been established in this chapter are summarized in Table 13.4. The largest value in Table 13.4 corresponds to the effect of cycling on stiffness in the $\pm 45^{\circ}$ case. The value is generally less than $10 \%$ at room temperature, but note that at a temperature of $120^{\circ} \mathrm{C}$, the drop is larger. The strength reductions in Table 13.4 are all less than, or equal to, about $6 \%$.

Table 13.4. Summary of property reductions due to prior load effects

\begin{tabular}{|c|c|c|c|c|}
\hline \multirow{2}{*}{ Prior load } & \multicolumn{2}{|c|}{ Tensile } & \multirow{2}{*}{$\begin{array}{l}\text { Fatigue } \\
\text { strength }\end{array}$} & \multirow{2}{*}{ Creep deformation } \\
\hline & $\mathbf{E}$ & UTS & & \\
\hline \multicolumn{5}{|c|}{ $\pm 45^{\circ}$ Fiber orientation } \\
\hline Short-time static to $\mathrm{S}_{0}(55 \%$ UTS $)$ & $4.0 \%$ & $0 \%$ & & \\
\hline Fatigue cycling to $n / \mathbf{N}_{\mathbf{f}}=0.05$ & $\leq 10 \%$ & $\sim 0 \%$ & & Deformation increased \\
\hline Creep at $S_{t}$ for $1000 h$ & $4.4 \%$ & $3.7 \%$ & $5.0 \%$ & \\
\hline \multicolumn{5}{|c|}{$0 / 90^{\circ}$ Fiber orientation } \\
\hline Short-time static to $\mathrm{S}_{0}(56 \%$ UTS) & $\leq 0.3 \%$ & $0 \%$ & & \\
\hline Fatigue cycling to $n / N_{f}=0.05$ & $<3.0 \%$ & & & \\
\hline Creep at $S_{t}$ for $1000 \mathrm{~h}$ & $4.8 \%$ & $6.0 \%$ & & \\
\hline
\end{tabular}



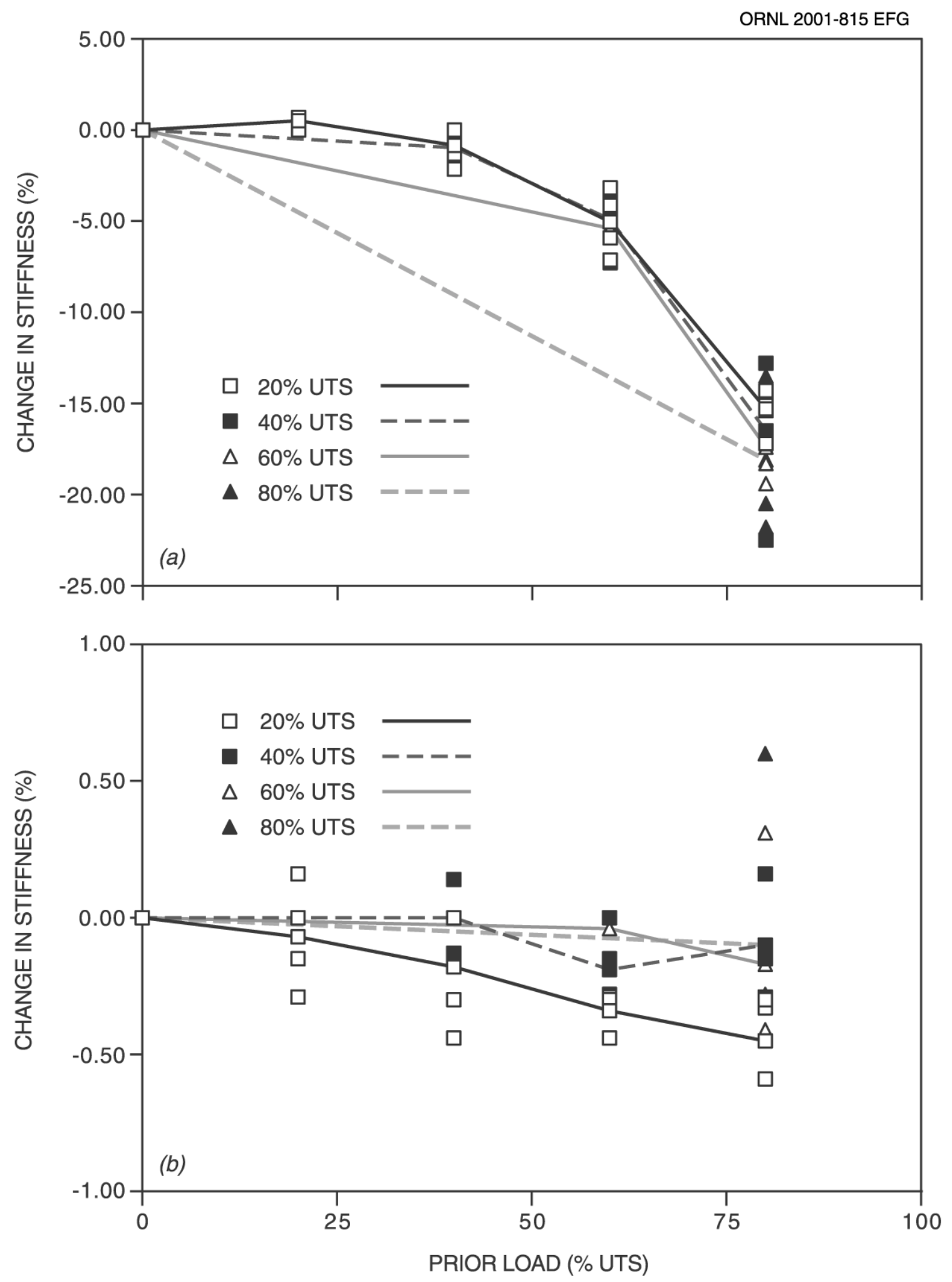

Fig. 13.1. Effect of prior short-time loads on stiffness: $(a) \pm 45^{\circ}$ orientation and $(b) 0 / 90^{\circ}$ orientation. 

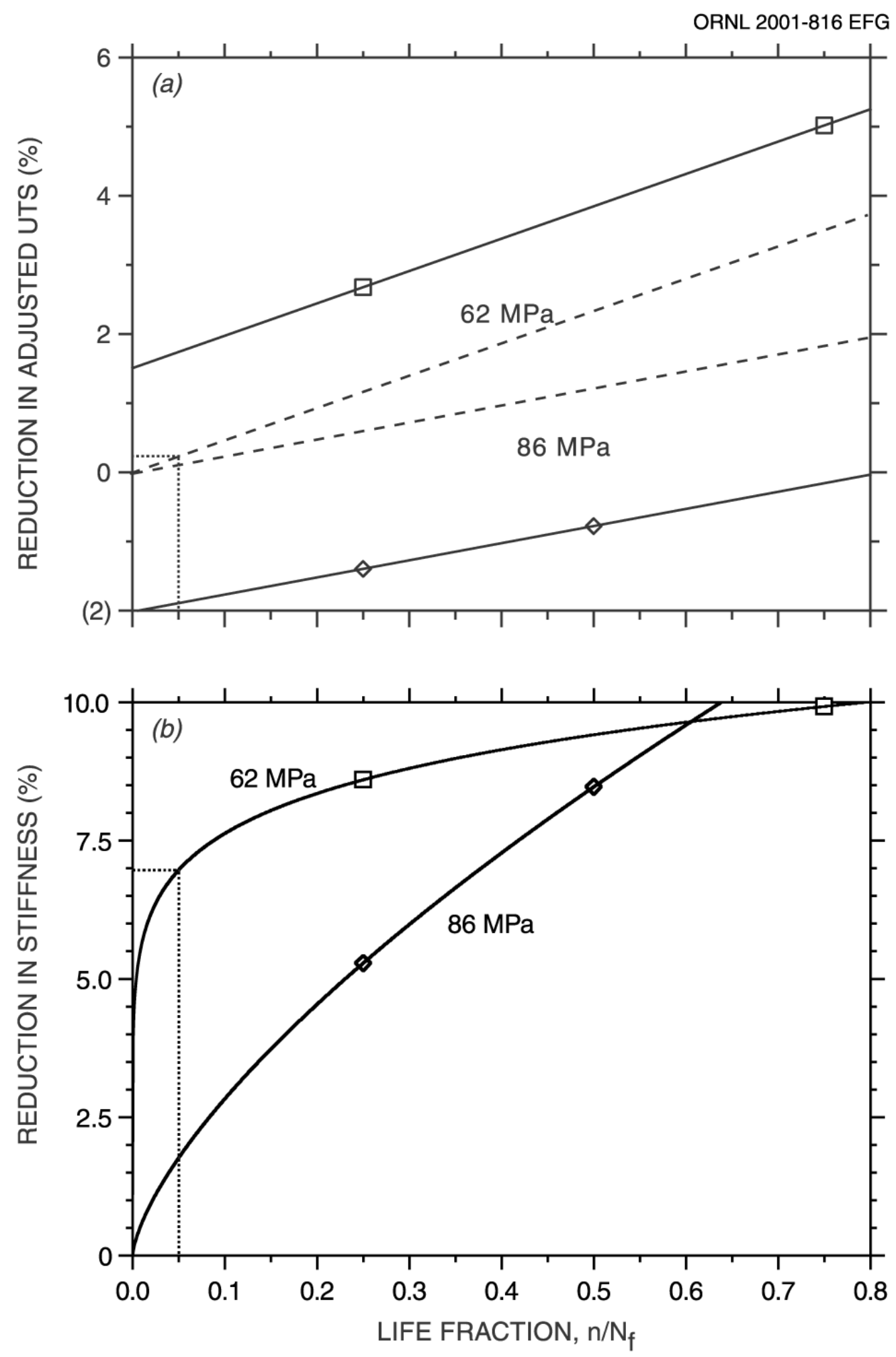

Fig. 13.2. Effect of prior fatigue cycles on $\pm 45^{\circ}$ tensile strength and stiffness: (a) UTS and $(b)$ stiffness. 


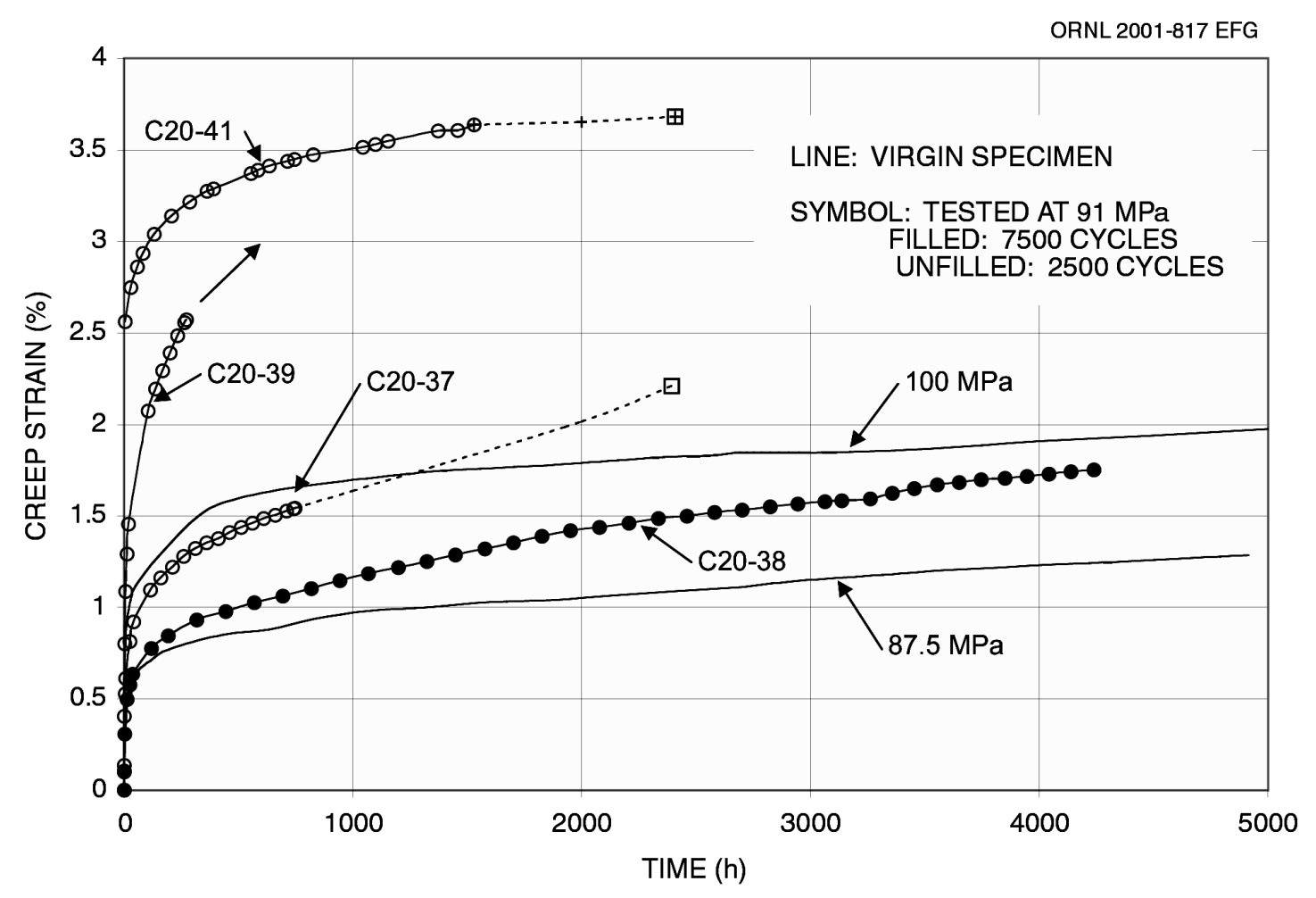

Fig. 13.3. Time-dependent creep curves for specimens precycled in tension $(R=0.1)$ at a maximum stress of $86 \mathrm{MPa}$.

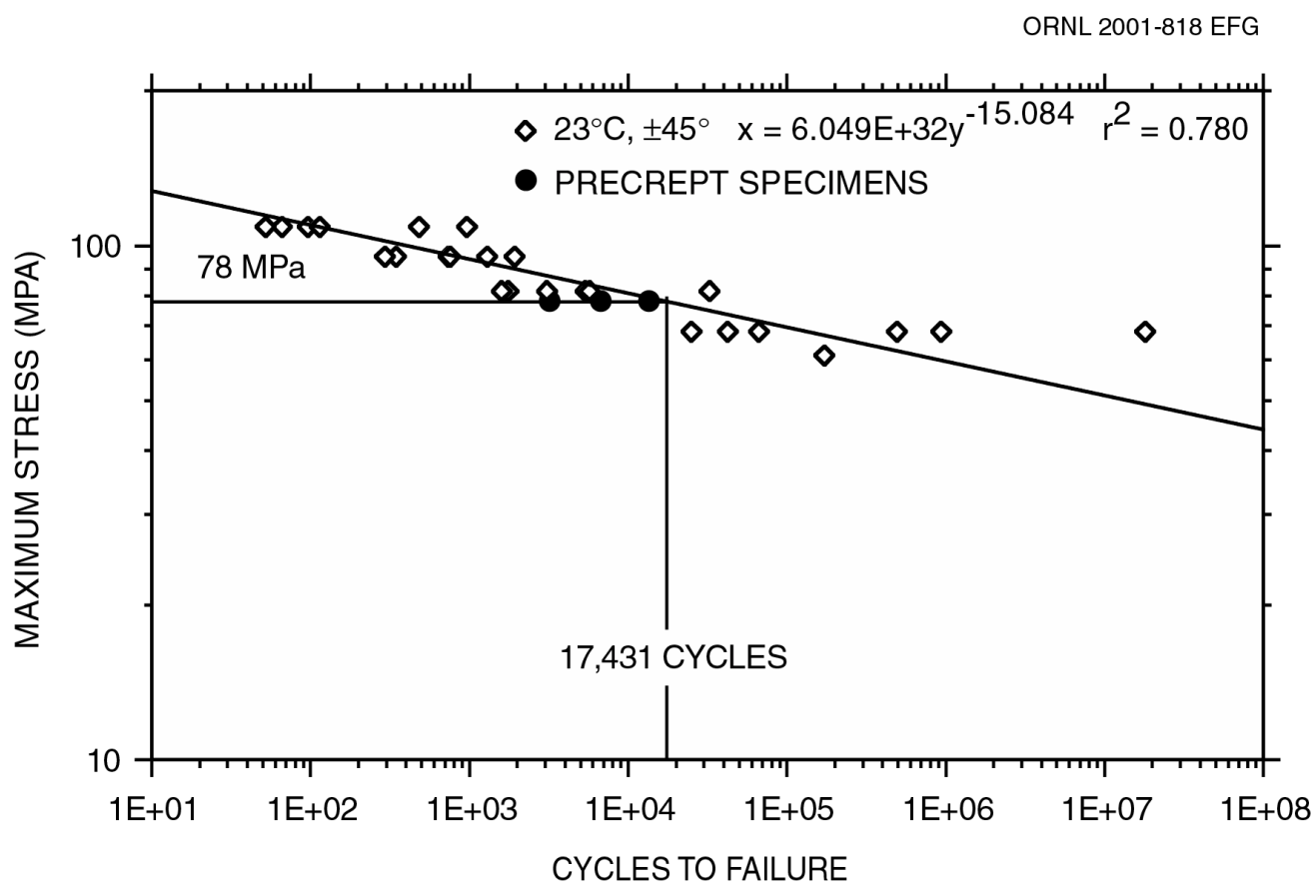

Fig. 13.4. Results of fatigue tests of three precrept $\pm 45^{\circ}$ specimens compared to baseline fatigue data from Fig. 9.1. 


\title{
14. DAMAGE TOLERANCE
}

\author{
J. M. Corum, R. L. Battiste, M. B. Ruggles, and W. A. Simpson, Jr.
}

\subsection{INTRODUCTION}

The damage tolerance assessment procedure in Chap. 5 of Part 1 consists of two parts: (1) demonstrating structural adequacy in the presence of a 6.4-mm-diam hole in the worst possible location and (2) determining the damage area and strength degradation for specified lowenergy impacts such as kickups of roadway debris, tool drops, and load drops in a pickup truck box. This chapter provides the background data and correlations for the latter part.

Baseline impact damage area correlations were based on the results of tests in a pendulum impact facility and an air-gun facility, representing events such as tool drops and roadway kickups, respectively. Specimens were the same in both cases - $3.2 \mathrm{~mm}$-thick by 229 -mm-square plates. The facilities are the same as used previously for random-glass-fiber composites and are described in Ref. 8. The specimens were clamped on 203-mm-diam circles and impacted at the center.

In addition to baseline tests, tests were performed to assess the effects of moisture. Also, brick-drop tests were performed to determine the ability of the baseline correlations to cover that event. Finally, each impact specimen was cut into tensile, compressive, or fatigue specimens that were tested to determine property degradation as a function of damage area. These tests and the results are presented in the following sections.

\subsection{IMPACT TESTS}

\subsubsection{Baseline Results}

Tables 14.1 and 14.2 list all of the pendulum and air-gun tests, respectively, performed on the crossply carbon-fiber composite. The tables list the velocity of the impactor just prior to impact, the calculated kinetic energy of the impactor, and the measured damage areas, both including and excluding delaminations (discussed below). In the pendulum case, the maximum force reached during the impact, as measured by a miniature load cell mounted behind the impactor point, is also listed. Finally, the "property tests" columns indicate the type of mechanical property test specimens cut from each impacted plate specimen. Note that both specimens with $0 / 90^{\circ}$ and with $\pm 45^{\circ}$ fiber orientations were tested.

The pendulum impactor mass was $11.52 \mathrm{~kg}$ with a $12.7-\mathrm{mm}$-diam hemispherical hardenedsteel impactor point. The air-gun projectile was a $12.7-\mathrm{mm}$-diam hardened-steel cylinder with a hemispherical point. The projectile mass was $0.0224 \mathrm{~kg}$.

Damage areas were determined from ultrasonic $\mathrm{C}$-scans of the impacted plate specimens. Unlike the case of the previously tested random-glass-fiber composites, where impact damage was contained in a relatively small central area, long narrow delaminations often ran from the central damage area in the direction of the surface ply fibers. These delaminations occurred on the back side of the specimens (opposite the impacted side) and were more prevalent in the air-gun specimens than in the pendulum specimens.

Figure 14.1 depicts a typical specimen with delaminations. This specimen was impacted with the air-gun projectile; the delamination, which was less than or equal to just one unidirectional ply in thickness, extended several inches in each direction from the central damage site. Figure 14.2 is the $\mathrm{C}$-scan image corresponding to Fig. 14.1. Contrary to the central damage area, which is mostly black or dark gray, corresponding to almost no reflected energy (maximum damage), most of the diagonal delaminations are white, corresponding to nearly $100 \%$ energy reflectance. 
Table 14.1. Results of pendulum impact tests

\begin{tabular}{|c|c|c|c|c|c|c|c|}
\hline \multirow{2}{*}{$\begin{array}{l}\text { Specimen } \\
\text { No. }\end{array}$} & \multicolumn{2}{|c|}{ Property tests } & \multirow{2}{*}{$\begin{array}{c}\text { Velocity } \\
(\mathrm{m} / \mathrm{s})\end{array}$} & \multirow{2}{*}{$\begin{array}{c}\text { Energy } \\
\text { (J) }\end{array}$} & \multirow{2}{*}{$\begin{array}{c}\text { Maximum } \\
\text { force } \\
\text { (N) }\end{array}$} & \multicolumn{2}{|c|}{$\begin{array}{l}\text { Damage area } \\
\left(\mathrm{mm}^{2}\right)\end{array}$} \\
\hline & $\pm 45^{\circ}$ & $0 / 90^{\circ}$ & & & & $\begin{array}{c}\text { With } \\
\text { delamination }\end{array}$ & $\begin{array}{c}\text { Without } \\
\text { delamination }\end{array}$ \\
\hline \multicolumn{8}{|c|}{ 12.7-mm diam, $11.52 \mathrm{~kg} —$ baseline } \\
\hline C32-4 & Compression & & 1.14 & 7.37 & 2855 & 173 & 173 \\
\hline C33-4 & Tension & & 1.12 & 7.07 & 3070 & 41 & 41 \\
\hline C34-2 & & Compression & 1.50 & 12.67 & 3392 & 326 & 186 \\
\hline C35-2 & & Tension & 1.51 & 12.75 & 3681 & 255 & 171 \\
\hline C36-4 & Compression & & 1.66 & 15.46 & 3747 & 530 & 225 \\
\hline C37-4 & Tension & & 1.60 & 14.32 & 3689 & 449 & 194 \\
\hline C38-4 & & Compression & 1.85 & 19.23 & 3730 & 965 & 322 \\
\hline C39-2 & & Tension & 1.83 & 18.75 & 3788 & 642 & 357 \\
\hline C40-1 & Compression & & 1.08 & 6.56 & 2690 & 107 & 107 \\
\hline C40-4 & Tension & & 1.11 & 6.97 & 2789 & 122 & 28 \\
\hline C41-1 & & Compression & 1.50 & 12.73 & 3648 & 336 & 188 \\
\hline C41-4 & & Tension & 1.55 & 13.59 & 3582 & 335 & 143 \\
\hline C42-1 & Compression & & 1.83 & 18.93 & 3928 & 629 & 322 \\
\hline C42-4 & Tension & & 1.84 & 19.10 & 3813 & 668 & 250 \\
\hline C43-1 & & Compression & 2.03 & 23.14 & 3606 & 683 & 481 \\
\hline C43-4 & & Tension & 2.06 & 23.94 & 3738 & 865 & 490 \\
\hline C44-1 & Fatigue & & 1.21 & 8.22 & 2814 & 194 & 97 \\
\hline C44-4 & & Fatigue & 1.23 & 8.47 & 2954 & 159 & 84 \\
\hline C45-1 & Fatigue & & 1.58 & 14.05 & 3086 & 607 & 459 \\
\hline C45-4 & & Fatigue & 1.59 & 14.15 & 2913 & 591 & 591 \\
\hline \multicolumn{8}{|c|}{ Water-soaked $\left(1000 \mathrm{~h}\right.$ at $\left.23^{\circ} \mathrm{C}\right)$} \\
\hline C32-1 & Compression & & 1.12 & 7.01 & 2657 & 77 & 19 \\
\hline C34-3 & & Compression & 1.46 & 11.94 & 3293 & 280 & 143 \\
\hline C36-1 & Compression & & 1.73 & 16.80 & 3648 & 601 & 239 \\
\hline C38-3 & & Compression & 1.96 & 21.54 & 3532 & 908 & 317 \\
\hline
\end{tabular}


Table 14.2. Results of air-gun impact tests

\begin{tabular}{|c|c|c|c|c|c|c|}
\hline \multirow{2}{*}{$\begin{array}{l}\text { Specimen } \\
\text { No. }\end{array}$} & \multicolumn{2}{|c|}{ Property tests } & \multirow{2}{*}{$\begin{array}{c}\text { Velocity } \\
(\mathrm{m} / \mathrm{s})\end{array}$} & \multirow{2}{*}{$\begin{array}{c}\text { Energy } \\
\text { (J) }\end{array}$} & \multicolumn{2}{|c|}{$\begin{array}{c}\text { Damage area } \\
\left(\mathrm{mm}^{2}\right)\end{array}$} \\
\hline & $\pm 45^{\circ}$ & $\mathbf{0} / 90^{\circ}$ & & & $\begin{array}{c}\text { With } \\
\text { delamination }\end{array}$ & $\begin{array}{c}\text { Without } \\
\text { delamination }\end{array}$ \\
\hline \multicolumn{7}{|c|}{ 12.7-mm diam, $0.02244 \mathrm{~kg}$-baseline } \\
\hline C32-3 & & Tension & 36.89 & 15.27 & 207 & 149 \\
\hline C33-3 & & Compression & 38.11 & 16.30 & 275 & 163 \\
\hline C34-1 & Tension & & 41.98 & 19.77 & 385 & 197 \\
\hline C35-1 & Compression & & 41.79 & 19.60 & 301 & 176 \\
\hline C36-3 & & Tension & 48.54 & 26.44 & 647 & 219 \\
\hline C37-3 & & Compression & 46.88 & 24.66 & 639 & 421 \\
\hline C38-1 & Tension & & 55.70 & 34.81 & 1362 & 532 \\
\hline C39-1 & Compression & & 55.25 & 34.25 & 1243 & 645 \\
\hline C40-2 & & Tension & 34.03 & 12.99 & 199 & 125 \\
\hline C40-3 & & Compression & 33.98 & 12.95 & 199 & 99 \\
\hline C41-2 & Tension & & 46.48 & 24.24 & 469 & 199 \\
\hline C41-3 & Compression & & 46.57 & 24.34 & 438 & 183 \\
\hline $\mathrm{C} 42-2$ & & Tension & 54.10 & 32.84 & 1179 & 363 \\
\hline $\mathrm{C} 42-3$ & & Compression & 52.84 & 31.34 & 980 & 279 \\
\hline C43-2 & Tension & & 61.26 & 42.11 & 1287 & 497 \\
\hline C43-3 & Compression & & 61.76 & 42.80 & 1811 & 314 \\
\hline C44-2 & & Fatigue & 37.51 & 15.79 & 158 & 158 \\
\hline C44-3 & Fatigue & & 37.01 & 15.37 & 306 & 132 \\
\hline C45-2 & & Fatigue & 47.54 & 25.36 & 1434 & 303 \\
\hline C45-3 & Fatigue & & 46.58 & 24.34 & 714 & 408 \\
\hline \multicolumn{7}{|c|}{ Water-soaked $\left(1000 \mathrm{~h}\right.$ at $\left.23^{\circ} \mathrm{C}\right)$} \\
\hline C33-2 & & Compression & 42.81 & 20.56 & 347 & 132 \\
\hline C35-4 & Compression & & 41.91 & 19.71 & 398 & 188 \\
\hline C37-2 & & Compression & 48.00 & 25.85 & 709 & 219 \\
\hline C39-4 & Compression & & 55.79 & 34.93 & 1283 & 434 \\
\hline
\end{tabular}

This is due to the air space and the reflectance of the associated surfaces between the delamination and the bulk of the specimen. The values in the first damage area column in Tables 14.1 and 14.2 include the delaminations and, referring to Fig. 14.2 as an example, the gray areas that are associated with them and with the dark central damage area. The second damage area column in the two tables contains measured values that exclude the white delamination areas and the gray areas associated with them.

As will be discussed in Sect. 14.3, the reason for possibly ignoring the delaminations is that tensile and compressive mechanical property specimens cut so that they contained a transverse delamination, but not the central damage area, showed essentially no property degradation caused by the delamination. The larger area that includes the delamination may be of cosmetic interest only.

Figure 14.3 depicts a pendulum-impacted specimen that exhibited no visible delaminations (this was not always the case). The corresponding C-scan, shown in Fig. 14.4, has no indication 
of delaminations, such as those visible in Fig. 14.2. There is a fairly significant gray area around the boundary of the central dark damage area. Most of these sorts of indications were ignored in determining values for damage areas exclusive of delaminations. These areas in Tables 14.1 and 14.2 thus err on the side of being minimal values.

The final set of impact damage images, Figs. 14.5 and 14.6, represent a case where no visible damage occurred. However, Fig. 14.6 shows that the $\mathrm{C}$-scan did indicate the presence of a small peanut-shaped area of damage.

In the following two subsections, correlations of damage area with impactor mass and velocity are developed separately for (1) the case where damage areas include delaminations and (2) the case where they do not.

\subsubsection{Damage areas inclusive of delaminations}

There are 20 baseline pendulum test results provided in Table 14.1 and 20 baseline air-gun test results tabulated in Table 14.2. The corresponding results are plotted in Fig. 14.7, where damage area (with delaminations included) vs impactor kinetic energy is shown. Also shown, for comparison, are the results of the baseline impact tests on the P4 chopped-glass fiber composite. ${ }^{3}$ In that case, kinetic energy provided a very good correlation; the pendulum and air-gun data curve fits coincided, so no distinction is made between pendulum and air-gun data points in Fig. 14.7. The damage areas are much greater for the carbon-fiber composite than for the glassfiber one, particularly at the higher energy level.

One obvious reason for the greater damage areas for the carbon-fiber composite in Fig. 14.7 is the fact that delamination occurred and are included in the areas. Another reason is that the carbon-fiber composite is stiffer, at least in the $0 / 90^{\circ}$ fiber orientation direction, than the choppedglass fiber composite. This means that less of the energy is absorbed by plate specimen deflection. Thus, peak impact forces and damage are higher. This is illustrated in Fig. 14.8 where the maximum measured forces in the pendulum tests are plotted vs impactor velocity for both the carbon-fiber composite and the chopped-glass fiber composite. The carbon-fiber forces are clearly higher, particularly at the lower velocities where damage was not so large.

Both the pendulum and air-gun data for the carbon-fiber composite in Fig. 14.7 are reasonably well represented by power-law fits over the range shown. Unlike the chopped-glass-fiber case, however, the curves do not coincide, indicating that kinetic energy is not an adequate correlating parameter.

An improved correlating parameter is used in Fig. 14.9. Here, area is expressed as a powerlaw function of the parameter mass ${ }^{0.527} \times$ velocity. $^{*}$ The solid curve represents all of the data, while the dashed and dotted curves represent the pendulum and air-gun data, respectively. The fact that all three curves almost coincide attests to the suitability of the correlating parameter chosen.

\subsubsection{Damage areas exclusive of delaminations}

Figure 14.10, which corresponds to Fig. 14.7, shows damage areas without delaminations vs kinetic energy. Again the chopped-glass-fiber results are shown for comparison. Comparing Fig. 14.10 with Fig. 14.7 shows that the carbon-fiber composite damage areas are more scattered in the case where delaminations are excluded. (This is reflected in the lower $\mathrm{r}^{2}$ values for the curve fits in Fig. 14.10.) Further comparison of the two figures shows that excluding the delaminations does significantly lower the plotted areas. At low kinetic energy levels, the damage areas

\footnotetext{
*While the power-law represents the data over the range shown, it is likely invalid below some threshold, where no damage occurs, and at higher energy levels where damage is likely limited.
} 
in Fig. 14.10 for the carbon-fiber composite are about the same as those for the glass-fiber composite; however, at higher levels, the carbon-fiber composite values are higher.

Figure 14.11, which corresponds to Fig. 14.9, exhibits damage areas without delaminations vs the parameter $\mathrm{m}^{0.533} \mathrm{v}$. In this case, the individual pendulum and air-gun curves do not coincide as well as in Fig. 14.9, but the solid curve is still deemed to be adequate. Again the scatter is greater in Fig. 14.11 than in Fig. 14.9.

The question of which correlation-Fig. 14.9, with delaminations considered, or Fig. 14.11, without delaminations - should be used will be delayed until the "Summary and Discussion" at the end of this chapter.

\subsubsection{Moisture Effects}

Eight impact tests - four pendulum and four air gun-were performed on specimens that had been soaked for $1000 \mathrm{~h}$ in distilled water. The specimens were removed from the water immediately prior to the tests. The results of these tests were included in Tables 14.1 and 14.2.

The resulting damage areas are depicted in Fig. 14.12 relative to the baseline test results for virgin specimens. The damage areas in Fig. 14.12(a) are inclusive of delaminations, while those in Fig. 14.12(b) are exclusive of delaminations. In Fig. 14.12(a), the results for the presoaked specimens all fall very close to the baseline correlation, indicating no effect of the water soak. In Fig. 14.12(b), all of the presoaked-specimen results fall below the baseline correlation, indicating a slight beneficial effect, due probably to the plasticizing effect of the water on the matrix. This same improvement was observed in the case of the chopped-glass-fiber composite. ${ }^{3}$

\subsubsection{Brick-Drop Tests}

The test results presented in the previous subsections were all for smooth hemispherical steel impactor points. Brick drops, which are one of the loadings specified for the ACC Focal Project II pickup box, provide an opportunity to determine if the results are applicable to impacts from more irregular objects.

Eight brick-drop tests were performed, as tabulated in Table 14.3. The bricks had an average mass of $1.67 \mathrm{~kg}$. The bricks were dropped from heights of $0.61,1.2,1.8$, and $2.4 \mathrm{~m}(2,4,6$, and $8 \mathrm{ft}$ ). They were dropped so that they hit on a corner, with the center of gravity in line with the impact point. The same clamped specimen design as in the previous case was used.

Table 14.3. Results of brick-drop tests

\begin{tabular}{|c|c|c|c|c|c|c|}
\hline \multirow{2}{*}{$\begin{array}{c}\text { Specimen } \\
\text { No. }\end{array}$} & \multicolumn{2}{|c|}{ Property tests } & \multirow{2}{*}{$\begin{array}{l}\text { Velocity } \\
(\mathrm{m} / \mathrm{s})\end{array}$} & \multirow{2}{*}{$\begin{array}{c}\text { Energy } \\
\text { (J) }\end{array}$} & \multicolumn{2}{|c|}{$\begin{array}{c}\text { Damage area } \\
\left(\mathrm{mm}^{2}\right)\end{array}$} \\
\hline & $\pm 45^{\circ}$ & $0 / 90^{\circ}$ & & & $\begin{array}{c}\text { With } \\
\text { delamination }\end{array}$ & $\begin{array}{c}\text { Without } \\
\text { delamination }\end{array}$ \\
\hline C32-2 & Compression & & 3.46 & 9.94 & 51 & 51 \\
\hline C33-1 & Tension & & 3.46 & 9.94 & 71 & 38 \\
\hline C34-4 & & Compression & 4.89 & 19.88 & 775 & 316 \\
\hline C35-3 & & Tension & 4.89 & 19.88 & 764 & 265 \\
\hline C36-2 & Compression & & 5.99 & 29.82 & 948 & 540 \\
\hline C37-1 & Tension & & 5.99 & 29.82 & 1050 & 535 \\
\hline C38-2 & & Compression & 6.91 & 40.11 & 668 & 479 \\
\hline C39-3 & & Tension & 6.91 & 40.11 & 846 & 846 \\
\hline
\end{tabular}


Although the front (impacted) side of some of the brick-drop specimens had a gash from the brick edges, the $\mathrm{C}$-scan images looked similar to those for the baseline pendulum test specimens. Some specimens had visible delaminations; some did not. Figure 14.13 compares damage areas produced by the brick drops with the baseline correlation and data from the pendulum and air-gun tests. Again, both the correlations with and without consideration of delaminations are shown. The brick data, in either case, are clustered near or below the curves in Fig. 14.13, indicating that the baseline correlations can be conservatively applied to bricks, and presumably to other irregularly shaped objects as well.

\subsection{DEGRADATION OF STRENGTH PROPERTIES}

As was indicated in Tables 14.1-14.3, each of the 56 impacted plate specimens was cut into test specimens for either tensile, compressive, or fatigue testing. Because two fiber orientations are of interest, one-half of the 56 impact specimens were cut into mechanical properties specimens with a $0 / 90^{\circ}$ fiber orientation, and one-half were cut into specimens with a $\pm 45^{\circ}$ fiber orientation. The cutting plans are illustrated in Fig. 14.14 for tensile-type specimens. The 0/90 specimens were always cut perpendicular to the surface fibers and thus to any delaminations that were present. The tensile specimens were the standard $203-\mathrm{mm}$ long by $25.4-\mathrm{mm}$ wide. The outer specimens containing no visible damage were dogboned.

The plan was to have one specimen containing the central damage area, in some cases specimens containing only a delamination, and two outer specimens containing neither damage nor delaminations. The latter specimens were to provide baseline strength values that, together with values from the center specimen, would allow strength reduction ratios to be calculated. Because of space limitations, only three $0 / 90^{\circ}$ tensile specimens could be obtained, and sometimes one or both of the outer specimens contained delaminations. However, these delaminations had no consistent discernible effect on strength, so baseline strength values were still obtained from the specimens. In the $\pm 45^{\circ}$ case, the outer specimens never contained delaminations. The two inner specimens adjacent to the central damaged specimen were only obtained if there were delaminations. Again, however, the delaminations had no discernible effect on strength.

Compression specimens were the standard 133-mm long by 25.4-mm wide. Because of the shorter length, five specimens could be obtained, if necessary (if there were delaminations) for both the $0 / 90^{\circ}$ and $\pm 45^{\circ}$ fiber orientations. Similar to the tensile case, there was no consistent strength loss in those compressive specimens containing delaminations.

A total of 64 tensile tests was performed; 96 compressive tests were performed; and 24 fatigue tests were performed. The results of these tests are presented in the following subsections.

\subsubsection{Tensile and Compressive Strengths}

The strength results of the tensile and compressive tests of mechanical property specimens cut from the baseline impact plate specimens are plotted in Figs. 14.15 and 14.16, respectively. In each case the strength reduction is the ratio of the strength of a center specimen, which contains the damage area, to the strength of specimens cut from undamaged regions. In each case, damage areas that include delaminations are used in $(a)$, while damage areas that exclude delaminations are used in $(b)$. The conclusions are the same, regardless of whether the $(a)$ or $(b)$ figures are considered.

- For both tension and compression, the $0 / 90^{\circ}$ strength degradation (filled points) is slightly larger than is the $\pm 45^{\circ}$ strength degradation (open points).

- For both the $0 / 90^{\circ}$ and the $\pm 45^{\circ}$ orientation, the loss in tensile strength is very slightly larger than the compressive strength loss. 
- For both tension and compression, the pendulum and air-gun tests appear to give the same results for the $\pm 45^{\circ}$ orientation; but in the $0 / 90^{\circ}$ orientation, the pendulum results are generally lower at the lower levels of damage.

In the case of the swirl-glass-mat composite, tensile strength was significantly more degraded than was compressive strength. ${ }^{2}$ The degradation was greater than in the crossply carbon-fiber composite, even when delaminations were excluded from the damage areas [Fig. 14.15(b)]. In the P4 chopped-glass-fiber composite, tensile strength was not degraded at all, while compressive strength was significantly degraded. ${ }^{3}$ The P4 glass-fiber composite compressive strength degradation was greater than in the crossply carbon-fiber composite, even with delaminations excluded from the damage areas [Fig. 14.16(b)].

\subsubsection{Fatigue Strength}

Specimens from eight impacted plates were earmarked for tensile fatigue tests. One-half of the plates had been impacted with the pendulum and one-half with the air gun; one-half of each were cut into $\pm 45^{\circ}$ specimens and one-half into $0 / 90^{\circ}$ specimens. The plan was to test each specimen at a stress predicted to produce failure in $10^{4}$ cycles in the undamaged specimens. This proved to be difficult. In the $0 / 90^{\circ}$ case, where fatigue life variability is high, the fatigue curves are nearly flat, and the stresses involved are near ultimate (see Chap. 9); all of the damaged specimens failed on loading, and the undamaged specimens were all runouts.

In the $\pm 45^{\circ}$ case, where fatigue would be of more practical importance, the plan was somewhat more successful. All of the undamaged specimens failed within the expected range of cycles. Two of the four damaged specimens failed on loading and two failed in fatigue. The results, in terms of strength reduction, are shown in Fig. 14.17 superimposed on the $\pm 45^{\circ}$ tensile strength reduction data of Fig. 14.15(a). The two failures in the initial loading were treated as UTS values and ratioed to the average undamaged UTS of the plaques. The fatigue failure cycles were ratioed to the average cycles to failure from undamaged specimens from the same impact plate. To convert to a strength reduction ratio, a family of parallel fatigue curves was assumed.

While the data in Fig. 14.17 are too limited to draw concrete conclusions, it would appear that the tensile fatigue strength reduction is no greater than the corresponding ultimate strength reduction. Figure 14.17 is based on damage areas that include delaminations. The same conclusion is reached when the damage areas exclude delaminations. Consequently, that plot is not included here.

\subsubsection{Effects of Moisture on Strength Degradation}

All of the water-soaked impact specimens listed in Tables 14.1 and 14.2 were cut into compressive specimens, with the expectation that compressive strength, if any, would be most affected. The resulting compressive strength reduction ratios are plotted vs damage area (with delaminations) in Fig. 14.18, where they are compared with the baseline data points (shown smaller). In all combinations (pendulum, air gun, $0 / 90^{\circ}$, and $\pm 45^{\circ}$ ), the compressive strength retention of the presoaked impact specimen is equivalent to that of the unsoaked specimens. A similar plot in which the damage area excludes delaminations shows increased scatter but supports the same conclusion: the water soak had no effect on a compressive strength degradation.

\subsubsection{Strength Degradation Produced by Brick Drops}

Of the eight brick-drop impact specimens listed in Table 14.3, four were cut into tensile test specimens (two $\pm 45^{\circ}$ and two $0 / 90^{\circ}$ ), and four were cut into compressive test specimens. The 
resulting strength reduction ratios are compared in Fig. 14.19 with the baseline pendulum and airgun data. With the exception of one $0 / 90^{\circ}$ tensile data point in Fig. 14.19(a) and possibly one 0/90 $0^{\circ}$ compressive data point in Fig. 14.19(b), the brick-drop data all fall within the baseline pendulum and air-gun data band. In similar figures in which delaminations are excluded from the areas, all of the brick-drop data points are within the baseline data band. Thus, while it would appear that the strength degradation due to a brick drop is essentially the same as for the baseline pendulum and air-gun data, the one data point in Fig. 14.19(a) leaves some uncertainty. More data would be required to arrive at a more firm conclusion.

\subsection{SUMMARY AND DISCUSSION}

Unlike the random-glass-fiber composites previously evaluated, the layered crossply carbonfiber composite exhibited frequent delaminations of the outer ply on the surface opposite the point of impact. These delaminations added to the damage areas indicated by ultrasonic $\mathrm{C}$-scans. The damage areas were correlated with impactor mass and velocity in two ways - one with the delaminations included in the damage area and one with them excluded. The delaminations were a significant part of the indicated damage areas, but even with them excluded, the damage areas still tended to be larger in the crossply carbon-fiber composite than they were in the glass-fiber composites. One reason for this is that the stiffer carbon-fiber composite led to higher impact forces, and thus more damage.

Impact damage was correlated with the quantity $\mathrm{m}^{\mathrm{a}} \mathrm{v}$. In the case where delaminations were included in the damage areas, the exponent, a, was 0.527 . When delaminations were excluded, the exponent was 0.533 . For the damage tolerance design guidance suggested in Chap. 5 of Part 1 , delaminations were included for two reasons. First, there was less scatter in the areas, and the correlation was somewhat better. Second, from at least a cosmetic standpoint, the delaminations may be of importance. As far as strength degradation is concerned, it makes little difference which area is used. Damage area is just an intermediate quantity in relating strength degradation to impactor mass and velocity.

The "design" curve given in Part 1 for determining damage area was derived from the baseline pendulum and air-gun data, as shown in Fig. 14.20, where the curve is compared with the data. A power-law relationship was assumed that provided an upper bound to all of the data except one air-gun point. Use of this curve would generally provide a reasonable margin.

Soaking the impact specimens for $1000 \mathrm{~h}$ in distilled water prior to testing had either no effect on the damage area or was slightly beneficial, depending on whether delaminations were considered or not. Thus, the design curve in Fig. 14.20 is still applicable.

The same conclusion was reached in the case of brick drops. Whether delaminations were considered or not, the brick-drop damage-area data were clustered near or below the baseline curve.

Property degradation tests were performed on 25.4-mm-wide specimens. A strength reduction factor was determined by ratioing the strength - tensile, compressive, or fatigue - of a specimen containing the impact damage area to that of undamaged specimens from the same impacted plate. These reduction ratios were plotted as a function of damage area, as shown in Fig. 14.21, for tensile and compressive tests of specimens and from the baseline impact specimens. The following conclusions were drawn.

- The pendulum and air-gun tests resulted in the same strength degradation in specimens with a $\pm 45^{\circ}$ fiber orientation, but the pendulum resulted in greater degradation in both tensile and compressive strength for $0 / 90^{\circ}$ specimens. Overall, the $0 / 90^{\circ}$ strength was thus degraded more than the $\pm 45^{\circ}$ strength.

- The loss in tensile strength was greater than the loss of compressive strength. 
In Fig. 14.21, the curve shown was chosen to represent the lower data points in the band. This is the "design" curve recommended in Part 1 for establishing tensile and compressive strength degradation.

Soaking the impact specimens in distilled water prior to impact testing appeared to have no effect on strength degradation (only compressive strength was assessed). The curve in Fig. 14.21 should thus still be adequate. Likewise, tensile and compressive tests of specimens cut from brick-drop impact specimens fell, with one exception, within the scatter band of the baseline tensile and compressive strength degradation data, respectively. Thus, the curve in Fig. 14.21 should be adequate for brick drops.

While the geometry and support conditions of the impact specimen were chosen to typify, as closely as possible, a structural component away from any discontinuities, it is recognized that many areas of a component may respond quite differently. Thus, caution should be used when attempting to extrapolate the results of this chapter to actual components. 


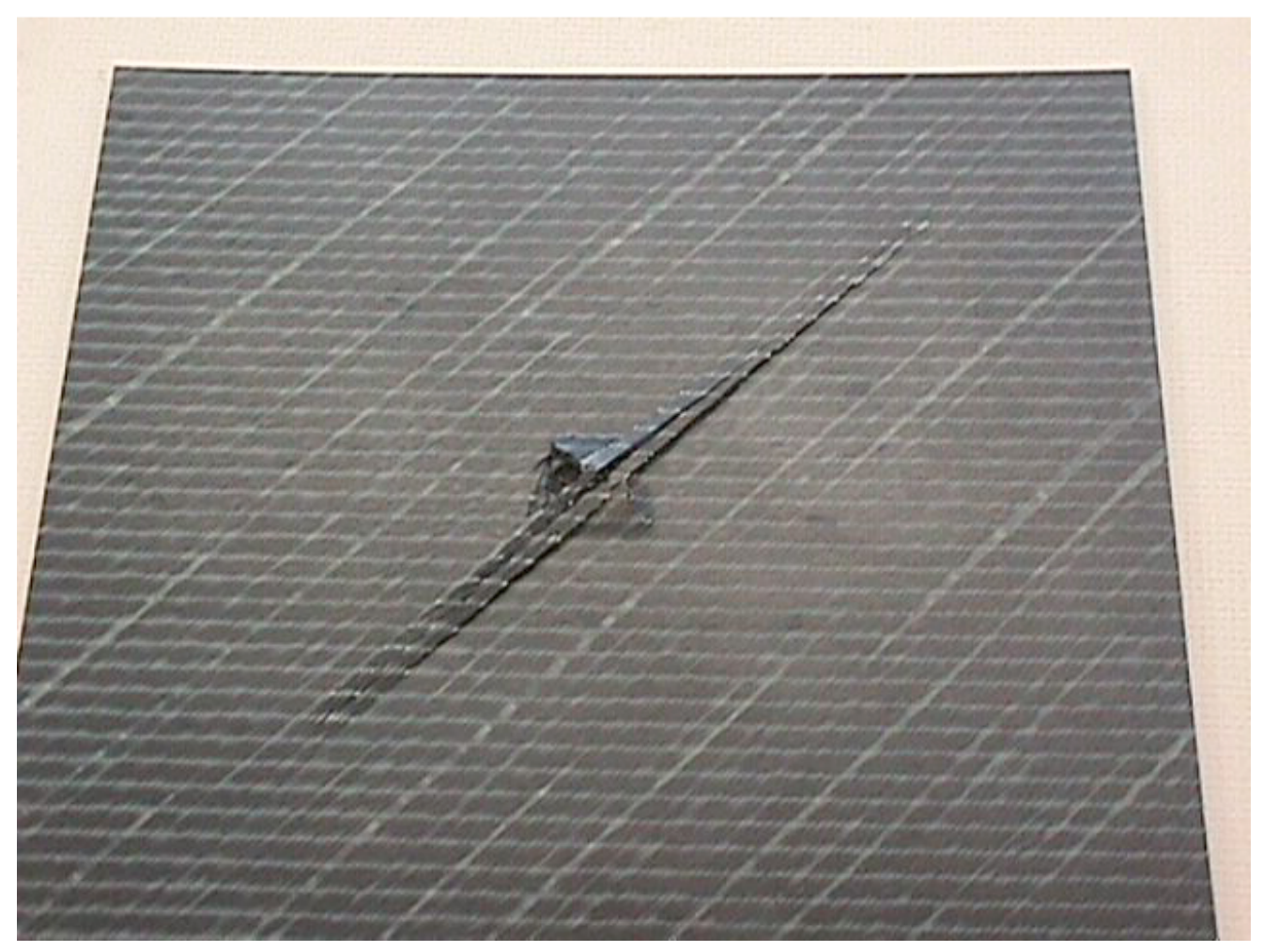

Fig. 14.1. Photograph of back of specimen C38-1, impacted by air-gun projectile.

ORNL 2001-820 EFG

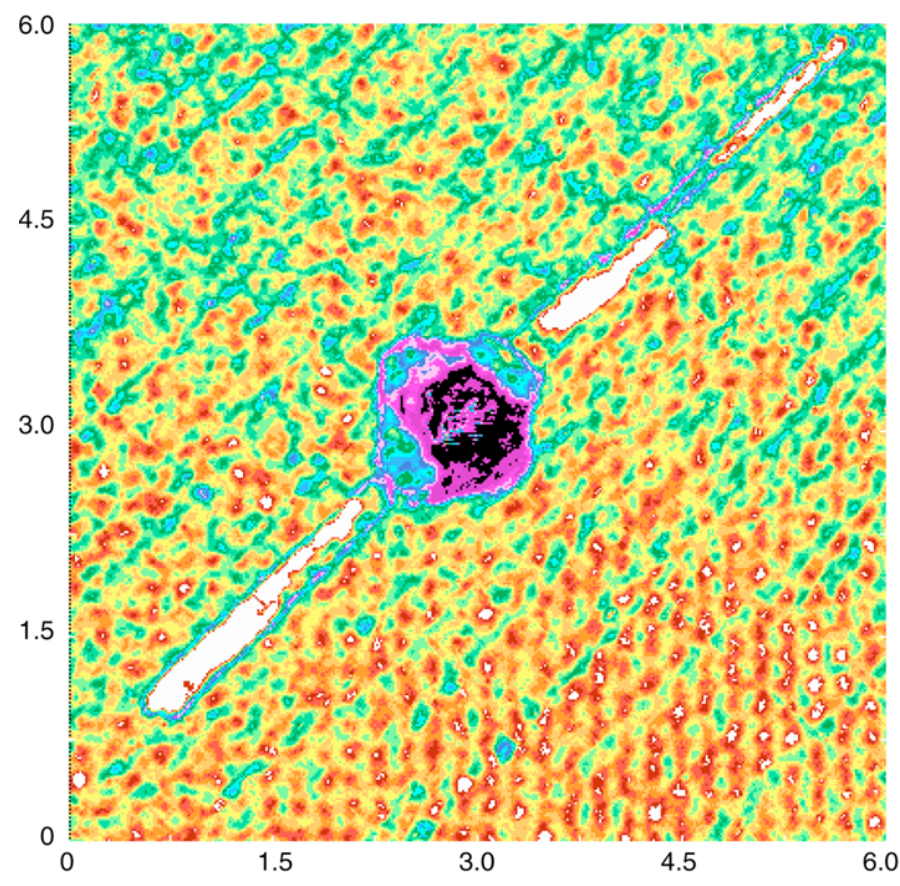

C38-1.CS0

Fig. 14.2. C-scan of impact specimen C38-1. 


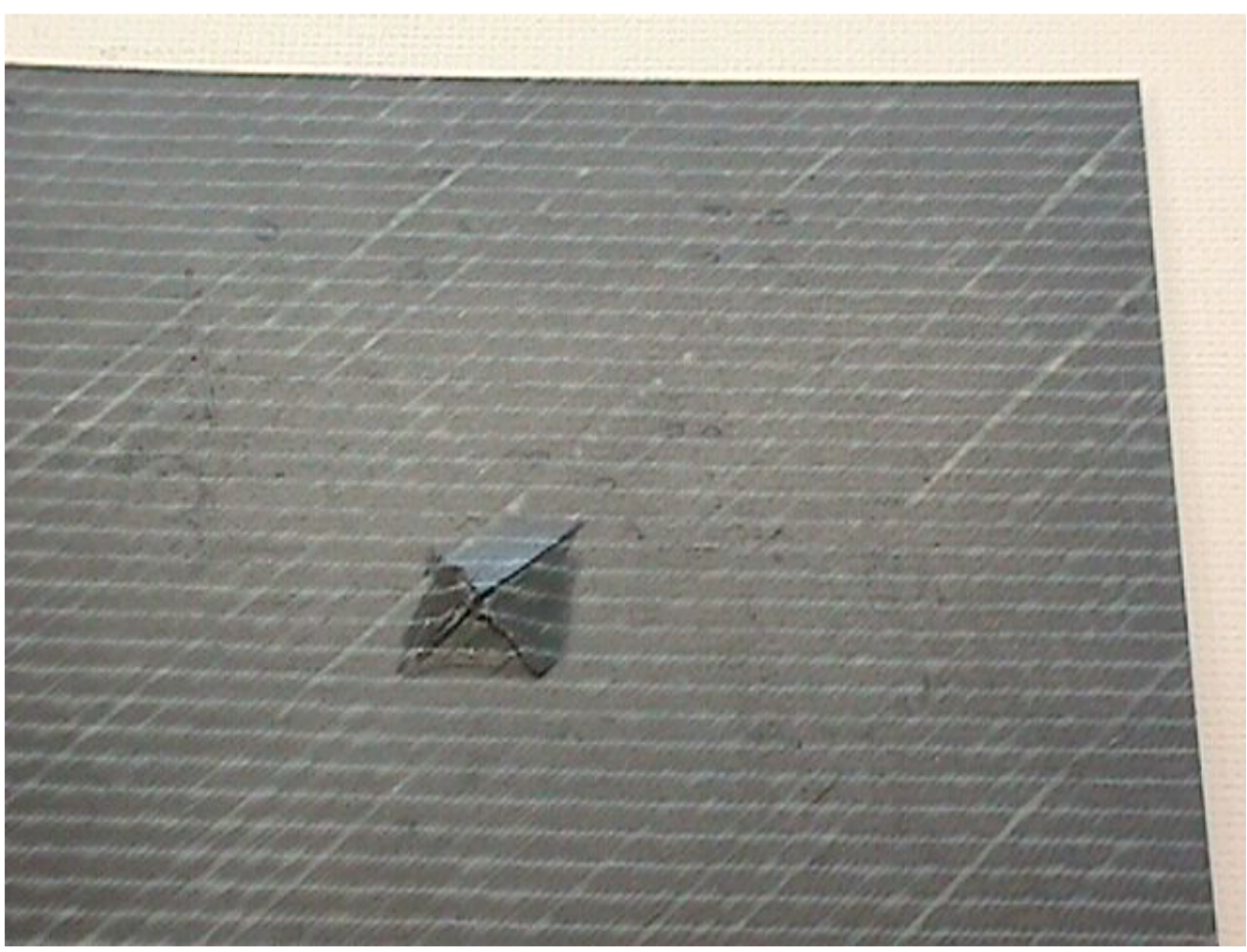

Fig. 14.3. Photograph of back of specimen C43-1, impacted by pendulum.

ORNL 2001-822 EFG

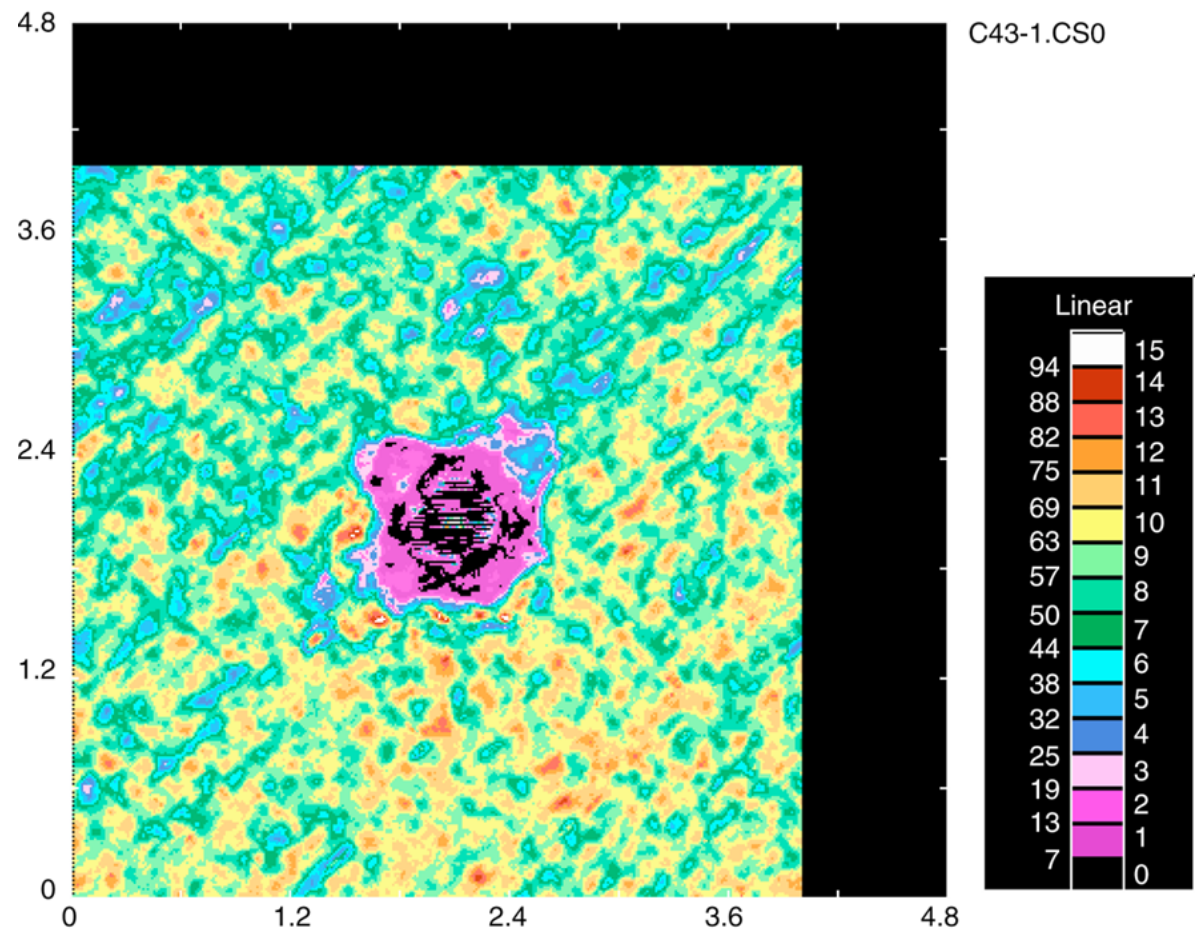

Fig. 14.4. C-scan of impact specimen C43-1. 


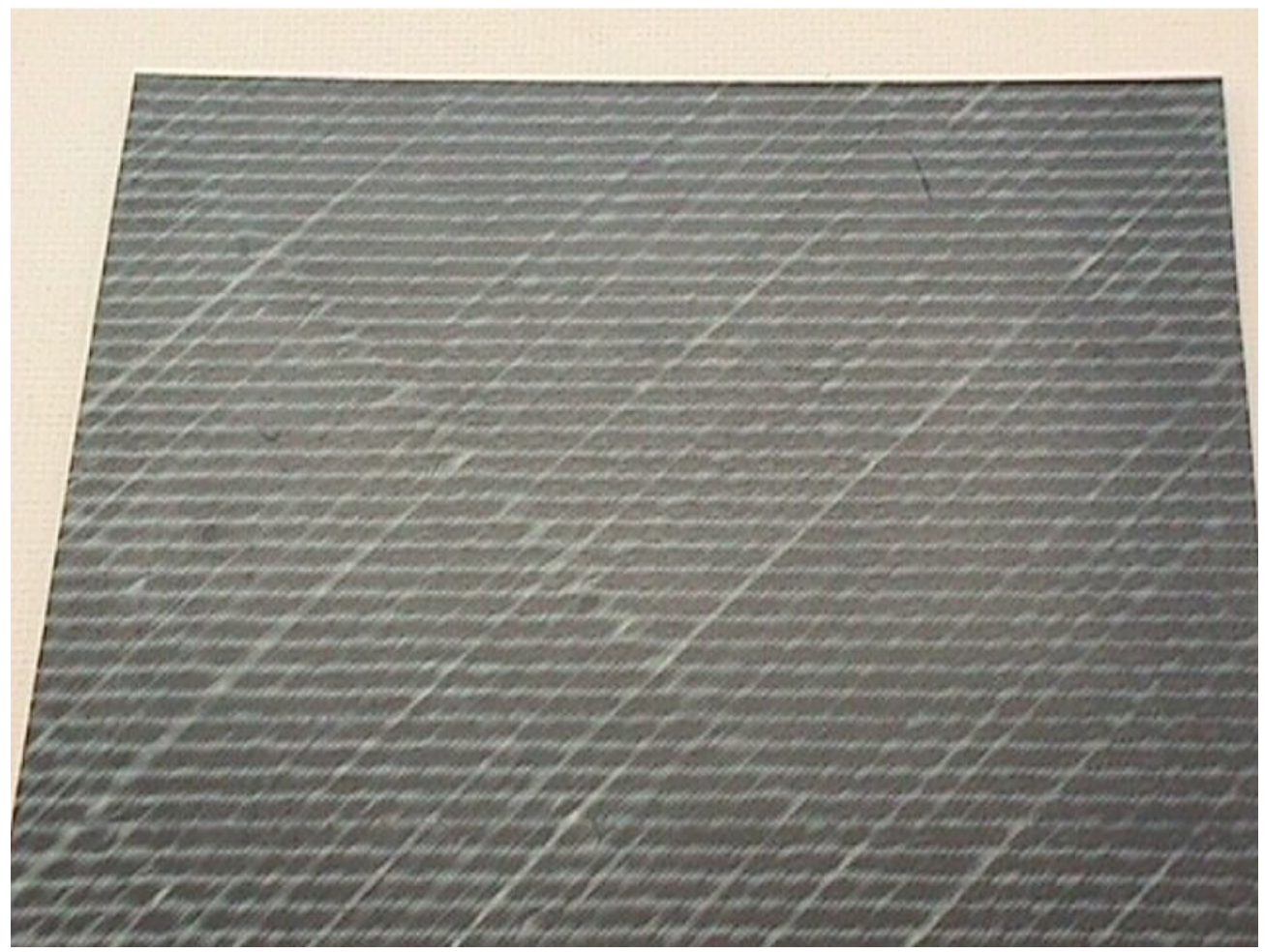

Fig. 14.5. Photograph of back of specimen C33-4, impacted by pendulum. There is no visible damage.

ORNL 2001-824C EFG

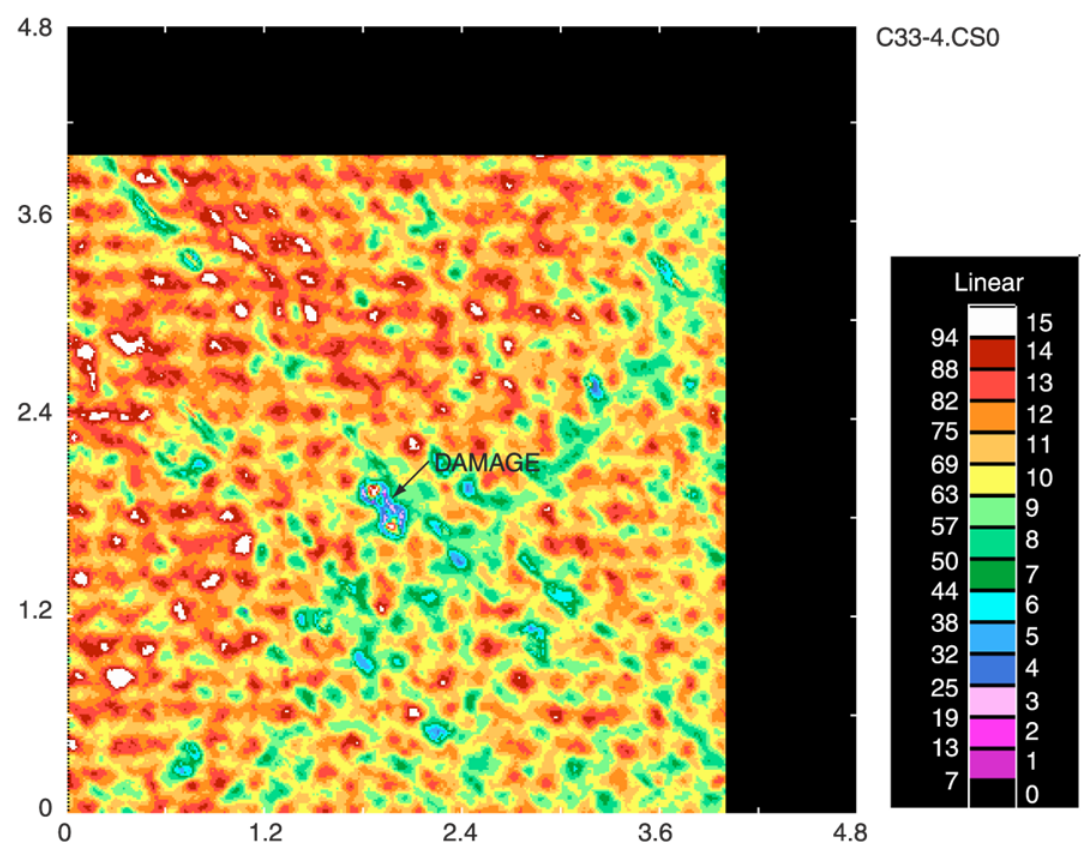

Fig. 14.6. C-scan of impact specimen C33-4. Note small peanut-shaped damage area in the middle of the specimen. 
ORNL 2001-825 EFG

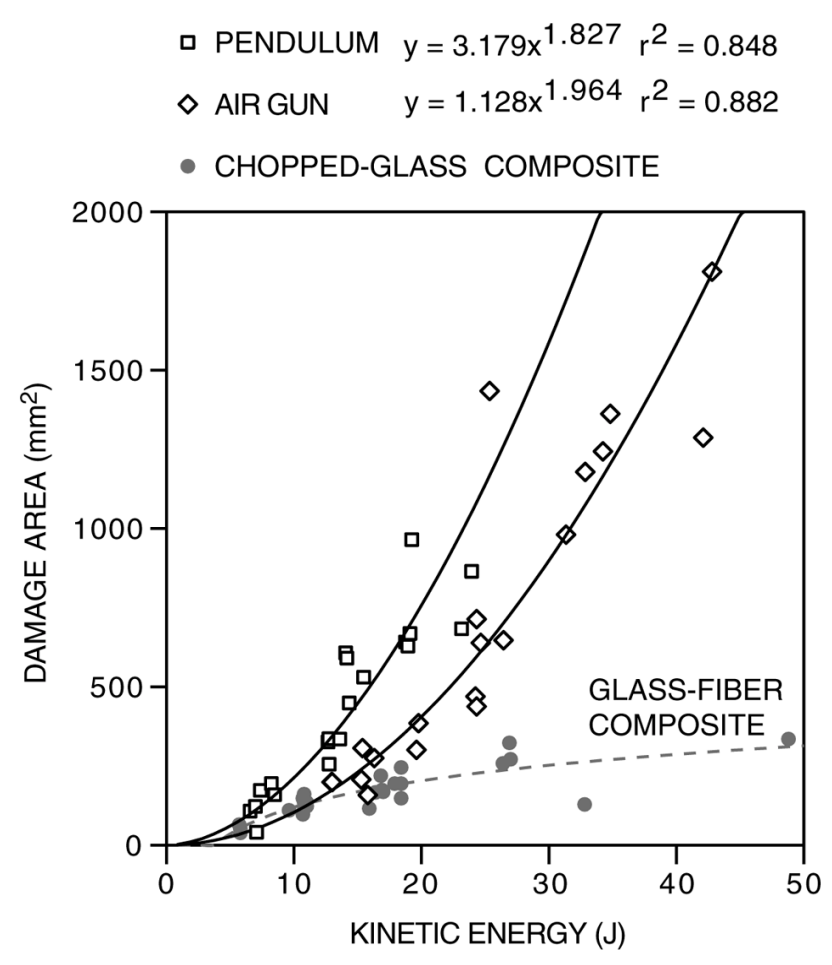

Fig. 14.7. Baseline impact damage areas (with delaminations) vs kinetic energy.

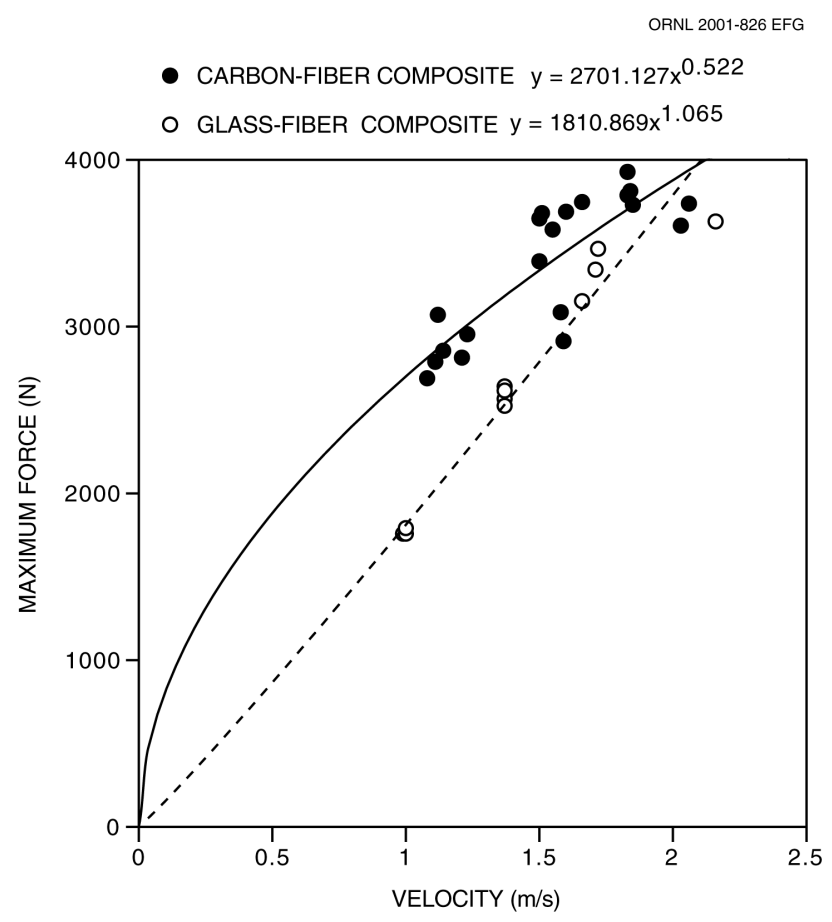

Fig. 14.8. Comparison of peak impact forces measured in pendulum tests of crossply carbon-fiber composite and chopped-glass-fiber composite. 


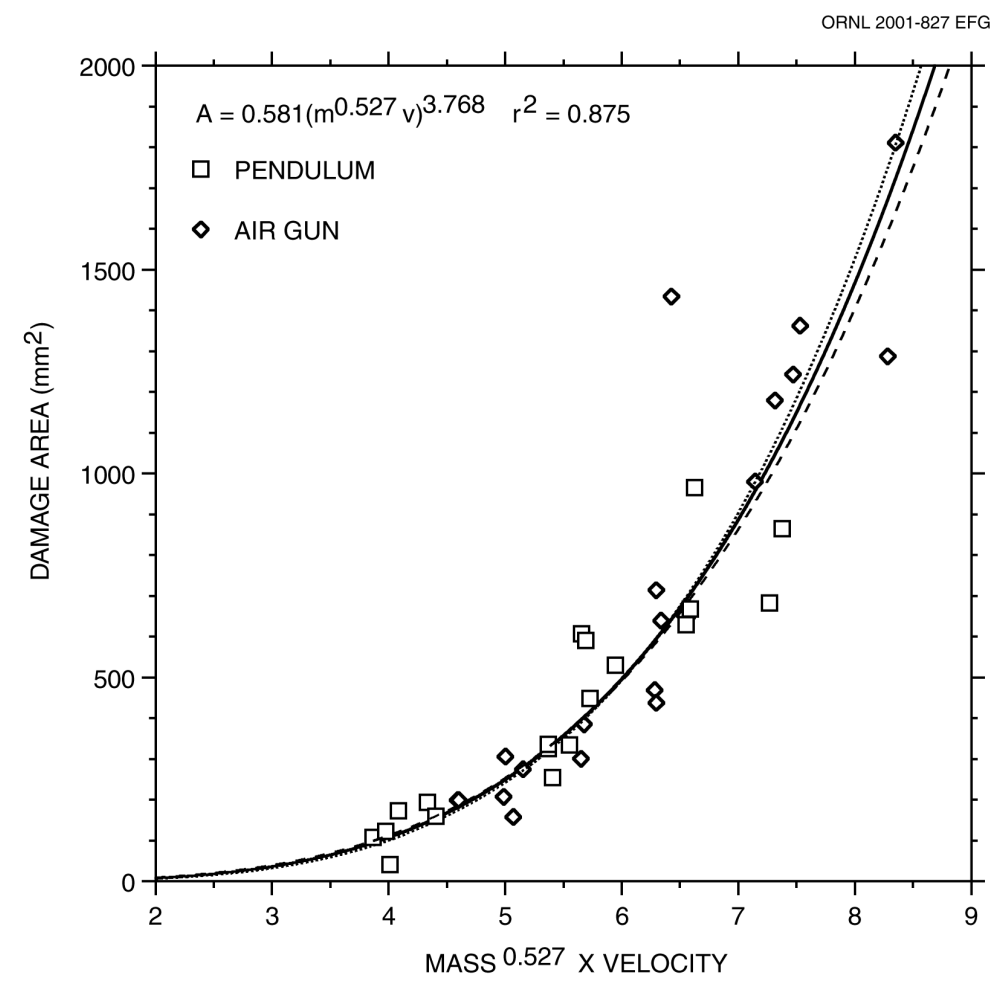

Fig. 14.9. Baseline impact damage areas (with delaminations) vs $\mathrm{m}^{0.527} \mathrm{v}$ (mass in $\mathbf{k g}$, velocity in $\mathbf{m} / \mathbf{s}$ ). The solid curve and equation represent all the data, the dashed curve represents the pendulum data alone, and the dotted curve represents the air-gun data alone.

ORNL 2001-828 EFG

口 PENDULUM, W/O DELAM. $y=3.133 x^{1.609} r^{2}=0.681$

$\diamond$ AIR GUN, W/O DELAM. $\quad y=4.968 x^{1.236} r^{2}=0.743$

- CHOPPED-GLASS COMPOSITE

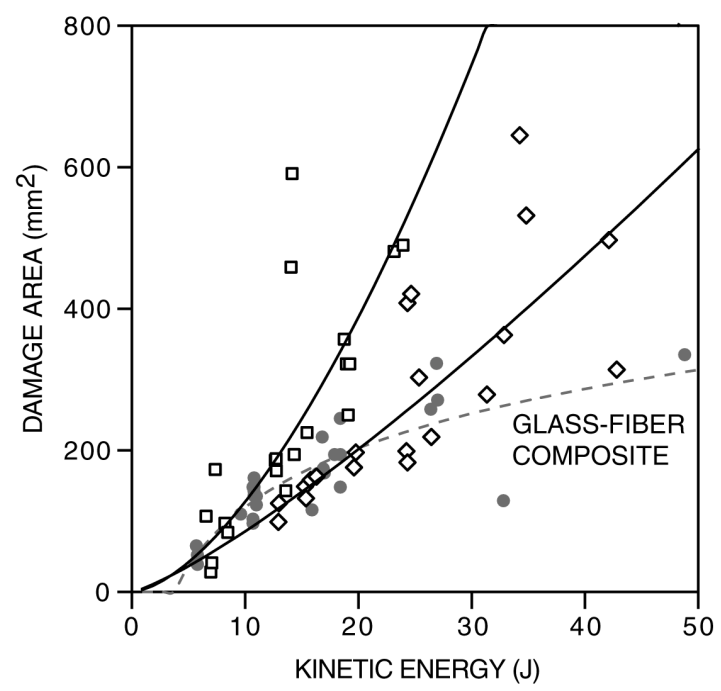

Fig. 14.10. Baseline impact damage areas (without delaminations) vs kinetic energy. 


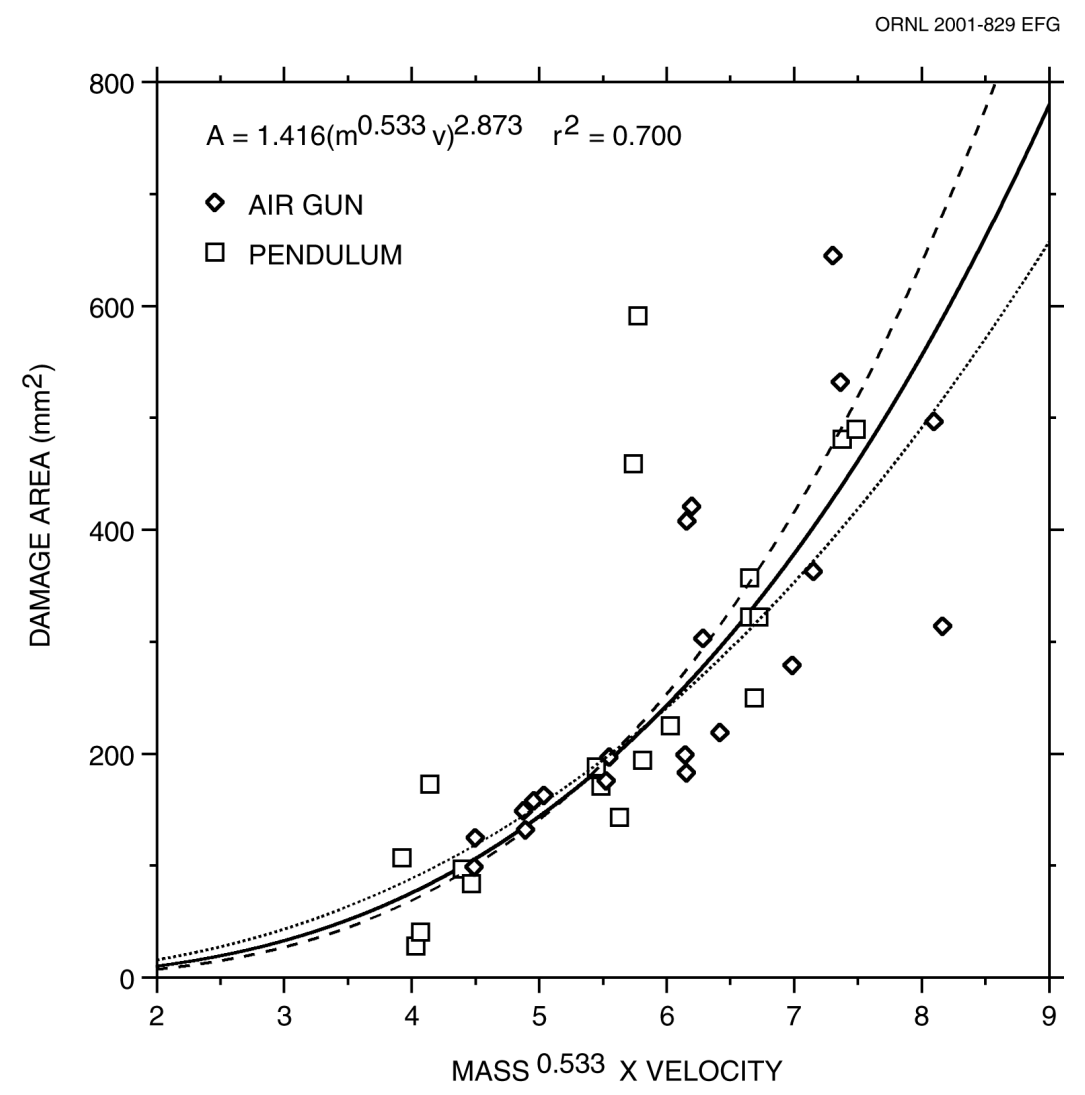

Fig. 14.11. Baseline impact damage areas (without delaminations) vs $\mathbf{m}^{\mathbf{0 . 5 3 3}} \mathbf{v}$. The solid curve and equation represent all of the data, the dashed curve represents the pendulum data alone, and the dotted curve represents the air-gun data alone. 


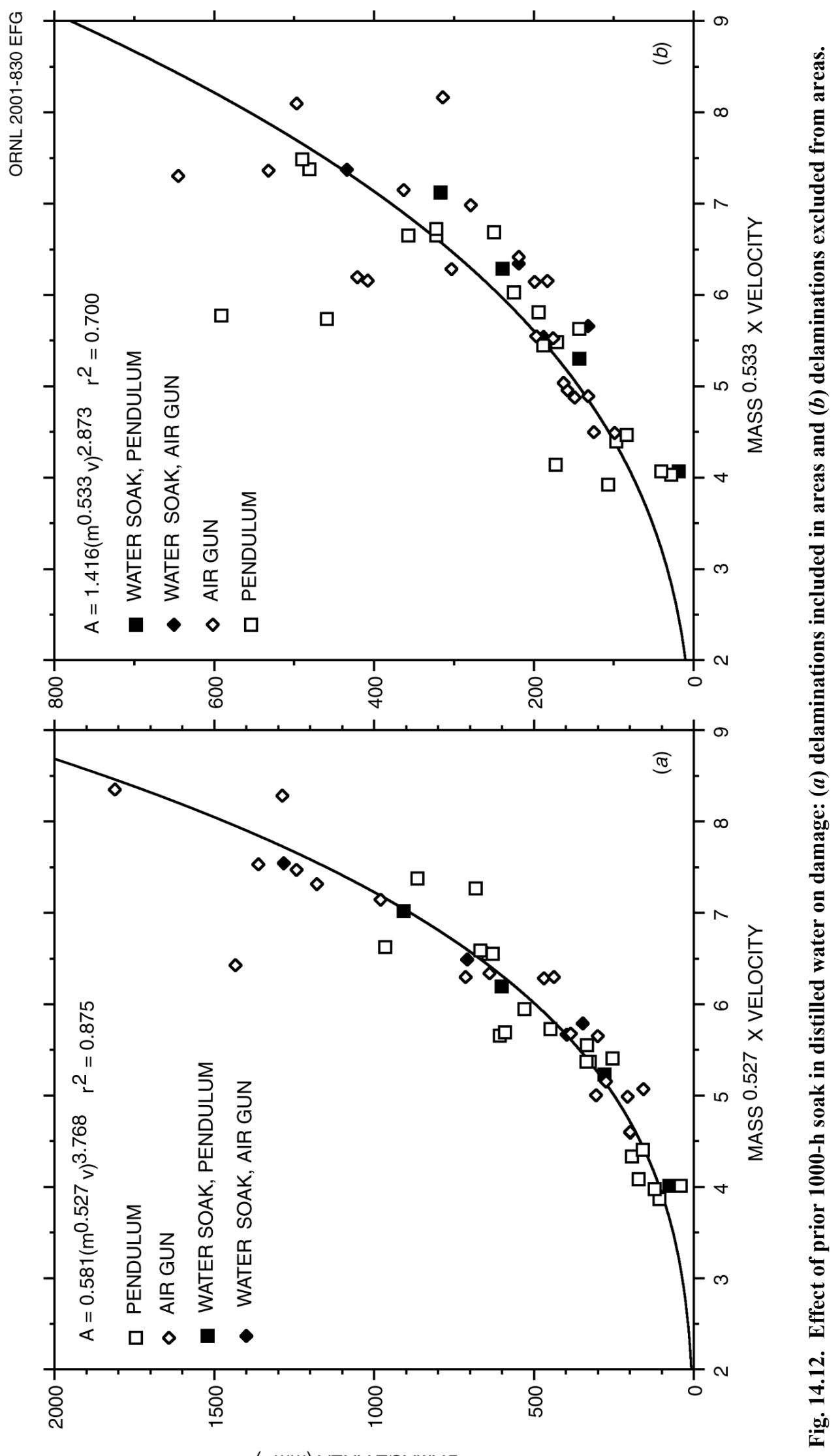

(حmu) $\forall \exists y \forall \exists \Xi \forall W \forall 0$ 


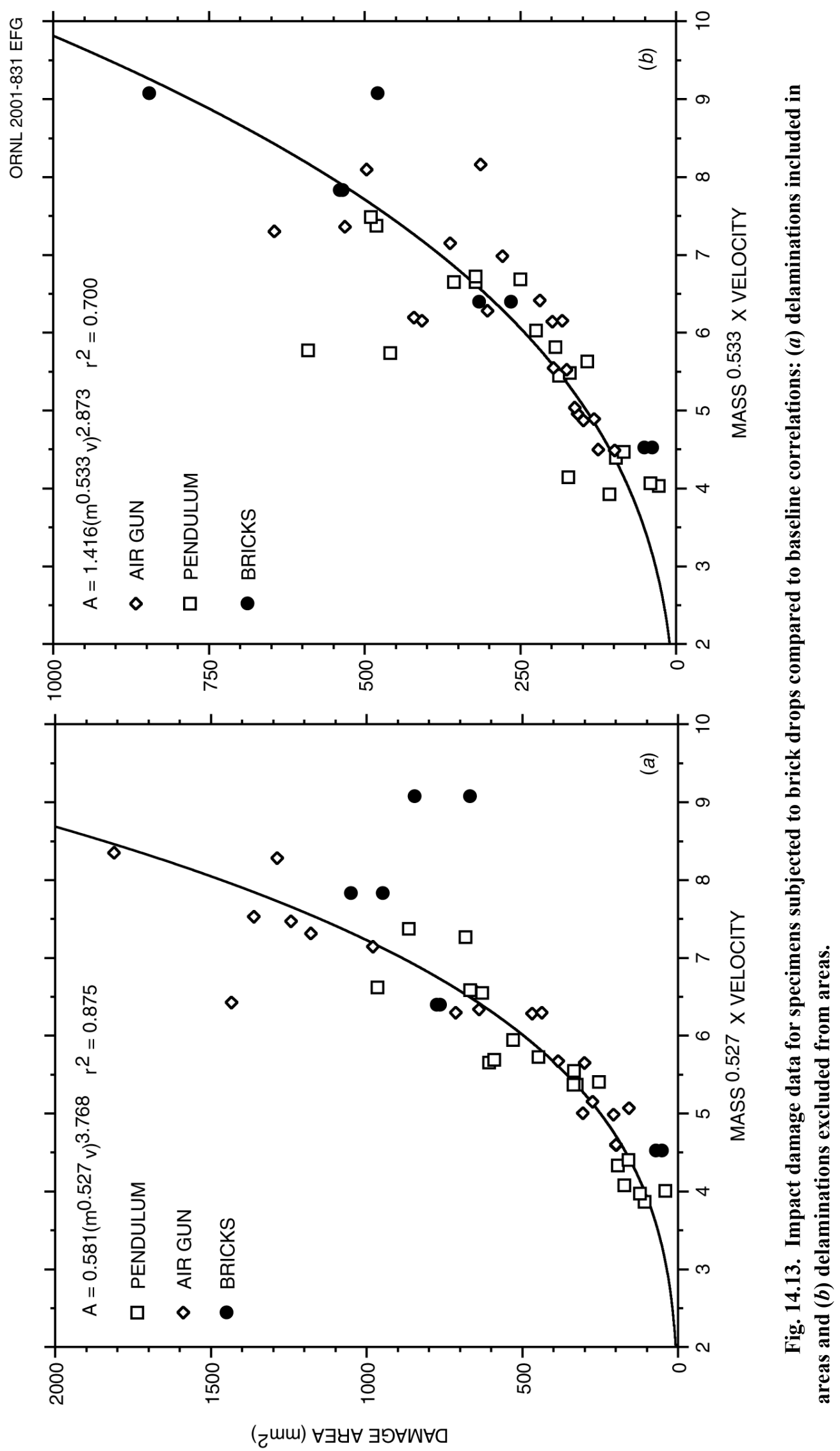


ORNL 2001-832 EFG

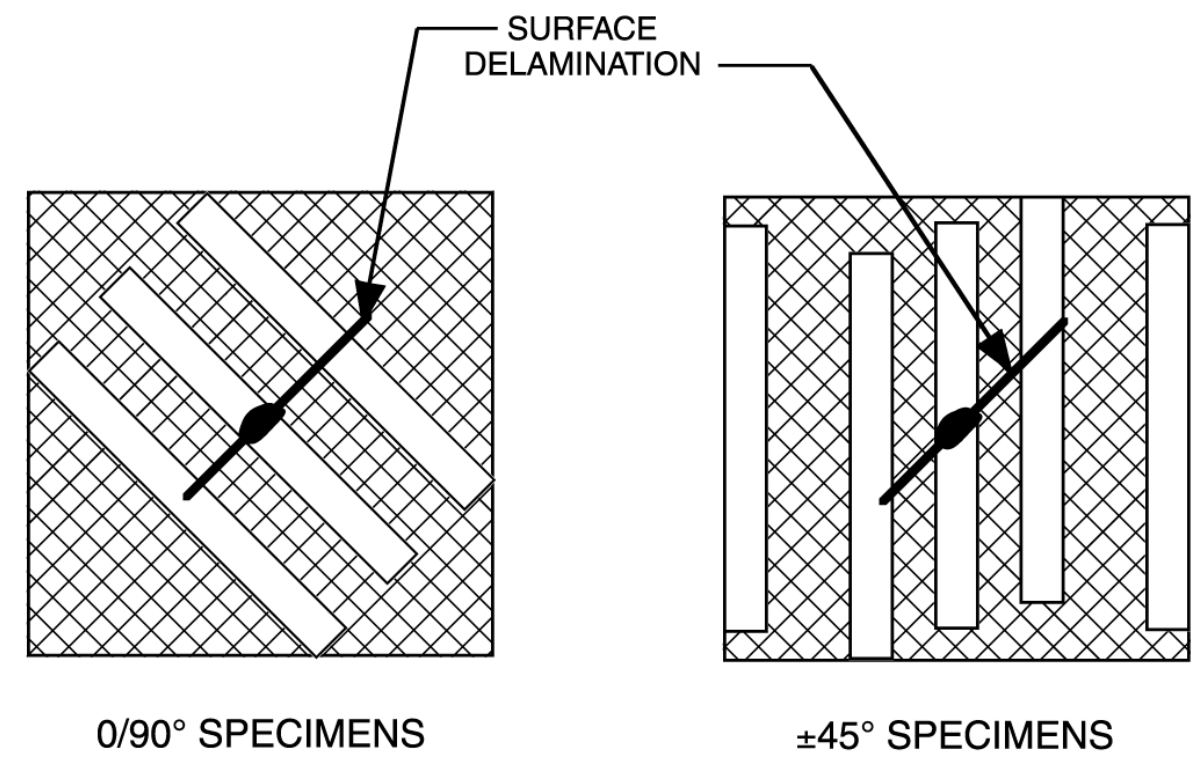

Fig. 14.14. Schematic of cutting plan for tensile specimens obtained from impacted plate specimens. The back side (maximum damage) of the impacted plates is shown. 


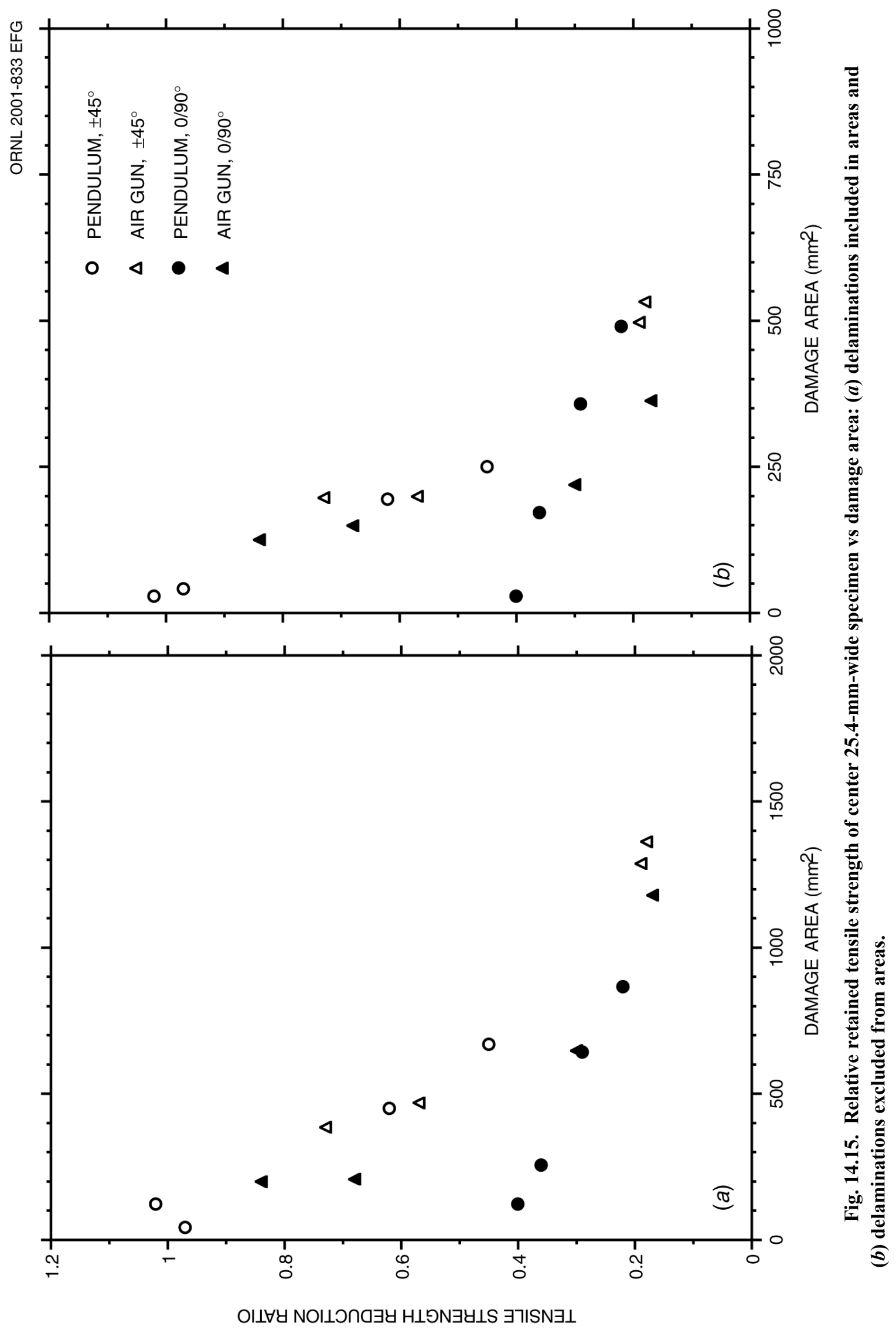




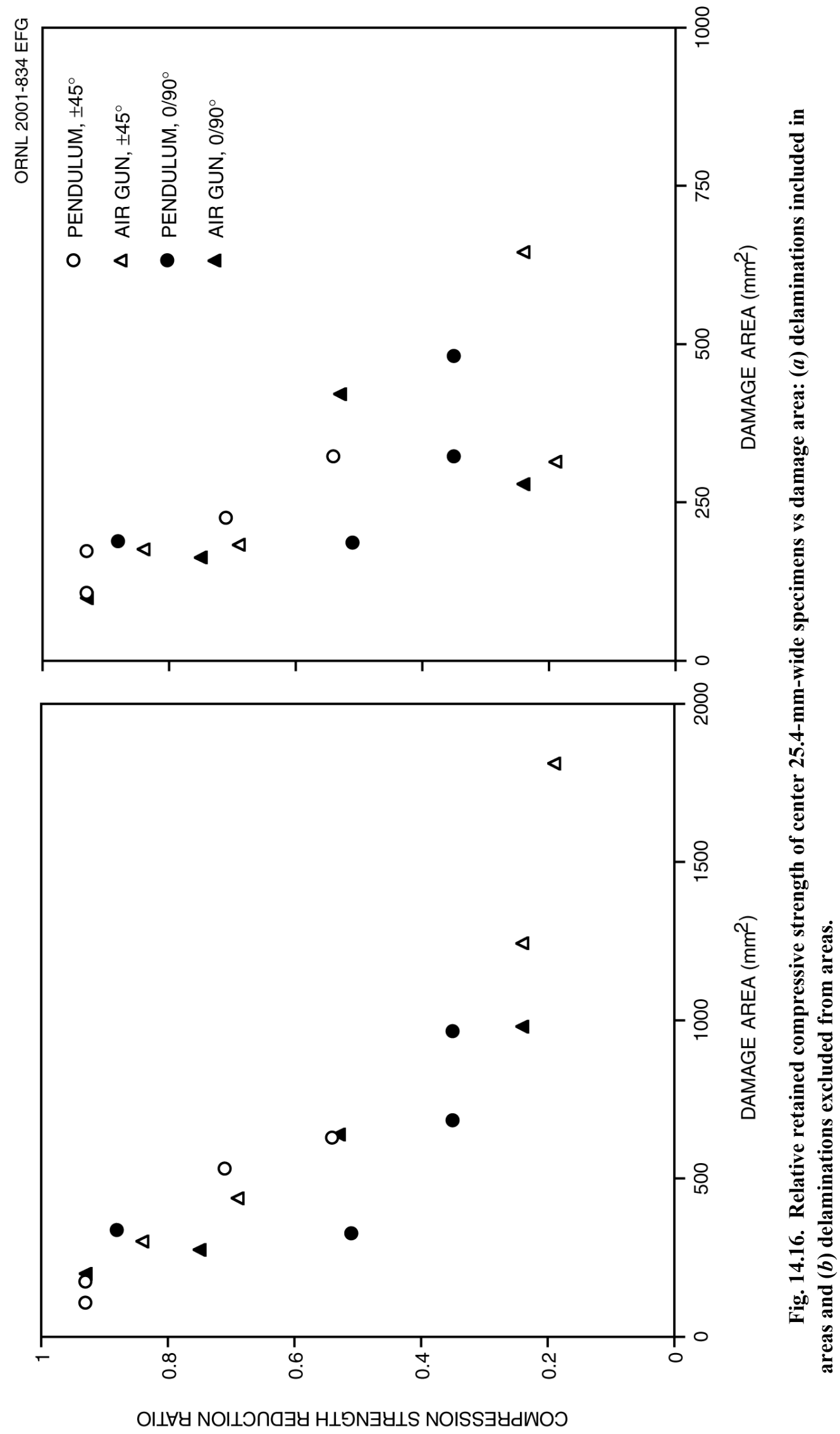




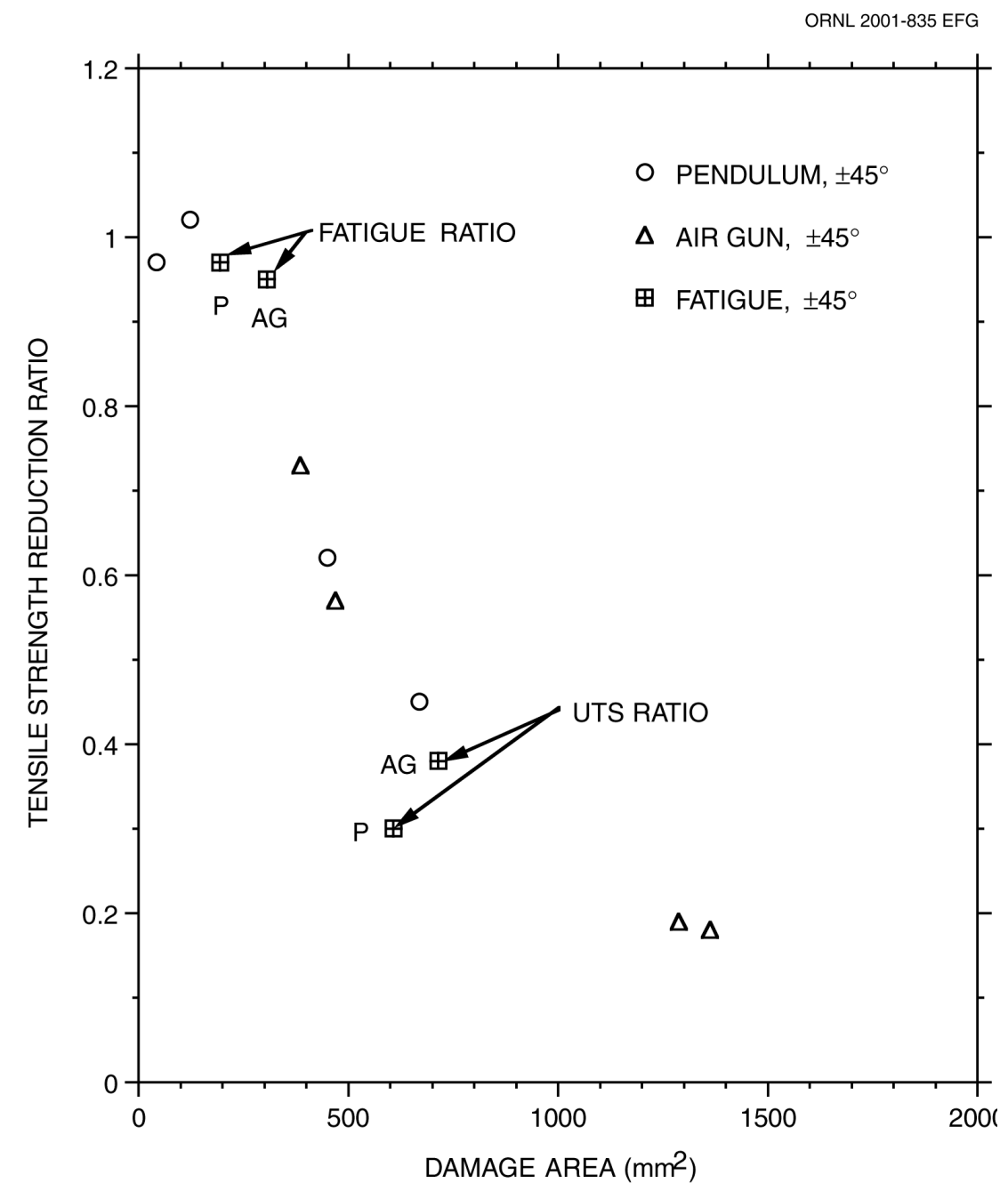

Fig. 14.17. Tensile fatigue results superimposed on $\pm 45^{\circ}$ tensile strength degradation data from Fig. 14.15(a). Damage area includes delaminations; $\mathrm{P}$ and AG refer to data from pendulum and air-gun impact specimens, respectively. 
ORNL 2001-836 EFG

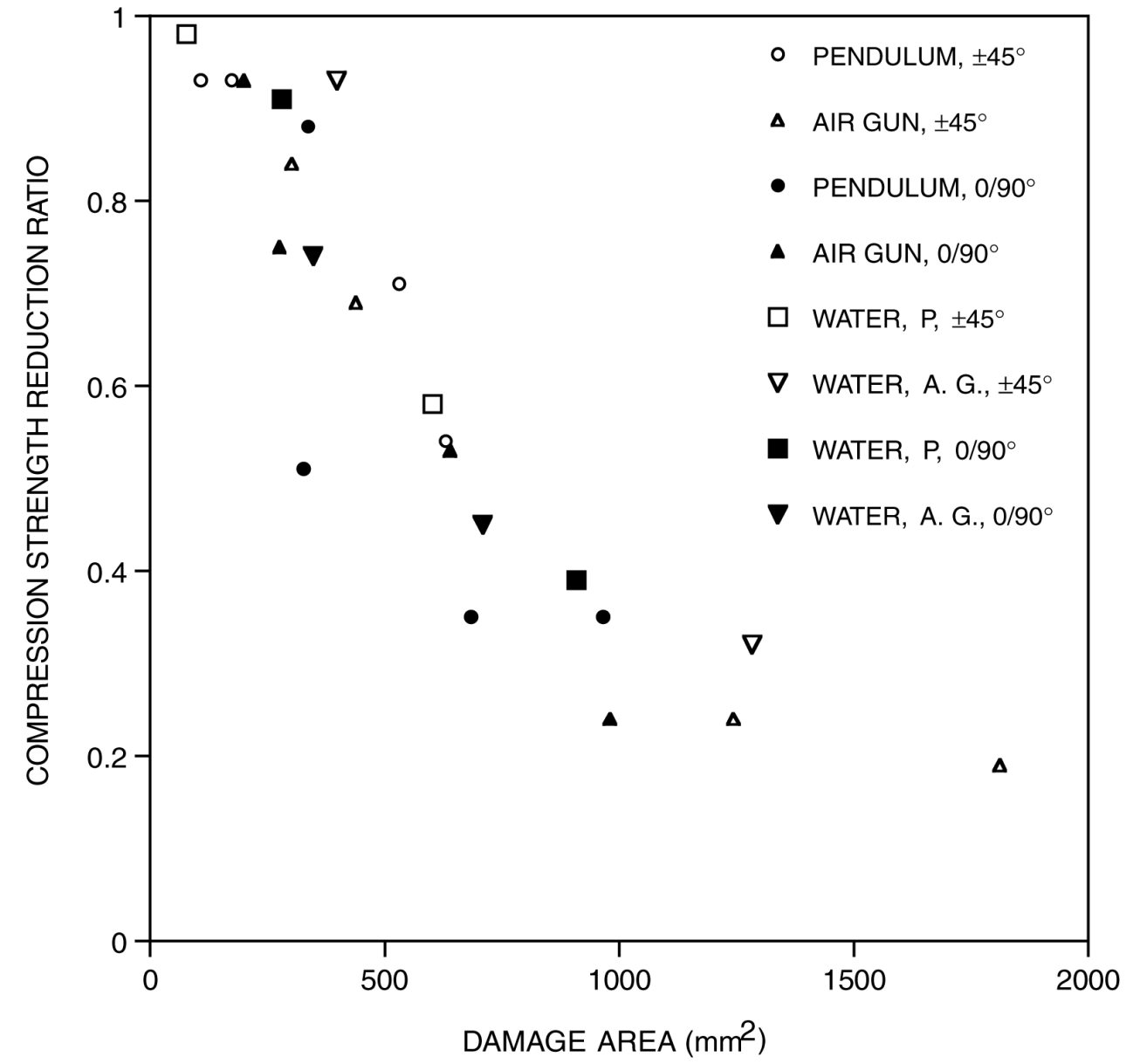

Fig. 14.18. Comparison of compressive strength retention in presoaked impact specimens to baseline data. Damage area includes delaminations. 


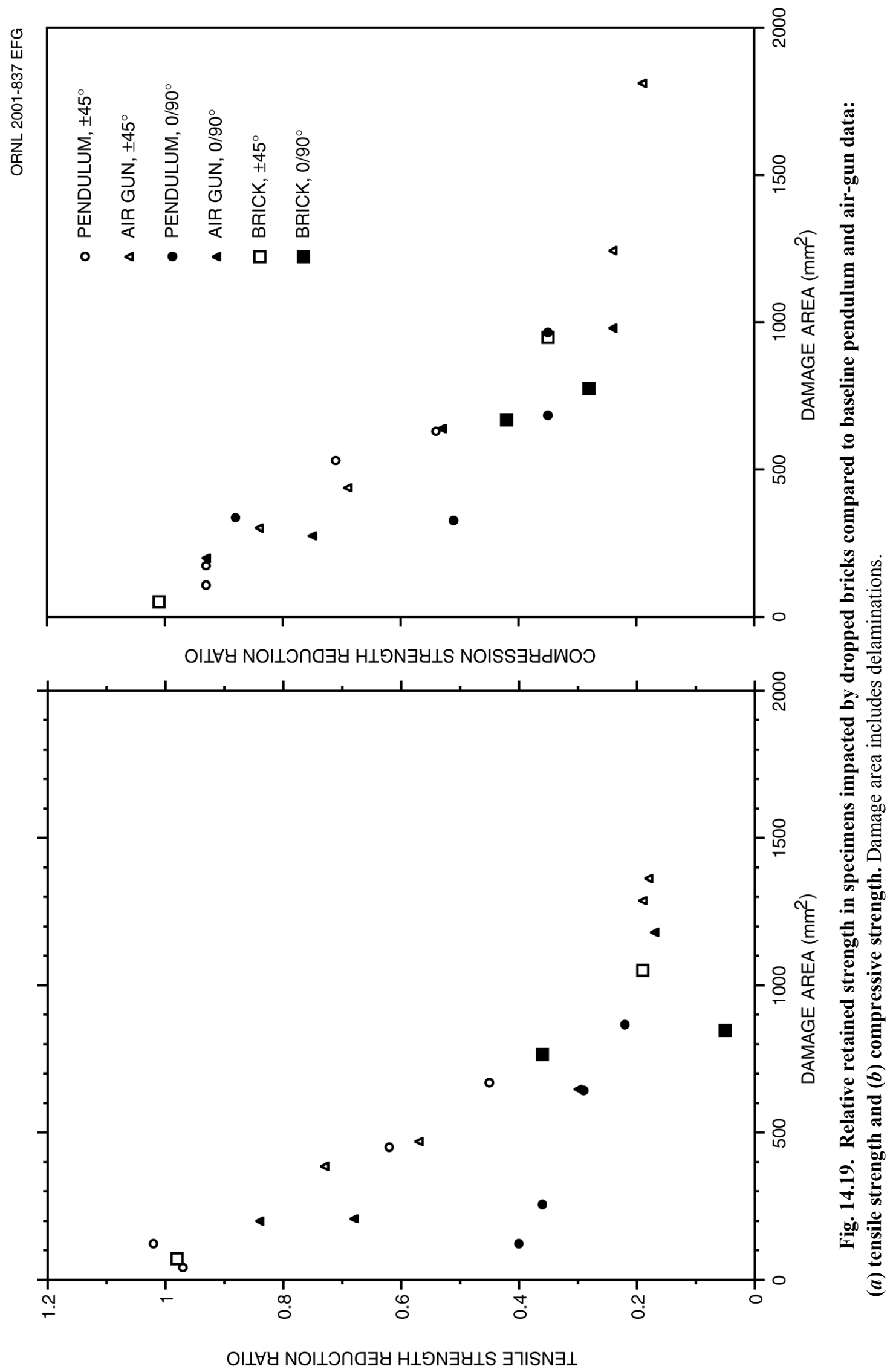




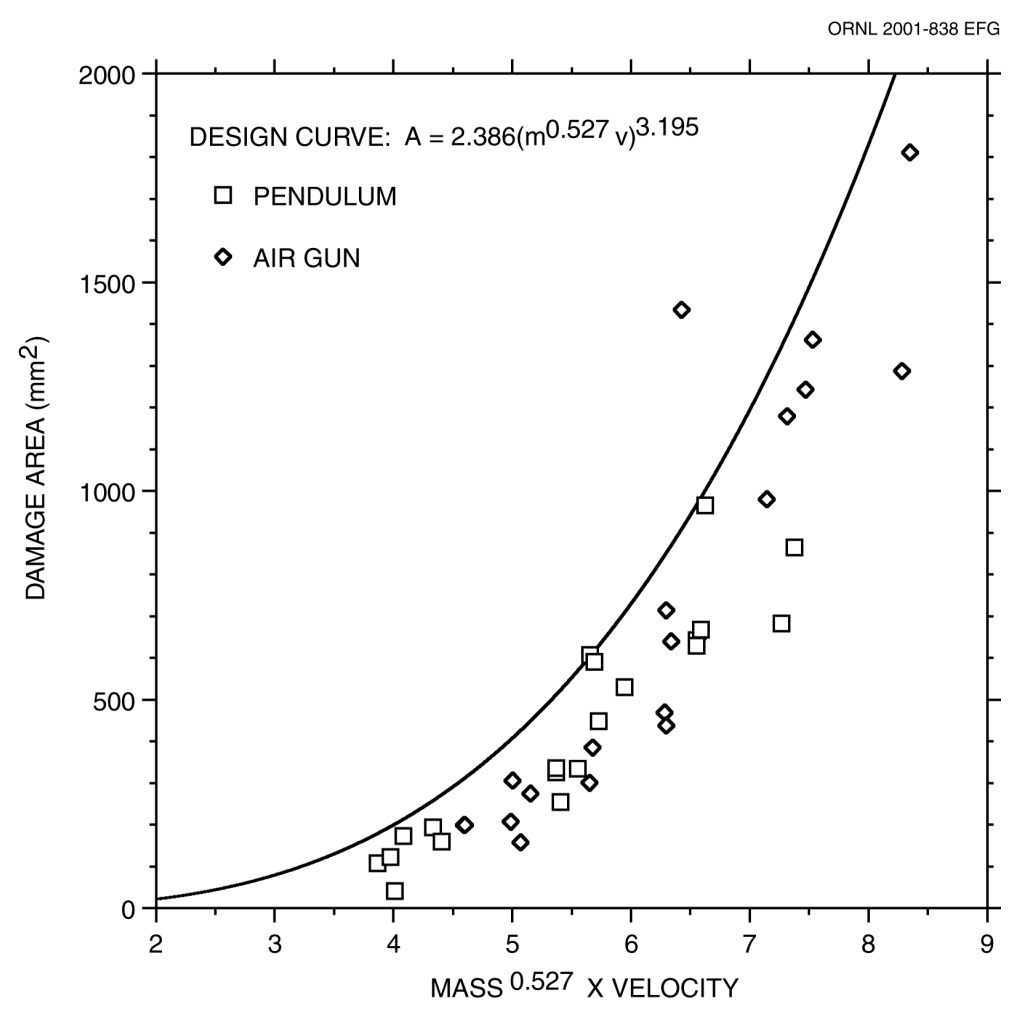

Fig. 14.20. Suggested curve for conservatively estimating impact damage areas. Data points are baseline tests (with delaminations included).

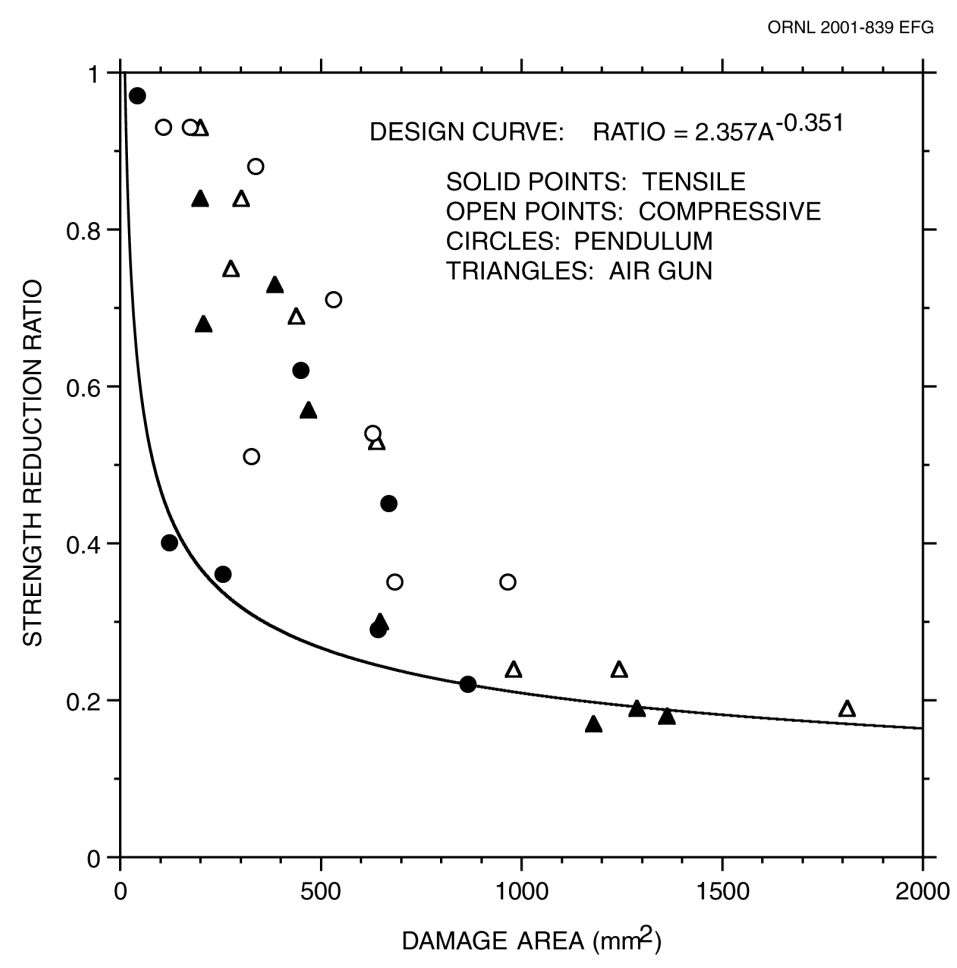

Fig. 14.21. Suggested curve for conservatively estimating strength loss. Damage area includes delaminations. 


\section{REFERENCES}

1. J. M. Corum et al., Durability-Based Design Criteria for an Automotive Structural Composite: Part 1. Design Rules, ORNL-6930, Lockheed Martin Energy Research Corp., Oak Ridge National Laboratory, February 1998.

2. J. M. Corum et al., Durability-Based Design Criteria for an Automotive Structural Composite: Part 2. Background Data and Models, ORNL-6931, Lockheed Martin Energy Research Corp., Oak Ridge National Laboratory, February 1998.

3. J. M. Corum, R. L. Battiste, W. Ren, and M. B. Ruggles, Durability-Based Design Criteria for a Chopped-Glass-Fiber Automotive Structural Composite, ORNL/TM-1999/182, Lockheed Martin Energy Research Corp., Oak Ridge National Laboratory, November 1999.

4. N. G. Chavka and J. S. Dahl, "P4: Glass Fiber Preforming Technology for Automotive Applications," pp. 281-292 in 4th International SAMPE Symposium, May 1999.

5. The Composite Materials Handbook-MIL 17 Volume 1, Guidelines for Characterization of Structural Materials, Revision MIL-HDBK-17-1E, Technomic Publishing Co., Inc., Lancaster, Pennsylvania, January 1997.

6. J. M. Whitney and R. J. Nuismer, "Stress Fracture Criteria for Laminated Composites Containing Stress Concentrations," J. Compos. Mater. 8, 253-265 (July 1974).

7. S. Abrate, Impact on Composite Structures, Chap. 6, "Residual Properties," Cambridge University Press, 1998.

8. J. M. Corum, R. L. Battiste, W. Ren, and M. B. Ruggles, Recommended Minimum Test Requirements and Test Methods for Assessing Durability of Random-Glass-Fiber Composites, ORNL-6953, Lockheed Martin Energy Research Corp., Oak Ridge National Laboratory, June 1999.

9. ASTM Standard D3410-87, Standard Test Method for Compressive Properties of Unidirectional or Crossply Fiber-Resin Composites, American Society for Testing and Materials.

10. S. Kellas, J. Morton, and K. E. Jackson, "Damage and Failure Mechanisms in Scaled Angle-Ply Laminates," Composite Materials: Fatigue and Fracture, Fourth Volume, ASTM STP 1156, W. W. Stinchcomb and N. E. Ashbaugh, Eds., American Society for Testing and Materials, 257-280 (1993).

11. S. Deng and Y. J. Weitsman, Mechanical Responses of Stitched T300 Mat/Urethane 420 IMR Composite Laminates: Property/Orientation Dependence and Damage Evolution, ORNL/TM-2000/103, UT-Battelle, LLC, Oak Ridge National Laboratory, March 2000.

12. ASTM Standard D 2344, Test Methods for Apparent Interlaminar Shear Strength of Parallel Fiber Composites by Short Beam Method, American Society for Testing and Materials.

13. ASTM Standard D 790, Test Methods for Flexural Properties of Unreinforced and Reinforced Plastics and Electrical Insulating Materials, American Society for Testing and Materials.

14. A. Conle and J. P. Ingall, "Effects of Mean Stress on the Fatigue of Composite Materials," J. Comp. Tech. Res. 7:1, 3-11 (Spring 1985).

15. K. C. Liu and W. Ren, "Creep and Creep-Rupture Behavior of a Carbon-Fiber Reinforced Polymeric Composite," pp. 155-163 in SAMPLE-ACCE-DOE-SPE Midwest Advanced Materials and Processing Conference (September 2000).

16. J. M. Corum et al., Basic Properties of Reference Crossply Carbon-Fiber Composite, ORNL/TM-2000/29, UT-Battelle, LLC, Oak Ridge National Laboratory, Oak Ridge, Tenessee, February 2000.

17. S. Deng and Y. J. Weitsman, "The Deformation of Carbon Fiber/Urethane Resin Composites Under Load and Temperature," pp. 145-154 in Proceedings of SAMPE-ACCE-DOE-SPE 
Midwest Advanced Materials and Processing Conferences, Society for the Advancement of Material and Process Engineering (SAMPE), Dearborn, Michigan, USA, September 12-14, 2000.

18. M. Daniel and O. Ishai, Engineering Mechanics of Composite Materials, Oxford University Press, 1994.

19. J. Gao and Y. J. Weitsman, The Tensile Mechanical Properties and Failure Behavior of Stitched T300 Mat/Urethane 420 IMR Composite, MAES98-2.0-CM, The University of Tennessee, July 1998.

20. M. Elahi and Y. J. Weitsman, On the Mechanical Response of Chopped Glass/Urethane Resin Composite: Data and Model, Lockheed Martin Energy Research Corp., Oak Ridge National Laboratory, ORNL-6955, October 1999.

21. C. Pipkin and T. G. Rogers, "A Non-Linear Integral Representation for Viscoelastic Behavior," J. Mech. Phys. Solids 16, 59-72 (1968). 
Appendix A

MATERIAL AND PROCESSING 


$$
\text { A-2 }
$$




\title{
Appendix A. MATERIAL AND PROCESSING
}

\author{
E. M. Hagerman \\ Automotive Composites Consortium/General Motors
}

The reference carbon-reinforced crossply composite is based on a commercially available fiber widely used in the aerospace industries along with a urea/urethane automotive resin matrix. The carbon fiber is produced by Amoco with the trade name Thornel. Specifically, Thornel T300 in the 6K version was used here. These fibers are produced by a thermal treatment of a polyacrylonitrile (PAN) precursor to produce a continuous-length, high-strength, high-modulus, fiber bundle consisting of 6000 individual filaments. According to the manufacturer's data, these fibers have the following properties:

- $\quad$ strength-3.20 GPa

- modulus-228 GPa

- failure strain-1.4\%

- filament diameter $-7 \mu \mathrm{m}$

- density- $1.76 \mathrm{mg} / \mathrm{m}^{3}$.

The fibers were converted into a mat form by Johnson Industries of Phoenix City, Alabama. The mat consisted of two unidirectional plies stitched together in a $\pm 45^{\circ}$ configuration. Each ply of the mat had an areal density of $200 \mathrm{~g} / \mathrm{m}^{2}$. The plies were stitched together with $7 \mathrm{~g} / \mathrm{m}^{2}$ of polyester stitching threads, producing an overall mat areal density of $407 \mathrm{~g} / \mathrm{m}^{2}$.

The matrix resin is a urethane-based material produced by the Bayer Corporation and identified as 420 IMR, where the IMR indicates that the product contains an internal mold release. Conventional polyols and polymeric isocyanates are used with an amine coreactant to produce a cross-linked ureaurethane basic structure. The urea component contributes to the heat resistance of the final composite. With this urea-urethane system, the time required for the liquid-to-solid transformation is of the order of $15-20 \mathrm{~s}$.

The composite plaques were produced via the "Injection-Compression Procedure." For this process, a preform is produced by assembling six of the above described carbon fiber $\pm 45^{\circ}$ mats and introducing them into the mold, which is shown in Fig. A.1. After the preform is loaded into the mold, the mold is left open approximately 10-15 mm. The matrix is then produced via the Structural Reaction Injection Molding (SRIM) process in which the two reactive streams, polyol and polymeric isocyanate, are pumped at high pressure into an impingement mixing chamber to quickly produce a uniform mixture of the components. The reacting mixture is then pumped into the partially open mold that contains the reinforcement. The mold is then fully closed. This allows the resin to first flow, with little resistance, across the upper surface of the preform and then, under increasing closing pressure, flow into the thickness direction of the preform. This procedure results in less disturbance of the fiber orientation and produces a more uniform, void-free, distribution of resin through the carbon preform. A 2.5-min cure time is allowed before the mold is opened and the part ejected. Final postcure was $1 \mathrm{~h}$ in a preheated oven at $130^{\circ} \mathrm{C}$.

The Automotive Composites Consortium (ACC) instrumented "shear-edge mold" shown in Fig. A.1 was used in the manufacture of the carbon-fiber-reinforced plaques. In this mold, the upper mold half telescopes into the lower mold half during closure. In this way, the composite material being molded carries the full molding pressure from the press. With materials of this type, appreciable shrinkage occurs during the chemical reaction. In the shear-edge mold, the upper mold half follows the chemical shrinkage through the telescoping action of the mold halves to produce smooth molded surfaces. In addition, the mold includes an efficient mold vacuum system that produces up to $710 \mathrm{~mm}$ of vacuum. The vacuum assists in reducing the void content of the molded plaques. 
In the plaques produced by the procedures just described, several apparent abnormalities have been noted that are related to the materials and/or processing. The first of these is a reoccurring position-toposition variation in thickness within the molded plaques. Data generated during the testing program have shown differences between the minimum and maximum thickness within a single plaque of as much as $28 \%$. The instrumented mold used in the molding has displacement transducers at the four corners to observe the motions of mold halves during mold closure. Before molding begins, a zero plane is determined by applying shims between the mold and the press platens such that there is minimal difference between the readings of the displacement transducers when the mold is fully closed and pressurized. Without a carbon fiber preform in place or matrix resin injection, the mold opens and closes in a uniform, parallel motion. The maximum difference observed between displacement transducers during this "dry cycling" is of the order of $0.05-0.15 \mathrm{~mm}$ during the closure and virtually zero when fully closed and pressurized. Based on these setup data, we would anticipate a thickness variation of no more than a few percent in a 3-mm-thick molded plaque.

To understand the material $/ \mathrm{mold} /$ press interactions that produce the observed thickness variation, a description of the press used in these moldings is required. The press is a 150-ton Newman hydraulic press with 1.2- by $1.8-\mathrm{m}$ platens and is of the four-post design with the upper platen moveable. The ACC mold is about $1-\mathrm{m}$ square and is installed in the center of the press platens. If during the molding operation, the load becomes uncentered, several degrees of freedom in the motions of the upper platen relative to the lower platen become possible. These include front-to-back tilt, left-to-right tilt, rotation about the right front-left rear diagonal, and rotation about the left front-right rear diagonal. In fact, some of the rotation and tilt modes can occur at the same time. The loading force capability, 150 tons, is sufficient to initiate deflections in the posts and can emphasize deflections originating from wear in the platen bushings.

To complete the argument, all that is needed is a mechanism to produce an uncentered load. This occurs as the result of the $\pm 45^{\circ}$ fiber orientation of the preforms and the flow of the resin component during resin injection and subsequent mold closure. If resin is injected into the mold without a preform, a circular puddle is produced that uniformly increases in diameter as the mold is closed. If a $\pm 45^{\circ}$ preform is present, the ply adjacent to the injection port deflects the flow in the fiber direction of that ply. In these systems, flow occurs more easily in the fiber direction than in the cross direction. Secondly, earlier data have suggested that tilt of a few hundredths of a millimeter can direct flow away from the thin dimension side and toward the more open side. A combination of these mechanisms can produce the initial unbalance that becomes more extensive as the mold closes and the molding pressures approach their peak. Peak molding pressure with these materials is of the order of 3.5 MPa. Data from the displacement transducers during molding operations show maximum corner-to-corner differences of the order of $1 \mathrm{~mm}$ as maximum molding pressure is approached. Added to this scenario is the fact that the time from initial mix of the two components of the urethane system until solidification is only around $20 \mathrm{~s}$, and the viscosity increases exponentially during that period. This latter factor makes it extremely difficult to level any flow imbalance after one has been initiated. It is thought that combinations of these factors produce the observed thickness variations.

The second factor that was observed is some misalignment of the $\pm 45^{\circ}$ fiber orientation. This is also the result of material and/or material and process interactions. In the manufacture of the stitch-bonded mats, the individual fiber bundles are pulled in, through, and around the processing equipment to be placed in the proper orientation before the stitch-bonding operation. It is apparent that during this operation some tension is applied to the fiber mat that is retained in the stitch-bonded product. The stitchbonded mat is supplied as a $1.25-\mathrm{m}$-wide roll. From that roll, $0.6-\mathrm{m}$ squares are cut to form the preform for the molding operation. It has been observed that as a result of cutting the $0.6-\mathrm{m}$ squares, the retained tension in the roll is relieved, which results in a dimensional change from the desired square to a rectangle with dimensions that are a function of the degree of tension in the mat. Attendant to that dimension change is a change in the orientation of the fibers contained in the plies. A second source of misalignment 
occurs as the liquid urethane components are impacted into the preform mat during the injection stage of the injection-compression process. In some instances, this can exceed the capability of the stitching fibers to retain the orientation, which results in physically moving fibers away from the desired orientation. In some extreme cases, a football-shaped resin-rich area is formed around the injection port. Obviously, such extreme cases are discarded; however, almost all plaques and parts manufactured in this way show some degree of fiber movement.

The process just described and the observed abnormalities inherent in such processes tend to illuminate the differences between classic aerospace processing and the high-speed, high-volume processes used in automotive industries. Aerospace processing works with very uniform, thin, 0.1-mm lamellae, which are stacked together in prescribed patterns to fulfill specific applications. These lamellae contain resins that require hours under heat and low pressure to cure and further hours in postcure to produce the final parts. Automotive processing, in contrast, works with high-pressure high-flow rate processes that are complete in 4 min or less and are intrinsically more difficult to control relative to fiber orientation and material thickness. More sophisticated fast-acting molding presses with hydraulic leveling can minimize the thickness variation but probably would not result in complete elimination of all the thickness variability. 
ORNL 2001-840 EFG

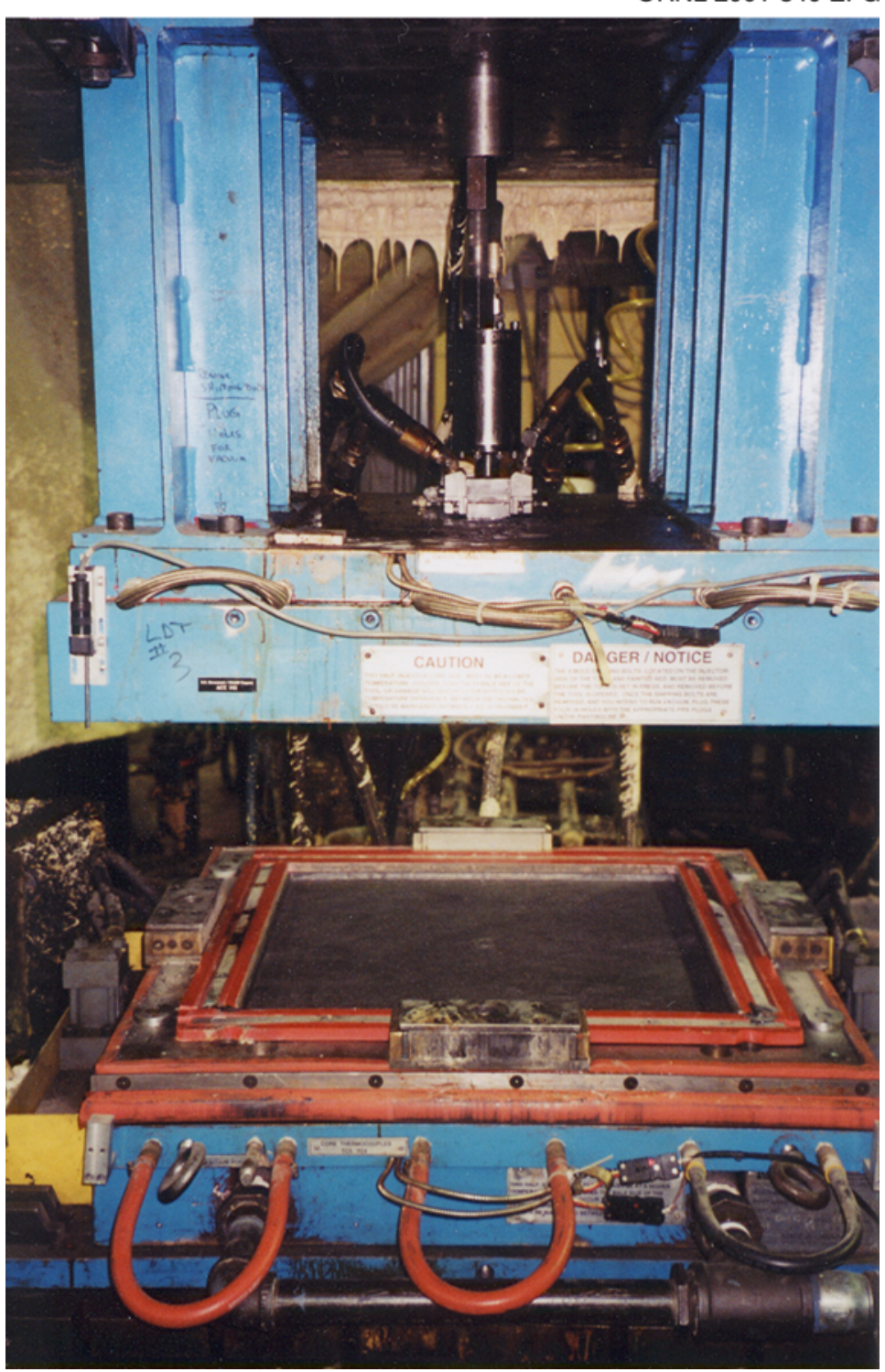

Fig. A.1. ACC mold in hydraulic press with carbon-fiber preform in place. 
Appendix B

PLAQUE RECORDS 
B-2 


\section{Appendix B. PLAQUE RECORDS}

Table B.1 lists the 60 carbon-fiber composite plaques provided to the ORNL Durability of CarbonFiber Composites Project by ACC. In addition to the ORNL and ACC plaque designations and calculated plaque fiber volume contents, the table shows what each plaque was used for and the plaque average tensile strength and stiffness values, if available. The UTS values generally came from at least three designated reference specimens set aside from each plaque. The stiffness values often came from many more specimens, since virgin stiffness values were often measured before using specimens for another purpose. The unweighted averages for all plaques were calculated assuming that the tabulated plaque averages were the true plaque values, irregardless of how many specimens were used to determine them. The values may thus differ slightly from the values tabulated in Table 7.1 of Chap. 7.

The three letters in the ACC plaque designation denote the molding run. As can be seen, the plaques came from four different molding runs. At least three different carbon-reinforcement rolls were used: TBC-1 through TBC-18 and the TRI plaques used one roll (56112); TBC-19 through -24 used a second roll (64296); the DTB plaques used a third unnumbered roll; and it is not certain what roll was used for the DEV plaques. At least two different batches of resin components were used.

The fiber mat weight and the finished plaque weight were measured in each case. From these measurements, ACC calculated the fiber volume contents given in Table B.1.

The fiber misalignment appeared to average $2^{\circ}$ or $3^{\circ}$ in the TBC and TRI plaques. It was somewhat higher in the DEV plaques (as high as $7^{\circ}$ or $\left.8^{\circ}\right)$, and it was very low $\left(0^{\circ}\right.$ in some cases) in the DTB plaques.

Although the intent was to have a symmetric stacking order of the reinforcement, $\left( \pm 45^{\circ}\right)_{3 \mathrm{~S}}$, the order in the first 20 plaques, $\mathrm{C} 1-\mathrm{C} 20$, and in $\mathrm{C} 58-\mathrm{C} 60$, was unsymmetric, $\left( \pm 45^{\circ}\right)_{6 \mathrm{~T}}$. This is not thought to have had a significant effect on the in-plane properties presented in this report. 
Table B.1. Information on composite plaques used in the durability study

\begin{tabular}{|c|c|c|c|c|c|c|c|}
\hline \multirow{2}{*}{$\begin{array}{c}\text { ORNL } \\
\text { designation }\end{array}$} & \multirow{2}{*}{$\begin{array}{c}\text { ACC } \\
\text { designation }\end{array}$} & \multirow{2}{*}{$\begin{array}{c}\text { Fiber volume } \\
\text { content } \\
(\%)\end{array}$} & \multirow[t]{2}{*}{ Use } & \multicolumn{2}{|c|}{$\begin{array}{l}\text { Average UTS } \\
\text { (MPa) }\end{array}$} & \multicolumn{2}{|c|}{$\begin{array}{c}\text { Average stiffness } \\
\text { (GPa) }\end{array}$} \\
\hline & & & & $\pm 45^{\circ}$ & $0 / 90^{\circ}$ & $\pm 45^{\circ}$ & $0 / 90^{\circ}$ \\
\hline $\mathrm{C1}$ & TBC 1 & 42.7 & Basic properties & & 503 & & 44.7 \\
\hline $\mathrm{C} 2$ & TBC 3 & 44.1 & Creep, basic properties & & 514 & & 46.2 \\
\hline $\mathbf{C 3}$ & TBC 5 & 41.4 & Fatigue, basic properties & & 485 & & 43.8 \\
\hline $\mathrm{C4}$ & TBC 6 & 40.5 & Creep, basic properties & & 477 & & 42.4 \\
\hline C5 & TBC 7 & 42.2 & Fatigue, basic properties & & 496 & & 43.9 \\
\hline C6 & TBC 8 & 39.1 & Creep & 132 & & 10.7 & \\
\hline C7 & TBC 9 & 41.5 & Time-dependent modeling & 141 & 514 & 11.7 & 45.1 \\
\hline C8 & TBC 10 & 41.7 & Not used & & & & \\
\hline C9 & TBC 11 & 41.2 & Fatigue & 139 & & 10.3 & \\
\hline C10 & TBC 13 & 41.7 & Tab study & & & & \\
\hline C11 & TBC 14 & 40.2 & Basic properties & 126 & & 10.1 & \\
\hline $\mathrm{C12}$ & TBC 15 & 41.2 & Basic properties & & 408 & & 43.2 \\
\hline $\mathrm{C13}$ & TBC 16 & 39.8 & Specimens not used & & 439 & & 40.3 \\
\hline C14 & TBC 17 & 39.5 & Basic properties & 133 & & 11.1 & \\
\hline C15 & TBC 18 & 42.7 & Fatigue, basic properties & & 472 & & 46.2 \\
\hline $\mathbf{C 1 6}$ & TBC 23 & 38.8 & Fatigue & 112 & & 10.4 & \\
\hline $\mathbf{C 1 7}$ & TBC-24 & 38.6 & Fatigue, basic properties & 107 & & 10.2 & \\
\hline $\mathrm{C18}$ & TRI 24 & 43.1 & Fatigue & & 451 & & 44.6 \\
\hline C19 & TRI 25 & 45.1 & Fatigue & & 475 & & 51.9 \\
\hline $\mathbf{C 2 0}$ & TRI 29 & 44.4 & Basic properties, fatigue, prior load & 127 & & 13.1 & \\
\hline $\mathrm{C21}$ & DEV 50 & 44.4 & Basic properties & & 444 & & 50.7 \\
\hline $\mathrm{C22}$ & DEV 59 & 44.1 & Creep, basic properties & & 458 & & 48.5 \\
\hline $\mathrm{C23}$ & DEV 47 & 41.8 & Creep, short-beam shear, prior load & & 399 & & 48.4 \\
\hline $\mathbf{C 2 4}$ & DEV 56 & 44.7 & Creep, basic properties, prior load & 161 & & 12.7 & \\
\hline $\mathbf{C 2 5}$ & DEV 60 & 43.8 & Basic properties & & 461 & & 50.1 \\
\hline $\mathrm{C26}$ & DEV 45 & 39.4 & Basic properties & 173 & & 15.9 & \\
\hline $\mathbf{C 2 7}$ & DEV 61 & 43.8 & Flexural properties & 153 & 476 & & 50.3 \\
\hline $\mathbf{C 2 8}$ & DEV 54 & 44.4 & Fatigue (mean stress) & 151 & 504 & 14.2 & 50.8 \\
\hline $\mathbf{C 2 9}$ & DEV 57 & 44.4 & Hole specimens & & & & \\
\hline $\mathbf{C 3 0}$ & DEV 65 & 44.1 & Hole specimens & & & & \\
\hline $\mathbf{C 3 1}$ & DEV 49 & 43.2 & Biaxial flexure & 149 & & 13.8 & \\
\hline $\mathbf{C 3 2}$ & DTB 9 & 40.7 & Impact & 165 & & 11.1 & \\
\hline $\mathbf{C 3 3}$ & DTB 3 & 38.1 & Impact & 153 & & 10.2 & \\
\hline $\mathbf{C 3 4}$ & TBC 2 & 41.0 & Impact & 140 & & 10.7 & \\
\hline C35 & DTB 7 & 39.4 & Impact & 158 & & 10.3 & \\
\hline C36 & DTB 8 & 39.2 & Impact & 160 & & 10.5 & \\
\hline C37 & DTB 18 & 38.3 & Impact & 149 & & 10.5 & \\
\hline C38 & DTB 19 & 39.9 & Impact & 156 & & 10.4 & \\
\hline C39 & DTB 10 & 39.7 & Impact & 155 & & 10.4 & \\
\hline $\mathrm{C40}$ & DTB 11 & 38.8 & Impact & 163 & & 10.6 & \\
\hline C41 & DTB 12 & 39.1 & Impact & 163 & & 10.4 & \\
\hline $\mathrm{C42}$ & DTB 14 & 38.1 & Impact & 159 & & 10 & \\
\hline C43 & DTB 16 & 38.9 & Impact & 158 & & 10.1 & \\
\hline
\end{tabular}


Table B.1. (continued)

\begin{tabular}{|c|c|c|c|c|c|c|c|}
\hline \multirow{2}{*}{$\begin{array}{c}\begin{array}{c}\text { ORNL } \\
\text { designation }\end{array} \\
\mathrm{C} 44 \\
\end{array}$} & \multirow{2}{*}{$\begin{array}{c}\text { ACC } \\
\text { designation } \\
\text { DTB } 6 \\
\end{array}$} & \multirow{2}{*}{$\begin{array}{c}\begin{array}{c}\text { Fiber volume } \\
\text { content } \\
(\%)\end{array} \\
40.2 \\
\end{array}$} & \multirow[t]{2}{*}{ Use } & \multicolumn{2}{|c|}{$\begin{array}{c}\text { Average UTS } \\
\text { (MPa) }\end{array}$} & \multicolumn{2}{|c|}{$\begin{array}{c}\text { Average stiffness } \\
\text { (GPa) }\end{array}$} \\
\hline & & & & 163 & & 10.7 & \\
\hline $\mathrm{C45}$ & DEV 48 & 40.7 & Impact & 151 & & 12.3 & \\
\hline C46 & DEV 53 & 44.4 & Fatigue (mean stress) & 155 & 476 & 12.8 & 49.5 \\
\hline $\mathbf{C 4 7}$ & DEV 58 & 43.5 & Not used & & & & \\
\hline $\mathrm{C48}$ & DEV 62 & 44.6 & Tensile width study, beam creep & 158 & 518 & 12.7 & 49.7 \\
\hline C49 & DEV 64 & 45.7 & Time-dependent modeling & & & & \\
\hline C50 & DEV 55 & 45.0 & Time-dependent modeling & & & & \\
\hline C51 & DTB 20 & 40.2 & Time-dependent modeling & & & & \\
\hline C52 & DTB 21 & 38.3 & Basic properties, beam creep & 165 & 522 & 11.2 & 47.1 \\
\hline C53 & DTB 23 & 38.9 & Time-dependent modeling & & & & \\
\hline C54 & DTB 15 & 38.9 & Time-dependent modeling & 155 & & 10.1 & \\
\hline $\mathrm{C55}$ & DTB 17 & 37.6 & Time-dependent modeling & & 564 & & 44.3 \\
\hline C56 & DEV 46 & 40.2 & Basic properties, prior load & & 409 & & 47.3 \\
\hline C57 & DTB 4 & 39.1 & Basic properties, prior load & 159 & & 11.5 & \\
\hline C58 & DEV 51 & 44.1 & Time-dependent modeling & & & & \\
\hline C59 & DEV 52 & 44.3 & Time-dependent modeling & & & & \\
\hline C60 & DTB 13 & 39.9 & Not used & & & & \\
\hline & & & Unweighted averages: & 150 & 476 & 11.3 & 46.8 \\
\hline
\end{tabular}


ORNL/TM-2000/322

\section{INTERNAL DISTRIBUTION}

$\begin{aligned} 1-2 . & \text { R. L. Battiste } \\ 3 . & \text { R. G. Boeman } \\ 4-13 . & \text { J. M. Corum } \\ 14 . & \text { S. Deng } \\ 15 . & \text { D. L. Erdman } \\ 16 . & \text { J. G. Hansen } \\ 17 . & \text { L. D. Klett } \\ 18-19 . & \text { K. C. Liu } \\ 20 . & \text { W. J. McAfee } \\ 21 . & \text { R. E. Norris }\end{aligned}$

\author{
22-23. M. B. Ruggles \\ 24. S. Simunovic \\ 25. P. A. Sklad \\ 26. J. M. Starbuck \\ 27. T. K. Stovall \\ 28. C. D. Warren \\ 29-30. Y. J. Weitsman \\ 31. R. E. Ziegler \\ 32. ORNL Central Research Library \\ 33. ORNL Laboratory Records-RC
}

\section{EXTERNAL DISTRIBUTION}

34. M. G. Abdallah, Hexcel Carbon Fibers, Research and Technology, P.O. Box 18748, Salt Lake City, UT 84118-0748

35. M. M. Fisher, American Plastics Council, 1300 Wilson Boulevard, Suite 800, Arlington, VA 22209

36. R. B. Freeman, The Budd Company, 1515 Atlantic Boulevard, Auburn Hills, MI 48326

37. R. Gjerde, Textron Automotive Company, 100 Brady Road, Americus, GA 31709

38-67. E. M. Hagerman, Automotive Composite Consortium, General Motors, 30500 Mound Road, I-6, Box 9055, Warren, MI 48090-9055

68. J. M. Henshaw, Department of Mechanical Engineering, The University of Tulsa, 600 S. College Avenue, Tulsa, OK 74104-3189

69. G. A. Holmes, National Institute of Standards and Technology, Bldg. 224, Room B116, Mail Stop: Room B108, Gaithersburg, Maryland 20899

70. P. K. Johnson, Zoltek Corporation, 3101 McKelvey Road, St. Louis, MO 53044

71. S. H. Johnson, BP Amoco Polymers, Inc., 4500 McGinnis Ferry Road, Alpharetta, GA 30005-3914

72. D. Kossak, Cambridge Industries, 29333 Stephenson Highway, Madison Heights, MI 48071

73. F. G. Krautz, Vetrotex Certainteed, 4515 Allendale Road, Wichita Falls, TX 763102199

74. G. R. Miesel, Ashland Chemical Company, 900 Wilshire Drive, Suite 100, Troy MI 48084

75. E. Ostwald, Dow Automotive, 1600 Harmon Road, Auburn Hills, Michigan 48326

76. S. R. Reeve, National Composite Center, 2000 Composite Drive, Kettering, $\mathrm{OH}$ 45420

77. W. Ren, AFRL/MLLN, 2230 Tenth St., Bldg. 655, Room 23, WPAFB, OH 45433-7817

78. G. Sandgren, Owens Corning Science \& Technology Centre, 2790 Columbus Road, Route 16, Granville, OH 43023-1200

79. C. R. Schultheisz, National Institute of Standards and Technology, Building 224, Room A209, Gaithersburg, MD 20899 
80. T. D. Seagrave, Bayer Corporation, 100 Bayer Road, Pittsburgh, PA 15205

81. D. R. Secrist, Fortafil Fibers, Inc., 121 Cardiff Valley Road, Rockwood, TN 37854

82. L. V. Smith, Washington State University, School of Mechanics and Materials Engineering, Pullman, WA 99164-2920

83. D. Stewart, Stewart Automotive Research, LLC, 1260 Shotwell Street, Houston, TX 77020

84. X. J. Xin, Department of Mechanical and Nuclear Engineering, Kansas State University, 338 Rathbone Hall, Manhattan, KA 66506-5205

85. S. J. Winckler, Cyclics Corporation, 747 Pierce Road, Clifton Park, NY 12065

86-89. J. A. Carpenter, U.S. Department of Energy, 1000 Independence Avenue SW, Washington, DC 20585

90. M. Rowlins, U.S. Department of Energy, Oak Ridge Site Office, Oak Ridge, TN 37831

91. S. Diamond, U.S. Department of Energy, 1000 Independence Avenue SW, Washington, DC 20585 